\title{
GAMBLING AND SOCIETY
}

2
3
3
3
3
3

है
$11 \mathrm{~V}$
6713
618
1976
c. 2

Interdisciplinary Studies on the Subject of Gambling

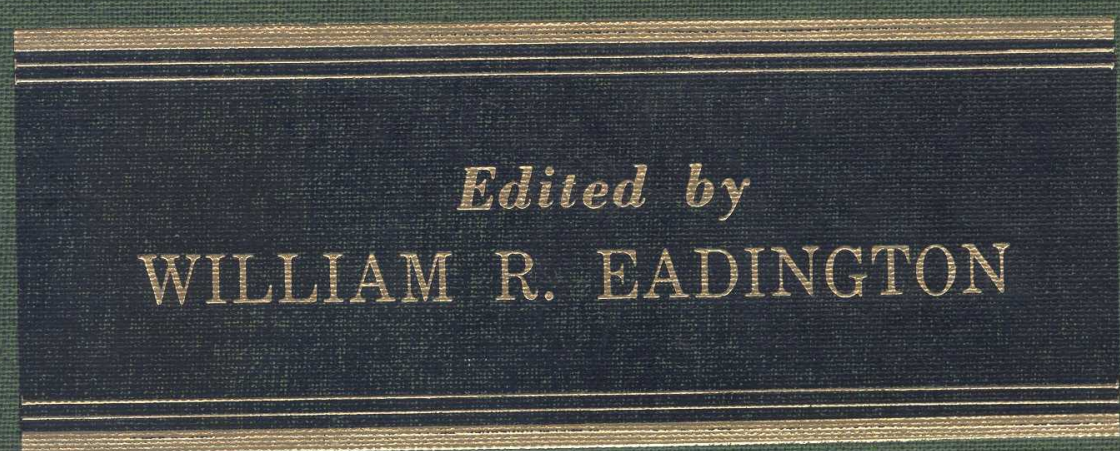

MAIN 


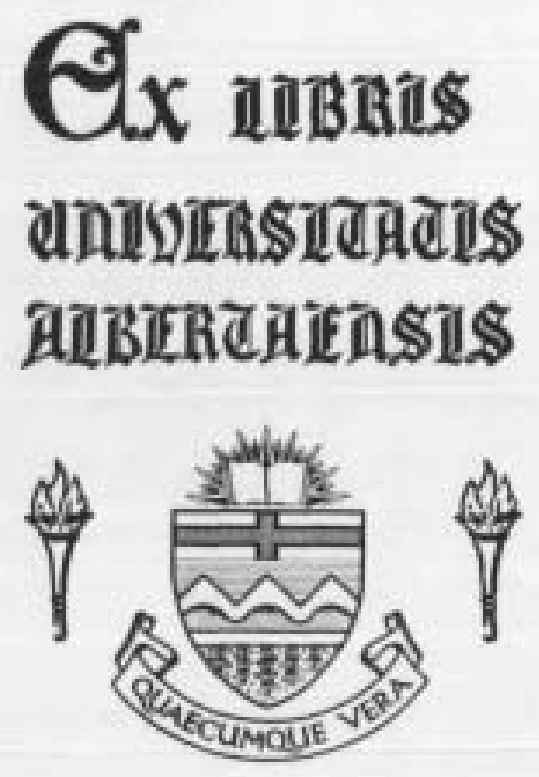




GAMBLING AND SILIETY 



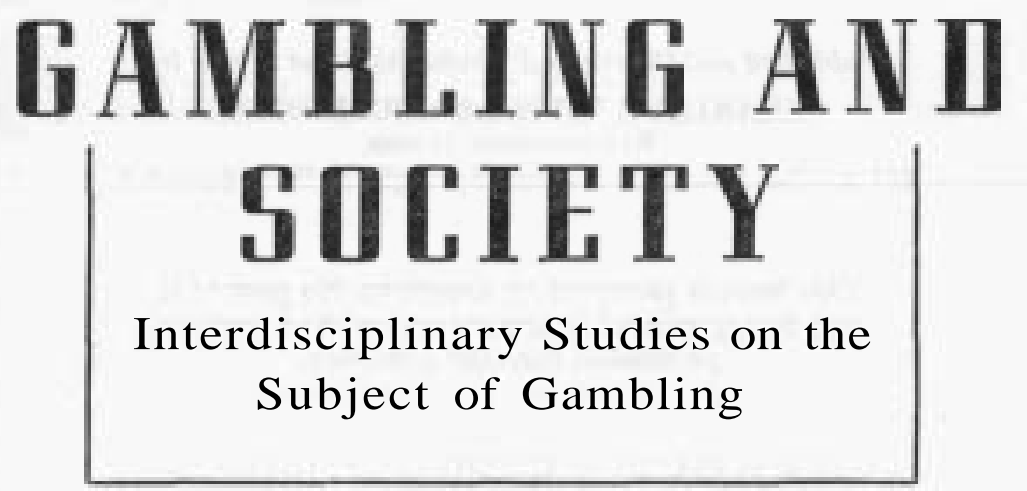

Edited by

WILLIAM R. EADINGTON

University of Nevada

Reno ${ }_{p}$ Nevada

\section{CHA RL ES C THOMAS $\quad$ T PU B L I SH ER} Springfield ' Illinois - U.S.A. 
Published and Distributed Throughout the World by

CHARLES C THOMAS • PUBLISHER

BAswrestons HOUSE

301-327 East Lawrence Avenue, Springfield, Illinois, U.S.A.

This book is protected by copyright. No part of it may be reproduced in any manner without written permission from the publisher.

\section{(C) 1976 , by CHARLES C THOMAS - PUBLISHER ISBN 0-398-03459-1 \\ Library of Congress Catalog Card Number: 7511976}

With THOMAS BOOKS carefulattention is given to all details of manufacturing and design. It is the Publisher's desire to present books that are satisfactory as to their physical qualities and artistic possibilities and appropriate for their particular use. THOMAS BOOKS will be true to those laws of quality that assure a good name and good will.

\section{Printed in the United States of America}

\section{$N=\mathbb{I}$}

Library of Congress Cataloging in Publication Data

Main entry under title:

Gambling and society.

"Most of the articles . . . initially presented at the First Annual Conference on Gambling held in Las Vegas, Nevada, in June of 1974."

Bibliography: $\mathrm{p}$.

Includes index.

1. Gambling - Congresses. I. Eadington, William R. 
To Margaret

2587848 



\title{
CONTRIBUTORS
}

\author{
JAMES J. BLASCOVICH \\ Professor of Psychology \\ Marquette University \\ Milwaukee, Wisconsin \\ DARRELL W. BOLEN, M.D. \\ Department of Psychiatry \\ University of California \\ Los Angeles, California \\ WILLIAM H. BOYD, M.D. \\ Department of Psychiatry \\ University of California \\ Los Angeles, California
}

HAROLD J. BRUMm, JR.

Professor of Economics and Statistics

California State University

Los Angeles, California

DUANE V. BURKE

President NLW Advisory, Inc.

Publisher of the NLW Newsletter

Boca Raton, Florida

DAVID P. CAMPBELL

Professor of Psychology

Center for Creative Learning

Greensboro, North Carolina

FELICIA CAMPBELL

Department of English

University of Nevada

Las Vegas,Nevada 
MICHAEL E. CANES

Professor of Management

University of Rochester

Rochester, New York

STUART E. Curms

State of Nevada Gaming Control Board

Economic Research Division

Carson City, Nevada

J. GEORGE DREWS

Treasurer and Controller

Harrah's Incorporated

Reno, Nevada

WILLIAM R. EADINGTON

Professor of Economics

University of Nevada

Reno, Nevada

GERALD P. Ginsaurg

Professor of Psychology

University of Nevada

Reno, Neveda

EDWARD GORDON

Department of Economics

Claremont Graduate School

Claremont, California

PETER GRIFFIN

Professor of Mathematics

California State University

Sacramento, California

JAMES N. HANSON

Professor of Computer Sciences

Cleveland State University

Cleveland, Ohio

ROBERT D. HERMAN

Professor of Sociology

Pomona College

Claremont, California 
RENE C. HOWE

Department of Psychology

University of Nevada

Reno, Nevada

HARRY L. HUMPHRIES

Department of Sociology

University of Nevada

Las Vegas, Nevada

\section{GEORGE IGNATIN}

Professor of Economics

University of Alabama

Birmingham, Alabama

TERRY J. KNAPP

Department of Psychology

University of Nevada

Reno, Nevada

ERIC S. KNowtes

Professor of Psychology

University of Wisconsin

Green Bay, Wisconsin

MICHAEL KUHLMAN

Professor of Psychology

University of Delaware

Newark, Delaware

\section{ICOR KUSYSZYN}

Professor of Psychology

York University

Toronto, Ontario, Canada

WEN LANG LI

Professor of Sociology

Ohio State University

Columbus, Ohio

TOMAS Martinez

Professor of Sociology

University of California

Riverside, California 
JAMES J. NOEL

State of Nevada Gaming Control Board Economic Research Division

Carson City,Nevada

FREDERICK PRESTON

Professor of Sociology

University of Nevada

Las Vegas, Nevada

RICHARD SCHUETZ

Department of Economics

University of Utah

Salt Lake City, Utah

MARTIN H. SMITH

Professor of Sociology

Ohio State University

Columbus, Ohio

ROBERT SMITH

Professor of Economics

Louisiana State University

Baton Rouge, University

RONALD W. SMITH

Professor of Sociology

University of Nevada

Las Vegas, Nevada

EDWARD O. THORP

Professor of Mathematics

University of California

Irvine, California

THEODORE Tsumahara, JR.

Professor of Economics

Pomona, College

Claremont, California 


\section{PREFACE}

THE OLDEST PROFESSION known to civilized society may very well be prostitution, but probably just as old as a leisure activity or as a more serious endeavor is the phenomenon of gambling. To stake something of value on the outcome of an uncerlain contingency is how it is usually defined, but to explain why so many diverse societies and individuals have been fascinated, even enamored, by the trappings of gambling in its various forms eludes any short explanation. Exploring different facets of gambling, how it affects the individual, the society in which the gambler exists, and where present trends in attitudes concerning gambling are taking us are the main purpose of this book.

Most of the articles included in this volume were initially presented at the First. Annual Conference on Gambling held in Las Vegas, Nevada. in June of 1974. The Conference was put together for the purpose of bringing together researchers with different areas of expertise and different views on the subject of gambling so that a greater understanding of gambling in modern society could be implemented. In spite of its long and often colorful history, gambling has never achieved the status of legitimacy, especially among academics and other serious researchers. As a result, most of what is known about gambling today is based on hearsay, gut reactions, religious beliefs or fears, or, occasionally, on sound research and analysis. It is hoped that the Conference, future conferences and this volume will begin a process of sorting through the hearsay and gut reactions to provide some definitive answers as to what gambling implies for modern society.

Can the serious study of gambling be justified? In the state of Nevada, the legal gaming industry is literally the lifeblood of the state's economy; twenty-five percent of all jobs in the state are associated with gaming and tourist-related activities, and at least that many jobs again owe their existence to the infusion of spend. ing by the more than 20 million tourists that visit the state each 
ycar. At this time thirteen states have established state-operated lotteries, eleven of them since 1970. Also, with the growing popularity of certain spectator sports such as professional football, it is likely that sports wagering, whether legal or illegal, will continue to grow at a rapid pace throughout the 1970 's.

But what of the effects on society? Most states which have considered gambling legalization point to the potential tax revenues which gambling can provide; they argue that gambling will exist anyway, and the status of illegality allows all benefits to go to members of organized crime. On the other hand, many people have long argued that widespread gambling will Iveaken the moral fiber of society and create undue hardships for those who are unable to control their gambling behavior.

Even with these relatively straightforward claims, there are presently no well-defined answers. Therefore, in order to provide better information on which to base future decisions on the role of gambling in society, basic research on its social, psychological and economic implications will be needed. This book is a start.

There are many other benefits which can arise from the study of gambling aside from the direct and pragmatic ones linked to the legalization questions. For example, the origins of probability theory can be traced to inquiries concerning the outcomes of dice games in the seventeenth century. Today, many of the concepts of probability are best illustrated by popular gambling games. In economics, the study of consumer behavior under conditions of risk and uncertainty has utilized wagers and lotteries to develop theories, and investment and speculation behavior has some obvious parallels to gambling situations. Compulsive gambling, it can be argued, is very similar in structure to compulsive drinking or other compulsive behavior. As such, its analysis may reveal considerable information about the nature of compulsions in general. Many playing and betting strategies can be developed for certain gambling games which allow for the sophisticated application of mathematical and statistical tools. These analyses can broaden the understanding of such abstract subjects as information theory, game theory and decision theory. In general, the study of gambling from a particular perspective or from a 
specific academic discipline can deepen the understanding not only of gambling, but also of the discipline in which the researcher is based.

Another benefit accrues when gambling is studied from a number of different perspectives. Gambling is a natural interdisciplinary subject. Therefore, by studying the sociology of gambling, the psychology of gambling or the economics of gambling, for example, an individual can learn about the methods and analytical approaches of sociology, psychology and economics. Further, when the methods and approaches of different disciplines interface on the same problems they can often be synthesized to the ultimate benefit of the disciplines involved.

In this book, as with much of the research on the subject of gambling, the reader must be somewhat careful in what he accepts as "true." Prior research in gambling has been plagued by too many inaccurate or invalid statistics and by too many implicit value judgments. Statistics cited in these studies are usually about as reliable as the sources from which they were drawn. Since many of the included studies were not profesionally reviewed or refereed, there may be instances where arguments are based on relatively weak statistical claims. It is up to the reader to use his own judgment in determining the reliability and accuracy of empirical arguments included herein.

The articles included in this book however provide a unique opportunity to examine a subject of significant historic and social importance in a manner which has not previously been possible. The study of gambling is fascinating, perhaps because it is so easy to relate it to parallels in areas of our everyday lives. But the surface has only been scratched; many questions remain to be satisfactorily answered: why people gamble, how gambling affects their values, why gambling has long been of questionable morality, and why gambling and criminal activity have been highly correlated. 



\section{ACKNOWLEDGMENTS}

WOULD LIKE TO THANK the Bureau of Business and Economic 1 Research of the University of Nevada, the Western Economic Association, and Ms. Sheila Adams and Professor Bob Herman for their help with the First Annual Conference on Gambling and with suggestions and prodding for this book. As with any book of readings the quality is only as good as the contributed articles; in this respect, I have been very fortunate to have been associated with excellent scholars. I would also like to thank my typist, Therisia Peterson, for her excellent work with the manuscript. Finally, I must thank my advisor, social organizer, assistant conference co-ordinator and wife, Margaret, for her time and understanding.

W.R.E. 


\section{CONTENTS}

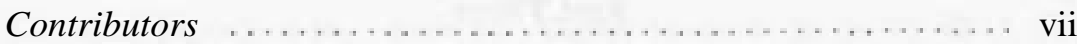

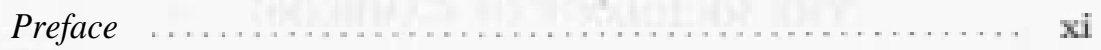

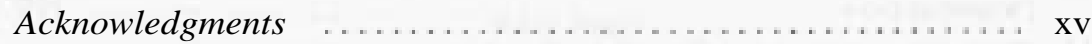

\section{Part One \\ THE LEGALIZATION OF GAMBLING}

Chapter

Introduction ................................. 5

1. GAMBLING: HISTORICAL HIGHLIGHTY AND TRENDS AND THEIR IMPLICATIONS FOR CONTEMPORARY SOCIETY-

Darrell W. Bolen, M.D. ................... 7

2. THE LEGALIZATION OF GAMBLING IN THE UNITED STATES: AN ANALYSIS AND ForecasT-Duane V. Burke ............. . 39

3. SOME OBSERVATIONS ON LEGALIZED GAMBLING-

William R. Eadington ......................... 47

4. SPORTS, TECHNOLOGY, AND Gambling-Richard J. Schuetz, Jr. 57

\section{Part Two \\ THE ECONOMICS OF GAMBLING}

Introduction .................................... 65

5. THE ECONOMICS OF Gamalung-George Ignatin and

Robert F. Smith ................................ 69

6. ECONOMIC RATIONALITY, PSYCHOLOGY AND DECasion-Making

UNDER UNCERTAINTY-Theodore Tsukahara, Jr. and

Harold J. Brumm, Jr. . . . . . . . . . . . . . . . . . . . 92

: 7. THE MARKET FOR PRO FOOTBALL Berting-Michael E. Canes . 108 -

8. ECONOMIC ASPECTS OF NEVADA'S GAMING INDUSTRY-

William R. Eadington 
XV111

Gambling and Society

Chapter

Page

9. THE BUSINESS OF GAMING: AN INSIDER'S Vuw-J. George Drews 159

10. PROFITABILITY AND BEHAVIOR OF THE GAMING INDUSTRY

RELATIVE TO THE STOCK MARKer-James J. Noel and

Stuart E. Curtis

Part Three

THE SOCIOLOGY OF GAMBLING

Introduction , . . . . . . . . . . . . . . . . . . . . . . . . . 187

ill. THE PROPENSITY TO GAMBLE: SOME STRUCTURAL

Detraminants-Wen Lang Li and Martin H. Smith .. . . . . . 189

12. MOTIVATIONS TO GAMBLE: THE MODEL OF ROGER CAILLOIS-

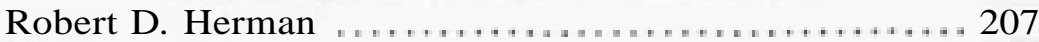

13. GAMBLING, A Posmrive Vrzw-Felicia Florine Campbell ...... 218

14. ALIFNATION FROM WORK: A STUDY OF CAsINo CARD DEALERS-

Ronald W. Smith, Frederick W. Preston and

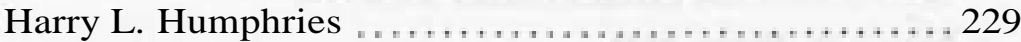

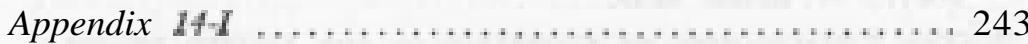

Part Four

THE PSYCHOLOGY OF GAMBLING

Introduction , . . . . . . . . . . . . . . . . . . . . . . 249

15. How GAMBLING SAVED ME FROM A MISSPENT SaввaticaL-

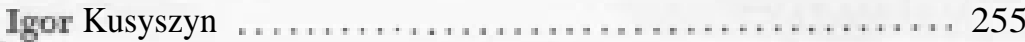

16. WHO WANTS TO BE A PROFESSIONAL GAMrifr?-

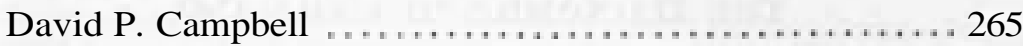

n. A FUNCTIONAL Analysis OF GAMBLING BEHAVIOR-

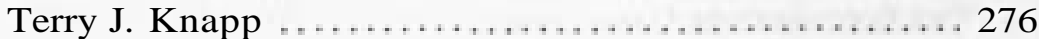

78. SEARCHING FOR THE MOTIVATIONS IN RISK TAKING AND

Gambeng-Eric S. Knowles . . . . . . . . . . . . . . . . 295

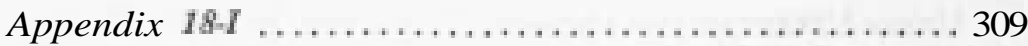

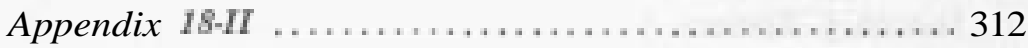

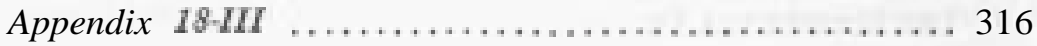

19. INDIVIDUAL DIFFERENCES IN CASINO GAMBLING-

D. Michael Kuhlman 
Chapter

Page

20. RISK-TAKING IN THE PRESENCE OF OTHERS: BLACKJACK IN THE LABORATORY AND IN THE FIELD-G.P. Ginsburg,

James J. Blascovich and Rene' C. Howe 336

21. COMPULSIVE GAMBLING AND THE CONSCIOUS MOOD

PERspeCtive-Tomas Martinez . . . . ... 347

22. EXCITEMENT: THE GAMBLER'S Druc-William H. Boyd, M.D. 371

\section{Part Five \\ THE MATHEMATICS OF GAMBLING}

Introduction

23. OPTIMUM STRATEGY IN BLAGKJACK-A NEW ANALYSIS-

Edward Gordon

24. NONLINEAR PROGRAMMING, SIMULATION AND GAMBLING

THEORY APPLIED TO Black JAck-James N. Hanson ........ 407

25. THE RATE OF GAIN IN PLAYER EXPECTATION FOR CARD GAMES CHARACTERIZED BY SAMPLING WITHOUT REPLACEMENT AND AN EVALUATION OF CARD COUNTING SYsTEMs-Peter A. Griffin ... . 429

26. PROBABILITIES AND STRATEGIES FOR THE GAME OF FARO-

Edward O. Thorp . . . . . . . . . . . . . . . . . . . . . . . . . . . . . 443

Appendix $26-I$.................................... 463 

GAMBLING AMD SOCIETY 


\section{PartDne}

\section{THE LEGALIZATION DF BAMBLING}




\section{INTRODUCTION}

Since the end of World War II the popularity of both legal and illegal gambling has immensely increased in the United States and throughout the world. In Nevada and on many islands in the Carribean legal casino gambling has become a respectable, sometimes glamorous recreational activity. From 1964 to 1974, thirteen state-operated lotteries appeared in the United States, mostly on the East Coast, and the rise in professional sports, especially televised professional football, has brought about significant increases in the volume of sports betting in this country in spite of the fact that sports wagering is still illegal in all states but Nevada.

The growth in the general appeal of gambling has been paralleled by changing attitudes concerning the morality of gambling. In much the same fashion as with other victimless crimes, society has been re-evaluating its traditional stances concerning the effect of widespread gambling on society. As a result, many of the dogmatic beliefs of the past are being analyzed again in light of new information and evidence. This is not to say that the old beliefs will be found wrong, but rather that the pressures to legalize more and more forms of gambling in the United States have necessitated finding objective estimates of the costs and benefits which legal gambling could have on society.

In a sense this entire book concerns itself with the question of legality versus illegality. However, the chapters of Part One deal directly with the pro and con arguments of legalization, as well as with projections of what is likely to happen with legal gambling in the United States in the near future. The article by Darrell Bolen presents a short history of gambling and gamblers, then discusses the relationship between gambling, corruption, morality and the law. Bolen runs through most of the standard arguments for and against legal gambling and offers his opinions and suggestions on how the gambling propensities of society could best be harnessed by legislators. 
Duanę V. Burke is president ofNLW Advisory, Incorporated, a firm which specializes in public gaming research and in keeping tabs on legislative actions concerning gambling. His article discusses the present state of legal gambling in the United States and forecasts future trends on the legalization question.

The article by Eadington discusses the likely effect legalized casino gambling would have on an individual living geographically close to casinos. He then presents an argument on the influence that the geographic location of casinos will have on their likelihood of economic success.

The final article in this section, by Richard Schuetz, traces the evolution of the relationship between organized sports in this country and the individual as a sporting participant. Gambling, he argues, could be the next logical link in this evolutionary chain. 


\title{
Chapter 1
}

\section{GAMHLING: HISTORICAL HIGHLIGHTS AND TRENDS ANI THEIR IMPLICATIUNS FUH CONTEMPORARY SOCIETY}

\author{
DARRELL W. BOLEN
}

THROUGHOUT HISTORY GAMBLING has been one of man's most 1 frequent endeavors. In one form or another, gambling has been present in all cultures, all periods of time and widely participated in by those of all societies and social strata. Anthropological studies reveal its ubiquitous occurrence in the most primitive of societies and that modern games of chance are merely sophisticated versions of games once played by our forebearers (Bolen and Boyd, 1968).

\section{THE OBSCURE ORIGINS OF GAMBLING}

Exactly how gambling was invented in antiquity is an obscure matter of speculation. It probably originated out of primitive man's fascination with early religion, divination and primitive justice. For the primitive mind, as well as the unconscious mind of modern man, nothing-especially an uncertain event-is without cause and effect (Cohen and Hansel, 1956). Cohen (1970) maintains that games of chance developed as a gradual secularization of primitive religious divinitory rights. Thus, pagan priests cast lots or rolled primitive dice to compel the Gods to reveal secrets of the future and to reduce uncertainty in decision-making. Since they believed that the Gods controlled the fate of the dice and, hence, answered complex problems presented to them, enterprising priests-quite unbecoming to such devoted men-are said to have loaded the cubes trying to outwit the dieties (Aginsky and Aginsky, 1950). These religious men were probably the first 
in a long series ofcheaters who have peopled gambling history.

In essence, unpredictable events were felt to be determined by supernatural agencies to which one could magically appeal for favor or decisions. This is illustrated in the identification of criminals by nut spinning or casting of lots in some precivilized societies (Bolen and Boyd, 1968). Variants of gambling and gambling paraphernalia have been used by the witchdoctor in primitive medical practice to divine if a gravely ill person would recover or to attempt to influence the gods to favorably effect a cure (Reid and Demaris, 1963) - As civilization has advanced and games of chance have become more sophisticated, the elements of superstition, magical thinking and appeals to dieties are now less apparent. Nonetheless, the unconscious mental processes of modern pathological gamblers are quite similar to those of primitive gamblers. There is a type of gambler, the so-called praying John, who silently or audibly uses incantation and magical thought in order to solicit luck or good fortune. Lucky items, e.g. coins, rabbits' feet, and lucky rituals such as blowing on the dice or the timely passing of gas are superstitions of the modern gambler. Thus, the modern gambler behaves as though he subjectively believes that he can control or contradict the laws of probability by certain types of thought or action. He is not unlike the sorcerer who has similar ceremony and paraphernalia. The dieties to which the modern gambler directs his appeal are the fickle Lady Luck and punitive Father Fate.

The ancient Greeks institutionalized gambling more formally in their religion and had a specific goddess of gaming and fortune called Tyche. Fortuna was a similar female diety of the Romans. For the Greeks, the intimate relationship of gambling and religion was expressed in many of their myths. One is especially noteworthy and involves the origin of the universe and the Gods which directed the various portions of it. In this myth, three brothers shot dice for the universe in the highest-staked crap game of all time. Zeus won the heavens, Poseidon won the oceans and Hades lost and was sent to hell as master of the underworld (Wagner, 1972) .

Anthropological studies uniformly have found primitive 
gambling to occur in an institutionalized, tribal setting in which various social and religious activities predominate (Bolen and Boyd, 1968; Devereux, 1950). The modern gamblers' superstitions and paleological thought processes are merely more sophisticated and cleverly disguised than those of primitive gamblers who also engaged in numerous taboos and restrictions as well as positivistic actions in attempting to secure luck. Stroking rattlesnakes and manipulating specific gambling items such as animals' bones during the course of elaborate dance, prayer and song are some of the rituals of primitive gamblers (Bolen and Boyd, 1968).

\section{HIGHLIGHTS OF THE HISTORY OF GAMBLING}

Although clearly a fascinating topic, a considerable amount has been written on this aspect of gambling. The interested reader is referred to other exhaustive treatments of the subject (Ahrnborg, 1950; Chafetz, 1960) .

Gambling has an exciting and checkered past, and innumerable colorful characters and outright knaves have peopled it in one way or another. Let me cite but a few examples. The compulsive gambler was recognized as early as biblical Egypt where he was sent to the quarries to work off his markers by honing stones for the pyramids, and the loaded dice used by many of the Pharaohs, who were compulsive, and crooked gamblers, have recently been excavated by archeologists (Wagner, 1972) . In Greek mythology, Palamedes invented the dice and taught his fellow soldiers how to play craps in order to relieve boredom during the long seige of Troy. He soon learned the practice of trick dice throwing, which modern gamblers call whip shooting or riding the dice, and was eventually stoned to death for using these deceptive gambling practices (Reid and Demaris, 1963). Palamedes has the questionable distinction of being the first gambler cheater to be put to death for deceptive gambling practices. Throughout history, similar lynch law justice and quick draw pistol execution of cheaters continued in the bawdy saloons of the western frontier, the Klondike and amidst the luxury in the gaming rooms of the Mississippi riverboats. 
As a result of their gambling activities certain individuals have made unusual cultural and scientific contributions. The Earl of Sandwich invented the item of food which bears his name in order that he could snack quickly and informally without interrupting his gambling (Barrow, 1969). The prince of gamblers of the early 1900 era, Richard Canfield, invented the card game of solitaire which has given untold pleasure to millions of lonely hearts (Wade, 1973). However his true contribution to gambling history was (1) being the first to master and perfect the fine art of buying police and judicial protection for illegal gambling operations and (2) establishing elegant gambling casinos which catered to the dignitary and social elite of the time. His casinos were the forerunners of the modern Las Vegas type and gave gambling an air of respectability in contrast to the dives and hovels where it had been characteristically conducted. During the Renaissance, Gerolamo Cardano, a renowned and controversial physician, inventor and philosopher, was also an inveterate gambler. He authored the first how to handbook of gambling (Liber de Ludo Aleae or The Book on Games of Chance) in which he formulated the rudiments of probability theory (Ore, 1963). It is a matter of historical controversy whether Cardano or Blaise Pascal is to be considered the true father of probability theory, but even Pascal was forced to think out and formulize his early concepts about probability theory based on a complex gambling problem posed to him by a gambler.

Many famous men have been gamblers. The best and worst of mankind from all walks of life have been afflicted by the gambling mania. The soldiers of Pontius Pilate gambled for the clothing and meager possessions of Jesus after they had crucified him. The novelist Dostoevsky's intemperate gambling is well-known and seen as an artistic necessity; it was during the period of dejection and humiliation after losing everything that the creative spirit moved him with renewed force, enabling him to write (Squires, 1935) - As a student the composer Richard Wagner was given to transient excessive gambling in which he dissipated his elderly mother's pension checks; this caused him to comment, "the despair over lack of good luck Haired my passion into an in- 
sane craving" (Stekel, 1958). The Emperor Nero was addicted to dice. George Washington gambled excessively in a wide variety of ways. His nightly poker parties upon the crude table in his Revolutionary War tent headquarters was a source of embarrassment to the military establishment, especially when they continued after he was forced to issue a military order that all gambling must cease in order to quell rampant gambling at cards amongst subordinate military personnel. In addition, George gambled on and sponsored cock fights, owned and raced horses, and regularly made book for his friends at a 10 percent commission.

Racketeer operators and gangsters have typically been gambling devotees. The mobster-professional gambler, Arnold Rothstein, holds the unofficial world record for winning the largest single pot in the history of poker- $\$ 605,000$-from Nick the Greek. However, Rothstein is better known for his alleged role in fixing the 1919 World Series (Wade, 1973). Rothstein was also a pioneer in organizing illegal gambling in conjunction with g9Mprostitution rings, illicit narcotic traffic and prohibition rum1. running along a corporate basis with respectable, legitimate busijness fronts until he was assassinated after welching on his gambling markers after a long series of losses. Apparently emotionally upset after being given a divorce notice by his wife, he developed an atypical compulsive losing pattern at his gambling.

The prosperity and free and easy atmosphere stemming from the prohibition era and the two world wars spawned a host of colorful, high rolling, Runyonesque gamblers unparalleled in their conspicuous consumption and notoriety. Nick the Greek, Bet-A-Million Gates, Diamond Jim Brady and Chicago O'Brien are but a few. Less well-known was Pittsburg Phil (alias George E. Smith) -probably the most successful horse handicapper of all time-who died with an estate of nearly two million dollars in cash earned exclusively from playing the nags (Cole, 1908) . Lastly, there was Titanic Thompson, a gambler and hustler who is still without parallel for his ingenious trick gambling wagers and propositions. This is said with all due respect to the considerable abilities of Bobby Riggs and Amarillo Slim. 
The Hollywood movie colony has always been fascinated with and extensively involved in horse racing. Thus, during a Santa Anita race meet some years ago, Groucho Marx appeared at the office of an MGM executive clad in a jockey uniform because, he said, "This is the only way you can get to see a producer these days" (Rosten, 1967).

Many other historical facts and incidents could be cited. Like most historical facts they may be interesting or entertaining but are not especially useful in themselves. Thus, the remainder of this chapter will consider some historical trends, axioms and sociological problems which have characterized man's gambling history. These historical lessons have direct relevance to our contemporary gambling scene and to related problems. They should be useful pragmatically in evaluating the current legislative proposals for liberalized gambling which are sweeping this country and others.

\section{AXIOMS AND TRENDS IN THE HISTORY OF GAMBLING}

GAMBLING AS A UNIVERSAL PHENOMENON. In the history of man, gambling is unique due to its ubiquitous presence. It has been participated in widely by all men in all societies throughout all of recorded time, and it has persisted despite recurrent and often Herculean religious, political and legal efforts to control or eradicate it.

Balzac put the matter simply, "the gambling passion lurks at the bottom of every heart" (Epstein, 1967). Cohen points out, "the analysis of gambling practices, age-old and world-wide as they are, suggest that ... some of the most profound and complex features of the human mind" are involved with the implications extending "far beyond the gaming table or the pack of cards into risk-taking and decision-making" processes in a wide variety of life experiences (Cohen, 1970).

However we are left without an adequate explanation of why gambling occurs as a practice that is so ancient, universal and ineradicable. At least in part, the author feels it has to do with two fundamental properties of the human mind. One is the need of the human mind for stimulation and excitement. To the extent 
that much of human life is routine and boring, gambling provides a source of excitement and self-stimulation and, thus, provides a basic commodity needed by the human organism. The second property involves the hatred of the human mind for uncertainty. The psychotherapist is intimately familiar with the innumerable defense mechanisms, illusions and self-deceptions of the human mind that attempt to minimize or prevent uncertainty and insecurity. For some individuals religion may involve a way of dealing with the uncertain issues of death and life after death. The purchase of property insurance or life insurance involves, in part, such a mental gymnastic and an attempt to minimize risk by turning a potential loss into a profit if our house were to burn or we were to die earlier than our measure. Here one snatches a partial victory from the jaws of loss in attempting to overcome these uncertain events.

Just as the pagan priest used gambling devices in divinitory rights as a means of reducing uncertainty in decision-making, the modern gambler appeals to the disguised divinities of Lady Luck and Father Fate. At this point we reach a sticky philosophical paradox in which the gambler consciously undertakes a hazardous, risk-taking event in order to gain the illusion of certainty by appealing to luck and disguised dieties. In fact gambling may be the most absurd paradox in which man engages, namely, the gambler engages in the uncertain business of gambling as an exciting counterphobic means of attempting to achieve the illusion of certainty or to force certainty in a risky situation.

A literary example may make this idea less vague. In the gambling scenario of the play Guys and Dolls, Sky Masteson pleads and commands in the song "Luck Be A Lady Tonight" and, thus, tries to force Dame Fortune to turn the dice in his favor.

SOCIAL PREJUDICES AND THE ILLEGITIMACY OF GAMBLING. There is an aphorism which is also a historical truth. It goes, "you can legalize gambling, but you can -never-make it legitimate." Gambling has never met with widespread approval and at best it is viewed as a minor vice. Meanwhile the moralist considers it a $\sin$ and views it with contempt and disdain. The anthro- 
pologist, Devereux, puts the matter aptly when he says, "Gambling like prostitution is ancient, widespread, and widely disapproved" (Devereux, I968).

The tenacious and addictive power that gambling holds over the pathological or compulsive gambler fills his acquaintances, friends and loved ones with feelings of irritation, frustration, ineffectiveness, awe, disgust and jealousy. As the exasperated wife of a pathological gambler once put it in a therapy group for gamblers and their spouses, "I wish it were another woman; at least I could fight that" (Boyd and Bolen, 1970) .

Unfortunately these attitudes about gambling extend to the legitimate and scientific study of gambling and the problems posed by excessive gambling in pathological gamblers. A friend of the writer was bypassed for academic promotion because his excellent studies and papers about gambling were considered not to be respectable, appropriate subjects for scientific investigation by his superiors. In addition, his telephone was bugged by governmental officials who suspected him of who-knows-what-type of nefarious activities.

Some years ago, when Dr. Boyd and the writer were residents in psychiatric training, it was widely suspected by their superiors (and partly accurately) that their forays to Las Vegas and to the Los Angeles race tracks were more an excuse to engage in gambling than to satisfy the requirements of a research project of our training program. We found social workers reluctant to work with the families of pathological gamblers, and they exhibited a maze of excuses and rationalizations for their disinterest and avoidance.

Hopefully scientific conferences on gambling will help overcome such prejudices and help make the study of gambling in general, and pathological gambling in particular, a legitimate as well as legal subject of scientific investigation. This is a matter of paramount importance since the issues involved are vital ones at individual, socioeconomic and scientific levels.

RECENT DEVELOPMENT IN SCIENTIFIC STUDIES OF GAMBLING AND RELATED PROBLEMS. There is a recent historical trend that is most reassuring in this regard. It involves the increasingly fre- 
quent appearance of papers in the scientific literature dealing with the wide variety of matters related to gambling and risktaking behavior (Kusyszyn, 1973) .

Prior to the late 1960's a paucity of psychiatric and scientific studies of gambling and the pathological gambler existed (Bolen and Boyd, 1968) - Most involved case studies of pathological gamblers treated in psychoanalysis or intensive therapy. Only a few psychometric studies of personality correlates of gamblers and risk takers existed, and these focused on trivial issues about artificial gambling and risk-taking situations. Usually, the subjects were college students or other paid volunteers. The results of these studies had little if any utility when applied to real-life gambling situations and actual gamblers.

In the late 1960's a flurry of papers about gambling and related problems appeared in the scientific literature from many countries. In part, this was due to gambling and pathological gambling having been poorly and inadequately studied topics and, also, because gambling was rapidly increasing worldwide. Its scientific study became increasingly imperative. Theoretical papers about gambling and clinical case studies of gamblers appeared. (Bolen and Boyd, 1968; Bolen, 1971; Kusyszyn, 1972; Montgomery and Kreitzer, 1968; Moran, 1970a, 1970b, 1970c). Papers appeared describing the application of recent treatment techniques to individuals with problematical gambling. A wide variety of treatment methods were involved and included Gambler's Anonymous (Scodel, 1964), marital couple group therapy (Boyd and Bolen, 1970), conjoint marital therapy (Bolen, 1968), the technique of paradoxical intention (Victor and Krug, 1967), and the behavior therapy techniques of (1) electric shock aversion therapy (Barker and Miller, 1968; Goorney, 1968; Seager, 1970) and (2) a stimulus satiation extinction technique (Peck and Ashcroft, 1970). Ingenious empirical psychological and sociological studies have been conducted in actual gambling situations at bookie joints (Zola, 1967), policy parlors (Drake and Cayton, 1967), race tracks (Herman, 1967; Knox and Inkster, 1968; Kusyszyn and Rubenstein, 1971; Scott, 1968), Gambler's Anonymous meetings (Pokorny, 1972), etc. Even the monotonous- 
ly boring experimental studies of artificial risk-taking and gambling behavior have shifted in recent years to methodology and issues more similar and applicable to real life gambling situations (Kusyszyn, 1973) ; however, the writer does not feel particularly qualified in this area except to exercise his right of free expression of impressionistic opinion. However, he feels confident that these types of studies which are appearing with increasing frequency in the scientific literature and the high quality of scientific papers being presented in this volume are our best bet to insure that the scientific study of gamblers and gambling-related problems will become a legitimate, respectable and important area of investigation.

EVOLUTION AND IMPROVEMENT OF GAMES OF CHANCE. Throughout history, there has been constant streamlining and improvement in games of chance which are demanded by the gambling instincts of man and the process of cultural change. Often these innovations have been clever maneuvers to escape the latest antigambling statutes. Roulette, a dignified, slow-paced type of gambling popular in the Victorian era has given way to the currently more popular fast action types of games like craps, slots and blackjack which are more consistent with our modern style and pace of life. The modern dice are much improved over their historical predecessors, the polished astragals (tali), made from the knuckle bones of sheep or goats. Another example is the current slot machine. Its effortless levers, sleek elegance, jackpot flashing light-buzzer devices, and master jackpot payoff gimmicks are a far cry from their simpler, sturdier predecessors jerked by the rugged cowboys in frontier saloons. Pinball machines, legally defined as gambling devices in some states, are a refined electronic derivative of an ancient Greek game which involved rolling balls down a maze and obstacle-studded hill toward a goal at the bottom (Coggins, 1966) .

INEFFECTIVENESS OF LOGIC AND KNOWLEDGE IN CONTROL OF GAMBLING. Just as gambling has persisted despite legal and religious efforts to eradicate it, it has also been impervious to rational and educational methods to control it. Man's knowing the odds that the chances of winning are slim to nonexistent are 
matters of profound indifference to inveterate gamblers. Gamblers seek out the excitement or action in gambling, and all else is irrelevant. There is an old gambling story told in many forms. It involves the gambler who is cautioned by friends not to continue playing in a game run by rogues who cheat, that he has virtually no chance of winning, and most certainly will continue to lose. To this the gambler responds, "I know, but it's the only game in town."

It is a curious historical fact that vile gambling joints peopled by knaves, sharpers, ropers and steerers have only served to heighten the excitement and increase their patronage. Muggers known to be awaiting in the dark alleys outside the gambling dens to rob the few fortunate enough to escape with winnings further increased their allure.

According to a friend, after World War II, illegal gambling flourished at a historic old country club in Denver. The club was raided at least weekly by a mutual agreement between the club and the police department. The publicity which surrounded this caused crowds of gamblers to flock there to gamble illegally and participate in the notoriety, excitement and chaos of the raid.

GAMBLING AND FRAUD AS INTIMATE BEDFELLOWS. Another truism from gambling history is that dishonesty and fraud have invariably been an integral part of the gambling business. Cheating and gambling have always been a hand-in-glove proposition. In spite of house odds or skill factors in their favor, greed has always motivated gamblers and gambling establishment operators to attempt to increase their advantage through sleight of hand, the rigged wheel or machine, or loaded dice. In animal racing the glory days of ringers*; jockey-manipulated, fixed races; the dutch bookt; and the administration of stimulant or depressant drugs

*A ringer is a horse of superior ability that is cleverly and illegally substituted in a race for a less able horse. Ideally, the horses are similar or identical in color and markings. Prior to the current lip tatoo method of identification, expert cosmetologists were available and could transfer the color and markings of one horse into a dead ringer of another.

tPrior to the pari-mutuel era a clever gambler could bet all the horses in a given race at fixed odds with several bookmakers in such a fashion that he could turn a net profit regardless of the winner. 
are part of the nostalgic past due to the current strict regulation by honest racing officials and the pari-mutuel machine. Nonetheless, man's ingenuity in cheating at gambling is infinite and an occasional crooked gambling coup in animal racing still occurs.

Not even lotteries and sweepstakes have been immune from cheating practices. Rigged drawings were typical abuses of the early colonial lotteries (Weiss and Weiss, 1966).

Although it is a federal offense to import and sell Irish Sweepstake tickets, the practice is widespread in this country. Newspapers perpetuate the tradition by printing lists of potential and then the eventual winning ticket holders. Further, they glorify the process with rags to riches human interest stories about the winners. No publicity is given, however, to the fact that the vast majority of Irish Sweepstake tickets are counterfeit (Blanche, 1950). For years, racketeers have maintained their own bogus printing press in order to pocket the entire take from the proceeds of these tickets that allegedly go to charity hospitals in Ireland.

The refined techniques of the modern cheat are a far cry from the crude ones utilized by Elijah Skaggs and his carefully schooled clan of sharpers who roamed the gambling arenas of frontier saloons in the mid 1800's or the three-card monte knaves such as George Devol or Canada Bill Jones of the riverboat era (Chafetz, 1960) - The novel Goldfinger (Fleming, 1959) and the 1968 trial over the Los Angeles Friar's Club cheating scandal illustrates the degree to which elaborate electronic and optical equipment have been adapted to modern gambling trickery.

Card games have been the most readily adapted to ruthless cheating techniques with craps utilizing trick dice, (e.g. loaded, hollowed out, shaved or beveled, magnetized, etc.) running a close second. Innumerable books are readily available which describe and teach time-honored card sharper sleight of hand techniques (e.g. second dealing, bottom dealing, stacking, stripping, etc.) - The mail order sale of gambling cheating equipment is a multimillion dollar industry (Morehead, 1950). A wide variety of crooked gambling devices are available on the open market and include such items as marked decks of cards, card decks with 
strippers ${ }^{*}$, small reflective mirrors, specially tinted contact lenses for reading ink and phosphorescent ink-marked cards, minute fingernail insert card cutters and markers, shirt sleeve inserted card hold out machines and cold deck machines, magnetic belts and aprons to effect loaded dice, remote control electronic and magnetic equipment for gambling wheels and crap tables, battery operated radio cue prompters by which one cardplayer can transmit his hand in code to another gambler via small electric shocks or hearing device beeps (U.S. Senate Hearings, 1967).

THE PARALLEL EXPANSION OF ILLEGAL FORMS OF GAMBLING AND RELATED PROBLEMS WITH LIBERALIZED LEGAL GAMBLING. History has repeatedly shown that legislative sanction expanding gambling quickly results in mass gambling and greatly increases its illegitimate offspring. Proprietors of illegal gambling operations regularly support and promote expanded legal gambling because they know their business will increase proportionately. With this expansion of gambling, the bulk of the economic loss is usually sustained by those of low income groups who are least able to afford it (Bolen and Boyd, 1968). This has occurred recently in England, and Moran (1970a) has demonstrated how the greater availability of gambling facilities was directly proportional to the increased number of compulsive or pathological gamblers.

For substantiating evidence of this historical trend, we need look no further than articles in our recent newspapers. In the past ten years, first New Hampshire and then twelve other states have instituted state lotteries. In addition, New York initiated legal off-track wagering. The final judgment on these gambling experiments is not in, but, overall, the initial results range from disappointing to early indications of possible disaster, and it is probably too early a time frame for these lotteries to fall into the usual historical pattern of corruption and utter failure.

David Smothers (1973) recently reported in the Los Angeles Times that a United Press International survey of gambling in America revealed that more Americans are gambling more exten-

*Strippers are slightly enlarged cards that are easily and undetectably pulled out or stripped from the deck when needed to make a hand. 
sively, both legally and illegally, than ever before. William Endicott (1973) reported on a Los Angeles Times survey of the legal state lotteries and concluded that the programs are an unstable source of revenue, that the costs of promoting them are unexpectedly high, the net profits are far less than predicted, they have made no successful inroad into illegal forms of gambling as anticipated, and they have created a whole new set of bettors drawn from the middle class who seldom wagered previously.

A recent study by the New York City Police Department concluded that legal off-track betting was associated with a 62 percent increase in illegal betting (mainly on sports), that the number of mobsters involved in illegal gambling had increased, and the effect of reducing crime had been minimal. All these results were contrary to prior police predictions and the justifications politicians had used to initiate off-track wagering. Perhaps this is why the New York Police Department officially disclaimed the results of their internal memorandum as premature and misleading.

In a 1950 article entitled "Lotteries Yesterday, Today and Tomorrow" Ernest Blanche had the foresight to anticipate the results and effects of today's lotteries. He noted that the worthy purposes which had won support for the unsuccessful lotteries of the original thirteen colonies and the Revolutionary War Lotteries were again being cited in drives for new American lotteries and stated,

Morally and legally wrong and outlawed, lotteries do more than mulct the rich and poor alike; lotteries change the very pattern of living, distort the sense of values, and incubate the eggs of crime. Examine the sociological and economic implications of the lottery and you will behold a Frankenstein monster capable of consuming both those who run the lottery and those who play them. The financial returns, insignificant in proportion to the national income or the federal expenditures, are like the 30 pieces of silver paid for the betrayal (Blanche, 1950).

The supreme irony of the lottery experiment to date is that New Hampshire first started it all to obtain funds for education since it ranked fiftieth among the states in aid to education. Today, ten years later, New Hampshire still ranks last in aid to 
education, and property taxes have risen there as elsewhere. Nonetheless, New Hampshire residents are widely approving and enthusiastic about their state lottery (Endicott, 1973).

THE HOLY Trinity-Gambling, CRIME, CORRUPTION. In American gambling history, from the casino-saloons of the frontier or boom town mining camps to the modern metropolis, a holy alliance has existed between illegal gambling, syndicated crime and widespread corruption of public officials. This triad has been so ubiquitous and invariable as to be almost as American as the hamburger. It is unlikely to be changed even by the social and political reverberations stemming out of the Watergate Affair.

Protected illegal gambling has long been the wheel of fortune which financed the bulk of underworld activities in the United States, especially the funds to underwrite narcotic rings (Kennedy, 1967). Only crude guess-estimates of the amounts of money wagered and the net profit from illegal forms of gambling are available. Estimates vary widely, but the annual handle on all forms of illegal gambling involves billions of dollars, and is in excess of the United States defense budget with a profit of nine billion dollars or more for the underworld operators (Bolen and Boyd, 1968).

A large part of these enormous profits (approximately 50\%) goes forjuice money or influence purchasing with key politicians, local magistrates and law enforcement officials. Thus, antigambling statutes can be subverted anywhere along the hierarchy from the local policeman, higher police officials, elected or appointed political officials, or by the judiciaries-the latter frequently administering penalties with great leniency and inconsistency (Peterson, 1950) .

In recent years, racketeers have shifted from an image of gang rule and violence to one of respectability, gentility and the legitimate corporate business front. This has paid off handsomely and syndicated crime flourishes as never before in our history. The interested reader is referred to other sources (Reid and Demaris, 1963; Peterson, 1950; Lawrence, 1950; Turner, 1965) for the details about this particular holy trinity. Fred Cook, in his book 
with the unlikely title, A Two Dollar Bet Means Murder (1961) dramatically points out how the innocent, illegal two-dollar bet with a bookie by the average citizen eventually finances corporate crime, prostitution rings, narcotics traffic, corruption of public officials and hired contract murder.

GAMBLING AND ABSURDITIES. From whatever perspective gambling is viewed, one encounters absurdities of unparalleled dimensions. In our society a host of curious paradoxes and rationalizations exist regarding gambling. Both church and state have long known that man's charitable and taxable nature are far less than adequate to meet their expense accounts, and bingo, raffles, lotteries and other taxable forms of gambling are condoned as a matter of financial expediency. Religious organizations often condemn gambling as immoral and a $\sin$ while simultaneously promoting and profiting from bingo and various raffles with the justification that the end (charity) justifies the means (gambling). Frequently, religious and charitable organizations exert improper methods of influence on law enforcement officers identical to those employed by criminal elements to obtain leniencies and promote these charitable forms of gambling (Peterson, 1950). Racketeers frequently administer charity forms of gambling in conjunction with church, state or charitable organizations. Often enterprising individuals resort to the respectable charitable facade in the illegal promotion of gambling, then pocket the entire profits.

The public press, man's other great antigambling defendant, "sporadically inveighs against gambling and its attendant evils yet facilitates it by publishing the data essential to gambling in many forms" (Ploscowe and Lukas, 1950) .

The FBI investigates and the federal government enacts against the professional gambler-racketeer, yet both recognize him as a legitimate, though crafty, taxpayer, and income tax evasion is the usual way in which he is entrapped.

Another inconsistency is the average citizen who predictably will defeat gambling enactments at the polls, but who is not deeply interested in the enforcement of laws against games of chance. In fact, he may vote against them and then widely par- 
ticipate in forms of illegal gambling. The difficulty in enforcing antigambling statutes is clear-cut-inadequate federal and local laws are inadequately enforced; not much is done and that which is done is done poorly. A humorous illustration of this involves a story told by an attorney acquaintance. Years ago, he had worked for the city attorney's office in a division which prosecuted apprehended bookmakers. On the other hand, he and his legal peers daily used city telephones during work hours to call in their own off-track bets to their own unapprehended bookie.

RATIONALES AND JUSTIFICATIONS FOR LEGALIZED GAMBLING. Throughout history there have been several categories of assumptions and/or rationales for liberalizing gambling, for legally allowing certain forms of gambling and for allowing certain illegal forms of gambling to continue unmolested. Historically these assumptions are as recurrent in their persuasive good intentions as they are repetitively fruitless and often philosophically inconsistent. Usually these proposals seem logical and make good common sense-until one scrutinizes them closely.

THE CHARITY EXEMPTION. This rationale involves a the end (justifies the means proposition. For small local organizations the charity carnival, raffle or bingo night is an effective fund raiser precisely because people would rather throw a certain amount of money away having fun than endure the agony of parting with it by a donation or assessment. In colonial days charitable lotteries contributed to the settlement of the colonies, helped build the forerunners of famous colleges, and financed the construction of roads and other public works, but charity faded as greed, corFuption and other abuses ensued, and the lotteries were progressively repealed. Look closely at most large-scale gambling promotion schemes-the charity facade is being used to promote a get-rich-quick scheme by a few private gambling enterpreneurs.

After 1966, pinball machines were outlawed in Alaska as being gambling devices according to that state's legal definition of -gambling. Operators of them were given a three-year grace period in order to amortize their investment. As the deadline for pinball pperations approached, pro-pinball machine forces presented a proposal that would have allowed continued operation of the 
machines subject to a special taxation. The revenue obtained was to be used to create a statewide free school lunch program. Sponsors of the measure claimed "a vote for pinball machines meant there would be no more starving children in our schools." The measure was never launched since the anticipated revenues would have been inadequate to purchase enough food to feed the few animals in the Anchorage City Zoo.

In 1964, California voters turned down an aid to education lottery measure by a wide margin. The charity facade was recognized as pure balderdash, and the crucial issue was recognized as a clever, disguised attempt by a small private corporation with reported underworld ties to establish and operate a lottery monopoly.

Animal racing associations typically allocate a few of their racing dates to charity. On these days, the track's gross revenue is donated to worthy causes. Other legal forms of gambling similarly sponsor scholarships or donate to worthy public causes for public relations purposes and possibly in the spirit of good will.

THE GAME OF SKILL EXEMPTION. This exemption typically utilizes a loophole in state law and involves a legal semantic gymnastic which defines a form of gambling as a game of skill and, therefore, not gambling. Antigambling statutes are frequently circumvented by local ordinance in this fashion in order to allow and tax legal gambling in card clubs, bingo parlors, etc., thus the euphemism, "It's a game of skill, not gambling!" The game of amusement exemption is identical in nature; thus pinball machines, carnival games, fascination, punchboards, bingo parlors, card casinos, etc., are often allowed through a local ordinance which specifically defines a form of gambling as not being gambling but, instead, a game of skill and/or amusement. For instance, in Gardena, California, one can play variants of poker due to a loophole in state law in luxurious licensed casinos where they are legally considered games of skill. On the other hand, if one plays the same games privately with friends in his own home across the street from the casinos, he is gambling illegally and is subject to arrest.

Bergler (1957) has commented on this and pointed out that 
psychologically all forms of gambling are equivalent, and that the various rationalizations about the importance of skill, judgment, handicapping, systems, etc., are meek attempts to deny the hard fact that such forms of gambling are, nonetheless, gambling.

THE PAINLESS SOURCE OF REVENUE JUSTIFICATION. One raison d'etre for allowing legal gambling or expansions of it is that gambling, especially lotteries, are a painless and/or voluntary form of taxation and revenue. Also, there is the harmless theory of taxation. Translated, politicians using these terms are saying that gambling is an easy and expedient way to gain more tax revenues without raising the ire of their constituents who would probably unseat them in the next election if taxes were raised in conventional ways.

Max Goldman of Mathematica, which designed several of the Eastern lotteries, objects to the idea of lotteries being labeled a vehicle of taxation since they are not compulsory. Instead, he holds lotteries are really "governmentally operated commercial enterprises" (Endicott, 1973). Goldman defends the concept of the thirty-two-foot Keno-mobile that speeds into various New Jersey cities for the weekly lottery drawings as "marketing" and "not huckstering or carnival stuff." However, the atmosphere and hard-sell marketing techniques present at the drawings seem indistinguishable from those used by the traveling medicine men of old or the carnival game and sideshow promoters of today.

The conservative columnist, George Will, puts the matter succinctly, "It is more accurate to say lotteries are sneaky taxation. If governments want more money than they raise through regular taxation, why do they not say so?" (Will, 1979).

It is true that certain forms of gambling, especially animal racing, are relatively efficient generators of tax dollars, and in 1972, \$497,366,076 was the total revenues to the twenty-seven states involved from all forms of legalized horse racing. This is because the pari-mutuel system promotes honesty and prevents skimming. Also, the pari-mutuel era ushered in the modern era of strict, effective regulation by racing officials and large purses which promoted honest competition. Purse economics made racing for the pot lucrative enough to cover the expenses of 
racing stables. The outmoded tricks of the old bookmaker system era such as ringers, performance manipulation of horses, dutch books and other attempts at betting coups became unnecessary and, paradoxically, too risky.

In 1963, the total state and local taxes from gambling nationally was 345 million dollars with $\$ 18$ million dollars coming from legalized pari-mutuel betting and 19 million dollars from state and local taxes in Nevada. Although these figures seem large, they represented only eight-tenths of one percent of total state and local revenues that year. They involved 19.1 percent, 5.2 percent and 4.7 percent of the total state taxes in the three leading states of Nevada, New Jersey and New York respectively (Zubrow, 1966). In 1964, gambling tax dollars represented only 1.6 percent of the total state tax revenue for the nation, and only 2.3 percent of the total revenues of the twenty-nine states with legalized gambling (Zubrow, 1966). Thus, gambling generates only a token source of tax dollars and a small percentage of the total revenues needed and expended. It is not the financial panacea, even though politically palatable, that the proponents of liberalized gambling espouse on the basis of painless taxation theories.

Opponents of gambling question not only the efficiency of gambling as a vehicle of taxation, or a governmental commercial enterprise if one prefers euphemisms, but also whether gambling truly involves a painless and harmless type of taxation. Historically, gambling has been a regressive form of taxation. However, the initial evidence from our new gambling ventures indicates the poor continue to play ghetto games and bet with bookies, and we are instead taxing (or doing commercial business) with a new set of middle class, white-collar gambling recruits. How harmless this is or isn't will be known soon enough. Critics of expanded gambling contend that for every tax dollar generated, there follows a greater financial cost in increased welfare loads, increased crime, expanded legal services and an increased load in law enforcement problems which inevitably ensue. Also, the human misery and hardship suffered by the families of addicted gamblers, the loss of sales and income to conventional business, and 
other social costs are of an order which do not readily tally in the accountant's ledger.

THE CURRENT JUSTIFICATIONS FOR LIBERALIZED GAMBLING. In lotteries we have old wine in new bottles for they are old and recurrent failures historically. Legalized off-track betting and potential legal invasion into sports wagering and the ghetto games (e.g. numbers and policy) are new ventures for this country. By analogy, here we have new wine in new bottles, and the new containers or justifications are a curious lot for which there is no historical precedent. However, from a sociocultural perspective and the results of recent sociocultural studies, the writer fears they are doomed to failure. In fact, some of the assumptions and justifications are so incredibly naive that it is almost unbelievable that educated men would expound them or that politicians would act upon them.

First, there is the promise of vast revenues. The theory goes that since the illegal gambling handling and profit is enormous, why not expropriate this pot of gold legally. We are now finding that the amount of revenue predicted from these new legalized forms of gambling is exaggerated and unstable.

There is a rationale of taxing illegal gambling by legalizing it. The theory is basically since you can't stop it, legalize it and decriminalize it. Yet there are many unpreventable crimes and no one proposes that they be legalized or taxed out of existence. A politician who proposed taxing and legalizing rape, murder, robbery and prostitution in order to stop them would likely be committed to an insane asylum rather than elected to public office.

There was a theory that, by legalizing gambling, the action would be taken away from the illegal bookies and the crime lords and, thus, create a crack-down on organized crime. This has not occurred and was a starry-eyed delusion when first envisioned. Bookies, racketeers and legitimate businessmen at gambling always support any and all types of expanded gambling. As experts in the nature of man's gambling habits, they know their business, and profits will skyrocket.

In the East there is a push to establish Las Vegas-style casinos at Atlantic City and at Catskill Mountain resorts in order to 
bolster the sagging economy there. A few years ago, proposals circulated in California to construct luxurious casinos in remote areas along the Nevada state line. One politician stated, "Why shouldn't we get some of all that money that our residents and the tourists drop in Vegas?'" Syndicated crime lords and honest, legitimate businessmen-gamblers would love such expansion to new and greener pastures for they know they would get the lion's share of the action and profits. Experiments such as these are likely to fail also for reasons stated by the Las Vegas oddsmaker, Jimmy the Greek Snyder who said, "I'm against legalizing gamIsling anywhere else (but Nevada), although I'm sure there will be a state somewhere that's going to want to try it. It will be a nlistake. A heavily populated community would go crazy." Snyder ' did not lay odds on his prediction, but presumably they would be long ones.

Another unstated, but implied assumption in the new justifications for legalized gambling enterprises is that governments can run lotteries, bookmaking, ghetto games and other gambling games better than the criminals and their other natural operators. Unfortunately, the facts are the opposite. Governments seldom do anything better than anybody, and if the Nixon administration had subcontracted Watergate out to a private detective firm, Watergate probably would have passed us as stealthily as a thief in the night. Support for this contention comes from the initial reports about the Maryland State Lottery which indicate that the new gambling converts there have quickly learned what the veteran gamblers already knew-that the illegal bookies and numbers rackets have better odds and more efficient service, extend credit and pay off quicker in tax-free winnings through their runners.

To understand why the likelihood of success is slim for legalized extension of gambling into bookmaking and ghetto games requires an understanding of certain unique sociological and ethnic factors involved. Both bookmaking and ghetto games involve complex formal and informal social institutions and customs. Important social and interpersonal interactions and transactions are involved against which the red tape, bureaucratic in- 
efficiency and typical lack of human empathy inherent in government operations are ineptly equipped to compete. Numbers and policy are integral, functional aspects of ghetto society. They are the poor man's nickel and dime avenue of excitement and perpetually renewed hope against a cultural backdrop of despair and poverty from which the prospects of escape are meager. They provide employment or additional income for the runners, the writers and other operators. In addition, they are positions of considerable prestige. A semireligious cult and magical air of excitement surrounds the drawings despite the hopelessly high odds against success. Dream books and mystic-interpreters are present to translate dreams, the names of relatives and unusual public occurrences (e.g. death of a famous person) into specific numerical sequences to play (Drake and Cayton, 1967).

Light (1974), in a sociological analysis, points out how the illegal ghetto gambling syndicates have, in effect, served as major financial institutions in black communities by extending credit and serving as an atypical savings association due to the unavailability of conventional financial enterprises. Light also demonstrates how numbers gambling promotes community solidarity and many other benefits to the poor despite the fact this adaptation is poverty-perpetuating and disadvantageous in net effect.

Louise Meriwether's (1970) touching autobiography, Daddy Was A Number Runner, illustrates the essential aspect of hope in the midst of despair, poverty and drugery provided by the numbers game in Harlem. Income from a "hit" (win) was sought and used for the necessary expenses of family living, and her father's employment as a number's runner provided an essential, albeit irregular, source of income.

Caucasian, high-salaried, white-collar civil servants muscling in on these ghetto games, recording social security numbers of winners for income tax purposes, etc., would be as unwelcome and unsuccessful as were the British tax agents prior to the Boston Tea Party.

Illegal bookmaking is also an institution replete with social custom and unique social interchange. The relationship between a bookie and his client is one of an ambivalent love-hate type 
based upon greedy competition. A profound interpersonal symbiosis exists between these two who are simultaneously rivals and friends.

The bookie needs his clients to profit, and he selects a regular and good clientele. By good he contemptuously means steady losers. One bookie acquaintance divided his clients into two types -"suckers" and "smart players." He indicated the essential difference between the two was that "it takes longer to get the money from the smart players." The bookie must forever be on the lookout for welchers and various ingenious types of betting coups by hostile clients out to get the bookie, and his is a dangerous life if he welches or gets too independent of the layoff men or other superiors. An acquaintance once lost a substantial amount of money owed him by a bookie who was murdered after overextending his territorial rights and underpaying on his take.

Although hated, the bookie is also a friend who extends credit, may carry loans on losses at high interest, provides efficient telephone service, and provides personal quick tax-free payoffs when his clients win. To his best clients (e.g. big losers) he may even take on a pseudoparental role and forgive all or part of their debts on holidays (especially Christmas), birthdays and in situations of tragedy or of undue financial hardship. As an offended bookie acquaintance once responded to a student's question in a seminar on gambling that the writer was conducting, "Why should you bet with me! Why shouldn't you bet with me? I give better odds than the track, " extend credit and you can bet with me in the comfort, privacy and safety of your own home. There are no traffic jams, no parking or admission fees, you won't get mugged going back to your car, and you don't have to leave work and lose time and money."

I ask you, how can government-run legalized bookmaking hope to compare with all these types of personal services and comforts that a bookie offers? Besides, it is human nature that doing something illegally is always more exciting, alluring and re-

This is not true. A bookie pays off at track odds, but only to a relatively low maximum limit. This prevents him from being wiped out by customers successfully selecting long shots. 
belliously heroic than doing it legally.

GAMBLING AS A PHASIC PHENOMENON. Another historical truism about gambling involves its periodicity. The extent and frequency of gambling in any society tends to be cyclical with a perpetual alteration between phases of expanded gambling and subsequent waves of moral reform. Basically, it is the politician who limits the extent and frequency of gambling. Thus, antigambling laws have been present in most societies when protected social legislation was demanded due to the economic costs and the social ills associated with the peak phases of feverish speculation attending the human weakness to pursue Lady Luck. Thus, every state (or nation) has resorted to repressive legislation or has alternated between that and progambling sanctions as a function of need of revenue or when forced with the unenforcibility of such enactments (Peterson, 1950).

Lotteries tend to cycle in historical time frames of several centuries. With the exception of Nevada, card clubs, slot machines, bingo parlors and other minor forms of gambling tend to cycle in various states and municipalities in much shorter periods of time. Even the sport of kings, horse racing, has had its highs and lows during the wide-open era of bookmakers and its attendant abuses. Animal racing, however, was saved and has flourished since the introduction of the pari-mutuel machine in the 1930 's (Day, 1950; McDonald, 1967). Today, it is our most sacred form of gambling in terms of generation of tax revenues; the breeding, sales and racing industry associated with it are a major national and international economic institution.

MORAL ISSUES AND GAMBLING. To the social and behavioral scientist, the moral issues related to gambling are an inescapable nuisance. As scientists we are concerned primarily with objective data about subjective states of mind, observable interpersonal reactions, and overt behavioral responses of gamblers and risktakers in a variety of gambling and risk-taking situations. However solidly based by firm experimental design and observation our facts and statistical figures are, the significant historical debates and political decisions regarding gambling have always been, and probably always will be, based on the results of pole- 
mical discussions centering upon the moral issues related to gambling. The matter is no longer as simple as the old controversy about whether gambling is a sin or the stewardship of God's property argument. With increasing affluence, increased leisure time available, and with widespread alienation from the job in our age of automation, gambling is clearly one of the ways Americans are spending their leisure time and money.

The modern theologian and philosopher raises substantive issues about whether liberalized gambling is a healthy development for our society and its moral fiber. (Blanche, 1950; Coggins, 1966; Starkey, 1967, 1964). Clearly, gambling is a predatory activity where the villains and victims are not readily discernible. Are humanistic concerns for one's fellow man inversely related in a society which increasingly emphasizes gambling? Does gambling incite appetites of greed for wealth without effort which undermines the work ethic? Does gambling elevate money and the quest for material gain at the expense of concern for the common good? Put in another way, do materialistic motives replace charitable and altruistic ones? Does gambling stimulate values and spending styles that are counterproductive to conventional business and society in general? Does gambling truly redistribute wealth from the many to the privileged few who legally and/or illegally own and operate gambling establishments? Is increased gambling really symptomatic of deep distress in our society? These will be left as open questions for the polemically inclined to debate and future historians to answer.

It is true that lotteries and rampant gambling were present in ancient Rome as that great empire collapsed, but it is doubtful that a convincing case for a cause-and-effect relationship can be established. In view of the recent gambling epidemic in England and the apparent early phase of a new cycle of expanded gambling in this country, one must wonder if these waves of liberalized gambling are not symptomatic of the decline of the oncegreat British Empire and of our own country's steadily diminishing international power and status.

THE UNIMAGINATIVE USE OF GAMBLING BY POLITICIANS AND SOCIETIES. The closing is a personal interpretation of gambling 
history. It will probably prove controversial, and hopefully it will stimulate productive thought and discourse. Namely, in spite of the ubiquitous, ineradicable, human proclivity to gamble, gambling-especially lotteries-has never been utilized or exploited in an imaginative legislative way. Basically, this is because politicians are not especially creative or innovative individuals. This is not meant critically, but merely as a statement of fact anyone can verify by reading his local newspaper or watching the news on television. Politicians are practical men who, of necessity, must be oriented to the business of getting elected and keeping elected while acting within the realm of their constituents' desires or some semblance of that. A politician cannot afford to be creative with controversial proposals too far ahead of their time since that is a sure way to help elect his opponent.

When enacting progambling legislation, politicians usually enact statutes based upon a tired, time-honored, politically safe formula which involves (1) granting gambling operating privileges-often monopolistic-to a wealthy corporate few who typically reap fantastic profits, and (2) the specification of a certain percentage of the gross gambling financial take to go into state and/or municipal treasuries. As indicated previously, the total amounts of revenue raised are a relatively insignificant percentage of the total governmental revenues and expenditures.

Perhaps the time is right to try something new in legislative approaches to gambling. This is especially true with lotteries since they are such recurrent historical flops perpetually packaged in the same old tried and untrue formulas justified by revenue generation arguments.

What if the ubiquitous urge to gamble was channeled into engineering human behavior toward efforts that generated benefits for the common good of society rather than generating trivial amounts of money for governments to spend as poorly as they do their larger sources of revenues? Some practical examples include: what if citizens were given a lottery ticket for every one hundred pounds of newsprint, ten pounds of aluminum beverage cans, or ten pounds of waste plastic turned in at recycling centers? Here a piece of newssheet, a single beer can or a small piece of 
plastic worth virtually nothing at an exchange rate of a few pennies per pound would become of inestimable value when applied toward a lottery ticket and a chance at winning a large monetary prize. To control population growth rates and prevent further overpopulation, give citizens lottery tickets for undergoing surgical birth control procedures, utilizing nonsurgical methods of birth control, or for simply not having any children during a specified period of time (e.g. two or three years). People could then gamble and make love, not babies, at the same time-a delightful combination indeed.

There are other examples limited only by imagination and the effort to implement them. Give people a lottery ticket for every ten pounds of litter cleaned up along our badly littered state and national highways during controlled environmental clean-up rallies. William F. Buckley, Jr. (1974) has proposed a patriotic bicentennial government-sponsored bond drive to finance antipollution programs. This idea is doomed to failure due to the paucity of patriotism in our country, the low interest rate paid on such bonds, and the return of inflation-riddled dollars upon bond maturity. However, such a program might have broad appeal if combined with a lottery drawing for large prizes. To promote energy conservation measures, give people lottery tickets on the purchase of small, gas-saving cars, installation of home solar energy units and for insulating their homes, etc. As in England and certain Iron Curtain countries, lottery drawings could be promoted based upon savings account numbers (Editors of Business Week, 1967; Editors of East Europe, 1967). Specific spending trends could be promoted if lotteries were utilized to promote the purchase of domestically-produced automobiles or other merchandise in lieu of foreign-produced items. Theoretically, the ubiquitous urge to gamble, especially for large stakes with minimal investment or effort, could be channeled to create situations of favorable benefit for this and future generations. This type of engineering of human behavior could result in environmental clean-up programs, recycling programs of our precious natural resources, population limitation programs, energy conservation measures and financing of antipollution pro- 
grams. Further, specific saving, spending and investing patterns of economic behavior could be engineered.

The dangers inherent in such government-operated programs of people manipulation are obvious. The defenseless, humanoid, conditioned man of the movie, Clockwork Orange, and the society envisioned by B. F. Skinner in his book, Beyond Freedom and Dignity, (1971) become frighteningly more real, but then, how noble are our current gambling practices with the inevitable increased number of addicted gamblers which will ensue? The writer, personally, would rather see someone addicted to cleaning up rubbish or scavaging garbage cans for recyclable beer cans or pieces of plastic than addicted to one-armed bandits or playing numbers gigs.

\section{REFERENCES}

Aginsky, B. W., and Aginsky, E. G.: The Pomo: A profile of gambling among Indians. Ann Am Acad Polit Soc Sci, 269:108, 1950.

Ahrnborg, B.: Betting on football matches in Sweden. Ann Am Acad Polit SocSci, May, 1950.

Barker, J. C., and Miller, M.: Aversion therapy for compulsive gambling. $I$ Nerv Merit Dis, I46:285, 1968.

Barrow, L.: Compulsion. Sydney, West Publishing Corporation PTY Ltd., 1969.

Bergler, E.: The Psychology of Gambling. New York, Hill \& Wang, Incorporated, 1957.

Blanche, E. E.: Lotteries, yesterday, today and tomorrow. Ann Am Acad Polit Soc Sci, 269:77, 1950.

Bolen, D. W.: Sexual and nonsexual factors in gambling. Sexual Behav, $l: 77_{*}$ 1971.

Bolen, D. W.a Treatment of compulsive gambling. Lancet, 7:1253, 1968.

I Bolen, D. Wr and Boyd, W. H.; Gambling and the gambler: A review and I preliminary findings. Arch Gen Psychiatry, 18.617, 1968.

Boyd, W. H., and Bolen, D. W.: The compulsive gambler and spouse in group therapy. In! J Group Psychother, 20:11, 1970.

Buckley, W. F., Jr.: Buckley's bondage. Intellectual Digest, April, 1974, p. 57.

Chafetz, H.: Play the Devil: A History of Gambling in the United States from 1492-1955. New York, Bonanza Books, 1960.

Coggins, R. (Ed.): The Gambling Menace. Tennessee, Bradbury Press, 1966.

Cohen, J.: The nature of gambling. Scientia, CV:l, 1970.

Cohen, John, and Hansel, M.: Risk and Gambling. Toronto, Longmans Canada Ltd., 1956. 
Cole, E. W.i Racing Maxims and Methods of Pittsburgh Phil. New York, American Bank Note Company, 1908.

Cook, F, A Two Dollar Bet Means Murder. New York, The Dial Press, Incorporated, 1961.

Day, J. L.: Horse racing and the pari-mutuel. Ann Am Acad Polit Soc Sci, 269:55, 1950.

Devereux, E. C., Jr.: Gambling in psychological and sociological perspective. In the International Encyclopedia of the Social Sciences, 1968, vol. 6, pp. 53-62.

Devereux, E. C., Jr.: Psychodynamics of Mohave gambling. American Imago, 7:55, 1950.

Drake, S. C., and Cayton, H.: Policy: Poor man's roulette. In Herman, R. D,; Gambling. New York, Harper and Row, 1967.

Editors of Business Week: In Britain gambling is a growth industry. In Herman, R. D.: Gambling. New York, Harper and Row, 1967, p. 76.

Editors of East Europe: The jackpot: Gambling in the Soviet Bloc. In Herman, R. D.: Gambling. New York, Harper and Row, 1967, p. 69.

Endicott, Wa State lotteries: Small payoff in raising revenue. Los Angeles Times, November 8, 1973.

Endicott, W.: Wandering showmobile: New Jersey keno layout on wheels really pays. Los Angeles Times, November 8, 1973.

Epstein, R.: Theory of Gambling and Statistical Logic. New York, Academic Press, 1967.

Fleming, I.: Goldfinger.New York, Glidrose Productions, Ltd., 1959.

Goorney, A. B.: Treatment of a compulsive horse race gambler by aversion therapy. Br J Psychiatry, 114:329, 1968.

Herman, R. D.; Gambling as work: A sociological study of the race tracks. In Herman, R. D.: Gambling: New York, Harper and Row, 1967.

Kennedy, R. F.: The baleful influence of gambling. In Herman, R. D.i Gambling. New York, Harper and Row, 1967, p. 169.

Knox, R. E, and Inkster, J.4 Postdecision dissonance at post time. / Pers Soc Psychol, 8:319, 1968.

Kusyszyn, I.: The gambling addict versus the gambling professional: A difference in character? Int J Addict, 7:387, 1972.

Kusyszyn, I-: Gambling, risk-taking and personality: A bibliography. In Int J Addict, 8:173, 1973.

Kusyszyn, I-, and Rubenstein, L.: Locus of Control and Race Track Betting Behavior. Paper presented at the Annual Meetings of the Canadian Psychological Association, St. John's Newfoundland, June 1971.

Lawrence, L. A.: Bookmaking. Ann Am Acad Polit Soc Sci, 269:46, 1950.

Light, L: Numbers Gambling: A Financial Institution of the Ghetto. Paper presented at First Annual Conference on Gambling, Las Vegas, June 10$11,1974$.

McDonald, J.: Sport of kings, bums, and businessmen. In Herman, R. D,: 
Gambling. New York, Harper and Row, 1967, p. 53.

Meriwether, L.: Daddy Was A Number Runner. New York, Prentice-Hall, Incorporated, 1970.

Montgomery, H., and Kreitzer, S. F.: Compulsive Gambling and Behavior Therapy. Paper presented at California State Psychological Association Convention, Santa Barbara, 1968.

Moran, E.: Gambling as a form of dependency. BrJ Addict, 64:419, 1970a.

Moran, E.: Pathological gambling. Br J Hosp Med, 4:59, $1970 \mathrm{~b}$.

Moran, E.: Varieties of pathological gambling. $\mathrm{Br} J$ Psychiatry, I16:593, 1970c.

Morehead, A. H.: The professional gambler. Ann Am Acad Polit Sci, 269:81, 1950.

Ore, O.: Cardano: The Gambling Scholar. New York, Dover Publications, Inc., 1963.

Peck, D. $F_{\text {-z }}$ and Ashcroft, J. B.: The use of stimulus satiation in the modification of habitual gambling. In Proceedings of the Second BEA Conference on Behavior Modification. Kilkenny, Ireland, 1970.

Peterson, V. W.: Obstacles to enforcement of gambling laws. Ann Am Acad Polit Soc Sci, 269:9, 1950.

Ploscowe, N., and Lukas, $\boldsymbol{E}_{\text {: }}$ Foreword to issue entitled "gambling." Ann Am Acad Polit Soc Sci, 269:VII, 1950.

Pokorny, M. R.: Compulsive gambling and the family. $\mathrm{Br} \mathrm{J}$ Med Psychol, 45:355, 1972.

Reid, $\mathbb{E}_{\text {, }}$ and Demaris, O.: The Green Felt Jungle. New York, Trident Press, 1963.

Rosten, L.: The adoration of the nag. In Herman, R. D: Gambling. New York, Harper and Row, 1967.

Scodel, A.: Inspirational group therapy: A study of gamblers' anonymous. Am J Psychother, 18:115, 1964.

Scott, M. B.; The Racing Game. Chicago, Aldine, 1968.

Seager, C. P.: Treatment of compulsive gamblers using electrical aversion. Br J Psychiatry, 117:545, 1970.

Smothers, D.: Americans gambling at record rates, Los Angeles Times, December 16, 1973.

Skinner, B. F.: Beyond Freedom and Dignity. New York, Alfred A. Knopf, 1971.

Squires, P. C.: Fyodor Dostoevsky: A psychopathological sketch. Psychoanal Rev, 24:365, 1935.

Starkey, L. M-, Jr.: Christians and the gambling menace. In Herman, R. D.a Gambling. New York, Harper and Row ${ }_{\Perp}$ 1967, p. 225.

Starkey, L. M.n Jr.: Money, Mania, and Morals. Nashville, Abingdon Press, 1964.

Stekel, W.: Gambling. In Von Teslaar, J. S. (Trans-Ed.): Peculiarities of 
Human Behavior. New York, Liveright Publishing Corporation, 1958, vol. 2.

Turner, W.: Gambler's Money: The New Force in American Life. Boston, Houghton, Millin Company, 1965.

U. S. Senate Hearings: Crooked gambling devices. In Herman, R. D.: Gambling. New York, Harper and Row, 1967, p. 188.

Victor, R. G., and Krug, C. M.: Paradoxical intention in the treatment of compulsive gambling. Am J Psychother, 2I.808, 1967.

Wade, H.: The Greatest Gambling Stories Ever Told. Ontario, Greywood Publishing Ltd., 1973.

Wagner, W:i To Gamble or Not to Gamble. New York, World Publishing, 1972.

Weiss, H. B., and Weiss, G. M.: The Early Lotteries of New Jersey. Trenton, The Past Times Press, 1966.

Will, G.: On state-run lotteries and the loss of old virtues, Los Angeles Times, September 2, 1973.

Zola, I. K.: Observations on gambling in a lower-class setting. In Herman, R. D.: Gambling. New York, Harper and Row, 1967.

Zubrow, R. A.: Legalized gambling - Source of revenue. In Coggins, R.i The Gambling Menace. Tennessee, Bradbury Press, 1966, p. 77. 


\title{
Chapter 2
}

\section{THE LEGALIZATIUN OF GAMBLING IN THE UNITED STATES: AN ANALYSIS AND FUHECAST ${ }^{1}$}

\author{
DUANE V. BURKE
}

\section{T} HE THREE THINGS to be covered are: (1) what is happening in the United States and why with respect to the legalization of gambling, (2) what is likely to happen throughout the rest of this decade, and (3) some suggested topics for academic research based on the writer's personal observations.

First of all, what is happening now and why? Most persons are aware that the legalization of gambling is spreading rapidly in the United States. State lotteries have in effect become the leading edge of this trend. The modern day, government-operated lotteries started with New Hampshire in 1964, the first legal lottery in over eighty years; the last was the infamous Louisiana Lottery which was so scandal-ridden that the majority of the states in the United States were convinced to change their constitutions to prohibit lotteries, and the federal government passed laws which, in effect, crippled lotteries of that sort. Many of the states in the United States still have this prohibition of state lotteries.

In 1967, New York State started a lottery. In 1971 there was a total of three state lotteries with the advent of the highly successful New Jersey State lottery. As a result of New Jersey's success, several other states became interested. By the end of 1972 there were seven state lotteries operating: New Hampshire, New York, New Jersey, Massachusetts, Connecticut, Pennsylvania and Michigan. Maryland started in 1973, and by the end of 1974 there will be a total of thirteen state-operated lotteries with the addition of Rhode Island,

"Copyright, 1974, by NLW Advisory, Inc. 
Maine, Ohio, Illinois and Delaware.

It" should be emphasized that these are government-operated gambling enterprises in contrast to what you see in Las Vegas, which is strictly licensed private enterprise-operated gambling.

Off-track betting started in New York City in 1971 and in Schenectady in 1972. Schenectady is a small town near Albany with a population of 72,000 . This trend spread to western New York in 1974. The State of Connecticut is scheduled to start its off-track betting in late 1974. That constitutes the off-track betting in the United States today. Again, with the exception of Nevada which has licensed private enterprise bookmaking, all of this new legalized off-track betting is state or local government-operated.

In the pari-mutuel industry, that is horse racing, harness racing, dog racing and jai alai, most recent expansion has been in dog racing and jai alai. Over the last few years three states have added dog racing-New Hampshire, Nevada and Alabama.

Jai alai, which has for years been the sole province of the state of Florida, has now expanded to Nevada, Rhode Island and Connecticut, although it is still in the development stage in Rhode Island and Connecticut.

Sports betting, although reportedly the major form of illegal gambling in the United States, is still legal only in Nevada and, again, as licensed private enterprise bookmakers, despite considerable recent interest by states in operating legal sports betting of some sort.

Numbers betting, which the United States Justice Department reports to be the second largest form of illegal gambling in the United States in terms of dollars bet, has yet to be legalized in any state. However, in 1973 New Jersey took a first try at designing a competitive game, the daily lottery, which apparently has had limited success in competing with illegal numbers playing in the state. Finally, casino gambling is still legal only in the State of Nevada, but again, it is licensed privately-operated gambling as opposed to the current trend of state or local government-operated gambling.

What are the motivations for this trend? The primary motivation for the state lotteries has been the need for revenue. 
The lotteries were started based on need by the states formore money. Off-track betting was started based on a need by local governments for more money, and even the pari-mutuel industries, horse racing, dog racing and jai alai, have been allowed to begin primarily because the states are interested in the revenue they can derive from these activities.

The writer believes it can be fairly stated that most people in the United States are unhappy about their tax bite, and that even includes people in states where tax rates are lowest, so state lotteries, off-track betting and other forms of legalized gambling are for the most part being legalized as a revenue alternative to compulsory forms of taxation. The state lotteries have not been a great boon as far as state revenue is concerned. The total revenue from state lotteries in comparison to total state revenues is running less than 3 percent for most states, but although it is not a large percentage, it turns out to be a way to get sizeable additional funds without increasing the sales tax a fraction or increasing or adding some other taxes.

Why is this current trend toward the legalization of gambling continuing and accelerating in the United States? Perhaps if there had been any scandals in the New Hampshire lottery as has been witnessed in Nevada's privately-operated gambling over the years, or has been seen in privately operated racing activities, one would not find this trend continuing. A key reason for the success of the new government-operated games is the honesty and integrity of the government officials running the games for the states. This point can't be overemphasized. Another important reason is the integrity and security of the system which has been designed to safeguard the public, to keep the games honest, and to keep the hoodlums out. The high public confidence in the games has been demonstrated by the high percentage of participation.

The flow of money to out-of-state legal lotteries has been one of the motivations for new states to go into the lottery business. The state of New Jersey, with its very successful lottery, influenced the states around it to go into the lottery business simply because money was flowing out of surrounding states into New Jersey, into its state lottery and into its government coffers. That is not a popu- 
lar thing to have happen, and it is not a thing legislators like to be accused of letting happen.

The promotion of the games themselves has been a key factor in the continuing trend. State lotteries are very dependent on highly effective marketing techniques. Off-track betting's success has been significantly enhanced by promotion and marketing. Again, these are government-operated games. Another factor is the increasing awareness that illegal gambling is widespread in the United States, putting billions of dollars in the hands of organized crime and an awareness that it is a primary source of police and other official corruption. In a recent unpublished research study done by the Justice Department, it was estimated that between 29 billion and 39 billion dollars are going through the hands of either organized crime organizations (i.e. mafia) or independent crime organizations as a result of illegal gambling activities. Of these billions of dollars, the study estimates 64 percent are spent on sports betting nationwide, 25 percent on numbers betting and 11 percent on illegal horse race betting; those three comprise the major categories of illegal gambling in the United States today. Of the 29 billion to 39 billion dollars, about 42 percent is estimated by the Justice Department to go through the hands of the organized crime families to be used to finance other illegal and corruptive activities. States are interested in legalizing and operating some of their games in order to get that money flowing into legitimate and more desirable circles. A desire on the part of the public to see the games in which they are interested legalized, so they don't have to sneak around to play, is another important factor. Except in the South, where it is still a moral issue, gambling is viewed by most as recreation.

Now that the reader has some idea of where we stand, some insight into the motivations for this current trend of legalized, government-operated gambling and the reasons it is continuing, he is probably interested in what is likely to happen in the United States as to the further legalization of gambling.

First of all, gambling is going to continue; it is going to continue at a fairly rapid rate; and it is going to continue, as a matter of fact, at an accelerated rate. As the number of gambling enter- 
prises operated by states increases, that base in turn will cause further increases.

Here are some of the key factors which will effect that ratesome negative and some positive-and it won't necessarily be pointed out which is which as we go, but it will be fairly evident.

1. The existing federal laws and regulations currently constrain state lotteries. For example TV cannot be used to promote state lotteries and radio cannot be used to promote state lotteries because TV and radio waves cross state lines. Newspapers cannot be used to promote state lotteries if those papers cross state lines. The postal service cannot be used either to promote a state lottery at all, so there are a number of federal laws which have their origin in the scandals of lotteries in the late 1800 's which are currently inhibiting state-operated lotteries.

2. Another point in regard to these federal laws is the enforcement of them. It is understood by the writer that there are many federal laws as well as state and local laws which are not enforced or are enforced with varying degrees of enthusiasm. With the increase in state lotteries, federal agencies with some enforcement responsibilities are taking an increasing interest in their enforcement of the federal antigambling statutes; for example, the IRS has two activities going at the present time, the Justice Department has a third, and the postal service a fourth which is aimed at bringing the states in line with these agencies' interpretation of the law.

3. Another factor which is going to affect future trends is change in the federal law. There are about twenty-three bills in the Congress right now, some of which have been heard by a subcommittee of the House Judiciary Committee. If they are passed they will have a significant impact on the popularity and availability of state lotteries. For example, if the laws prohibiting the use of TV are taken away, there may be an immediate increase in the sales of 25 percent or more, and after the lottery directors have a chance to use their imaginations in this new media, it should go much higher than that. For this reason the federal laws under study are going to have an effect.

4. The relative success of new lotteries and new off-track betting 
services are going to have an impact. As each of these new services starts it will encourage or discourage other states interested in starting.

5. The attitudes of law enforcement people at all levels will have a bearing on it. Many law enforcement people throughout the country are opposed to state lotteries. In spite of the fact that they have no factual data at the moment to support their concern, they do have an underlying concern that perhaps, if not the state lotteries themselves, then some of these other games that are being legalized are going to result in increased law enforcement problems rather than decreased problems.

6. The financial condition of the state and local governments is also going to have an important bearing on what is going to happen. If the states are in great shape, that is going to reduce the pressure for additional revenues and reduce the need for going into something like this.

7. Finally, there is a federal gambling commission that has been instituted and is operating to study this field. The executive director of that commission is Mr. James Ritchie. Commission on the Review of National Policy toward Gambling is the commission's title. I think there is a good chance that this commission will have some impact on the further legalization of gambling in the United States. Taking these and other factors into account, here is what will probably be seen in this decade as far as the further legalization of gambling is concerned.

a. State lotteries will stretch to twenty-eight states. Those twenty-eight states will be operating sixty-four separate state lotteries.

b. Off-track betting will spread to six out of the seven independent OTB regions in New York State, and beyond that will spread to five additional states for a total of twelve separate OTB entities in the United States; that is besides licensed bookmaking in Nevada.

c. Sports betting, which is considered the major source of illegal gambling and is legal only in Nevada through licensed bookmakers, will be operated by at least seven states 
by 1980 .

d. Numbers betting, which is regarded as the second largest source of illegal betting, will be legalized by six states over the next five years and will be operated by the existing state lottery organizations.

e. Pari-mutuel gambling will continue to expand although harness racing and horse racing will be expanding at a subdued rate because of the recurring scandals and because of the continuing problems with reduced public interest, but they should expand to a total of thirty-five states from the existing thirty by 1980. Dog racing will be found (the writer predicts) in twelve states. Jai alai should expand to six states by 1980 .

f. Finally, casino gambling (the writer believes) will be found in total of three states by 1980 . However, privatelyowned and privately-operated casino gambling as it is operated in Nevada is a phenomenon not likely to be repeated in other states. It is the writer's belief that the other states that legalize casino gambling will operate it themselves, and by so doing will avoid many of the past and current problems that have marked Nevada gambling.

Now, some suggestions for academic research:

a. One obvious possibility, given the preceeding forecast for the expansion of legalized gambling in the United States, is the possibility of serious economic and social problems that are going to be cropping up in this decade or the next as a result of this increased availability of gambling and the diversion of funds to gambling which have heretofore gone for other activities or products.

b. Another subject worth pursuing is: what is the real cost of enforcing existing antigambling statutes and the real benefits, and, along with that, what are the changes in the criminal justice costs when gambling is legalized and are there any changes in social welfare costs? No significant work has been done in these areas insofar as the current trend of legalized government-operated gambling is concerned. 
c. Finally, characteristics of laws, systems, government and, perhaps most important, of administrators can keep government-operated gambling operating honestly, responsibly and for the public's benefit and the general welfare of the citizens. 


\title{
Chapter 3
}

\section{SOME DBSERVATIONS DN LEGALIZED GAMBLING}

\author{
WILLIAM R. EADINGTON
}

\section{INTRODUCTION}

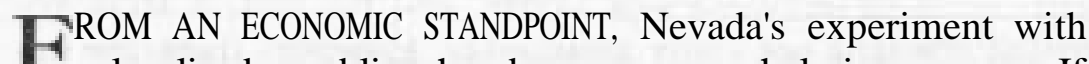
I legalized gambling has been an overwhelming success. If this is the case, then why haven't other states moved to legalize casino gambling to reap the occupational and tax benefits which Nevada experiences? And if other states did follow Nevada's lead, would the industry which now supports so much of the state die out, returning Nevada to the way it was forty years ago? Such questions are asked again and again about Nevada because no one really knows what would happen if casinos became as common on a national scale as, say, country clubs. However, a number of reasonable predictions based on Nevada's experience can be made. As with most predictions, these are not much more than educated guesses and, as such, are subject to question; the only true method of verification would be for other states to legalize casinos, then observe the results. Short of that, the arguments are only as good as their consistency with the available evidence.

Legalized gambling is far from unique to Nevada; over thirty other states allow gambling in some form or other, ranging from pari-mutuel betting on horse races and jai alai to slot machines and church-sponsored bingo games. In terms of state tax revenues derived from legalized gambling, excluding revenues from stateoperated lotteries, Nevada ranks a distant fourth behind New York, California and Florida. In fiscal year 1973, for example, gambling tax collections in New York were more than twice as 
large as those in Nevada, (\$156.7 million to $\$ 62.3$ million) .*

It should also be noted that, where legal gambling is prohibited, illegal gambling usually abounds. Conservative estimates of the annual take of illegal gambling promoters are seldom less than six or seven billion dollarst so it is naive to assume that the choice for any state is between legalized gambling and no gambling at all. The major question which needs to be analyzed is, if a state legalizes casino gambling, will the benefits it receives from increased tourism, job creation, greater tax revenues, etc., outweigh the social and economic costs which will be generated? This question is too broad to be fully answered by economic analysis alone; gambling, like alcohol, can be either beneficial or destructive to individuals in society, and the cost of these potential effects is not easily measurable. However, there are important implications to be drawn from analyzing the economics of Nevada gambling, and even though these cannot answer the difficult social and moral questions involved, they can be helpful in stating more precisely what a state's alternative choices are.

\section{THE RESIDENT CASINO GAMBLER}

Although no thorough statistical investigation has been undertaken, it is commonly felt that Nevada residents who frequent casinos are either new to the state or to its gambling, or they tend to be from lower middle or lower income classes. ₹ The apparent absence of Nevada's professional and white collar workers from its gaming tables carries an important message concerning the nature of casino gambling and is one that should be acknowledged by any state considering the legalization of casinos.

The reasons why middle and upper income Nevada residents would gamble very little can best be explained by considering how a new resident gambler views casino games. At first glance,

"Source: Nevada Gaming Control Board. It should be noted, however, that in the past four years, Nevada's state tax revenues from gambling have increased by 87.1 percent, while New York's have increased by only 2.7 percent.

PFor example, see Rufus King, Gambling and Orgenized Crime, Washington, Public Affairs Press, 1969, pp. 32-33.

tSee, for example, In Vegas, glitter gulch finds luschbox trade beats high rollers. Wall Street Journal, May 22, 1972. 
casinos provide a kind of entertainment which is unique. The new gambler is probably motivated in much the same way as the tourist gambler; the thrill derived from participating in casino games and occasionally winning is enough to bring him back to the tables again in spite of overall losses. However, as time passes and the uniqueness of casinos wears off, a couple of things become apparent. Most casino games offer fairly small (i.e. evenmoney) payoffs with the house holding a slight advantage (1\%$10 \%)$ over the player. If these games are played, they can occasionally be beaten over a short duration, but it is almost impossible to keep from losing for very long. Therefore, the longer the resident gambler plays, the stronger is the realization that he will inevitably lose and that, in effect, he is paying a relatively steady amount for the privilege of gambling.

A good deal of the excitement in gambling comes from the feeling of being lucky, but luck is an inverse function of the volume of participation; the longer the individual gambles, the less important are fluctuations in winnings and losses. His actual losses per dollar wagered will closely approximate the expected value of the game he plays. As a result, the resident gambler eventually loses a strong motivating factor to gamble. The uncertainty of the outcome of a few wagers is replaced by the relative certainty of the outcome of a large number of bets, which simultaneously destroys most hopes of winning overall and dampens considerably the thrill of participation. Consequently, both the wealth and entertainment motives tend to disappear as the volume of gambling increases.

At this juncture, the resident gambler has three alternative courses of action to pursue-he could quit altogether since most of the reasons he gambled in the first place have been removed; he could continue to gamble as he did in the past, acknowledging, however, that he must lose in the long run; or he could change his games or strategies of betting so that losses are not inevitable; for instance, he could shift to low probability, high payoff wagers which need to be won only once to put him ahead for quite a while. These in effect could reintroduce the motivation of hoping to be a winner in the long run. However, gambling as a form of investment is inefficient for most middle and upper income in- 
dividuals who have less costly and more probable avenues of achieving higher levels of wealth." Since this type of betting would characterize a wealth-motivated gambler, it is unlikely that many middle and upper income individuals would choose this alternative.

For lower income individuals, gambling can be an efficient means of achieving higher levels of wealth; therefore they are more likely to continue gambling than middle and upper income groups whose motivations are aimed at entertainment rather than wealth creation. For this reason any community in which casino gambling is legal can expect the socioeconomic background of its residents who gamble to be somewhat lower than the distribution of the community as a whole.

If the above argument is true in general for Nevada residents, then why doesn't the same reasoning apply to California residents who frequently visit Nevada's casinos? To some extent it probably is appropriate; it is likely that a significant portion of tourist-gamblers eventually become jaded to their chances of winning and discontinue their Nevada visits. There is an important difference between the visitor and resident concerning how they view their gambling experience however. Because of the geographic separation of his residence from the casinos, the touristgambler can treat his gambling flings as distinct from one another much more easily than can the resident gambler. Since each visit is relatively short, the possibility and hence the anticipation of coming home a winner is strong for each visit, and because the visits can be treated as separate entities, the visitor can much more easily postpone the aggregation of his gambling performance over a number of visits than can the resident. In other words, the tourist gambler is better able to gauge how he does at the gaming tables in terms of distinct short-term trials; for the resident, it is difficult to keep separate gambling periods from running into one another. Therefore, the visitor can be motivated by the hope of quitting ahead, but for the resident that hope is almost nonexistent unless he plays low probability, high payoff games or strategies. Therefore, middle and upper income in-

*See Alex Rubner. The Economics of Gambling, London, Macmillan, 1966 pp. 5152. 
dividuals are more prone to gamble if they live where gambling is not legal, but legal gambling is not too distant. Alternatively, the socioeconomic distribution of Nevada's tourists who gamble is probably higher than that of Nevada residents who gamble.

The implications for any state considering legalized casino gambling are obvious. If the gambling is to have broad appeal to anyone but lower and lower middle income individuals, it will have to be spatially separated from the residences of its prime middle and upper income markets. Also, the proportion of gamblers who are lower and lower middle income will have to be relatively small if the appeal to middle and upper income gamblers is to be sustained. Therefore, if Nevada-style casino gambling is to be implemented by a state or locality, a strong indicator of its potential success is how much tourist gambling relative to resident gambling it can draw.

In the past few years, a number of states have made overtures toward legalizing Nevada-style gambling; the above argument may have considerable importance in how well they do. Some of the suggested locations for legalizing casinos support the argument; relatively remote locations such as Catalina Island off the coast of California; the Catskills in upstate New York; Miami Beach, Florida; and Atlantic City, New Jersey, have all been mentioned. Since each of these places either has a small indigenous population or already possesses considerable tourist trade, it is likely that they could be successful with legalized casinos; actual success though would depend upon many other factors, 1 foremost of which is the administration and regulation of the casinos themselves.

The western states of Wyoming, New Mexico and Montana have recently considered casino gambling as a potential tax source and tourism booster; however, it is doubtful that they could ever build a gaming industry much larger than that found in many eastern Nevada communities such as Elko or Ely. The major reason for this is that they do not have large population centers close enough to them to generate a weekend tourist-gambler trade. Even though these states have a fairly large number of out-of-state visitors each year, it is unlikely that the gaming revenues per tourist would be anywhere near what Nevada re- 
ceives. The primary purpose of visiting these states would not be to gamble for the vast majority of tourists, and therefore the tourists who did gamble would be cautious with their losses. Consequently, the industry would have to be supported in large part by residents of those states, and there will be a tendency for the residents who gamble to come from lower and lower middle income classes. Because of this, tax revenues from gambling would be primarily from local residents instead of from tourists, and gaming taxes themselves would be highly regressive with respect to income. Finally, without the large volume of tourist gambling, it is doubtful whether the tax revenues generated would be as large as state officials anticipate. For example, Nevada tax revenues from gaming relative to California population amounted to only about three dollars per Californian in fiscal 1973 (and less than 1\% of California's budgetary needs); it is therefore doubtful that a small state such as Montana or Wyoming could expect to do even that well, especially if it has to depend primarily on resident gambling.

The recent success of the state lottery and the Off-Track Betting Corporation in New York has encouraged legislators to consider legalizing casinos in that state on a local option basis. Such a proposal may be ill-advised for a number of reasons. First, the geographic separation of casinos and customers would not be present if a large number of localities did legalize, and this could discourage middle and upper income individuals from gambling for the reasons previously stated. Secondly, there seems to be a considerable positive spillover effect when casinos are clustered together; this allows gamblers to wander from casino to casino as they desire with little effort. Legalization on a local option basis would probably spread the industry too thin to allow for much geographic concentration. Finally, if casinos did prove successful in some communities because of their ability to draw tourists, the temptation for other communities to follow suit could lead to difficulties for all the casinos. The suggestion of legalizing casino gambling only in regions which can draw tourists to the extent that they make up the predominant proportion of customers is much more likely to be successful than unrestricted legislation. 
In summary, for casino gambling to be economically successful, it needs to draw tourists as its main customers. It is unlikely that this objective can be fulfilled unless the casinos are spatially separated from their major markets. Attempts to locate casinos in urban areas will probably lead to almost exclusively lower income casinos which are undesirable because of the lack of revenues they are capable of generating, as well as the high social costs they might create.

\section{LOTTERIES AND SPORTS GAMBLING}

Since the mid 1960's thirteen states have legalized publiclyoperated lotteries and, at the present time, a number of others are seriously considering lotteries because of their tax revenue generating potential. New Hampshire instituted the first of the state lotteries in 1964, and even though they had hoped to earn four million dollars per year for state education from the lottery, they generated a net win of only 10.7 million dollars in their first seven years of operation. New York State established its lottery in 1967 and expected to net over 100 million dollars per year, but by the end of 1970 the state's gross for the four years had only been 233 million dollars. The lackluster performance of the New York and New Hampshire lotteries was countered by the amazing success of New Jersey's lottery which was started at the beginning of 1971. In their first eight months of operation, gross receipts were 100 million dollars, and first-year tax revenues from the lottery exceeded 50 million dollars, over five times as much as what was initially expected. Since then ten other states have established lotteries primarily for the purpose of generating tax revenues.

The reasons given for the success of New Jersey's lottery in light of the initial disappointments of New Hampshire and New York deal with the structure of the lottery operation itself. Most drawings in New Jersey occur on a weekly basis; this compares to three drawings a year in New Hampshire's original set-up and monthly drawings in New York. New Jersey set the base price of lottery tickets at fifty cents, compared to one-dollar to three-dollar prices in the other two states. Also, for every million tickets sold 
in New Jersey, a 50,000 dollar prize is awarded over and above the weekly drawings. Their formula has apparently worked; most of the other state lotteries are now patterned after New Jersey's.

In 1971, the Off-Track Betting (OTB) Corporation established legal bookmaking shops in New York City, and during their first year of operation they handled about 200 million dollars in horse race bets. The bulk of legal gambling in the United States is done on horse racing, but OTB was the first time outside of Nevada that off-track betting parlors were legally sanctioned. However, horse race betting is apparently a small portion of the total wagering that illegal bookmakers handle; one estimate states that nearly 90 percent of bookmakers' action is on team sports and that perhaps as many as half the people who watch professional football games regularly wager on their outcomes. Consequently, there is strong evidence that a broad market for sports betting and lotteries already exists; the trend toward legalization will undoubtedly extend the wager markets to those who are presently deterred by the illegality or inaccessibility of the present situation.

It is difficult to determine whether the tendency toward legalized lotteries and bookmaking will increase or diminish the demand for casino gambling. On the one hand, the added exposure which gambling would receive may have an overall discouraging effect on many people who would otherwise be inclined to gamble occasionally. When losses become overly redundant, a negative attitude toward all forms of gambling is possible; this is more prone to occur among high than low income bettors because of their gambling motivations.

On the other hand, lotteries and sports betting are considerably different in structure and methods of play than casino games, and therefore might be considered complementary by most gamblers. Lotteries, for example, allow the participant no immediate outcome for his wager, a negligible chance of payback, and, in general, very little of the thrill of actually playing. Of the factors listed in the Royal Commission on Betting, Lotteries and Gambling Report of 1951 which contribute to overindulgence in wagering, none are particularly influential in lotteries. The factors which were stated are "the frequency of opportunity of gam- 
bling, the degree of personal participation in it, the existence of credit betting, the odds against winning, the extent to which the gambler thinks he is exercising skill, and the element of entertainment or connection with some sporting activity." " In simple terms, the reason people do not tend to overindulge in lotteries is that the actual participation is singularly unexciting.

Although sports betting possesses more of the characteristics which contribute to the thrill of gambling than do lotteries, there are enough differences that make them imperfect substitutes with casinos at best. The atmosphere of excitement of a casino is not as present at race tracks and almost totally absent in betting parlors. The time lag from when the wager is made to when the results are known is usually longer than casino bets; this has the effect of making the bettor more deliberate but probably more prone to boredom. On the positive side, sports betting allows for the exercise of the gambler's skills, either real or illusory, as he tries to outhandicap either the general public (as in pari-mutuel betting) or the professional handicappers (as in odds and point spread betting on team sports). Vernon Smith argued that the existence of a wager market could be explained solely by the application of individuals' skills in handicapping, and although it is highly doubtful that this motive alone can explain very much of the large illegal bookmaking market, its presence is undoubtedly felt. ${ }^{\top}$ Casino games, on the other hand, allow for very little exercise in personal skills. The present coexistence of California's large and growing horse race industry along with Nevada's gaming industry suggests that the two types of gambling are not viewed too much as substitutes, but horse race tracks are not betting parlors. Without further evidence it is hard to say what

"Cited in Robert K. Kinsey. The Role of Lotteries in Public Finance. Ph.D. dissertation, Columbia Univenity, New York, 1959.

PVernon Smith, "Economic theory of wager markets," Western Economic Journal, Vol. 9(3), 5eptember, 1971, 242-255.

The basic flaw in Smith's argument is that, in order for people to believe that they can actually outhandicap the market, it is necessary for their actual performance to not diverge considerably from their subjective expectations. However, this at best could be the Case for a small portion of the participants because of the high return estimated for bookmakers. If his explanation is to hold, it can only hold as long as the majority of bettors are able to fool themselves into thinking that they actually can win by way of their handicapping skills. 
effect legal sports betting would have on Nevada-style gaming. Also, because of their structure, lotteries as presently established would have almost no influence on the demand for casino games.

\section{CONCLUSIONS}

The issue of legalized gambling in the United States has, for better or worse, become increasingly important in the past few years as more and more state and local governments have turned to it as a possible means of raising revenues, eliminating a major source of police corruption and removing a significant revenue source from organized crime. The morality of gambling has long been debated along with the socioeconomic influences it can have on the general public. It is by no means a simple issue to discuss in any discipline; both its proponents and opponents supply reasonable but too often unsubstantiated arguments on the merits and demerits of legalized wagering. Most studies admit that as a tax revenue generator, gambling is regressive, but at the same time it needs to be emphasized that attempts to enforce antigambling statutes have been both unpopular and unsuccessful.

Consequently, gambling presents a problem to society which cannot be solved by inaction. Because of the sheer size and impact of both legal and illegal gambling in America today, the questions of its moral, social and economic effects will take on a growing urgency and demand to be answered.

\section{REFERENCES}

In Vegas, glitter gulch finds lunchbox trade beats high rollers. Wall Street Journal, May 22, 1972.

King, Rufus Gambling and Organized Crime. Washington, Public Affairs Press, 1969, pp. 32-33.

Kinsey, Robert K.: The Role of Lotteries in Public Finance. Ph.D. dissertation, New York, Columbia University, 1959.

Rubner, Alex: The Economics of Gambling. London, Macmillan, 1966, pp. 51-52.

Smith, Vernon: Economic theory of wager markets. Western Economic Journal, 9(3):242-255, September 1971. 


\title{
Chapter 4
}

\section{SPDRTS, TELHNULOGY AND GAMBLING}

\author{
RICHARD SCHUETZ
}

\begin{abstract}
THE NEED, DESIRE AND DRIVE to compete is an irrevocable truth 1 in America. The basis for this phenomenon is unimportant, but be it innate, learned or culturally produced, it is unquestionably with us. This tendency toward competitiveness is reflected in America's government, politics, business, education and every other institution. It is reflected in areas fromphilosophy to literature and has made it possible for the whole country to classify every event by diametrically opposed sides. Mutually beneficial events and outcomes have no place in the American credo. At times, the effects of this competitive spirit have yielded some very unjust and inequitable developments within the institutional framework of this country. What is to follow is a discussion of how this spirit can surface in a very innocent fashion.
\end{abstract}

"There is no substitute for hard work."

THOMAS ALva EDISON

From the start of this country, almost every male was involved in some form of physical activity. The country was composed of a large number of people whose livelihoods depended on physical exertion. Economic positioning was largely a function of the law of the musculature, and the vast majority of the population was tied to the land or machines which necessitated human strength, stamina or exertion. In essence, for a large segment of the population, man was the indigenous beast of burden.

With the high incidence of male involvement in physically active occupations, sports participation became a natural extension of this society. Sports evolved as a function of the surrounding social sphere and was established on a localized basis, usually friends and kin. Entrance into the sporting world was easily at- 
tained. Because in most local areas population was small and poor transportation restricted large gatherings, the only requirements needed to participate were the essential extremities and the will to compete. The costs of the sporting implements were also negligible. Sports participation then became a common and accepted form of leisure. The physical exertion was generally no more strenuous than required in one's occupation, and requirements, both in skill and cost, were minimal.

Things, however, began to change in America. Technological advancements advanced at an ever-increasing rate while population began an exponential growth pattern of unknown proportions. The pounding of machinery replaced the serenity of the previous era, and the industrial state began its turbulent childhood. The American state transformed its physical plant overnight, and as the physical properties of the country began to transform, pressure was placed upon the human inputs in this system to change as well, and change they did, not consciously or along any planned course, but rather by simply adapting to an environment of the machine's creation. Soon one machine became two machines, two machines became a company, the companies became corporations, and the state of this country was radically changed; so too were the role opportunities available to its human inhabitants.

With this metamorphosis of the American state, the male was somewhat alienated from the necessities of physical prowess. The law of the musculature began to concede to the service and professional sectors. Concurrent with this was a growth of population centers. More and more people gave up their isolation to reap the benefits they felt were only possible by congregating in cities. The inhabitants of America, as if attracted by a magnet, began to gather in ever-increasing numbers.

With this gathering of people, sports began to have a large population to draw from, and the demand for talent began to eclipse the mere desire to participate. The physical requirements of the competitive sports arena were extreme in contrast to the people's occupations while outside interests, too, began to restrict many from participation. Eventually, small areas were established 
where those who could not participate were conceded the right to watch those who could. With this, a new relationship began to form between the spectator and the team as a whole. The ability to view a team in conflict with another team became a substitute for the previous practice of actual participation. People began to align themselves with a team because of some identifying characteristic, and during the play of the contest attached themselves emotionally to the outcome. The spectator was now developing.

The spectator combined all of the tenets of emotionalism, chauvinism and complete devotion. Viewers became a charismatic retinue of professional sports. They were envious of the participants, they idolized the players' physical abilities, and they often mysticized their own great feats upon the field. The spectator became chauvinistic toward a team by reason of its location or roots of origin. Each of these caused an emotional attachment which heightened the competitive spirit for the man in the stands. By viewing a contest, the American male could assimilate that competitive spirit he had at one time received from the actual competition, for the spectator had his competitive counterpart in the opposing stands and could only gain at his loss or lose at his gain.

America did not stop moving, though. The population continued to explode; city boundaries began running into one another. A new sound joined the pounding of machinery-the silence of the computer. Once again pressure was exerted upon the human inputs within the system to change, and change again they did, once more following the direction prescribed by the technological leadership. With this change the role of sports again adopted a new relationship with the people-the nuclear relationship.

The nuclear orientation toward the role of sports was dominated by a continued specialization of the talent necessary for participation. It was no longer a realistic consideration to believe that, as an individual, one would possess the optimum mix of talents and opportunities to become involved in the complexities of institutionalized sports. This area was so divorced from the average individual that it became unique merely to know some- 
one who was a member of the sporting world. The sporting world was no longer an ancillary event ofone's total life, but tended to contradict one's occupation and life style. The costs, physical restraints and time involved separated the head of the nuclear family from the possibility of participation.

No longer could the individual assimilate the competitive spirit of the contest via the spectator. Sporting events became centralized in large metropolitan areas. Lower echelons of sporting activity could not compete with the specter of the ultimate form. The spectator was prohibited from fulfilling his role by stadium capacity, distances and time. Even when it was possible to secure a position within the audience it became difficult to assimilate the competitive properties of the contest. It was no longer the case of winner or loser, but also of the emotionally detached viewer.

ITEM: In 1970 over 300 television sets were destroyed during the course of football games. One individual is reported to have kicked in two sets on New Year's Day alone, the second attack resulting in numerous stitches.

The role of the spectator was now no longer a viable means of fulfilling the competitive spirit of the American male. The male was first removed from the contest on the field, then from the contest in the stands and was rendered to the inert position of watching from a television set. This, to the American male's competitive spirit, was tantamount to castration. The competition was lost, the spectator alienated, and the American male's competitive spirit was channeled away from this once viable outlet.

This journey from complete sports participation to the stands to the nuclear environment can be paralled by the development of today's male child. This macrocosm/microcosm development is significant in that it removes the vent for competition from the male through his development as in the previously discussed historical-technological case.

The male child is introduced to (or exhibits) the competitive spirit at a very early age. His access to the actual play during the grade school years is almost guaranteed. Once this child reaches high school his chance of actual participation is diminished by 
restraints of size and talent. This estrangement is partially appeased by means of a very complex system of peripheral events through the school and within the stands. Pep groups, bonfires and poster parties become the object of attention of those unable to compete. Once this child, if possible, goes off to an institute of higher learning, his chances of participation become miniscule. Once the child leaves college, his chances of participation in the ultimate form are essentially nonexistent.

As with the growing male child, the American male never decides that he no longer wants to compete in the sporting world, but rather is excluded from competition by his surrounding environment over which he has no control. Although the stadium appeased the male for a time, this is no longer a viable means of assimilating the competitive sports spirit, and it is time to consider a new alternative.

The alternative now exists as the result of essentially a free market decision process of the most classical nature; this is sports betting. Unfortunately, this alternative suffers from the taint of illegality. The betting arena, however, is an excellent alternative because it emulates the bipolar nature inherent in the spirit. As with the contest on the field, betting allows for a winner and a loser and the opportunity to personally be one or the other.

The effects on the following of football would be a very marked increase in the interest and degree of interest bestowed upon the sport by the American male. This would be a result of the delineation between winner and loser becoming clear once again. His reaction would be both of heightened emotionalism and greater chauvinism toward the game. His chauvinism toward a local or favorite team would increase because they would now become partners with something at stake. His emotionalism would be a direct result of the pecuniary incentive contained in betting, but also because of the tendency to become involved in the essence of the contest. Even though separated at times by hundreds of miles and a television set, the fact remains that the viewer assumes partial responsibility for the outcome of the contest as his participation is as essential as that of the actual participants. This participation would become mandatory when his competitive spirit was awakened by the ability to bet. 

Part Two

THE ECONOMICS

OF GAMBLING 



\section{INTRODUCTION}

The task of the economist when studying a subject such as gambling is to examine the economic motives of the participants, the workings of the relevant institutions, and the interactions of groups with divergent interests to explain how and why events and trends in markets happen the way they do. In this series of articles various tools of economic analysis are used to examine a number of aspects of gambling, gambling markets and Nevada's gaming industry.

The article by Ignatin and Smith begins by examining how gambling has been viewed throughout the years by economists and how economic motives for gambling can be discussed in terms of traditional consumption and investment categories. Parallels between gambling markets and speculative financial asset markets are noted, and the role of information in handicapping and predicting the future is discussed for gambling markets, and, in particular, sport wagering markets. Observations are then made on the likely economic consequences of legalizing wager markets throughout the country.

The question of what constitutes rational behavior has provided the base of many philosophic arguments among economists. In general, an individual is considered economically rational if he has a particular objective in mind and pursues the quickest (or least expensive) means of achieving that objective. In economic models characterized by assumptions of perfect knowledge and certainty, rationality is usually clearly defined. However, when risk and the uncertainty of outcomes of alternative decisions are introduced, the concept of rationality quickly becomes clouded. The topic of economic rationality under certainty and under conditions of risk and uncertainty is addressed in the article by Tsukahara and Brumm. In particular, they approach the questions of how a man ought to behave if he has a particular objective in mind, how he does behave and how he adjusts his actions as new information becomes available. A programming 
model for a casino gambler is devised to illustrate how gambling activity can be explained in terms of rational economic behavior.

In "The Market for Pro Football Betting" Michael Canes describes how illegal markets for football betting are organized and how they operate on a week-to-week basis during the football season. The setting of correct odds or game lines is undertaken by bookmakers so that ideally, regardless of the outcome of the contest in question, the bookmaker will earn a positive return. The mechanism by which odds and lines are set is very similar to the traditional market mechanism. Bettors vote with their wagers, thus altering the prices for betting on one team or another. A formal model of betting behavior is developed by Canes to explain this equilibrating process, then certain hypotheses concerning the ability to outpredict the market are empirically tested. Canes checks out a number of potential "trading-rules" (similar to those used in stock and commodity markets) to determine if market-determined wager odds and point spreads can be systematically beaten.

The final three articles of this section deal specifically with Nevada's legal casino gaming industry. Eadington examines the state's four main gambling areas in light of their facilities and income-generating abilities. He finds that the amount of play and profitability of the major casino games varies considerably from one area to another, and that this probably reflects the gambling preferences of the different types of tourists who are attracted to the four areas. He also estimates a production function for the gaming industry, relating the generation of gaming revenues to the size and composition of gaming operations.

Harrah's, Incorporated, is the largest gaming operation in northern Nevada with casino/hotel complexes in both Reno and at Lake Tahoe. J. George Drews, Treasurer and Controller of Harrah's, presents a discussion of how a large gaming operation is organized, what management and marketing strategies are pursued, and in general, what is necessary to successfully run a casino/hotel/entertainment operation such as those found in Nevada.

Before 1967 all of the owners of any gaming operations in 
Nevada had to be licensed with the state's regulatory agency, the Gaming Control Board. This effectively prevented any casinos from being owned by publicly traded corporations; it also restricted the financial avenues available to casinos. As the industry grew, it became more and more difficult for single individuals or partnerships to raise the capital necessary to finance large casino/hotel complexes. Changes in the state laws in 1967 and 1969 allowed public corporations to own casinos and consequently added considerable sophistication to the financing and operations of many of Nevada's large gaming establishments. The article by Noel and Curtis examines the new publicly owned Nevada casinos and compares their economic performance over the past few years to the state's closely held large casinos and to the performance of other publicly traded leisure activity corporations. 



\title{
Chapter 5
}

\section{THE ECONUMICS OF BAMHLING}

\author{
GEORGE IGNATIN AND ROBERT SMITH
}

\section{INTRODUCTION}

AMBLING HAS BEEN an important economic activity for hundreds of years and illustrations involving gambling have been extremely important in the development of the theory and tools of both statistics and economics. Recently, state governments in the United States have started to encourage legal gambling as a source of revenue. The issues that have been raised involve among other things mathematical probability, risk and uncertainty, investments and portfolio management, utility theory and welfare economics, public finance and the nature of productive work and leisure.

Our study begins with a short historical survey of the economic treatment of gambling. Section II discusses the consumption aspects of gambling. Section III analyzes the investment aspects of gambling and attempts to develop a consistent set of definitions and assumptions which are relevant to some of the issues in actual gambling activities. Section IV is on the economics of bookmaking.

\section{SECTION I - HISTORICAL TREATMENT OF GAMBLING}

The evolution of thought on gambling (and some of the other topics mentioned above) began with Daniel Bernoulli's (1738) assumptions of decreasing marginal utility of wealth $\left(\mathrm{MU}_{\mathrm{w}}\right)$ and homogeneous expectations* of both means and variations of gambles. He argued that the sum of the utilities (U) associated with different possible outcomes was the proper measure of the value of a gamble intsead of the naive measure of the utility of the expected value (EV) of the gamble. Symbolically, Bernoulli argued for S(U)

-The term homogeneous expectations means that all parties to a gamble have identical expectations as to the outcome. 
rather than $\mathrm{U}(\mathrm{EV})$ or for $\mathrm{\Sigma}(\mathrm{U})=\Sigma\left[\mathrm{U}_{1}\left(\mathrm{X}_{1}\right)=\mathrm{P}_{1}+\mathrm{U}_{2}\left(\mathrm{X}_{2}\right)-\mathrm{P}_{2}+\cdots+\mathrm{U}_{\mathrm{n}}\left(\mathrm{X}_{\mathrm{n}}\right)=\mathrm{P}_{\mathrm{n}}\right]$

where $\mathrm{U}_{1}\left(\mathrm{X}_{1}\right)$ is the utility of outcome $\mathrm{X}_{1}$, and $\mathrm{P}_{1}$ is the probability that $\mathrm{X}_{1}$ will occur. Bernoulli argued against:

$$
\mathrm{U}(\mathrm{EV})=\mathrm{U}\left(\mathrm{X}_{1} \cdot \mathrm{P}_{1}+\mathrm{X}_{2} \cdot \mathrm{P}_{2}+\cdots+\mathrm{X}_{\mathrm{n}} \mathrm{P}_{\mathrm{n}}\right)
$$

where $\mathrm{X}_{1}$ is the dollar value of outcome $\mathrm{X}_{13}$ and $\boldsymbol{P}_{1}$ is the probability that $\mathrm{X}_{1}$ will occur. This argument has gained wide acceptance in the literature and lies at the heart of modern investment theory.

From these assumptions, Bernoulli deduced (1) that any bet between persons of equal wealth would be irrational, but (2) persons with different amounts of wealth might well engage in a rational bet, and (3) that it is always rational to spread risk by diversification.

Adam Smith, in $1776_{2}$ argued that people would participate in unfair lotteries (i.e. where $\mathrm{EV}<\mathrm{O}$ ) or enter professions where some incomes were very high, but average incomes were low because

The over-weening conceit which the greater part of men have of their own abilities, is an ancient evil remarked by the philosophers and moralists of all ages. Their absurd presumption in their own good fortune, has been less taken notice of. It is, however, if possible, still more universal .... The chance of gain is by every man more or less over-valued, and the chance of loss is by most men under-valued, ..... (Smith, 1937)

While in substantial agreement with Bernoulli, Smith recognized that two parties to a transaction might have different expectations. This important observation, unfortunately, has been generally ignored in the modern literature while some of Smith's (1937) explicit value judgments, such as his attempt to distinguish between productive and unproductive labor have been followed implicitly.

Alfred Marshall (1920) stated his assumptions explicitly and agreed with Bernoulli that $\mathrm{MU}_{\mathrm{w}}$ decreases logarithmically. He 
argued that fair and even (i.e. $\mathrm{EV}=\mathrm{O}$ )* one-shot bet involved an economic loss (in utility). ${ }^{\dagger}$ Marshall recognized that since the loss was totally due to diminishing $\mathrm{MU}_{\mathrm{w}}$ it was necessary to assume that there was no utility involved in gambling per se.

Friedman and Savage (1948) developed a utility function which was both convex and concave to rationalize observed behavior patterns that appeared to be economically irrational, given the assumption of continuously diminishing $\mathrm{MU}_{W} .7$ The Friedman-Savage article precipitated a massive outpouring of articles, most of which were attempts either to (1) specify more precisely additional circumstances (or assumptions) that could justify observed gambling behavior or (2) describe in economic jargon the trade-offs made between risk and expected value by rational investors. Without exception these later articles have examined gambling and investment activities in which means and variations of future income streams were assumed to be known.

Samuelson (1971) wrote a terse (one-page) summary of many of the issues, recognizing the value judgments and consumption activities involved; and he argued that most people who gamble eventually lose money because they engage in unfair bets (i.e. $\mathrm{EV}<\mathrm{O})$.

*A "fair and even" gamble occurs whenever the expected value (EV) in dollars $\equiv$ 0 . The simplest "fair and even" bet involves a coin flip where the probability of a head $\left(\mathbb{P}_{B}\right)$ is 0.5 and the probability of a tail $\left(P_{T}\right)$ is 0.5 . If a bettor wins $\$ 1$ if a head occurs $\left(S_{H}\right)$ and loses $\$ 1$ if a tail occurs $\left(S_{T}\right)$, then expected value $(\mathrm{EV})=$ $\mathrm{P}_{\mathrm{H}} \mathrm{Xs_{ \textrm {H } }}+\mathrm{P}_{\mathrm{T}} \mathrm{X} \mathrm{s}_{\mathrm{T}}=0.5 \mathrm{X}(+1)+0.5 \mathrm{X}(-1)=0$. However, this is a nonmathematical use of the concept of EV peculiar to the "gambling" and "investment" literature.

† Marshall's argument, a restatement of Bernoulli's, was that, given diminishing $\mathrm{MU}_{\mathrm{W}}$, the utility of an additional dollar is less than the utility of the previous dollar. Since a "fair" bet has an equal expectation of a win or a $100 s_{1}$ and since the person with diminishing $\mathrm{MU}_{\mathrm{W}}$ puts a lower value on the dollar that might be lost, he will not bet.

¿Assumea small risk $(\mathrm{P}=.01)$ of losing a large amount of money $(\$ 100,000)$. If a person paid more than $(\$ 100,000 \times .01=\$ 1,000)$ to protect against the loss, the expected loss from the insurance $(\$ 1001 \mathrm{X} 1.0=\$ 1001)$ would be greater than the expected loss from the risk. Thus, persons who purchase insurance have decreasing $\mathrm{MU}_{\mathrm{W}}$. The problem is to explain the behavior of persons who both gamble and buy insurance. 


\section{SECTION II - CONSUMPTION ASPECTS OF GAMBLING}

One of the misconceptions in the literature is the common assumption that gambling and investment are concerned only with the acquisition of wealth. Starting from a market model that assumes perfect knowledge, rational behaviort and a belief that the only way to acquire wealth is to produce an economic good or service, economists have found it difficult to explain exchanges of money which are not directed toward the production of goods or services. Thus, the concept of investment has been expanded to include any behavior designed to make money. Ignoring the criticisms of Veblen and Tawney et al., even activities like speculation have been justified on the grounds that such activities, while not directly productive, enable actual producers to be more efficient.

Since gambling obviously does not increase production, economists have been unable to rationalize it, and instead have criticized it for being not only unproductive but immoral. Thus, in answer to the question, Why is gambling considered a bad thing? Samuelson answers, "morals, ethics and religion" (Samuelson, 1971). Moreover, he argues that "a substantial economic case [can] be made against gambling .... it involves simply sterile transfers of money or goods ... [which] absorb time and resources. When pursued beyond the limits of recreation . . . gambling subtracts from the national income."

Value judgments, clearly, have played an important role in the economic analysis of gambling, but when economists assume away "pleasure-oriented" gambling (Hirshleifer, 1965), then develop models which "prove" that gambling is irrational, that fair bets (in dollar terms) involve a loss (in utility), and that therefore people are foolish to gamble, this is a form of intellectual arrogance which avoids the facts. Gambling has been an important leisure or recreation activity of human beings for thousands of years. First, there is clear evidence that gambling activities not only are almost universal today, but have been so through time.

IIn economics, rational behavior means the attempt to maximize (a) profits by entrepreneurs, (b) utility by consumers, and (c) income by owners of resources. 
Even if gambling occurs only in specific environments, clearly there have been enough such special environments that they are not abnormal. According to Kaplan, (1960) "Gambling is common everywhere in the world today, and evidence of its practice [is] found in early excavations." Second, gambling has maintained its popularity in spite of laws and exhortations opposing it. (Kaplan, 1960; Kraus, 1971). Gambling has always been looked upon as an inferior activity and has been forbidden like almost all forms of recreation-dances, ball games, etc. This, Kraus says, "football was forbidden in some cities, including London, because it drew men away from the more useful sport of archery." (Kraus, 1971) - Kraus further says, "in each of the countries where Protestanism took effect there were similar strenuous attempts to curtail public amusements, sports, the arts, or the pleasurable use of leisure." "Third, the distinction between gambling and other (more highly regarded) "investment" activities has never been rigid. Kraus reports that Lloyd's of London "developed from a coffee house where businessmen met to gamble on the safe transport of cargoes overseas" (Kraus, 1971) -

Fourth, gambling has always been complementary to numerous activities-particularly sporting events. Even footracing became a gambling activity in the nineteenth century in the United States (Kraus, 1971). Fifth, given the universality of gambling activities and the belief that such activities are immoral and unproductive, it is not surprising that gambling has been regulated and even declared illegal. Moreover, given the desire to gamble and its illegality, it is predictable that illegal markets will develop. It has been estimated that only about one sixth of the money bet on horseracing is wagered at the track, and that the rest is gambled illegally with private bookmakers (Kraus, 1971). One reputable source (Life, 1967) claimed that "each year . . . the Mafia exploits the human urge to gamble to the extent of handling 20 billion dollars in illegal bets on racing and a variety of other major sports events, of which it keeps 7 billion dollars

\footnotetext{
"Even today, all major religions in the U.S. condemn gambling that does not augment the working capital of churches.
} 
in profits." Even though there have been numerous estimates of questionable accuracy, $t$ it seems that gambling in the United States involves a large amount of money.

Sixth, governments tend to condone or overlook gambling, vice, drinking and numerous other forms of illegal activities in which few people are hurt. Given the universal desire to gamble and the universal tendency to make gambling illegal, law enforcement officers do not enforce the laws uniformly. The issue of whether to legalize gambling, then, may be whether the public as a whole should benefit from gambling taxes or whether individual public officials should amass all of the benefits from bribes.

Gambling is universal and economists do not need to rationalize it, but they should understand it. People gamble for numerous reasons in addition to the desire for money, and most of these other reasons involve attempts to increase "utility." 1 This means that the assumption of risk aversion is wrong if applied to the total population or to the average man, and that the assumption of diminishing $\mathrm{MU}_{\mathrm{w}}$ is superfluous; even if additional dollars provide less utility than previous dollars, gambling is rational if the utility gained from it $\left(\mathrm{MU}_{\mathrm{G}}\right)$ is greater than the costs or price

\footnotetext{
*Where Life got its estimate is not certain, but the Kefauver Crime Committee estimated that "illegal gambling of all kinds" amounted to \$20 billion per year.

†If the mafia does handle 20 billion dollars in bets per year, they would not make 7 billion dollars, not even gross margin. Total revenues of 7 billion dollars made on baseball imply gross wagers of between 294 and 538 billion dollars. If made on football, such revenues imply a minimum of 154 billion dollars. An article in National Observer (April 8, 1972, p. 16) stated that in 1971, "gross profit for [Nevada's] gambling halls came to $\$ 633,000,000$, which means $\$ 3.2$ billion was wagered." This implies a house margin of 19.78 percent. However, since the margin is 5.28 percent at roulette, 1.41 percent at craps and indeterminate at blackjack, a "gross profit" of 0.63 billion dollars implies gross wagers of at least 12 billion and possibly as much as 45 to 50 billion dollars.

?Being in doubt about the outcome of an event and having alternative money values attached to different outcomes apparently increase the utility some people derive from watching the event. A baseball fan (and M.D.) is quoted to have said: "My trouble is I tend to view these games viscerally. Baseball gives me that endogenous epinephrin. I'm hooked on my own adrenalin." [Roger Angell, "The Sporting Scene (Bascball)", The New Yorker, September 17, 1973, p. 159]. Why people gamble is outside our competence; that people do gamble is an important fact that we cannot ignore.
} 
of gambling $\left(\mathrm{P}_{\mathrm{G}}\right) \cdot \mathrm{MU}_{\mathrm{q}}$ is a measure of whatever it is that gives consumers utility, and $\mathbf{P}_{\mathbb{Q}}$ includes expected losses, transportation and time costs, etc.

Gambling is time-consuming, utility-bearing and potentially profitable. Only because of the last attribute is gambling likened to investment which, usually, is considered to be devoid of any direct utility. Gambling possesses both consumption and investment aspects, and to make matters even more complicated, $\mathrm{MU}_{\mathrm{G}}$ probably rises as $\mathbb{P}_{Q}$ decreases. That is, $\mathrm{MU}_{\mathrm{Q}}$ is, in part, determined by winnings. As a gambler's winnings increase $\mathbf{P}_{\emptyset}$ decreases and $\mathrm{MU}_{\mathrm{g}}$ rises.

Economists assume that a person can spend time either productively (i.e. earning money) or on consumption, but not both. Work is believed to be painful (i.e. yielding disutility) while leisure is pleasurable. People who work (i.e. derive utility from both the income-earning activity and the income) are considered exceptions. Given these assumptions it is difficult to understand why economists, who believe that gamblers must lose, do not infer that the act of gambling must, therefore, provide utility. However, regardless of the conclusions that some economists deduce from their assumptions, clearly there are numerous activities including gambling which provide both direct utility and the hope of financial gain.

\section{SECTION III - GAMBLING AS INVESTMENT: PROBLEMS, DEFINITIONS AND MARKETS}

\section{A. Gambling}

In general, economists define a gamble (often implicitly) as a nonproductive zero-sum game involving money transfers. Gambling usually involves a contrived risk in that the bettors voluntarily enter into a transaction either for its own sake or because of a difference of opinion about the outcome of some event. Most gambling is done for consumption purposes, although the hope of financial gain also motivates gamblers. In addition, many kinds of risk-taking behavior not involving money transfers have been labeled gambling in the popular press. This latter use of the term, however, only complicates matters. 


\section{B. Risk and Uncertainty}

Webster's Dictionary defines risk as either (a) the chance of loss, or (b) the degree ofprobability of loss. Frank Knight (1965) defined risk as a situation in which "the distribution of the outcome in a group of instances is known" while for uncertainty "it is impossible to form a group of instances because the situation dealt with is in a high degree unique."

Donald Farrar (1967), agreeing with Knight, added,

To qualify as a risk situation .... an experiment must be repetititive in nature and must possess a frequency distribution from which observations can be drawn and about which inferences can be made by objective, statistical procedures.

Uncertainty, in contrast, is said to be present when the experiment in question cannot be carefully replicated by (or upon) other persons or at other times or places; that is, when the situation is unique. Its frequency distribution, therefore, cannot be objectively specified. This is undoubtedly the setting in which most investment decisions take place.

The question is whether gambling (or investment) is characterized by risk or uncertainty. While Knight and Farrar thought uncertainty was the normal situation, most economists have been concerned with risk, and have used simplistic illustrations where everyone is assumed to know the expected value (EV) and variation of an uncertain set of future events. It is usually assumed that all parties to a bet not only have such homogeneous expectations, but that the expectations will prove to be correct.

\section{Probability and Expected Value}

While agreeing on the definitions of risk and uncertainty, that risk is the normal situation, and that all parties to a bet expect and know the actual outcome (what Knight (1965) has called "the assumption of practical omniscience"), economists have been unable to agree on the definitions of probability and EV. Broadly, the opposing definitions can be classified into two mutually exclusive categories:

1. The objectivists define probability as the long run relative frequency that an event occurs-the mathematical concept of EV where it is the mean of a frequency distribution as the number 
of events approaches infinity.

2. The subjectivists define probability as the degree of subjective belief that an event will occur-subjective estimates of unique events. The Bayesian branch of the subjectivists add an errorlearning model to improve subjective estimates as the number of events increases.

With the objectivist definition it is impossible to have an EV for one event. With the subjectivist definition neither the mean nor the variation can be known (for certain) before events occur. Thus, the objectivist definition is correct whenever there is a large number of repetitive trials (such as coin-flipping), and the subjectivist concept is appropriate for unique events (like boxing matches) - Unfortunately, most writers have assumed (implicitly) that all gambles are identical and that either the objectivist or subjectivist definition must be correct for all situations. Moreover, the example of a one-shot fair bet, used to prove assumption of diminishing $\mathrm{MU}_{\mathrm{W}}$ involves a contradiction of both definitions of EV because there cannot be a mean for one event and it is impossible for the dollar value of one bet to be zero (the bettor either wins or loses). Economists for 200 years, however, have tried to stretch the analogy too far and have assumed that what is true for one bet must be true for many, but while one flip of a coin will come up either heads or tails, 1,000 flips will yield between 470 and 530 heads 95 percent of the time. Whether a person is rational to bet on one coin flip is entirely different from whether it is rational to bet on 1,000 flips.

\section{Gambling As Investment}

The typical assumption in the literature is that investors desire high values for expected returns or expected value (EV) and low values for risk or variability of return (R) . Most writers draw indifference curves showing the trade-off between $\mathrm{R}$ and $\mathrm{EV}$ on the assumption that investors are indifferent between a combination of low R and low EV and high R and high EV. Clower and Due (1972) call their curves "Iso-Return" and say, "Each of these curves indicates various combinations of risk (variance of returns) and earnings (rate of return) between which the firm 
is indifferent. By hypothesis, the firm prefers higher returns for any given level of risk, lower risk for any given level of returns."

However, while it is clear that a firm would prefer higher returns, other things equal, it is not clear why a firm would give up high returns to acquire lower risk particularly as risk is defined (or attempted to be measured). A person engaged in a large number of small uncertain investments (bets) would have a high expectation of obtaining the expected value of the bets under the law of large numbers. Thus, (rich) people who can afford to engage in a large number of risky investments which have a positive expectation of return $(\mathrm{EV}>\mathrm{O})$ have a better chance of obtaining the EV than would (poor) persons who have a higher probability of going bust from a short-run of bad luck.

Clower and Due (1972) recognize that often "risks cannot be projected with any degree of certainty from past experience," but then they add, "intuition and sheer guess-work will determine the relative certainty of various returns." However, it would be more precise to say that estimating or predicting future events cannot be done with certainty. Only the future unfolding of events will determine the relative accuracy of various estimates of returns. Thus, risk really means estimation of variation or estimation of the probabilities of the occurrence of certain future events.

Sometimes estimates of EV and R are what are needed; at other times, the most important statistic involves an estimation of the most likely range. In most cases, however, the only important estimate is EV. As the number of trials (gambles, investments, etc.) increases and as the size of each gamble decreases relative to the income or wealth of the gambler, the more important EV becomes and the less important $\mathrm{R}$ is. Indeed, the formula for $\mathrm{EV}$ includes an explicit estimation of the probabilities associated with the alternatives: $\mathrm{EV}=\mathrm{P}_{1} \cdot \mathrm{X}_{1}+\mathrm{P}_{2} \cdot \mathrm{X}_{2}+\cdots+\mathrm{P}_{\mathrm{n}} \cdot \mathrm{X}_{\mathrm{L}}$ where $P_{\mathbb{I}}$ is the probability that $\mathrm{Xi}$ will occur, and the $\mathrm{X}_{\mathbf{i}}$ 's are mutually exclusive and all inclusive.

Most of the writers on risk and uncertainty assume that higher risk assets must have greater returns ( $\mathrm{EV}$, interest) and that a higher rate of return is required to offset greater risk, but it is necessary to state whether we are talking about a stated or actual 
rate of return and what is meant by the word offset. Thus, income-producing assets can be ranked according to their stated rates of return and their risk-i.e. the probability that their actual rate of return will fall below their stated rates. Table 5-I illustrates this.

Assume an investor (lender) can choose between the purchase of only five types of bonds, each of which sells for 1,000 dollars and has a stated rate of return (interest or nominal yield) as indicated in Column $3\left(\mathrm{X}_{1}\right)$. Assume that the investor (lender) is concerned only with (a) the stated rates and (b) the probability that the issuer of the bond (borrower) will not pay any interest

TABLE 5-I

\begin{tabular}{lcccccc}
\hline \multicolumn{1}{c}{ Bond } & $\begin{array}{c}\text { Risk } \\
\text { Premium }\end{array}$ & $\begin{array}{c}\mathrm{X}_{\mathbf{I}} \text { (stated } \\
\text { return) }\end{array}$ & $\boldsymbol{P}_{\mathbf{a}}$ & $\mathrm{X}_{\mathbf{2}}$ & $\boldsymbol{P}_{\mathbf{2}}$ & $\begin{array}{c}\text { EV (actual } \\
\text { return) }\end{array}$ \\
\hline 1. Federal Government & 0 & +4.0 & 1.00 & -100 & .00 & +4.00 \\
2. State Government & 1.05 & +5.05 & .99 & -100 & .01 & +4.00 \\
3. High-Grade Corporate & 2.12 & +6.12 & .98 & -100 & .02 & +4.00 \\
$\begin{array}{l}\text { 4. Medium-Grade } \\
\quad \text { Corporate }\end{array}$ & 3.22 & +7.22 & .97 & -100 & .03 & +4.00 \\
5. Low-Grade Corporate & 4.33 & +8.33 & .96 & -100 & .04 & +4.00 \\
\hline
\end{tabular}

where $P_{1}$ is the probability that the investor will receive $X_{1}$ and $\mathrm{P}_{2}$ is the probability that the investor will not receive $\mathrm{X}_{1}$ and will lose his entire principal

$$
\mathrm{EV}=\mathrm{P}_{1} \bullet \mathrm{X}_{1}+\mathrm{P}_{2} \bullet \mathrm{X}_{2}
$$

TABLE 5-II

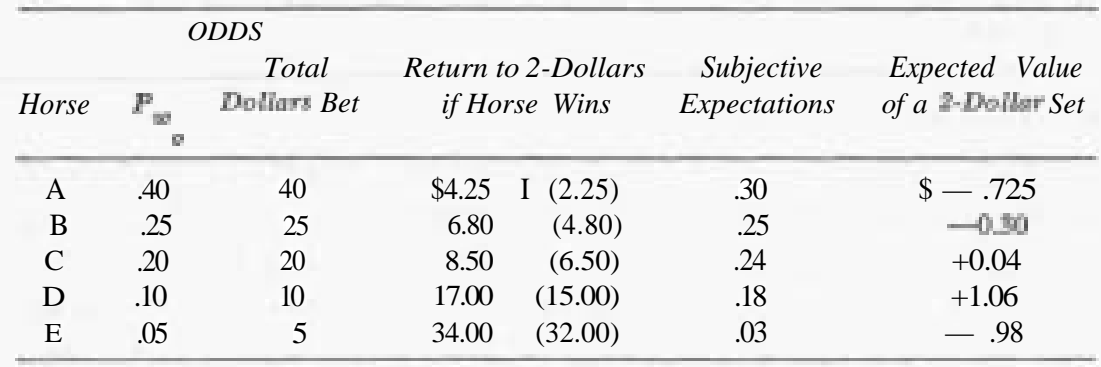

where $\mathrm{P}_{\mathrm{W}_{0}}$ equals the objective odds determined by the parimutuel tote board based on the actual dollars wagered by all bettors 
and will default on the repayment of the principal. Assume that there are no other risk factors, and that the investor holds the bond for one year.

For EV to be constant, the higher the probability that the borrower will default, the greater the stated rate of return must be. Thus, the term, "Iso-Return" (equal EV), is correct if the lender is indifferent between various combinations of stated earnings and risk; that is, the lender is indifferent between two bonds which yield equal EV or actual rate of return. Therefore, we argue that $\mathrm{R}$ is avoided because it lowers EV while the typical writer believes that risk is avoided for its own sake and that, as Watson (1972) says, "Reward is of course expected utility and risk is expected disutility."

While it is easy to list actual and stated returns (there are obviously an infinite number of possible combinations of rates of return and risk) it is very difficult to estimate the probabilities associated with each of these returns. Indeed, this is the heart of the matter: an investor is uncertain when he is unable to estimate precisely the probabilities of attaining different rates of returns. If he could make these estimates precisely, i.e. if his estimates were always borne out, there would be no problem of uncertainty or risk. Risk does not refer to known returns but the degree of uncertainty associated with alternative possible returns. The probabilities attached to different outcomes are subjective estimations based on whatever data and methods are at our disposal. It is in this sense that such investments are perceived properly as gambles.

\section{E. Gambling Markets}

There are four broad kinds of existing markets for gambling in the United States: (1) state-operated horse and dog-racing systems involving pari-mutuel (tote) boards which determine the odds by summing up the total plays of the bettors; (2) private games of skill, e.g. golf or poker where the odds are determined by mutual agreement and are based on subjective evaluations made by each player about the relative competence of every player; (3) public operations geared to football, baseball, basketball, 
etc., in which the odds are determined by a small group of professional odds-makers according to their (subjective) evaluations of alternative outcomes; (Amateur gamblers then play these odds according to their own subjective evaluations) and (4) games of luck, e.g. roulette or lotteries in which the actual objective long-run EV are capable of being known to all participants.

While most articles on gambling and investment state as assumptions the peculiar conditions underlying the last market, the first three probably are more important both in numbers of persons involved and amount of dollars wagered. Although number 4 is an important gambling market, it is not very interesting; people who participate obviously find the utility of the play (including all the trappings) to be greater than the expected loss (which is equal to the percentage the "house" takes)." Thus, number 4 will be ignored.

1. The basic problem for a bettor in a pari-mutuel game is to outpredict the other bettors. Table 5-II illustrates this. A winning bettor on horse A receives $\$ 4.25-\$ 2.25$ profit plusthe bet of $\$ 2.00$. The bettor must determine (1) what the parimutuel odds are and (2) what the real odds should be (subjective expectations.) If, as in Table 5-II, there is an underlay i.e. less money has been bet on a horse than is justified, the bettor should bet on that horse. In the long run, a bettor who bets nothing but underlays will be a winner. In Table 5-II both horses $\mathrm{C}$ and $\mathrm{D}$ are underlays, but $\mathrm{D}$ is a better bet. Horses A and E are overlays while horse B is an overlay in the sense that bets on $\mathrm{B}$ will lose money in the long run due to the track's take.

2. Very little can be said about private games of skill. While

\footnotetext{
*In roulette, a person who bets one dollar on red one hundred times would expect to win forty-seven times and lose fifty-three times, thereby losing six dollars. Since it takes about three hours for one hundred spins of the wheel, it costs two dollars $/ \mathrm{hr}$. for the game. A professional football game takes two to three hours (plus the time spent traveling to and from parking, which usually is far greater and more aggravating than the travel to the roulette wheel) and costs six dollars to fifteen dollars. Analyzed as an entertainment rather than an investment, roulette does not seem irrational.
} 
enormous amounts ofmoney probably change hands regularly, the only general statement that can be made is that these are zero-sum games in which friendship and leisure time play a large role. Whether these games are productive in the long run may be more a matter of personal speculation than of empirical verification. While there are regional variations in games played, millions of people engage in regular gambling activities, $t$ and there is a mixture of motives. It is possible that some men (pool or golf hustlers) consider gambling as investment or work, although most probably think of their gambling as enhancing the utility they receive from their leisure.

3. Public gambling on sporting events is legal in Nevada and illegal everywhere else in the United States, yet it is reasonable to assume that every city with more than 10,000 persons probably has some illegal bookmaking activities, and these activities probably increase with the number of persons in the area and the amount of interest in sporting events, which is itself a function of the number of local teams and TV coverage.

Thus we would expect (a) more betting in New York City than Kansas City, (b) heavier betting on college football than on pro football in South Bend, Indiana, (c) more hockey betting in Montreal than Miami, and (d) more money bet on televised than non-televised games. Even though we have no systematic data to support our belief, we think that gambling on sports in illegal markets is the main form of gambling in this country and may involve as much as 200 billion dollars per year, and clearly more than the estimates of twenty to fifty billion dollars made by other observers.

f While we have no systematic data, it is our impression that in all sections of the country, poker is probably the most important (in terms of wagers) men's card game. In the North, and in the Navy, pinochle runs poker a close second. In the South, gin is in second place. Bridge is played by a large number of men and women, but mostly for small stakes. Likewise, Mah-Jongg, Cribbage, Hearts, Casino, Domino's, Checkers, and even Chess are played "for money". Probably more men play golf for money than any other sport, but all sports played by men have "side-bets" — if only beer. 
While gambling on sporting events cannot be considered simply as short-run, high-risk and, therefore, potentially highyield investments, there are some interesting parallels between traditional investment markets and sports gambling. Just as there are numerous investment counselors who offer (sell) advice concerning conventional investment opportunities, it has been estimated that in 1971 there were "about 200 sports information services around the country" (Wall Street Journal). The number of such services probably has increased during the past three years. (The 1973-74 issue of Street and Smith's Basketball lists advertisements for about a dozen such services ranging from fairly inexpensive newspapers with forecasts to rather elaborate and expensive services, sometimes including the provision of information by telephone).

The operation and efficiency of investment (securities) markets it often discussed with respect to the depth, breadth and resilience of the market. Depth refers to the volume of actual and potential transactions at or near the market price; breadth refers to the number of buyers and sellers in the market; and resilience refers to responses to changes in the market price (Polakoffet al., 1970). One difficulty in analyzing sport-gambling markets is that there are a large number of individual markets which vary considerably with respect to depth, breadth and resiliency. The bookmaking business includes some very large operations and some very small operations in various types of market structures and situations (Merchant, 1973) .

One characteristic of a market with substantial depth and breadth is that the difference between bid and asked prices will be less than if the market were shallower and/or narrower. In gambling markets this difference can be considered to be the odds that the gambler gives the bookmaker-often called vigorish, juice or grease. In wagering on football or basketball, typical odds in betting on a particular game (with a given point spread) are 11/10-the bettor risks eleven dollars to win ten. However the odds of $11 / 10$ are not universal. A very large bettor, especially in a market that has great depth may be able to bargain or exercise monoposonistic power and place his bets at odds of $10.5 / 10$ or 
even money (10/10) if he takes the wrong side, i.e. the opposite side from that taken by the majority of bettors. Similarly, a small bettor, particularly in a shallow market, may find that he has to give (lay) odds of $12 / 10$.

\section{SECTION IV - THE ECONOMICS OF BOOKMAKING}

It is widely believed that the bookmaker's (book's) object is to achieve a Dutch Book-definedas a situation in which the book wins equal amounts of dollars regardless of which side of a line wins. Thus, it is assumed that the book tries to establish a line (or price) such that half of the bettors think its too high and half think its too low. What this means in practice, though, varies. Consider the following examples:

A. Assume a twenty-cent baseball line." Assume the line is 11/10-pick it. To win $\$ 100.00$ the bettor must lay (put up) $\$ 110.00$. If $\$ 110.00$ is bet on both teams, the book will win $\$ 10.00$ regardless of the outcome.t

B. Assume a twenty-cent line. Assume the line is $15 / 10$. A bettor must risk $\$ 150.00$ to win $\$ 100.00$ if he bets on the favorite (F) and $\$ 100.00$ to win $\$ 130.00$ if he bets on the underdog (U) . If $\$ 150.00$ is bet on $F$ (to win $\$ 100.00$ ) and $\$ 100.00$ is bet on $U$ (to win $\$ 130.00$ ), the book wins twenty dollars if $\mathrm{U}$ wins and 0 if $\mathrm{F}$ wins. This is not a Dutch Book. The book needs approximately $\$ 108.70$ bet on $U$ (to win $\$ 141.31)$ to guarantee him $\$ 8.70$ gross profit regardless of the outcome. If the line is $18 / 10$ and $\$ 180.00$ is bet on F (to win $\$ 100.00)$, the book needs approximately $\$ 107.69$ bet on $U$ to guarantee $\$ 7.70$ profit.

C. Assume a ten-cent line. If $\$ 105.00$ is bet on both teams (to win $\$ 100.00)$, the book is guaranteed five dollars in profit.

D. Assume a ten-cent line. If the line is $15 / 10$ and $\$ 150.00$ is bet on $\mathrm{F}$ (to win $\$ 100.00$ ), the book needs $\$ 104.17$ bet on $\mathrm{U}$ (to win $\$ 145.84$ ) to guarantee $\$ 4.17$ profit. If the line is $18 / 10$,

*A twenty-cent line means that there is twenty cents per one dollar difference between what those who bet on the favorite (F) must lay compared to what those who bet on the underdog $(U)$ would receive.

tThat is, if the game is played to a decision, losers pay and winners are paid. 
and $\$ 180.00$ is bet on $F$, the book needs $\$ 103.70$ bet on $U$ to guarantee a profit of $\$ 4.70$.

The implications are:

1. The higher the line, the smaller the book's margin as a percent of the amount wagered. Most baseball action is geared to ten-cent lines in the United States; thus, a 1.05-pick-it line returns five dollars per $\$ 210.00$ wagered or 2.38 percent, a $15 / 10$ line returns $\$ 4.17$ per $\$ 254.17$ wagered or 1.64 percent, and an $18 / 10$ line returns $\$ 3.70$ per $\$ 283.70$ wagered or 1.30 percent.

2. If the $15 / 10$ line is normal and books earn one billion dollars in gross profits, almost 61 billion dollars would have been wagered!

3. Given the low percentage returns and the high costs of operation, only those books handling large amounts of bets can be successful by achieving Dutch Books. A book with gross wagers of one million dollars would have a gross margin of only $\$ 16,400.00$. These are revenues of the book; to determine profits, subtract costs of operation-rent, telephones, labor, materials and police insurance. Perhaps the most important costs to the book (and the most difficult to estimate) are the costs of collection including the risk that bettors will not pay. In addition, books must have an extremely large fund of working capital to pay off winners before collecting from losers.

E. In basketball and football the line is always $11 / 10$,plus or minus points. Say $F$ is favored to beat $U$ by 6.5 points ( $F$ - 6.5; $\mathrm{U}+6.5$ ). If $\mathrm{F}$ wins by more than 6.5 points, those betting on $\mathrm{F}$ win and those betting on $\mathrm{U}$ lose. If $\mathrm{F}$ wins by less than 6.5 those betting on $\mathrm{F}$ lose and those betting on $\mathrm{U}$ win. One hundred ten dollars (to win $\$ 100.00$ ) bet on each side guarantees the book ten dollars $(4.55 \%$ of 220$)$.

F. Assume the line is seven. A one hundred ten-dollar bet on each side guarantees the book ten dollars unless $\mathrm{F}$ wins by exactly seven, then all bets are off (pushed). The book's gross profits are ten dollars times the probability that $\mathrm{F}$ will not win by exactly seven. If we assume that probability is .95 , the book's expected profit equals $\$ 9.50(\$ 10.00 \times .95+0 \times, 05)$ or $4.32 \%$ of $\$ 220.00$. 
More profitable than the Dutch Book is a line which induces the majority of bets (in dollars) to be on the losing side. Recognizing this, many books try to outsmart their customers by moving the line. Many books are compulsive gamblers who have become books to improve their odds. Once they become books, however, they still believe that they can handicap better than the Nevada professionals, so, even though they now are gambling at better odds than previously, they still are gambling and not booking. In addition to the high cost of operation mentioned earlier, this explains much of the turnover in the industry.

A far safer method of outperforming the Dutch Book is to middle or scalp points. The legalization of gambling in Nevada has made that state a focal point in the establishing of prices (point spreads or odds) in illegal gambling markets in other states. There is an elaborate process in which some big bettors are allowed to bet an early outlaw line in Nevada; these bets serve to establish lines that are then disseminated by various means throughout the nation. (See Merchant, 1973 for a description of this process.) From this point, changes in lines occur through an interplay of market forces. Some bookmakers apparently have great faith in the handicapping systems that establish the initial prices and make changes infrequently; other bookmakers change their prices quite often in response to bets they receive. The result of this process is that point spread differences (and differences in odds) of several points may exist between markets throughout the nation, and some differences may even exist in particular local markets.

Just as in securities markets, the degree of resilience in gambling markets is related to the degrees of depth and breadth. In a market with substantial depth and breadth a 0.5 point change in a point spread (or a 0.05 change in the odds in a baseball game) may elicit a substantial volume of bets on the team that the bookmaker wants more action on. A book may want more action on a team either to approach a Dutch Book or because he likes the other side. On the other hand, in a shallower and/or narrower market the change in the price (or spread) necessary to effect a substantial change in the relative amounts bet on the two teams 
may be so great that the bookmaker does not want to risk being caught in the middle of his point spread (i.e. he may be able to balance his books by moving a six-point favorite to an eight-point favorite, but if $\$ 110.00$ is bet on F-6 and $\$ 110.00$ is bet on $U+8$ and if $\mathrm{F}$ wins by six or eight points, the book loses one hundred dollars, and if $\mathrm{F}$ wins by 7 , the book loses $\$ 200.00$ ) . Thus, he may elect to take a team off the board if he has what he considers an excessive amount of wagers on one team rather than test the resiliency of the market.

The practice of arbitrage, which often plays an important role in increasing the efficiency of securities and commodities markets, may also be significant in gambling markets. A practice sometimes called scalping points is essentially the same thing as arbitragea bettor will bet on both teams in a particular game taking advantage of differences in the lines of two bookmakers. Although this practice does have the effect of increasing the efficiency of gambling markets (increasing resiliency-mitigating fluctuations in prices), some bookmakers take a rather dim view of the practice and will not deal with bettors who hit them for middles.

The book can achieve a super Dutch Book by reversing middles. Given regional variations in tastes, an objective line made in Nevada will attract varying amounts of money on the $F$ and $U$ in different parts of the country. For example, when the Nevada lines makes Miami a seven-point favorite over Minnesota, it is likely that Miami will be a nine or ten-point favorite in Miami and other AFC cities and a five or six-point favorite in Minneapolis-St. Paul and other NFC cities. A Miami book can speculate and buy 20,000 dollars worth or F-7 on the early Nevada line, then post a price of F-10 in Miami. If he has anticipated his players correctly, he will wind up with, say, 10,000 dollars on $\mathrm{U}+10,30,000$ dollars on F-10 and he will have bet 20,000 dollars on $\mathrm{F}-7$ (which is similar to having his players bet $\$ 20,000.00$ on $\mathrm{U}+7)$. If $\mathrm{F}$ wins by 6 or less, he wins 1,000 dollars $(33,000.00$ from those who bet $\mathrm{F}-10$, minus $\$ 10,000.00$ he loses to those who bet $\mathrm{U}+10$, minus $\$ 22,000.00$ he loses to the Nevada line-makers). If $F$ wins by 11 or more, he wins 1,000 dollars $(\$ 11,000.00$ from those who bet $\mathrm{U}-10, \$ 20,000.00$ from the Nevada line-makers, 
minus $\$ 30,000.00$ to those who bet $\mathrm{F}-10$ ), but ifF wins by $7,8,9$ or 10 , the book has hit a middle and wins the following amounts.

AMOUNT WON BY BOOK FROM:

\begin{tabular}{ccccc}
\hline Fwins by & bettors: $\mathrm{U}+10$ & bettors: $\mathrm{F}-10$ & Nevada $[\mathrm{U}+7)$ & Total \\
\hline 7 & $-10,000$ & $+33,000$ & - & $+23,000$ \\
8 & $-10,000$ & $+33,000$ & $+20,000$ & $+43,000$ \\
9 & $-10,000$ & $+33,000$ & $+20,000$ & $+43,000$ \\
10 & - & - & $+20,000$ & $+20,000$ \\
\hline
\end{tabular}

Since this method pays such great returns when the book speculates correctly, many large-scale books will be induced to try it. This, in turn, provides useful information to the Nevada linemakers. If most of their customers like one side, they will move the line. The line is right only when approximately half of all dollars wagered are on each side. For the linemaker who receives as much as 10 or 20 million dollars per game, an approximate Dutch Book means large guaranteed profits.

The major implication is that illegal gambling markets differ considerably with respect to market structure, depth, breadth, resilience and attitudes of participants, and that any imposed change in these markets should consider these differences. Rigorous enforcement of antigambling laws or some form of legalization of gambling on sports will have differing effects on various gambling markets.

The current federal gambling tax of 10 percent per bet clearly is too high to be an effective revenue measure, The tax, if paid, would yield the government more than twice the gross margins of bookmakers on football and basketball. On high-line (e.g. 18/10) baseball games a bettor on F has to lay 198 dollars to win one hundred dollars, and a bettor on $U$ has to lay $\$ 114.77$ to win $\$ 176.30$. Regardless of the outcome, the book earns $\$ 3.70$ gross margin, but the government receives $\$ 28.37$. Obviously, illegal gambling is a better arrangement for the book (more profitable) and the bettor (less costly). Thus, the federal tax will work as a prohibitive tax if enforced, and will drive both bettor and bookie

TEAitor's note: the federal gambling tax was reduced to two percent at the end of 1974. 
underground unless low cost methods ofenforcement are devised.

The moral and legal questions raised include whether we should levy taxes which are so difficult to enforce and provide such strong incentives to be avoided. Is gambling such a heinous vice that it should be made a criminal activity, or should we recognize that gambling is a normal human activity that government should regulate in the public interest? If the latter, then the tax on gambling should be low enough to make the risk of avoidance* greater than the costs of payment. It is our belief, based mostly on a priori considerations, that a low tax will yield the government greater revenues than the current prohibitive tax. Indeed, any revenues received from gambling are a net bonus to the government because the bettor pays income taxes on his income and may not deduct gambling losses while the book will pay some income tax on his profits. Since prohibitive taxes either cannot or, in practice, will not be enforced, and since the elasticity of gambling tax collections may be quite high, the government should experiment with lower rates to test the issue.

Should states other than Nevada decide to legalize gambling, discrepancies in lines might result unless the other states decide merely to parrot the Nevada lines in which case some states will run large risks from unbalanced books. If Notre Dame plays Texas, a line that equates the dollar amount of bets nationally would leave the Texas gambling commission with too many bets on Texas while the Indiana and Illinois commissions would have too much bet on Notre Dame. The result of the game could have a significant effect on the states' treasuries. On the other hand, with interstate line differences there would be an incentive for bettors to engage in arbitrage or scalping, and the ability of large regional books to hit reverse middles would be diminished. If state gambling commissions try to compete on lines, the end result will be excellent lines and very little revenue for most states.

*The risk of avoidance is a subjectivist concept involving the gambler's estimate of the probability he will be caught times the expected costs of being caught. If the costs of avoiding capture are greater than the profits to be earned, the gambler will exit from the industry. The gambler's subjective estimate will be a function of the costs incurred by, and the efficiency of, the regulators, and the gambler's risk-aversion. 
It is conceivable that some states might even lose money if their lines are particularly bad, thus the states should coordinate themselves or have the federal government act as central bookie. However, even then the very large and difficult problem of determining the right lines will remain.

In conclusion, while most laymen (and government officials) believe that gambling operations are highly lucrative, our own examination, based on a priori reasoning and (casually) empirical study, leads us to believe that the gambling industry is competitive and risky, and in the absence of a large monopolist, probably low profit. Governmental units should not only be aware of the difficult problems involved in running gambling operations on sporting events, but should be aware that such operations will not yield highly significant revenues.

\section{REFERENCES}

Angell, Roger: The sporting scene (baseball). The New Yorker, p. 139, 1973. Bernoulli, Daniel: Exposition of a new theory on the measurement of risk.

Originally published in Latin in 1738, translated in Econometrica, XXII: 23-36, January 1954.

Clower, Robert W., and Due, John F.: Microeconomics. Homewood, Richard D. Irwin, p. 292, 1972.

Farrar, Donald E.: The Investment Decision Under Uncertainty. Chicago, Markham Publishing Company, 1967, p. 2.

Friedman, Milton, and Savage, Leonald J.: The utility analysis of choices involving risk. JPE, 56:274-304, 1948.

Hirshleifer, J.: Investment decision under uncertainty - choice-theoretic approaches. Quarterly Journal of Economics, LXXIX(4):532, November, 1965.

Kaplan, Max: Leisure In America: A Social Inquiry. New York, John Wiley \& Sons, Inc., 1960, pp. 104 and 147, 157, 173, and 318.

Knight, Frank H.: Risk, Uncertainty and Profit. New York, Harper Torchbooks, 1965, p. 233.

Kraus, Richard: Recreation and Leisure in Modern Society. New York, Appleton-Century-Crofts, 1971, pp. 145, 147.

Life: The Mob. September 8, 1967, p. 91.

Marshall, Alfred: Principles of Economics, 8th ed. Originally published in 1920. Reprinted by Macmillan \& Co. Ltd., 1964, p. 111.

Merchant, Larry: Bet, book and handle. Sports Illustrated, 39(10):67, 68, 1973.

Polakoff, Murray E., et al.i Financial Institutions and Markets Boston, 
Houghton Mifflin, 1970, p. 427.

Samuelson, Paul A.: Economics, 9th ed. New York, MoGraw-Hill, 1971, p. 409.

Smith, Adam: The Wealth of Nations. Edited by Edwin Cannan. New York, The Modern Library, 1937, p. 107, 321-325

Wall Street Journal, Friday, November 12, 1971, p. 1.

Watson, Donald Stevenson: Price Theory And Its Uses, 3rd ed. Boston, Houghton Mifflin Company, 1972, p. 153.

Webster's New World Dictionary of the American Language, College ed. Cleveland, The World Publishing Company, 1960, p. 1257. 


\section{Chapter G}

\section{ECONUMIC, HATIINALITY, PSYCHOLOGY ANII DECISION-MAKING UNIIER UNCERTAINTY}

THEODORE TsUKaHARA, JR. AND HAROLD J. BRUMm, JR.

\section{INTRODUCTION}

Ignorance is like subzero weather: by a sufficient expenditure its effects upon people can be kept within tolerable or even comfortable bounds, but it would be wholly uneconomic entirely to eliminate all its effects. And, just as an analysis of man's shelter and apparel would be somewhat incomplete if cold weather is ignored, so also our understanding of economic life will be incomplete if we do not systematically take account of the cold winds of ignorance (Stigler, 1968).

PERHAPS FEW ATTEMPTS have been made at a behavioral theory of 1 individual economic action because we fail to put much faith in the actions of those whom we observe everyday, even our colleagues and ourselves. For example, many of us fail to see any rational economic operation in the American stock markets, however few of us pass up the opportunity to tempt Dame Fortune to try and parlay our meager professorial wages into a more comfortable income stream." Once we admit the presence of ignorance in an economic world, we leave the comfortable confines of certainty and find ourselves in the wilderness of risk or in the swamp of uncertainty. It is in these environments that a behavioral theory has most significance. "The real acid test of any behavioral theory is provided by choice among uncertainties" (Gerogeseu-Roegen, 1958) .

To illustrate the conventional interpretation of a model of con-

\footnotetext{
*The most notable attempt to formulate a behavioral model of individual choice may be found in Simon (1955).
} 
sumer choice* in an environment of certainty we adopt Arrow's (1958) formulation,

What may be termed a rational model of choice (or decision making) has the following well known form: An individual is assumed to rank all alternative logically possible decisions in order of preference; in any given situation, only some of the logically possible alternatives are in fact available, due to budgetary or other limitations, and the individual is assumed to choose among the alternatives available that one which is highest on his ranking. The ranking or ordering is assumed to have the usual consistency properties so that, if alternative $\mathrm{A}$ is preferred to alternative $\mathrm{B}$, and $\mathrm{B}$ to $\mathrm{C}$, and $\mathrm{A}$ is preferred to $\mathrm{C}$.

In brief, Arrow suggests that the individual ranks all possible alternatives, chooses the highest ordered alternative available, and conforms to the transitivity assumption. Many economists would argue that an assumption of certainty is not necessary to fulfill the conditions described by Arrow. For example, Houthakker (1961) holds that "the traditional theory of consumers' choice is not, as is often believed, a theory based on the assumption of certainty. What is assumed is that an individual can rank all objects available to him in order of desirability." We agree that an assumption of certainty is neither a necessary nor a sufficient condition for a ranking, which is the heart of the conventional analysis of consumer choice. Certainty, in the present context, really implies an assumption of knowledge as Quandt (1956) correctly indicates.

The assumption of knowledge is composed of two distinct assumptions.

First, it is assumed that the consumer knows the available alternatives.

Secondly, it is assumed that he is familiar with the methods of finding a set of strategies which will maximize his chances of attaining his goals.

In other words, the individual knows all available final objects of choice and the possible means of obtaining the highest ranked object. Once selected, the probability of acquiring the highest ordered choice is equal to one. The individual is never disappointed because a sold out condition cannot exist. There is always certainty in supply.

Rationality, or rational behavior, is implied in the assumptions

*We specify choice in the manner to distinguish work in economics from the work by psychologists such as Coombs and Luce. 
of transitive behavior and optimizing behavior. An individual conforming to the assumptions above is called an economic man. All citizens of certainty are economic men in the sense that they are always efficient maximizers. Deviants do not exist in this world, for all consumers act as good consumers should act. Thus, in certainty we have no need for a behavioral theory of consumer choice.

Individuals facing situations where the alternatives are in the form of lotteries or gambles have been variously described as acting in environments of risk or uncertainty. As in the certainty case, the individual is assumed to rank the available alternatives, choose the most favorable and conform to the transitivity assumption. However, the choice is more difficult. Some alternatives may result in a set of possible final objects, each with a probability of occurrence less than one. The task of ranking alternatives and the selection of the best strategy become more complex for the individual since he does not possess full knowledge of the situation, i.e. he lacks knowledge either of the complete set of available alternatives or of the probabilities of the outcome of final objects, or of the optimal strategies. Excellent surveys of the literature in these areas have been by Arrow (1951) and Edwards (1954). In the main, these studies entail the establishment of some sort of economic man in the various economic environments of risk and uncertainty by assuming that the individual conforms to a set of rationality assumptions. Usually the individual is cast as some sort of efficient maximizer by the proper use of statistical decision theory* and thus could easily be called a "statistical man," Therefore, to most economists, a rational decision-maker is the only acceptable citizen in any economic world.

No behavioral theory of consumer choice exists in the literature for the environment of risk and uncertainty. We recognize as does Hoyt (1965) that the most fruitful direction to take to remedy this "Simon (1957), in a critical vein, writes, "Neither of these devices (statistical decision theory or game theory) simplifies the computational problem that faces the decision maker, and hence cannot be expected, by themselves to lead to a satisfactory theory of rational choice."

tThis term is adopted in the spirit of Marschak (1946). He also interprets the converse, i.e., that a "statistical man" implies an "economic man" because, in order to define the best inference procedure, one has to assume that the loss due to errors of inference is to be minimized. 
situation would be to integrate the research in psychology with the developments in economics since they share an interface in the theory of choice. It is upon this premise that the present study is developed.

\section{ECONOMIC RATIONALITY}

To say that an individual is rational is to characterize the nature of his behavior. Generally, any action taken by the individual should be deemed rational if, in light of the best available evidence, that action is most likely to produce the desired result. An issue that is often raised at this point is whether or not the behavior should be preceded by conscious deliberation and reflection in order to be termed rational. For example, is John's behavior rational if he automatically looks up and down the street before entering an intersection? John would be rational if, asked to justify his behavior, he could give appropriate and good reasons for his actions. Thus, for behavior to be rational it need not always be accompanied by deliberate reflection, but it must be purposeful and a voluntary action.

This now leads to the means-ends dichotomy. The usual formulation is to take the rationality of the ends as given and evaluate the behavior in terms of the means taken to achieve the ends. It is interesting to note the assumption of the rationality of the ends as given is quite similar to the economic assumption of the individual's preference ordering as given. Rationality, in the context of the social sciences, is thus defined,

Action is rational in so far as it pursues ends, possible within the conditions of the situation, and by the means which, among those available to the actor, are intrinsically best adapted to the end for reasons understandable and verifiable by positive empirical science. (Parsons, 1949).

Simply, rational behavior must be goal-directed.

Parsons (1931) sets forth the historical foundations of rationality in economics in his analysis of Marshall's attitude toward the concept of economic man.

This creature has generally been endowed with two leading qualities: egoism and rationality. On the one hand, he has been thought of as engaged solely in the pursuit of his own self-interest; on the other, as 
acting rationally in the attainment of that interest. The two attributes have commonly been linked together, though it may be doubted whether they are not perfectly separable. If man be conceived as acting rationally to satisfy his wants whatever they are, the question whether those wants are wholly egoistic or include altruistic desires is irrelevant to the understanding of the behavior issuing from them. But there is no doubt of the historical association of the two elements.

It should be clear from the above passage that Marshall's economic man is indeed rational in the sense of the term established earlier in this section. It is a rationality of means, not ends, for, as Parsons points out, it is irrelevant to discuss the rationality of the ends, i.e. either egoistic or altruistic.

Another important issue is whether or not economic man is merely a Platonic ideal or a fully fleshed reality. Parsons again interprets Marshall on this point.

He expressly repudiates any abstract methodological assumption of an economic man of any sort. He asserts quite emphatically that he is talking about real people as they actually act in the business of everyday life. (In every respect economics takes man just as he is in ordinary life) [Principles.]

Moreover it is equally clear that he did not consider the actual men with whom he dealt to be unmitigated egoists. (Whenever we get a glimpse of the economic man he is not selfish [Memorials]; the motives which induce business men to compete are not altogether sordid [Memorials] $]^{*}$

Some writers feel, however, that traditional economic man does not possess the humanity of Marshall's creature. For example, Simon (1955) interprets economic man in the traditional sense.t

Traditional economic theory postulates an "economic man" who in the course of being "economic" is also "rational". This man is assumed to have knowledge of the relevant aspects of his environment which, if not absolutely complete, is at least, impressively clear and voluminous. He is assumed also to have a well-organized and stable set of preferences, and a skill in computation that enables him to calculate, for the alternative courses of action that are available to him, which of

"Bracketedl statements are footnotes found in Parsons' text citing works by Marshall.

†Simon uses "economic man" and "rational man" as equivalent statements. A philosopher might be tempted to say that for man, being economic is one of the essential consequences of being rational. 
these will permit him to reach the highest attainable point on his preference scale.

Katona (1953) reinforces Simon's views of traditional economic man and forcefully implies only a methodological existence.

Basic among these propositions are the following three which traditionally have served to characterize the economic man or the rational man:

(1) the principle of complete information and foresight .. .

(2) the principle of complete mobility.

(3) the principle of pure competition.

One final view of traditional economic man is presented by Edwards (1954) in a survey of economics addressed to his fellow psychologists. "What is an economic man like: He has three prop erties. (a) $\mathrm{He}$ is completely informed. (b) $\mathrm{He}$ is infinitely sensitive. (c) $\mathrm{He}$ is rational." He feels that the crucial fact about economic man is his rationality. Anticipating the critical observations of his colleagues that economic man does not conform to reality, Edwards (1954) states.

It is easy for a psychologist to point out that an economic man who has the properties discussed above is very unlike a real man. In fact, it is so easy to point this out that psychologists have tended to reject out of hand the theories that result from these assumptions. This isn't fair. . the most useful thing to do with a theory is not to criticize its assumptions but rather to test its theorems.

There has been some movement among the behaviorist social scientists to alter the assumption of rationality of economic man. The views range from Parsons' (1949) outright suggestion that traditional economic man be banished to an intellectual limbo to Simon's (1957) moderate Principle of Bounded Rationality. Recently Katona (1968) has suggested that the rationality assumptions be discarded altogether.

In the proposed theory of consumer behavior the assumption is abandoned that consumer behavior is based on fully rational decision making. A genuine decision reached after careful weighing of alternative courses of action is an exception rather than the rule, in view of the great frequency of habitual behavior as well as the influence of long established stereotypes.

While rejecting the notion of rationality in the traditional ec- 
onomic man Katona (1968) offers a behavioral theory of choice based on the following four principles:

1. Human response is a function both of changes in the environment (stimuli) and the "person". . Motives, attitudes and expectations are intervening variables that mediate between stimuli and responses and are acquired through past experience. They influence the perception of changes in the environment and response to them.

2. Individuals (and families) function as parts of broader groups. The groups to which people feel they belong, with which they identify themselves and share a common fate, may be constituted by face-toface groups (friends, neighbors, colleagues), by the firm or corporation for which they work, as well as by such broad groups as all those in similar occupations, or the community, or the entire country.

3. Wants are not static. Levels of aspiration are not given once and for all time.

4. Frequently neither success nor failure is experienced. In the absence of major personal financial stimuli or of significant information about general economic trends, habitual behavior prevails.

Katona seems to be trying to incorporate the recent results of experimentation in psychology regarding the factors which influence decision-making by the individual." At best we can say that these experimental findings are inconclusive and, moreover, do not imply anything which can be interpreted as identifying rational behavior. Katona either forgets or simply rejects the conventional notion that the term "rational" is properly descriptive of theories of behavior and not of behavior itself.

Another omission in Katona's analysis is his failure to recognize the behavioral foundations of the traditional theory of consumer choice. He looks at consumer choice simply from its normative facet and completely disregards its implicit behavioral content. Economic man in the traditional theory is a creature of habit. Granted this creature is not like his real cousins; however, his behavior is rational. For him habitual choice is unquestionably the most efficient strategy. He, thus, incurs no explicit or implicit costs in securing information for decision-making nor any implicit costs in calculations, musings or deliberations. $\mathrm{He}$ is still able to maximize his satisfaction. His behavior is certainly economic and goal-

\footnotetext{
*A short survey of work in this area may be found in Tsukahara (1970).
} 
directed; thus it is rational."

Finally, Katona fails to recognize the distinction between decision-making and choice. The conventional economic model of the consumer is strictly a choice model because it assumes that economic man has solved the decision-making problem, i.e. he has solved the problem of the selection of a proper strategy to achieve his goal and all that remains is for him to utilize the selected strategy.

The economic man observed by Simon and Katona lives in environments of risk and uncertainty. Thus, it is quite easy for them to observe that the behavior of real men is quite unlike that postulated for traditional economic man. Rather than reject traditional economic man outright because he does not exist in the real world, we should place him in his proper environment and develop new notions of economic man for real world environments.

\section{THE STATE OF UNCERTAINTY}

If one statement had to be made to summarize economists' views of uncertainty it would have to be, "There is nothing certain about uncertainty." The end product of this confusion is that formerly no economic man has been developed for this environment.t $\mathrm{He}$ is a very elusive creature. Many economists believe he was captured and identified by Von Neumann and Morgenstern, but they are mistaken. Von Neumann's and Morgenstern's find is really the inhabitant of the world of objective risks.

The clearest statement to describe rational choice under uncertainty available in the literature was made by Arrow (1958),

The rational model of choice under uncertainty can be summarized as follows: There are a number of possible actions we can take. We do not know which state of nature, among a certain class is the true one. We have to take an action the consequence of which will depend upon which state of nature is the true one. The problem is to choose which action to take among those which satisfy the constraints of the situation. The consequences are completely determined by the action

"Becker (1962) views habitual decision-making by households as irrational behavior.

PA crude attempt to develop such a theory may be found in Tsukahara (1970). The key elements of this theory are summarized at the end of this section. 
and the state of nature, and presumably are ordered as in the case of uncertainty.

The uncertainty in the problem lies in the lack of knowledge of the objective probabilities of the potential outcome, i.e. the true state of nature. Rationality thus applies to theories of behavior which describe how the individual chooses an action, i.e. a decision strategy to maximize satisfaction from the potential consequences. Thus, for Arrow (1959) the task of a theory of behavior is as follows:

The problem of a theory of behavior under uncertainty is that of defining the rational choice of an action $a^{*}$ from any given opportunity set of actions a when the consequences of the action a are defined by a function $\mathrm{c}(\mathrm{a}, \mathrm{s})$. This rational choice function is, in most theories, defined by an ordering of the space of actions, just as choice under uncertainty is defined.

However, if the outcomes are known and the states of nature, i.e. minimally the family of probability distributions, are known, we are in the decision environment of risk." The writers therefore suggest that the theory of behavior under uncertainty which would conform to the rationality suggested by Arrow would be one which insures that the individual acts to reduce uncertainty to some risk equivalent. A rational ordering of the action spaces is only possible if the decision environment has been reduced to what is usually defined as risk.

The writers suggest that the process the individual follows to reduce uncertainty to risk is the acquisition of a sufficient amount of information which in turn is transformed into a critical mass of knowledge.t This level of knowledge, which is unique to each decision maker, will be, minimally, just enough for the individual to act in subjective risk. The critical level will vary according to the individual's attitude toward risk. For example, risk aversion would require more knowledge than risk loving for the same individual.

-Appendix 6-I presents a classification scheme for the various concepts of certainty, risk, and uncertainty which the economist encounters in the literature. This framework was originally developed in Tsukahara $(1970)$.

PWe focus only upon the individual as a producer in his information acquisition activities. We omit from the present study the effects of idle curiosity, that is, the individual as a consumer ofinformation. 
For now, it is suggested that the minimal amount of knowledge needed is that which will reduce each of the uncertainty environments to subjective risk. It is reasonable to assume that more knowledge would be needed if we desired to reduce uncertainty to either class of objective risk. In first order objective uncertainty the minimum knowledge needed to reduce the situation to subjective risk is a subjective probability distribution over the possible outcomes. In second order objective uncertainty, we would need enough knowledge to determine a subjectively relevant set of outcomes and a probability distribution over them. The case of subjective uncertainty is similar to second order objective uncertainty, but the acquisition of knowledge may be more formidable.

Our use of the notion of knowledge is not unique; in fact, it is quite conventional. For example, Quandt (1956) states,

The assumption of knowledge is composed of two distinct assumptions. First, it is assumed that the consumer knows the available alternatives. Secondly, it is assumed that he is familiar with the methods of finding a set of strategies which will maximize his chances of attaining his goals.

The writers suggest that for a behavioral theory of choice, economic man in uncertainty would seek to acquire the amount of knowledge suggested above.

\section{Gambling: An Application}

And now that I have told of gluttony,

I'll take up gambling, showing you thereby

The curse of chance, and all its evil treat;

From it proceeds false swearing and deceit,

Blaspheming, murder and - what's more - the waste

Of time and money;

From Canterbury Tales by Chaucer

Like the heavens, gambling has been intensely studied over the centuries by a vast array of scholars, both professional and amateur, and, like the classic elephant, gambling is usually studied from the particular side of the subject the discipline of the investigator assumes. For example, the psychologist may seek to find determinants of gambling behavior which correlate with personality variables while the mathematician may search for an optimum strategy for 
playing blackjack. The small contribution of the writers to gambling research is a model which attempts to integrate economics and psychology to explain the choice of gambling activities.

The orthodox treatment of gambling by contemporary economists stems from the work of Friedman and Savage (1948). Since their article appeared, there have been numerous attempts to provide alternative explanations for gambling behavior. For example, Rosett (1965) alludes to the influence of human information processing on gambling behavior. A more promising approach taken by Eadington (1973) is based on the integration of activity analysis concepts in consumption theory. The model provided here is a modification of Eadington's tourist gambler. The writers reinforce the activity choice problem of the tourist by casting their model in a mathematical programming format.

\section{THE MODEL}

The individual will seek to maximize utility:

(1) $\mathrm{uz}=\mathrm{U}$

subject to resource constraints

(2) $\mathrm{Az}=\mathrm{r}$

and nonnegative activity levels

(3) $\mathrm{z} \equiv 0$

where

$\mathrm{u}=1 \mathrm{X}$ n vector of utility measures

$\mathrm{z}-\mathrm{n} \mathrm{X} 1$ vector of activities

$\mathrm{A}=\mathrm{mX} \mathrm{n}$ matrix of technical coefficients

$\mathrm{r}-\mathrm{m} \mathrm{X} 1$ vector of resource inputs

$0=\mathrm{n} X 1$ zero vector

We define the resource inputs to be income, time, knowledge and stamina available to the individual during a fixed decision period, e.g. a day. The matrix of technical coefficients assumes that we have a fixed input-output relationship between the resources available and the activity choices for the decision period. These coefficients would represent, for example, the amount of money, time, knowledge and stamina required to play blackjack.

The solution of this programming model will establish the 
efficient utifization of resources in activities. The solution to the dual of this program will yield the shadow prices for the resources. For this model, these shadow prices will be equivalent to the marginal utility of money, of knowledge and of stamina. By use of parameric programming techniques it would be possible, for example, to measure the effects of changes in tastes reflected in alterations of the utility coefficients, of increases and decreases of the available amount of income, and of technical change represented in modifications of the A matrix on the shadow price of time.

With this model it is possible to illustrate both the choice of gambling activities as well as nongambling activities. Suppose we have the following problem:

$$
\begin{aligned}
& b_{1} x_{1}+b_{2} z_{2}+b_{3} z_{3}+p_{1}^{z_{4}}+p_{2}^{z_{5}}+p_{3} x_{6} \leq y^{0}
\end{aligned}
$$

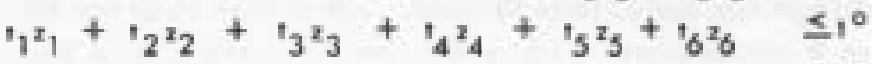

$$
\begin{aligned}
& k_{1} z_{1}+k_{2} z_{2}+k_{3} z_{3}+k_{4} z_{4}+k_{5} z_{5}+k_{6} x_{6} \leq k^{0}
\end{aligned}
$$

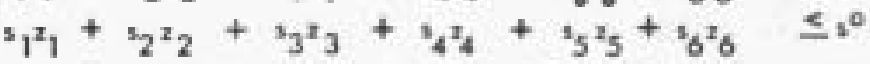

$$
\begin{aligned}
& v_{1} z_{1}+v_{2} z_{2}+v_{3} z_{3}+v_{4} z_{4}+v_{5} x_{5}+v_{6} z_{6}=u(\operatorname{mox})
\end{aligned}
$$

where

$\mathrm{b}_{1}, \mathrm{~b}_{2}, \mathrm{~b}_{\mathrm{a}}-$ price of gambling activities $\mathrm{z}_{1}, \mathrm{z}_{2}, \mathrm{z}_{\mathrm{a}}$

$\mathrm{p}_{1}, \mathrm{p}_{2}, \mathrm{p}_{\mathrm{a}}=$ price of nongambling activities $z_{1,}, z_{3}, z_{0}$

$t_{1}-$ time required for one unit of activity $z_{\mathbb{1}}$

$k_{1}=$ knowledge required from one unit of activity $z_{1}$

$s_{1}-$ stamina required from one unit of activity $z_{\sharp}$

$\mathrm{u}_{4}=$ utility derived from one unit of activity $\mathrm{z}_{1}$

$\mathrm{y}^{\circ}=$ available income

$\mathrm{t}^{\circ}=$ total time endowment

$\mathrm{k}^{\circ}=$ total knowledge endowment

$\mathrm{s}^{\circ}=$ total physical or stamina endowment

The solution to the problem will depend on the relative utilities of the gambling choices and of the nongambling choices, subject to available resources. It should be clear that the shadow prices of the resources will reflect their relative scarcity in the production of activities.

The existence of slack solutions for this problem provides some 
insight into gambling behavior. For example, let us assume that $z_{1}$ is playing blackjack and $\mathrm{z}_{\Sigma}$ is playing the slots. It would be reasonable to assume that the vector of coefficients for $z_{1}$ are element for element greater than or equal to the elements of the vector of coefficients for $z_{\mathrm{\beta}}$. If we find an optimum solution for an individual to be Z2 and slack for income, time and stamina, we know that knowledge is the binding constraint. This solution would imply that the individual was a casual gambler, i.e. it was not optimal for him to allocate resources prior to arrival at a gambling site to acquire the knowledge necessary to play blackjack.

The flexibility of this model is illustrated by the following examples. A serious gambler will always seek to maintain his peak skills, and hence play the game of his choice at the maximum possible advantage (or minimum disadvantage if one believes that all games have a house edge). Thus, he will get proper rest and sustenance during his stay at the gambling site to minimize errors due to fatigue. This activity choice would be illustrated by a negative sign for $\mathrm{s}$ in a nongambling activity to indicate resource augmentation. Also, the serious gambler recognizes the possibility of an adverse run against him, and may need to call upon reserve income to approach the actuarial value of his trip. A negative sign for $\mathrm{p}$ in a nongambling activity indicates the possibility of augmenting income by credit or by some other means. We assume that only knowledge cannot be augmented. If a gambler believed that he had a strategy that would tip the odds of a game in his favor, the corresponding $b$ for the gambling activity would have a negative sign and would appear in the optimum solution. It would also be clear that income would not be the binding constraint.

For the repeat visitor to a gambling site, the previous trips assist in determining the knowledge resource. The experience of the previous visits provides information regarding individual decision behavior. If errors of judgment were made in playing blackjack due to fatigue, the gambler would budget time for rest. If the gambler found himself confused with the pace of craps so that he did not take full odds, he would spend some resources upon return to his usual routine to sharpen his understanding of the game if there may be a probability of a return to a gambling site. 
Thus, rational choice in this model would be reflected in the selection of gambling and nongambling activities which would maximize utility subject to full resources constraints. For most individuals, knowledge will be the binding constraint. Therefore, the choice of a gambling activity with negative expected payoff, e.g. slots, would be quite reasonable since the visitor to Las Vegas would feel his experience incomplete without some fling with Lady Luck. However even the most accomplished gambler must remember that, like the chess grand master, the activity of gambling requires peak physical condition if he is to make full use of his decision-making abilities. Cheating on sleep will cost him his competitive edge.

Finally, it may not be completely obvious that prior knowledge acquisition by the gambler will have an impact on the technical coefficients. For example, the student of blackjack will have a b coefficient close to zero (or even negative as some authors will claim!). The system player of roulette may not improve his overall odds, but may have an impact on the amount of time required for each play. His system facilitates a reduction in decision time required in placement of bets. Therefore, the behavior of an individual facing an activity with risky outcomes, e.g. a gambling activity, to acquire knowledge of the activity will have an effect on the optimum use of time, money and stamina. Since the acquisition of knowledge is not costless it is reasonable to find different individuals making different choices of gambling activities. To view the choice of an individual of playing the slot machines as irrational behavior, a priori, is to ignore the overall resource allocation problems of the individual.

\section{REFERENCES}

Arrow, K. J.: Alternative approaches to the theory of choice in risk-taking situations. Econometrica, XIX:404-437, 1951.

Arrow, Kenneth J.: Functions of a theory of behavior under uncertainty. Metroeconomica, XI(1-2):12-20, April-August, '1959.

Arrow, Kenneth J.: Utilities, attitudes, choices: A review note. Econometrica, XXVI(1):I, 1958.

Becker, G. S.: Irrational behavior and economic theory. / Polit Econ, LXX(1): I, 1962 .

Eadington, W. R.: The Economics of Gambling Behavior: A Qualitative 
Study of Nevada's Gambling Industry. Reno, University of Nevada, Bureau of Business and Economic Research, Report No. II, 1973.

Edwards, W.: The theory of decision making. Psychol Bull, LI(4):380, 1954. Frieman, M., and Savage, L. J.a The utility analysis of choices involving risk. / Polif Econ, LVI(4):I79, 1948.

Gerogeseu-Roegen, N.: Threshold in choice and the theory of demand. Econometrica, XXVI:157, 1958.

Houthakker, H. S.: The present state of consumption theory: A survey article. Econometrica, XX7X(4):704, 1961.

Hoyt, E. E.: Choice as an interdisciplinary area. Q/ Econ, p. 112,February, 1965 .

Katona, G.: Consumer behavior: Theory and findings on expectations and aspirations. Am Econ Rev, LVIII(2):19, 1968.

Katona, G.: Rational behavior and economic behavior. Psychol Rev, LX: 307, 1953.

Marschak, J.: Neumann's and Morgenstern's new approach to static economics. I Polit Econ, LIV(2)=97, 1946.

Parsons, T.: The rise and decline of economic man. / Gen Educ, $4(1): 47$, 1949.

Parsons, T: The Structure of Social Action. Glencoe, The Free Press, 1949.

Parsons, T.: Wants and activities in Marshall. Q JEcon, XLVI:101, 1931.

Quandt, R. E.; A probabilistic theory of consumer behavior. Q / Econ, LXX(4):507, 1956.

Rosett, R. N.: Gambling and rationality. / Polit Econ, LXXIII:595, 1965.

Simon, H. A.: A behavior model of rational choice. $Q J$ Econ, LIX(1):99, 1955.

Simon, H. A.: Models of Man. New York, John Wiley and Sons, Incorporated, 1957.

Stigler, G. J-: The economics of information. J Polit Econ, LXIX(3):I, 1968.

Tsukahara, $\mathrm{T}_{\mathrm{z}} \mathrm{Jr}$.: The Behavioral Foundations of the Theory of Consumer Choice Under Uncertainty. Unpublished doctoral dissertation, Claremont Graduate School, 1970. 


\section{APPENDIX 6-I}

\section{A CLASSIFICATION SCHEME FOR CERTAINTY, RISK AND UNCERTAINTY}

Objective $\quad$ Subjective

\section{Certainty}

Set of outcomes $\mathrm{O}_{j}$ is completely known, and $\mathrm{P}(\mathrm{Oj})$ is either 1 or 0 .

\section{1st order:}

Set of outcomes $\mathrm{Oj}$ is completely known, and $\mathrm{P}\left(\mathrm{O}_{j}\right)$ is known, i.e., $0<\mathrm{P}(\mathrm{Oj})<1$ and $2 \mathrm{P}(\mathrm{Oj})=\mathrm{I}$.

\section{2nd order:}

Set of outcomes $\mathrm{Oj}$ is completely known, and a family of $\mathrm{P}(\mathrm{Oj})$ is known. Further, an objective probability distribution of the parameters of the particular family of distributions is known

\section{1st order:}

Set of outcomes Oj is completely known, however no $\mathrm{P}(\mathrm{Oj})$ or family of $\mathrm{P}(\mathrm{Oj})$ is known.

\section{2nd order:}

Set of outcomes $\mathrm{Oj}$ is partially known or completely unknown, thus $\mathrm{P}(\mathrm{Oj})$ is unknown.
Set of subjectively relevant outcomes $\mathrm{Oj}$ is known, and $\mathrm{S}(\mathrm{Oj})$ is either 1 or 0 .

\section{Risk}

Set of subjectively relevant outcomes $\mathrm{Oj}$ is known, and $\mathrm{S}(\mathrm{Oj})$ is known, i.e. $\mathrm{O}<\mathrm{S}\left(0_{\mathrm{j}}\right)<1$ and $2 \mathrm{~S}\left(\mathrm{O}_{\mathrm{j}}\right)=\mathrm{I}$.

\section{Uncertainty}

Set of outcomes Oj is meaningless 


\title{
Chapter 7
}

\section{THE MARKET FUH PHU FUUTHALL BETTING}

\author{
MICHAEL E. CANES*
}

\section{INTRODUCTION}

$1^{\mathrm{T}}$

Ts ESTIMATED THAT more than 12 billion dollars is bet annually in the United States on sporting events other than horse or dog racing. O $£$ this, about 50 percent is bet on baseball, 40 percent on football and the rest on basketball, hockey and boxing. In many areas ofthe country, individuals may legally bet one another on the outcome of sporting events, but, except in Nevada, state laws prohibit the making of a market for such betting and various federal statutes also inhibit it." Nevertheless, markets for sport gambling operate throughout the United States. Further, although sport betting is prohibited by law, in many communities there is lax enforcement, and sportswriters openly quote game odds, and in some cases even detail their personal bets. 3

Recently public officials in New York and elsewhere have suggested that sport gambling markets be legalized with the states

\footnotetext{
Thanks are due Professor Lyn D. Pankoff of the Graduate School of Business Administration, Washington University, St. Louis, for making available football betting data he collected.

fIs Nevada it is legal to make a market for sport betting subject to licensing by the Nevada State Gambling Commission. Several establishments in Nevada specialize in such market-making. Since 1961 it has been illegal under federal law to engage in interstate transmission of gambling information. For example, it is illegal to use interstate telephone facilities to place a bet or to report results or to quote odds. In addition there is a two percent Federal Wagering Tax which applies to gambling turnover. Federal law also once required betting market-makers to pay an annual fifty dollars registration fee, but that law was declared unconstitutional in 1968 .

FFor example, each week during the professional football season, major newspapers such as the New York Post provide local betting odds. For one example of a sportswriter detailing his personal bets, see Merchant (1975) .
} 
taxing these markets to increase public revenues. Thirteen states have already legalized markets for lottery betting, and New York, Connecticut and Pennsylvania have also legalized off-track betting on horse races. These give indication that legalized sport betting markets probably are not far off, and provide a rationale for studying the behavior of bettors and those who make a market for betting.

In this chapter the market for professional football betting is examined. This market is similar in kind to betting markets for college football, baseball, basketball, hockey and boxing, but more published information is available for the pro football betting market than for the others." The football betting market is described, and several hypotheses advanced regarding bettor behavior. Some of these hypotheses are then tested with a limited set of data concerning betting odds and game outcomes. The findings indicate that the odds offered the public are such that bettors about break even on their betting, less payment to the market-maker. Further, most of the evidence presented here indicate that the pro football betting market is efficient in the sense that market odds are unbiased predictors of game outcomes. However, a betting rule is advanced that appears to consistently make money when tested with the data available. The rule is based on the behavior of professional bettors who bet before the general public. Data limitations, however, leave uncertain whether the rule is viable.

\section{Description of the Pro Football Betting Market}

Markets for betting are made by individuals known as bookmakers or bookies. The essence of the service provided is that of standing ready to take bets on a game at a quoted set of odds. In this, a bookmaker is similar to a stock specialist who stands ready to take buy or sell orders at a quoted set of prices.

\footnotetext{
"The main sources of description of the football betting market are Merchant (1973), the New York State Commission of Investigation (1961) and the Gambler's Digest (1971). Merchant's book, while written from a gambler's viewpoint, has a particularly extensive discussion of how the football gambling industry functions.
} 
In the football betting market, a bookmaker quotes a point spread between competing teams.t Such a point spread provides a handicap for the underdog, a bettor being given the choice whether to bet on the underdog plus some number of points (the spread) or else on the favorite minus the points. Thus, for example, if the spread for a game between Cleveland and Cincinnati favors Cleveland by three points, then a bettor backing Cincinnati will win if Cincinnati loses by two points or less or ties or wins, whereas a bettor backing Cleveland will win if Cleveland wins by four points or more.

Each week during the pro football season a bookie will quote a set of point spreads (called a line) covering all of that week's games. The opening line usually is quoted on Tuesday, subject to change as the week proceeds. The basis for most bookmakers' opening lines is the line quoted by Las Vegas bookmakers, but there is some variation among local bookmakers. Generally, bookmakers will accept bets until game time on Sunday or Monday, the last quoted line being the closing line. The payoff on each bet is made according to the spread at which the bet was made.

A variety of types of bets can be made on pro football games, the simplest being a wager on one of two opposing teams at the prevailing point spread. One alternative is a parlay, which is a wager on all of a set of teams, each competing in a different game. For a bettor to win a parlay on, say, four teams, each of the four must beat the point spread for its game. Most bookmakers will accept either single game or parlay bets, but there is, in addition, an extensive market dealing exclusively in parlay betting. In this market, parlay cards are distributed to bettors who must choose some minimum number of games on which to bet. Usually extremely small amounts of money may be wagered with both point spreads and odds fixed regardless of the distribution among teams of monies bet. Despite the extent of the parlay betting market, there is little published information regarding it, and the discussion in this paper relates mainly to single-game bets placed

†Point spreads also are used for basketball games and sometimes for hockey. For baseball and boxing and sometimes for hockey, odds are quoted on each contestant. 
with bookmakers.

The price to bet varies with the size of bet and with the state of competition among bookmakers in a particular area. Where competition is extensive the usual terms are 11 to 10 odds, and return of all money if a game outcome exactly equals the spread (called a $p u s h)$. Thus, bettors put up eleven dollars to win ten, the bookmaker receiving approximately 5 percent of the total betting turnover." The percentage take of the bookmaker is known as his vigorish. At 11 to 10 odds, if a football bettor is to make money he must win approximately 53 percent of a set of bets of equal dollar amount.

Under less competitive conditions 6 to 5 odds are commonly charged, and even where there is competition many bookmakers quote 6 to 5 odds for bets under one hundred dollars.t If these are the market odds, a bettor to make money must win approximately 55 percent of a set of equal dollar bets, ;

Terms for parlay bets presumably also vary with the extent of market competition, but no evidence of that can be presented here. A set of odds said to be typical is 5 to 1 for three games (the minimum allowed to be bet), 10 to 1 for four, on up to 300 to 1 for twelve, with all bets lost when any of the game outcomes exactly equal the point spread* (New York State Commission of

*Of course, there are many other dimensions of bookmaker terms. Among these are the point spreads he quotes, the probability that he will pay off and collect, the credit he will extend, his availability to bettors during the week, and the limit he sets on the amount that can be bet at any one time.

PReported in New York State Commission of Investigation (1961) and Merchant (1973). In a 1966 study of football betting markets, Pankoff (1968) reported odds of 6 to 5 for the city of Chicago, and speculated that these reflected monopoly conditions in that market.

[Does the pricing system described discriminate against those who wager larger sums? Costs of arranging bets, including those of avoiding arrest, surely fall per dollar bet with the size of a bet, but other costs, principally those of laying off and of dealing with bettors with inside information probably rise per dollar bet with the size of bet. Thus 11 to 10 odds quoted for all bets greater than one hundred dollars is not necessarily inconsistent with competitive pricing.

"Merchant (1973) reports parlay odds in New York City of 9 to I on four games and 100 to 1 on eight. Since the market for betting seems to be competitive there, his quote provides an estimate of competitive parlay odds. However, other factors such as extent of local police action against gambling also will affect what are competitive odds. 
Investigation, 1961) - IE parlay point spreads are unbiased predictors of game outcomes, then the chances of a bettor winning three games are slightly less than 1 in 8 , four games less than 1 in 16 , and twelve games less than 1 in 4100 .

Because bookmaking is illegal everywhere in the United States except Nevada, bookmakers outside that state operate so as to reduce the chances of detection and arrest by the legal authorities. Most contacts between bookmakers and clients take place by telephone, with some bookmakers using screening devices such as code words or answering services, others placing calls to their clients at appointed hours from public telephones, and still others operating from rented private homes or businesses. It is also said to be common for bookmakers to pay off policemen and other public authorities to ignore their operations.t Bookmaking firms range in size from one-man operations to offices in which runners are employed as customer contacts, collecting and disbursing payments in return for a percentage of customers' net losses, 7

Enforcement of laws against the booking of sport bets reduces bettor choice concerning bookmakers with whom to bet. A person wishing to bet with a bookmaker for the first time will usually require an introduction from an established customer, and even then may not be allowed to bet for some time." However, a bettor need only be able to place his bets with someone who is a trusted bookmaker customer, and there are probably enough of these that the choice to bet is not much restricted.

The number of bookmakers operating at present in the

tAccording to Newsweek (1972) an estimated 2 billion dollars annually is spent by the bookmaking industry for payoffs to public officials.

iBecause runners are in direct contact with customers, they bear the highest risk of arrest, and part of their job is to take the rap when an arrest occurs. Compensation for this includes payment by the office of all legal fees, fines and bail, and care for the runner's family in the rare case of incarceration (New York State Commission of Investigation, 1961).

"According to a detective on the Rochester, New York, vice squad, in that city, anywhere from two to six months of informal contact between a bookmaker and a potential new customer is necessary before the bookmaker will accept a bet (author's personal interview, February 20, 1974). Presumably the care exercised by bookmakers in an area will be directly related to the extent of police antigambling activity there. 
United States is not known with accuracy. However, a rough estimate can be made by extrapolating a New York State Commission of Investigation estimate that during 1958 and 1959 there was about one bookmaker per 2500 population in central New York State. Since then, federal antigambling laws have been strengthened and off-track betting has been legalized in some localities, reducing the return to illegal bookmaking. On the other hand, incomes and population have risen, and there is more widespread interest in professional sport, all of which probably have increased the demand to bet. Having no a priori estimate of which of these effects is greater, simple extrapolation of the 1958-59 figures suggests there are something like 85,000 people in the United States today deriving income from bookmaking activities.

Since passage of federal legislation prohibiting interstate transmission of gambling information in 1961,Las Vegas has been the center of what remains of interstate gambling in the United States. Because of the federal law, Las Vegas bookmakers will not accept bets nor quote betting lines over interstate telephone, but, according to Merchant (1973), large syndicates of bettors outside Nevada hire contacts within that state to provide information about betting lines and to place bets, while smaller syndicates bet through people who in turn have such contacts.

As in organized securities markets, a large number of firms sell advice on where to place money. In the football betting market, such firms are known as touts. It is estimated that there are about 200 tout services in the country, ranging in price from that of a local newspaper where Jimmy the Greek is likely to be syndicated, to one hundred dollars per week, which entitles the buyer to telegram service (Merchant, 1973). Pankoff (1968) found evidence that at least some football touts are sufficiently knowledgeable that money can be made by following their advice.

The Setting of the Opening Line

As stated above, the basis for opening point spreads used by bookmakers around the country is the line originating each week 
in Las Vegas, Nevada. This line is arrived at in the following way.

A group of bookmakers in Las Vegas employ a handicapper who provides his best estimate of point spreads that will induce equal amounts bet on opposing teams in that week's games." This line is known as the service line. The service line is then exposed to a small number of professional bettors who are allowed to bet limited amounts of money at the service spreads. If for a particular game a professional bets the limit, the spread is adjusted by 0.5 point in the direction of the team bet on (e.g. a seven-point favorite bet on is moved to 7.5 ). The professional can then bet again, the process ending when there is no further tendency for the professional's memory to favor either team at the prevailing spread. When this process has been carried out with each of several professional bettors for all of a week's games, the service line is adjusted to reflect the betting opinions of the professionals. The resulting opening line then is made available to public betting, and is disseminated to bookmakers around the country.

Presumably the Las Vegas bookmakers allow professional bettors access to the service line because this is profitable. For this to be so the professionals must bet so as to move the line closer to one at which the public cannot earn a positive return on its betting. Apparently the professionals" unbiased estimates of game outcomes would provide such a line since, if the professionals are at least as expert at predicting game outcomes as the public, further moves of the line will go toward the game outcome no more than about half the time, " but as will be seen shortly, even if the professional bettors openly compete in making bets, they will not necessarily supply unbiased estimates of game outcomes.

The Las Vegas opening line offers bookmakers elsewhere an estimate of what point spreads will induce equal amounts bet on opposing teams in that week's games. This estimate has value be-

\footnotetext{
"Through 1972, this handicapper was Mr. Robert Martin, who also was a licensed Nevada bookmaker. Martin reportedly is the best handicapper of pro football games in the United States. According to him, "the handicapper's primary concern is bringing out money on the underdog team. He may feel that two teams are an even bet, but if public opinion strongly favors one, a point handicap is necessary" (McQuaid, 1971).
}

PAssuming no new information during a week relevant to game outcomes. 
cause it reflects expert judgment concerning both the relative strengths of opposing teams and the betting tendencies of those who will bet in Nevada. However, not every bookmaker offers exactly the Las Vegas line to his customers (Merchant, 1973). Presumably, this is because there is variation in bookmaker beliefs about money-equalizing point spreads, and because costly legal impediments reduce opportunities for arbitrage among football betting markets.t

\section{Bookmaker Alternatives}

If a bookmaker provides the service of standing by to take bets immediately at the line he quotes, then when more money is bet on a team than its opponents at the opening spread, the bookmaker must accept the excess himself. If the bookmaker wishes to equalize amounts bet, he can then change the spread in a direction to induce more money bet on the opponent. By varying the spread sufficiently, the bookmaker can always equalize the total amounts bet on each team in a game, but if he does this he will lose more bets than he wins."

An alternative open to a bookmaker receiving assymetric amounts bet at his point spreads is to lay off the excess by placing or trading bets with other bookmakers. Thus, for example, if a bookmaker receives more money bet on the favorite than the underdog in a particular game, he can bet the difference on the favorite with other bookmakers or trade bets with a bookmaker who has an excess of money bet on the underdog. Many bookmakers have arrangements with larger bookmaking operations to

tAccording to Merchant, bookmakers within a given city sometimes differ in their line by 0.5 to one point per game, while bookmakers in separate states sometimes offer lines that differ by as much as two or three points for a game (personal correspondence with author). The wider interstate differential is consistent with the conjecture that more stringent legal proscriptions against football gambling reduce opportunities for arbitrage.

*For example, suppose the bookie sets a three-point spread and gets an excess of money bet on the favorite. He accepts the excess himself and moves the spread to, say four points, where an excess is bet on the underdog equal to the previous excess on the favorite. Then the bookie loses half his bets and pushes the other half whenever the favorite wins by either three or four, and breaks even on his bets at any other outcome. 
lay off their excess bets, the charge for these services being the vigorish on the amounts bet. Thus, layoffs involve a reduction in a bookmaker's potential return for a reduction in his betting risk. However, if substantially more money is bet on one team than another over all bookmakers in an area, neither the individual bookmakers nor the larger bookmaking operations will be willing to accept layoff money at mutually acceptable spreads."

A variant is for a bookmaker to anticipate how his customers will bet a game and to lay off before they bet. Such a practice is called taking a lead. Much early-in-the-week betting is said to consist of bookmakers taking leads. Of course, a bookmaker may guess wrong concerning his customers' betting on a game in which case he either will hold more bets than otherwise on the one side, or engage more extensively in laying off after his customers have bet. However, if he is right he will have avoided the possibility of having no one with whom to lay off, or of having to pay very high prices to do so.

Another alternative is to simply refuse further bets on a side receiving the bulk of the betting in a game. Customers so refused are likely to search elsewhere to place their bets, and, insofar as they do, they provide the refusing bookie a layoff service. Presumably a bookmaker could not long survive if he consistently refused bets that unbalanced his books unless he granted unusual concessions for those bets he accepted.

A final alternative for a bookmaker is simply to accept any excess of wagers. This amounts to the bookmaker taking betting positions on games. If a bookmaker's bettors are consistently wrong about game outcomes he will profit by such a policy. If the bettors are right only about half the time, then over the long run he will about break even on his positions, but in the short run he will run the risk of experiencing sufficient losses to exhaust his

"Prior to the 1961 federal antigambling legislation, organized layoff centers existed in several large United States cities. These centers were sufficiently capitalized to withstand short-tenn losses on games in which the betting was one-sided. Since 1961, Las Vegas probably has been the main layoff center, but as noted earlier, there are substantial costs for bookmakers outside of Nevada to lay off there. The disappearance of the layoff centers has undoubtedly raised costs of bookmaking, and suggests that the industry would be organized differently were private bookmaking legalized. 
capital reserves, i.e. to bankrupt him. Ifa bookmaker's customers have better information about games than he, the bookie will lose more than half his bets. If this is generally the case, then for bookies to stay in business in the long run, their betting losses must be covered by the odds they charge."

\section{A Simple Model of the Pro Football Betting Market ${ }^{\dagger}$}

Consider an individual with local risk preference in a competitive market for pro football betting, ${ }^{*}$ In assessing how much to bet on a particular game he will consider the market point spread and his subjective probability distribution over game outcomes. It seems plausible that the greater the cumulative probability that his estimate of the game outcome is less (more) than the market spread, given that his median spread is less (more) than the market spread, the more he will bet. Let

$\mathrm{B}=$ amount bet (in dollars)

$\mathrm{S}_{\mathrm{At}}$ - market point spread

$\mathrm{SB}=$ median point spread of the bettor's estimated probability distribution over game outcomes

$P_{s}=$ cumulative probability that bettor's estimate of game outcome is less (more) than $\mathrm{S}_{\mathrm{M},} \mathrm{S}_{\mathrm{B}}<\mathrm{S}_{\mathrm{IC}}\left(\mathrm{S}_{\mathrm{E}}>\mathrm{S}_{\mathrm{M}}\right)$

Then

$$
\begin{gathered}
\text { (1) } \mathrm{B}=\mathrm{B}\left(\mathrm{P}_{\mathrm{C}}\right) \\
\text { (1.1) } \underset{\partial \mathrm{B}}{\partial \mathrm{B}}>0
\end{gathered}
$$

For any given subjective probability distribution over a

\footnotetext{
"An analogous argument has been offered by Jack Trepnor (1971) ("Walter Bagehot") to explain bid-ask spreads set by stock specialists. Treynor divides traders into those with and those without "inside information." On the average, specialists break even on transactions with traders without inside information, but consistently lose to the insiders. The spread between bid and ask price per share can then be explained as the amount necessary (given the volume of trading) to compensate the specialist for his trading losses. Merchant (1973) mentions that some bookies try to reduce the advantage of those they consider insiders by only accepting bets from them late in the week, when the line will have adjusted to whatever new information was produced by the previous week's games.

tSome of the ideas here developed are similar to those in Smith (1971). His model, however, applies to wagering generally.

tFormally, over the relevant range of wealth the individual prefers a risky choice to the certain payment of the expected value of the risky choice.
} 
game's outcome, the cumulative probability that a bettor's subjective estimate is less (more) than the market spread, for $\mathrm{S}_{\mathrm{H}}$ less than $S_{x}\left(S_{B}\right.$ more than $\left.S_{x}\right)$, will be positively related to the absolute difference between $S_{2 S}$ and $S_{B}$. Hence, the greater this difference, the more the bettor will bet." Defining $A-\mid S_{B}-S_{M C}($,

(2) $\mathrm{B}=\mathrm{B}(\mathrm{A})$

\section{(2.1) $\quad \partial \mathrm{B}>0$}

dA

A representation of individual bettor behavior is given in Figure 7-1. The curve in that figure shows how much the bettor will bet on a particular game at alternative market point spreads. At $\mathrm{S}_{\mathrm{M}}=\mathrm{SB}$ for the game, the bettor bets a minimum; as $\mathrm{S}_{\mathbf{X S}}$ not equal to $\mathrm{SB}$, the bettor bets amounts that increase with the differencet

A betting market can be established if there are at least two bettors, each having a different median estimate of the game spread. A representation of two such bettors is given by the solid curves of Figure 7-2.

In this representation, bettor 1 estimates a smaller spread for a particular game than bettor 2 so that, at any spread between $\mathrm{S}_{\mathrm{B}_{1}}$ and $\mathrm{S}_{\mathrm{B}_{2}}$ individual 1 will bet the underdog, 2 the favorite. Dotted curve $\mathrm{B}_{\mathrm{B}}$ is the net amount bet on one or the other team by the bookmaker. The bookmaker's bets are treated as a residual, resulting from his function of standing ready to take any sum bet at a quoted spread. At any market spread between $\mathrm{S}_{\mathrm{B}}$ and $\mathrm{S}_{\mathrm{B}_{2}}$ the bookmaker's net betting is the difference between $B_{1}$ and $B_{2}$ and at spreads to either side of $S_{B_{1}}$ and $S_{B_{2}}$ it is the sum of $B_{1}$ and $B_{2}$. At $S_{M}$ the bookmaker's net betting is zero, each bettor betting

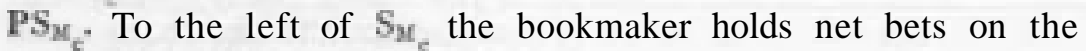
underdog, and to the right on the favorite.

* Of course, at some difference between the market spread and the individual's estimate he will calculate a net gain from the bet and, therefore, need no longer prefer risk in order to bet.

IIn Figure 7-1 the bettor's minimum is shown as zero, that is, the cost of betting is assumed greater than the price he will pay for a fair bet. Also, since there is no need of it here, we do not hypothesize whether the amount bet increases at an increasing or decreasing rate with $\mathrm{A}$.

IAII this assumes both bettors place all of their money at one point spread. Relaxation of this assumption would add little at this point, and would complicate the diagrammatic exposition. 


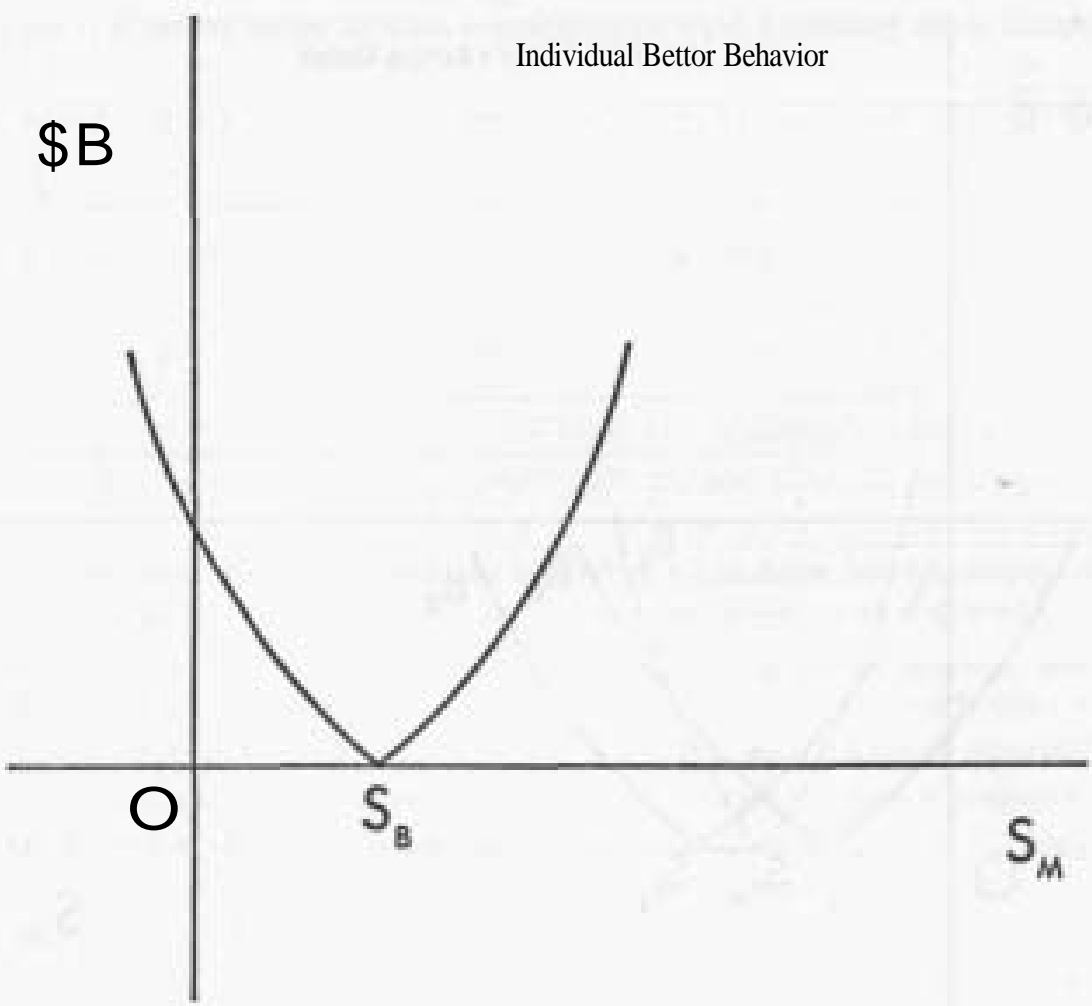

Figure 7-1,

Several propositions follow from the above representation. First, if the bookmaker minimizes self-betting, and if he knows the estimated point spread distributions of the bettors, he will set $S_{9}$ such that $B_{1}$ equals $B_{2}$. At this spread his revenue is simply the vigorish on an amount bet of $\mathrm{PS}_{\mathrm{x}}$ per bettor.

Second, all else the same, the greater the difference between $\mathrm{S}_{\mathrm{B}_{1}}$ and $\mathrm{S}_{\mathrm{B}_{2}}$, the more the bettors will bet at $\mathrm{S}_{2 \mathrm{C}}$ and the greater the bookmaker's total vigorish at that spread. More generally, the greater the dispersion in $\mathrm{S}_{\mathrm{B}}$ among bettors, the more will be bet at the bookmaker's self bet-minimizing point spread, and the greater his vigorish at that spread. Widely varying opinions on a game result in more betting than a near-consensus. 


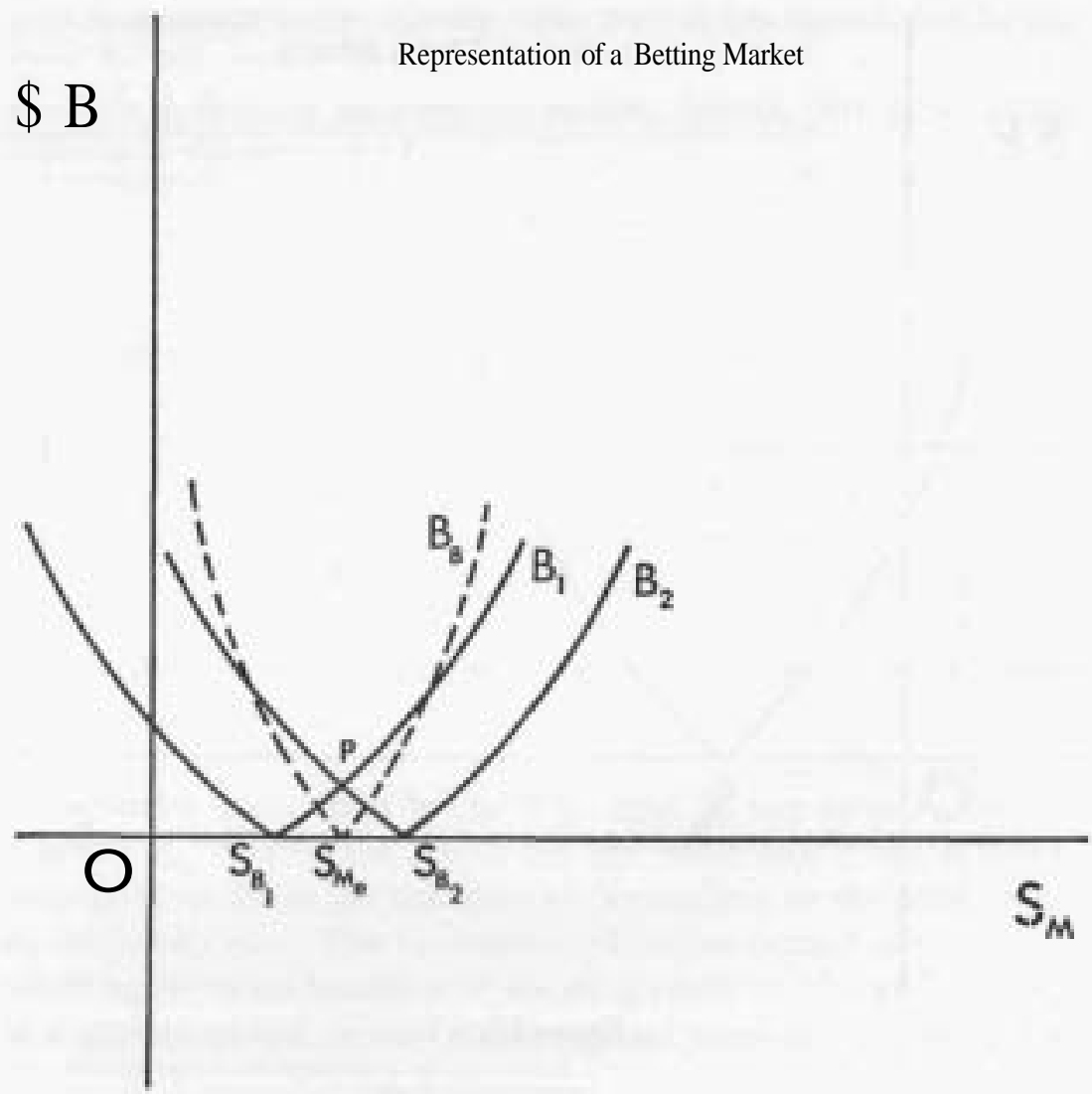

Figure 7-2.

Third, the more bettors there are holding differing opinions concerning a game's outcome, the greater the amount bet at $\mathrm{S}_{\mathrm{Yr}}$ and the greater the total vigorish. All else the same, more bettors bet more than less.

Fourth for a given difference in $\mathrm{S}_{\mathrm{B}}$ and $\mathrm{S}_{\mathrm{B}}$, the greater the rate at which bettors increase their amounts bet, the greater the bookmaker's vigorish at $S_{\mathbf{y}}$. Presumably wealthy bettors increase their amounts bet by more than poor, and bettors who are more sure of their estimates also increase their amounts bet by more. There is some indication that the amount bet in a market is 
positively related to (aggregate) income (Ahrnborg, 1950). Further, if being more certain is coincident with knowing more about a team, the latter may explain why bookmakers in National Football League cities receive more money bet on games involving the cities' home teams than on other games.

In fact, bookmakers take net betting positions on most games. Plausibly, it is prohibitively costly for a bookmaker to gain perfect information about the amounts each of his customers will bet at alternative game point spreads, and the result of having imperfect information is a spread that induces more money bet on one team than the other, but so long as a bookmaker's customers do not have systematically better information than he about game outcomes, in the long run he will win about half of his net bets.

An alternative hypothesis is that bookmakers have systematic information advantages over their customers. For example, a bookmaker who estimates self bet-minimizing point spreads that differ from his estimates of median game outcomes, and who is more expert than his clients at estimating game outcomes generally will obtain more revenue by betting himself. Such a situation is shown in Figure 7-3. At $\mathrm{S}_{\mathrm{IS}_{\mathrm{e}}}$ the bookmaker's revenue is $2 \mathrm{PS}_{\mathrm{Mf}_{\mathrm{e}}}$ times the vigorish per dollar bet, but at $S_{I_{Q}}$ the bookmaker (if right) wins $\mathrm{RB}$ in bets plus $\mathrm{BS}_{\mathrm{It}_{Q}}+\mathrm{RS}_{\mathrm{Uq}_{0}}$ times the vigorish per dollar bet. Assuming the total amount bet by customers is not reduced, the bookmaker's expected income is increased by his expected betting winnings. However, even a bookmaker who can systematically better estimate game outcomes than his bettors will not always obtain more revenues by betting if his information advantage is small relative to the uncertainty surrounding game outcomes, and if the cost of additional capital to the bookmaker is very high. In that case, a string of betting losses could put the bookmaker out of business even though in the long run his advantage would have paid off. This suggests that the greater a bookmaker's information advantage over his customers relative to the uncertainty surrounding game outcomes, the more he will take net betting positions, but the greater the cost of additional capital to him, the less such betting he will do. Finally, since there are many games during a season, a bookmaker with information advantages over his customers can reduce the probability 


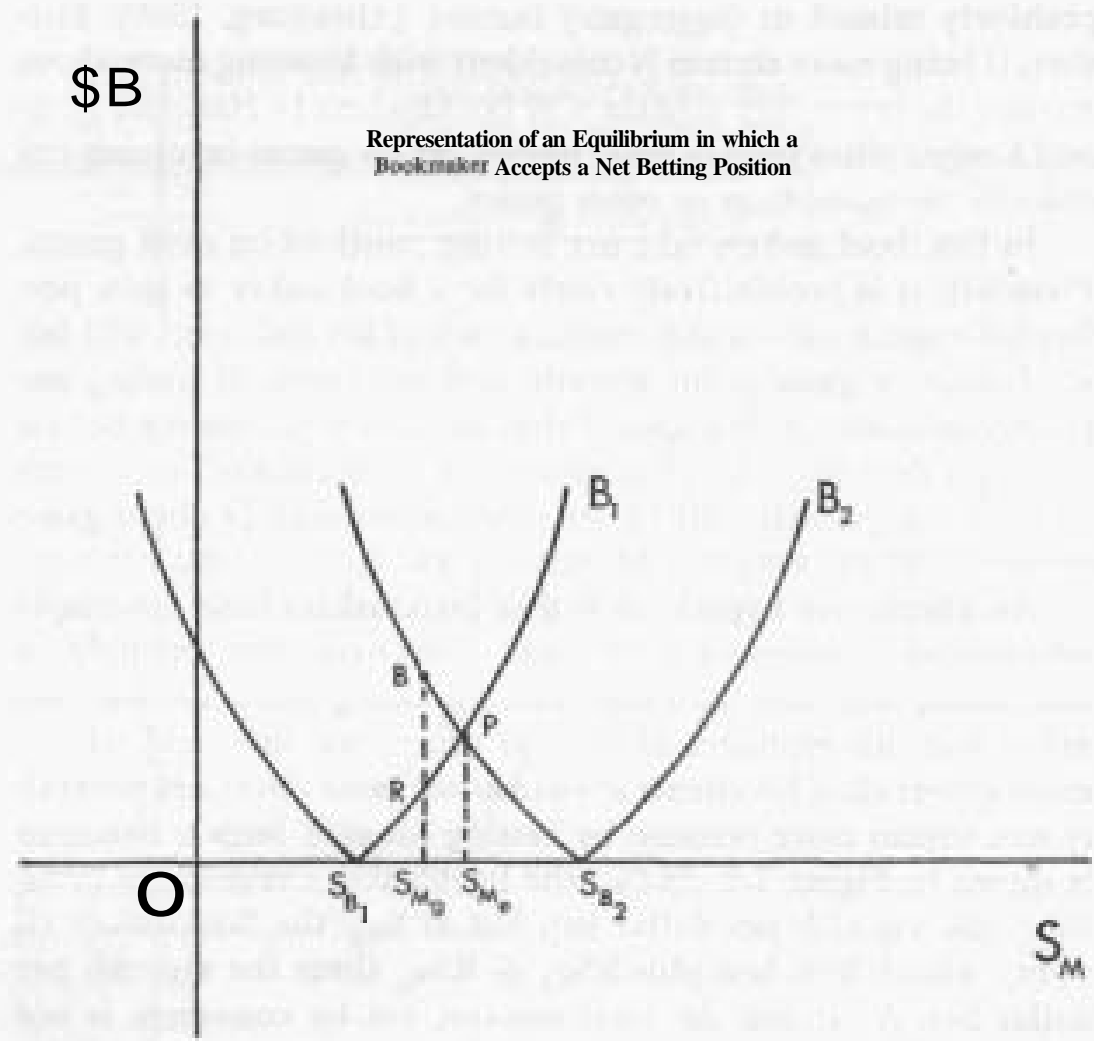

Figure 7-3.

that betting losses will bankrupt him by betting small amounts on many games rather than large amounts on few. In either case the expected gain from bookmaker betting is positive, whereas if bookmakers bet simply because they do not know the self betminimizing point spread, their expected betting gain is zero.

To the writer's knowledge no data has been collected to test whether bookmakers systematically make money on their net betting. There is indication that at least some bookies consistently win (Merchant, 1973) * If they do, one possible reason is that

"Merchant personally is of the opinion that bookmakers win more bets with their customers than they lose (correspondence with author, February 21, 1974). Also, a 
in dealing directly with bettors, bookmakers can discern those who, on the average, bet correctly. Ifsuch exist, and if demand to bet on a particular side is elastic with respect to a small change in the game point spread, a bookmaker can profit by moving his spread so as to induce net betting in opposition to the expert.

\section{A Model of the Professional Bettor's Market}

Earlier, a process was described whereby the Las Vegas service line is transformed into an opening line through exposure to a group of professional bettors. Assume now that these professionals maximize profit, and, for simplicity, that they have a uniform betting opinion. If the transformation of the line is occasioned via net amounts bet at the limit on one team or the other, this is equivalent to representing the net professional bettor opinion.

The market for the professionals' betting differs from the model presented above because there is a limit that can be bet at any given point spread, and because bets at that limit change the point spread at which further bets will be accepted. The former limits the amount the professionals will bet at any given spread, and the latter introduces previous amounts bet as a determinant of the amount they will bet at the present spread.

In calculating how much to bet on a particular game at a given point spread, the professionals will consider the cumulative probability that their subjective estimate of the game outcome will be less (more) than the point spread, the amount already bet on that game at previous spreads, the transaction cost of betting," and also their estimate of the eventual market equilibrium point spread (the equilibrium reached once the public places its bets) - Because of the limit on betting at each service spread, the professionals bet at most this limit, but they can bet less at a

Newsweek report (1974) gives indication that some bookmakers gain sufficient "inside information" to consistently win more bets with their customers than they lose, but Bob Martin, whose job as a Las Vegas line-setter and bookmaker has given him extensive contacts among bookmakers around the country, is of the opinion that bookmakers generally lose more bets with their customers than they win (author's personal interview, June 11, 1974).

*The professionals are charged 11 to 10 odds for all bets into the service line. 
spread afterwhich it does not change. Let

$\mathbf{B}_{p}=$ total dollar amount bet by the professionals

$\mathrm{L}=$ limit on the amount bet at any given service spread

$\mathrm{a}=$ an amount bet that is less than $\mathrm{L}$ and, hence, occasions no further move in the service spread

$\mathrm{S}_{\mathbf{M}}=$ the professionals' estimate of the market equilibrium point spread

$\mathrm{S}_{\mathrm{p}}=$ the professionals' estimate of the median game outcome

$\mathrm{S}_{\mathrm{E}}=$ the service spread

$\mathrm{S}_{\mathrm{Q}}=$ the spread at which the pros no longer wish to bet the limit (which by definition becomes the opening spread)

Given the nature of the betting, with 0.5 point moves in the line occurring with each limit bet, the total amount bet by the pros is

$$
\text { (2) } B p=2 L|| s_{0}-s_{s} \mid+\square
$$

We now seek to determine what value $S_{0}$, the opening line, will take. Assume first that $S_{M}$ equals $S_{p}$; that is, the professionals' estimates of the public market equilibrium and the median game outcome are the same. Then, at most $\mathrm{S}_{\mathrm{o}}$ equals $\mathrm{S}_{\mathrm{p} i}$ the professionals bet the limit at all spreads other than the estimated median game outcome. In this situation, if the professionals can better estimate game outcomes than those who set the service spread, they will have moved the line toward the game outcome on the average, the public will about break even on its betting, and the line will not move systematically from $\mathrm{S}_{0}$ -

It is plausible that $S_{0}$ doesn't equal $S_{p-}$ First, given the transaction cost of betting, the professionals may be insufficiently confident of their game outcome estimate at $\mathrm{S}_{\mathrm{p}}$ not equal to $\mathrm{S}_{\mathrm{p}}$ to find it profitable to bet the limit. Second, if the professionals are averse to staking large amounts on the outcome of any one game, the more already bet on a game, the less the incremental amount bet. If $S_{a}$ falls between $S_{a}$ and $S_{p}$, then on the average both professional and public bettors will move the line toward the game outcome, and the two groups will move the line in the same direction. This and the situation of $S_{\mathrm{g}}$ equals $S_{p}$ are shown as case 1 of Table 7-I, From the above, the relationship of $S_{0}$ to $S_{2}$ depends on $L$. The 
TABLE 7-I

PRO BETTOR MARKET EOUILIBRIA.

\begin{tabular}{|c|c|c|}
\hline Case & $s_{g}$ & Implication for Public Betting \\
\hline (1) $s_{p} \neq s_{p}=s_{14}$. & if $s_{0}=5$, & $\begin{array}{l}\text { Public brcaka even, line does } \\
\text { not move systematically. }\end{array}$ \\
\hline & if $s_{0} \lesseqgtr s_{0}$ & $\begin{array}{l}\text { Public moves line toward game } \\
\text { outcome as did pros. }\end{array}$ \\
\hline (2) $s_{6} \frac{\zeta}{>} s_{n} \lesseqgtr s_{p}$ & $s_{0} \leq s_{n I}$ & $\begin{array}{l}\text { Public breaks even, line does } \\
\text { not move systematically, would } \\
\text { pay to bet as did pros at } 5_{0}\end{array}$ \\
\hline (5) $5_{0} \leq \frac{5}{>} \leq 5_{2 n}$ & $s_{b} \leq s_{p}$ & $\begin{array}{l}\text { If } s_{0}-S \text {, public moves line } \\
\text { systematically away from game } \\
\text { outcome. If } s_{0}=S \text {, public } \\
\text { moves line in same direction } \\
\text { as did professionals, but } \\
\text { first toward and then away } \\
\text { from tDe game outcome. }\end{array}$ \\
\hline (4) $\mathrm{s}_{2 \mathrm{ar}} \leq \mathrm{s}_{,} \leq \mathrm{s}_{\mathrm{p}}$ & $s_{0}=5$ & $\begin{array}{l}\text { Pros do not bet, public moves } \\
\text { line such that betting against } \\
\text { the move wins on average. }\end{array}$ \\
\hline
\end{tabular}

greater $\mathrm{L}$ is, the closer $\mathrm{S}_{Q}$ to $\mathrm{S}_{\mathrm{q}}$ will be, and the further from $\mathrm{S}_{p \text {. }}$ Thus, assuming $\mathrm{S}_{\mathrm{P}}$ equals $\mathrm{S}_{\mathfrak{X}}$, a lower $\mathrm{L}$ provides the bookmakers more precise information about $\mathrm{S}_{\mathrm{M}}$ the experts' estimate of the median game outcome, but the lower $\mathrm{L}$ is, the less professional betting money booked per bet.

Suppose now that $S_{p}$ doesn't equal $S_{x \in}$ that is, the professionals' estimates of the median game outcome and the betting market equilibrium differ." The implications of this are summarized in Table 7-I. If $S_{M_{e}}$ falls between $S_{a}$ and $S_{p}$ (case 2), the professionals will move the line at most to $\mathrm{S}_{\mathrm{at}}$ - This is so because it will be more profitable for them to bet with the public at $S_{21}$ than with the bookmakers at spreads closer to $S_{p}$. If the professionals are correct in their estimation of $S_{x}$ and $S_{p s}$ then the public will break even on its betting, the line will not move systematically during the public betting, and those who bet as did the professionals at the opening line will on the average bet correctly.

\footnotetext{
"Say, because the professionals expect the public market to be dominated by the uninformed, they will emotionally bet money.
} 
If $S_{p}$ falls between $S_{\geq}$and $S_{M}$ (case 8 ), then at most the professionals will bet such that $S_{0}$ equals $S_{p}$ for they would expect to lose bets at point spreads between $S_{p}$ and $S_{x p}$. If $S_{0}$ equals $S_{p r}$ the public line systematically will move in the same direction as during the service betting, but away from the game outcome, and it will not pay to bet as did the professionals at $S_{0}$. However, if $\mathrm{S}_{\mathrm{o}}$ doesn't equal $\mathrm{S}_{\mathrm{p}}$ the public will move the line first toward, and then away from the game outcome; the line will move in the same direction as during the service betting; and betting as did the professionals at $S_{0}$ will result in more betting wins than losses.

Finally, if $S_{w}$ falls between $S_{M}$ and $S_{p}$ the professionals will not bet into the service line at all since they will expect more favorable betting opportunities once the public has access to the line. In such a case, the public systematically moves the line away from the game outcome so that betting against the public wins on average.

\section{A Test of the Model of the Professional Bettors' Market}

The model of the previous section relies heavily on the professionals' estimates of equilibrium in the public market. Tests of that model would be obscured if new information came to light during each week that materially affected betting point spreads in the public market since such information presumably also would have affected the professionals' betting.

Data for service, opening and closing spreads for the 1972 regular pro football season were taken from Merchant (1973). * In using this data, it is assumed that no new information affected 1972 betting point spreads once the service line was set so that service, opening and closing betting lines are all equilibria rela-

"Merchant's data was obtained mostly from bookmaker contacts in the New York City market and from bettor contacts in Las Vegas. Unfortunately, although Merchant represents his data as pertaining to the professional betting process herein described, what we call the service line he synonymously calls both the service and the "outlaw" line. The outlaw line, however, refers to something else, namely a line quoted each week by unlicensed Nevada bookies prior to the service line. If the data we have used is in fact taken from 1972 outlaw lines, then our tests are invalid. 
tive to a given body of data. ${ }^{\uparrow}$

A regression model was formulated with the following notation:

$\mathrm{S}_{\mathrm{a}}=$ the service spread for game $\mathrm{i}$ (the number of points by which the favorite is favored in game i)

$\mathrm{S}_{\mathrm{o}}=$ the opening spread for game $\mathrm{i}$

$\mathrm{S}_{\mathrm{e}_{1}}=$ the closing spread for game $\mathrm{i}$

$\mathbf{F}_{1}=$ the actual game score of the betting favorite in game $\mathrm{i}$

$\mu_{\mathrm{j}}=$ the actual game score of the betting underdog in game $\mathrm{i}$

To test whether the professionals can better estimate median game outcomes than those who set the service line, the following linear regression was estimated. *

(3)

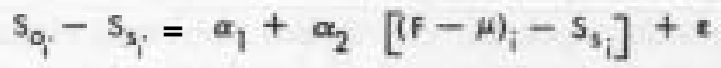

The bracketed term of expression 3 refers to the difference between the actual game outcome and the service spread, and the dependent variable is the difference between the opening (postprofessional betting) and service spread. A significantly positive a would be consistent with professional bettor expertise. The following parameter estimates were obtained (t-statistics in parentheses) :

$$
s_{0}-s_{3}=.273+.014
$$

$$
\begin{aligned}
{\left[(F-\mu)-s_{s}\right] \text { Adj. } } & R^{2}=.02 \\
& \text { F value }=5.1 \\
& \text { D.W. }=1.90 \\
& \text { d.f. }-177
\end{aligned}
$$

Under the assumption that no new pertinent information

in fact, there were probably some instances in 1972 in which new information occurring during a week materially affected public betting spreads, but because player injuries are probably the most important cause of changes in expected team performance, and because pro football teams are required by the league to publicly report all game injuries, it is doubtful that much relevant data was not already reflected in service spreads. On three occasions, the condition of a starting quarterback was uncertain during the week, and for these games no service or opening lines were posted.

"Pankhoff (1968) reports that the distribution of football point spreads is closely approximated by a normal distribution and the difference between two normal distributions is itself normally distributed. 
came to light once the service line was set, the significantly positive coefficient of the bracketed term indicates that on the average the professionals do predict game outcomes significantly more accurately than those who set the service line. This is supported by the raw data which show that the pros moved the spread closer to the actual game outcome (bet correctly) seventy-four times, further from the outcome (bet incorrectly) fifty-two times, and left the spread unchanged fifty-three times.

The significantly positive constant of expression (3.1) indicates that on the average the pros increased the spread. Apparently, service spreads systematically underestimated opening spreads during 1972. The raw data is consistent with this, showing that of a total of 179 instances in which both the service and opening lines were reported, the spread increased eighty times, decreased forty times and was unchanged fifty times.

The ability of the public to correctly predict game outcomes was tested via the following linear regression

$$
\mathrm{s}_{\mathrm{c}_{j}}-\mathrm{s}_{\mathrm{o}_{j}}=\beta_{1}+\beta_{2} \quad\left[\left(\mathrm{f}-\mu_{\mathrm{i}_{i}}-\mathrm{s}_{\mathrm{o}_{i}}\right]+\boldsymbol{d}\right.
$$

where $d$ equals a normally distributed random error term, $\mathrm{E}$ (d) equals 0.

In expression (4) the bracketed term is the difference between the actual game outcome and the opening spread while the dependent variable is the difference between the closing (postpublic betting) and opening spread. A significantly positive $\beta_{\mathrm{a}}$ would indicate that the public generally moves the line in the direction of the game outcome (i.e. bets correctly) .

The regression estimate is

$$
s_{c}-s_{c}=\underset{(6.01)}{.462}+.009
$$$$
\left[(\mathrm{F}-\mu)-\mathrm{s}_{\mathrm{o}}\right]
$$$$
\begin{aligned}
& \mathrm{R}^{2}=.01 \\
& \mathrm{~F} \text { value }=2.4 \\
& \text { D. } \mathrm{W}=1.85 \\
& \text { d. } \mathrm{f} . \quad-177
\end{aligned}
$$

The coefficient of the independent variable is not statistically significant, which is consistent with the view that the public does not move the line toward the game outcome any more than would be expected through chance. Again the constant is significant, 
indicating that the opening line consistently underestimated the closing. Both conclusions are borne out by the raw data, the public betting correctly only 50.3 percent of the time, but increasing the spread ninety-six times, decreasing it thirty-five times, and leaving it unchanged forty-eighttimes.

Finally, a bettor with knowledge of the service and opening lines, and betting as did the pros at the opening lines would have won seventy-three bets and lost fifty-two, a percentage correct of 58.4 percent; this is sufficient to make money at 11 to 10 odds. In the context of our model, $S_{\mathrm{u}}$ doesn't equal $\mathrm{S}_{\mathrm{p} \text {. }}$

This evidence is consistent with case 2 of Table 7-I. On the average the pros moved the line toward the game outcome, but did not provide an unbiased estimate of this outcome. Further, the public breaking even is consistent with $S_{0}$ equals $S_{2 x}$ If this was the case, and if the bookmakers desired to minimize their selfbetting, then the pros provided them an almost perfect set of spreads. The data also is consistent with case 3 of Table 7-I where $\mathrm{S}_{\mathrm{a}}$ doesn't equal $\mathrm{S}_{\mathrm{p}}$, but the raw data show no indication that the public moved the line toward then away from the game outcome." There was a slight tendency for the public to move the line in the same direction as did the pros (56 times as opposed to 38 times in the opposite direction), but it won on average when it did so $(68.9 \%)$. The overall 50 percent betting average of the public occurred because it lost on the average when it moved the line in the opposite direction to the pros $(42.1 \%)$, or when, it moved the line after the pros had not $(47.5 \%)$.

How much do the bookies pay for the services of the professional bettors? This payment can be measured as the amount of money the pros bet correctly less the amount they bet incorrectly less the vigorish.

If we assume no money bet without a spread change (that is, $\mathrm{a}=0$ in the context of the model), and also assume \$L bet per half point spread change, then the pro bettors would have won \$L X 90.50 - \$L X $54.50-\$ L$ X $5.45=\$ L$ X 30.55.t Thus, for

"In fact, this happened but once during the 1972 season.

TCalculated from data in Merchant (1973) According to that data, the pros moved the line toward game outcomes a cumulative total of 90.5 points, and away a total of 54.5 points. 
example, if the limit was $\$ 5000.00$, the professionals would have won about $\$ 153,000.00$ during 1972 . However, this is the maximum price paid the professionals by the bookies. In fact it is quite likely that professional bettors bet on both sides of at least some of the service spreads. Since the bookies collect II to 10 from such betting, the net to pro bettors from betting into the outlaw line is probably much less than the above figures indicate.

\section{Efficiency of the Pro Football Betting Market}

Researchers into securities markets have advanced a theory of the efficiency of such markets. If many buyers and sellers compete, and if they continuously profit-maximize, prices of securities will continuously incorporate all relevant information so that, at any point in time, each security's price will be an unbiased predictor of its future price. An implication of this theory is that securities price movements will not form predictable patterns so that, counting transactions and holding costs, a person who merely charts past securities price movements will not be able to use these to earn trading profits. Further, the theory implies that a person trading only on publicly available information (e.g. a newspaper report of a company's earnings) will not earn trading profits. However, the theory does not deny that a person who can systematically produce relevant information (e.g. because of superior analytical ability) can earn trading profits.

Some characteristics of gamblers and of football betting markets have been studied. Rosett (1965) has provided powerful empirical evidence that gamblers act rationally; that is, that for a given probability of winning they will choose a larger reward, and for a given reward they will choose a higher probability of winning. This evidence is consistent with the assertion that gam, bling markets are efficient.

Pankoft (1968) has tested the efficiency of the (professional and college) football betting market. He found no evidence that a bettor sophisticated in statistics could use data concerning past game outcomes and betting lines to earn above-normal returns. However, he did find evidence that some expert observers of football (sports reporters) are able to produce more accurate point 
spread estimates than the market consistently enough to profitably bet on their advice. This latter finding is weakly supported by data reported in Merchant (1973) showing that both he and three professional bettors with whom he had contact consistently picked more winners than losers among their pro football bets."

To further test the efficiency of the pro football betting market, several betting rules were hypothetically executed with betting line and game outcome data compiled for National Football league games for the years 1961-1965, 1972-1973.1 The assumed transaction cost is 11 to 10 odds since at least some bettors are able to bet at those odds.

Merchant (1973) is of the view that the public bets incorrectly more often than correctly. Given this premise, he suggests a rule of betting on teams the public bets against, that is, betting in the opposite direction to any change in the market line. The theory underlying such a betting rule is that the opening line that has resulted from betting by experts is a sufficiently superior predictor of game outcomes to any other line produced by the public's betting that both changes in the line caused by midweek events and transactions costs will be overcome. A slightly more sophisticated rule would throw out instances in which known midweek events changed the line since such events also would have affected the professional's betting. However, for lack of data on midweek events, only the naive rule can be tested here (betting rule 1 in Table 7-II). The rule is tested only with 1972 data as no data was available concerning midweek movements in the line for other years. As the public in 1972 moved the line toward the game outcome on sixty-eight occasions and away from it on sixty-seven, the rule would have resulted in a net loss for that season.

"But according to Merchant, one of the three professionals actually lost money because he bet more on losing picks than winners (correspondence with author, August 9, 1974).

tData for the 1961-1965 seasons was supplied by Professor Lyn D. Pankoft. His betting lines were taken from various issues of the Chicago Daily Tribune. Betting lines for 1972 are those in Merchant (1973) and reflect local New York City bookmaker odds. Lines for 1973 are taken from various Friday issues of the New York Times, and reflect an amalgam of local New York City and Las Vegas odds. 
Regression equation (4.1) implied that opening lines in 1972 contained a systematic bias, consistently underestimating the closing line. A relevant question for market efficiency is whether a person with foreknowledge of the bias could have made money from it. Trading rule 2 in Table 7-II reflects a strategy of betting on the favorite at the opening spread and the underdog if the closing spread was greater. The results are 136 wins and 127 losses, or 51.7 percent. Given transaction costs, the opening line bias was insufficient to make money on.

TABLE 7-II

HYPOTHETICAL RESULTS OF BETTING RULES IN PRO FOOTBALL BETTING MARKET

(Breakeven at $11-10$ odds $=52.49 \%$ )

\begin{tabular}{|c|c|c|c|}
\hline & $\begin{array}{l}\text { Games Set } \\
\text { Correctly }\end{array}$ & $\begin{array}{l}\text { Games Set } \\
\text { Incorrectly }\end{array}$ & $\begin{array}{c}\text { Percentage } \\
\text { Correct }\end{array}$ \\
\hline $\begin{array}{l}\text { 1. Bet opposite to movements in } \\
\text { line caused by public betting }\end{array}$ & 67 & 68 & $49.6 \%$ \\
\hline $\begin{array}{l}\text { 2. Bet on favorite at opening } \\
\text { spread, underdog (if move } \\
\text { in line) at closing }\end{array}$ & 136 & 127 & $51.7 \%$ \\
\hline $\begin{array}{l}\text { 3. Bet on team beating spread } \\
\text { more consistently in past } \\
\text { a. Second half of season }\end{array}$ & & & \\
\hline $\begin{array}{l}\text { (1st half data) } \\
\text { b. First half of season }\end{array}$ & 173 & 171 & $50.3 \%$ \\
\hline (previous year's data) & 120 & 128 & $48.4 \%$ \\
\hline $\begin{array}{l}\text { 4. Bet same way professional } \\
\text { bettors did against } \\
\text { service spreads }\end{array}$ & & & \\
\hline a. at opening spreads & 73 & 52 & $58.4 \%$ \\
\hline b. at closing spreads & 67 & 54 & $55.4 \%$ \\
\hline
\end{tabular}

Another betting rule was fashioned on the hypothesis that some teams' fans bet their emotions to such a degree that market spreads are biased indicators of team relative strengths. For example, if backers of Dallas more consistently bet on their team as a matter of pride than backers of other teams, the line will tend to overestimate the performance of the Dallas team. The rule formulated was to bet in each game on the team that had beaten the spread more often in the past. It was applied (1) over the 
second half of seasons from records compiled over the first half; and (2) over the first half of seasons from records compiled over the previous season. The results are shown under rules $3 a$ and $3 b$ in Table 7-II. Given transaction costs, a bettor following either rule would have lost money over the seasons studied.

Finally, it was reported earlier that professional bettors betting into the service line consistently moved the spread closer to the game outcome, but not to an unbiased estimate of the game outcome. Hence, a bettor with knowledge of both the service and opening lines might more than cover transactions costs by betting at the opening line on the same teams as did the professionals. The results of this betting rule are shown as trading rule $4 \mathrm{a}$ in Table 7-II. The rule applied to 1972 data provides a percentage correct of 58.4 percent, sufficient to make money at 11 to 10 odds. However, it is interesting that if the bets are placed at closing point spreads, the percentage drops to 55.4 percent. From these data there is a potential rule that would allow betting profits, but bettors in 1972 reduced the opportunity to statistical insignificance." Since it is unknown how quickly the line changed during the week in 1972, it is also unknown how efficiently the market adjusted or whether someone with knowledge of the service line could still profit from the rule. Further, one season's data is an extremely limited sample so that little significance can be claimed for the above observation.

\section{Concluding Remarks}

In this Chapter the writer has described the market for pro football betting and advanced several propositions concerning the behavior of those who trade there. At the present time this market operates under various state, local and federal legal constraints. One question for public policy is whether or not such betting should be legalized. Although there are several ways in which legalized betting markets might be structured (e.g. state monopo-

*At the closing spreads, the rule yields sixty-seven success of 121 trials. Against the hypothesis that each trial has probability 0.5 of success, an actual outcome of sixty-seven successes is not significantly different from the mean (60.5 successes) at any reasonable confidence level. 
ly, state-enfranchised private monopoly, state licensing of several betting firms), the discussion below is limited simply to the consequences of withdrawal of legal sanctions against sport betting markets. The discussion is presented in terms of pro football betting, but analogous arguments hold for betting markets for baseball, college football, basketball, boxing and other sports.

Since legal sanctions against sport betting markets impose costs upon those who make such markets, withdrawal of these sanctions would reduce operating costs to bookmaking firms. For example, costs of screening customers, of fines and prison terms, and of payoffs to policemen and other public authorities would be reduced with legalized sport gambling.

Under present law, bookmakers economize the use of technologies which raise the probability of detection and arrest; thus bookmakers keep few records of their bets, use relatively little capital equipment, and do not openly advertise. Also, since passage in 1961 of federal laws prohibiting interstate transmission of gambling information, bookmakers have made less use of largescale layoff centers. Insofar as such technologies would reduce costs, repeal of state and federal antigambling statutes would further reduce costs of making a market for betting.

There is evidence that, in at least some cities, organized crime syndicates impose taxes on the bookmaking industry." Legalization of bookmaking would make it more costly for the syndicates to collect such taxes, reducing bookmaker operating costs. Finally, if bookmakers have a distaste for dealing in an illegal service, legalization of betting markets will reduce the compensation required to draw bookmakers from legal employment. The aforementioned reductions in costs and in bookmaker compensation would lead to a reduction in the relative price to bet.

Lower relative prices for football betting would increase the number of bets made. In addition, if bookmakers could legally promote their services, the demand for pro football betting at all

-According to a Rochester, New York, newspaper report (Burke, 1974), organized crime members in that city presently force bookmakers to pay them a fee to operate. There is apparently no service provided in exchange. The fee a bookie pays is positively related to the volume of his business and, hence, can be approximated for analytical purposes by a per unit tax on output. 
prices would increase, and if people have a distaste for consuming an illegally-supplied service, legalization would further increase demands, thus a second consequence of legalization would be increased football betting.

If gambling on sports is a substitute for gambles on other types of events, legalization of sport betting would reduce betting on such events as horse and dog races, or reduce the relative rate at which such gambling increases. One consequence is that opposition to legalized sport gambling can be expected from proprietors of race tracks and from breeders of horses and dogs.

Organized professional sport leagues such as the National Football League actively oppose legalization of professional football betting. The leagues take the position that legalized betting would increase spectator suspicion of fixed games, and also that more fixes would be attempted, and more players tempted to join such fix attempts (See Smith, 1972) . At present, the NFL spends about $\$ 200,000.00$ per year to monitor its players and other personnel so as to allay fan suspicion and reduce the probability of a fix. If legalization increases the returns to the fixing of a game, then the cost to the NFL of maintaining a given probability of a fix would rise. However, there is an identity of interest among bookmakers and organized sport leagues in preventing fixed games. If in fact a game is (successfully) fixed but bookmakers are unaware of it, they will lose money accepting bets from those with knowledge of the fix. Since fix attempts are profitable only if bet on, and since such betting causes changes in game spreads that are not otherwise explicable, bookmakers are the first to suspect fix attempts, and their interest is to relay the information to those with power to disbar the athletes involved." Since legalization of football betting would allow more open publication of point spreads and of changes in these spreads, it is plausible that fix attempts would be detected more quickly.t

It also seems likely that legalized markets for betting will in-

*In fact bookmakers are said to cooperate with organized sport leagues. One of the NFL's chief means of detecting fixes is said to be close contact with bookmaking sources in league cities.

tBut if there is a larger volume of betting with legalization, it might be more difficult to detect a given amount bet by successful fixers. 
crease spectator and TV viewer demand for games, thus compensating professional sport leagues in part for increases in costs of preventing fixed games. For example, if for every one hundreddollar increase in betting, one additional TV viewer watches one game, an increase of 1 billion dollars in pro football betting per year from legalization would increase the annual number of game viewers by 10 million. If the league receives as much as one cent per game per viewer, this would increase its revenue by 100,000 dollars per year.

Further research might investigate some consequences of alternative schemes to legalize sport gambling. Many state governments are interested in the revenues that could be derived from legalizing and taxing this industry. What revenues would be derived from state production and promotion of sport gambling, and what from state licensing of private bookmakers, as is done in Nevada? Also, what would be the consequences for legalized state sport betting markets of (a) repeal of or exemption from the two percent Federal Wagering Tax versus (b) no such repeal or exemption? And finally, there appears to be little empirical evidence concerning either the present demand for sport betting or the supply of it. Estimates of gains to bettors or of potential state revenue from taxation of this industry would be aided by such evidence.

\section{REFERENCES}

Ahrmborg, B.; Betting on football matches in Sweden. Ann Am dcad Polit Soc Sci, May, 1950.

Burke, Judy: How Rochester bets. The Rochester Democrat and Chronicle, January 13-14, 1974.

McQuaid, C. (Ed.): Gambler's Digest. North Ficld, Digest Books, Inc., 1971.

Merchant, L.: The National Football Lottery. New York, Holt, Rhinchart \& Winston, 1973.

New York State Commission of Investigation: Syndicated Gambling in New York State. February, 1961.

Newsweek: Everybody wants a piece of the action. pp. 46-52, April 10, 1972.

Newsweek: The good doctor. September 2, 1974, pp. 63-64.

Pankoff, L. D.: Market efficiency and football betting. / Business, $1 I(2): 203$, 1968. 
Rosett, R. N.: Gambling and rationality. / Polit Econ, LXXIII:595,1965.

Smith, R.; Czars against sin in Howard's Lair. New York Times, p. 49, September 29, 1972.

Smith, V,: Economic theory of wager markets. Western Economic J,"9:3, 1971.

Strine, G.: Fishing for a fortune Sunday with those heavenly Dolphins. The Washington Past, p. 73, December 29, 1973.

Treynor, J.: The only game in town. Financial Analyst's J, March-April, 1971. 


\title{
Chapter 8
}

\section{ECUNIMIC ASPECTS OF NEVAIA'S GAMING INDUSTRY}

\author{
WILLIAM R. EADINGTON
}

\section{T} HE IMPORTANCE of Nevada's legalized gaming industry to anyone who visits any of the state's populated areas is overwelmingly obvious. The cities of Reno and Las Vegas, the recreational areas at Lake Tahoe, even the rural and isolated community of Elko all revolve around a booming and expanding gaming and tourist industry. Fully one fourth of the jobs held in the state fall into the hotel, gaming and recreation employment category. Over 40 percent of the state's general fund revenues are generated by gaming taxes. The industry is expanding at a rapid rate, and along with it, the rest of the economy of the state. From 1960 to 1970 casino gross gaming revenues (gambling winnings) rose from 194.1 million dollars to 543.7 million dollars; annual increases in gaming revenues of between 10 percent and 20 percent have long been the rule*. In 1973, gambling winnings by casinos statewide were over 875 million dollars, a 60 percent increase over 1970.

The state's population has also expanded rapidly, parallel with the gaming industry's growth. From 1960 to 1970, the population growth rate of Nevada was greater than that of any other state in the nation. Las Vegas was the fastest growing metropolitan area (SMSA) in the country during the decade of the I960's, Reno was ranked the sixteenth fastest growing among all SMSA's in the United States in spite of the closing of a nearby air force base. In 1973, the population of the Las Vegas metropolitan area exceeded 300,000 people, and it continues to grow rapidly. The population of the Reno-Sparks area is presently about 150,000 people, and its prospects for the near future are a continuing rapid growth stim"Nevada State Gaming Control Board, Nevada Gaming Abstract, Carson City Nevada, 1972. 
ulated mainly by expansion in its major industry-gaming-

The profitability and popularity of Nevada's legalized gaming has not gone unnoticed by other states. Since the inception of the New Hampshire lottery in 1964, thirteen states are now operating lotteries; two, including New York state, have legalized off-track betting on thoroughbred races; and a number of states have seen legislation which would legalize some forms of casino gambling." Since states look at legal gambling as a fairly painless means of generating revenues, and since many of the moral arguments against legalized gambling have lost their strength in the past few decades, it is likely that this trend toward legalization will continue, at least into the near future.

Another possible reason for the increased interest in legalized casino gambling is the decline of the idea that legalized casinos are an open invitation for organized crime to take over the gaming activities as well as state and local governments. From Nevada's experience, there are two main reasons for this decline. First, the industry's regulatory agency, the Gaming Control Board, has developed relatively efficient controls on the licensing and regulation of privately owned casinos; thus, there have been few incidents implying the presence of organized crime in Nevada for the past ten years. Secondly, in 1969, new state legislation allowed casinos to be owned by publicly-traded corporations. This significantly improved the access to capital markets of casinos and brought in a number of national corporations such as Recrion, Hilton, Caesar's World (Lums) and MGM to replace the often colorful owners of earlier years. This, in conjunction with the Howard Hughes casino acquisitions in Las Vegas and Reno during the late $1960{ }^{\prime}$, significantly diminished the perceived underworld ties to Nevada's gaming industry.

As a result of a lingering wariness, much of the legislation to

\footnotetext{
"Since 1972, New York, New Jersey, Wisconsin, Minnesota, Rhode Island and Pennsylvania have all had legislation introduced which would legalize casino gambling under various restrictions. One of these states, New Jersey, has passed a bill which placed a referendum on the November, 1974, ballot, to allow the voters the choice of whether to allow legalized casino gaming in Atlantic City on a five-year trial basis (it lost.) See the "NLW Newsletter" published monthly by NLW Advisory Service, Boca Raton, Florida, for regular reports on the status of state gambling legislation throughout the United States.
} 
legalize casinos in other states has invoked either outright state ownership and operation of casinos or, at the very least, stringent controls and comparatively high gambling tax rates to discourage any criminal element who would otherwise be interested." This may or may not prove to be a workable strategy for the overall financial success of the gaming operations, either in terms of profitability or tax revenues generated; it is too different from Nevada's set-up to draw reasonable predictions from comparisons. (For some possible indicators of the success potential of legalized casinos, see "Some Observations on Legalized Gambling" in Part I of this volume.)

In any event, since Nevada is presently the only state which allows casino gambling, it will probably be the major source of information and expertise about casino operations for those states who decide to legalize casinos. The purpose of this study is to examine one aspect of the industry: the relation between inputs (number of crap games, blackjack games, slot machines, employees, etc.) and output (gross gaming revenues). The approach taken is to construct a production function for gross gaming revenues and attempt to estimate its coefficients utilizing mixed cross-section and time series data from different resort regions in the state. From this basis, information on economies of scale, the marginal productivity of various games and devices, and the optimal mix of games and devices for a casino operation can be deduced.

\section{THE PRODUCTION FUNCTION AND FIRM BEHAVIORt}

The production function relates amounts of inputs used in a production process with the resulting quantities of output. In a typical manufacturing situation the inputs could be represented by labor, raw materials, and capital equipment; output would simply be the number of units of the finished product turned out.

*In Nevada the maximum tax rate on gross gaming revenues is 5.5 percent; the total amount of state and local gaming taxes paid by casinos averages less than ten percent of gross gaming revenues. By contrast, New Jersey was considering a tax rate on winnings of about forty percent.

tA more detailed discussion of the production function can be found in Walters (1970). 


\section{In mathematical terms}

$$
\text { (1) } Q=f\left(K, L_{2}, M\right)
$$

$\mathrm{Q}=$ volume of finished product

$\mathrm{K}=$ capital equipment (machine hours)

$\mathrm{L}=$ labor (man hours)

$\mathrm{M}=$ quantity of raw materials

It is assumed that the production function possesses certain general characteristics. First, the marginal product of any input is positive, but will decline as the amount of that input used is increased, other variables held constant. (Marginal product is defined as the change in total product brought about by a one unit change in the input). In calculus the above statement can be summarized as

$$
\text { (2) } \frac{\partial Q}{\partial x_{i}}>0, \quad \frac{\partial^{2} Q}{\partial x_{i}^{2}}<0
$$

where $\mathrm{Xi}$ is any variable input.

This states that as the amount of an input used in the production process increases, other variables held constant, it will bring about an increase in output, but successive increases in the input will lead to ever-smaller increases in output.

The degree of substitution of one input for another to generate the same level of output depends on the nature of the production process itself. Some processes allow for very little substitution between various inputs; with others the degree of possible substitution may be high. Mathematically, input substitution is defined as follows:

$$
\begin{aligned}
& \text { the rate of substitution of } x_{i} \text { for } x_{i}=-\frac{\partial \varrho / \partial x_{i}}{\partial Q / \partial x_{i}} \\
& =-\frac{\text { marginal product of } x_{i}}{\text { marginal product of } x_{i}}
\end{aligned}
$$

The rate of substitution states the amount of one input necessary to compensate for the loss of a unit of another input so that total output will remain the same. For example, the rate of sub- 
stitution would indicate how many five-cent slot machines would be necessary to generate the revenue lost by one blackjack table.

Finally, if the firm sells its product in a competitive market, and if it is a profit-maximizing firm, it will hire each input to the point where the ratio of the (value of the) marginal product of each variable input to its unit cost is the same for all variable inputs, or

(4) Profit maximizing condition:

$$
\frac{M P_{X_{1}}}{C_{1}}=\frac{M P_{X_{2}}}{C_{2}}-\ldots-\frac{M P_{X_{m}}}{C_{w_{m}}}
$$

where $\mathrm{C}_{\mathrm{L}}$ equals unit cost of the $\mathrm{i}$ th input.

If the ratio for a particular input were above that of other inputs, it would mean that the firm could get greater output for its expenditures by reallocating funds from the other inputs to that particular input, assuming the production process allows for substitution among the inputs.

In the short run for a particular firm it is assumed that certain inputs are fixed and cannot be varied; plant size or entrepreneurial skills, for example, might fall into this category. The existence of some fixed inputs is the usual explanation why the marginal product of all variable inputs will eventually decline.

In the long run the firm has the choice of varying all its inputs. If proportional expansion of all inputs leads to a greater-than-proportional increase in output, then economies of scale (or size) are said to exist. Alternatively, if expanding inputs leads to a less-thanproportional expansion of output, the situation is described as one with diseconomies of scale. In the long run, with competitive output markets, firms will expand their sizes as long as economies of scale can be realized, or they will contract to remove existing diseconomies of scale. If the output market is not purely competitive, then market demand for the firm's product rather than economies of scale will probably act as a limiting factor on firm size.

Empirically observing the long-run behavior of a firm often involves difficulties because too many conditions are changing considerably over time. However, the questions of economies of scale can be at least partially answered by looking at a cross-section of 
firms operating at different sizes at the same time. This will be the approach taken below.

\section{CHARACTERISTICS OF NEVADA'S GAMING REGIONS}

There are significant differences in the make-up of gaming operations at the different resort areas in Nevada. For example, the Las Vegas Strip is characterized by the expansive plush casino/hotel complex where a visitor wouldn't have to leave the premises to meet his vacation needs during a two to four-day stay. In Reno, on the other hand, most of the casinos operate without accompanying theatre-restaurants or hotels; those operations which are not casino/hotel complexes are typically smaller and more spartan than those to be found on the Strip.

There are four major resort areas in Nevada, each of which has its own distinguishing aspects. The largest and most unique of these is the Las Vegas Strip. In 1970, there were over 18,000 hotel or motel rooms available on the Strip, about two-thirds of them included in casino-hotel complexes." Gross revenues for the twenty largest operations on the Strip were nearly 600 million dollars in fiscal 1973, of which slightly more than 60 percent arose from gaming winnings (see Table 9-I). In 1970, the fifteen Strip hotels with main showrooms had an aggregate seating capacity of over 11,000 patrons per show; the dinner and cocktail shows in the major hotels could accommodate over 20,000 customers in an evening for shows which range in price from five to twenty-five dollars per patron. The general philosophy of operations on the Strip is to offer an entire recreation package of high quality; as a result, the Strip is more expensive than elsewhere in the state, and the type of gambler attracted spends more and gambles with significantly higher stakes.

Compared to other areas in the state, the Strip differs significantly in its visitors and their spending patterns. About 30 percent of all visitors to Las Vegas are airline passengers, and most of these

*In 1972, there were 26,619 rooms in the combined Strip and downtown Las Vegas tourist areas. This figure was forecast to increase to nearly 47,000 rooms by 1975 - a 75 percent increase in capacity in three years (Las Vegas Convention Authority Marketing Bulletin, 1973). 
stay on the Strip rather than downtown Las Vegas; this compares to less than 10 percent for Reno/Sparks and Lake Tahoe. Also, about 70 percent of the airline passengers arrive from cities and states other than California; thus the Las Vegas Strip captures much more of a national market than do the gaming operations elsewhere in the state (Las Vegas Convention Authority Marketing Bulletin, 1979). It is probably safe to assume that visitors arriving by plane tend to be more affluent in general than those who visit Nevada by other transportation means.

Because the Strip caters to higher spending gamblers, there is quite a bit more credit-play on the Strip than elsewhere in the state. This is reflected in the amount of gaming debts from patrons which go uncollected. In fiscal 1973, bad debts were about 14 million dollars on the Strip; this was 3.8 percent of gross gaming revenues. The percentage of bad debt to gaming revenues in the other resort areas of the state averages 1 percent or less (see Table 8-I). Since gambling debts are legally uncollectable in the United States, casinos are allowed to treat uncollectable debts arising from credit-play as expenses for tax purposes.

Gaming operations on the Strip are also characterized by a high level of complimentaries; in 1973, these amounted to nearly 80 million dollars, or 21.9 percent of gross gaming revenues. Comps are goods or services given to the casino's customers, and range from free drinks for almost anyone gambling to dinner or cocktail shows, free restaurant meals or free rooms for preferred customers. The complimentaries are declared at their retail value, so the 80 million dollars is the value of the goods and services which the casinos gave away if they were to be sold.

The most distinguishing aspect of Las Vegas Strip gamblers is the mix of casino games which they play (see Tables 8-II, 8-III and 8-IV) - Compared to other resort areas in the state, Strip gamblers play significantly more table games and fewer slots and keno games. Each crap table on the Las Vegas Strip grossed about 1.2 million dollars in winnings in 1973 on the average, compared to between 150,000 to 500,000 dollars for crap tables in Group 1 casinos elsewhere in the state. A blackjack table on the Strip generated about 350,000 dollars in casino winnings in fiscal 1973, compared to be- 


\section{TABLE B-I \\ FINANCIAL INFORMATION \\ NEVADA CASINOS 1973 \\ GROUP 1 CASINOS*}

\begin{tabular}{|c|c|c|c|c|c|c|}
\hline Location & $\begin{array}{l}\text { Number } \\
\text { of Casinos }\end{array}$ & $\begin{array}{c}\text { Gross } \\
\text { Revenues } \\
\text { (OOO's) }\end{array}$ & $\%$ Gaming & $\%$ Rooms & $\%$ Food & \% Beverage \\
\hline \multicolumn{7}{|l|}{ Las Vegas } \\
\hline \multicolumn{3}{|l|}{ Las Vegas } & 72.6 & 5.8 & 11.5 & 8.4 \\
\hline Strip & 20 & 594,441 & 60.3 & 12.8 & 15.3 & 10.2 \\
\hline \multicolumn{7}{|l|}{ South Shore } \\
\hline Lake Tahoe & 5 & 137,283 & 69.0 & 4.0 & 15.0 & 11.5 \\
\hline Reno/Sparks & 17 & 178,429 & 70.3 & 10.6 & 14.0 & 10.6 \\
\hline Elko & 5 & 14,903 & 60.4 & 11.5 & 18.7 & 11.5 \\
\hline Location & $\begin{array}{l}\text { Expenses } \\
\text { (OOO's) }\end{array}$ & $\begin{array}{c}\text { Salaries } \\
\& \text { Wages } \\
\text { as \% of } \\
\text { Gross } \\
\text { Revenues }\end{array}$ & $\begin{array}{l}\text { Bad Debt } \\
\text { as \% of } \\
\text { Gaming } \\
\text { Revenues }\end{array}$ & $\begin{array}{c}\text { Complemen- } \\
\text { taries } \\
\text { es \% of } \\
\text { Gaming } \\
\text { Revenues }\end{array}$ & $\begin{array}{c}\text { Gaming } \\
\text { Taxes } \\
\text { as \% of } \\
\text { Gaming } \\
\text { Revenues }\end{array}$ & $\begin{array}{c}\text { Net Opera- } \\
\text { ting Income } \\
\text { as \% of } \\
\text { Gross } \\
\text { Revenues }\end{array}$ \\
\hline \multicolumn{7}{|l|}{ Las Vegas } \\
\hline Downtown & $\$ 124,700$ & 33.1 & 0.4 & 12.1 & 8.9 & 16.9 \\
\hline \multicolumn{7}{|l|}{ Las Vegas } \\
\hline Strip & 492,790 & 27.4 & 3.8 & 21.9 & 6.4 & 9.6 \\
\hline \multicolumn{7}{|l|}{ South Shore, } \\
\hline Lake Tahoe & 106,120 & 30.2 & 1.0 & 13.0 & 7.6 & 13.5 \\
\hline Reno/Sparks & 142,590 & 34.6 & 0.6 & 12.1 & 8.2 & 11.4 \\
\hline Elko & 10,820 & 30.2 & 1.1 & 8.5 & 8.8 & 13.7 \\
\hline
\end{tabular}

Source: Nevada Gaming Abstract, 1973 Supplement

*Group 1 casinos include those licensees with an annual gross revenue of 1,000,000 dollars or more.

tween 80,000 dollars and 140,000 dollars elsewhere in Nevada (Nevada Gaming Abstract, 1973 Supplement) . About two thirds of all casino winnings come from those two games on the Strip, compared to approximately 40 percent elsewhere in the state.

On the other hand, slot machines in the Strip casinos were no more productive in terms of gross win than were slots in other resort areas. Keno, which is the casino equivalent to a lottery, earned substantially less per game than in any of the other major resort areas (see Table 8-III). Only about 20 percent of gross gam- 
ing revenues were generated by keno and slot machines on the Strip in 1973, compared to over 50 percent for each of the other resort regions.

TABLE 8-II

NUMBER OF GAMES AND DEVICES

Group 1 Casinos

Summer, 1972

\begin{tabular}{|c|c|c|c|c|c|c|c|c|c|}
\hline Lontion & $22 I '$ & Craps & $\begin{array}{l}\text { Rou- } \\
\text { lette }\end{array}$ & 5c Slots & rocSlots & $25 \mathrm{c}$ Slots & $50 \mathrm{e}$ Slots & $\$ 1$ Slots & Keno \\
\hline \multicolumn{10}{|l|}{ Las Vegas } \\
\hline Downtown & 209 & 50 & 23 & \multicolumn{2}{|c|}{5144588} & 819 & 56 & 59 & 11 \\
\hline Las Vegas & & & & & & & & & \\
\hline Strip & 373 & 108 & 37 & 5453 & 903 & 1331 & 72 & 132 & 17 \\
\hline $\begin{array}{l}\text { South Shore, } \\
\text { Lake Tahoe }\end{array}$ & 192 & 29 & 14 & 2537 & 882 & 828 & 124 & 106 & 8 \\
\hline Elko & 32 & 5 & 3 & 629 & 85 & 89 & 11 & 14 & 4 \\
\hline Reno/Sparks & 298 & 48 & 25 & 4898 & 1320 & 1100 & 189 & 243 & 22 \\
\hline
\end{tabular}

Source: Nevada Gaming Abstract, 1973 Supplement

TABLE 8-III

MEDIAN WIN PER UNIT

Group 1 Casino

Games and Devices

Summer, 1972

\begin{tabular}{|c|c|c|c|c|c|c|c|c|c|}
\hline Location & $22 I$ & Craps & $\begin{array}{l}\text { Row- } \\
\text { lette }\end{array}$ & $\begin{array}{c}5 c \\
\text { Slots }\end{array}$ & $\begin{array}{l}l O c \\
\text { Slots }\end{array}$ & $\begin{array}{c}25 c \\
\text { Slots }\end{array}$ & $\begin{array}{l}500 \\
\text { Slots }\end{array}$ & $\begin{array}{c}\$ 1 \\
\text { Slots }\end{array}$ & Keno \\
\hline \multicolumn{10}{|l|}{ Las Vegas } \\
\hline Downtown & $\$ 28,050$ & $\$ 110,700$ & $\$ 29,900$ & $\$ 2090$ & $\$ 2060$ & $\$ 3290$ & $\$ 2740$ & $\$ 4000$ & $\$ 285,200$ \\
\hline \multicolumn{10}{|l|}{ Las Vegas } \\
\hline Strip & 61,100 & 264,400 & 77,800 & 1980 & 2070 & 3520 & 3090 & 4330 & 195,600 \\
\hline \multicolumn{10}{|l|}{ South Shore } \\
\hline Lake Tahoe & 46,400 & 100,600 & 49,550 & 2200 & 2570 & 4220 & 5870 & 5880 & 310,400 \\
\hline Reno/Sparks & 27,100 & 53,100 & 25,800 & 1620 & 2060 & 3400 & 5090 & 4300 & 279,600 \\
\hline Elko & 23,100 & 82,600 & 6,800 & 1500 & 1990 & 3130 & 1820 & 5800 & 34,400 \\
\hline
\end{tabular}

These differences in gambling behavior could probably best be explained in terms of the socioeconomic characteristics of Nevada's gamblers. (See Eadington, 1973, for a detailed discussion of the various social and economic motives for casino games.) Craps is a game which has historically attracted males, allows for active and even aggressive participation, and is the source of the term "high 
TABLE B-IV

PERCENTAGE OF TOTAL GAMING REVENUE

Group 1 Casino

Games and Devices

Summer, 1972

\begin{tabular}{|c|c|c|c|c|c|c|c|c|c|}
\hline Location & $22 I^{\prime}$ & Craps & $\begin{array}{l}\text { Row- } \\
\text { lefte }\end{array}$ & $\begin{array}{r}5 e \\
\text { Slots }\end{array}$ & $\begin{array}{r}\text { los } \\
\text { Slots }\end{array}$ & $\begin{array}{r}25 \mathrm{e} \\
\text { Slots }\end{array}$ & $\begin{array}{c}50 c \\
\text { Slots }\end{array}$ & $\begin{array}{c}\$ 1 \\
\text { Slots }\end{array}$ & Keno \\
\hline \multicolumn{10}{|l|}{ Las vegas } \\
\hline Downtown & $19.8 \%$ & $18.9 \%$ & $2.5 \%$ & $23.5 \%$ & $3.8 \%$ & $8.7 \%$ & $0.6 \%$ & $0.7 \%$ & $8.9 \%$ \\
\hline \multicolumn{10}{|l|}{ Las Vegas } \\
\hline Strip & 27.4 & 36.7 & 3.7 & 10.1 & 1.9 & 4.7 & 0.2 & 0.7 & 3.5 \\
\hline \multicolumn{10}{|l|}{ South Shore } \\
\hline Lake Tahoe & 28.6 & 13.0 & 2.6 & 17.2 & 7.8 & 10.3 & 2.8 & 4.8 & 9.3 \\
\hline Reno/Sparks & 26.3 & 11.0 & 2.0 & 20.5 & 6.8 & 10.0 & 2.6 & 5.0 & 13.3 \\
\hline Elko & 27.7 & 14.8 & 1.2 & 31.2 & 4.9 & 10.1 & 0.7 & 3.0 & 5.2 \\
\hline
\end{tabular}

roller" for a big-money gambler. Blackjack, or ' 21 ', allows for individual choice and decision-making which can influence the outcomes of particular wagers, can be played with varying degrees of skill and offers head-to-head contact with a casino dealer. Both of these games offer even-money wagers as the standard bets and allow fairly high maximum wagers. For a big-money gambler, both can be made more attractive by adjusting both the minimum and maximum wager limits upward. For example, it is not uncommon to find tables with minimum bet requirements of twenty-five or even one hundred dollars in some of the Strip casinos during busy periods. Therefore, though still popular elsewhere in Nevada, craps and blackjack are by far most productive for their operators on the Las Vegas Strip, and the most attractive to the Strip's customers.

Slot machines and keno have considerably more appeal for gambling novices and "low rollers" than other available games. This is due to the ease of participation and the low minimum wager requirement. Slots can be played for as little as a nickel a pull (some penny slots can be found throughout the state), and return 80 percent to 95 percent of the total money wagered. Because of their ease in playing, and the anonymity they provide in gambling, slot machines are very popular with novice gamblers 
and women." Also, they usually offer jackpots which can return 20 to 1000 times the amount of the original wager which creates somewhat of a lottery aura about slot machines.

Keno games, which can return 25,000 dollars on a seventy-cent wager, are also very popular because of the lottery aspect of the game. Participation in keno is comparatively passive, and the game moves slowly, being played once every five or ten minutes. The casino keeps about 25 percent of the total amount wagered, making keno probably the worst major game to the player in terms of expected return. However, the high potential payoff to wager size ratio makes the game attractive in spite of the adverse odds.

In summary, keno and slots are more likely to be popular with gamblers who are novices, prefer to wager small rather than large amounts, or who are hoping for a large payoff with a fairly low downside risk. Such gamblers are more likely to be from lower and middle income groups than their opposites. The Las Vegas Strip tries to attract a more sophisticated and more affluent gambler; consequently keno and slots take on a less important role for Strip gambling than elsewhere.

The second largest gaming area in Nevada in terms of gross revenues is the Reno-Sparks area in northern Nevada. In 1970, Reno-Sparks had approximately 10,000 hotel and motel rooms, less than 30 percent of which were associated with hotel/casino complexes. As opposed to the Las Vegas Strip there are only two major showrooms in the area, one in Reno and one in Sparks. Most of the visitors to Reno arrive by automobile, and the great proportion of the visitors are from California and other Western states.*In general, Reno/Sparks caters to an older, less affluent and "One study on horse race gambling argued that women tend to bet "show" (thirdplace) more often than men because the wager offers frequent, though small rewards, and that these rewards are viewed as "frequent sparks against a background of dreariness." This rationale would also apply to woman slot players. (Herman, 1967.)

*For some dated estimates of the breakdown of Nevada visitors by place of origin, see Nevada Highway Department, 1963. Also, many Reno/Sparks area casinos import customers by offering special bus packages from urban areas in Northern California. Typically, these bus tours offer below-cost transportation and complimentary drink tokens and remain in the Reno area less than one day. The gaming revenues generated more than make up for the costs involved in financing the busses. 
less sophisticated visitor than does the Strip. This is reflected in the lower level of credit-play (bad debt to gaming revenue ratio of $0.6 \%$ vs. $3.8 \%$ for the Strip) and complimentaries (12.1\% of gaming revenues vs. $21.9 \%$ for the Strip). It also is demonstrated by the general appearance of the casinos in Reno/Sparks which tend to be crowded, functional and occasionally run down as opposed to the elegant, often gaudy decor of Strip casinos.

The best indicators of the differences between Reno and Las Vegas Strip gamblers are in the gaming revenues themselves. During the summer quarter, crap tables in Reno earn, on the average, about 20 percent of what Las Vegas Strip crap tables earn, and blackjack tables earn less than half of what a Strip blackjack table wins from the customers. (In the remaining three quarters the spread increases even more as Las Vegas is marked by relatively mild winters, Reno by fairly hard winters and occasionally impassible highways.) With regard to slot machines, both regions earn about the same per machine in dollars won, but a much larger percentage of Reno's gross win comes from slots than for the Strip (46.2\% vs. $18.6 \%$ in fiscal 1973) (Nevada Gaming Abstract, 1973 Supplement). Finally, keno games in Reno-Sparks earn more in terms of dollars per game than on the Strip ( $\$ 702,000$ vs. $\$ 686,000$ in fiscal 1973) .

The remaining major resort areas, downtown Las Vegas and South Shore, Lake Tahoe, are much more similar in characteristics and the type of gambler attracted to Reno/Sparks than they are to the Las Vegas Strip. In general, the South Shore casino games are more productive during peak tourist season than either Reno or downtown (see Table 8-III) . This could be due, however, to the present excess demand for casino facilities at Lake Tahoe. The past few years have been marked by legal battles between developers wanting to build more hotel/casinos at Lake Tahoe and the Tahoe Regional Planning Agency and environmentalists trying to prevent environmental deterioration at the Lake from too many tourists and too many tourist facilities. The South Shore has only five Group 1 casinos, three of which now have hotels and two of which have major showrooms. This compares to fifteen and seventeen Group 1 casinos in downtown Las Vegas and Reno respectively in 1974. All three areas cater mainly to drive-in visitors, support 
proportionately larger motel industries (as compared to hotel/ casino complexes) than does the Strip, and most of their visitors are from California or other Western states. As with Reno-Sparks, the gaming winnings from craps and blackjack are low relative to the Strip, and winnings from slots and keno are high relative to the Strip.

\section{EMPIRICAL ANALYSIS}

Using a production function approach, regression techniques were used to estimate the following equation and variations on it:

$$
\text { (5) } G=A_{0} N^{19} Q^{2} \frac{C^{3}}{C^{3}} R^{3} K^{2} E^{7} e^{r T} v
$$

where $\mathrm{G}=$ gross gaming revenues

$\mathrm{N}=$ number of nickel slot machines

$\mathrm{Q}=$ number of quarter slot machines

$\mathrm{C}=$ number of crap games

$\mathrm{R}=$ number of roulette games

$\mathrm{B}=$ number of blackjack games

$\mathrm{K}=$ number of keno games

$\mathrm{E}=$ number of casino/hotel employees

$\mathrm{T}=$ time $(1971=1,1972=2,1973=3)$

$\mathrm{u}=$ random variable

$A_{4} a_{1} \cdots a_{7}, r$ equal parameters to be estimated

This is the Cobb-Douglas form of the production function (Walters, 1970 ).

Use of the Cobb-Douglas production function involves a number of limiting assumptions which are implicit to the function's structure; these assumptions may or may not be valid in any particular application. First, the rate of substitution between any two inputs is proportional to the ratio of the amounts of the inputs. For example, if one hundred nickel slots were necessary to generate revenues lost by the removal of one crap table when the casino had ten crap tables and two hundred slots to begin with, then if there were twenty crap tables and one hundred nickel slots ( 1 to 5 ratio instead of 1 to 20 ), the rate of substitution would be twenty-five slots (instead of 100) necessary to generate revenues to 
compensate the loss of one crap table." Secondly, in the CobbDouglas format, the parameters $a_{12}{ }^{\prime}, '$, acan be interpreted as the percentage response of output to a 1 percent change in that particular input; this is referred to as output elasticity of an input. If, for example, $a_{1}=.5$, then a 10 percent increase in nickel slot machines would increase gaming revenues by 5 percent on the average. Since the parameters are assumed constant, the output elasticity for a particular input is constant regardless of the input mix. Finally, a Cobb-Douglas production function assumes that returns to scale are the same regardless of the output level, and these could be increasing, constant or decreasing returns, depending on whether $a_{1}+a_{2}+* * *+a_{7}$ is greater than one, equal to one or less than one respectively.

The coefficient $r$ measures the rate of growth in output from one period to the next which is not attributable to changes in inputs. For a gaming establishment, a positive $r$ might imply more intensive use of games and devices by customers, an increase in gross win due to, say, higher average wager sizes or some combination of the txvo. For example, if $r=.07$, then gross gaming revenues would have increased by 7 percent from one period to the next on the average with no change in the level of inputs; given expansion in some or all inputs, the actual increase in gaming revenues would exceed 7 percent.

Besides estimating gross gaming revenues, the total win per game or device was also estimated using the same general format as equation number 5 . The interpretation of the exponents $a_{1 a} \cdots " a_{i}$ is similar to the previous model where $a_{1}$ measures the percentage change in winnings at the game under question induced by a 1 percent change in the ith input. This information can be used to determine whether two games are complementary to one another (e.g. an increase in the volume of one increases the gross win for the other) or competitive (e. g. an increase in the volume of one game reduces the gross win for the other). If the parameter $a_{1}$ is

*To derive the rate of substitution for any two variable inputs, take the partial derivatives of the production function with respect to each input, and compute their ratio as in equation number 3 . For inputs $X$. and $X$. with exponents $I_{\text {a }}$ and $a_{i}$ this yields a result of: rate of substitution $X_{1}$ for $X .=a$. 
positive for the $\mathrm{jth}$ game, then game $\mathrm{i}$ complements game $\mathrm{j}$; if $a_{\mathrm{i}}$ is negative, the ith game competes with game $j$. The coefficient $r$ has the same interpretation as above except that it now applies to gross win for a particular game.

The data used in this analysis was drawn from Nevada Gaming Control Board files for the summer quarters of 1971, 1972 and 1973." Altogether, seven resort areas in the state were examined, generating a total of twenty-one observations. The resort areas are: Las Vegas Strip, Las Vegas downtown, Reno, South Shore of Lake Tahoe, Sparks, North Shore of Lake Tahoe, and Elko. This generated a very broad spread in the values of the variables, ranging, for example, from 2.9 million dollars in gross gaming revenues to 99.1 million dollars for the summer of 1973. Winnings of the games of craps, roulette, "21", five-cent slots, twenty-five cent slots and keno were the only winnings included; they make up 90 percent or more of gross win for all the regions examined.

The equations were estimated by using linear regression on the logarithms of the equations. This is one of the main advantages of using the Cobb-Douglas format. The results are presented in Table8-V.

Because of high multicolinearity among the inputs (simple correlations from 0.75 to 0.99 ), individual estimates of parameters are not too reliable; however the overall fits are good (high $\mathbf{R}^{2}$ values). In the first equation, the estimates of the parameters of twenty-five-cent slots, craps, blackjack and employment are significantly different from zero, but some results are unusual. The negative coefficient for blackjack seems to imply an increase in the number of blackjack games will reduce overall winnings, other variables held constant. One possible explanation for this result is the differences in the resort areas examined; proportionately fewer blackjack tables are found on the Strip than in other resort areas in the state, but win per table game is much higher on the Strip than elsewhere. As a result, in going from the Strip to elsewhere,

\footnotetext{
"Summer quarters were used because during this period most of the resort areas are running at or near capacity. In the other three quarters resort areas in northern Nevada have considerable seasonal decline in gaming activity where Las Vegas activity remains relatively stable.
} 
TABLE 8-V

SUMMARY OF REGRESSION RESULTS

\begin{tabular}{|c|c|c|c|c|c|c|c|c|c|}
\hline $\begin{array}{l}\text { Dependent /Independent: } \\
\text { Variable/Variables }\end{array}$ & 5c Slots & $25 \mathrm{e}$ Slots & Craps & Roulette & Blackjack & Keno & $\begin{array}{l}\text { Employ- } \\
\text { ment }\end{array}$ & Time & $R$ \\
\hline Gross Gaming & -.518 & 1.022 & .662 & -.090 & -884 & .185 & .478 & .071 & .9915 \\
\hline Revenues & $(-1.57)$ & $(6.29)^{* *}$ & $(4.12)^{* *}$ & $(-.39)$ & $(-2.87)^{\bullet}$ & (1.29) & $(3.57)^{00}$ & $(1.95)$ & \\
\hline $5 \mathrm{c}$ Slot & .752 & .742 & .408 & -284 & -.924 & .210 & .171 & $-00 s$ & .9651 \\
\hline winnings & $(2.25)^{*}$ & $(2.77)^{\star}$ & $(1.54)$ & $(-.68)$ & $(-1.95)$ & $(.89)$ & $(.73)$ & $(-.05)$ & \\
\hline 25c Slot & -.124 & 1.379 & .083 & -.292 & -.527 & .194 & .183 & .006 & .9872 \\
\hline winnings & $(-.56)$ & $(7.81)^{* *}$ & $(.48)$ & $(-1.07)$ & $(-1.05)$ & $(1.25)$ & $(1.19)$ & (.14) & \\
\hline Craps & -1.071 & .669 & 1.508 & .701 & -1.137 & -.599 & .606 & .170 & .9837 \\
\hline winnings & $(-3.05)^{*}$ & $(2.58)^{*}$ & $(5.41)^{\cdots *}$ & $(1.61)$ & $(-2.28)^{*}$ & $(-1.61)$ & $(2.46)^{*}$ & $(2.68)^{*}$ & \\
\hline Roulette & -.697 & 1.378 & .697 & .325 & -456 & -524 & .422 & .005 & .9816 \\
\hline winnings & $(-1.80)$ & $(4.42)^{* *}$ & $(2.26)^{*}$ & $(.67)$ & $(-.83)$ & $(-1.91)$ & $(1.55)$ & $(.06)$ & \\
\hline "gI' & -1.296 & 1.178 & .659 & .197 & -.594 & .275 & .356 & .121 & .9939 \\
\hline winnings & $(-6.95)^{* *}$ & $(8.52)^{* *}$ & $(4.70)^{* *}$ & $(.90)$ & $(-1.57)$ & $(2.21)^{*}$ & $(2.88)^{*}$ & $(5.80)^{* 0}$ & \\
\hline Keno & 1.123 & 1.421 & -200 & -1.395 & .367 & .169 & .129 & -.160 & .9829 \\
\hline winnings & $(4.09)^{* *}$ & $(6.45)^{* *}$ & $(-.93)$ & $(-4.68)^{*}$ & $(.942)$ & $(.872)$ & (.669) & $(-3.24)^{* *}$ & \\
\hline
\end{tabular}

Degrees of freedom $=12$

$\mathrm{t}=$ values in parentheses

Significant at the $5 \%$ level

Significant at the $1 \%$ level $*$ 
proportionately more blackjack tables would seem to bring about proportionately lower winnings. In order to get around this problem, dummy variables for some of the regions were tried (see Table 8-VI below). A similar problem may have arisen with the estimate for the twenty-five-cent slot parameter; its value is too high to be reasonable in the usual interpretation.

With respect to the relations between games, the following patterns emerge. Slot machines and keno tend to be complementary to one another, but competitive with the table games; the main exception is with twenty-five-cent slots and table games which tend to be complementary. The coefficient for time (r) is positive and significant for craps and blackjack, indicating more intensive play and larger average wagers at these games over the three years examined. Keno on the other hand showed a decline of about 16 percent per year, holding other variables constant. This could reflect less intensive play per keno game or a relative overexpansion in the number of keno games for the period in question.

Because of some of the unusual results, dummy shift variables were introduced into the production function and the following equation was estimated.

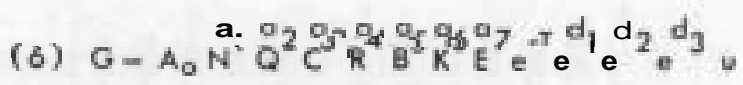

where all variables are defined as before and

$\mathrm{d}_{1}=(1$ if Las Vegas downtown or Reno

( 0 otherwise

$\mathrm{d}_{2}=(1$ of Las Vegas Strip

(0 otherwise

$\mathrm{d}_{3}=(1$ if South Shore Lake Tahoe

( 0 otherwise

The regression results are in Table 8-VI.

In general, most of the unusual results have been reduced in magnitude and significance though their signs did not change. The lack of significance for most of the estimates probably reflects the high multicolinearity among the input variables. The significance of the dummy variables for the gross gaming revenue equation indicates that the location of casino operations affect winnings over and above the difference attributable to different volumes and 
mixes of games. Further, these results indicate three distinct classifications for resort areas in the state: small-Elko, Sparks, Lake Tahoe North Shore; medium-Reno, downtown Las Vegas, Lake Tahoe Shore; and large-Las Vegas Strip. Going from small to large areas, winnings per game and winnings for a given casino size increase proportionately.

Finally, the evidence for returns to scale is inconclusive. In Table $8-\mathrm{V}$, the sum of the estimated output elasticities is 1.106 which is not significantly greater than 1.0, but would indicate increasing returns may be present as a resort area grows in size. There are two casual arguments which support this contention. First, it is likely that customers prefer to gamble in areas where they can choose among a number of games and a number of casinos; thus, if their luck is bad or if they feel cheated, they can move on to another game or casino. This argument is supported by the problems some isolated casinos, such as King's Castle at Lake Tahoe's North Shore, have had staying in business. Secondly, if diseconomies of scale for a resort area were to be realized, then the rate of growth of larger areas should slow down as they get larger. However, the Las Vegas Strip, which is easily the largest gaming area in the state, continues to grow at a more rapid rate than other areas and still seems to be improving in terms of profit potential. This would also indicate a strong positive spillover effect of the casinos in a resort area on one another.

\section{CONCLUSIONS}

The most important results of this study can be broken into three categories. First, there are two distinct groupings of games which tend to be complementary within each group but competitive from one group to another. Keno and slot machines are mutually complementary, but competitive with the major table games of craps and blackjack. This is consistent with the observation that the table games are far more profitable on the Las Vegas Strip than elsewhere in the state, where keno and slot machines are at a comparative and sometimes absolute disadvantage on the Strip as compared to elsewhere. It is also consistent with the claim that the Strip attracts a more affluent and sophisticated gambler and, relatively 
TABLE B-VI

SUMMARY OF REGRESSION RESULTS WITH REGIONAL DUMMY VARIABLES

\begin{tabular}{|c|c|c|c|c|c|c|}
\hline $\begin{array}{l}\text { Dependent /Independent } \\
\text { Variables/Variables }\end{array}$ & 5e Slots & 25e Slots & Craps & Roulette & $' 2 I '$ & Keno \\
\hline Gross Gaming & .093 & .829 & .218 &,- 122 & -.273 & -.052 \\
\hline Revenues & $(.265)$ & $(4.80)^{* *}$ & (1.73) & $(-.691)$ & $(-1.48)$ & $(-.232)$ \\
\hline $5 \mathrm{c}$ Slot & 1.367 & .030 & .039 & -542 & -.445 & -.058 \\
\hline winnings & $(3.35)^{* *}$ & $(.14)$ & $(.269)$ & $(-2.65)^{*}$ & $(-2.08)$ & $(-.24)$ \\
\hline 25c Slot & -0.09 & 1.038 & -.081 & -.372 & $-00 s$ & -032 \\
\hline winnings & $(.06)$ & $(5.91)^{* *}$ & $(-.63)$ & $(-2.08)$ & $(-.338)$ & $(-.23)$ \\
\hline Craps & .897 & .131 & .768 & .279 & -582 & -065 \\
\hline Winnings & (1.32) & $(.39)$ & $(3.18)^{*}$ & (.83) & $(-1.48)$ & $(-.24)$ \\
\hline Roulette & .736 & 1.25 & -.013 & .153 & .190 & -.518 \\
\hline winnings & $(1.44)$ & $(4.99)^{* m}$ & $(.07)$ & $(.60)$ & $(.71)$ & $(-1.60)$ \\
\hline "Zi" & -606 & .956 & .323 & .095 & -029 & .231 \\
\hline winnings & $(-1.40)^{* *}$ & $(4.13)^{* *}$ & (1.91) & $(.403)$ & $(-.12)$ & $(1.25)$ \\
\hline Keno & .234 & 2.01 & -006 & -1.24 & .297 & .024 \\
\hline winnings & $(.35)$ & $(5.10)^{* *}$ & $(-.23)$ & $(-5.09)^{*}$ & $(.71)$ & $(.08)$ \\
\hline
\end{tabular}

Degrees of freedom $=9$

Significant at the $5 \%$ level *

$\mathrm{t}$ - values in parentheses

Significant at the $1 \%$ level $* *$

speaking, discourages novices and lower income gamblers.

The second main finding relates to the question of economies of scale. As resort areas are ranked from smallest to largest in the state, gaming winnings tend to increase more than proportionately to the size of an area's total gaming operations. This indicates the existence of positive spillover effects of casinos on one another in a given location.

Finally, over the three summer quarters examined, the intensity of play for blackjack and craps increased at rates of 12 percent and 17 percent per year, respectively, for slots and roulette remained about the same, and for keno it declined by about 16 percent per year. This would indicate that expansion in the number of keno games from 1971 to 1973 was probably too fast, and that expansion of craps and blackjack games was probably too slow. Alternatively, the results for craps and blackjack clearly indicate the volume of wagering per game increased significantly over the three summers. 


\begin{tabular}{|c|c|c|c|c|c|}
\hline Employment & Time & $\begin{array}{c}\text { Las Vegas } \\
\text { Down Town } \\
\text { Dummy }\end{array}$ & $\begin{array}{l}\text { Las Vegas } \\
\text { Strip } \\
\text { Dummy }\end{array}$ & $\begin{array}{c}\text { South Shore } \\
\text { Lake Tahoe } \\
\text { Dummy }\end{array}$ & $\vec{R}^{2}$ \\
\hline-0.082 & .0767 & .725 & 1.465 & .659 & .9975 \\
\hline$(-.23)$ & $(2.81)^{*}$ & $(5.18)^{*}$ & $(5.12)^{\cdots}$ & $(3.86)^{* *}$ & \\
\hline-.171 & .057 & 1.60 & 2.35 & 1.66 & .9949 \\
\hline$(-1.23)$ & (1.83) & $(6.04)^{* *}$ & $(7.08)^{* *}$ & $(8.5 s)^{* *}$ & \\
\hline .016 & .0578 & 1.095 & 1.423 & .996 & .9967 \\
\hline$(.13)$ & $(2.11)$ & $(4.72)^{* *}$ & $(4.89)^{*}$ & $(5.72)^{\mathrm{*}}$ & \\
\hline-.091 & .053 & -573 & .795 & .183 & .9941 \\
\hline$(-.395)$ & (1.03) & $(-1.30)$ & $(1.45)$ & $(.55)$ & \\
\hline-.32 & -.114 & -.755 & .445 & -299 & .9969 \\
\hline$(-1.88)$ & $(-2.92)^{*}$ & $(-2.89)^{*}$ & (1.07) & $(1.18)$ & \\
\hline .006 & .106 & .298 & .891 & .410 & .9958 \\
\hline (.03) & $(2.93)^{*}$ & $(.97)$ & $(2.32)^{*}$ & (1.79) & \\
\hline .167 & -.161 & -.854 & $-w^{2}$ & -.754 & .9857 \\
\hline (.61) & $(-2.61)^{*}$ & $(-.68)$ & $(-1.14)$ & $(-1.93)$ & \\
\hline
\end{tabular}

The results of this analysis have to be considered as preliminary, however. Even though the overall fits are good for the estimated equations, some of the results are inconsistent with orthodox economic theory. Also, the data suffer from overaggregation; better results could be generated from more disaggregated data, e.g. firms rather than resort areas, viewed over a longer period of time. Some other explanatory variables such as entertainment and compsshould be incorporated into the regression analysis.

Finally, the evidence seems to indicate structural differences in the generation of gaming revenues between the Las Vegas Strip and the rest of the state. Therefore, these should be examined separately rather than lumped together, but this will require considerably more detailed information than that used in this study.

\section{REFERENCES}

Eadington, William R.: The Economics of Gambling Behavior, Bureau of Business and Economic Research, University of Nevada, Reno, 1973. 
Herman, Robert: Gambling as work; a sociological study of the race track. In Hennan (Ed.): Gambling. New York, Harper and Row, 1967.

Las Vegas Convention Authority Marketing Bulletin. December 17, 1973, PP. 2, 3.

Nevada Highway Department: Out-of State Vinitor's Survey. 1963.

Nevada State Gaming Control Board: Nevada Gaming Abstract. Carson City, Nevada, 1972.

Nevada State Gaming Control Board: Nevada Gaming Abstrach Carson City, Nevada, 1973 Supplement.

Walters, A. A.: An Introduction to Econometrics. New York, W.W. Norton Co., 1970. 


\section{Chapter 9}

\section{THE BUSINESS OF BAMING-AN INSIDER'S VIEW}

\section{J. GEORGE DREWS}

\section{INTRODUCTION}

\section{$\mathrm{T}$}

HIS CHAPTER WILL DISCUSS the nature and complexity of the gaming business, and, from an insider's point of view, relate some of the elements that he feels are necessary to run a successful casino/hotel/entertainment complex. Although the focus will be on Harrah's simply because the writer knows it best, the elements discussed will be true, perhaps not in detail and with some important variations here and there, for other major casino complexes as well.

The writer will cover basic business philosophy and strategy, management organization, how Harrah's is managed, operations and casino controls, financial controls and financial reporting and, very briefly, the long-range planning process. The reader will be impressed with the complexity of the business, the management requirements and the controls. Many people, including astute financial analysts and bankers who have never been taken behind the casino floor, were astounded to find that the business is run with some very sophisticated business methods. They believed that the owner ran the business out of his hip pocket, spent a great deal of time in the counting room with his green eyeshade, and personally paid the employees each day in cash out of the day's winnings.

\section{NEVADA GAMBLING IN PERSPECTIVE}

Gambling is big business, and the writer believes it will become increasingly important with a worldwide trend toward 
legalized gambling in one form or another. The twenty-nine states in the United States which have legalized gambling in one form or another collect over 700 million dollars in tax revenue each year.

Contrary to popular opinion, Nevada is not the largest gambling state in the nation. In 1972, Nevada ranked fourth in revenue from legalized gambling. New York State tax and license revenues from legalized gaming, at 166 million dollars, were three times that of Nevada's 55 million dollars. By the way, New York gambling revenues dropped in 1972 while Nevada's again increased substantially as Nevada moved up to fourth place. If Florida's tax revenues from gambling do not grow substantially, Nevada is likely to be in third place by 1974 .

In spite of the high volume of wagering in the leading states such as New York, California and Florida, gaming is relatively unimportant on a per capita basis and as a relative contribution to the state budget. New York for instance, has a population of over 18 million, while Nevada is just over one-half million. Because of the vast population differential, the revenue requirements of New York State and its local governments are more than thirty-six times that of Nevada's. Although New York State is much larger than Nevada in gaming revenues, gaming is nine times as important percentagewise to the Nevada State budget as it is to that of New York. About 43 percent of the Nevada State budget is supported by gaming revenues. As you can see, it would take an enormous increase in gaming volume in the large states for gaming to ever become an important percent contribution to state and local government revenues.

The gaming industry, directly and indirectly, provides approximately one half of Nevada's employment. About one quarter of the state's employment is in the gaming industry, and an additional quarter is provided by the state's other basic industries. Harrah's provides just under 10 percent of Nevada's gaming revenues and is the major employer in the Reno/Tahoe area.

Casinos would be a particularly costly and difficult method of raising new major revenue sources for large states. As we have seen, lotteries, off-track betting and other forms of wagering have 
been, and probably will continue to be, the most efficient and least complex way for most states to raise important gaming revenues. Although the growth in Nevada gaming revenues has been outstanding, and has averaged a 15 percent per year compound growth for the last twenty-eight years, we have never had the control problems a large state would have were it to suddenly legalize casino gambling on a large scale. If legalization were done on a small scale, it would, of course, by definition be relatively unimportant to the state. Casinos are successful and practical to operate in Nevada because it is a small state, drawing as a tourist state on a large neighboring population base. It started small and has controlled and promoted this form of gambling (and entertainment) for well over forty years. Gaming grew with the state, and the state grew with gaming.

More than 93 percent of Harrah's customers come from the four western states and only 7 percent of our business is from Nevadans, and interestingly, only 0.6 percent comes from New York. This pattern is quite different from that of Las Vegas which has a much higher proportion of Eastern business.

\section{REQUIREMENTS TO SUCCEED}

Operating a casino is not automatically a license to make money as many think. It is true that a good operation can be very profitable, but a poor one can be a financial disaster, as many have found out. Many operators fail because of a poor conception of the business, poor location, inexperienced management or undercapitalization. Various strategies are successfully employed by different operators. Some casinos, including Harrah's, actively promote the business and take on the responsibility of bringing tourists to Nevada. Harrah's, for instance, spends 24 million dollars per year on various promotional activities such as entertainment, advertising, bus programs, complimentaries and drawings. Others do relatively little true promotion, but emphasize food or other attractions. Some cater primarily to local trade and have unique attractions for this segment of the business. Others, probably through fortunate early purchases of land, are located on very expensive land near the major casinos which actively pro- 
mote the area. Their strategy is to capitalize on the overflow of the major casinos. They do almost no promotion, have low overhead and no doubt are very profitable. They are and probably always will be relatively small, however.

The writer feels that the real attraction Nevada offers the tourist is a total environment, not just gambling per se. Both the natural scenic vacation attractions and the entertainment and other man-made attractions have created a geographically-separated fantasy world which provides relaxation, excitement and entertainment. At this point in Nevada's development, one cannot just rely on some neon signs and an open table to successfully enter this business. The cost of entry is high, and, for the integrated hotel/casino operation, it is a capital intensive business with a high breakeven point. Location is all important, and land in the prime location of downtown Reno runs between 3 million and 7 million dollars per acre. A major hotel/casino complex such as those found in Las Vegas may require twenty acres of land or more. Harrah's assets are now 100 million dollars at book value, and at replacement cost would be substantially above this. The bulk of the assets (over $\$ 70$ million) are in property and equipment. Inventories and receivables are very low compared to most businesses, and cash requirements are high with as much as 4.5 million dollars of operating cash required in Harrah's casinos during peak periods. Although cash flow can be high (ours is well over $\$ 10$ million per year), the business is often seasonal, and one must be able to meet major commitments such as year-round fixed charges, large quarterly tax payments, and in our case a 45 million-dollar payroll. Conventional financing is often difficult to obtain, with some of the major banks and virtually all major insurance companies being unwilling to lend money to a gaming company.

\section{SOME INDICATIONS OF THE COMPLEXITY OF HARRAH'S BUSINESS}

Harrah's volume is now in excess of 100 million dollars per year, and along with a number of other major hotel/casinos, it would be in the Fortune Second 500 if it were an industrial company. Our earnings rate is well over 8 million dollars and has 
grown at a compound rate of approximately 20 percent per year for the last twenty years.

The casino floor space covers approximately two acres and is packed with 3,400 slot machines and over 200 table games. The doors never close and it employs, trains, schedules and pays over 6,500 employees during the summer. Well over half of the employees are in activities unrelated to gaming.

Harrah's is in many businesses besides gaming. It operates two luxury hotels and serves an average of 17,000 meals per day in its eight restaurants. The food and beverage business, at 30 million dollars per year, is in itself big business. Harrah's transports 200,000 people a year, most of them on Greyhound, making Harrah's their second largest customer after the United States Army. Two million people have now visited Harrah's Automobile Collection, and the visitor rate is 300,000 visitors per year. The entertainment bill approaches 9 million dollars. That pays for two theater/restaurants, two cabarets and all the stars and supporting acts it takes to entertain over one million people a year.

In a sense Harrah's is also a bank since it cashes 10 million dollars in coins and currency in a single month. Just the problem of the physical and accounting control and the movement of this cash is an interesting challenge in itself. To some extent Harrah's is also a manufacturing company, since it restores antique cars, boats and planes, and practically builds all of its slot machines from the ground up.

It also operates a small air force with two jets and two propeller-driven aircraft, and owns and operates a hunting lodge in the wilderness area of Idaho for the benefit of its entertainers and good customers. To manage this complex business, it employs personnel in forty-two distinct specialty departments such as advertising, accounting, aviation, computer services, cleaning, construction, legal, entertainment, industrial relations, security, purchasing, wardrobe and even fashion.

\section{MANAGEMENT}

One may wonder how such a complex organization is managed. Most of the management has been with Harrah's for more than fifteen years, and has been promoted from within. However, 
the company recognized the need for specialized expertise and new thinking as it grew and brought some members of management in from the outside in fields such as finance, legal, hotel management, food and beverage management, personnel and fashion.

Harrah's has a college recruiting program and conducts intensive training classes for all levels of employees. Even courses in management development and finance are offered. Hiring emphasis in public contact positions is on appearance as well as capability, and an exceptional number of clean-cut young people will be found at Harrah's. Persons are promoted from within whenever possible. Harrah's is nonunion, and the way to advance at Harrah's is through merit, not seniority.

The management style could be characterized as highly centralized and detail-oriented. Management is oriented toward perfection in even the slightest detail, and the company emphasis is on quality, courtesy and friendliness and, of course, absolute honesty.

Because of the many specialized disciplines in the company, a committee structure is relied upon heavily. This is not to imply that decisions are made by committee, but committees do bring all information and points of view to bear on complex, interdepartment issues. Formal committees include executive committee, finance, personnel, construction, entertainment, retirement and advertising.

Communications and prompt decision-making are important in an organization which operates around the clock, seven days a week and never closes. Harrah's operates with a depth of four complete shifts in operations, and even most staff departments must maintain seven-day coverage. The top management (which has twenty-four-hour responsibility) meets each morning at 9:30 (including those who are in on weekends) for an informal coffee discussion to communicate any immediate problems or information. Weekly status reports are another method of keeping fully informed in an organization as large and widespread as this. Everyone on the organization chart, a group of about twentyseven, writes a weekly report of his activities which is reviewed by 
top management every Monday morning. Ultimately, all of the reports are routed to each of the group of twenty-seven so everyone is informed of the other's activities.

\section{CASINO CONTROLS}

There is a dramatic difference between a gaming company and other ventures. A key difference is that the gaming company's stock in trade is cash. Approximately 400 million dollars a year changes hands, and to police the situation, Harrah's has developed what are probably the best controls of any business. It is worth mentioning that the Nevada Gaming Commission adopted Harrah's internal control procedures virtually without change when they updated accounting regulations for the entire gaming industry a number of years ago.

The key control is visual observation supplemented by an entire range of reasonableness tests. Special training classes are held for dealers, and dealing and gaming have been highly procedurized. Observers behind one-way mirrors in the catwalks and two-way radios are employed to monitor adherence to procedure and prevent cheating or stealing. In many ways it is like a bank, supermarket or a department store in having to be constantly alert to these threats. The writer suspects, however, that their losses are far less than that of most stores due to the tight controls. Areas where cash moves are under constant television observation and multiple observation and multiple signatures are employed with each transfer of cash.

Counting rooms have one-way glass and are under constant observation. Management is not allowed to enter and has no access to cash, chips or money transfer prior to it being in the books of account. There are checkers and observers on all counts, and there is random checking of the cash counts by both internal and external auditors.

Cash on the games is maintained in locked drop boxes and this is counted for every eight-hour period. Knowing the fills and credits to each game thus makes it possible to know drop (or volume) and winnings by game and by shift. This data is cap- 
tured in the computer and is also used in a daily report. Cash from the slot machines is weighed, and an IBM card identifying the cash bag and slot machine number is inserted into the scale and records the weight of the coins which is converted to the dollar value. These cards are matched up in the computer with other cards which show jackpot payoffs for the same period; it is, therefore, possible to produce computerized volume, win and win percentage figures for each of the slot machines on a routine basis.

There is a system of daily reports each day by shift from all areas of operations. These reports, which run about fifteen pages and are written in an abbreviated style, include catwalk observation reports on players, dealers and the quality of employee service. Other reports show food counts, every customer complaint, hotel and entertainment comments, show counts, listings of complimentary services and dollars by person, large wins and losses, and the number and limits of games open. The gaming information, in particular, is correlated with other reports and data and becomes part of the reasonableness test.

\section{FINANCIAL CONTROLS}

Harrah's is a highly computerized operation with its own 370/145 Computer which is in use twenty-four hours a day, but, before getting into that, an interesting set of reports which are prepared by hand should be described, namely a daily profit and loss statement. A summary and detailed profit and loss on each gaming area, restaurant, bar and hotel for each shift is prepared for each day, and is available to management by 11:00 A.M. of the following morning. A large cash audit staffis employed in the controller's department to reconcile all cash receipts within twelve hours after the end of a shift. This makes it possible to base the profit and loss volumes on actual daily volume or cash receipts. Wage data which is accurately available each week and estimated for the current week is combined with the departmental volume and winnings or gross margin figures. A good companywide estimate of overhead and general and administrative expenses is also included; this results in a summary profit 
and loss statement for the company. Month-to-date comparisons with the prior year and budget are also provided. With this data and the appropriate wage and winning percentage comparison, and when correlated with the large wins and losses from the daily reports, management is in a position to spot out-of-line conditions and take prompt corrective action where indicated.

As mentioned before, Harrah's is a highly computerized operation. The payroll, accounting, general ledger, receivables, credit, management reporting and even records of the hold and payouts on each slot machine are on the computer. It is presently in the process of using a 370 computer in a time share or on-line mode, and will have approximately 500,000 credit customers on file for almost instant credit verification. Harrah's also has central showroom reservations for Reno and Tahoe on-line. With a system 7 minicomputer and local terminals supplementing the big computer, it will have slot jackpot payouts on-line. This on-line slot machine verification system will not only pay for itself in labor savings, but will further improve controls by instantaneously spotting discrepancies.

Harrah's payroll system is its major computer application simply because of sheer size. This system, which is continuously being refined, pays up to 6,500 employees who are on very flexible and continuously changing schedules. It pays up to three different rates per employee for three shifts every single day of the year. It is now on-line with remote payroll input and readout terminals at prior year, versus possibly at some future date, a target wage ratio for all operating departments. The objective, of course, is to better control and improve the efficiency of the 45 million-dollar payroll which is by far the most important single expense.

In the computerized monthly management report are 190 different profit and loss and cost centers. Each restaurant, for instance, is a profit center. Each cost and profit center automatically sums to the next higher management level and provides a summary for the food manager of Reno, and another for the food and beverage manager of Harrah's, and so on to the top level of the company. Subsidiary corporations such as Harrah 
Realty, Harrah South Shore Corporation, etc., are automatically consolidated by coding appropriate intercompany expense and income items to eliminate each other. The detailed departmental reports for the entire company behind this summary are two and one-half inches thick, and the computer is programmed to give each manager an individual package for his own area of responsibility. This report is available seven or eight calendar days after the end of the month. Three sets of data are compared here. In the center columns are actuals for the month, and the appropriate gross margin, hold and expense ratios are computed. The lefthand set of columns show prior year data, the dollars the actuals have changed, the percentage point of change (i.e. an $8.01 \%$ increase in volume and a $17.85 \%$ increase in net income). Similar budget comparisons are also made in the right-hand set of columns. An identical set of schedules is also prepared for the month itself, as opposed to the year-to-date schedules.

In addition to the computer schedules, by the tenth of each month a management financial white book is prepared. This goes to the finance committee, the board of directors and our internal and outside auditors. It starts with a written financial review or analysis of performance. Following are month and year-to-date profit and loss statements down to earnings per share for the month and year-to-date. The profit and loss statement is then broken into successively finer detail by location and function, such as casino, food and beverage detail. Expense detail is also shown and summarized, and appropriate relationships with prior year and volume are made. A balance sheet, footnotes and funds flow or change in financial position statements are also presented. This monthly book is, therefore, a complete and permanent record of the financial performance and statistics.

Perhaps the most important part of the financial picture (and this is no doubt true of many other major casinos also) is not merely the availability and timeliness of the reporting, but management's attitude toward and use of the data. Management makes active and immediate use of this data whenever indicated. Deviations in trends, changes from budget, out-of-line expenses, changes in gross margins and hold percentages all must be ex- 
plained in detail by the responsible manager, and prompt remedial action is expected where indicated.

\section{LONG-RANGE PLANNING}

A major objective of most companies, as in this one, is to grow at a healthy rate. Harrah's has ambitious expansion plans. It has a good market and an extremely high occupancy rate which confirms the demand for additional facilities. It is felt that the major growth rate limitation, if any, is not the market, but the availability of cash or financing for expansion.

To determine the rate at which it can invest and absorb additional debt, Harrah's has developed computer models of the company which gives income statements, balance sheet and cash flow projections through 1978. (Harrah's also does a daily cash projection 30 days out so excess cash can be invested for even a few days.) These projections, which are done at three levels (i.e. most likely, optimistic and pessimistic), indicate the probable range in internal cash flow from the existing business and the additional capacity for debt at any point in time. Knowing the range of theoretically available internal and debt cash by time period, it then, after allowing for a reasonable safety factor, superimposes the desired expansion expenditures in a time frame which reasonably coincides with available funds. It is expected that it will be possible to invest an average of at least 15 million dollars per year in facility expansions.

The writer hopes this has provided some perspective of casino operations as a business, and, to some extent, illustrates the capital requirements and the diverse and highly specialized management skills required. 


\title{
Chapter III
}

\section{PHIFITABILITY AND BEHAVIOH OF THE GAMING INIISSTHY BELATIVE TO THE STOCK MARKET}

\author{
JAMES J. NOEL AND STUART E. CURTIS
}

\begin{abstract}
B Y LAW, THE GAMING INDUSTRY in Nevada is a privileged in$B$ dustry. The privilege of gambling is first given to the people of Nevada by the state legislature; it can be, and in fact has on two occasions been revoked by the legislature.

Prior to Nevada's statehood in 1864, the section of the Utah Territory which later became Nevada had already adopted gaming as a way of life. In $186 \mathrm{I}$, while still a territory, the first prohibition of all forms of gaming was made law; however, the Nevada Legislature, in 1869, legalized it over Governor Blasdel's veto.
\end{abstract}

Effective October 1, 1910, gaming in all forms was again prohibited by law although, on Governor Oddie's recommendation, the 1915 legislature somewhat relaxed this prohibition.

The second level of privilege is in the issuance of a gaming license. By regulations a gaming license is ... "a revocable privilege and no person holding such a license is deemed to have acquired any vested rights therein." Over the years many licenses have been revoked for various infractions of the law.

\section{MODERN HISTORY}

Nevada began its modern era of legalized gambling in 1931 when Governor Balzar signed the state assembly's so-called wide open gambling bill. Through the mining camp days, and on into the early part of this century, Reno, Las Vegas and the outlying counties for the most part catered to the local gamblers, and 
there was no concerted effort to lure the big time gamblers from outside the state.

Las Vegas, prior to World War II, was little more than a water-stop on the Union Pacific Railroad, and even in 1940, Clark County (of which Las Vegas is the county seat) accounted for less than 15 percent of the state's population. By 1970, Clark had 56 percent of the state's population, and by 1973 they had 66 percent of the gaming. Today, due largely to the advent of corporate gaming, Las Vegas is a metropolitan area of over 300,000 which caters to more than 17 million visitors a year.

Washoe County, which in earlier times was the big county as far as population and gaming were concerned, has continued to grow at a much slower rate than Clark, and now accounts for less than 19 percent of the state's gaming.

Douglas County, the third major gaming county in the state, grew from virtually nothing to just over 12 percent of the state's gaming in the twenty-three years from 1950 to 1973.

The other fourteen counties, the so-called cow counties, accounted for almost 54 percent of the gaming in 1940, but by 1973 had declined in importance to only 3 percent.

Statewide, the gaming industry has grown from 21.5 million dollars of gross gaming revenue during the fiscal year ending June 30, 1946, to 804.3 million dollars by fiscal year 1973, a 37fold increase in twenty-seven years. For the nine months ending March 31, 1974, gross gaming revenue was 667.8 million dollars, up 15 percent over the corresponding 1973 period. Assuming no major setbacks, the industry should gross 1 billion dollars by fiscal 1976.

The average rate of increase over the past ten years has been 12.4 percent per year. Over the last five years it has been nearly 15 percent per year.

\section{CORPORATE GAMING LAWS}

For many years, after the legalization of gaming in $193 I_{2}$ most of the business enterprises conducting gaming were organized as proprietorships and partnerships. This worked satisfactorily as long as the casinos remained fairly small. 
As some of them grew, though, and required larger investments, it became necessary to involve more investors. In some instances this was done by taking in more and more partners. One partnership (which ran what is now Caesars Palace) grew to approximately fifty partners, while several others had from twenty to thirty partners.

The corporate form, while not prohibited by the state, was certainly not encouraged. It was, in fact, discouraged by the simple expedient of requiring all stockholders as well as the corporation to be licensed. One exception to this policy was the Golden Nugget in Las Vegas which was grand-fathered in as a publicly held corporation when the gaming control act was passed in 1955.

This restriction did not deter all groups though, as several corporations were formed from time to time to operate a casino. Of course most of them had only a few stockholders. Even two or three publicly traded corporations managed to get into gaming. A limited number of officers or directors of the publicly traded corporation would form an independent Nevada corporation, or a partnership to conduct the gaming and operate the other facilities. In some cases these new corporations or partnerships purchased the land and buildings and acted as landlord to another newly formed entity which conducted the gaming.

The legislature in 1967 and 1969, with the goal of providing a broader base for investment in the industry, and in the hope of changing the image of gaming from the green felt jungle to the gray flannel suit, passed an act which permitted publicly traded corporations to be registered. Instead of requiring all stockholders to be licensed, now only major stockholders of publicly traded companies and all officers and directors of the corporation holding the gaming license (which must be a Nevada corporation) are licensed. A publicly held corporation acting as a parent, landlord or holding company of the gaming licensee is found suitable and registered as are its controlling stockholders, officers and directors who are involved in the activities of the gaming subsidiary.

The new bill maintains the important right to remove any 
stockholder of a publicly held corporation of his position as a stockholder if it is determined to be contrary to the best interests of Nevada.

\section{PUBLICLY HELD SECTOR OF THE GAMING INDUSTRY}

The publicly owned segment of Nevada's gaming industry is a significant portion of the whole. In the fiscal year ending June $30,1973_{2}$ fifteen publicly owned locations grossed 45.7 percent of the total gaming revenue in the state. Four more small locations which have not been included in our overall analysis together grossed another 1 percent of the total. From now on this point will be referred to the fifteen largest publicly held casinos only.

Five corporations, owning twelve locations between them, account for 37.1 percent of the total gaming revenue for fiscal 1973.

\begin{tabular}{|c|c|c|}
\hline RECRION & 2 LOCATIONS & $5.9 \% \mathrm{OF}$ \\
\hline DEL E. WVEBB & 4 & $8.5 \%=$ \\
\hline HILTON HOTELS & 2 & $7.8 \%=$ \\
\hline HARRAH'S & 2 & $8.6 \%=$ \\
\hline CAESAR'S WORLD & 2 & $6.3 \%=$ \\
\hline
\end{tabular}

The Thunderbird Hotel on the Las Vegas Strip, which was purchased by Caesars World from Del E. Webb during this fiscal year, is allocated between the two corporations (4 months to Del Webb and 8 months to Caesars World). The remaining three locations are owned by Continental Connector Corporation, Golden Nugget, Incorporated and Showboat, Incorporated; together they produce 9.1 percent of the total gaming revenue.

\section{FINANCIAL STATEMENTS}

Until the establishment by regulation in 1967 of the standard financial statements and a uniform chart of accounts, financial reporting to the State by the gaming licensees was spotty at best. These regulations required that, for years beginning on or after January 1, 1968, all Group I licensees (those casinos grossing over 1 million dollars annually from gaming) must file standard 
financial statements which have been audited by independent public accountants. Of course, a year or two was required to get this program running smoothly, and it was not until 1970 that sufficiently reliable data was assembled to conduct this study.

Fiscal years ending June 30 of 1970, 1971, 1972 and 1973 were chosen, and with the help of the State computer service, a composite balance sheet and income statement was created for each year.

\author{
COMPOSITE FINANCIAL STATEMENTS \\ OF CASINOS
}

CONTROLLED BY PUBLICLY TRADED CORPORATIONS

\begin{tabular}{lcccc}
\hline & \multicolumn{5}{c}{ Millions of Dollars } \\
& \multicolumn{3}{c}{ Fiscal Years Ended June 30} \\
& $\mathbf{1 9 7 0}$ & $\mathbf{1 9 7 1}$ & $\mathbf{1 9 7 2}$ & $\mathbf{1 9 7 3}$ \\
\hline BALANCE SHEET & & & & \\
Current Assets & $\$ 93.8$ & $\$ 99.1$ & $\$ 92.3$ & $\$ 106.4$ \\
Fixed Assets & 273.1 & 271.3 & 271.2 & 284.0 \\
Other Assets & 24.6 & 30.4 & 33.5 & 38.3 \\
\cline { 2 - 6 } Total Assets & $\mathrm{f391.5}$ & $\$ 400.8$ & $\$ 397.0$ & $\$ 428.7$ \\
Current Liabilities & $\$ 61.5$ & $\$ 63.5$ & $\$ 62.9$ & $\$ 71.0$ \\
Long-Term Liabilities & 171.3 & 171.8 & 157.7 & 144.7 \\
Other Liabilities & 4.9 & 8.1 & 10.7 & 12.2 \\
\cline { 2 - 6 } Total Liabilities & 237.7 & 243.4 & 231.3 & 277.9 \\
Total Capital (Net worth) & 153.8 & 157.4 & 165.7 & 200.8 \\
\cline { 2 - 6 } Total Liabilities \& Cap & $\$ 391.5$ & $\$ 400.8$ & $\$ 597.0$ & $\$ 428.7$ \\
\hline INCOME STATEMENT & & & & \\
Total Gross Revenue (Sales) & $\$ 418.8$ & $\$ 485.1$ & $\$ 515.9$ & $\$ 555.4$ \\
Gross Gaming Revenue & $\$ 270.7$ & $\$ 305.5$ & $\$ 325.8$ & $\$ 355.8$ \\
Net Operating Income & & & & \\
$\quad$ (Before Federal Income & & & & \\
Tax and Extraordinary & $\$ 55.4$ & $\$ 51.3$ & $\$ 58.2$ & $\$ 77.3$ \\
Items) & & & & \\
\hline
\end{tabular}

This composite shows that total assets have increased by 9.6 percent over the four-year period. The increase was not in equal steps however, nor did each class of assets grow at the same rate. Fixed assets after 1970 declined, slightly in 1971 and in 1972, which can be attributed to normal depreciation. Investments in fixed assets by Harrah's of 22.1 million dollars, and Showboat of 
5.2 million dollars and the removal of the Thunderbird Hotel from the list for 1973 made a net gain or 4.7 percent over 1972 for fixed assets. The increase in long-term debt covering these investments was more than offset by reductions of debt by other casinos and by the removal of Thunderbird,"

On the income statement, total gross revenue and gross gaming revenue have shown good growth each year-approximately 8 percent per year. Net operating income also has shown growth over the four years; however, 1971 dropped below the 1970 figure. The fiscal year 1973 increased nearly 33 percent over 1972 which must, in part at least, be attributed to the removal of the Thunderbird, which in recent years operated at a loss-the only casino in this publicly owned group to do so.

\section{RATIO ANALYSIS}

Prior to publishing the Nevada Gaming Abstract in November, 1972 by the Economic Research Division of the Gaming Control Board, no ratio analysis had been done on the gaming industry's financial statements, and since this abstract did not look at the publicly owned casinos as a group by themselves, there are no established standards to refer to and say this ratio is good or that ratio is bad.

The current ratio-current assets to current debts-has been quite stable at 1.5 to 1 . The net worth to total debt ratio indicates an improving capital position which is due, in part, to removing the Thunderbird Hotel. However in 1972 there was improvement even with Thunderbird included.

\section{BALANCE SHEET RATIOS}

\begin{tabular}{lcccc}
\hline & 1970 & 1971 & 1972 & 1973 \\
\hline Current Ratio & 1.5 to 1 & 1.6 to 1 & 1.5 to 1 & 1.5 to 1 \\
Net-worth To Total Debt & $64.7 \%$ & $64.7 \%$ & $71.6 \%$ & $88.1 \%$ \\
Net-worth To Current Debt & $249.9 \%$ & $248.0 \%$ & $263.4 \%$ & $282.9 \%$ \\
Net-worth To Fixed Assets & $56.3 \%$ & $58.0 \%$ & $61.1 \%$ & $70.7 \%$ \\
Working Capital To Total Assets & $8.2 \%$ & $8.9 \%$ & $7.4 \%$ & $8.3 \%$ \\
Current Debt To Total Debt & $25.9 \%$ & $26.1 \%$ & $40.2 \%$ & $81.1 \%$ \\
\hline
\end{tabular}

Thunderbird was removed for this one year because it was purchased during the year by Caesars World from Del Webb, and no full-year operating statements were available. 
Of the years analyzed, there has been fluctuation in expense items (recorded as a percentage of total gross revenue), and thus there is little which indicates any real trends.

INCOME STATEMENT RATIOS

\begin{tabular}{lcccc}
\hline & 1970 & 1971 & 1972 & 1973 \\
\hline $\begin{array}{l}\text { Total Gross Revenue } \\
\text { Selected Expenses As A Percent of }\end{array}$ & $100.0 \%$ & $100.0 \%$ & $100.0 \%$ & $100.0 \%$ \\
$\quad \begin{array}{l}\text { Total Gross Revenue: } \\
\quad \text { Bad Debts (including gaming) }\end{array}$ & $2.4 \%$ & $3.6 \%$ & $2.2 \%$ & $1.8 \%$ \\
$\quad$ Gaming Taxes & $\mathbf{4 . 7 \%}$ & $3.6 \%$ & $4.6 \%$ & $4.5 \%$ \\
$\quad \begin{array}{l}\text { Other Taxes } \\
\text { Advertising, Promotion and }\end{array}$ & $1-0 \%$ & $0.9 \%$ & $0.9 \%$ & $0.9 \%$ \\
$\quad \begin{array}{l}\text { Complimentaries } \\
\text { Salaries and Wages (excluding } \\
\text { officers and owners) }\end{array}$ & $13.2 \%$ & $12.3 \%$ & $10.9 \%$ & $13.4 \%$ \\
$\quad \begin{array}{l}\text { Net Before Federal Income Tax } \\
\text { and Extraordinary Items }\end{array}$ & $30.3 \%$ & $29.6 \%$ & $30.1 \%$ & $28.3 \%$ \\
\hline
\end{tabular}

Dun \& Bradstreet's key business ratios for corporations provides us with useful comparisons. For example, gaming's fouryear average for bad debts was 2.5 percent, which is more than ten times that of D \& B retailers. Only in the finance field-banks, trust companies, savings and loan companies and personal credit agencies-is the ratio of bad debts higher. Of the 185 lines of business listed by D \& B, nothing outside this one field even approaches gaming's average.

Another expense item, taxes (which for the gaming industry is 80 percent direct taxes on the gaming activity) is exceeded by less than 9 percent of D \& B's 185 businesses and not even approached by the large majority. The gaming average of 5.1 percent of gross revenue going to satisfy taxes is exceeded only by sixteen of D \& B's businesses with the malt liquor manufacturing industry being the leader with 23.1 percent of its gross revenue going to satisfy their tax bill. Gaming's four-year average, advertising, promotion and complimentaries expense (which includes free drinks, meals, rooms, etc.) is 12.3 percent of gross revenue. No industry listed by D \& B exceeds this ratio and only one, the soap and detergent manufacturers, approaches it with 10 
percent of their gross revenues spent on advertising.

Even after these higher-than-average expenses the casinos net, before federal income taxes and extraordinary items, an average of 12.3 percent on total revenues.

The interstatement ratios-those ratios tying the income statement to the balance sheet-in some instances reflect favorable trends, and in others a trend is difficult to discern.

INTERSTATEMENT RATIOS

\begin{tabular}{lrrrc}
\hline & 1970 & \multicolumn{1}{c}{1971} & \multicolumn{1}{c}{1972} & 1973 \\
\hline Total Gross Revenue to Fixed Assets & $153.4 \%$ & $178.8 \%$ & $190.5 \%$ & $195.6 \%$ \\
Total Gross Revenue to Net Worth & $272.4 \%$ & $308.1 \%$ & $311.3 \%$ & $276.6 \%$ \\
Total Gross Revenue To the Sum of & & & & \\
$\quad$ Long-Term Debt and Net Worth & $128.9 \%$ & $147.3 \%$ & $159.5 \%$ & $160.7 \%$ \\
Net Operating Income To Net Worth & $36.0 \%$ & $32.6 \%$ & $35.1 \%$ & $38.5 \%$ \\
Gross Gaming Revenue To Fixed Assets & $99.1 \%$ & $112.6 \%$ & $120.2 \%$ & $125.3 \%$ \\
Gross Gaming Revenue To Net Worth & $176.1 \%$ & $194.0 \%$ & $196.6 \%$ & $177.2 \%$ \\
\hline
\end{tabular}

The ratio total gross revenue to fixed assets indicates an improving utilization of fixed assets in producing total revenue. Also, gross gaming revenue to fixed assets reveals the same trend. Total gross revenue to the sum of long-term debt and net worth shows improved use of all capitalization while the ratios relating total gross gaming revenue and net operating income to net worth fluctuate with changes in long-term and current debt.

\section{Comparison with Other Casinos}

In order to compare the operation of our publicly held casinos with the closely held casinos, the top thirty casinos have been analyzed (based on gross gaming revenue). Of this top thirty, fifteen are publicly owned and fifteen are closely held corporations.

The two groups are reasonably comparable as to size and type of operation with all but one of the publicly owned group being a complete hotel/casino resort, and all but two of the closely held group being hotel/casinos. On the basis of gross gaming revenue, the top five casinos, and eight of the top ten casinos in the state are publicly owned. 
FINANCIAL STATEMENT RATIOS

Publicly controlled casinos compared with closely held casinos FISCAL YEAR 1973

\begin{tabular}{lcc}
\hline & $\begin{array}{c}\text { Publicly } \\
\text { Controlled } \\
\text { Casinos }\end{array}$ & $\begin{array}{c}\text { Closely } \\
\text { Held } \\
\text { Casinos }\end{array}$ \\
\hline BALANCE SHEET & & \\
Current Ratio & 1.5 to 1 & 2.0 to 1 \\
Net worth To Total Debt & $88.1 \%$ & $122.4 \%$ \\
Net worth To Current Debt & $282.9 \%$ & $368.1 \%$ \\
Net worth To Fixed Assets & $70.7 \%$ & $83.3 \%$ \\
Working Capital To Total Assets & $8.3 \%$ & $14.4 \%$ \\
Current Debt To Total Debt & $31.1 \%$ & $33.2 \%$ \\
INCOME STATEMENT & & \\
Net Operating Income (Before & & \\
$\quad$ Federal Income Tax and & & \\
Extraordinary Items) To Total & $13.9 \%$ & \\
$\quad$ Gross Revenue & & \\
INTERSTATEMENT & $195.6 \%$ & $236.8 \%$ \\
Total Gross Revenue To Fixed Assets & $276.6 \%$ & $284.1 \%$ \\
Total Gross Revenue To Net Worth & & \\
Total Gross Revenue to the Sum of & $160.7 \%$ & $194.5 \%$ \\
$\quad$ Long-Term Debt and Net Worth & $38.5 \%$ & $30.5 \%$ \\
Net Operating Income To Net Worth & $125.3 \%$ & $154.7 \%$ \\
Gross Gaming Revenue To Fixed & & $185.6 \%$ \\
Assets & $177.2 \%$ & \\
Gross Gaming Revenue To Net Worth & & \\
\hline
\end{tabular}

\section{Comparing Financial Statement Ratios of the Two Groups Reveals Differences Not Otherwise Apparent}

First, it appears that the publicly held locations are more highly leveraged than the closely held corporations, as the net worth to total debt and the net-worth to current debt ratios indicate; second, the publicly owned group have a higher percentage of total assets in fixed assets as represented by the substantial investments in the hotels; third, the publicly owned locations are making more efficient use of their equity investment (net worth) than are the others; and fourth, the publicly owned casinos seem to have better control or their operating expenses as is shown in the net operating income to total gross revenue ratio. 


\section{FORTUNE "500"}

Fortune Magazine's yearly analysis of the top 500 industrial companies also provides us with a good comparison; and their listings of the fifty top merchandising firms and fifty transportation companies has proved useful. Of course none of our corporate gaming licensees is near the size of even the smallest of the 500 (based on the total sales), although some of our largest might place in the second 500. Even so, the financial statement ratios used by Fortune are comparable.

Before discussing actual comparisons a few words should be said about the period of time covered by gaming data. During the time covered in this analysis, even though the state required the use of a standard financial statement, no uniform closing date had been established; thus the casinos filed their standard statements as of the close of their business year. The computer was programmed to place all statements which closed on June 30, or any of the immediately preceding eleven months, into a fiscal year ending June 30. Thus, in the case of the fifteen publicly owned casinos, for the fiscal year ending June 30, 1973, ten casinos actually closed their books on December 31, 1972; two closed on September 30, 1972; one closed on March 31, 1973; and two closed on June 30, 1973. All fifteen statements covered the same peak season-July, August and September of 1972. In other words, even though the writers, for their own purposes, show the data as being for fiscal 1973, the bulk of the data actually is 1972. Likewise, to be consistent, Fortune's data for 1972 has been listed as 1973. It is evident from the similar movement of the various curves on the following charts that this timing is proper.

Looking at the charts, net income has been plotted as a percent of assets, invested capital and total sales. Net income is calculated after provision for income taxes and the addition of any extraordinary items.

Net as a percent of assets shows gaming fluctuating with the 500 and with the fifty transportations. The top fifty retailing companies' ratios so closely paralleled the 500 industrials that they were not plotted. By 1973 each dollar of gaming industry assets was producing 11.4 cents of net income; the 500 industrials pro- 
duced 5.7 cents, and the transportation companies 1.5 cents. Each dollar of equity capital produced 24.4 cents for gaming; the 500 industrials returned 10.9 cents, and the fifty transportations 3.8 cents.

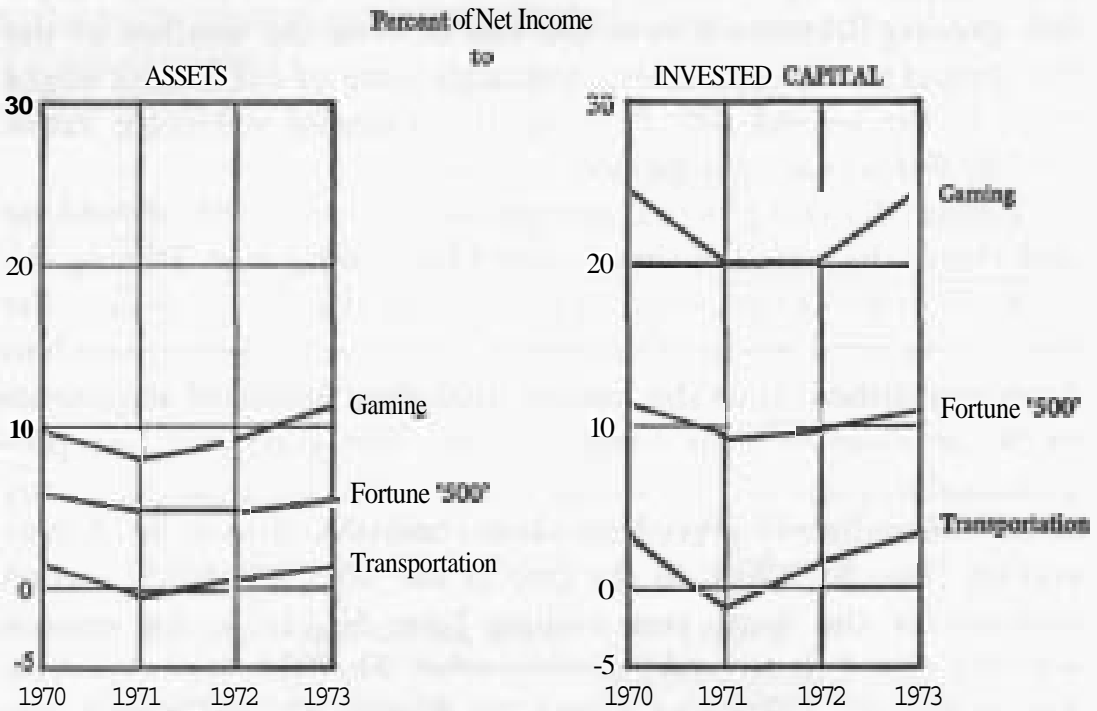

Figure 10-1.

Gaming net as a percent of total sales was less volatile than the fifty top transportation companies, but more so than the 500 industrials. Starting at 9.1 percent for 1970 , gaming had 8.8 percent in 1973. The industrials went from 5.6 percent in 1970 to 5 percent in 1973. While the transportation companies dropped sharply from 3.3 percent in 1970 to minus 0.7 percent in 1971, they had climbed back to 2.6 percent by 1973 .

\section{EARNINGS PER SHARE, PRICE EARNINGS RATIOS AND STOCK QUOTATIONS}

In Nevada gaming has always been looked upon as a business. In recent years the financial world has recognized the hotel/ casino business as just that, a business. In some environments it 
Net as a percent of total sales

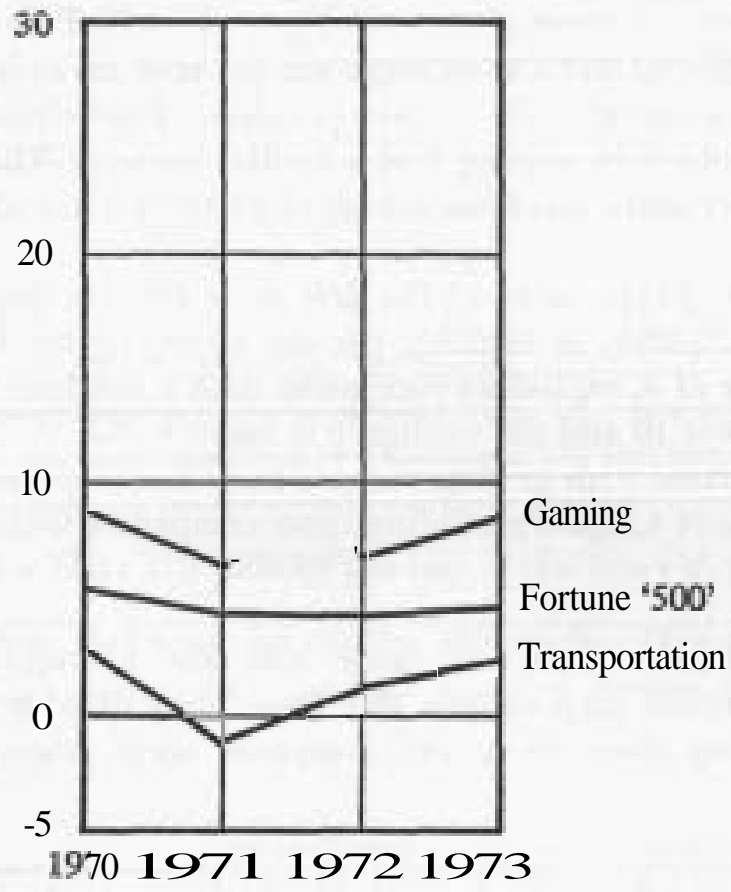

Figure 10-2.

may be thought of as having a different product or service; however, gaming certainly is not the only business that is bidding for the leisure time industry dollars.

The writers have created a leisure industry index, composed of eighteen firms whose product or service is to a great extent involved in competing for the public's leisure time and money. The eighteen companies that have been called the leisure industries group, all have their stock listed for trading on the New York Stock Exchange.

There are currently eleven publicly traded corporations that are a part of the gaming industry. Some of these companies have not been directly connected with gaming long enough to have the impact of gaming reflected in their earnings. However, the price 
earnings ratio and market price undoubtedly does reflect the fact they are in the gaming industry.

Earnings per share of those companies selected in the leisure industries group had a wide range for the year 1973-from a high of $\$ 4.83$ to a low of $\$ 6.23$ net loss per share. Publicly traded companies involved in gaming had a similar pattern. The range in earnings per share was from a high of $\$ 3.39$ to a loss of $\$ 2.36$ per share.

Price earnings ratios of the leisure industries group had as wide a fluctuation as earnings per share ranging from a high of 24 to a low of 5 , excluding companies with a net loss. The mean $\mathrm{p} / \mathrm{e}$ ratio was 10 and the median $\mathrm{p} / \mathrm{e}$ ratio, 8 . For the companies directly related with gaming the p/e ratio ranged from a high of 24 to a low of 4 , again excluding those companies with a net loss, the mean p/e ratio was 9 , and the median p/e ratio was 7 .

For further comparison, we have charted the quarterly average stock quotation-high/low range and the average-for eight publicly traded corporations that have been directly connected with gaming since 1970, and compared their prices with our

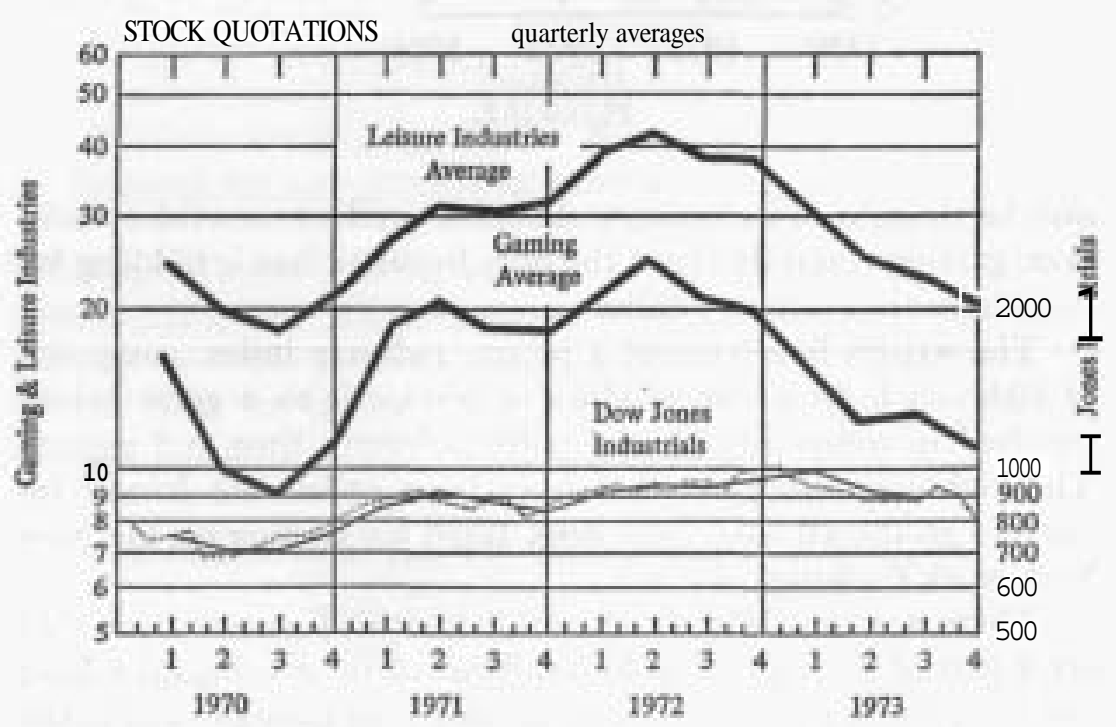

Figure 10-3. 
leisure industry group and the Dow Jones Industrials Average. Both the leisure industry group and gaming are much more volatile than the Dow Jones. Both gaming and the leisure industries group peaked in the second quarter of 1972 and were on the way down when the Dow Jones was still reaching for its high early in January, 1973.

\section{CONCLUSION}

What does all this mean for Nevada, and its legalized gaming industry? Gaming is, of course, the state's number one industry, and it has been growing at a very good rate: 12.4 percent per year for the past ten years and nearly 15 percent for the last five.

Even though the acceptance of publicly traded corporations in gaining has been instrumental in the expanded growth of the industry, the concept of publicly controlled casinos was controversial at first, and some opposition still exists. This opposition feels there is a danger that the state will lose control due to the large number of stockholders involved in publicly traded corporations. In spite of this opposition, a viewpoint which has not been borne out, it may be that public ownership of casinos will be the pattern of the future. 



\section{Part Three}

\section{THE SDCIDLDGY DF GAMBLIMG}





\section{INTRODUCTION}

The reasons people gamble, the games they play and the frequency with which they participate depend on a large number of personal, psychological, social and economic factors. However, the present state of information on who plays what gambling games for whatever reasons is based mainly on hearsay beliefs or opinion and on casual observations. The articles in this section provide a more serious approach to finding important social and psychological determinants behind the gambling habits of different groups in society.

The article by Li and Smith puts forth a number of sociological hypotheses based either on prior sociological studies of gambling or on their own a priori observations. With the aid of a 1971 Gallup survey, they tested various hypotheses against survey results. Even though the correlations they find are weak, their results are significantly different than zero, and the evidence is consistent with their hypotheses. One of $\mathrm{Li}$ and Smith's notable conclusions is that the propensity to gamble tends to increase as income increases, contrary to commonly held beliefs that lower income classes gamble more than middle and upper income groups.

In the article, "Motivations to Gamble: The Model of Roger Caillois," Robert Herman examines why people participate in gambling by looking at the characteristics of the games themselves rather than the attributes of the gambler. He argues that particular games can be described in tenns of the degree of competition they offer, the chance versus skill elements involved, the degree of ritualistic mimicry or play-acting, the amount of thrill or vertigo, and the flexibility in the game's rules allowed to the participants. Using this framework, Herman develops a number of testable hypotheses about games and people who gamble. This alternative approach could be a significant contribution to the understanding of gambling motives.

Many of the long-standing moral arguments against gambling 
are based on its potential debilitating effects on the social and financial stability of those exposed to it. In "Gambling: A Positive View," Felicia Campbell argues otherwise. Basing her study on interviews with residents of Las Vegas, Nevada, she concludes that gambling can be and is fulfilling to many people for various social and psychological reasons. She classifies a number of types of gamblers and explores their motives from the perspective of what gambling does for them rather than to them.

The final study of this section looks at the occupation of the casino dealer and how it relates to the concept of alienation from work. Basing their study on interviews with Las Vegas casino card dealers, Smith, Preston and Humphries examine the degrees to which dealers feel powerlessness, self-estrangement, social isolation and meaninglessness in their work. They find that, even though being a casino dealer offers good monetary remuneration, certain negative social and psychological aspects of dealing can reduce its overall appeal. 


\title{
Chapter 11
}

\section{THE PHIPENSITY TO GAMBLE: SOME STHULTUHAL DETERMINANTS}

\author{
WEN LANG LI AND MARTIN H. SMITH
}

\section{INTRODUCTION}

Cy

AMBLING IS ONE OF THE LEAST UNDERSTOOD forms of Social

havior. Up to the present, it has been the focus of little sociological study. Although it is ubiquitous in most cultures, gambling is often perceived as a deviant behavior and is socially condemned. In most of the United States gambling is illegal with the exception of pari-mutuel betting and a growing incidence of states with lotteries. Despite this, it is estimated that at least 23 million American adults bet money every month in various forms of gambling (Li, Smith and Udell, 1973). However, this prevalent phenomenon, as

I such, has scarcely been empirically investigated. Little systematic I attention has been aimed at explaining gambling behavior.

Among the few attempts to explain gambling behavior, the most common is to deal with it in terms of the basic nature of mankind. It is often suggested that gambling is innate in human beings. Davis (1955) , for example, states that "the urge to gamble, to risk a little in hopes of gaining a good deal, the desire to get something for nothing, seems to be one of the most fundamental traits of human nature." Nevertheless, as human nature is such a grandiose concept, it is hardly an explanation for gambling behavior.

Another level of explanation includes psychological studies generally based on the individual experiences obtained by psychoanalysts during the treatment of gambling patients. Wagner (1972) suggests, for instance, an association between the sex drive and gambling as he quoted a Las Vegas clinical psychologist, "We find that people who are big gamblers are usually not highly sexually stimulated. For some reason, the excitement and the need for gam- 
bling seem to replace the sex drive." He also postulates that inability and unwillingness to accept reality, emotional insecurity and immaturity may also be factors which might be associated with gambling behavior. A well-known work by Bergler (1957) has greatly publicized the psychological explanation of gambling. His theory is that, as odds against winning are so great, people must gamble in order to lose to punish themselves. The following quotation is perhaps one of the most characteristic:

The act of gambling in itsclf is a denial of the "reality principle." In this act of denial, the gambler is expressing his neurotic aggression against those who have taught him the "reality principle" — in most cases his parents. In losing, he is simply paying the penalty for the aggression (Bergler, 1957).

Although it is not the purpose of this paper to deny the importance and usefulness of psychological explanations of the gambling behavior, it should be recognized that, given the widespread nature of the behavior, it may not be possible to classify all of the estimated 23 million Americans who bet on something as neurotic. Instead, it is more likely that different types of gamblers exist. The neuratic gambler accounts for only a very negligible few of the total group. Scimecca (1971) for example, presents a seven-fold typology of gamblers in an attempt to distinguish between the many types of individuals associated with some forms of gambling behavior. Acknowledging the wide varieties in motivation and participation in gambling, it is the purpose of this study to look to sociological variables for their usefulness in explaining gambling behavior.

\section{SOME SOCIOLOGICAL HYPOTHESES}

Any sociological study of gambling behavior must consider social class as an agent of patterning how people bet. Differences based on class may be reasonably hypothesized to exist with respect to the frequency, volume and type of gambling. Yet, amazingly, in literature there is a paucity of research on gambling from a sociological perspective. Thorstein Veblen's thesis (1899) of gambling remains one of the very few sociological suppositions.

Veblen considers gambling to be a vestige of the archaic past as 
he does the entire leisure class scheme of life. To him, one of gambling's two major elements, and its earliest, is the belief in luck. This belief predates even the barbarian culture, and holds that propitiation of the latent animism inherent in objects of games of chance will lead to a desired end. The other element in gambling, as Veblen puts it, is "the desire of the anticipated winner, or the partisan of the anticipated winning side, to heighten his side's ascendency at the cost of the loser." This latter element is the aspect of gambling which reflects the penchant for invidious comparison so prominent in the leisure class framework.

One main characteristic of the leisure class is maintaining standards, in consumption of goods and canons of taste. They differ from the industrial class primarily because of their emphasis on status differences, i.e. wealth and power, and in their conspicuous display. It is obvious that one cannot merely possess wealth and power without putting it in evidence, as esteem is awarded only on evidence. Accordingly, to the upper class members, gambling is an avenue of conspicuous consumption. For them it is necessary to live up to the social standards, conform with their fellows and play the favorites. Thus it can be hypothesized from the Veblenian per- : spective that social class and gambling are positively related. _

Somewhat related to economic status, there are some other sociological variables that may be important in explaining why people gamble. Life cycle is one of them. Generally, age tends to be associated with affluence. In addition, as one becomes older, his drive to adventure and excitement is likely to decrease. Gambling will thus be less appealing to him. The increase of age may also imply the less receptivity to peer group influence. As gambling is obviously al type of social activity which often involves acquaintances or peers, $j$ older persons may have lower propensity to gamble than younger; persons.

Unfortunately, no empirical study has attempted to derive a general observation between life cycle and gambling. The evidence accumulated so far is not conclusive. For example, Newman (1972) found that betting ar borses was equally prevalent among all agegroups, and football pools and bingo were found to be more common among older individuals, while casino gambling was more com- 
mon among the young. The New York betting survey found that the bettors were most likely to be in the twenty-six to fifty-nine age bracket, and were less common among the young and the old. It appears that such contradictory findings may be due partly to the lack of a general study which can account for all types of gambling. It is hypothesized that a general study may reveal that life cycle is negatively related to the gambling behavior.

Community characteristics, especially measures of urbanization, are also important considerations. Community size, for example, is a variable which may be related to economic status, age structure and the propensity to gamble. In the general sociological literature, population size and the accompanying measure of density have long been shown to be associated with such factors as a disproportionate increase in the number of social relations and an increased heterogeneity of social roles. Specific community studies have also shown associations between increasing population size and the trends toward pluralism, increases in psychic overload and the creation of mass society. These and many other findings point to the potential importance of community size as a determinant of gambling behavior.

Community size may also be related to the propensity to gamble at a more primary level. Obviously, an urban community tends to have a high concentration of relatively affluent people. Young people are also more likely to reside in urban communities. Such concentration may be a necessary prerequisite for the establishment of leisure class social standards, the maintenance of conformity with their fellows, or the development of a network of social relations capable of awarding esteem. In addition, urban environment tends to afford the facilities as well as the stimuli for gambling. Undoubtedly all these forces tend to reinforce one another. As a result, it is plausible that, other things being equal, an urban resident may have a higher propensity to gamble than his rural counterpart. The larger the community, the higher its residents' propensity to gamble.

Thus, life cycle and community characteristics can be postulated as two important antecedents in explaining Veblen's thesis, that is why economic affluence is necessarily related to gambling behavior. The relationship among these variables can be easily tran- 
scribed into a path model in which life cycle and community characteristics are treated as exogenuous variables, socioeconomic status as an endogenous variable, and the propensity to gamble as the dependent variable to be explained.

The essential postulation of the model is derived from Veblen's supposition that there should be a positive correlation between economic status and gambling behavior-the higher one's economic status, the higher his propensity to gamble. This thesis, however, can be challenged because it is only a static explanation. One may argue that what determines people to gamble is not their status characteristics, but rather the mobility aspiration to achieve higher economic status. A study of Swedish gambling by Nechama Tec (1964) seems to substantiate this argument. It posits a direct association between status frustration and gambling. The prevalence of gambling among the upper levels of the working class and the middle class is seen as indicative of the reaction toward status barriers. Gambling becomes a diversion of latent anger among this group which experiences frustration from deprivation and unfulfilled aspirations.

Another study by Scodel (1964) also labels gambling as a safety valve for the middle class who are often "afraid of losing their position or, in the case of upwardly mobile ethnic minorities, insecure about their claims to Americanism." Gambling is attractive to them because it provides an opportunity to demonstrate self-reliance, independence and decision-making which are less available in their other roles. In addition, gambling could be an obvious avenue through which they can attain success and recognition, allowing them to function in their communities without suffering the consequences of realizing that their opportunities are indeed limited. Accordingly, it can be hypothesized that status inconsistency and the propensity to gamble are related.

\section{Data and Variables}

This study surveys the general population of the United States in terms of their gambling activities. In January of 1971 the Gallup Organization conducted an omnibus survey using a national probability sample. Approximately 300 sampling points were used in the survey stratified by the size of the community. Sixteen hundred 
individuals age eighteen and above were personally interviewed by the trained Gallup staff members with pretested survey schedules. This sampling procedure was designed to produce an approximation of the adult civilian population living in the United States.

A question was asked in the survey as follows:

On this card are listed a number of ways in which people bet money. Sometimes people bet with members of their family or with friends, at charitable or religious organizations, or at facilities operated or licensed by the state, and sometimes at professional or commercial facilities that are not licensed. Thinking in terms of the past four weeks, would you read off the letter that best described how, if at all, you have bet on: bingo, lottery, blackjack, or poker, bridge, rummy or other card games, numbers, horse races, sporting events, slot machines, pin ball machine, craps, shooting dice, roulette, or any other ways (specify).

Gambling is thus operationally defined. Following this question, several other questions were also asked to tap the intensity, amount and perception of gambling behavior. Among the 1597 sampled individuals, thirty-two would not answer the questions concerning their gambling activities. This of course represents a negligible amount of sampling errors.

The variables to be analyzed in this study are as follows:

1. The propensity to gamble. Those respondents answering positively that they have bet money on at least one type of the games will be classified as gamblers and coded as $\mathrm{I}_{i}$ otherwise, nongamblers are coded 0 . The proportion of gamblers in our sample is about 23 percent, with the proportion of gamblers being equal to the mean value of the dummy variable.

2. Economic status. The respondents' family annual gross income (in dollars) is used as the measure of this variable. For the sake of contingency analysis, economic status is categorized into three levels: low (below $\$ 6,000.00)$, medium $(\$ 6,000.00-$ $\$ 12,000.00$ ) and high (above $\$ 12,000\rangle$. The percentage distribution for each level is respectively 19,45 and 36 percent.

3. Life cycle. Age is used as an indicator of life cycle. This is also trichotomized into three groups: young (15-34), middle (35-54) and old (55 and above).

4. Community size. This is measured by the size of its popula- 
tion. It ranges from under one thousand to over a million. In order to obtain a meaningful regression coefficient, the log-transformation of this variable is used. Also, the community is dichotomized into two categories: SMSA and non-SMSA.

5. Status inconsistency. This variable is derived by comparing a respondent's occupation and his income. If occupation is high, yet income is low, his status configuration is not consistent, and, as hypothesized, his gambling propensity could be high. The occupation variable is coded as low (unskilled and service workers, farmers and farm laborers), middle (sales, clerical and skilled workers) and high (professional and managerial workers) . The percentage distribution for each group is respectively 30,41 and 29 percent.

\section{Findings}

The analysis begins with computing zero-order correlations between various independent variables and the propensity to gamble. The results are presented in Table II-I. Before we proceed to interpret the meanings of the correlation coefficients, let us keep in mind that our sample size is 1,565 . Thus, a correlation coefficient could be statistically significant at the 5 percent level if its value exceeds \pm 0.049 . Using this criterion, it is clear that most of the correlation coefficients in Table $\mathbf{I} \mathbf{l}-\mathbf{I}$ are statistically significant. As expected from Veblenian perspectives, economic status is significantly correlated with propensity to gamble $(0.153)$. The higher the economic status, the higher the propensity to gamble. This obviously refutes the general contention that lower social class has the higher rate of gambling. In other words, the prevalence of gambling behavior may be higher among the lower social class only if one or two specific types of gambling are concerned (e.g. the numbers game), but they constitute only a small portion of the total gambling enterprise. The writers' findings assert that, in general, the lower social class, the lower the propensity to gamble.

In addition, the correlation between gambling and life cycle and community size are all statistically significant, as expected-0.154 for the former and 0.149 for the latter. It appears that both life cycle and community size have important effects on gambling 
TABLE HI-I

CORRELATION MATRIX

\begin{tabular}{|c|c|c|c|c|c|c|}
\hline & $x_{1}$ & $x_{2}$ & $x_{3}$ & $x_{4}$ & $\bar{x}$ & $s$ \\
\hline $\mathrm{x}_{\mathrm{a}}$ Life cycle & 1.000 & .001 & -.252 & -.154 & 43.9 & 17.4 \\
\hline $\mathrm{x}_{\mathrm{a}}$ Community size & & 1.000 & .116 & .149 & 3.7 & 2.7 \\
\hline $\mathrm{x}_{2}$ Economic status & & & 1.000 & .153 & 9,575 & 4,516 \\
\hline $\mathrm{x}_{4}$ Propensity to gamble & & & & 1.000 & 0.225 & 0.418 \\
\hline
\end{tabular}

behavior. As a person becomes older his propensity to gamble tends to decrease. Gambling is clearly a young man's game, and the majority of the gamblers are likely to be young. On the other hand, if a person lives in a large community he is more likely to be a gambler than a person living in a small community. In many metropolitan areas gambling is becoming a way of life. It is not only that some types of gambling are legalized (such as state lotteries), but also the normative tolerance toward gambling as a leisure activity is becoming prevalent.

The results of the correlation analysis confirm our previous speculation that there is a strong interrelationship among the independent variables. It is clear that as a person becomes older, his income status is likely to decrease $(\mathrm{r}--0.252)$. On the other hand, community size and economic status are positively related $(\mathrm{r}=$ 0.116). The average income among metropolitan residents is much more than nonmetropolitan residents. Accordingly, the interrelationship among the variables can be expressed in a path diagram which is presented in Figure 11-1.

The model postulates that both life cycle and community size can be treated as exogenous variables. They exert both direct and indirect effects on gambling behavior. The indirect effect is primarily operating through income status, a thesis proposed by Veblen. Accordingly, their functional relationships can be summarized as follows:

$$
\begin{aligned}
& x_{3}=p_{31} x_{1}+p_{32} x_{2} \\
& x_{4}=p_{41} x_{1}+p_{42} x_{2}+p_{43} x_{3}
\end{aligned}
$$

where $X_{1}, X_{2}, X_{3}$ and $X_{4}$ denote, respectively, life cycle, community 


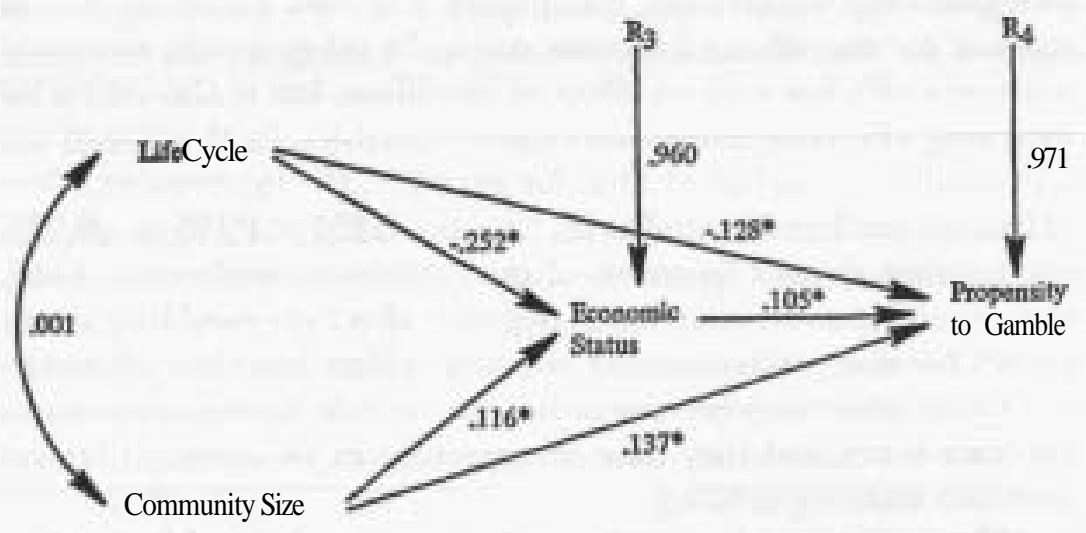

Figure 11-1. Path Diagram Relating Life Cycle, Community Size, Economic Status and Propensity to Gamble.

Note that $*$ denotes statistical significance at 5 percent level.

size, income status and the propensity to gamble.

One peculiar observation from our data is that life cycle and community size are not strongly related, that is, in general, we should not expect an individual's stage of life cycle to be associated with the size of the community in which he selects to live. The finding may seem to be contradictory to common contention, but it may indeed be the case as far as empirical facts are concerned. Although we tend to think of a huge flow of young population to large communities, there is little reason to believe that these young adults will continue to move to larger communities as they become older. In any event, the small and insignificant correlation between life cycle and community size simplifies greatly the interpretation of the causal relationships between the independent variable and gambling. Eliminating the possible interference of such correlation, the following equations can be obtained:

$$
\begin{aligned}
& r_{14}=P_{41}+P_{43} P_{31} \\
& r_{24}=P_{42}+P_{43} P_{32}
\end{aligned}
$$

These equations imply that the relationship between life cycle 
and gambling or between community size and gambling has to account for the effect of income status. In other words, economic status not only has a direct effect on gambling, but it also exerts intervening effects on many other causal variables. In the case of the community size and gambling, for example, the intervening effect of income can be estimated as $\mathrm{P}_{31}{ }^{\prime} \mathrm{P}_{4 a}=-0.252 \mathrm{X} 0.105=-0.026_{2}$, constituting about 17 percent of the correlation coefficient. Thus, the reason that life cycle has a negative effect on gambling is not simply because psychologically young gamblers lose their adventurous spirits when they become older, but because their income status becomes lower and they have fewer resources to invest on leisure activities such as gambling.

The same reasoning can be applied to the relationship between community size and gambling. In this case, the intervening effect of income status is positive, $\mathrm{Pan}-\mathrm{P}_{4 a}=0.116 \mathrm{X} 0.105=0.012$. It constitutes about 8 percent of the correlation coefficient. ThisA means that the positive effects of community size on gambling may not only be due to the facilities of gambling available in urban communities. Urban community populations tend to have higher incomes, and the higher income by itself tends to increase gambling propensity.

Thus, through path analysis it appears that income status exerts a distinctive causal effect on the propensity to gamble. The direct effect of income status on gambling is obvious in light of Veblen's theoretical postulations, but what Veblen has not articulated is its intervening effects. The writers' observations suggest that the effects of both life cycle and community size on the gambling propensity may be to some extent due to the reinforcement of income status. Income seems to contribute to the negative effect of life cycle, as well as the positive effect of community size, on an individual's propensity to gamble.

It is also noted that both life cycle and community size affect the relationship between income status and gambling. Generally speaking, the increase of income status tends to increase an individual's propensity to gamble, but the increment is not necessarily monotonic. In fact, it depends on both the stage of life cycle and the characteristics of the community. Figure 11-2 shows how the positive association could be interfered with by the effect of community 
size. Note that in both metropolitan and nonmetropolitan communities the propensity to gamble tends to increase as income status increases. However, the tendency to increase in the nonmetropolitan communities is rather slow among the low and middle income groups, and then drastically increases in the high income group. On the other hand, the tendency to increase in the metropolitan communities is markedly sharp from the low to the middle income groups, yet no significant increment is observed in the high income group. Therefore, the increment curve is more or less exponential in the nonmetropolitan communities, and parabolic in the metropolitan communities. As a result, among the middle class group, the propensity to gamble deviates the most between the two types of communities.

However, the effect of life cycle on the relationship between income and gambling appears to be the opposite. Figure 11-\$ shows the relationship by three age groups-young, middle and old. Again, within all three age groups the increase of income tends to lead to the increase of the gambling rate, but the increment is more linear among the middle ages than the other two groups. Comparing all three groups, it appears that the effect of life cycle on gambling is rather negligible among the middle income population. In fact, for those whose income is around 8,000 dollars, the gambling rate is about 25 percent regardless of the age group concerned, but the differences in gambling rates between ages are more salient in other income groups.

It is apparent that income status may not be linearly related to the propensity to gamble, though it is true that the correlation tends to be positive. The relationship is likely to be nonlinear, especially if other variables such as life cycle and community size are controlled. What is of interest is that the gambling rate of middle income groups could be very much affected by the type of community, and yet little affected by the stage of life cycle. It appears that occupational differentials may be an explanation as some previous researchers have asserted (Davis, 1955; Galdston, 1967; Scodel, 1964). Among the middle income population very little difference can be found in terms of occupational distribution between age groups, but this is not the case where community size is concerned. The middle income group is likely to be composed of clerical or 


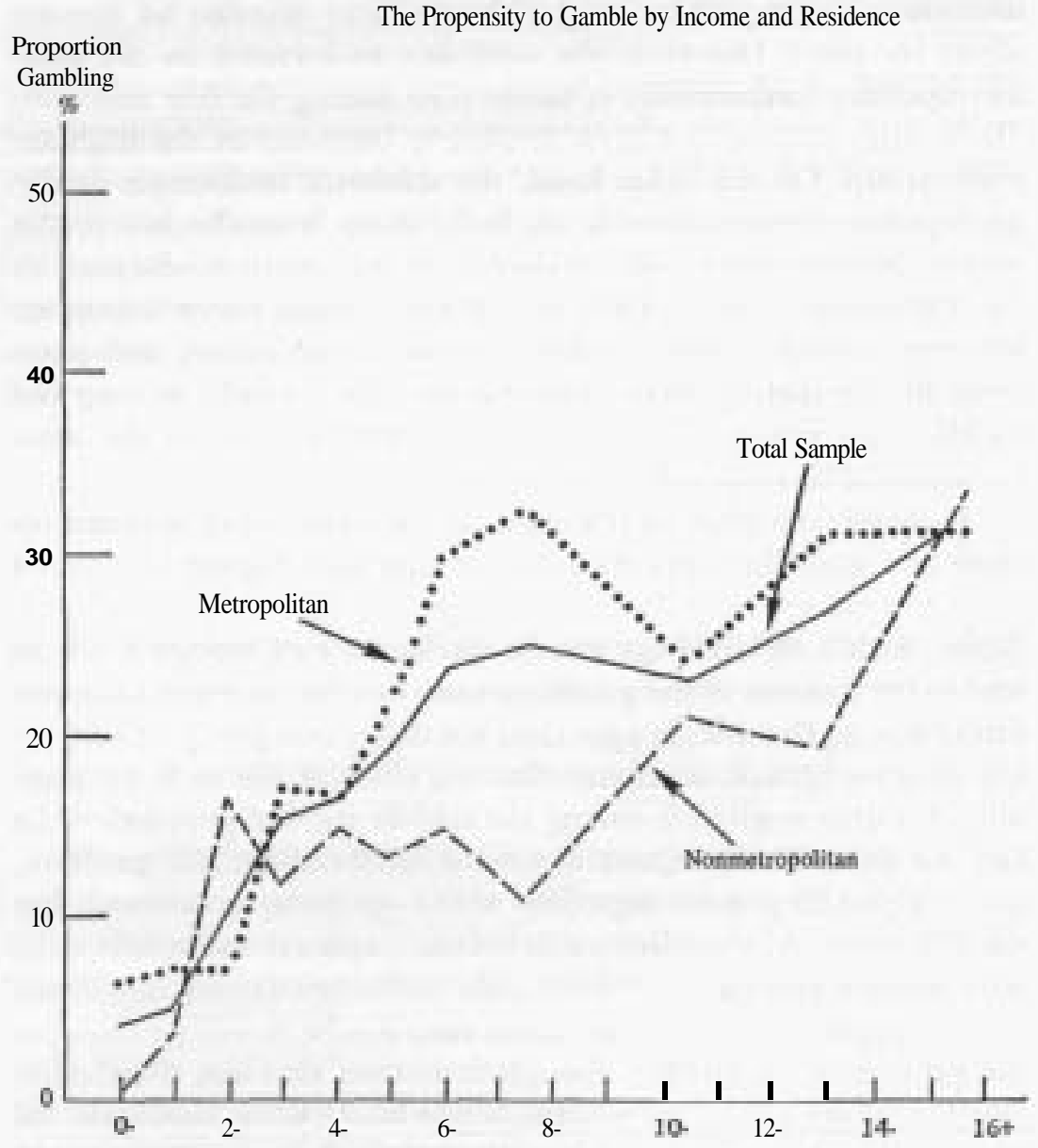

Family Income (in thousands)

Figure 11-2.

skilled laborers in the metropolitan communities; this is not necessarily so in the nonmetropolitan communities. The fact that the middle income group in metropolitan communities has a disproportionately higher propensity to gamble seems to be the reaction to the mechanical and routinized monotony of the clerical and opera- 
The Propensity to Gamble by Income and Age

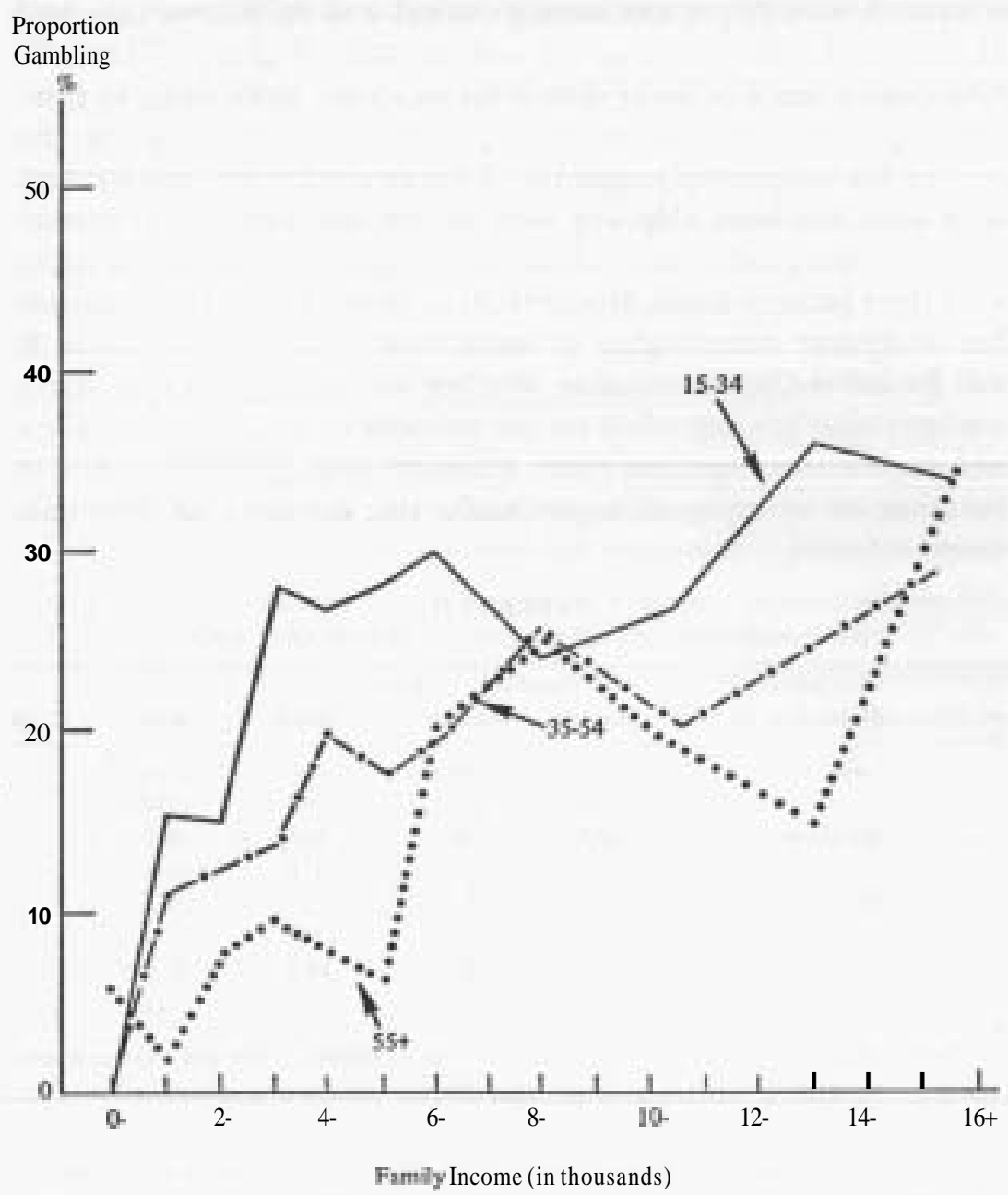

Figure 11-3.

torial occupations. In this sense, occupation is a variable which could exert a distinctive effect on gambling, independent from the effect of income status.

Table 11-II presents the gambling rate cross-classified by occupation and income statuses. Low occupation clearly has the 
lowest gambling rate. The rate is only 23 percent in this group, compared with 29 percent among clerical and skilled workers, and 31 percent for the professional and managerial group. The common contention that lower class individuals are more likely to gamble is again refuted. Instead, the higher the occupational status, the greater the propensity to gamble. This generalization is consistent with what has been observed with the income variable. However, there are many individuals whose occupation status is not consistent with their income status. Roughly 50 percent of the writers' sample has an income status higher or lower than its occupation status. It will be interesting to examine whether the incongruence in status configuration has any effect on the propensity to gamble. Previous sociological investigations often speculate that gambling tends to function as a scapegoat to reconcile the dilemma of economic disequilibrium.

TABLE $\|1-\|$

THE GAMBLING RATE BY OCCUPATION AND INCOME

\begin{tabular}{lcccc}
\hline $\begin{array}{l}\text { Occupation } \\
\text { Status }\end{array}$ & \multicolumn{3}{c}{ Income } & Level \\
Low & Medium & High & Total \\
\hline \multirow{2}{*}{ Low } & 12.8 & 31.3 & 17.5 & 23.2 \\
& $(78)$ & $(134)$ & $(40)$ & $(252)$ \\
Medium & 12.7 & 28.1 & 34.8 & 29.3 \\
& $(59)$ & $(167)$ & $(112)$ & $(338)$ \\
High & 23.5 & 30.1 & 32.0 & 30.5 \\
& $(17)$ & $(73)$ & $(147)$ & $(237)$ \\
Total & 14.0 & 29.7 & 31.1 & 27.8 \\
& $(154)$ & $(374)$ & $(299)$ & $(827)$
\end{tabular}

Note: Cases of observation are in parentheses. Included are only those whose occupation and income are reported.

The results from this data appear to substantiate the supposition that the status incongruence may be related to the propensity to gamble. It is shown that the gambling rate for those who have the same level of occupation and economic status is 26 percent, but the rate is 29 percent for the status inconsistent group. The difference between them is 3 percent. Thus, it seems that, for psychological reasons, status inconsistency does contribute to an increase of gambling propensity. However, one should be cautious to claim this too far as the relationship is not very strong. The test of signifi- 
cance of the differences yields a $t$ value of 0.93 , which means that there is about 15 percent probability that the relationship can be obtained through random variation.

Such intangible relationships may be due to the interactive effects of both occupational characteristics and income status. For instance, the relationship between occupation and gambling varies because of the level of income; among both low and high income groups, the clerical and skilled workers have the highest gambling rate. Yet, among the middle income group, the gambling rate is the lowest. Likewise, the relationship between income and gambling varies depending on the nature of occupational class; among unskilled and service workers the middle income group has the highest proportion of gambling, but among other occupational classes income and the propensity to gamble tends to be positively related. Thus, in general, the positive relationship between social class and gambling tends to prevail if occupation is controlled, but this is not the case if income is the controlled variable.

It appears that income effect is much stronger than occupation effect. This generalization can be further enhanced if gambling rates are examined within the status inconsistent group. A comparison is made between those whose income is higher than occupation and those whose occupation is higher than income. Calculated from Table $11-\mathrm{II}_{2}$ the results show that the gambling rate is 25 percent for those whose occupation is higher than income, and 38 percent for those whose whose income is higher than occupation. The overriding effect of income on gambling is obvious. A two-way analysis of variance yields an $\mathrm{F}$ ratio of 1.94 for the occupation effect, 4.66 for the income effect, and 2.55 for the interaction effect. Both the income and interaction effects are statistically significant at the 5 percent level while the occupation effect is not. The results substantiate the argument that income is indeed a much stronger determinant than occupation in affecting an individual's propensity to gamble. It should also be noted that the interactive effect of both income and occupation on gambling are worthy of further investigation. 


\section{Conclusion}

At this point one is forced to question if there is any general theory which can explain gambling behavior. Obviously there are many trivial explanations as to why people gamble. Gambling is often perceived as serving the function of fun, excitement, adventure and, perhaps, escape from a dull, boring life, but what this study has shown is that these psychological explanations may not be sufficient for there are some structural conditions that are significantly related to an individual's propensity to gamble.

I These data clearly substantiate Veblen's thesis that gambling is a leisure class activity-the higher the economic class, the higher the propensity to gamble. The observations refute the common contention that gambling is predominantly a lower social class phenomenon. Unfortunately, this common contention is widely accepted by many sociological studies which tend to follow the journalistic reports in exaggerating the prevalence of one or two types of gambling (e.g. the numbers game) among the lower class communities. Newman (1972), for example, states as follows:

Low class individuals are likely to gamble more often, more regularly, and despite their lower income and their more meager financial resources, they will, in absolute terms, spend more money than the other social groups on the various gambling activities.

Through path analysis this study suggests that the predominant effect of income status on gambling may also be due to the reinforcement of some other sociological variables such as life cycle and community characteristics. While the evolvement of life cycle tends to depress the propensity to gamble, the larger community size is likely to promote it, but both life cycle and community size are related to income status. The fact that life cycle has a negative effect on gambling is not simply because of psychological withdrawal, but because of the demotion of economic status which, in turn, decreases the likelihood of investing on leisure activity. Similarly, the positive effect of community size on gambling may be due not only to the available gambling facilities, but also to the fact that larger communities tend to attract a higher income population that is more gambling prone.

Although some previous sociological studies, e.g. Tec (1964) 
and Scodel (1964), have suggested the prevalence of gambling among middle class population, the data accumulated for this study have not clearly substantiated this argument. In general, the gambling rate among the middle class is not higher than the upper class. Nevertheless, it should be noted that there is a sharp increase in the gambling rate from lower to middle class, whereas the difference between middle and upper class is relatively smaller. Furthermore, within metropolitan communities the middle class's gambling rate could be as high as the upper class. In fact, it can be generalized that gambling tends to be a parabola function of income status in metropolitan communities while the functiontends to be exponential in nonmetropolitan communities. Therefore, these data suggest that the interactive effects of middle-class background and metropolitan characteristics may drastically increase the propensity to gamble.

There is also an interaction relationship between income level and occupation status in terms of their effects on gambling. For instance, among the unskilled and service workers the propensity to gamble is markedly high in the middle income group, though the pattern no longer prevails among other occupations. An examination of gambling rates among different income-occupation groups reveals that there is a slight tendency for status incongruity to lead to a higher propensity to gamble, and those who have high occupations and low incomes are more likely to gamble than those who have low occupations and high incomes. Nevertheless, these casual observations cannot stand the rigorous statistical tests. Using both t-test and analysis of variance, this study concludes that the inconsistency in status configuration may not significantly affect the gambling propensity. The explanation is simple-the effect of one of the status dimensions, income, is so strong and overriding that other variables become relatively insignificant.

\section{REFERENCES}

Bergler, E.: The Psychology of Gambling. New York, Hill \& Wang, Incorporated, 1957.

Davis, C. B.: Something for Nothing. New York, J. B. Lippincott Company, 1955.

Galston, La: The gambler and his love. In Herman, Robert D.: Gambling. 
206

Gambling and Society

New York, Harper and Row, 1967, pp. 131-136.

Li, W. L., Smith, G. W., and Odell, J.: The gambling business in the U.S.A. Bull Business Res, 68:1, 1973.

Newman, O.: Gambling: Hazard and Reward. London, Athlone, 1972.

Scimecca, J. A.: A typology of the gambler. Int J Contemp Sociol, 8:56, 1971.

Scodel, A.: Inspirational group therapy: A study of gamblers' anonymous. Am

J Psychother, 18:115, 1964.

Tee, N.: Gambling in Sweden. Totowa, The Bedminster Press 1964.

Veblen, T.: The Theory of the Leisure Class. New York, The Viking Press, 1899.

Wagner, W.: To Gamble or Not to Gamble. New York, World Publishing, 1972. 


\title{
Chapter 12
}

\section{MITIVATIINS TO GAMBLE: THE MODEL OF HUGER CAILLOIS}

\author{
ROBERT D. HERMAN
}

IN TRYING TO ADDRESS the question of why people gamble and 1 what they accomplish when doing so, the writer has found it confusing to deal with two assumptions which are mutually contradictory, yet quite common in our culture. The first is that gambling is so widespread that it can be regarded as something everyone does; therefore it is natural for people to gamble, and no special theory is needed to account for it. On the contrary, a special theory would be needed only to explain the avoidance of gambling. The other assumption is that gambling is irrational and costly, if not immoral and dangerous. Therefore, a special vocabulary of motives must be invoked if one is to understand why people indulge in it.

The facts suggest that the first assumption is incorrect (unless the term gambling is stretched to include any form of risk-taking behavior, however trivial or however it is forced upon the individual, as in having to buy fire insurance or having to choose among alternative job offers, alternative educational paths or alternative marriage partners). Many people in our culture do not gamble in the usual sense that is being considered here. On the other hand, many people $d o$, and, in fact, gambling attracts so many people and so much time, money and energy that it can be argued to be an ordinary part of our way of life.

When gambling is regarded as comprising its own separate world, one in which people voluntarily risk money in games in which the odds are in favor of the promoters, and where it is assumed that intelligent people do not do that in the real, nongambling world, the temptation exists to describe gambling in 
what might be called put-down metaphors. These are usually expressed, in one form or another, as an illness model in which pathology, compulsion, addiction and other departures from routine good judgment, common sense and hard work are labeled. Persons described in this manner are represented as predisposed in some way to membership in this special world, and we as behavioral scientists, are asked then to examine their histories, that is the childhood experiences that led to developmental aberrations. The model for this examination is the clinical one in which the gambler is regarded as a patient who, although his conduct is suspect, is asked to rely on his memory, and, with the help of the physician's imagination, to supply the desired details of the case history. Together they search for chains of events which can be regarded as causes of the present states of recklessness. Invidious comparisons are then made with normal folk, and the contrasts are taken as constituting an explanation of gambling.

So round and round we go, half believing or switching back and forth between convictions that gambling is normal or that it is abnormal. It is into this debate, if it can be called that, that the writer wishes to introduce a. classificatory scheme which he believes may help tip the balance in favor of the gambling-isnormal argument. His scheme is borrowed entirely from a book, Man, Play and Games, published in 1958 by the French humanist, Roger Caillois. His work is known to relatively few American scholars even though the book is listed in a number of bibliographies, and his concepts certainly have not been exploited by writers about gambling. (The same may be said of the efforts of another European humanist who preceded Caillois by a generation, Johan Huizinga. Huizinga's book, Homo Ludens, published in 1938, seems to be much better known to English professors than to social scientists in spite of the fact that his principal assertion is that play is thoroughly interwoven with culture, and indeed it is "one of the bases of civilization.") It is surprising and somewhat discouraging to note that Huizinga and Caillois have had so little impact on social scientists who write about games. This neglect may have more to do with the fact that their credentials are not those of empiricists than it has to do with the char- 
acter of their analyses. It also seems that many of us are convinced that play and games are really only analogues of real life, not to be taken seriously as objects of analysis in their own right.

One of Huizinga's assumptions was that, although the realm of play interacted with other cultural phenomena, it was somehow marked off from the rest of the world. He even used such terms as "magic circle" to describe this segregation. Caillois, on the other hand, was more interested in those properties of games which follow from the fact that they are controlled by and to some extent bounded by rules and self-imposed constraints of various kinds. *

Caillois considered first the possibility of classifying games by their objective characteristics, such as the use of certain paraphernalia (cards, dice, words, physical strength), location (card tables, stadia) or number of players involved. He found this to be futile, and, instead, proposed categories based on the subjective experiences of participants.

After examining different possibilities, I am proposing a division into four main rubrics, depending upon whether, in the games under consideration, the role of competition, chance, simulation, or vertigo is dominant. I call these agon, alea, mimicry, and ilinx, respectively. . . . One plays football, billiards, or chess (agon); roulette or a lottery (alea); pirate, Nero, or Hamlet (mimicry); or one produces in oneself, by a rapid whirling or falling movement, a state of dizziness and disorder (ilinx).

Translating these terms a bit to correspond to more conven-

*It is these boundary-maintaining attributes which make game metaphors so popular. If models can be concocted which emphasize rules, closed systems and rationalized frameworks, they can be used to generate novel insights and hypotheses which are otherwise very difficult to state clearly and to subject to rigorous tests. Not only have mathematicians explored "game theory," but others in very different disciplines have used game metaphors also. When Berne described Games People Play for psychoanalytic use, he sought a helpful analogy which could be applied to, say, the activities of family members caught up in "the real living of real intimacy." Another psychiatrist, Thomas Szasz, devotes several chapters of his influential book, The Myth of Mental Illness to the "game-model analysis of behavior." Like Berne his interest was in making his readers more aware of the rules they habitually accept without full awareness. "Confusion arises whenever different actors in the real life drama play by different sets of rules, all the while assuming that they adhere to the same script." 
tional usage recognized in American dictionaries, the first term, agon, refers to agonistic games. The term comes from the Greek agonistikos pertaining to the classical agonies of intense strife or contest. It identifies games which are normally experienced as calling for competition and strategy. (However, terms like daring, courage, drive and even skill do not uniquely define this concept apart from the others.) The second term, aleatory games, refers to chance, uncertainty and luck. Mimicry needs no translation, but the fourth category, ilinx, shall be referred to as vertigo. (Ilinx is whirlpool in Greek.) It appears that the third and fourth concepts, mimicry and vertigo, were suggested to Caillois by children's play behavior. Regarding mimicry, Caillois says:

All play presupposes the temporary acceptance, if not of an illusion (indeed this last word means nothing less than beginning a game: in-lusio) then at least of a closed, conventional, and, in certain respects, imaginary universe. . . . One is confronted with a diverse series of manifestations, the common element of which is that the subject makes believe or makes others believe that he is someone other than himself. He forgets, disguises, or temporarily sheds his personality in order to feign another.

Caillois uses the concept of vertigo to refer to an attempt momentarily ". . . to destroy the stability of perception and inflict a kind of voluptuous panic upon an otherwise lucid mind." This experience, presumed by Caillois to be sought for its own sake, includes experiences which carry one to and through the normal limits of traction and control, such as falling, sliding, speeding and rapid acceleration. However, vertigo is not restricted to physical phenomena. "In parallel fashion, there is a vertigo of a moral order, a transport that suddenly seizes the individual. This vertigo is readily linked to the desire for disorder and destruction, a drive which is normally repressed" This may account, in large measure, for the kind of behavior that John Roberts calls "self-testing" in "expressive" driving and flying. That is, the explanation for aggressive driving may be closer to that of a search for the pleasures of vertigo than for the chance to "test" oneself against some abstract standard (Sutton-Smith, Roberts and Kozelka, 1963). The search for vertigo may also offer an explanation for the reason 
some people act out, participate in street fights, riots, dangerous voyages and a host of other dramatic activities, many of which are interpreted as deviant behavior by the relatively sober citizens among us.

In addition to his consideration of the extent to which each of these four characteristics dominates particular play and game situations, Caillois proposed that the amount of freedom of expression, movement and emotion is another variable, one which indicates ways of playing and which cuts across everything else. "At one extreme an almost invisible principle, common to diversion, turbulence, free improvisation, and carefree gaiety is dominant. It manifests a kind of uncontrolled fantasy that can be designated by the term paidia." At the other extreme is the desire to invent rules, arbitrary and often tedious conventions which require effort, patience, skill and ingenuity to work with, for which he uses the term ludus. The concept refers to competition with obstacles erected by rules rather than by competitors.

When cross-classified, Caillois's ideas generate the taxonomy shown in Table I2-I (taken from Table I in Caillois) .

So much for Caillois's conceptual scheme. His book is mainly an exegesis of this material. For example, in taking up the fact that games bring together players of differing capabilities, Caillois repeatedly emphasizes the manner in which equality among participants is maintained in games. In (agonistic) competitive play, handicaps and matching procedures are commonly employed to correct imbalances in order that personal responsibility may be given full vindication by the outcome of the struggle. In (aleatory) games of chance, however, the participants are automatically reduced to equal advantage by the operation of shuffling cards, tossing coins, rolling dice or of some other decision device. Rather than relying upon personal responsibility for the determination of outcomes, chance alone determines the outcomes.

Why would a player wish to submit himself to the equalizing process involved in alea? Caillois suggests two general reasons, / (1) He may be divining the intentions of Dame Fortune. "Alea signifies and reveals the favor of destiny. The player is entirely "Paidia is the root word for child. 
CLASSIFICATION OF GAMES

\begin{tabular}{|c|c|c|c|c|}
\hline & $\begin{array}{c}\text { AGON } \\
\text { (Competition) }\end{array}$ & $\begin{array}{l}\text { NLFA } \\
\text { (Chance) }\end{array}$ & $\begin{array}{l}\text { MIMICRY } \\
\text { (Simulation) }\end{array}$ & $\begin{array}{c}\text { nuxx } \\
\text { (Vertigo) }\end{array}$ \\
\hline TAIDIA & & & & \\
\hline $\begin{array}{l}\text { Tumult } \\
\text { Agitation } \\
\text { Immoderate laypene }\end{array}$ & $\begin{array}{ccc}\text { Racing } & 1 & \\
\text { Wrenting } & & \text { not } \\
\text { etc. } & & \text { regulated } \\
\text { Athletics } & \text { | } & \end{array}$ & $\begin{array}{l}\text { Countangout } \\
\text { rhymes } \\
\text { Heads or tails }\end{array}$ & $\begin{array}{l}\text { Oildnes ' initiations } \\
\text { Carnes of illusion } \\
\text { Tag, Arms } \\
\text { Mals, Disguises }\end{array}$ & $\begin{array}{l}\text { Children "waikire"" } \\
\text { Horseback riding } \\
\text { Swinging } \\
\text { Waltzing }\end{array}$ \\
\hline $\begin{array}{l}\text { Kite-flying } \\
\text { Solitaire } \\
\text { Patience } \\
\text { Crossword } \\
\quad \text { puzzles }\end{array}$ & $\begin{array}{l}\text { Boxing, Billiards } \\
\text { Fencing, Checkers } \\
\text { Football, Gruss } \\
\text { Contests, Sports } \\
\text { in perneral }\end{array}$ & $\begin{array}{l}\text { Betting } \\
\text { Roulette } \\
\text { Simple, comples, } \\
\text { and continuing } \\
\text { lotteries }\end{array}$ & $\begin{array}{l}\text { Theater } \\
\text { Spectacles in } \\
\text { general }\end{array}$ & $\begin{array}{l}\text { Voladve } \\
\text { Traveling carnivals } \\
\text { Skiing } \\
\text { Mountain climbing } \\
\text { Tyltrop walking }\end{array}$ \\
\hline Lupes & & & & \\
\hline
\end{tabular}

In each vertical selsmen games are classified in such an order that the psina element is constantly increasing while the Ambelement is ever increasing.

Table I2-I. From Gaillois' Man, Play, and Games (1958) 
passive; he does not deploy his resources, skill, muscles, or intelligence. All he need do is await, in hope and trembling, the cast of the die." (2) Or, he may realize the futility of trying to change his life through work and planning.

. . . many people do not count on receiving anything much on personal merit alone. They are well aware that others are abler, more skillful, stronger, more intelligent, more hard-working, more ambitious, healthier, have a better memory, and are more pleasing or persuasive than they are. Also, being conscious of their inferiority, they do not trust in exact, impartial, and rational comparisons. They therefore turn to chance, seeking a discriminatory principle that might be kinder to them.

The writer is not interested in the construction of this taxonomy as an end in itself, and neither was Caillois. He believes it can be put to several uses, not the least of which is that when it is lifted from its preoccupation with childhood games, it can be made an organizational scheme for much of the literature that purports to describe and analyze gambling. That is, these several categories can be made to subsume many of the bits and pieces of information and many loose ends in the literature. It is reasonably wide in scope and is comprehensive in a way that many other descriptive statements applied to gambling are not.

For example, this scheme implies that the fun or the entertainment function often ascribed to gambling can be understood to be one or more of these variables in combination. The writer believes that it implies that risk-taking may often be a minor rather than a major feature of gambling." He suggests that mimicry and vertigo account for the ostentation of high rollers; that mimicry efficiently describes much of what is meant in various writings by "role playing," "preparation" or "rehearsal" (Sutton-Smith, Roberts and Koselka, 1963) for adult life, or display of "character" (Goffman, 1967) in casinos. Vertigo may sub-

*We can almost do without the concept of risk in understanding many specific cases of gambling behavior, but we cannot do without money (or its equivalent). The function of money seems to be that of reifying the game, of making it more immediate and intense. In the phrase of Nick the Greek, money is merely "a way of keeping score," and keeping score allows the game to acquire other characteristics such as those cited by Caillois. 
sume such categories as the release of pleasurable-painful tension, thrills and expressive self-lesting,as well as many of the fanciful sexual metaphors that have plagued this field since Freud conjured up his essay on Dostoevsky and his father. The writer suggests that, when validated, this conceptual scheme will constitute a more efficient paradigm than the medical model with its overdramatic imputations that gamblers tend to be self-destructive, death-seeking, irrational, wasteful and marked by infantile megalomania (Bergler, 1957). Again, the reason for preferring Caillois's model to the medical one is not just that the former is less outlandish and more parsimonious, but that it is based on an evaluation of games played by children and adults, games generally and properly understood to be thoroughly interlaced with the normal, the typical, the mainstream life of the larger culture. Competition, chance-taking, mimicry, vertigo and rule-making are all conventional, acceptable, mundane aspects of life. They are learned the same way anything else is learned, and they can be expressed in hundreds of different ways, including gambling.

There is another measure of the value of a conceptual model quite apart from whether or not it is parsimonious. Can it generate testable hypotheses? The writer will suggest some hypotheses that state relationships between one or more of Caillois's concepts and some other variable which has been or might be measured. (These have been drawn for illustrative purposes from a much larger list developed to be published in a forthcoming book.)

Hypothesis 1 . The larger the probability of winning a prize (and therefore the smaller its size relative to other possible prizes), the more the agonistic experiences are enhanced, but (Hypothesis 2) the less vertigo is enhanced.

In most gambling situations, as the relative size of a prize increases, the chances of winning it decrease. There are exceptions such as stock market speculation where the size of a prize may increase as the speculator watches it grow in popularity, but for most gambling the inverse relationship holds. Nothing seems to encourage the competitor more effectively than the experience of winning and of winning fairly frequently and with some regularity. (Behavioristic learning principles apply here with clarity.) 
The vast majority of regular horse players bet on short-prized horses which, again, are those with the best chances of winning. (Favorites, for example, win approximately one third of all races.) It is apparently the desire to win some prize, however small, that accounts for the phenomenon called prohibitive favorites. To the extent that horse playing may be regarded as an agonistic game, that is that players regard each other as competing for portions of the same pari-mutuel pool, this example illustrates the hypothesis. Another illustration of the way in which the appearance of probable victory encourages competitive effort is found in the principle technique employed by poolroom hustlers and poker players (Polsky, 1967; Gerogeseu-Roegen, 1958). Both of these players must encourage other players in the illusion that they, the victims, are more skillful than they really are. To do this requires the use of various deceitful methods including making shots or good moves as though by accident, allowing the player with inferior ability to win a few games, but not too easily.

Hypothesis 3. The greater the sense of physical distance between a player's home and the gambling arena, the more aleatory games are encouraged, and, (Hypothesis 4), the more mimicry is encouraged, and (Hypothesis 5) the more vertigo is encouraged.

The phrase sense of is used here to make a distinction between geographical distance and the impression that one is in another place from that which he ordinarily frequents. As it happens, in the United States the only legal casinos are in the state of Nevada which is remote in distance from any concentration of population. (It takes about five hours to drive to Las Vegas from southern California cities, for example; longer from any other metropolis.) Yet most American cities have horse race tracks very close at hand. (Aqueduct race track has its own subway station inside the track area.) European cities frequently have their own casinos inside the immediate city limits, but, in many instances, local citizens are prohibited from gambling in their own cities; the reason given for this ruling is that it is desirable to attempt to protect citizens from daily temptations, but, as this hypothesis suggests, chance-taking, mimicry and vertigo are all encouraged as a consequence. The writer also means to draw attention here 
to the sense of being in an unfamiliar location. If one is forced to travel a considerable distance in order to gamble, and especially if one finds that the gambling place is located in a geographically different spot (a spa, desert, tropical island, a ship cruising or anchored off-shore, as in some of the ocean-going casinos still in existence but more popular in American waters a couple of decades ago), then this sense is strongly reinforced.

The sense of distance from home is very useful in releasing the individual from the bind of conventional responsibilities and controls. Chanciness can then increase in influence. As Golfman says, "For chanciness to be present, the individual must ensure he is in a position (or be forced into one) to let go of his hold and control of the situation. . . " (Goffman, 1967). One must let other forces gain influence than those which are accorded primacy in the conventional, ordinary world at home. Moreover, this sense of separation from the places in which one plays his normal roles is helpful if he is to play roles (mimicry!), if one is to enact another identity in a new scene.

Hypothesis 6 . The more interdependent a series of gambling events are, the more aleatory games are encouraged, and (Hypothesis 7) the more vertigo is enhanced.

I have in mind here those kinds of sequences often referred to as parlays or exotic bets, bets which accumulate all the possible winnings from one event, then provisionally become assigned as stakes in subsequent plays. Also included are bets on a single event which specify a particular order of winning as in exacta betting. Craps rules call for conditional bets as in the procedure for coming out with a requirement of subsequently making a point. Also included are the simple dependencies of series of draws, as in bingo-like games in which players hope for specific numbers before the game is won by rivals. The direct effect of such sequences is to increase payoff odds which intensify the desire for the final prize with each successful stage or cycle. Enhancement of vertigo is the result. The writer would argue that exotic betting enhances aleatory involvement much more than agonistic involvement, and, in fact, it may actually detract from the latter. Directly related empirical research is badly needed 
regarding this hypothesis, however, and this should be fairly simple to do given the fact that in both horse race tracks and casinos there are now large numbers of people who make one or the other or both kinds of bets (that is, simple, straight bets versus complex sequences) .

To summarize this chapter the writer has argued that Caillois has given us a taxonomy of game-playing motives which describes gambling activity more efficiently and more comprehensively than other models currently in use. The model can also generate verifiable hypotheses as one test of its capacity to predict and account for gambling motives. This conceptual scheme is based on the analysis of a wide variety of conventional games, and when translated to gambling contexts, it points to their conventional, ordinary, normal qualities rather than their more eccentric $c_{4}$ bizarre and deviant characteristics.

\section{REFERENCES}

Bergler, E.: The Psychology of Gambling. New York, Hill \& Wang, Incorporated, 1957.

Caillois, Roger: Man, Play and Games. 1958.

Gerogeseu-Roegen, N.: Threshold in choice and the theory of demand. Econometrica, XXVI:157, 1958.

Goffman, E.: Interaction Ritual: Essays on Face-to-Face Behavior. Garden City, Anchor Books, 1967.

Huizinga, Johan: Homo Ludens, 1938.

Polsky, N.: Hustlers, Beats and Others. New York, Doubleday, 1967.

Sutton-Smith, E, Roberts, J. M.s, and Koselka, R. M.: Game involvement in adults. J Soc Psychol, 60:15, 1963.

Szaz, Thomas: The Myth of Mental Illness. 


\section{Chapter 13 \\ BAMHLING: A POSITIVE VIEW \\ FELICIA CAMPBELL}

Even if gambling were altogether an evil, still on account of the very large number of people who play, it would seem to be a natural evil. . . Thus it is not absurd for me to discuss gambling, not in order to praise it, but in order to point out the advantages in it, and, of course, also its disadvantages, so they may be reduced to a minimum.

GERALAMO CARDANO, LIBER LUDO ALEAE (Circa 1530)

T Is TIME THAT WE VIEW gambling both as realists and as 1 humanists and consider the positive effects that it may have both for the individual and for society at large. The professional literature on gambling, at least that in English, largely ignores gambling as a normal part of human behavior, treating it much as the Victorians treated sex. Most of the behavior studies are flawed, either because the investigators have known too few gamblers who are not familiar enough with gambling, or because they possess cultural and emotional bias of which they are largely unaware.

For example, Edmund Bergler's The Psychology of Gambling (1957) is considered the classic in the field in the English language, and almost all psychological studies refer to it, yet Bergler was personally not very familiar with gambling and viewed any consistent gambling as psychomasochistic. His theory was that, since the odds against winning are great, people must gamble in order to lose to punish themselves for something. His study was based on a group of sixty neurotic patients, most of whom did not consider their gambling a harmful activity until he had convinced them of it through long analysis. Concerned about gambling as an attack on bourgeois values, he called the gambler "a rebel," attacking what he called his "invariable individualism." Further, 
seemingly to believe in an ordered universe, Dr. Bergler attacked the irrational in gambling, feeling that "the lucky gambler is a myth."

Much of his theory echoes Thorstein Veblen who called gambling "a hindrance to the highest industrial efficiency of the aggregate in any community where it prevails" and concluded that "it should be seen as destructive in an industrial society" (Veblen, 1899) .

While it is not necessary to belabor the point with numerous quotations from the literature, it should be noted that the decision-maker who sought contemporary information on normal gambling has until very recently found nineteenth century ideas couched in twentieth century terminology.

The writer's participant observation studies in Las Vegas, where gambling makes up a major portion of the economy, show that, by and large, gambling is beneficial to the gambler and increases rather than decreases his efficiency and productivity.

A word about Las Vegas is in order here. Las Vegas provided the writer a unique laboratory for this study as it is the largest city in the United States in which all forms of gambling are legal. It is a city of approximately 305,000 persons with a work force of 133,000 ; almost 80,000 or about 60 percent are directly or indirectly dependent on gambling for their livelihood. In the last decade when the national population increased by 12 percent, the population of Las Vegas increased by 112 percent. On a busy weekend as many as 50,000 tourists swell the population, a figure that will be greatly increased within the next few years by the opening of several new hotels such as the massive M.G.M. which is claimed to be the largest hotel in the world. Thus, it can be seen that gambling is simply a fact of existence in this city.

Aside from the gambling Las Vegas is a typical American city. The large residential areas are similar to those everywhere except that they are all new. The University of Nevada, Las Vegas, has about 7,000 students studying everything from hotel management to desert biology. The crime rate is about average for America, and one may walk alone at night without fear.

It might be noted here that the writer was anticipated in these 
findings by Geralamo Cardano, sixteenth century universal genius, who prescribed gambling for melancholy, noting that it lightened cares that one would not otherwise be able to endure, and that "play may be beneficial in times of grief and that the law permits it to the sick and those in prison and those condemned to death" (Cardano, 1963) .

The latter practice is most humane, and Nevada, whose prisons are notorious, allowed gambling in these until recent years. One former inmate told me that being allowed to gamble was all that saved his sanity during his years of incarceration, and that he was sure that the same was true for others also. He explained that gambling provided for him an oasis in the midst of the vermin, bad food and brutality in that for the moment he $\mathrm{j}$ could lose himself in the play, making decisions and feeling for 1 the moment that he was human again.

- Perhaps if prisons are to be other than expensive means of vengeance for society, gambling might be included as a form of recreation along with retraining to return convicts to society as other than embittered habitual criminals.

Karl Jaspers (1951) has said that "whenever people are reduced to the position of those who merely have to perform an allotted task, the problem of the cleavage between being a human creature and being a worker plays a decisive part in the individual's fate." Thus, man strikes out; the preservative impulse becomes manifest as the individual strives to sustain energy and courage. That preservative impulse may take the form of gambling. This preservative impulse has also been called the adventure within us, and lies at the root of the gambling mystique. It involves the wooing of the unknown, chance, danger and all that is new, thus it is the action that the gambler loves, not the money in most cases, except that it allows him into more action.

As the preservative impulse is necessary for the preservation of the self, it would seem not only wise in humanistic terms, but practical in economic terms to capitalize on it in all of its forms rather than attempting to stifle it.

To illustrate from her observations in Las Vegas, the writer stresses findings among both the aged and the working classes. 
In the following discussions, she quotes from her forthcoming book, as yet untitled. The first group of persons she calls "elderly life seekers." Old people throng to Las Vegas, often choosing to retire there. They are so numerous that natives often refer to the town as an old folk's home.

The writer confined her interviews with aged to the downtown casinos where locals of slender means are more likely to gather than on the more expensive Strip. As the locals have a tendency to pick favorite spots to play in, it is fairly easy for a researcher to habituate a spot long enough to be considered a regular, and to be able to speak with ease to the other players.

Many of these players are elderly women, some wearing house dresses, others wearing bright slacks and clogs, all clutching cups of coins as they watch the bell, fruit and bar twirl again and again. They are totally absorbed as are most real gamblers. In that absorption lies the clue-they are once more engaged in life. A representative selection of their comments illustrates this. One sixty-eight-year-old woman, a native of Kansas, told the researcher that she lives alone and has a very small pension. Her daughter had wanted her to come to live with her, but the woman refused. As she explained it, "I didn't want to be no built-in baby sitter. I raised my kids. I kept my house. Now I want something different. Here I can wear what I want and play the machines. I never lose much and I like to play. Whenever the money drops, I feel real good. I won something, and I ain't won a lot of things in my life."

If one considers the possibilities of this woman's life, or the lives of others like her who are legion in the area, it becomes evident that she has, in a sense, made a choice for life. She has her independence, and the small victories that she experiences at the slots are probably greater victories than she might have experienced had she remained at home in Kansas.

It should be added here that subsequently putting one's winnings back into the machines seems in no way to diminish the pleasure gained from the jackpots. The day is counted not in how much was taken home, but in how many jackpots were won and the amount of play that one was able to sustain on the amount of money invested. In other words, as for the adventurer, it is the 
action that counts.

The size of the investment naturally varies with the finances of the player. For example, there are a number of one-cent machines in Las Vegas. One would assume that there could be little or no thrill involved in playing for such small stakes, yet the penny players seem as absorbed as the bettors hazarding thousands. Conversation with some of them revealed why. A typical respondent, a woman of about sixty, remarked, "I get five chances instead of one for my nickel. I don't have much money and it makes it last longer. I know I can't win much, but when a winner comes up it makes me feel awful good, Honey. When those pennies fall down, I feel like I'm ahead even if it is just pennies." One is reminded of Dostoevsky's Alexii, "What is paltry to Rothschild is wealth to me. . ." Other penny slot players do so primarily when the end of the month is near and they cannot afford anything else.

Bingo is also popular with elderly persons on fixed incomes. Here they can achieve a kind of camaraderie while they play; this is not so evident with slot players. Further, bingo has a generally respectable reputation because it has been so widely used around the country for fund-raising for church and civic groups. Here, once more, is a form of life involvement. Further, all persons playing such random games as slots, bingo and keno are essentially equal. Skill is not reflected to any appreciable extent, and the rich dowager and the cleaning woman have the same chance of marking their cards correctly. Thus, one who may never have had a chance in life, here, for the moment, has a chance equal to that of anyone else. The odds may be against winning, but they are equally against the winning of all of the participants.

These people are not occasional gamblers. According to the dealers the same persons play night after night and year after year. Gambling for those persons, albeit for small stakes, is a substantial part of their life style, and one from which this researcher would be loath to wean them.

Many old men also frequent the downtown casinos. Far from being persons who have destroyed themselves gambling (as tour- 
ists often assume), they are typically the retired of the working class. Railroad men, factory workers and ex-servicemen abound.

They seem to favor craps and roulette which can be played for nominal sums in the downtown casinos. Their motives seem to be similar to those of the women discussed above. The researcher feels that it is probable that old male players of random games discussed above have similar motives to those of the women; however it was much more difficult to converse with the male players than with the women. Therefore, the information about male crap players (craps being a game in which skill can enter) was gained from downtown casino dealers. Of course, there are also women who shoot craps.

Playing cautiously, old male players often manage to add to their meagre holdings and feel an increased self-esteem. They usually frequent casinos with a homey air where they are known, and a good deal of their socialization occurs in the casinos. Here, either before or after play, they can talk with their cronies over a forty-nine-cent breakfast or a ninety-eight-cent buffet. Thus, the whole scene provides them with a reason for being. While gambling may not be the most laudable of reasons for existence, it may well be as valid as any other if one is to think in existential terms. Davis (1955) calls gambling a concentrated simulation of life itself which, if true, as it well may be, could provide an additional explanation for its enchantment for the old. Momentarily they feel alive and involved; possibilities exist; victories are possible and tomorrow the game exists to be played again. These are not inconsiderable factors in a culture which no longer honors its aged, excluding them from productive life before their capabilities are gone, and shutting them away whenever possible.

From the writer's observations it seems a shame that old persons are not, in general, allowed access to gambling. The homes for the aged might do well to incorporate some forms of gambling into their program to add spice to the old peoples' lives rather than keeping them stupified on tranquilizers during their last years as is too often the case.

Another class of gambler the writer calls the dream buyer. The chance in a million is a very important one for millions of people 
for whom the American dream is unlikely to become a reality. If one is to spend one's life as a "mophead and toilet brush for the white folks" as one character put it in Iceberg Slim's Mama Black Widow, then a ticket on the numbers (or in keno) is one of the best investments that can be made, as it provides momentary hope at minimum cost, and there is always the chance of making a score, a chance which exists on no other level if one is to consider circumstances realistically.

The lower-middle class working individual described by Robert C. Wood when he was undersecretary of HUD also shares the desperation motive) for, although not excluded from the dream, it has not worked for him either.

$\mathrm{He}$ is a white employed male. . earning between five and ten thousand dollars a year. He works regularly, steadily, dependably, wearing a blue collar or a white collar. Yet the frontiers of his career expectations have been fixed since he reached the age of 35 , when he found that he had too many obligations, too much family, and too few skills to match opportunities with expectations (Schragg, 1966).

\section{His futility is described by Cartwright,}

For wherever we look about to see what it was we were working for, what do we see: a house that wasn't built well enough to raise our children, broken appliances in the garage, two cars falling apart while only one or two-years-old, furniture that was once so pretty you felt you had to cover it with plastic, an electric kitchen with a trash box full of TV dinner tins (Cartwright, 1970).

Archie Bunker of the American television series represents this working individual. As Schragg says, "He does all the right things, obeys the law, goes to church, and insists usually that his kids get a better education than he had. But the right things don't seem to be paying off." Realistically, there is nothing he can do about his situation. He probably has little or no chance for decision-making in his job. As an outlet he may play the horses. "If you win," as Schragg notes in passing, "you figure you have in some small way controlled your world, have surmounted your impotence. If you lose, bad shit."

Interviews in Henderson, Nevada, confirmed that persons in this situation gamble as an outlet of this nature. Henderson is an 
industrial community located a few miles outside of Las Vegas. Built during the World War II, the town is supported mainly by chemical industries such as Stauffer and Titanium, and lies beneath a heavy cloud of acrid chemical fumes which have been known to become strong enough to cause the foliage to drop from the trees and the gardens to wilt. Persons working there are aware of the probable danger they are doing to their health by living and working among the fumes, but there is little they can do. Unemployment is heavy and the plants are complying with EPA recommendations as slowly as possible. Many, many Hendersonites gamble. In Henderson, as in the casino center area of Las Vegas, one may play for very low stakes if he wishes, and the casinos have a homey, sawdust-type atmosphere.

The following comments are typical of those gleaned from Hendersonites. The first comment comes from a man about fortyfive years old who came to Nevada from Missouri. He says, "I work in the goddam plant all day. My kid don't like school; he'll probably work there too. Might as well be here as anywhere else. Sure I gamble. I'm a man, ain't I?"

Even though women gamble as frequently if not more frequently than men, many men seem to equate gambling with manhood. It may have something to do with the feeling of surmountung impotence mentioned earlier.

Time Buyers. A cleaning woman in the following quotation gives a reason for gambling often mentioned by dealers as part of their motivation in the days when they could move easily from job to job. (This was during the era before the large corporations took over the casinos, bringing with them the idea that job-hopping is bad.)

I'll tell you what gambling means to me. I may never hit it big, but when I hit it little, I call in sick and I don't go to work for as many days as I got money. It buys me some time for myself. It's the only way I can get anything for me. I'd rather have the time than to buy something. I know I'll work till I drop. I need time now. The people I work for won't fire me. I do good work and it's too hard to find anybody else. I like to play here because I know people and it's friendly. I know the twenty-one dealers real well and it makes a nice game. I don't use the money for the bills and I never spend a lot. 
Thus, brief freedom from an unrewarding occupation is the reward sought by some along with the pleasure of play.

Small Rebels. The response of a man about thirty years old Was,

What the hell else are you going to do on a Saturday night? I use gambling money when I gamble. The wife would kill me if I took the living money. 'Course I get outta line once in a while, but you gotta expect that of a man. I ain't no saint. 1 wouldn't have no respect for a man who never got outta line. All day long, you do what them dumb supervisors tell you. Don't make no difference if it makes sense or not. Sometimes you just gotta get outta line and I take my check and have one hell of a time (laughter). When I win, I take the money if I come to in time (more laughter) and give it to the wife. She gets something she or the kids seem to be wanting. She don't care. I'm easier to live with for a while, I guess.

This man's need to get out of line seems to represent the need to make a choice to assert his freedom from both his supervisor and his wife. One wonders what avenue this urge would take if he lived in another community. In most states, if he wants to gamble he will have to do so illegally, perhaps freighting his outlet with guilt.

One author has noted in a study of Hollywood horse racing that "racing represents an artificial crisis to jaded spirits" (Rosten, 1967). It may provide the same emotion for the trapped factory worker, a crisis which allows him to function fully at the moment.

An elementary school teacher, a young man just out of college and on his first teaching assignment, described his feelings a little differently,

I teach school all week. Somehow I thought I would be doing more good. Do you know a lot of my kids come to school hungry? They've got problems I can't touch. Anyway, I get depressed, so I make a few bets. Of course, they're small. A teacher's salary. But I feel better. It takes me out of things for a while. I get lost in the game. I suppose that's what most people do. It helps.

Thus, gambling helps him to stave off depression and enables him to go back to work to do what he can.

A young secretary has more grandiose dreams,

I suppose I shouldn't gamble, but I'm not hurting anybody; and God, do you know what it would mean to get out of here? No more 
typing, no more desert, no more Henderson. I mainly like to play keno on the Strip. It's more glamorous. If I hit it big, wow! I can never save enough to be somebody, but I just might win enough. That's why I play keno. You can win a lot forjust a little money.

Miller feels that "lower class individuals feel that they have relatively little control over the forces that rule their lives and that direct effort toward a goal is futile" (Miller, 1958). This young woman illustrates the truth of that principle, a denial of its futility.

Dire economic circumstances seem to stimulate gambling. Gaming personnel on all levels have noted that during a recession the amount of gambling increases. As Chafetz remarked, "The depression, far from having a sobering effect on gamblers, stimulated them. They reasoned that it was better to dispense with what little they had for a chance of hitting the jackpot than to worry along with less than enough" (Chafetz, 1960).

This is a kind of decision-making. Rather than submit to what the fates seem to have decreed, the gambler reacts. As Alexii says, $" .$. a strange desire rose up in me, a sort of defiance of fate, a desire to challenge it, to put my tongue out at it" (Dostoevsky, 1945).

So we find that millions of small gamblers, men and women, with families and without, often find that gambling provides $\mathrm{j}$ them with the opportunity to participate in the decision-making process that is often denied them in factory, office or home. It offers them the opportunity to win and to experience the joy that comes with winning, and it offers momentary hope. Seldom venturing more than they can afford, they are for the moment able to escape the humdrum of their daily existences and experience the peak emotion of total involvement.

From the above it seems reasonable that experiments should be run on gambling as recreation for these persons. It seems possible that accident rates could be cut and absenteeism reduced if the workers were given gambling breaks, perhaps run by the firm, much as they are given coffee breaks today. It would not even be necessary for the prize to be in cash. As has been illustrated, time off can often be as valuable to the worker as money itself. 


\section{REFERENCES}

Bergler, E.: The Psychology of Gambling. New York, Hill \& Wang, Incorporated, 1957.

Cardano, G.: Liber de Ludo Aleae, Sydney H. Gould (Trans.): Cardano, by Ore, 1963.

Cartwright, L. W: The new hero. In Butz, Otto: To Make a Difference,Reprinted in Hard Rains, Robert Disch and Barry Schwartz (Ed.). Englewood Cliffs, Prentice-Hall, 1970.

Chafetz, H.: Play the Devil: A History of Gambling in the United States from 1492-1955. New York, Bonanza Books, 1960.

Davis, C. B.: Something for Nothing, New York, J. B. Lippincott Company, 1955.

Dostoevsky, F.: The Gambler. Constance Garnett (Trans.), New York, Dial Press, 1945.

Jaspers, K.: Man in the Modern Age. London, Routledge and Kegan Paul, Ltd., 1951.

Miller, W. B.: Lower class cultures as a generating milieu of gang delinquency. J Soc Issues, 14:5, 1958.

Rosten, L.: The adoration of the nag. In Herman, R. D.: Gambling. New York, Harper and Row, 1967.

Schragg, P.: The forgotten American. Harpers Magazine, August, 1966, p .29.

Veblen, T.: The Theory of the Leisure Class. New York, The Viking Press, 1899. 


\title{
Chapter 14
}

\section{ALIENATION FROM WORK: A STUDY OF CASINO CARD IIEALEHS}

\author{
RONALD W. SMITH, FREDERICK PRESTON AND HARRY L. HUMPHRIES
}

$\mathrm{E}$

ARLY SOCIOLOGISTS frequently linked the concept of alienation to the world of work. (See the following sources for a general discussion of the concept of alienation: Feuer, "What is Alienation; The Career of a Concept," in Stein and Vidich (1963), Israel (1971), Kon (1967). For example, Marx felt that creative work is man's most important activity. It allows man to experience himself as an active and conscious being, to freely express his personality and to satisfy his basic needs. Marx contended that the worker who is subjected to the capitalistic conditions of manipulation and exploitation, mechanical processes and division of labor would not only become alienated from his work, but from all of his social world (Bottomore; 1964). Weber also expressed concern about the new industrial order and its alienating effect on workers. The bureaucratic rationalism of the new order would force workers to become impersonal with each other, would create a greater worker dependence on administrative authority and decisions, and would subjugate workers to the status of being a cog in the bureaucratic machine (Nettler, 1957).

Based on the tradition of Marx and Weber, contemporary sociologists have continued to examine the alienation of the worker. C. W. Mills (1951) emphasized that workers in bureaucratic organizations, regardless of their standard of living, become alienated because they are asked to engage in monotonous and uncreative work, and because they are forced into interpersonal relations which are based on manipulation and exploitation of others. Walker and Guest (1952) and Guest (1955) found that automobile assembly line workers viewed their jobs as meaning- 
less tasks. Similarly, Chinoy (1955) found that automobile workers experienced no intrinsic rewards from the job and that only the extrinsic rewards of salary and other material benefits supplied motivation for these workers to continue their work. Blauner (1964) found that the powerlessness, meaninglessness, isolation and self-estrangement dimensions of alienation were unequally distributed among manual workers across four industries-textiles, printing, chemical and automobile. He concluded that the nature of a specific industry's technology and work organization produced different dimensions of worker alienation. Pearlin (1962) studied the alienation of nursing personnel in a mental hospital, and observed that highly alienated workers were often placed in situations of great positional disparity in reference to their superiors, and were frequently lacking friendship bonds with fellow workers. Aiken and Hage (1966) examined worker alienation within sixteen welfare organizations and found that alienation from work and alienation from expressive relations were more prominent in highly centralized and highly formalized organizations. Finally, Miller (1958) found that lack of freedom in research choice and lack of professional climate were strongly related to alienation from work among all types of professional workers.

This study is a further examination of the concept of alienation as related to the world of work. It is concerned with Las Vegas casino card dealers' feelings of alienation in reference to their work and the possible causes of that alienation. Although professional card-dealing is a relatively small occupation in American society, and one about which few people have any direct information, many have an image of the occupation which resembles the riverboat gambler character portrayed in early motion pictures. That character was portrayed as living in a special world of excitement, variety, contemporary life, mystery, money and power, and contact with glamorous people. The researchers doubted that dealers viewed their own work in such a manner and thought that dealers might experience an unusually high degree of alienation in reference to their work, i.e. possibly dealers see themselves as involved in an extremely boring, un- 
imaginative, meaningless and powerless job. It was thought that those interested in the areas of sociology of occupations and industrial sociology, the phenomena of alienation and its causes, and the relationship between a societal problem and a specific work setting could benefit from such a study.

\section{RESEARCH METHODOLOGY}

A context-specific approach was utilized in the study to examine dealers' feelings of alienation. To examine alienation by this approach the researcher should select a smaller social system, postulate who within the system is alienated, postulate what dimensions of alienation are experienced by these individuals, postulate from whom and/or what within the system the individuals experience alienation, and develop some type of indicators such as test items which take into account the postulated dimensions and from whom and/or what within the system the individuals experience alienation (Smith, 1971, 1972). Contemporary researchers are increasingly using context-specific strategies to examine alienation rather than using the traditional global approach. A context-specific approach allows the researchers to delineate better the dimensions of alienation, to develop a more justified rationale for indicators of alienation, to understand more completely the relationship between or among dimensions of alienation, and to understand better the causes of alienation."

The researchers had some knowledge about the gambling subculture of Las Vegas before the study began. In fact, one researcher had been a part-time casino dealer. This background knowledge was helpful in the formulation of the study and led the researchers to think that dealers might experience the dimen-

*A global approach views man's alienation as experienced from larger, ill-defined social systems and conditions, such as society, culture, life and war. See Dean (1961), Nettler (1957) and Srole (1956) for examples of where alienation has been viewed as a global concept. In contrast, a context-specific approach examines man's alienation within a more specified social situation. See Clark (1959), Pearlin (1962) and Stinchcombe (1964) for examples of where a context-specific approach has been utilized. 
sions of powerlessness, normlessness, meaninglcssness, social isolation and self-estrangement in reference to their work.1 The researchers characterized each of these dimensions to fit the occupation to be studied. For example, powerlessness was characterized as the dealer's feeling that he had no control over his immediate work conditions such as pay, promotions, shift to be worked, status of the game to be played, and vacations. Each dimension was characterized in various ways. It should be noted that there was no strong commitment that dealers had to subjectively experience these and only these postulated dimensions.

Two research tools were used in the study. The first tool was a sixty-four-item Likert summated-rated type scale designed to measure dealer alienation. Items were developed based on the characterizations within each of the five postulated dimensions. Furthermore, some items included references about three groups of people with whom dealers were assumed to have close contact in their jobs: bosses, customers and fellow workers. After the items had been pretested and checked for face validity, the researchers reduced the scale to thirty-five items. After the sample of dealers had taken the thirty-five-item scale, items were then subjected to a test of item homogeneity." This test aided the researchers in seeing how well specific items clustered in reference to postulated dimensions. Eventually, only twenty-three items were considered valid indicators of dealer alienation and were used in the data analysis.

Structured questions concerned with the dealer's history of employment, marital status, age and similar indicators, and the alienation scale items were asked of participants in an interview situation. (See Appendix 14-I for retained alienation scale items.) After the dealer had responded strongly agree, agree, undecided, disagree or strongly disagree to each scale item, he was asked if he wished to explain or expand upon his answer. Furthermore, after

tThese dimensions of alienation have been prominent themes in social science literature. See Seeman (1955), for a discussion of the traditional meanings given to these dimensions of alienation.

"The test of item homogeneity examined the degree of interitem similarity within each postulated dimension. The test provided clues as to unidimensionality in terms of what specific items were intended to measure (Roweboom, 1966). 
the alienation scale had been given, researchers probed at great length into issues and factors possibly related to the dealer's alienation. This second unstructured technique consisted of asking neutral probe questions of participants about their work. The usage of the two research techniques helped to corroborate evidence from which the researchers could draw inferences.*

Forty-four Las Vegas casino dealers were interviewed from December, 1972, to March, 1973. The dealers who participated in the study represented many different casinos in the community and were primarily involved in the game of twenty-one. The sample was dominated by Anglo male dealers because of the few females, blacks and other minority group members found in the occupation. Only seven Anglo females and two black males were interviewed in the study. Furthermore, the sample was dominated by married individuals, and those in the sample were of a relatively young age. Only eleven dealers were single, and only twelve dealers were over age thirty-five. There were many problems involved in obtaining a representative sample. For example, there was no way of knowing how many dealers existed in Las Vegas or exactly how many dealers were females, blacks, married and so on. There was also the major problem of lack of cooperation on the part of some casino managements in reference to researchers watching or questioning dealer employees. It was this problem that kept the researchers from using any kind of observational technique in the study. However, the researchers felt that the forty-four interviewed dealers provided valuable insight into the feelings of dealers in reference to their jobs. Dealers were approached and asked on a volunteer basis to participate in the study. Although this means of obtaining a sample cannot be interpreted as systematic, it was the only practical way to reach dealers and to encourage them to participate in the study. The interviews were always held in a setting away from the casino in which the dealer worked to help assure anonymity and truthfulness in responses from participants. Interviews lasted from one to two hours and were recorded on tape.

"The researchers carefully examined both the manifest and latent content of dealers' statements made during the taped interview. For a discussion of the manifest-latent approach in interpreting data see Holsti (1969). 


\section{FINDINGS}

\section{Powerlessness}

Dealers in the sample experienced a high degree of powerlessness in reference to their work. For example, the seven items in the alienation scale measuring powerlessness yielded a grand mean of 4.23 among all respondents. This score indicated a high degree of powerlessness since a value of 5.00 was the highest score possible. Also, thirty-eight of the forty-four participants received a mean score of 3.50 or higher on powerlessness items.

In the unstructured part of the interview the dealers indicated that they experienced much of their powerlessness with reference to casino bosses, particularly pit bosses." These bosses have immediate control over dealers. They were frequently characterized as being dictators and were said to hold the attitude that the casino is all important and that the dealer is just a cog in the machine. It appears that pit bosses virtually control every aspect of the dealers' work. For example, the pit boss can reduce the amount of tokes or tips a dealer earns by placing him on day shift or placing him on a table where there is little gambling action. The pit boss also controls promotions and dismissals. Thirty-two participants indicated that pit bosses could not be relied upon to help the dealer keep his job. Some bosses were said to have fired dealers without forewarning and without real justification. Bosses were reported to have fired dealers on the basis of the dealer simply losing too much of the casino's money,? talking to customers too much, not following superstitious rites that bosses believed would bring the casino good luck, just once playing house cards the wrong way, not detecting a customer who

"Powerlesenes as a dimension of alienation had its origin with Marx and was discussed by Weber, C.W. Mills (1951) and others.

tThe term toke developed from the use of chips or tokens as a primary means of exchange in casinos. Tokes are actively encouraged by dealers.

tMany casino bosses are superstitious gamblers themselves, unable to rely on the standard house percentages $(6 \%$ for $21,1.4 \%$ on craps, $5.3 \%$ for roulette, 1.3$3.5 \%$ for baccarat and $18.6 \%$ for the money wheel). Bosses often change both dice and dealers when a crap shooter is having a good run of luck and consistently speak of lmchy and unlucky dealers. If a dealer establishes himself as very unlucky, he finds that it takes a great amount of juice to keep his job. 
was cheating, or simply dealing the cards too slowly. Dealers evidently have no alternatives other than accepting the decisions made by pit bosses.

The entire sample indicated that juice or close connections with influential people such as gamblers in other cities, casino owners and managers, wealthy individuals and politicians is the major factor that helps a dealer change aspects of his job.t Skill and experience in one's job were considered to be of much less importance. Having juice often enables the person to get his first dealing job, helps the person move from the older and less glamorous downtown casinos to the prestigious Strip casinos, sometimes allows the person to receive special favors from bosses in day-to-day work activity, and appears to be a prerequisite if a person wishes to enter hotel-casino management jobs or obtain the much desired and lucrative position of baccarat dealer. Dealers who do not have juice are placed in a particularly insecure and vulnerable position in reference to their jobs.

The sample indicated that unions have never been and probably will never be considered by Las Vegas dealers as a vehicle for gaming job improvements. The rejection of unions by dealers is due to several reasons. First, dealers are not a cohesive occupational group. Many dealers are young and define the job as a temporary way to make money. People are continually moving in and out of the occupation and moving from one casino to another. Dealers are divided in their loyalties to management and to their own occupational group. Some dealers have close loyalties to bosses and are instructed both to vote against unions and to talk unfavorably about unions to fellow dealers. In brief, there is a great deal of transiency and divisiveness within the occupational group. Second, dealers distrust union officials and feel that union officials are corrupt and self-seeking. Third, casino management

qLike tokes, juice seems to be peculiar to the casino subculture and has its origins in the old days of small time crooked dice and roulette games which were controlled by hidden electromagnets. The electricity or juice enabled dealers to influence the games of the juice foints.

SThe terra Strip casinos generally refers to those casinos located in the large hotel complexes on Las Vegas Boulevard (Tropicana, Caesar's Palace, Hilton „ Dunes, Stardust, Sahara ${ }_{2}$ MGM Grand, etc.). 
often uses coopting devices such as giving dealers small favors to not to vote for unions. For example, one casino remodeled the dealer's lounge area shortly before a union vote was taken by dealers. Fourth, those dealers who do support unions must face the negative consequences from bosses once the union has been voted down. A dealer may be forced to work without days off, given worse tables, fired or even blacklisted so he cannot obtain another dealer job in a Las Vegas casino. Fifth, dealers believe that unions cannot realistically help them earn more money in their jobs, and, in fact, many believe that unions would actually inhibit how much money they could earn. The nature of the occupation is such that dealers who make a great deal of money do so from the tokes they receive from customers. They believe that the amount of tokes received is dependent upon the general economy, the prestige of their casino, and the favors they receive from bosses, and that these factors are beyond the power of any union to change. Furthermore, the dealers who believe unions would hurt their income explain that unions would require complete accountability of their earnings. Of course, dealers oppose public knowledge of their income since a significant portion of the tokes they receive are never declared as taxable income.

Of additional interest are the findings in reference to minority group members who are dealers. The sample indicated that black dealers and particularly female dealers usually have little juice and are generally disliked by Anglo male dealers, casino bosses and old time gamblers. Each casino is required to have a government-enforced ten percent quota of blacks and females among all dealers who are employed. The sample reported that blacks and females are sometimes placed on the day shift, at bad tables, and are promoted infrequently. Females are even considered to be unlucky dealers. One might think that minority group dealers would experience a greater degree of powerlessness than most dealers, but the opposite appears to be the case, at least among females. Six of the seven female dealers in the sample indicated low degrees of powerlessness as judged by their responses to scale items and informal comments. All six were proud to have broken into a male occupation and to be making a good income. As one female stated, "I don't care if I have any control in my job or if 
I ever move up the ladder. I make good money and it's better than being a cocktail waitress, hooker, nurse or secretary, which is all there is left for a woman to do." Possibly the fewer occupational opportunities available to women encourage female dealers to overlook the negative aspects of their work.

With the exception of female dealers in the sample, it appears that feelings of powerlessness in terms of changing the larger occupation and daily work conditions exist among most dealers. Furthermore, there was no difference in such feelings between those dealers who worked downtown and those who worked at the more prestigious Strip casinos.

\section{Meaninglessness}

In the study the dimension of meaninglessness generally referred to the dealer's lack of intrinsic pride in his work. (This characterization of meaninglessness is somewhat like that discussed by Seeman [1955].) Dealers experienced a high degree of meaninglessness. The four items measuring this dimension yielded a grand mean of 3.99 among all respondents. Also, thirty-five of the dealers received a mean score of 3.50 or higher on items measuring meaninglessness. Only three in the sample reported that they saw their occupation as giving a sense of personal satisfaction. Twelve dealers indicated that the job was so boring that they planned to leave the occupation as soon as another job came along. One dealer thought that 90 percent of all dealers were totally bored with their work and another dealer thought most of his coworkers hated their work because of boredom.

Participants consistently reported that they had no chance to express creativity or imagination because of the strict game and casino rules and the close surveillance by bosses, guards, customers and government investigators. Comments by dealers indicated that most see themselves as machines, just like the slot machines in the casino, which are there only to collect money. They are neither required nor encouraged to think in their daily work."

"Dealers are required to be very mechanical in their work as the rules under which they perform are very exacting. For example, a 21 dealer must take another card when his hand totals 16 or less and must not take another card when his hand totals 17 or more. 
Based on the comments of the sample, it seems that dealers see few intrinsic rewards in their jobs. The salary and tokes they receive are the only motivation for them to remain at their work, and evidently are the justifying factors that help them give less importance to or to repress the unpleasant aspects of their jobs.

\section{Social Isolation}

In the study the dimension of social isolation generally referred to the dealer's lack of meaningful and confiding relations with others in his work.t The sample expressed such feelings to a moderately high degree. The six items measuring social isolation yielded a grand mean of 3.61 among all respondents. Also, twenty-five of the dealers received a mean score of 3.50 or higher on social isolation items. Virtually all of the participants said that there were seldom any close friendships among people who were employed by the casino. Dealers often stressed that they wished they had more meaningful relations with fellow dealers, but that these people were difficult to get close to because of the variety and types of people who got into dealing, the large amount of dealer turnover within some casinos, and the close loyalties that some dealers maintained with bosses. Participants generally said they would seldom go to a fellow dealer for advice because most could care less about their problems. As one dealer stated, "Why should dealers care about each other? They come and go, and if one leaves or is fired, then that leaves room for someone else to get a job or get a raise." Some dealers reported that small dealer cliques sometimes developed that drank together and talked basically about women and sports, but that dealers were certainly not a cohesive group.

Apparently, the dealer sees himself as an isolated person. He is not allowed to form meaningful relations with customers for fear by management that he will get his mind off his work or that he will conspire with a customer to steal from the casino. He lacks

ISimmel's early discussion of the individual in conflict with the metropolis is one such example of how social isolation has been used in this way. See Nisbet (Nettler, 1957) for a discussion of simmel in this regard. 
close relations with bosses as previously discussed, and he cannot turn to fellow-dealers with his problems.

\section{Self-Estrangement}

In the study self-estrangement generally referred to the dealer's development of a social personality solely for the purpose of manipulation of others and gaining rewards. Under such extreme conditions the individual becomes estranged from himself." The sample experienced such feelings to a moderately high degree. The three items measuring self-estrangement yielded a grand mean of 3.54 among all respondents. Also, twenty-six dealers received a mean score of 3.50 or higher on self-estrangement items.

Participants often stated that their occupation had forced them to change aspects of their personality and their view of life. The dealers explained that the job forced them to treat virtually everyone in their occupation like objects to be manipulated. One participant characterized the whole casino as a stage where acts were performed by employees for the benefit of gaining money from customers and gaining favors from bosses. Several dealers thought that the occupations had made them callous and unresponsive people, not only in reference to others in their occupation, but in reference to all people. Eleven dealers indicated that their work had even affected their relationships with their marital partners. One participant stated, "Dealing makes you lose the value of everything. I first began to hate the local degenerate gamblers and then everybody." When dealers were asked to evaluate themselves in reference to their occupation, common reactions were that they sometimes felt degraded to be a part of the occupation and that they tried not to disclose their occupation to their neighbors or to discuss their jobs with close friends and relatives. Finally, fifteen dealers thought that they had resorted to greater usage of alcohol, pills and marijuana to escape the problems and pressures of their work.

It was the impression of the interviewers that most partici-

"Fromm (1955), Mills (1951) and Riesman (1950) have emphasized this general notion in describing self-estrangement. 
pants would tend to perform the role of riverboat gambler at the beginning of the interview. For example, dealers would initially flaunt the argot of their occupation by using terms such as George, Stiff, bleeder, third base, sawdust joint, shill, eye-in-the-sky. mechanic, box man, gaff, Mr. B, rabbit and shoe to possibly set themselves apart as existing in a special world." Virtually all participants would, at the beginning of the interview, emphasize the money and material objects that dealers possessed, the celebrities that played at their tables, the gambling knowledge they possessed, the unique superstitions of the occupation, the mysterious figures associated with gambling, and the special favors they received from people in the business. Toward the end of the interview, however, participants would begin to present quite a different picture of their occupation and their feelings toward it. The participants would tend to drop their fronts and begin to be more self-reflective, emphasizing the less glamorous aspects of their jobs. One dealer said, "I think dealers, and that includes me, are always acting big and important, but deep down they know how boring the job is and how much crap they have to take from people." Like so many devices that individuals use to protect themselves possibly dealers use the riverboat gambler front or image to glamorize their jobs so they can better ease the discomfort they feel in their daily work.

\footnotetext{
*The term George refers to a person who tips well whereas a stiff is a person who does not tip well. A bleeder is a boss who continually is angry with dealers, particularly when they are losing to customers. Third base is the position in the game of twenty-one which is dealt to last by the dealer. A sawdust joint refers to small casinos or casinos which existed in the early days of legal gambling. A shill is an employee of the casino who uses the casino's money in a game to stimulate more betting. An eye-in-the-sky refers to security people who watch the gambling action through one-way mirrors in the ceilings of the casinos. A mechanic is a player. Box man refers to the supervisor of a crap table who oversees all chips and exchanges on his particular table. A gaff is a fix and a gaffed game would be a crooked game. $M r . B$ is simply an abbreviation of $M r$. Big and is used in reference to both good tippers and those with jwice, It is also common for dealers to refer to players they know by the initial of the players last name; Mr. Cross being known as Mr. C. A rabbit is a very timid player. A shoe is a box from which cards are dealt used in both 21 and baccarat.
} 
Normlessness

The dimension of normlessness was characterized as a feeling held by dealers that there were either conflicting, ambiguous or nonexistent norms for them to follow in their work activity. "The participants' responses to scale items measuring normlessness and comments in the unstructured interview indicated that dealers experienced this dimension only to a small degree. The three items in the alienation scale measuring normlessness yielded a grand mean of only 2.11 among all respondents. Also, twentyeight of the dealers received mean scores of 2.50 or less on normlessness items, indicating a moderately low degree of normlessness. Dealers in the sample explained that they knew well the informal and formal rules governing their jobs. The rules were well-defined and dictated by bosses in reference to any job problem the dealer might encounter.

\section{Additional Findings}

An examination of the participants' total alienation scores (all 23 items combined) yielded some significant findings. For example, it appears that male dealers are more alienated from their work in an overall sense than are female dealers $(t=3.88$, 42 d.f. $_{i}$ significant at .001 level for two-tailed tests). Also, those dealers who had attended college experienced more total alienation from their work than those who had received less formal education $(\mathrm{t}=3.15,42$ d.f., significant at .01 level for two-tailed test). It also appears that unmarried dealers experienced more total alienation from their work than married dealers $(\mathrm{t}-3.42$ 42 d.f., significant at .01 level for two-tailed test) .

Information about the dealers' backgrounds indicated that most of their fathers had blue collar-type jobs such as bartenders, small time gamblers and small time salesmen. It was also found that thirty-two participants had worked in two or more Las Vegas casinos prior to their present jobs. This finding likely reflects the transient nature of the occupation and/or the career pattern of

\footnotetext{
*This characterization of normlessness was based largely on the work of Merton
} (1968) and Seeman (1955). 
most dealers of moving from less prestigious casinos to better casinos.

\section{Summary Comments}

The findings here indicate that casino card dealers feel a high degree of powerlessness and meaninglessness, a moderately high degree of social isolation and self-estrangement, and only a small degree of normlessness in reference to their work. The findings suggest that many aspects of the occupation are related to these feelings of alienation. The overcontrol and close surveillance of dealers by bosses, the dictatorial attitude and unfair practices of bosses, the necessity of having juice for job protection and upward mobility, the monotony and boredom of the job, and the lack of solidarity among dealers in terms of interests and loyalties all appear to be major factors in the occupation which produce feelings of alienation among dealers. It also appears that the alienation dealers experience in their daily work has a negative impact upon other aspects of their social world, such a lack of meaningful friendships and marital problems.

The findings suggest that the major factor motivating dealers to continue their work is the salary and tokes they receive. The job apparently does not satisfy such needs as curiosity, new experiences, freedom of thought, responsiveness from others, security and self-fulfillment. Finally, the findings may indicate that dealers use two pyschological devices to cope with the negative aspects of their work. The first is the riverboat gambler role which they portray to others and themselves. This role may help them give less importance to or repress the displeasures of work. The second is that dealers have learned to accept many negative aspects of their work so they can satisfy their material needs. Alienation has essentially been accepted as a necessary aspect of their work to be endured.

This study has provided insights into the occupation and has possibly provided clues about other occupations in society. It may well be that the work conditions related to the dealers' alienation, the forces that motivate dealers to continue their work, and the psychological mechanisms of dealers that help them cope with their work may reflect many job situations today. 


\section{APPENDIX 14-I}

\section{DEALER ALIENATION SCALE}

1. PFU Generally bosses at the casino where I work are very fair in their treatment of dealers.

$$
\begin{array}{ccccr}
\text { SA } & \text { A } & \text { UD } & \text { D } & \text { SD } \\
1 & 2 & 8 & 4 & 5
\end{array}
$$

2. PFU Most of the bosses where I work are actually nothing more than dictators.

$$
\begin{array}{ccccc}
\text { SA } & \text { A } & \text { UD } & \text { D } & \text { SD } \\
5 & 4 & 3 & 2 & 1
\end{array}
$$

3. PFU When bosses make decisions concerning my job, the bosses are usually very understanding and sympathetic to my personal desires and goals.

$$
\begin{array}{ccccc}
\text { SA } & \text { A } & \text { UD } & \text { D } & \text { SD } \\
\text { 1 } & 2 & 3 & 4 & 5
\end{array}
$$

4. PFU The bosses where I work can hurt me any time they want and I can do nothing about it.

$\begin{array}{ccccc}\text { SA } & \text { A } & \text { UD } & \text { D } & \text { SD } \\ 5 & 4 & 3 & 2 & 1\end{array}$

5. PFU I can generally rely on the casino bosses to help me keep myjob.

$\begin{array}{crrrr}\text { SA } & \text { A } & \text { UD } & \text { D } & \text { SD } \\ \text { I } & \mathbf{2} & \mathbf{3} & \mathbf{4} & \mathbf{5}\end{array}$

6. PFU I have to be so cautious in my actions because casino bosses can totally destroy my life - by having me fired, blacklisted or physically harmed.

$$
\begin{array}{ccccc}
\text { SA } & \text { A } & \text { UD } & \text { D } & \text { SD } \\
5 & 4 & 3 & 2 & 1
\end{array}
$$

7. PFW I don't like it that some of my fellow dealers have power over me just because they have close connections with the casino bosses.

$$
\begin{array}{ccccc}
\text { SA } & \text { A } & \text { UD } & \text { D } & \text { SD } \\
5 & 4 & 3 & 2 & 1
\end{array}
$$

8. MFW This job is a career for me which I plan to pursue for some time.

$$
\begin{array}{crrrr}
\text { SA } & \text { A } & \text { UD } & \text { D } & \text { SD } \\
1 & \mathbf{2} & 3 & 4 & 5
\end{array}
$$


9. MFW I sure would like to look for another kind of work other than dealing.

$$
\text { SA A UD D SD }
$$

10. MFW Dealing is an exciting and stimulating job which is very appealing to me.

$$
\text { SA } \quad \text { A } \quad \text { UD } \quad \text { D } \quad \text { SD }
$$

11. MFW Dealing is a good job because it allows for creativity and imagination.

$$
\begin{array}{ccccc}
\text { SA } & \text { A } & \text { UD } & \text { D } & \text { SD } \\
1 & 2 & 3 & 1 & 5
\end{array}
$$

12. NFU Most of my bosses at the casino apply the work rules in a fair and equitable manner.

$$
\begin{array}{ccccc}
\text { SA } & \text { A } & \text { UD } & \text { D } & \text { SD } \\
1 & 2 & 3 & 4 & 5
\end{array}
$$

13. NFU Some times I am unsure as to whether I should follow house rules to not cheat or to go ahead and steal for my own personal gain.

$$
\text { SA A UD D SD }
$$

14. NFU One of the most confusing things about being a dealer is that I never know what the casino bosses want from me.

$$
\begin{array}{ccccc}
\text { SA } & \text { A } & \text { UD } & \text { D } & \text { SD } \\
5 & 4 & 3 & 2 & 1
\end{array}
$$

15. SIU Whenever I have a problem with my job I can usually turn to certain bosses for advice.

$$
\begin{array}{rrrrr}
\text { SA } & \text { A } & \text { UD } & \text { D } & \text { SD } \\
1 & 2 & 3 & 4 & 5
\end{array}
$$

16. SIU It seems to me that bosses in my job do not care about me as a person but more as a $\operatorname{cog}$ in a machine.

$$
\begin{array}{ccccc}
\text { SA } & \text { A } & \text { UD } & \text { D } & \text { SD } \\
5 & 4 & 3 & 2 & 1
\end{array}
$$

17. SIFW There are not many fellow dealers I can be friends with or get close to.

$$
\begin{array}{ccccc}
\text { SA } & \text { A } & \text { UD } & \text { D } & \text { SD } \\
5 & 4 & 3 & 2 & 1
\end{array}
$$

18. SIFW Dealers protect each other and look out for each other's welfare.

$$
\begin{array}{ccccc}
\text { SA } & \text { A } & \text { UD } & \text { D } & \text { SD } \\
1 & 2 & 3 & 4 & 5
\end{array}
$$


19. SIFW The casino is a lonely place to work because I can't really form meaningful relationships with anyone.

$$
\begin{array}{ccccc}
\text { SA } & \text { A } & \text { UD } & \text { D } & \text { SD } \\
5 & 4 & 3 & 2 & 1
\end{array}
$$

20. SIFW I can look to some of my fellow workers for advice when I have personal problems.

$$
\begin{array}{ccccc}
\text { SA } & \text { A } & \text { UD } & \text { D } & \text { SD } \\
5 & 4 & 3 & 2 & 1
\end{array}
$$

21. SE It seems to me that my whole work situation is one big con job, i.e. I constantly manipulate others to get my way.

$$
\begin{array}{ccccc}
\text { SA } & \text { A } & \text { UD } & \text { D } & \text { SD } \\
5 & 4 & 3 & 2 & 1
\end{array}
$$

22. SE I like it that my job gives me a chance to be really open and spontaneous with others.

$$
\begin{array}{ccccc}
\text { SA } & \text { A } & \text { UD } & \text { D } & \text { SD } \\
1 & 2 & 3 & 4 & 5
\end{array}
$$

23. SE Sometimes when problems and frustration arise in my job, I resort to such things as drinking, pills or other escapes.

$$
\text { SA A UD D SD }
$$

NOTES: PFU refers to powerlessness from higher-ups. Other letters indicate the following: PFW, powerlessness from fellow workers; MFW, meaninglessness from fellow workers; $\mathrm{NFU}_{a}$ normalessecss from higher-ups; $\mathrm{SIU}_{2}$ social isolation from higher-ups; SIFW, social isolation from fellow workers; and SE, self-estrangement.

The code for responses is as follows: SA means strongly agree; A, agree; $\mathrm{UD}$, undecided; $\mathrm{D}$, disagree; and $\mathrm{SD}$, strongly disagree.

\section{REFERENCES}

Aiken, N., and Hage, J.: Organizational Alienation: A Comparative Analysis. Am Sociol Rev, 31:497, 1966.

Blauner, R.: Alienation and Freedom: The Factory Worker and His Industry. Chicago, University of Chicago Press, 1964.

Bottomore, J. B.: Karl Marx: Early Writings. New York, MeGraw-Hill Book Company, Inc., 1964.

Chinoy, E.: Automobile Workers and the American Dream. Garden City, Doubleday and Company, 1955.

Clark, J. P.: Measuring alienation within a social system. Am Sociol Rev, 24: 849, 1959.

Dean, D. G.: Alienation: Its meaning and measurement. Am Sociol Rev, 26: 753, 1961. 
Fromm, E.: The Sane Society. New York, Holt, Rinchart and Winston, 1955.

Guest, R. H.: Men and Machines: An Assembly Line Worker Looks at His Job. Personnel, 3I:496, 1955.

Holsti, O.: Content Analysis for the Social Sciences and Humanities. Reading. Addison-Wesley Publishing Company, 1969.

Israel, J.: Alienation: From Marx to Modern Sociology. Boston, Allyn and Bacon, Inc, 1971.

Kon, I.a The Concept of Alienation in Modern Sociology. Social Research, 2f:507 (Autumn), 1967.

Merton, R. K.: Social Theory and Social Structure. New York, The Free Press, 1968.

Miller, W. B.: Lower Class Cultures as a Generating Milieu of Gang Delinquency. Journal of Social Issues, 14:5, 1958.

Mills, C. W.: White Collar. New York, Oxford University Press, 1951.

Nettler, G.: A measure of alienation. Am SociolRev, 22:670, 1957.

Pearlin, L.: Alienation from Work: A Study of Nursing Personnel. Am Social Rev, 27:214, 1962.

Riesman, D.: The Lonely Crowd. New Haven, Yale University Press, 1950.

Rozeboom, W. W,a Foundations of the Theory of Prediction. Homewood, Dorsey Press, 1966.

Seeman, M.: On the meaning of alienation. Am SociolRev, 24:783, 1955.

Smith, R.: Alienation: A context-specific approach, paper presented at the Pacific Sociological Asociation meetings, 1971.

Smith, R.: The context-specific approach to alienation, unpublished Ph.D. dissertation, 1972.

Srole, Ln: Social integration and certain corrolaries: An exploratory study. Am Sociol Rev, 21:709, 1956.

Stein, M.p and Vidich, A.: Sociology on Trial. Englewood Cliff, Prentice-Hall, Inc., 1963.

Stinchcombe, A. L.i Rebellion in a High School. Chicago, Quadrangle Books, 1964.

Walker, $\mathrm{C}_{\text {, }}$ and Guest, R.: The Man on the Assembly Line. Cambridge, Howard University Press, 1952. 


\section{Part Four}

\section{THE PSYCHOLOGY \\ OF BAMHLING}





\section{INTRODUCTION}

Psychologists have approached the study of gambling from two general perspectives. First, they have explored the fundamental motivations behind gambling behavior in terms ofvarious conscious and subconscious psychological dimensions. Much of this work has centered on the behavior of the compulsive or pathological gambler, and many studies have argued that compulsive gamblers are self-destructive and guilt-ridden individuals; thus, their gambling behavior is in some way the means by which they punish themselves. Psychological motivations for noncompulsive gamblers, on the other hand, have not been studied in as much depth.

The second way in which gambling has been used in psychological studies has been as the basis of experiments to analyze behavior under conditions of risk and uncertainty. In general, a gambling game is set up for the purpose of simulating a general decision-making situation for the participant. His behavior in the game format is supposed to provide information on how he would react to similar real life situations where decisions must be made under risky and uncertain conditions. In other words, it is assumed that gambling behavior is reflective of behavior in general, and that by examining how people react under differing circumstances in a gambling game, inferences can be drawn as to how they would react under more general circumstances.

The articles in this section provide illustrations of both the motivational and the experimental psychology perspectives. In "How Gambling Saved Me from a Misspent Sabbatical" Igor Kusyszyn examines the fascination gambling holds for participants who are not necessarily compulsive gamblers. Gambling, he argues, provides a highly absorbing play activity for the individual in which he can exercise varying degrees of commitment, decision-making and fantasizing, and from which he can derive "cognitive emotional-muscular arousals" or thrills which are somewhat unique to the gambling experience. He also reviews a 
number of theoretical and experimental studies on gambling motivations and puts forth the argument that, for most participants, gambling behavior reflects psychological health rather than illness.

In "Who Wants to be a Professional Gambler?" David P. Campbell analyzes data on occupational preferences collected with the Strong Vocational Interest Blank. He draws some interesting correlations between individuals in specific occupations and their reactions to the job category, professional gambler, and the idea of taking a chance in general. Among his findings are that males have a stronger inclination toward gambling and taking chances than do women; people in risky occupations such as actors, artists and investment fund managers are at the upper end of the risk preference scale, whereas bankers, teachers and farmers are risk averters; and that being a professional gambler is an occupation ranked about the same as being a computer operator in terms of popularity.

Slot machines are mechanical devices which seem to have a hypnotic effect on many people who frequent them. In spite of the obvious and repeated losses which slot players incur, their play is often characterized by its frantic pace, its long duration and an intense absorption in the entire gambling process. Terry Knapp examines this behavior from a functional rather than a motivational point of view, and argues that the behavior of slot machine players is largely due to the way in which they receive their pay-offs or rewards. The variable ratio schedule of pay-offs built into a slot machine has the effect of inducing more response from players than other types of reinforcement schedules which could be used. Knapp also discusses some other variations in slot machine formats and how they are likely to affect player responses.

In "Searching for Motivations in Risk Taking and Gambling" Eric Knowles begins by noting the relative lack of success psychologists have had in explaining risk-taking behavior from data derived from gambling experiments. In particular, people do not seem to be consistent with respect to various strategic dimensions of risk, such as probabilities of winning and losing, and potential winnings or losses. He suggests that the reason for the apparent 
inconsistency is that the strategic or "stylistic" risk measures commonly used in experiments are conceptually different from possible motivational measures of risk. The stylistic measures concern themselves more with how the behavior is performed than with the preference for performing the behavior. Previous experiments, therefore, have been trying to measure the wrong thing in looking at stylistic variables. As an alternative, Knowles defines variables which assess the willingness to approach or avoid risk, and finds that there is a fairly strong consistency between these measures and other "willingness to approach risk" situations.

Do the ways in which people participate in casino games reflect certain personality characteristics? Certain casino games and devices have their player stereotypes: the loud aggressive male at the craps table, the quiet but possessive woman at the slot machine, and the calculating systems player at 21 or roulette, just to name a few. In his article, D. Michael Kuhlman uses student volunteers in a gambling experiment to try to pick up two types of consistency-first, will people's gambling strategies (amounts wagered, preferred wagers) remain similar from one game to another, and from one gambling session to another; and second, what correlations exist between personality characteristics and gambling strategies? From his results, Kuhlman concludes that riskiness as a general dimension of personality cannot be defined in terms of one dimension (e.g. probably of winning, amount to be lost, expected return, etc.) but should be viewed in terms of a number of these dimensions; thus, examining individual consistency across these risk measures may provide a better operational definition of the elusive concept.

In decision-making situations characterized by risk and uncertainty about the outcomes of alternative choices, some individuals may pursue very cautious courses of action, others more risky approaches. However, a number of recent studies in social psychology have noticed that groups of individuals making joint decisions tend to make riskier choices than the same persons making individual decisions. This phenomenon is referred to as the risky shift hypothesis. In their article, Ginsburg, Blascovich and Howe use a blackjack game in a gambling laboratory to test for 
the risky shift. Among their findings are a verification of the risky shift; players tend to wager more at blackjack when other players are present than when they are not. Also, they find that if the other players at the blackjack table increase or decrease their wagers, an individual will tend to increase or decrease his wagers also. One explanation offered for this behavior is that moderate riskiness is valued in our culture, but individuals underestimate how others perceive moderate risk. Therefore, in the group context, when they observe that each other's attitudes toward riskiness are more positive than expected, they tend to pull up the amount of risk the group, acting as a unit, is willing to incur. For a casino, the implications of the risky shift provide a justification for hiring shills (casino employees who gamble to stimulate the play of other gamblers) - A general interpretation of the risky shift would indicate that, as decision-making units get larger, riskier decisions will be made; if the risky shift hypothesis is true, this should be observable throughout our society.

The final two articles of this section deal with the motives and behavior of the compulsive gambler. In the article, "Compulsive Gambling and the Conscious Mood Perspective," Tomas Martinez discusses the evolution of a compulsive gambler from his initial gambling experiences until he hits rock bottom. The conscious mood is the basic theoretical tool used in describing this evolution; in general, it means that a person defines his own identity in terms of his experiences, and as he experiences new conscious moods, his perception of self shifts. In becoming a compulsive gambler, an individual experiences the conscious moods of risktaking (control of a gambling situation), here and now (total involvement in the game), fantasy (dreaming luxurious dreams about the past, present and future), euphoria (highly pleasurable peak experiences such as winning a large bet) and mysticism (the ritualization of oneself into the gambling context and identification of oneself as a gambler). In general the individual views this evolution as a pleasurable experience, but soon he encounters a new set of conflicting experiences. The compulsive gambler loses large amounts of money; instead of considering it as a leisure activity, gambling becomes a measure of his personal self-esteem. 
He plays with money instead of forit, being more concerned with staying in the action than winning; he reverts to deception, lying and stealing to get back into the action; and gambling becomes an unpleasant experience which induces the gambler to begin hating himself. This process finally leads to the conscious mood of rock bottom in which the gambler acknowledges the identity into which he has evolved.

The article by William H. Boyd, "Excitement: The Gambler's Drug," argues from the basis that the behavior of a pathological gambler is a symptom of something else wrong rather than the disorder itself. Gambling is sought as a means of relief for some other problem in the individual's personality, and it is the complications which arise from gambling and losing that thwart the relief he seeks. Excitement is the commodity which provides short-term pleasure for the gambler, and this is the primary motive for his gambling; while participating, the individual is totally immersed in the activity, and outside reality-even the mathematical odds against him-does not exist in his perception. As long as the gambler can keep his head above water and get back into the action, he will avoid seeking any help. 



\title{
Chapter 15
}

\section{HOW GAMBLING SAVEI ME FRDM A MISSPENT SABBATICAL}

\author{
ICOR KUSYSZYN
}

THE FREQUENCY WITH WHICH I engaged in gambling stirred my curiosity and drove me to read every piece of psychological literature I could find that was in any way related to the problem of human motivation. As a result, after devouring some eighty volumes and scores of theoretical and research papers I find I have learned more about psychology in the last twelve months than in the past ten years. You may be curious at this point to know what I learned about gambling motivation. Bear with me for a moment, let me retrace my steps, and allow me to place you in the proper setting.

As I mentioned, I found myself gambling frequently. I did it during the football season with Bobby, the bookie; I did it during the thoroughbred season at lovely Woodbine Raceway; during the winter season at the trotting tracks, during the summer season in Las Vegas, and I did it the year round in high stakes card games in the best hotels in Toronto. I would still be doing it in the private card games because it was very, very lucrative, but being poor losers, my ex-hosts won't let me play any more. What is still puzzling, however, is why I continue to do it in all the other ways when the meager winnings from those forms of gambling barely cover my expenses. What is it then about gambling that has so pleasantly stolen thousands of hours from my life? What is it about gambling that makes it the largest industry in the nation? Thus far the answer is, we don't know. It is not the profit motive. Everyone knows you can't beat the races, and experts estimate that less than one person in 5,000 ends up a winner in the long run in other forms of gambling (Jacoby, 1963). What 
then is the attraction of gambling? At first I toyed with the method of self-observation in my search for the motives, but found that no matter where I was, at the racetrack, at a card table or in my living room watching football, it simply was impossible to examine myself while participating in the activity. The activity was so all-engrossing that no other thoughts were permitted. I found I could only examine the activity when alone in the quiet of my office, automobile or bed. After months of reflection and much note-taking, I managed to pin down the nature of gambling and will now allow it to speak on its own terms. As you will soon realize, gambling reveals itself most fully if it is seen as a play activity (Ellis, 1973; Kusyszyn, 1973).

The first thing we can note about gambling is that it is selfcontained. There is often a special place for it, a place with physical boundaries, i.e. a racetrack, casino, card room or bingo hall. It is completely apart from the routine activities of everyday working life. It occurs during leisure time, during a time that is unhurried, during a time when the organism's basic physiological needs are satiated. A second feature is that the participant independently and voluntarily selects the game and his mode of participation in it. We may say he is his own agent. A third feature is that all three classical dimensions of man are involved in gambling-cognitive (decision-making), conative (wagering) and affective(hope of winning, fear of losing). Risk and uncertainty are also always present and contribute to the cognitive, emotional and physical arousal of the organism.

The behaviors involved in gambling are complex in that they involve continuous chains of events which include decision-making, action, outcome, emotional reaction and cognitive appraisal of one's actions in relation to the outcome, further action and so on. The combination of these features allows for gambling to become an absorbing activity.

A very important and special feature of the enterprise is the fact that the gambler has under complete personal control the degree of his commitment to the activity. The degree of commitment can be altered at almost any point. For example, the gambler can commit himself to a large degree at the beginning by 
placing a large initial wager; should he lose that wager, his next wager may be smaller or it may be larger; the wager may even be twice as large if he is the type who believes in the gambler's fallacy, double-up and catch $u p$, and chases his losses. The selfregulation of involvement may be looked at psychologically as providing self-stimulation, self-testing, arousal-oscillation, feelings of individuation, power, effectiveness and so on.

Money loses its economic value during gambling. The gambler is seen to be playing with money rather than for money. Although money is not highly valued during gambling, the gambler does recognize differences in the sizes of his wagers, i.e. he realizes that a four-dollar wager is twice as great as a two-dollar wager; it is the market value of the money that is irrelevant. For example, a ten-dollar wager is not seen as the equivalent of the price of a dress shirt. (In casinos, chips are used in place of money for devaluation purposes.) Yet, as valueless as the betting money may become, it is essential to the continuation of the activity. Without money one is out of action, but still worse, as they chime in Las Vegas, When you're broke, you're a joke. One can still make imaginary or mind bets when one is broke, but with such wagers there is only token involvement; the gambler does not get excited or aroused to any noticeable degree when he has a mind bet riding. The paradox here is the fact that, although gambling money loses its economic value, it still retains some kind of incentive value which provides for the maintenance of the activity.

Gambling can provide many kinds of pleasurable feelings, interesting problems to solve, opportunities for the individual to participate in himself and to indulge his senses and cognitions. It provides for the exercising of biological as well as psychological urges. For instance, the gambler can increase his muscle tension, speed up his heart rate and become emotionally aroused, both positively (with enthusiasm, hope, joy, euphoria and excitement) and negatively (with anxiety, fear, disappointment, frustration, sorrow, regret and despair). Gambling also provides for the operation of cognitive-emotional states involving the self. It can yield the elicitation of pride, courage, self-esteem, self-blame and selfremonstration. Gambling also provides an opportunity for the 
experiencing of anger, hostility and aggression, and for externalizing such negative states unto wives, other gamblers, unto horses, jockeys, trainers, dealers, pit bosses, the government and the establishment.

Gambling also provides a release from reality through activity. The gambler very quickly (usually as soon as he begins to contemplate making his first wager) transports himself into a play world, a fantasy world in which he stays suspended until he is jarred back into reality by the finish of the last race or the disappearance of his money. While in this fantasy world he can, and usually does, act, feel and think with complete abandon, without superego control and without psychological defenses. We may say his free child (Berne), id (Freud) or instinctoid impulses (Maslow) emerge and indulge themselves in cognitive and emotional pleasures, It is this disinhibited self that is most evident in the gambling situation. (Remember the difficulty of maintaining a poker face in card playing?) In this regard, gambling situations become excellent projective tests for personality diagnosis.

The placing of the wager provides for the placing of the self in the hands of risk and uncertainty. The uncertainty of the event and the risk that is an integral part of it provide for the cognitiveemotional-muscular arousal of the individual. The arousal, coupled with the already affirmed belief that the situation is a safe one, free from the possibility of real failures and social punishments," leaves the gambler in a very comfortable state. This state is difficult to describe. It can be spoken of as a mood state, a peak experience, a trance, a high or even as a mystic state. However, it is not a uniform state. It is a general state that is altered many times (or more precisely, several different ministates are found to pass through the generally pervasive state) during a session of gambling by the individual's actions (wagers), the nature of the outcomes, his cognitive-emotional reactions, further (hopefully corrective and luckier) action and so on. This self-

\footnotetext{
"Social punishments from others have already been ruled out by the gambler through his past experience that no one gets punished while in the gambling arena. Although he may get punished when he gets home, this thought is rarely permitted by the self when gambling. Such real world thoughts are excluded and do not operate during gambling.
} 
regulated playing within the pleasantly safe fantasy mood state is probably the most important feature of gambling. It is this intrinsic feature of gambling that is so rich in psychological goodies for the gambler. Unfortunately, this important feature of human experience has only recently begun to receive serious attention. I am referring to the study of altered states of consciousness and the paranormal.

Let me give just one example of the similarity between the gambling experience and the psychic experience. I will quote directly from Lawrence LeChan's (1969) manuscript, Toward a General Theory of the Paranormal.

In a variety of places, Mrs. Garrett has referred to the state of high carelessness as being necessary before paranormal functioning can be attained, i.e. "I consider that the best results are obtained when the medium is in a state of high carelessness in an accelerated and joyful mood." = = It is important to be clear that it is not just a passive attitude of willessness that is described here. The whole personality is oriented to the subject as is "a dog to a rabbit." In the psychological sense, there is a set to receive information. . . . The sensitive must wait alertly, expectantly, and hopefully, but not "wish, demand, or try."

For those of you interested in the mood perspective, I recommend Dr. Tomas Martinez's excellent study, "Compulsive Gambling and the Conscious Mood Perspective," (Chapter 21).

Now let me briefly turn to some theoretical approaches that I came across in my reading. Although none of them were directed to the problem of gambling motivation, they are instructive to a degree.

Freudians viewing gambling in the context of play would recognize its wish fulfillment and conflict reduction functions (Waelder, 1935) - Maslow (1970) and Kelly (1955) on the other hand may see the needs to know and to understand operating. Hebb (1955) can point to the need for an optimal level of arousal and Berlyne (1957) has identified variables contributing to arousal, the variables such as novelty, uncertainty and suprisingness. J. McV. Hunt (1963) and McReynolds (1971) suggest that there is motivation inherent in information-processing and in action. Dember (1974) has very recently postulated "ideationa] 
motivation," stating that the brain is not like a computer but is alive with needs of its own, and these cognitive needs often take precedence over biological and other needs. Ideology can control emotionality as recent biofeedback research has shown. One idea can direct all of the person's behavior as is seen in fanaticism and martyrdom. Is it the idea of winning that keeps the gambler gambling? An idea so strong that it distorts, denies and defies reality? Perhaps so. Lefcourt (1973) has also recently shown the power of the ideational belief of "felt control" over a situation pointing out to Skinnerians that felt control can direct behavior and transcend actual control. How similar is Lefcourt's concept of "felt control" to that of "effectance" postulated by Robert White (1959) some years ago? Is the gambler attempting to have an effect on his environment? Why does he blow on the dice and root for his number? Is this not a belief in control or psychokine- sis? (See Strickland, Lewicki and Katz (1966)) . Does the gambler suffer from neurosis or existential anxiety? Is he trying to find the meaning of life through gambling (Frankl, 1973), or is he simply exhibiting David McLelland's need for achievement in a context that is free of a fear of failure? Is he attempting to raise his self-esteem (Rogers, 1961), or is he like the Skinner box rat, a prisoner of the partial reinforcement effect (PRE) ? Indeed, Skinner can take pride in (but he wouldn't) the real life demonstration of the power of the PRE, but what is the PRE? A search for the answer through some learning theory texts and several volumes of the Nebraska Symposium on Motivation showed me that learning theorists know very little as to the nature of the variables responsible for the PRE. It is quite likely, however, that gamblers are on very intimate terms with the important variables in question. Zuckerman (1971) suggests gambling is a disinhibitor, especially for swingers who also drink and party.

So much for theory; next I turned to a search of the research literature. A thorough search of the literature for studies of social (not clinically referred) gamblers produced a total of only four studies (Kusyszyn, 1972) - In an early study Hunter and Brunner (1928) contrasted a group of several hundred college students "with an excessive indulgence in games of chance" with a non- 
gambling group and found no differences between them on intelligence, psychoneurotic tendencies or on introversion-extraversion. However, they did find the gambling students' scores to be bimodal on both personality measures, suggesting an interesting typological possibility: gamblers are either stable or unstable, and either extraverts or introverts. They conclude by saying they failed to find support for the hypothesis of the study, which was stated as, "Clinical studies by the psychoanalytic method would indicate that the passion for gambling was an indirect emotional outlet, frequently with a sexual bias."

The second psychometric study of social gamblers is reported by Morris (1957). Morris compared twenty-nine Harvard undergraduates who gambled with nineteen who did not. He found the gamblers to be more secure, more dominant, more masculine, less socially responsible and as happy as the controls. Morris concedes that the findings did not fit his psychoanalytic predictions.

In another study McGlothlin (1954) tested a random sample of thirty-one female poker players who played in the commercial card clubs of California. The women were housewives with a mean age of thirty-seven years. They played an average of 2.7 times per week for about five hours each time. On the basis of psychoanalytic theory, McGlothlin hypothesized his sample would be emotionally insecure with a strong belief in the importance of luck. He found essentially the opposite. The measure used was the Bell Adjustment Inventory. McGlothlin states, "The women in this study are significantly better adjusted on the average than are the female adults of the general population. This applies to the scction on emotional, home, and social adjustment." A significant positive relationship between belief in luck and maladjustment was also found. However, contrary to psychoanalytic theory, McGlothlin found that "emotionally insecure individuals did not take more risks in the gambling situation, or tend to lose more often, than did persons evidencing better adjustment." Surprisingly, McGlothlin also found that "persons scoring high on the luck or superstitions test did not tend to take more risks in the poker game or lose more often than did the more rational subjects." In discussing his findings, McGlothlin concludes: 
"the game of poker, like other games, can be classified as ап госаре from reality, and persons who play as much as do the subjects in this study may be said to be using it in an extreme manner, rather than practicing moderation. In addition, such frequent playing is likely to cause financial hardship in some instances. Nevertheless, the subjects in this study appear to have achieved a satisfactory adjustment, at least as measured by an adjustment inventory."

McGlothlin's findings are extremely important for researchers studying gambling in two respects. First, they suggest that even extreme gambling may be related to psychological health and not illness; secondly, neither psychological maladjustment nor belief in luck are related to losing. Although these findings may be difficult for a clinician to accept, they readily support actualization theory (Kusyszyn, 1973) and are also consonant with the results of a recent sociological study of British gamblers reported by Newman (1972) - Newman summarizes his observations thus:

Indeed, within the situational reality of the typical urban industrial worker, gambling made sound rational sense. It provided an outlet of escape from humdrum depersonalised existence, it offered facilities for the otherwise repressed desires for expression of enterprise, initiative, concentrated effort and expertise; it constituted a harmless vehicle for the indulgence in fantasies of windfall wealth, and satisfied the personal needs for sociability and informal social interaction.

It should be mentioned that if the findings of the McGlothlin and Newman studies are replicated, they could have important moral, social and legal implications for the enterprise of gambling in this country. My students and I are currently planning a large study of racetrack gamblers in Toronto which should shed more light on Newman's and McGlothlin's findings. Our plan is to compare 600 gamblers with 600 nongamblers on fifty-three personality traits, motives and styles, making predictions from three general models of human motivation-the conflict or psychodynamic model, the activation or arousal model, and the self or actualization model. We feel that the study will be very revealing since our samples are not composed of only compulsive gamblers as is usually the case, and since we will allow for psychological health to show itself in gamblers if it is there (as well as illness) by including measures of health as well as measures of illness and 
measures of pure experiencing. For example, some of our measures of psychological health are self-esteem, self-acceptance, responsibility, affiliation, capacity for intimate contact, creativity, nurturance and need for understanding. Our conflict measures include neurotic anxiety, existential anxiety, repression, denial, depression, impulsivity, rebelliousness, hostility, dominance and aggression. Our experiencing or arousal measures include the need for change, complexity, sentience, internal and external cognitive and sensory experiencing, desire for novelty and risk, and sense of internal control. It will be very interesting to see which of the three theoretical models has the greatest predictive power in this study of social gamblers. I am betting against the conflict model and I am betting heavily on the actualization and arousal models.

In closing, I would like to invite you to suggest variables for our study which we may have overlooked, especially if reliable measures of them are available. Finally, I hope this study has made it clear to you and to my dean at the university how gambling saved me from a misspent sabbatical.

\section{REFERENCES}

Berlyne, D. E.: Uncertainty and conflict: A point of contact between information theory and behavior theory concepts. Psychol Rev, LXIV (6): 329, 1957.

Dember, W. M.: Motivation and the cognitive revolution. Am Psychol, 29: 161, 1974.

Ellis, M. J:= Why People Play. Englewood Cliffs, Prentice-Hall, Incorporated, 1973.

Frankl, V. E.: The Doctor and the Soul. New York, Vintage, 1973.

Hebb, D. O.: Drives and the C.N.S. (Conceptual Nervous System). Psychol Rev, 62:243, 1955.

Hunt, J. McV.: Motivation inherent in information processing and action. In Harvey, O. J.: Motivation and Social Interaction: The Cognitive Determinants. New York, Ronald Press, 1963, pp. 35-94.

Hunter, J-a and Bruner, A.: Emotional outlets of gamblers. I Abnorm Soc Psychol, 23:38, 1928.

Jacoby, O.: Oswald Jacoby on Gambling. New York, Hart, 1963.

Kelly, G. A.: The Psychology of Personal Constructs. New York, Norton, 1955, vol. 1.

Kusyszyn, L.: Psychology of gambling, risk-taking, and subjective probability. 
A bibliography. Listed in Journal Supplement Abstract Service Cafalog of Selected Documents in Psychology, 2:7, 1972.

Kusysyn, L.: The Psychology of Gambling: Unrelated Facts and Fancies. Invited address given at the Annual Meeting of the Rocky Mountain Psychological Association, Las Vegas, Nevada, May, 1973.

LeChan, L.: Toward a general theory of the paranormal. Parapsychol Monographs, No. 9, 1969.

Lefcourt, H. M.: The functions of the illusions of control and freedom. Am Psychol, 28:417, 1973.

Maslow, A. H.: Motivation and Personality, 2nd ed. New York, Harper and Row, 1970.

McGlothlin, W.: A psychometric study of gambling. / Consult Psychol, 18: $145,1954$.

McReynolds, P.: The three faces of cognitive motivation. In Day, H. I-, BerIyne, D. E., and Hunt, D. E.: Intrinsic Motivation: A New Direction in Education. Toronto, Holt Rinchart and Winston, 1971, pp. 33-45.

Morris, R. P.: An exploratory study of some personality characteristics of gamblers. / Clin Psychol, 13:191, 1957.

Newman, O.: Gambling: Hazard and Reward. London, Athlone, 1972.

Rogers, C. R.; On Becoming a Person. Boston, Houghton Mifflin, 1961.

Waelder, R.: The psycholanalytic theory of play. Psychoanal R, 2:208, 1933.

Strickland, L. J., Lewickin, R. J., and Katz, A. M.: Temporal orientation and perceived control as determinants of risk-taking. I Exp Soc Psychol, 2: $143,1966$.

White, R. W:i Motivation reconsidered: The concept of competence. Psychol Rev, 66:297, 1959.

Zuckerman, M.: Dimensions of sensation seeking. / Consult Clin Psychol, 36:45, 1971. 


\title{
Chapter 16
}

\section{WHO WANTS TD BE A PHOFESSIONAL GAMBLER?}

\author{
DAVID P. CAMPBELL*
}

$\mathrm{H}^{\mathrm{B}}$

EYWOOD BROUN, in one of the most widely circulated quotes on gambling, said, "The urge to gamble is so universal and its practice so pleasurable that I assume it must be evil."

This chapter contains some data relevant to that quotation, data collected with the Strong Vocational Interest Blank, one of the country's oldest, most widely used, most highly respected psychological tests. The Strong Blank, which was originally developed by Professor E. K. Strong of Stanford University in the 1920's, is essentially a long questionnaire which asks people to indicate their interest in each item on a long list of occupations, school subjects, hobbies, sports and so forth. Since the 1920's, an amazing array of information has been collected with this questionnaire, and much of this data is now meticulously stored at the University of Minnesota. The writer was in charge of this data bank from 1960 until 1974, when he left the university to move to North Carolina.

The Strong Blank has recently been revised, primarily in response to the criticism from the Women's Movement that it unduly restricted students' options by automatically designating some occupations as male and others as female. In response to the criticism, the inventory has been revised and in so doing a few new occupations were added to the list. One of the new ones is professional gambler; consequently, each person who fills in this inventory from now on will indicate how he or she feels about being a professional gambler.

"This paper was prepared for presentation at the First Annual Conference of Gambling, Las Vegas, Nevada, June, 1974. No state, federal or foundation funds were used in its preparation, and every administrator who has any responsibility for me in any way wants that clearly understood. 
The specific format of the item is shown in Figure 16-1, along with a few other items surrounding it to give you some idea of context. We have already tested several thousand people with this new form, and, consequently, can look at some statistics about how people respond to this occupation.

\begin{tabular}{|c|c|c|c|}
\hline & Like & Indifferent & Dislike \\
\hline Private secretary & ( ) & ( ) & ( ) \\
\hline Professional athlete & ( ) & () & ( ) \\
\hline Professional dancer & ( ) & ( ) & ( ) \\
\hline Professional gambler & () & ( ) & ( ) \\
\hline Psychologist & ( ) & ( ) & ( ) \\
\hline Public relations director & ( ) & ( ) & ( ) \\
\hline Rancher & ( ) & ( ) & ( ) \\
\hline
\end{tabular}

Figure 16-1.

There are two basic ways of studying responses to a single occupation: first, by seeing what other occupations and activities are selected by the people who choose this one; and, second, by studying the popularity of this occupation among samples of people actually employed in a variety of other occupations.

To study the first point, the relationship between the item, professional gambler, and the other 324 items on the inventory, a diverse sample of 600 people was tested, then correlations were run between the gambler item and every other item on the test. The items of interest are those showing the highest and lowest correlations, and they are reported in Figure 16-2.

As can be seen from the figure, the items correlating highest with professional gambler have a strong sense of adventure running through them, with considerable emphasis on physical risk. What these data indicate is that people who say they'd like to be professional gamblers are people who like to take chances.

The items showing the lowest correlations are in the bottom half of Figure 16-2, and what they demonstrate is that the least likely person in America to become a professional gambler is probably an artistically inclined, securely employed, church librarian who likes to make her own clothes. 
TEST ITEMS SHOWING EXTREMELY HIGH OR LOW CORRELATIONS WITH PROFESSIONAL GAMBLER

High Correlations

Be an auto racer

Pursue bandits in a sheriff's posse

Playing poker

Be a jet pilot

Be a professional athlete

Be a secret service agent

\section{Low Correlations}

$\mathrm{Be}$ a church worker

Be a librarian

$-.16$

Music and art events

$-.16$

Sewing

$-, 21$

Regular hours for work

$-.21$

Work for fixed salary

$-.22$

$-.23$

Figure 16-2.

This pattern of positive and negative correlations suggest, to no one's surprise, that those people who say they would enjoy being professional gamblers are risk-oriented people, and they especially select activities which are physically risky as opposed to other kinds of risks, such as intellectual or social risks. The pattern here is strictly machismo and decidedly masculine.

The second kind of information available on this item (professional gambler) are responses to it from samples of people employed in various occupations. Again, each person answering the questionnaire is asked to check either like, indifferent or dislike for each item, depending on how he or she feels about that occupation. By looking at the percentage of people in each sample answering like, something can be learned about both the popularity of the occupation and the characteristics of the people answering.

Table I6-I reports the percentage of like responses to the item, professional gambler for several samples of males, both students and employed adults. At the high end, over half of eight and ninth graders say they would like to be professional gamblers, which is 
substantially higher than any of the adult samples. Among the adult samples, the highest percentage was among life insurance agents; the lowest percentage was among male practical nurses. Perhaps the most important sample in the table is the sample labeled menin-general, as that is a sample of 300 carefully selected people designed to represent the population of employed males. As you can see, 25 percent of men-in-general answered like to the item, professional gambler, which gives an estimate of the popularity of that occupation. Of the 130 occupations listed in the Strong Blank, professional gambler ranks seventy-seventh on the index of popularity, just below computer operator and just above wholesaler.

TABLE 16-I

PERCENTAGE OF LIKE RESPONSES TO THE ITEM, PROFESSIONAL GAMBLER, FOR SEVERAL MALE SAMPLES

\begin{tabular}{|c|c|c|}
\hline Students & $N$ & $\begin{array}{l}\text { Percent } \\
\text { Response }\end{array}$ \\
\hline Minnesota 8th Graders - School A & 62 & 48 \\
\hline Minnesota 9th Graders - School A & 62 & 52 \\
\hline -School B & 86 & 32 \\
\hline \multicolumn{3}{|l|}{ Adults } \\
\hline Life Insurance Agents & 264 & 27 \\
\hline Husbands & 42 & 26 \\
\hline Veterinarians & 204 & 25 \\
\hline Men-in-General & 300 & 25 \\
\hline Nurses, R.N. & 291 & 24 \\
\hline Agribusiness Managers & 332 & 21 \\
\hline National Merit Scholars & 75 & 21 \\
\hline Speech Pathologists & 336 & 19 \\
\hline Dieticians & 327 & 17 \\
\hline Nurses, L.P.N. & 100 & 16 \\
\hline
\end{tabular}

Analogous percentages for females are shown in Table I6-II. The most important finding, of course, is that the popularity of this item among females is substantially lower than among males. For example, in what is the most technically accurate comparison, only 9 percent of the women-in-general sample answered like compared to 25 percent of the men-in-general sample. Among the female occupations, the percentage ranged from only 4 percent among Ph.D. 
physicists to 18 percent among female advertising executives. Although that rank ordering looks reasonable, the most important thing to note is that the range was fairly restricted.

TABLE I6-II

PERCENTAGE OF LIKE RESPONSES TO THE ITEM, PROFESSIONAL GAMBLER

FOR SEVERAL FEMALE SAMPLES

\begin{tabular}{|c|c|c|}
\hline Students & $N$ & $\begin{array}{l}\text { Percent } \\
\text { Response }\end{array}$ \\
\hline Minnesota 8th Graders - School A & 56 & 21 \\
\hline Minnesota 9th Graders - School A & 56 & 18 \\
\hline -School B & & 15 \\
\hline \multicolumn{3}{|l|}{ Adults } \\
\hline Advertising Executives & 215 & 18 \\
\hline Life Insurance Agents & 214 & 16 \\
\hline Veterinarians & 308 & 12 \\
\hline Wives & 42 & 12 \\
\hline National Merit Scholars & 37 & 11 \\
\hline Optometrists & 122 & 10 \\
\hline Wornen-in-General & 300 & 9 \\
\hline Credit Managers & 151 & 9 \\
\hline College Professors & 400 & 8 \\
\hline Physicists & 255 & 4 \\
\hline
\end{tabular}

To document directly the male-female difference, Table I6-III was prepared. It shows a direct comparison between comparable samples of males and females. The column on the right shows the differences between all these samples; they tend to center around 15 or 16 percent difference, which is an important difference and far beyond chance.

TABLE I6-III

PERCENTAGE OF LIKE RESPONSES TO THE ITEM, PROFESSIONAL GAMBLER

MALES VS. FEMALES

\begin{tabular}{|c|c|c|c|}
\hline Students & $\begin{array}{c}\text { Male } \\
\text { Percentage } \\
\text { Response }\end{array}$ & $\begin{array}{l}\text { Female } \\
\text { Percentage } \\
\text { Response }\end{array}$ & Difference \\
\hline Minnesota 8th Graders & 48 & 21 & 27 \\
\hline Minnesota 9th Graders - School A & 52 & 18 & 34 \\
\hline - School B & 32 & 15 & 17 \\
\hline
\end{tabular}


TABLE L6-III (cont.)

\begin{tabular}{lccc}
\hline Students & $\begin{array}{c}\text { Male } \\
\text { Percentage } \\
\text { Response }\end{array}$ & $\begin{array}{c}\text { Female } \\
\text { Percentage } \\
\text { Response }\end{array}$ & Difference \\
\hline Adults & & & \\
Life Insurance Agents & 27 & 16 & 11 \\
Husbands - Wives & 26 & 12 & 14 \\
Veterinarians & 25 & 12 & 13 \\
Men vs. Women-in-General & 25 & 9 & 16 \\
National Merit Scholars & 21 & 11 & 10 \\
\hline
\end{tabular}

The percentages for the adult male and female samples are presented graphically in Figure 16-3. Each zero in this figure represents a female sample and each cross, a male sample. This graph allows us to see the spread of the samples, and again to note the dramatic differences between the sexes.

\section{PROFESSIONAL GAMBLER}

Response percentage for 10 male and 10 female occupational samples

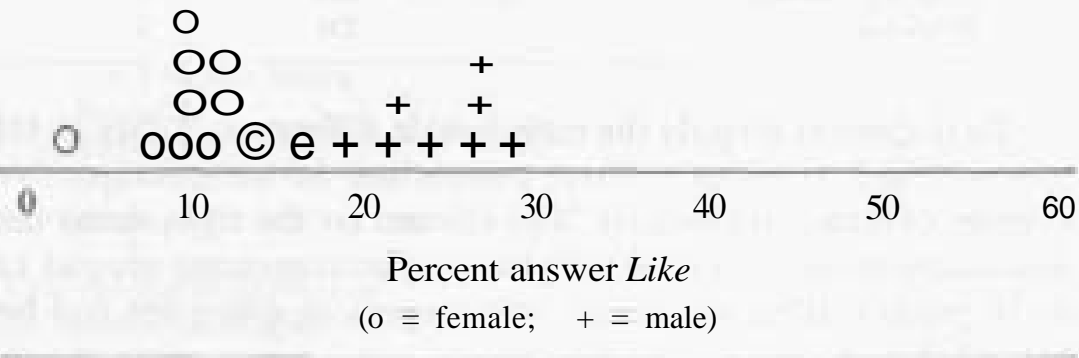

Figure 16-3.

Unfortunately, because the item, professional gambler, has been added only recently to the Strong Blank, extensive archival data on it has not been obtained. However, by generalizing from the data from a similar, related item, some idea of what the data might look like may be gained.

Take, for example, the item, taking a chance. This item correlates .30 with the professional gambler item, and a lot of data 
about it has been collected over forty years from several thousand people.

The correlations between the item, taking a chance, and the other items on the test have been calculated just as the professional gambler item, and the high and low ones are reported in Figure 16-4. The highest correlations look similar to those for the item, professional gambler, though the listings for the two items are slightly different, both because all items have their own peculiar flavor, and because only the extremes are listed here, and they are subject to slight variations from sample to sample.

\section{TEST ITEMS SHOWING EXTREMELY HIGH OR} LOW CORRELATIONS WITH TAKING A CHANCE

\section{High Correlations}

Thrilling, dangerous activities .50

Work with people who live dangerously

Be a criminal lawyer

Walk along the edge ofa steep cliff

\section{Low Correlations}

Be a private secretary

Be a receptionist

$\mathrm{Be}$ an office clerk

Be a hospital records clerk

Work for fixed salary

Figure 16-4.

The lowest correlations with this item show a consistent theme -that of clerical and office work. One concludes that the typical office environment must be one of the most sedate locations in our society, a conclusion that will likely be supported by anyone working in those settings where the most exciting event is the annual one-dollar World Series pool.

Data on how people in over 300 occupations respond to the item, taking a chance, has been obtained. The samples range in size from a few dozen people to over 1000 , with a median sample 
size being about 250 . For each of these samples, the percent responding has been calculated, and Figure 16-5 shows a frequency distribution of these percentages. Again, each male sample is represented by a cross, each female sample by a zero. As the distribution indicates, the percentage answering like to this item

TAKING A CHANCE

RESPONSE PERCENTAGES FOR 92 FEMALE OCCUPATIONAL SAMPLES

AND 200 MALE OCCUPATIONAL SAMPLES

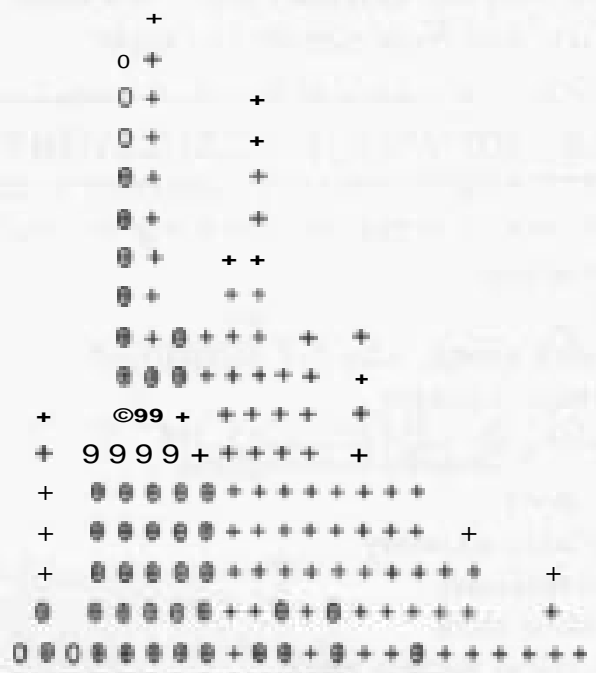

$0 \theta \theta \theta 0000000 \theta++\theta++++++\quad+$

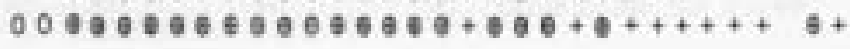

0

10

20

30

40

50

60

70

80

Percent Answering "Like"

$\left(0-\right.$ Fenole $_{\Perp}+-$ Male)

Figure 16-5.

varies widely over the samples, from a low of 8 percent to a high of 70 percent. The mean percent for males is about 40 and for females about 25. The most interesting samples, of course, are those samples at the extremes; they are listed in Table 16-IV for males and in Table $16-\mathrm{V}$ for females. Among men, salesmen 
dominated the high end of the distribution, along with artistically inclined people. Two occupations that barely missed the cut-off

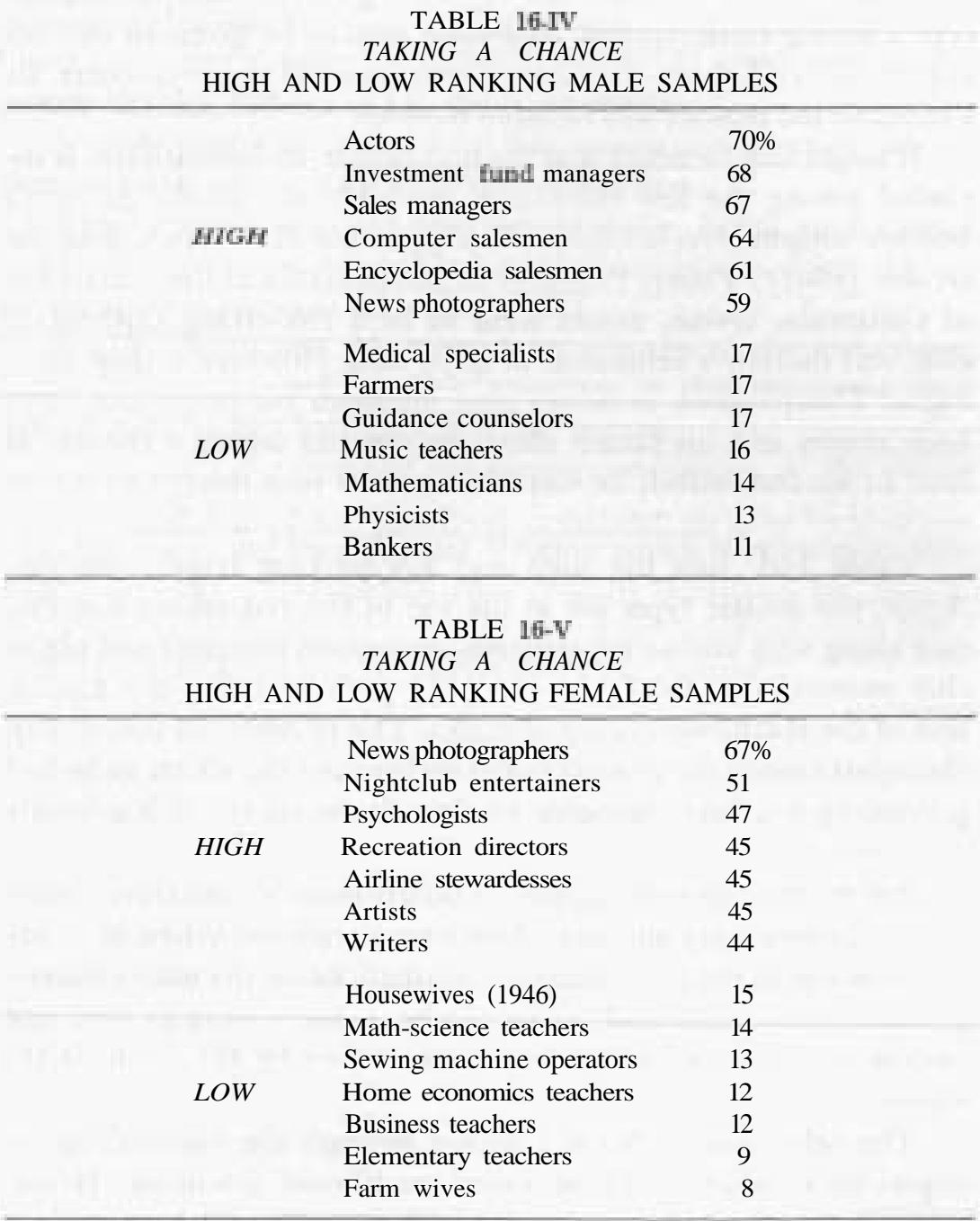

were artists and writers, which further supports the notion of artists as risk-takers. Finding the investment fund managers here is interesting. These data were collected in 1969 during a bull market. One wonders how these risk-oriented money managers 
are doing in today's market.

The low-ranking occupations are more heterogeneous, and there is no obvious theme running through those occupations, except a strong conservatism. Attention should be given to two occupations listed there-guidance counselors and music teachers. In a moment the reasons will be more obvious.

It might also be noted that the occupation, mathematician, is included among the low risk-takers. Probably one of the country's best-known gamblers is Edward Thorp, author of the book, Beat the Dealer (1962) . Thorp, Professor of Mathematics at the University of California, Irvine, would seem to be a risk-taking mathematician, and thereby a refutation of these data. However, a close reading of Thorp's book indicates that, although his palms may have been sweaty and his breath short, he was not taking a chance, at least in his own mind; he was betting on a sure thing where sure was defined with mathematical precision, not by intuition.

Table I6-V lists the high and low-ranking female samples. Again, the artistic types are at the top of the risk-taking distribution along with airline stewardesses, recreation directors and nightclub entertainers-the latter grouping perhaps being the equivalent of the machismo cluster of males. The presence of female psychologists among the group puzzles and amuses the writer as he had previously not been sensitive to this characteristic of his female colleagues.

Among the low-ranking female occupations is a startling cluster -that of elementary and secondary school teachers. When these are combined with the two education occupations on the male clusterguidance counselors and music teachers-one concludes that one bastion of conservatism, at least as measured by this item, is the schools.

The other major theme running through the low-ranking occupations is what might be called traditional feminism. Housewives, farm wives and sewing machine operators all have quite a traditional approach to the world.

This pattern of occupations is consistent with the pattern of correlations that was seen earlier in other data-women with traditional interests are frequently oriented toward office settings. 


\section{Conclusion: What Have We Learned from All These Data?}

First, the occupation, professional gambler, ranks slightly below average in popularity when compared with a long list of other occupations-among males, it ranked 77 out of 131 (59th percentile), among females, 124 out of 131 (94th percentile).

Second, obviously males find this occupation more attractive than do females by about a two-to-one difference.

Third, people who say they would enjoy being professional gamblers are oriented toward risk-taking; people who reject the occupation are traditional and conservative.

Fourth, artists and salesmen are at the top of the risk-taking hierarchy as measured by their responses to the test items, and school teachers and bankers are at the bottom.

So much for the data and the precise conclusions. As the writer suspects his audience is not filled with school teachers and bankers, he takes this quote from Samuel Johnson which is relevant to this setting and data. "He seldom lives frugally who lives by chance. Hope is always liberal; and they that trust her promises make little scruple of revelling today on the profits of the morrow."

\section{REFERENCE}

Thorp, E. O.: Beat the Dealer. New York, Blaisdell Publishing Company, 1962. 


\title{
Chapter 17
}

\section{A FUNLTIINALL ANALYSIS DF GAMBLING BEHAVIII}

\author{
TERRY J. KNAPP
}

Wow SHOUlD GAMBLING BEHAVIOR be described? Previous at1 tempts at producing a psychological account of gambling have appealed to such psychoanalytic hypotheticals and dynamics as an orally regressed neurotic personality, the discharging of multiple aggressive drives, and the secularization of divine rites; or to social psychological notions of norms, personality traits and need for achievement; or to an array of statistical mechanisms such as gambler preference and sensitivity to various values of probability, variance and expected value. These accounts stand in contrast to a functional analysis of behavior which attempts to identify and characterize as precisely as possible just those actual aspects of environmental circumstance under which gambling or any particular behavior is most likely to occur (Skinner, 1971, 1953). What counts as environmental circumstance and, for that matter, behavior itself is any component of the world which can be discriminated in some fashion by the person or instruments making the observation. Thus, environment should not be read narrowly as we are perhaps accustomed to in the social sciences, but rather in the broader sense of elements of influence or controlling variables (Skinner, 1969).

The goal of a functional analysis of behavior is the description of the controlling relationships which prevail between the behavior of an individual on the one hand, and the environmental influences on the other. Behavior is a function of its consequences and its antecedents. Events which, when they follow a behavior, produce an increase in the probability of that behavior are labeled rein- 
forcers, while events producing a decrease in the probability of behavior which they follow are termed punishers. Reinforcers and punishers are two examples of controlling variables. Events which precede behavior are also controlling variables because they also serve to determine under what circumstances certain behaviors are likely to appear. Technically, the latter are termed discriminative stimuli in the sense of discriminating in favor of some behaviors and not others; that is, they set the occasion for particular behaviors, making them more likely to occur. Discriminative stimuli and reinforcing stimuli are names employed for certain controlling variables in order to describe and analyze any piece of behavior. A discriminative stimulus, response and stimulus reinforcer together constitute a chain of events referred to as a contingency of reinforcement. Manipulation of such contingencies allows for the fine grain control of behavior through altering the consequences and antecedents of the particular behavior in question. This is, of course, the language of operant psychology. It stands in contrast to a trait or psychoanalytic approach in which behavior might be changed by attempting to alter a personality attribute or underlying dynamic construct, neither of which is directly accessible. Thus, the fundamental question posed by a functional analysis of gambling behavior is not Why do people gamble? but Under what circumstances will people gamble?

As in any scientific endeavor, standardized procedures exist for the experimental analysis of functional relationships (Sidman, 1960) - Previous research investigating gambling has generally utilized multiple-subject analysis by comparing either experimental and control groups through a statistical analysis, a group under one condition with itself under a later condition, or the average of several individuals across several conditions. No study has attempted to experimentally control the gambling behavior of single subjects on a within or between-session basis. In fact, Rapoport and Wallsten (1972) in their review of individual decision behavior conclude, "Since the concept of risk, as that of utility, would appear to be highly idiosyncratic, perhaps a more promising experimental procedure is to shift from multiple-subject to single-subject designs." Individual organism research methodology, an integral component 
in a functional analysis of behavior, seems an untapped resource for research on gambling activity.

In what follows, an attempt is made to categorize some of the variables which a functional analysis suggests may be operative in producing and maintaining gambling behavior. This is not the first undertaking of a functional analysis of gambling behavior (Skinner, (1953) and Montgomery and Kreitzer (1968)), but it does represent the most extensive attempt, both with respect to interpretation, and with respect to investigation of relevant studies."

\section{The Response of Betting}

What is the nature of the gambling response to which a functional analysis is addressed? Three characteristics seem to typify the behavior observed in casino play, and while such gambling may in fact constitute only a small portion of what is subsumed under the rubric of gambling games, it is especially suited for analysis due to the ease and readiness with which it may be observed! First, there is the rate at which persons make bets by putting coins in slots, chips on tables or paying cash at windows. For example, while it is true that the parameters of the rate of pulling a slot machine lever are fixed within fairly narrow limits, simple observation in any casino shows the rates to be typically near the maximum capability of the machine. Similarly, persons can be seen operating two or more machines at such a rate that they do not observe the spinning reels, nor when payoffs occur do such persons divert their attention from placing coins in the other machines they have under play. While all these are anecdotal accounts, they do illustrate the importance of rate of betting as a component of gambling. When people gamble they do so at a high frequency.

Second, there is the duration of gambling behavior. Everyone is all familiar with the legendary marathon poker game in which a Paul Newman-like character sends out for sandwiches and more booze. One can easily gather similar anecdotal data from medical

*A number of studies report the employment of behavior therapy in connection with gambling; unfortunately, most such attempts utilize aversive techniques, e.g. Barker and Miller (1966), Barker and Miller (1968), Cotler (1971), Goorney (1968), Peck and Asheroft (1970) and Seager $(1970)$. 
personnel at Reno or Las Vegas hospitals. For example, they tell tales of people treated for exhaustion or cardiac difficulties produced by standing too long at machines, failing to leave in order to eat or rest. Casino personnel tell of one older gentlemen who regularly refused to abandon machines in play to the point of urinating on the spot rather than going to a nearby rest room. While such accounts testify to the duration of betting behavior, it is simply true that we lack the kind of neat descriptive data, norms if you prefer, which tell us with more assurance how long people are likely to play. For example, a few years ago Rice and Blascovich (1971) reported in an unpublished manuscript social and demographic characteristics of gamblers who played a particular set of slot machines. This kind of naturalistic observation is desperately needed, and of course would be even more valuable to a functional analysis if individual persons rather than machines were tracked.

Third, without doubt, the hallmark of interest and, for some, the mystery of gambling, is the persistence of the behavior. Not only do people gamble at a high rate for long durations, but they do so in spite of obvious and repeated losses-losses which send them back again and again to the cashier's cage to write check after check with which to continue gambling. Each betting response costs the gambler, and repeated responses which do not turn into wins soon become heavy losses, but the gambling continues. The persistence in the face of loss is reflected in such subsequent activities as obtaining credit with which to gamble, turning to special out-ofstate check cashing services which take up to 20 percent of face value, getting loans from friends and perhaps finally turning to illegal methods of obtaining money with which to gamble. Compulsive gamblers frequently first come to the attention of helping agencies through referral from law enforcement personnel following a bad check-writing spree. What controlling variables produce a response which persists in the absence of any obvious gain, and at a high response cost?

Finally, a fourth attribute of the gambling response, unique to those risk situations in which one bets money for money, includes such measures of responding as average value of bets, total amounts wagered, total dollars lost, ratio of losses to wins, and a variety of 
similar measures which can be constructed because bets are monetary in nature. Unfortunately, such measures of betting, although easily allowing quantification, may be a mistake since they tend to make one look toward macro aspects of gambling, as for example net amount lost rather than micro aspects such as fine grain changes in rate, amount of bet and payoff schedule.

These three characteristics-rate of betting, duration of play, and persistence of gambling in the presence of losses-are the parameters which seem to constitute the intensity, excitement and compulsion often attributed to gamblers.

\section{Discriminative Stimuli}

Certain events which precede actual responding may serve to increase the probability or likelihood of gambling; they in some sense set the occasion for gaming. Hess and Diller (1969), though casting them in a different conceptual system, have done an excellent job of describing such stimuli as they exist in the casino-other persons are playing; bells ring with wins; lights flash; machines paying jackpots may be announced over the PA system; signs advertise liberal slot machines, inexpensive meals, complimentary drinks; and numerous other services are readily available. All of these could be characterized as appeals to motives, but a functional analysis would more simply describe them as stimuli which raise the probability, set the occasion or discriminate in favor of making a betting response. In addition to general environmental stimuli, slot machines themselves are equipped with discriminative stimuli designed to increase the likelihood of play. This is clearly evident if one visits the Liberty Bell Saloon owned by the grandsons of slot machine inventor, Charles Fey. On display are numerous machines ordered as they historically evolved, each with increasing numbers and density of discriminative stimuli: lights going on and off, shiny metal and the like. The only advance that has not been made is to replace the rather uninteresting acorns and cherries with pictures of sensuous young sirens in various states of nakedness.

\section{Response Priming and Reinforcer Sampling}

The technique of giving away free packets of nickles may be aptly described as response-priming inasmuch as it increases the 
likelihood that the receiver of the free nickels will make a gambling response." A similar procedure is commonly and successfully used to first introduce reluctant psychiatric patients to the contingencies of a token economy (Ayllon and Azrin, 1968). The procedure itself becomes more effective, and may be termed reinforcer sampling when potential gamblers are given tokens which must be placed in a slot machine in order to receive the free number of nickels. The customer has now been induced to make what topographically resembles a gambling response, and he has been reinforced for doing so. The procedure would be even more effective if customers were to be given a number of such free tokens, and the machine paid off on a low variable ratio (VR) schedule of reinforcement rather than a continuous reinforcement schedule.

\section{Schedules of Reinforcement}

The relationship which defines either temporally or numerically which response will be followed by a reinforcer is termed a schedule of reinforcement. The variable ratio schedule of reinforcement in which responses are followed by a reinforcer after a varying and unpredictable number of responses is regarded as singularly important in an analysis of gambling behavior.t This schedule in the early days of learning theory was termed partial reward, and its effect of creating greater resistance to extinction in comparison to continuous reinforcement, was termed the partial reward effect $(P R E)$. While such terminology and experimental work is now only of historical interest, it is perhaps important to note that in a series of very early research studies, Lewis (1952) and Lewis and Duncan (1956, 1957 and 1958) utilized a modified twenty-five cent slot machine to demonstrate that "the persistence of the leverpulling response is an inverse function of the percentage of re-

*A good example of this is the procedure at the Frontier Hotel in Las Vegas. Neophyte players are provided with free nonnegotiable chips and a special dealer who instructs them in 21 and other games. It has been reported that "many do in fact head directly for the casino from the instruction table" (Sumdance Country: Hughes Airwest Magazine, 1974).

†Goodman (1965) and Noland (1970) have described the mechanical manner in which slot machine payoffs are determined. In the laboratory a VR schedule may be programmed by (1) an electronic probability generator, (2) a continuous punched film fed through a programmer, or (3) a punched-tape reader. 
ward." Such work should not, however, be identified with the more refined control exerted by various schedules of reinforcement.

Skinner (1953) has characterized the effect of a variable-ratio schedule of reinforcement in connection with gambling in this manner:

The efficacy of such schedules in generating high rates has long been known to the proprietors of gambling establishments. Slot machines, roulette wheels, dice cages, horse races and so on pay off on a schedule of variable-ratio reinforcement. Each device has its own auxiliary reinforcements, but the schedule is the important characteristic. Winning depends upon placing a bet and in the long run upon the number of bets placed, but no particular payoff can be predicted. The ratio is varied by any one of several "random" systems. The pathological gambler exemplifies the result. Like the pigeon with its five responses per second for many hours, he is the victim of an unpredictable contingency of reinforcement. The long-term net gain or loss is almost irrelevant in accounting for the effectiveness of this schedule.

Since Skinner wrote these words in 1953, considerable experimental work on schedules of reinforcement has been undertaken (Ferster and Skinner, 1957 and Thompson and Grobowski, 1972) The principle characteristics of a VR schedule, which distinguishes it from other schedules, may be summarized as (1) the production of highest overall rate of response in comparison to any other schedule, (2) an increase in the rate of response immediately following reinforcement, (3) extreme resistance to extinction, responding being maintained for long periods of time in spite of nonreinforcement, and (4) the reduction of responding when it does occur in extinction consisting of increasingly longer pauses between responding at high rates-that is, the pausing gradually increases in length while responding between pauses remains at a relatively high rate.

The powerful effects of the schedule in maintaining behavior in the absence of little reinforcement have been aptly described by Skinner (1953), "A mean ratio can be reached at which reinforcements occur so rarely that the pigeon or rat spends more energy in operating the device than he receives from the reinforcement with food, while the human subject steadily loses money. All three subjects, however, continue to play."

Researchers interested in gambling and risk behavior have ex- 
hibited some interests in the PRE (Devereux, 1968) phenomena, or the more contemporary VR schedule (Bolen and Boyd, I968 and Moran, 1970). Two studies in this connection which should perhaps be discussed in some detail are Greenburg and Wenier (1966) and Levitz's doctoral dissertation (1971) .

Greenburg and Wenier (1966) assessed the effects of reinforcement history. In a single one-hour session, 132paid volunteers were given bingo cards, of which there were nine different versions depending on ratio of wins to losses $(8-1,4-4-1,1-8)$, and the amount of money won or lost $(1.20, \$ 0.00$ and $-\$ 1.20)$. Nine drawings by a stooge participant produced the above treatment conditions, at which point the subjects were directed to: (1) select one bet among possible bets varying in probability $(1 / 20$ to $20 / 20)$, (2) increase their original bet by multiples of $2,3,4$ and 5 if they wished, and, finally, (3) indicate what they thought their probability of winning was on a 0 to 100 scale. The results of the twobet measure supported earlier findings in that a subject's preference among gambles is independent of the amount of money won or lost. The ratio of the number of wins to losses did produce significant effects inasmuch as high-risk gambles were exhibited by subjects who had experienced either very high or very low ratios. Based on this preliminary investigation the authors conclude, "these results indicate a need for the experimental analysis of reinforcement schedules in future studies of risk-taking behavior."

Levitz (1971) undertook to extend these initial data by examining the effects different histories of VR schedules produce on subsequent persistence at play during extinction; hence the title, "The Experimental Induction of Compulsive Gambling Behavior." Ninety paid male undergraduates participated in two periods (22 trials and 51 trials, respectively) of playing an experimenter-contrived four-choice gamble. During Period I, each subject was required to gamble, and played across conditions of winning (VR $36 \%$ ) or losing (VR 14\%), and high, average or low relative equity with respect to most other subjects. In Period II, equity information was withdrawn, subjects chose to gamble or not gamble, but all subjects lost when they did gamble since only the 14 percent VR schedule was in effect. A variety of dependent measures were employed, the most important of which was the number of trials 
gambled in Period II. Those subjects who had either a winner payoff schedule or a relative high equity persisted at the gambling task to a significantly greater degree than subjects who had lost.

Both of these studies had a similar goal-to build a particular behavioral history into the subjects under investigation-and in that respect they resemble previously cited work (Lewis, 1952 and Lewis and Ducan, 1956, 1957 and 1958) and also resemble the intent of a functional analysis. Unfortunately, the studies, while seeking environmental variables, employed a group design with statistical control rather than experimental control. Lewis and Duncan (1958) for example, note, "It has been pointed out several times before that group data and individual data do not always yield the same results. This study affords a graphic illustration of this point."

Other schedules analytically defined and experimentally assessed in the operant laboratory may be found to operate in the casino. For example, some laboratory slot machines have employed a fixed ratio-variable ratio mixed schedule. A clock on the face of the machine is advanced from fifteen minutes to zero in five-second steps with each pull of the lever, thus, at the end of forty-five pulls, the player is guaranteed a reinforcer (typically a fifteen-dollar jackpot) : at the same time the lever pulls are also paid off on an unpredictable VR schedule. Similarly, in another machine, the player is guaranteed a reinforcer if ten consecutive bets do not yield a payoff. Machines joined together for play are examples of multiple schedules of reinforcement. An individual playing more than one machine at a time is on a concurrent schedule of reinforcement. Many of these schedules have been studied extensively in subhuman species. As may now be evident, the contingencies which operate in a slot machine or other gambling devices in general can be easily described with standard operant nomenclature (Mechner, 1959 and Snapper, Knappand Kusher, 1970) as well as programmed with standard operant laboratory equipment.

\section{Conditioned Reinforcers}

Various aspects of gambling may come to maintain play by their association with the generalized reinforcer of money. The topography of the response itself should not be overlooked. For example, 
a slotmachine mechanic recently described to the author the attempt to replace the lever-pulling response with a simple push button where the machine did all the work. The innovation was a miserable failure. It seems people would rather pull levers than push buttons, even if the former is the more effortful response. In this connection a series of experiments by Tarte (1974) may be relevant. In a wide variety of settings across a wide range of subjects, if individuals are given the opportunity to earn $M \& M$ 's® or coins by pushing a plunger or simply taking them out of a dish, there is a consistent preference for obtaining the items by leverpulling.

The immediate consequences of pulling a lever, the reels spinning, seems enough of a payoff to maintain responding at the same strength. For a period of time a slot machine was on the premises of the Behavior Therapy and Research (BTR) Center in Reno. Despite the fact that the machine was British, and hence no money in the ordinary sense could be won, and despite the fact that the payoff magazine was empty, and hence the machine did not pay off on winning combinations, the staff, psychiatrists, psychologists, technicians, interns and secretaries continued to drop a sixpence piece into the slot just in order to pull the lever and watch the reels turn.

Skinner himself has called attention to a third kind of conditioned reinforcement that may be operating to maintain responding. "By paying off very generously-with the jackpot-for 'three bars," the device eventually makes two bars plus any other figure strongly reinforcing. 'Almost hitting the jackpot' increases the probability that the individual will play the machine, although this reinforcer costs the owner of the device nothing" (Skinner, 1953). These interpreted sources of conditioned reinforcement, while anecdotally supported, stand in need of experimental assessment.

\section{Response Cost Contingency}

The betting response a gambler makes costs something; such a contingency is typically termed response cost. While little laboratory attention has been directed toward response cost contingencies, the available investigations provide additional insight into under- 
standing gambling behavior. Weiner (1970) for example, has shown that paid subjects given a ten-session history of fixed ratio responding persist in responding at FR rates when switched to a fixed-interval, ten-second schedule despite the nonnecessity of such responding, and despite the fact that such responding costs and, hence, results in losses. Subjects working for points lost, on the average, 105 points per session, and subjects working for money lost on the average $\$ 1.25$ per session. Weiner concluded that "under certain conditions, operant behavior may persist despite the fact that it produces withdrawal of reinforcement, such persistence may occur even when these withdrawals are preventable."

\section{Variable Magnitude of Reinforcement}

When reinforcement does occur in gambling games, the magnitude varies both as a function of the bet and, perhaps more importantly, as a function of the contingencies of the gambling device. A recent experiment by Essock and Reese (1974) while employing pigeons as subjects, provides some preliminary evidence on the functional relationship of response and varying reinforcement magnitude. Pigeons worked on an FR schedule for either a fixed or variable period of access to food. Pecking rates were higher during the variable period of access component, pigeons in a concurrent schedule showed an initial, and in most cases, sustained preference for the variable period of reinforcement. When the average variable duration for one subject was reduced to half of the fixed duration, continued preference for the variable component resulted in a loss of up to 30 percent of the available reinforcement time. The earlier-described slot machine at the BTR Center became uninteresting with a few plays when the reinforcement magazine was filled because, while it had several payoff combinations, the magnitude of reinforcement, except for jackpots, was always two coins. Still more complex arrangements of reinforcement magnitude are evident in machines with adjusting schedules in which each pull of the lever increases the magnitude of jackpot reinforcement.

\section{Adventitious Contingencies}

Contingencies of reinforcement involve functional relationships in which the response serves to reliably produce some speci- 
fied outcome, but contingencies can prevail in which the response is only adventitiously related to the reinforcer. In early animal studies such arrangements were referred to as "superstition" (Skinner, 1948; Morse and Skinner, 1957; and Hernstein, 1966). Animals would engage in bizarre behaviors, for example, turning counterclockwise, tossing the head upward, swinging of the head and body in a pendulum-like fashion, simply because reinforcement was made to occur at timed intervals not related to anything that the organism was doing. The process closely resembles what is characterized as "beginner's luck" (Bolen and Boyd, 1968). The behavioral process of adventitious reinforcement is even more evident in the highly idiosyncratic manner in which some gamblers pull the slot machine lever, throw the dice or insist upon a wide variety of similar exotic maneuvers before making a betting response. Such behaviors are viewed as in some way affecting the outcome, much in the same manner that the pigeon acts as though its behaviors, bizarre as they may be, affect the outcome. In either case, adventitious reinforcement seems a viable interpretation.

What has been said of slot machines is of course an interpretation, not an experimental analysis of behavior." Thus, it stands against other interpretations as, for example, personality analysis or psychodynamic interpretations. It is true that by selecting slots as the exemplar of gambling, things are made easier for a functional analysis, and in making a beginning investigation it is perhaps best to be easy on oneself.t A real test, of course, is to see how some of the variables categorized above actually do affect the rate, duration and persistence of slot-gambling by a single subject across time. The research suggestions which follow may assist in making such a test possible.

\footnotetext{
"Rachlia and Frankel (1969) employed an experimental analysis to assess the effects of probability of winning, variance and expected value on choice, rate of response and rate of gambling. Subjects showed no preference for one gambling situation over another, but did show a preference for conditions with higher $\mathrm{ex}$ pected value, and matched their probability of gambling to the probability of winning. While subjects received payment for participation, they did not risk their own funds, nor was the gambling game a naturally occurring one.

tFor a very humorous account of an encounter between Morton, Peggy and a "one armed bandit" see Whaley and Malott's (1971) "Honeymoon for Three."
} 


\section{Suggestions for Research}

While no explicit reviews of gambling literature are available, the extensive bibliography by Kusyszyn (1972) along with his paper, "The Psychology of Gambling" (1973) provided some indication of the methodologies employed by researchers of gambling behavior as does the more general review of risk-taking by Rapaport and Wallsten (1972). Most such studies employ, almost without exception, group comparison designs and games constructed specifically for the laboratory. Earning points on a counter, playing an experimenter-contrived gamble or specifying hypothetical bets are all behaviors which functionally lie some distance from the race track, casino or corner bookie. Even when investigators attempt to replicate their laboratory results in the natural environment (Lichenstein, 1973), they bring with them their PDP-7 computer and CRT scope rather than turning to the casino games of slots, roulette, keno and craps (Blascovich, Veach and Ginsburg, 1973) . A laboratory setting which contains a blackjack table, stools, slot machines, coins, carpeting and one-way mirrors more closely approximates the actual environment of a real gambling casino. In fact, preliminary related research on risk-taking has revealed differences when natural gambling games in such a setting* are compared to traditional artificial procedures (Higbee and Stufert, 1969). The research suggestions which follow simply extend the innovative environment of Ginsburg, Blascovich and Veach, and substitute experimental analysis for its statistical counterpart.

A TOTAL LIVE-IN LABORATORY. The above-mentioned laboratory might be enlarged to include not only a small casino, but also other types of activities which regularly compete with gambling as, for example, television, radio, eating, sleeping, reading, talking, drinking and the like. What is being suggested is the construction of a laboratory environment which approximates the natural one in every possible respect. One would then hire subjects to live in the laboratory, spending and gambling their earnings much as they might if they resided in or visited Las Vegas, Reno or Tahoe. This may sound like a "Mission Impossible"-sort of suggestion, and one

*For examples of investigations conducted in the natural environment with natural games, see Knox and Inkster (1968) and Munson (1962). 
might agree if it were not for the fact that a similar sort of environment and a similar sort of research project has already been completed in connection with an experimental analysis of alcoholic behavior (Nathan and O'Brien, 1971).

PLACING GAMES IN THE NATURAL ENVIRONMENT. While the total live-in laboratory environment is intriguing, it remains a laboratory. One can more closely approximate natural circumstances by selecting a restricted setting and population, for instance, a neuropsychiatric ward, preschool or summer camp. Not long ago, for example, the author took part in a research project attempting to increase activity among geriatric patients. A slot machine was included among other automated games placed on a geriatrics ward of a state mental health institution. In such a setting, where the population remains relatively stable both in terms of number and identity, tracking the rate, duration and persistence of play by selected individuals is relatively easy. If a token economy were also imposed on the population, the possibilities for manipulation studies of a microeconomy where gambling is a component are, as Kagel and Winkler (1972) have noted, endless and interesting.

STUDIES IN THE NATURAL ENVIRONMENT. The next step is, of course, the natural environment itself, the real world of slots, bookies, craps and keno. Applied behavior analysis has had considerable success in the analysis of controlling variables where the natural environment is that of the psychotic ward, preschool, normal classroom or mental retardation ward (Ulrich, Stachnik and Mabry, 1966, 1970 and 1974) - Recently, similar successes were reported in the controlling of littering in a theater (Burgess, Clark and Hendee, 1971) and a public park (Clark, Burgess and Hendee, 1972) as well as bus ridership on a campus transit system (Everett, Hayward and Myers, 1974). Suppose an experimenter undertook something of this sort. He located persons who, upon their arrival in Las Vegas or Reno, would consent to letting observers follow them at a distance while they spent their vacation weekend. The experimenter would collect data on the rate, duration and persistence of play. Of course, the participants would be paid for rendering such a service, and this itself could be a manipulation in terms of when they are paid and in what form, etc.

SUBHUMAN SPECIES AS SUBJECTS. The final suggestion is actually 
much less expensive and may be many more times informative than the earlier ones. Why not employ subhuman species as experimental subjects? Harlow has demonstrated that a great deal about human behavior can be gleaned from the behavior of primates. He and his co-workers, for example, are currently able to produce behaviors in rhesus monkeys which closely resemble autism and depression in humans (Harlow, Harlow and Suomi, 1971), and nearly everyone is familiar with his extension research on learning love (Harlow, 1971). The advantages of subhuman species as experimental subjects lie mainly in the fact that a much more comprehensive control of the environment and behavioral history is possible than that which would be obtainable or ethical with regard to Homo Sapiens. Some may disagree that subhuman species are capable of engaging in anything that remotely resembles human gambling behavior, but surely if chimpanzees can talk (Gardner and Gardner, 1971 and Premack, 1970), they can gamble and maybe even tell us about their experiences. For that matter, if the interest is in functional relations, and not in topographical ones, the rat or pigeon may be equally enlightening in experimentally seeking out the variables of which the gambling response is a function.

\section{CONCLUSION}

A functional account or experimental analysis of gambling behavior would thus emphasize three methodological innovations. First, the controlling variables of gambling responses would be sought in the immediate environment of the organism, and in the organism's environmental history, rather than in a personality or some other underlying dynamic or construct. Second, rather than employing a group comparison design with the related statistical control procedures, a functional analysis would attempt to evidence the experimental control of gambling responses in the behavior of a single subject across time. Third, while functional rather than topographical relationships form the foundation of an experimental analysis of betting behavior, the importance of naturalistic observation and assessment cannot be ignored, especially in the light of demonstrated differences between contrived and natural 
games. We simply need to know more about the circumstances under which people gamble.

B. F. Skinner's most recent work, About Behaviorism (1974), contains a paragraph devoted to the subject of gambling; it seems an appropriate manner in which to conclude, and, in doing so, to summarize the point of a functional analysis.

All gambling systems are based on variable-ratio schedules of reinforcement, although their effects are usually attributed to feelings. It is frequently said, for example, that people gamble because of the excitement, but the excitement is clearly a collateral product. It is also sometimes said that people gamble "to satisfy their sense of mastery, to dominate, to win" - in spite of the fact that gamblers almost always eventually lose. The inconsistency is explained by calling the gambler who ruins himself and his family "compulsive" or "pathological," his "irrational" behavior thus being attributed to an illness. His behavior is "abnormal" in the sense that not everyone responds with similar dedication to the prevailing contingencies, but the fact is simply that not everyone has been exposed to a program through which a highly unfavorable ratio is made effective. The same variableratio schedule affects those who explore, prospect, invent, conduct scientific research, and compose works of art, music, or literature, and in these fields a high level of activity is usually attributed to dedication rather than compulsion or irrationality. . . - It is characteristic of intermittent reinforcement that behavior may be sustained over long periods of time with very little return. This has been explained by saying "Human beings are creatures of hope and are not genetically designed to resign themselves," but there is nothing essentially human about the effects, and it is not hope or resignation but the contingencies which are the conspicuous and accessible cause.

\section{REFERENCES}

Ayllon, T., and Azrin, N.: The Token Economy: A Motivational System for Therapy and Rehabilitation. New York, Appleton-Century-Crofts, 1968.

Barker, J. C., and Miller, M.: Aversion therapy for compulsive gambling. INery Mene Dis, I46:285, 1968.

Barker, J. C, and Miller, M.: Aversion therapy for compulsive gambling. Lancet, 10:491, 1966.

Blascovich, J., Veach, T. L., and Ginsburg, G. P.: Blackjack and the risky shift. Sociometry, 36:42, 1973.

Bolen, D. W $W_{z}$ and Boyd, W. H.: Gambling and the gambler: A review and preliminary findings. Arch Gen Psychiatry, 18.617, 1968.

Burgess, R. L., Clark, R. N-, and Hendee, J. C.; An experimental analysis 
of anti-litter procedures. / Appl Beh Anal, f:71, 1971.

Clark, R. N., Burgess, R. L., and Hendee, J. C.: The development of antilitter behavior in a forest campground. / Appl Behay Anal, 5:1, 1972.

Coder, S. B.: The use of different behavioral treatment in treating a case of compulsive gambling. Behav Ther $2: 579,1971$.

Devereux, E. C., Jr.: Gambling in psychological and sociological perspective. In the International Encyclopedia of the Social Sciences, 1968, vol. 6, pp. 53-62.

Essock, S. M.., and Reece, E. P.: Preference for and effects of variable as opposed to fixed-rcinforcer duration. / Exp Anal Beh, 21:89, 1974.

Everett, P. B., Hayward, S. C., and Meyers, A. W.: The effects of a reinforcement procedure on bus ridership. / Appl Beh Anal, 7:1, 1974.

Ferster, C. B., and Skinner, B. F.: Schedules of Reinforcement, New York, Appleton-Century-Crofts, 1957.

Gardner, R. T., and Gardner, R. A.: Two-way communication with an infant chimpanzee. In Schricr, A. and Stollnitz, F.: Behavior of Nonhwmant Primates. New York, Academic Press, 1971.

Goodman, M.: Slots and Pinballs, Las Vegas, Gambling International, 1965.

Goorney, A. B.a Treatment of a compulsive horse race gambler by aversion therapy. Br J Psychiatry, 114:329, 1968.

Greenberg, M. G. and Weiner, B,; Effects of reinforcement history upon risktaking behavior. / Exp Psychol, 71:587, 1966.

Harlow, H. F.: Learning to Love. San Francisco, Albion, 1971.

Harlow, H. F.s Harlow, M. K., and Suomi, S. J.a From thought to therapy: Lessons from a primate laboratory. Am Sci, 59:598, 1971.

Hernstein, R. J.: Superstition: A corollary of the principles of operant conditioning. In W. K. Honig: Operant Behavior: Areas of Research and Application. New York, Appleton-Century-Crofts, 1966, pp. 33-51.

Hess, H. F-, and Diller, J. Y:i Motivation for gambling as revealed in the marketing methods of the legitimate gambling industry. Psychol Rep, 25: 19, 1969.

Higbee, K. L.n and Stufert, S.: Perceived control and riskiness. Psychonomic Sci, $I 7: 105_{i} 1969$.

Kagel, J. J-, and Winkler, R. C.: Behavioral economics: Areas of cooperative research between economics and applied behavior analysis. / Appl Beh Anal, 5:343, 1972.

Knox, R. E., and Inkster, J.: Postdecision dissonance at post time. / Pers Soc Psychol, 5:319, 1968,

Kusyszyn, I.; The psychology of gambling. In Psychology $73 / 74$ Encyclopedia Guilford, Dushkin Publishing Group, Incorporated, 1973, pp. 104-105.

Kusyszyn, I.: Psychology of gambling, risk-taking, and subjective probability: A bibliography. Listed in Journal Supplement Abstract Service Catalog of Selected Documents in Psychology, 2:7, 1972.

Levitz, La: The Experimental Induction of Compulsive Gambling Behavior. 
Doctoral Dissertation, University o£ Illinois, Ann Arbor, Xerox University Microfilms, No. 21-169, 1971.

Lewis, D. J.: Partial reinforcement in a gambling situation. / Exp Psychol, 43:447, 1952.

Lewis, D. J and Duncan, C. P.: Effect of different percentages of money reward on extinction of a lever-pulling response. / Exp Psychol, 52:23, 1956.

Lewis, D. J. and Duncan, C. P.: Expectation and resistance to extinction of a lever-pulling response as functions of percentage of reinforcement and amount of reward. / Exp Psychol, 52:115, 1957.

Lewis, D. J $\rightarrow$ and Duncan, C. P.: Expectation and resistance to extinction of a lever-pulling response as functions of percentage of reinforcement and number of acquisition trials. / Exp Psychol, 55:121, 1958.

Lichtenstein, $S_{2}$ and Slovic, P.: Response-induced reversals of preference in gambling: An extended replication in Las Vegas. / Exp Psychol, 101:16, 1973.

Mechner, F. A.: A notation system for the description of behavioral procedures. J Exp Anal Beh, 2:133, 1959.

Montgomery, H., and Kreitzer, S. F.: Compulsive Gambling and Behavior Therapy. Paper presented at California State Psychological Association Convention, Santa Barbara, 1968.

Moran, E.: Varieties of pathological gambling. Br J Psychiatry, 116:593, 1970.

Morse, W. H., and Skinner, B. F.: A second type of superstition in the pigeon. Am J Psychol, 70:308, 1957.

Munson, R. F: Decision-making in an actual gambling situation. Am J Psychol, 75:640, 1962.

Nathan, P. E, and O'Brien, J. S.; An experimental analysis of the behavior of alcoholics and nonalcoholic during prolonged experimental drinking: A necessary precursor of behavior therapy? Behav Ther, 2:455, 1971.

Nolan, W. I.: The Facts on Slots. Las Vegas, Gambler's Book Club, 1970.

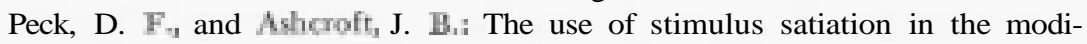
fication of habitual gambling. In Proceedings of the Second BEA Confer. ence on Behaviour Modification. Kilkenny, Ireland, 1970.

Premack, D.: A functional analysis of language. I Exp Anal Behav, 14:107, 1970.

Rachlin, H. C., and Frankel, M.: Choice, rate of responding, and rate of gambling. I Exp Psychol, 80:444, 1969.

Rapoport, A- and Wallsten, T. S.; Individual decision behavior. Ann Rev Psychol, 23:131, 1972.

Rice, W. H., and Blascovich, J. J.a Socio-Demographic Characteristics of Slot Machine Gamblers in Reno, Nevada. Unpublished manuscript, 1971.

Seager, C. P.: Treatment of compulsive gamblers using electrical aversion. Er J Psychiatry, 117:545, 1970.

Sidman, M.: Tactics of Scientific Research. New York, Basic Books, 1960. 
Simon, H. A.: A behavior model of rational choice. Q / Econ, $\operatorname{LIX}(1)=99$, 1955.

Skinner, B. F.: About Behaviorism. New York, Alfred A. Knopf, 1974.

Skinner, B. F.: Contingencies of Reinforcement:A TheoreticalAnalysis. New York, Appleton-Century-Crofts, 1969.

Skinner, B. F.: Science and Human Behavior. New York, Appleton-CenturyCrofts, 1953.

Skinner, B. F.: Superstition in the pigeon. / Exp Psychol, 38:168, 1948.

Snapper, A. G., Knapp, J. Z., and Kushner, H. K.a Mathematical description of schedules of reinforcement. In Schoenfeld, W. N.: The Theory of Reinforcement Schedules. New York, Appleton-Century-Crofts, 1970, pp. 247275.

Sundance Country: Hughes Airwest Magazine. Learn how to gamble on the house. 3,5:38, 1974.

Tarte, R. D.: Barpressing in the presence of free rewards in humans. Unpublished manuscript, University of Nevada, Las Vegas, 1974.

Thompson, T., and Grabowski, J. G.: Reinforcement Schedules and Multioperant Analysis. New York, Appleton-Century-Crofts, 1972.

Ulrich, R., Stachnik, $T_{7}$ and Mabry, J.: Control of Human Behavior. Glenview, Scott, Foresman, and Company, 1966, vol. 1.

Ulrich, $\mathrm{R}_{2}$, Stachnik, $\mathrm{T}_{z}$ and Mabry, J.: Control of Human Behavior. Glenview, Scott, Foresman, and Company, 1970, vol. 2.

Ulrich, R., Stachnik, $T_{7}$ and Mabry, J.: Control of Human Behavior. Glenview, Scott, Foresman, and Company, 1974, vol. 3.

Weiner, H.: Human behavioral persistence. Psychol Record, 20:445, 1970.

Whaley, D. L., and Malott, R. W,: Elementary Principles of Behavior. New York, Appleton-Century-Crofts, 1971. 


\title{
Chapter 18
}

\section{SEARCHING FOH MOTIVATIONS IN RISE-TAKING AND GAMDLING}

\author{
ERIC S. KNowus
}

$\mathrm{F}^{\mathrm{o}}$

OR ALL THE YEARS THAT humans have been subjected to risks, taking risks and creating risks, we really know surprisingly little about risk behavior. It is clear that people differwidely in this behavior-how many risks they take, what risks they take and when they take risks-but the reasons for these differences are unclear. We do not yet have very good answers to the question of why people take risks.

As a personality researcher, the writer's inclination is to find those aspects of people, their experiences and their individuality that correlate with and predict risk behavior. These antecedent predictors then form one sort of explanation of why people take risks. Many other researchers have followed this general strategy without apparent success. Numerous findings suggest that personality variables are virtually unrelated or inconsistently related to individual differences in risk behavior (Casey, 1969; Kogan and Wallach, 1964; Liverant and Scodel, 1967; Scodel, Ratoosh and Minas, 1959; Strickland, Lewickin and Katz, 1966; and Weinstein, 1969). After reviewing a number of studies on the predictors of risk-taking, Kogan and Wallach (1967) offered the conclusion that risk-taking is more a function of the situation than of the person. However, any conclusion at this point in the development of our understanding seems premature.

It is the writer's analysis that we cannot meaningfully answer the question of why people take risks until we develop an answer to a prior question: What is risk-taking? It appears that we do not yet have a clear understanding of the dependent variable, risk-taking. Until we do have a model and definition of the 
phenomenon we wish to study, we don't really know how to go about asking the question ofwhy people take risks.

The literature on risk-taking as a dependent variable is quite clear on two counts: (a) there are wide differences among people in their choice of a probability level, variance level and in their choices along most other dimensions of risk (Coombs and Pruitt, 1960; Knowles, 1969; Lichtenstein, 1965; Pruitt, 1962; Slovic and Lichtenstein, 1968), and (b) these individual differences are not consistent from one risk situation to another (Kogan and Wallach, 1964; Slovic, 1962; Weinstein and Martin, 1969; Weinstein, 1969). When a variety of risk-taking measures have been administered to the same subjects, the intercorrelations among the measures have revealed virtually no common association. Findings such as these have led to the characterization of risk-taking as an ephemeral and situation-specific phenomenon.

Perhaps these multimeasure studies have asked the wrong questions of their data. Slovic (1964) for instance, suggested the possibility that risk-taking is multidimensional, that is, risk-taking may include several aspects, each coherent, but discreet and unrelated to the others. Thus, instead of looking for the total convergence among various risk measures, perhaps it would be worthwhile to look for the patterns of convergence and discrimination among measures.

\section{A Search for Consistency in Risk-Taking}

The writer and several colleagues (Knowles, Cutter, Walsh and Casley, 1973) embarked on a multimeasure study of risktaking in the hope of identifying dimensions of risk on which people would be consistent. It included thirteen different measures related to risk. These included measures of what dimensions of risk information the subjects attended to, their expectations of winning, their judgments of how luck affected outcomes, various probability and variance preferences and an interpersonal rating of the subjects' risk-taking tendencies. Fifty-six student nurses, nonvolunteers, served as subjects.

The intercorrelation matrix paralleled earlier studies. An 
average intercorrelation of $\mathrm{r}-0.000$ was found among the measures. A factor analysis of the correlation matrix produced six orthogonal factors. Clearly, there was not much convergence among the thirteen measures studied, nor was it easy to see the coherence of each of the six identified factors; in part it was hard to make category descriptions for the particular measures that loaded on a factor, and, in part, the small number of measures loading on a factor prohibited any confidence in tentative descriptions.

\section{Differentiation Between Motivational and Stylistic Aspects of Risk-Taking}

Gradually, one difference among the factors did emerge and become more apparent. The first and strongest factor in the matrix appeared to include measures that were qualitatively different from the measures included on the other five factors. This first factor included three measures. First was a measure that indicated a subject's preference for playing a series of Duplex Gambles (Slovic and Lichtenstein, 1968) . A high score was obtained when a subject indicated stronger preferences or more preferences for playing bets than not playing bets. Second was the interpersonal rating of risk-taking. This measure indicated how high a risk-taker the subject was as judged by his or her peers. Third was a measure called the "win estimate." After evaluating a series of gambles, subjects estimated how many of the twentyseven bets they would win, break even and lose. The number of wins minus the number of losses was used as the win estimate, and indicated the general optimism of the subject. None of the measures of risk strategy appeared on this factor, though they did appear on all the others.

This first factor appeared to be more descriptive of a general preference for entering risk situations and to optimism about these situations than descriptive of any particular strategies that are assumed once in a risk situation. This distinction was reminiscent of Allport's differentiation between motivational aspects of behavior and stylistic aspects of behavior (Allport, 1937). The 
motivational aspects are the directional tendencies that initiate action and concern the question of what behavior is engaged in. Stylistic aspects, on the other hand, deal with the strategies and style of behavior and concern the question of how behavior is performed.

The first factor, which we have labeled the risk-approach dimension of risk-taking, appeared to us to be more related to the motivational aspects of risk behavior-a subject's preference for entering or avoiding risk situations. The measures on this factor did not involve choices among risk strategies, but indicated preferences for and expectations about risk situations in general.

This distinction between what people do and how they do it is most relevant for the areas of risk-taking and gambling. Clearly, it is a descriptively useful distinction. For instance, it is fairly easy to categorize the studies in this volume into those that deal with the motivational aspects of gambling and those that deal with the stylistic or strategy aspects of gambling, but the distinction is theoretically relevant in separating two classes of dependent variables which may be independent from each other and explained by different sets of variables. The distinction between motivation and strategy aspects of risk behavior may take us one step closer to answering the question of what risk-taking is, if not by providing an answer, at least by clarifying the questions we should be asking.

The Search for Consistency in Motivational Aspects of Risk-Taking

Information on the consistency of risk behavior suggests that people are not particularly consistent in their strategies of playing different kinds of risks. However, the distinction between strategy and motivational aspects of risk-taking raises the question of whether people are consistent in their motivation, that is their willingness to approach or avoid risk situations.

In the study mentioned earlier (Knowles et al., 1973) through a factor analysis three measures were identified which seemed to assess this willingness to approach or avoid risk situations. This study went on to analyze some auxiliary data collected from the 
subjects to see if the risk approach measures were consistent with other indicators of the willingness to enter risk situations. Although our student nurse subjects were more or less captives (they lived on or near the hospital and were assigned to this study) eighteen of the fifty-six subjects missed at least one of the four data collection sessions. After postulating an approach-avoidance motivational dimension to risk-taking, it was hypothesized that these subjects who missed a session should be lower on the risk approach dimension than the subjects who attended all sessions. Significant differences were found in the predicted direction for two of the three risk approach measures. Incomplete data subjects were seen by their peers as less risky than the complete data subjects $(\mathrm{t}=2.05, \mathrm{df}=52, \mathrm{p}<.025)$, and had lower preferences for playing the Duplex Bets $(t=1.93, \mathrm{df}=47, \mathrm{p}<.05)$.

In addition significant correlations were found between the peer-given risk-rating and the number of risk concepts a subject listed in twelve minutes $(\mathrm{r}-.57 \mathrm{df}=19)$, the score on a risky driving questionnaire $(\mathrm{r}-.43 \mathrm{df}=23)$, and whether or not the subject smoked cigarettes $(\mathrm{r}=.62, \mathrm{df}=23)$. The preference for playing the Duplex Bets also produced positive correlations, but were significant only for cigarette-smoking $(\mathrm{r}-.58$, df $=23)$.

These findings in total suggest a pattern of consistency in the willingness to enter and engage in risk situations. Subjects who have a greater preference for gambling are seen by their peers as risk-takers, and are less likely to avoid research sessions dealing with risk, are more likely to report risky driving behavior, have more associates to the concept of risk, and are more likely to smoke cigarettes. The pattern and level of association between these variables suggests a fairly strong personal consistency in the willingness to approach risk situations.

Independence of Motivational from Stylistic Aspects of Risk-Taking

The motivational aspect of risk-taking has close parallels to the concept of utility for risk introduced by von Neumann and Morgenstern (1947). Ziller (1957) described the utility for risk as "Liking to gamble or willingness to take a risk ..." Operation- 
ally, the utility for risk has been defined as the percentage of test items a person guesses on under penalty for wrong answers or the constant in a regression equation of probabilities and payoffs in a series of gambles against the amounts bid for a gamble (Komorita, 1964) - This latter procedure produces an index that is functionally similar to the preference for playing the Duplex Gambles used in Knowles, et al. (1973) . The utility for risk is independent from the specific situational parameters of a gamble and denotes a general willingness to take more risks or higher risks in a situation.

The comparison of the approach-avoidance aspects of risktaking with the concept of the utility for risk suggests further that the motivational aspects of risk-taking may be independent from the strategy aspects. Whether one decides to enter or avoid a risk situation may be unrelated to how that person would perform once in the risk situation; the decision to gamble may be independent of the riskiness or cautiousness of playing the gamble.

Botwinick (1966, 1969) has presented data suggesting that these two aspects of risk-taking are independent and that they have been confused in the past. He notes that Wallach and Kogan's (1961) finding, that risk-taking on the Choice Dilemma Questionnaire (CDQ) decreases with age, failed to make a distinction ". . . between a person who avoids problems and a person who is cautious in his solution of them" (Botwinick, 1969). Botwinick studied younger and older subjects using two CDQ versions, one which had five levels of odds between one in ten and nine in ten chances of success, and one which had the additional option, as in the Wallach and.Kogan version, of not risking the new course of action no matter what the odds, usually scored as 10 in 10.

Older subjects appeared more cautious by virtue of their choosing the no risk option more often. However, when this option was unavailable, instead of choosing the next most cautious probability, they chose probability levels that were comparable to the young subjects. It appears, then, that the older subjects were using the no risk option not as the most cautious probability, but as a means of indicating that they would rather avoid 
the risk situation. Age, it seems, may be related to decreases in the willingness to approach risk situations rather than to changes in the cautiousness of risk strategies chosen.

R. Dennis Middlemist and the writer are in the process of completing a study which attempts to assess the independence of motivational from stylistic aspects of risk-taking. An unpublished personality test they developed was used-the Risk Taking Questionnaire (RTQ)-which is believed to represent the resultant force of the risk approach motivation minus the risk avoidance motivation. (A copy of the RTQ and some preliminary information are presented in Appendix I.) In this study it was reasoned that if the RTQ measures resultant risk approach motivation, and that if this aspect of risk-taking is independent from the strategy aspects of risk-taking, then the RTQ should differentiate subjects who are willing to gamble from those who are not, but should be unrelated to the riskiness or cautiousness of the odds which are chosen.

We studied the responses of 166 subjects to a hypothetical gambling situation and of thirty-three subjects to both a hypothetical and a real gambling situation. (A fuller description of the study is presented in Appendix II.) The larger questionnaire study indicated that the RTQ had a significant correlation $(\mathrm{r}=$ .35) with the subjects' decision to enter the hypothetical gambling situation (keeping a $\$ 1.00$ stake vs. wagering it) , Contrary to expectation, the RTQ also showed a significant association with the riskiness of the bets chosen $(r=.23)$. This latter relationship, however, was not apparent in a follow-up study with eighteen high-risk approach and fifteen low-risk approach subjects who were actually given a dollar and asked whether they wanted to wager it. These two groups were virtually identical in the riskiness of their hypothetical bets.

In the real gambling situation, 89 percent of the high-risk approach as opposed to 53 percent of the low-risk approach subjects chose to wager the stake $\left(\chi_{e}^{z}=4.91, \mathrm{df}=1, \mathrm{p}<.05\right)$. The riskiness of the bets selected by the eight low-risk approach and sixteen high-risk approach subjects who did wager their dollars were not significantly different, but were less risky in the real situation 
than in the hypothetical situation $\left(\mathrm{F}=7.96, \mathrm{df}=1 / 22_{\mathrm{s}} \mathrm{p}<.01\right)$.

The results of this study provide some construct validation for the RTQ as a measure of risk-approach motivation. Scores on this measure are related to the willingness to gamble in both a hypothetical and a real gambling situation. The positive correlation between the RTQ and the riskiness of the bet chosen in the hypothetical situation argues against the independence of motivational and stylistic aspects of risk-taking. However, in the real gambling situation, albeit with many fewer subjects, the relationship between the RTQ and gambling strategy was not apparent. In partial support of the hypothesis, it appears that the RTQ is more strongly related to the motivational aspects of gambling than it is to the strategy aspects. Of course, the observed correlations with gambling strategy may reflect imperfections in the RTQ as a measure of only risk approach motivation."

The findings presented thus far have brought us closer to answering the question of why people take risks, not so much by providing answers as by clarifying the question. The distinction between motivational and strategy aspects of risk-taking appears to be very useful. While many researchers have noted a lack of personal consistency in strategies of risk-taking, the results presented here indicate that people do behave consistently and predictably in their willingness to approach risk situations. It appears that there are some enduring, personality-related components to risk behavior, at least in the motivational aspects of risktaking.

\section{Subjective Processes in Risk Approach Motivation}

Noting that high-risk approach subjects consistently behave differently from low-risk approach subjects leads again to the question of why. One of the constant issues in the analysis of risktaking concerns the relationship between the subjective and objective risks. Cohen $(1960,1964)$ notes that there is a distinction between "hazard" which is the objective probability of loss or harm, and "risk" which is the subjective estimate of the likeli-

"The writer notes as an aside that this is one of the few studies of risk-taking that has observed too many signficant correlations between different risk behaviors! 
hood of loss or harm. He and many others (e.g. Edwards, 1962) have noted that there can be a large discrepancy between subjective judgments of risk and the objective hazards. This discrepancy raises an issue which Slovic has succinctly outlined, "Observation of choices made among acts entailing various degrees of objective risk cannot distinguish the extent to which [risk-taking] is determined by individual differences in perception of risk or by differences in reaction to that perceived risk" (Cohen, 1960).

Thus, the observed differences between high and low-risk approach subjects may reflect two different underlying processes: (1) high-risk approach subjects may prefer higher levels of subjective (and, consequently, objective) risk, and (2) high-risk approach subjects may consistently judge situations as involving lower subjective risk. Many researchers have assumed that only the first alternative was operating-that differences in objective risk reflect differences in the preference for risk. Several other researchers (Cohen, 1964 and Kogan and Wallach, 1967) have pointed out that the second alternative alone may account for differences in objective risk-taking. These differences, they note, may reflect different subjective assessments of the amount of risk in a situation; although the objective risks differ, high and low risk-takers may be operating at similar levels of subjective risk, or it is possible that both processes are operating and combining to produce the differences in objective risk-taking.

In the absence of an independent criteria of risk-taking with which to differentiate subjects, these issues are extremely difficult to study. One has to hold either the subjective assessment of risk or the preferred level of risk constant while studying variations in the other (Edwards, 1962). Such a procedure does not allow assessing the degree to which both factors operate at the same time. The RTQ, however, does allow an independent assessment of the subject's risk approach motivation.

The writer conducted a study of these issues using the RTQ to look at how risk approach motivation is related to the subjective assessment of and preference for risk situations. The procedure was adapted from Carney's (1971) studies of "real life" activities. The one hundred subjects in the present study rated the risk in- 
volved in each of twenty activities-hitchhiking, drag racing, getting a job, smoking cigarettes, etc. (The full list of activities and a more complete description of the study are presented in Appendix III.) High, moderate and low-risk approach subjects could then be compared for differences in the subjective assessment of the degree of risk involved in the twenty activities. The subjects also indicated their preferred level of risk using the same scale that they used to evaluate the activities.

The results of this study suggest that risk approach motivation is related to both subjective processes. High-risk approach subjects viewed the twenty activities as significantly less risky than did low-risk approach subjects $(\mathrm{p}<.05)$. At the same time, highrisk approach subjects, particularly females, preferred higher levels of subjective risk than did low-risk approach subjects $(\mathrm{p}<$ ,001).

It appears that part of the difference in the behavior of high and low-risk approach subjects can be explained by differences in the subjective assessment of risk. High-risk approach subjects tend to see an activity as involving less risk while low-risk approach subjects tend to see it as more risky. Thus, in part, high risk approach subjects may be more willing to enter a risk situation because they don't see it as being as risky as do low-risk approach subjects.

The differences in subjective assessment of risk, however, are only part of the difference between high and low-risk approach subjects. High-risk approach subjects also prefer higher levels of subjective risk. They find higher risks more attractive and agreeable. Risk approach motivation, then, appears to be related to the willingness to engage in activities of higher subjective risk as well as activities of higher objective risk.

\section{What Is Risk?}

The studies described in this paper suggest that risk approach motivation is related in consistent and predictable ways to how people respond to risk situations. These findings suggest that people are attending to and responding to situational differences. However, to fully develop an answer to the question of why 
people take risks, we need to turn from studying the personality correlates ofrisk approach motivation to studying the situational determinants that engage risk approach motivation. What aspect of a situation is it that subjects are responding to? The answer to this question essentially amounts to a definition of risk.

The usual definitions of risk typically refer to one or both of the following criteria: (a) the probabilistic rather than certain nature of the outcomes, and (b) the amount of loss that is possible (Kogan and Wallach, 1967; Luce and Raiffa, 1957; and Slovic, 1964). While at a conceptual level these definitions may cover many aspects of a situation, risk is usually operationalized in a narrow way. Typically, a single dimension is selected as the operational definition of risk-the level of probability (Wallach and Kogan, 1961 and Cutter and Heilizer, 1968), variance of the outcomes (Coombs and Pruitt, 1960) and skewness of a bet (Lichtenstein, 1965). Even when several of these dimensions are considered together (Pruitt, 1962; Kogan and Wallach, 1964; and Liverant and Scodel, 1967), little consistency has been found across situations. These negative findings suggest that these dimensions of risk are not what people are responding to, particularly in deciding whether or not to engage in risk. Some other, perhaps more molar aspect of risk must be involved. In concluding this paper, the writer would like to suggest two situational dimensions that seem, mostly on face value, to warrant consideration in our search for a behaviorally relevant definition of risk -indeterminacy and excitancy.

INDETERMINACY. A distinction is usually made between risk, where the outcomes of a decision are less than certain, but the exact probabilities are known, e.g. dice, poker, roulette choices, and uncertainty, where the outcomes are also less than certain, but the probabilities are unknown, e.g. investment, personnelhiring, horse race decisions (Luce and Raiffa, 1957 and Brim, et al., 1962). This, however, is too limiting a definition of uncertainty for it presumes perfect knowledge of the range of possible outcomes, a complete lack of knowledge about the probabilities involved, and also presumes that the decision-maker has no influence over the results. In fact, ambiguity of information about 
both outcomes and probabilities (Ellsberg, 1961 and Shackle, 1949) and a degree of control over the outcomes of a decision (Cohen, 1960 and McClelland, et al., 1953) appear to be key aspects of many decision situations.

Shubik (1954), in a discussion of various types of uncertainties, notes that a state of indeterminacy characterizes many decisions. At the point of decision there is imperfect information about the range of possible outcomes and their probabilities, but both are presumed to be contingent, in part, on the future actions of the decision-maker. What information is available may be ambiguous, that is, its reliability, applicability or meaningfulness may be in doubt (Ellsberg, 1961). Indeterminacy is a general (though perhaps vague) term referring to the state of information a person has about what might happen as a result of his decision.

Perhaps indeterminacy is the situational dimension that engages risk approach motivation. The finding by Strickland, Lewicki and Katz (1966) that subjects bet more conservatively on dice that had already been thrown (but not seen) than they did before the dice were thrown suggests that indeterminacy may even be a subjective component of pure risk situations. Risk defined as indeterminacy is broader in scope than the more usual definitions of risk, but seems more characteristic of the everyday risk situations that we must eventually account for.

There is a possibility that a person's preferred level of indeterminacy or his gradients of approach and avoidance of indeterminacy may result from early experiences with unpredictable environments. Wendt (1969), in an interesting program of research, has found surprisingly high relationships between risky job preferences and general measures of risk preference in young adults with the nature of their social environment during critical periods of their early childhood development. High risk-takers, he found, were those who learned to walk under conditional rather than consistent rules. Thus, if a child is allowed to play freely in some rooms but not others, or is allowed to be boisterous with some adults but not others, he is faced with ". . . an environment which is definitely 'conditional' and-fromhis point of view, that is-involves fairly unpredictable and illogical events . . . ." 
EXCITANCY. Perhaps risk-taking is not a cognitive orientation (e.g. a preference for a specific probability level, a preference for indeterminacy), but rather an orientation toward excitement. If this were the case, the crucial characteristic of a risk situation would be its potential to excite, arouse or stress the individual (Berlyne, 1960 and Klausner, 1968). The optimal level of stimulation or arousal (Leuba, 1955; Berlyne, 1960; and Fiske and Maddi, 1961) may be a personality dimension that is closely related to risk approach motivation. High risk-takers may seek a higher level of stimulation or stress than low risk-takers, thus the indeterminacy, danger and potential surprise in a risk situation may be attended to because they produce states of arousal in the risk-takers (Shackle, 1961). While the momentary increase in arousal may be stressful and aversive, the drop in the arousal level is pleasurable (Berlyne, 1960 and Klausner, 1968). Gambling provides a good illustration of this momentary arousal sequence; the arousal created by placing the wager is quickly relieved, but the pleasure comes from reducing the state of arousal, not from the outcome (Klausner, 1968).

Klausner $(1967,1968)$ suggests that the mix of pain and pleasure in the arousal situation is in part learned, and varies for individuals. Thus, the extent that the initiation of arousal is seen as aversive and its relief is seen as pleasurable may be responsible for individual differences in arousal-seeking, and these differences, in turn, may be related to a person's preference for entering or avoiding risk situations.

While the studies reviewed in this paper suggest that there are consistencies in the motivational aspects of risk behavior, and that risk approach motivation appears to be useful in explaining some risk behavior, we have only come part way in answering the question of why people take risks. A fuller explanation awaits clarification of the situational dimensions that risk-takers are responding to, and the enunciation of these situational presses will help us understand more clearly the motivational aspects of risk-taking and gambling. 



\section{APPENDIX 18-I}

The Risk-Taking Questionnaire (RTQ) Used to Assess Risk Approach Motivation

THE RISK-TAKING questionnaire (RTQ) presented below is a

1 paper and pencil measure of risk approach motivation. SCORING. The scale has been presented to subjects as the Subjective Opinion Questionnaire with the following instructions:

Below are twenty different statements. We would like to know your subjective opinion of each of these statements. Thus, will you please rate how much you agree or disagree with each statement. A scale is given below where 1 - Agree very much and $5=$ Disagree very much. Please use this scale to rate each of the twenty statements.

\begin{tabular}{ccccc}
1 & 2 & $\$$ & 4 & 5 \\
\hline Agree & Mildly & Neutral & Mildly & Disagree \\
Very Much & Agree & & Disagree & Very Much
\end{tabular}

Eleven risk-avoidant items are scored directly; nine risk-approach items are reversed so that a higher total score indicates greater risk approach.

DEVELOPMENT. An original pool of forty items were developed and edited to indicate a willingness to approach risk situations and a desire to avoid risk situations. The ratings of sixty-one subjects were used to reduce the number of items to 25. A factor analysis was performed on the intercorrelations among items. Twenty-six items had a loading on the unrotated first factor of greater than .40. One of these items was dropped because of difficult wording. The twenty-five items were then rated by 342 undergraduate subjects. The items were correlated with the total score minus that item, and the twenty highest correlating items were retained.

RELIABILITY. The internal consistency of the scale has been measured at $r_{20}=.85$ for a sample of 146 undergraduates, and in 
another sample was found to be comparable for males $\left(\mathrm{r}_{20}-.84\right.$, $\mathrm{n}=178)$ and females $\left(\mathrm{r}_{20}=86_{\mathrm{n}} \mathrm{n}=145\right)$. The correlations of the items with the total score minus the item are presented with the scale along with the mean responses.

VALIDITY. Various studies with the twenty-five-item scale and the current twenty-item scale indicate a degree of concurrent validity. The scales correlate highly with subjects' self-ratings as being risk-takers $\left(\mathrm{r}=.67, \mathrm{n}=47 ; \mathrm{r}=.71_{1} \mathrm{n}=134\right)$, with the fastest speeds at which they have ever driven a car $(\mathrm{r}=.69, \mathrm{n}-$ 47 ), with the evaluation component of a semantic differential assessing the concept of risk $(\mathrm{r}=.56, \mathrm{n}-40)$, and with scores on the Sensation Seeking Scale $(\mathrm{r}=.73, \mathrm{n}=47)$. The RTQ also tends to correlate with whether or not the subject is a cigarette smoker $(\mathrm{r}=.50, \mathrm{n}=47 ; \mathrm{r}=.22, \mathrm{n}=134 ; \mathrm{r}=.23, \mathrm{n}=166)$.

The RTQ tends to be uncorrelated with sex $(\mathrm{r}=-19, \mathrm{n}=$ $136 ; \mathrm{r}=-.04, \mathrm{n}=166)$, birth order $(\mathrm{r}-.10, \mathrm{n}=47 ; \mathrm{r}=.09$, $\mathrm{n}=166)$, and need for approval $(\mathrm{r}--.13, \mathrm{n}=136)$.

Assessments of construct validity are reported in Appendices II and III.

TWENTY-ITEM RISK TAKING QUESTIONNAIRE (RTO)

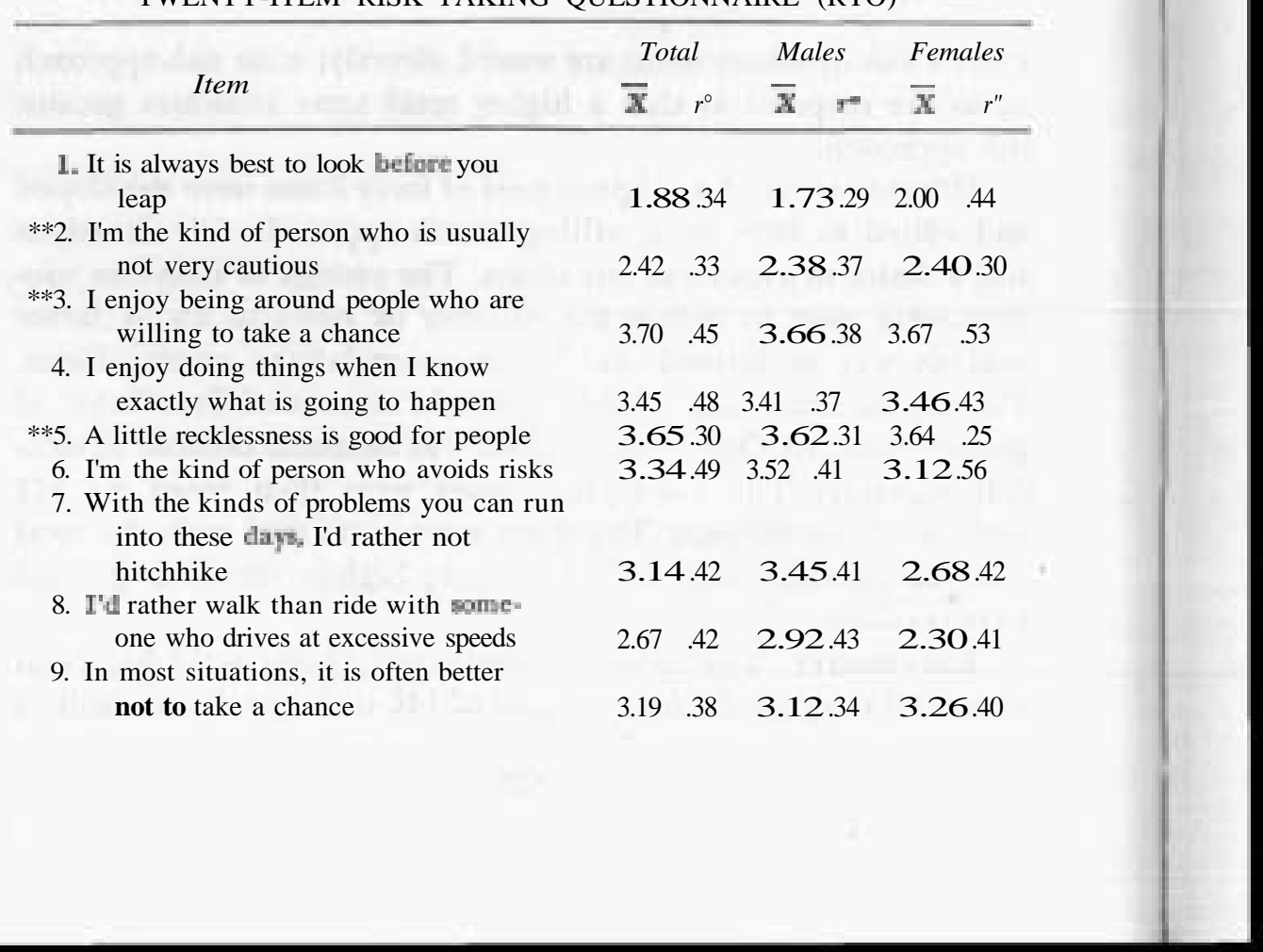


TWENTY-ITEM RISK TAKING QUESTIONNAIRE (RTO) (contd.)

Ilom $1 \begin{array}{lllll}\text { Total } & \text { Males } & \text { Females } \\ \overline{\mathrm{X}} & \mathrm{r} & \overline{\mathrm{X}} & \mathrm{r} & \overline{\mathrm{X}}\end{array}$

10. I'd rather not gamble if there is some other way of doing things

$\begin{array}{llllll}2.48 & .39 & 2.49 & .30 & 2.42 & .44\end{array}$

**11. I'm the kind of person who enjoys risks

12. In most things, it is probably better $\begin{array}{lllllll}\text { to know exactly where you are going } & 2.81 & .46 & 2.67 & .51 & 2.90 & .46\end{array}$

13. I stay away from situations that are likely to be dangerous

$\begin{array}{llllll}3.12 & .58 & 3.21 & .52 & 2.97 & .64\end{array}$

$\begin{array}{llllll}2.81 & .46 & 2.67 & .51 & 2.90 & .46\end{array}$

$\begin{array}{llllll}2.85 & .53 & 2.92 & .52 & 2.71 & .51\end{array}$

**14. I tend to like people who have a wild streak in them

$\begin{array}{llllll}3.50 & .43 & 3.49 & .46 & 3.50 & .46\end{array}$

$»$ *15. I sometimes gamble just for the excitement it brings

16. I'm the kind of person who is usually careful about what he does

**17. I'd rather play with fire than not play at all

18. It is better to be safe than sorry

"19. There is a certain excitement in breaking someone else's rules

**20. I enjoy getting into situations that

I don't know if I can get out of

$\begin{array}{llllll}3.45 & .44 & 3.51 & .47 & 3.34 & .40\end{array}$

$\begin{array}{llllll}2.53 & .55 & 2.52 & .55 & 2.54 & .56\end{array}$

$\begin{array}{llllll}3.10 & .48 & 3.16 & .52 & 2.95 & .45\end{array}$

$\begin{array}{llllll}2.50 & .56 & 2.48 & .54 & 2.52 & .58\end{array}$

$\begin{array}{llllll}3.30 & .36 & 3.34 & .38 & 3.18 & .38\end{array}$

\section{Total Score \\ Standard Deviation}

$\mathrm{N}$

\begin{tabular}{cccccc}
2.34 & .51 & 2.41 & .44 & 2.20 & .61 \\
\hline 59.42 & & 60.01 & & 58.18 & \\
11.33 & & 10.73 & & 12.11 & \\
342 & & 180 & & 149 &
\end{tabular}

"Correlations are of the item with the total score minus the item score.

"The scoring of these items are reversed so that a high score indicates risk ap" proach motivation. 


\section{APPENIIX 18-II}

\section{Risk Motivation in Hypothetical and Real Betting Situations}

A N EXPERIMENT tested the hypothesis that risk approach moti- vation, as measured by the RTQ, is related to the decision to enter a risk situation, but not to the riskiness or cautiousness of the strategies chosen once in a risk situation.

METHOD. One hundred eighty-six students in two large classes were asked to complete a questionnaire booklet which included the RTQ and several gambling options. Twenty students failed to answer key portions of the booklet and were dropped from the sample, leaving 166 subjects.

The subjects were first asked to indicate whether in a hypothetical situation they would decide to gamble or not. The situation was presented as follows:

Suppose that you had participated in an experiment and had received $\$ 1.00$ as payment. After giving you the $\$ 1.00$, the experimenter informed you that you could either keep the dollar or you could wager it on a gamble that, if won, would return more than a dollar. You could choose from among a series of gambles that vary in the likelihood of winning and in the amount to be won. Over the long run, each of the gambles would average $\$ 1.00$ return per person, but some people would lose their wagers and other people would win more than a dollar. If you were given this choice, what would you do?

The subjects were given two options, the order of which was counterbalanced, Keep the one dollar or Wager the one dollar. By choosing one of these two options, the subject indicated only his/her willingness to gamble without any indication of the strategy that might be selected.

A second hypothetical situation also asked subjects to suppose that they had participated in an experiment and had received one dollar as payment. However, this time the experimenter required them to wager the dollar on one of nine bets. The bets were in 
the form of, Wager a dollar on a bet that has nine chances in ten to win \$1.11. All bets had a zero expected value with odds ranging from nine chances in ten to one chance in ten. Subjects were asked to indicate which of the gambles they would take. This second hypothetical situation required subjects to gamble, and thus measured the subject's gambling strategy but not the willingness to gamble.

Approximately two months after they had filled out the questionnaire, eighteen subjects who had scored in the top third of the RTQ distribution (high risk, approach subjects) and fifteen subjects who had scored in the bottom third (low risk approach subjects) were scheduled for participation in an experiment for which they would be paid. After participating for twenty to thirty minutes in some undergraduate experiments, the subjects were ushered into a room, one at a time, to receive their payment. The experimenter, blind to the subjects RTQ score, handed the subject one dollar and stated that the subject could keep the dollar or could wager it on one of a series of gambles that, if won, would return more than a dollar. The gambles were identical to the ones listed in the second part of the questionnaire study. After explaining the alternatives, the experimenter asked for the subject's choice and recorded whether the subject chose to bet, and, if so, what bet was chosen. Gambles were played by having the subject select one of the ten numbered spade cards lying face down on a table. The subject won if the card number matched or was lower than the number of chances in ten of the selected bet.

RESULTS. Correlational analysis of the questionnaire data from 166 subjects indicated that sex of the subject was unrelated to the RTQ $(\mathrm{r}-.04)$, the decision to gamble $(\mathrm{r}=-.03)$, and the riskiness of the gamble selected $(\mathrm{r}=, 05)$ - As predicted, the RTQ correlated positively with the decision to gamble $(r=.35, p<$ .001). High risk approach subjects were more likely to wager the dollar in the hypothetical situation than were low risk approach subjects. Contrary to prediction, the RTQ also correlated significantly with the riskiness of the gamble selected $(\mathrm{r}=.23, \mathrm{p}<.01)$. High risk approach subjects were also more likely to choose riskier bets in the hypothetical situation. Thus, the RTQ does 
not appear to be independent from the subjects' risk strategies, at least for the hypothetical situation. However, note that the RTQ explains over twice as much variance in the decision to gamble $\left(\mathrm{R}^{2}=.12\right)$ than in the choice of a bet $\left(\mathrm{R}^{2}-.05\right)$.

For the eighteen high and fifteen low risk approach subjects who participated in the real gambling experiment, their answers to the hypothetical gambling situation were compared to their answers to the real gambling situation. Table I8-I presents the relevant motivational and stylistic behavior in both situations.

\section{TABLE I8-I}

GAMBLING BEHAVIOR OF LOW AND HIGH RISK APPROACH SUBJECTS IN HYPOTHETICAL AND REAL GAMBLING SITUATIONS

\begin{tabular}{lrrrr}
\hline & \multicolumn{2}{c}{$\begin{array}{c}\text { Low Risk Approach } \\
\text { Hypothetical }\end{array}$} & Real & \multicolumn{2}{c}{ High Risk Approach } \\
& Hypotheal & Real \\
\hline Percent choosing to gamble & 53 & 53 & 78 & 89 \\
Mean odds ofhypothetical bet & 2.80 & & 2.82 & $\ldots$ \\
Mean odds chosen by real & 3.38 & 4.75 & 2.94 & 3.75 \\
$\quad$ gamble bettors & & & & \\
\hline
\end{tabular}

High risk approach subjects were more likely to wager the dollar than were the low risk approach subjects. The differences in choosing to gamble were not significant for the hypothetical situation $\left(\chi^{z}=1.92, \mathrm{df}=1\right)$, but were significant for the real situation $\left(\chi_{e}^{z}=4.91, \mathrm{df}=1, \mathrm{p}<.05\right)$. Again, high risk approach subjects as measured by the RTQ were more likely to enter a gambling situation. In contrast to the earlier finding of a correlation between RTQ and the riskiness of the gamble selected in the hypothetical situation, the two groups of subjects selected for this experiment selected almost identical mean odds in the hypothetical gamble $(\mathrm{t}-.04, \mathrm{df}=31)$.

Eight low risk approach and sixteen high risk approach subjects did decide to wager their dollar in the real situation. For these subsamples, the odds chosen in the hypothetical and real situations were subjected to a least squares analysis of variance. Although there is a tendency for high risk approach bettors to choose riskier odds, this difference was not significant $(\mathrm{F}<\mathrm{I}$, 
$\mathrm{df}=1 / 22)$. There was a significant difference between the hypothetical and real betting situations $(F=7.96, d f=1 / 22, p<.01)$. Both groups of subjects tended to choose less risky odds in the real situation than they did in the hypothetical situation. 


\section{APPENDIX 18-III}

\section{The Relationship of Risk Motivation to the Subjective Assessment of Risk and the Preference for Risk*}

QEVERAL RESEARCHERS (Slovic, 1964 and Kogan and Wallach, $\checkmark$ 1964) have suggested that differences in risk-taking may reflect either of two underlying processes: (1) high risk-takers may prefer higher levels of subjective risk than do low risk-takers, or (2) high risk-takers may assess a situation as involving less risk than do low risk-takers. In the latter case, people may be operating at similar levels of subjective risk while differing in the assessment of the degree of risk involved. Either or both of these processes may be related to the differences between high and low risk-takers.

The present study assessed whether risk approach motivation, as measured by the RTQ, is related to either or both of these subjective judgment processes. High risk approach subjects could be more willing to enter a risk situation because (1) they prefer higher risk situations, or (2) they judge the situation to have lower risk.

METHOD. Fifty male and fifty female subjects were paid $\$ 1.50$ to fill out a booklet that included the RTQ and a series of risk judgment questionnaires. The first of these, the judgment of activity riskiness, is reported in the present study. In a procedure adapted from Carney (1971), subjects were given a list of twenty real life activities, e.g. hitchhiking, drag racing, getting a job, smoking cigarettes (see Table I8-II for the full list of activities), and asked to rate how risky each of the activities was. The specific instructions stated, "Some activities people engage in are risky, others are not risky at all. For each of the activities listed below, indicate your estimation of how risky the activity is, on the

"This research was supported by a grant from the Wisconsin Alumni Research Foundation. 
average, for most people." Subjects made their ratings using a fifteen-point scale, where 1 indicates not risky at all, and 15 indicates extremely risky. Following these ratings, the subjects were asked to indicate the position on that scale that represents the level or amount of [risk] that you find most attractive and agreeable-that is, the position on that scale that you most prefer. These risk preference ratings were made on the same fifteen-point scale.

RESULTS. The subjects were divided into high, moderate and low risk approach groups by dividing the RTQ distribution into thirds. Within each group, males and females were then separated. Ten subjects were randomly discarded to achieve equal cell frequencies $(n=15)$ for males and females in each risk approach group. Table 18-II presents the mean responses for each of these subsamples.

The relationship between risk approach motivation and the judgments of activity riskiness were assessed in a three-factor analysis of variance. Risk approach group and sex of subject were independent factors, and the twenty activities were treated as a repeated factor. The results of this analysis (Table I8-III) indicated that the three risk approach groups differed significantly in their judgments of how risky, on the average, the activities were $(p<.01)$. There was a significant negative linear trend in the sum of the activity ratings $(F=5.01, \mathrm{df}=1 / 84, \mathrm{p}<.05)$, indicating that higher risk approach subjects tended to judge the activities as less risky. This finding suggests that risk approach motivation is related to the subjects' assessment of the amount of risk involved in these situations.

TABLE I8-II

RISKINESS RATINGS OF 20 ACTIVITIES BY MALE AND FEMALE, LOW, MODERATE AND HIGH RISK APPROACH MOTIVATION SUBJECTS

\begin{tabular}{lccccccc}
\hline \multirow{2}{*}{ Activity } & \multicolumn{4}{c}{ Lo Risk } & \multicolumn{2}{c}{ Mod Risk } & \multicolumn{2}{c}{ Hi Risk } \\
& Mean & Male & Female & Male & Female & Male & Female \\
\hline $\begin{array}{l}\text { 4. Getting a job } \\
\text { 10. Participating in a protest }\end{array}$ & 4.2 & 4.2 & 3.7 & 4.7 & 3.9 & 5.2 & 3.4 \\
$\quad$ demonstration & 5.9 & 7.9 & 5.7 & 6.1 & 5.5 & 6.7 & 3.7 \\
16. Use of marijuana & 6.4 & 6.2 & 8.2 & 6.5 & 6.3 & 6.8 & 4.7 \\
8. Smoking cigars or pipes & 6.5 & 8.7 & 6.1 & 7.5 & 6.9 & 5.6 & 4.1
\end{tabular}


TABLE I8-II (contd-)

\begin{tabular}{|c|c|c|c|c|c|c|c|}
\hline \multirow{2}{*}{ Activity } & \multirow[b]{2}{*}{ Mean } & \multicolumn{2}{|c|}{ Lo Risk } & \multicolumn{2}{|c|}{ Mod Risk } & \multicolumn{2}{|c|}{ Hi Risk } \\
\hline & & Male & Female & Male & Female & Male & Female \\
\hline 13. Unmarried heterosexual & & & & & & & \\
\hline intercourse & 6.7 & 5.5 & 9.0 & 7.1 & 6.1 & 6.9 & 5.3 \\
\hline 11. Riding a motorcycle & 6.7 & 8.7 & 7.3 & 5.5 & 7.5 & 6.7 & 4.7 \\
\hline 12. Buying a term paper & & & & & & & \\
\hline $\begin{array}{r}\text { for a class } \\
\end{array}$ & 7.0 & 7.3 & 9.5 & 6.6 & 8.1 & 5.6 & 5.1 \\
\hline 15. Hitchhiking & 7.2 & 6.9 & 9.3 & 6.3 & 8.5 & 6.6 & 5.5 \\
\hline 9. Drinking alcohol & 7.2 & 9.1 & 7.1 & 6.8 & 7.9 & 6.9 & 5.5 \\
\hline 14. Homosexual acts & 8.0 & 8.2 & 7.7 & 9.9 & 7.5 & 9.1 & 5.3 \\
\hline 1. Smoking cigarettes & 8.7 & 10.5 & 7.7 & 10.0 & 9.1 & 8.1 & 6.7 \\
\hline 17. Cheating (on tests, & & & & & & & \\
\hline taxes, etc.) & 8.7 & 9.1 & 9.2 & 8.8 & 9.2 & 8.2 & 8.0 \\
\hline 5. Having an abortion & 8.9 & 8.5 & 9.1 & 8.1 & 9.0 & 10.1 & 8.7 \\
\hline 6. Drag racing & 10.1 & 10.8 & 11.5 & 10.3 & 9.1 & 9.1 & 9.6 \\
\hline 19. Fighting (two-person & & & & & & & \\
\hline or gang-type) & 10.6 & 12.1 & 10.3 & 11.6 & 10.6 & 10.7 & 8.1 \\
\hline $\begin{array}{l}\text { 3. Committing vandalism or } \\
\text { minor theft }\end{array}$ & 10.8 & 11.7 & 12.3 & 10.9 & 10.7 & 10.1 & 9.1 \\
\hline 7. Use of pep pills & & & & & & & \\
\hline or speed & 11.1 & 12.0 & 11.6 & 12.0 & 10.5 & 12.2 & 8.3 \\
\hline 18. Use of LSD & 12.7 & 13.4 & 12.4 & 13.7 & 13.0 & 13.3 & 10.6 \\
\hline 2. Stealing a car & 13.6 & 13.9 & 14.4 & 13.8 & 13.5 & 13.9 & 12.1 \\
\hline 20. Use of heroin & 14.5 & 14.7 & 14.5 & 14.7 & 14.8 & 14.8 & 13.3 \\
\hline Mean rating of riskiness & 8.8 & 9.5 & 9.3 & 9.0 & 8.9 & 8.8 & 7.1 \\
\hline Preferred risk level & 8.8 & 7.8 & 5.7 & 9.5 & 9.1 & 10.0 & 10.5 \\
\hline
\end{tabular}

TABLE IB-III

ANOVA SUMMARY: EFFECTS OF RISK APPROACH MOTIVATION, SEX OF SUBJECT AND ACTIVITIES ON THE ASSESSMENT OF ACTIVITY RISK

\begin{tabular}{crccc}
\hline Source & Mf & MS & $F$ & $P$ \\
\hline Between Subjects & 89 & & & \\
Risk Approach Motivation & 2 & 334.97 & 5.89 & $<.01$ \\
Sex of Subject & 1 & 209.44 & 3.68 & n.s. \\
Risk X Sex & 2 & 125.92 & 2.21 & n.s. \\
Ss Within & 84 & 56.86 & & \\
Within Subjects & 1710 & & & \\
Activities & 19 & 676.64 & 69.02 & $<.001$ \\
Risk X Acts & 38 & 9.12 & $<1$ & n.s. \\
Sex X Acts & 19 & 22.78 & 2.32 & $<.01$ \\
Risk X Sex X Acts & 38 & 10.10 & 1.03 & n.s. \\
Acts X Ss Within & 1596 & 9.80 & & \\
\hline
\end{tabular}


The significant and large main effect for activities in Table 18III indicates that the activities did vary widely along the dimension of riskiness. The significant interaction between the sex of the subject and the activities suggests that some of the activities are seen as more risky by males and others as less risky than by females. This is not a particularly surprising finding; many of the activities appear to be sex-role linked and to have different degrees of risk for the different sexes, e.g. dragracing, having an abortion and hitchhiking.

The relationship between risk approach motivation and the preferred risk level was assessed in a second analysis of variance. Sex of subject was again treated as a second independent factor. The results of this analysis (Table I8-IV) indicated that risk approach motivation had a large and significant relationship with the preferred risk level $(\mathrm{F}=46.09$, df $=1 / 84, \mathrm{p}<.001)$ with high risk approach subjects preferring higher levels of risk.

TABLE 18-IV

ANOVA SUMMARY: EFFECTS OF RISK APPROACH MOTIVATION AND SEX OF SUBJECT ON PREFERRED RISK LEVELS

\begin{tabular}{lrrrc}
\hline Source & df & MS & \multicolumn{1}{c}{$F$} & $P$ \\
\hline Risk Approach Motivation & 2 & 96.53 & 24.68 & $\leq .001$ \\
Sex of Subject & 1 & 9.34 & 2.39 & n.s. \\
Risk X Sex & 2 & 12.58 & 3.22 & $\leq .05$ \\
$\quad$ Ss Within & 84 & 3.91 & & \\
\hline
\end{tabular}

A significant sex of subject $X$ risk approach motivation interaction indicates that males and females differ in the relationship between risk approach motivation and preferred risk level. The means involved in this interaction are included in the plots in Figure 18-1. The interaction appears to be the result of a significant difference between low risk approach males and females ( $\mathrm{F}$ $=8.19, \mathrm{df}-\mathrm{l} / 84, \mathrm{p}<, 01)$. Males do not significantly differ from females at moderate risk approach $(F<1)$ or at high risk approach $(\mathrm{F}<\mathrm{l})$. The simple effects of risk approach motivation on preferred risk level are significant for males $(\mathrm{F}=13.37$, df $=$ $1 / 84, \mathrm{p}<.001)$ and for females $(\mathrm{F}=28.82$, $\mathrm{df}=\mathrm{I} / 84, \mathrm{p}<.001)$, both trends are only linear, and the linear trends do not signif- 


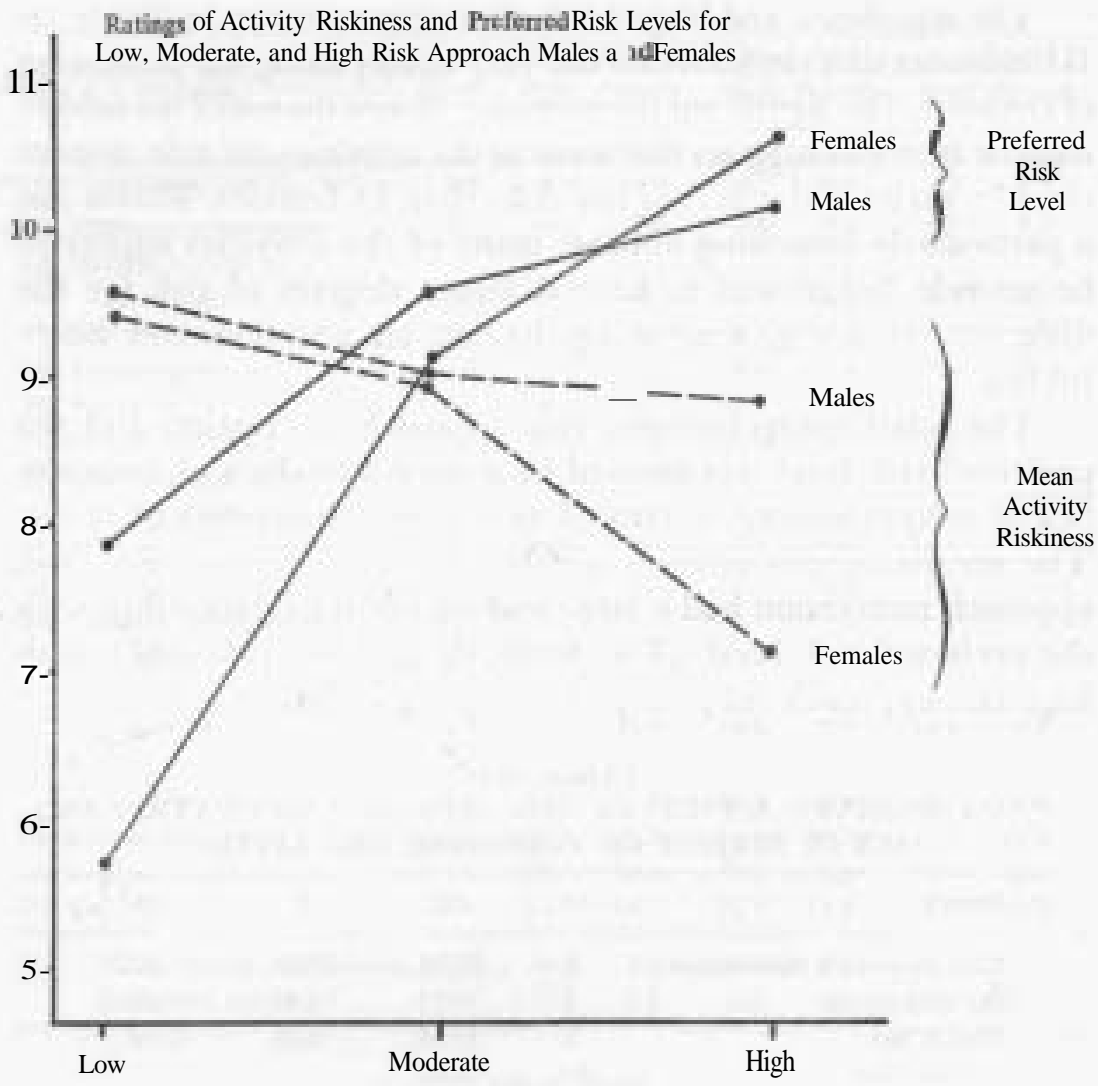

Risk Approach Motivation

Figure 18-1.

icantly differ $(\mathrm{F}-3.08$, df $=1 / 84, \mathrm{p}>, 05)$.

In summary, the results suggest that risk approach motivation is related to both the assessment of risk and the preference for risk. High risk approach subjects tend to judge situations as involving lower risk than do low risk approach subjects, and, at the same time, prefer higher levels of subjective risk.

\section{REFERENCES}

Allport, G. W.a Personality: A Psychological Interpretation. New York, Holt \& Company, 1937. 
Berlyne, D. E.: Conflict, Arousal and Curiosity. New York, McGraw-Hill, 1960.

Botwinick, J.: Cautiousness in advance age. / Gerontol, 21:347, 1966.

Botwinick, J.a Disinclination to venture response versus cautiousness in responding: Age difierences./ Genet Psychol, 115:55, 1969.

Brim, O. G., Jr., Glass, D. C., Lavin, D. E., and Goodman, N.: Personality and Decision Processes: Studies in the Social Psychology of Thinking. Stanford, Stanford University Press, 1962.

Carney, R. E.; Attitudes toward risk. In Carney, R. E. (Ed.): Risk-Taking Behavior. Springfield, Thomas, 1971.

Casey, N. A.: Anxiety and Perceived Locus of Control in Risky and Conservative Decision Making. Dissertation, Boston University, 1969.

Cohen, J.: Behavior in Uncertainty. New York, Basic Books, 1964.

Cohen, J.: Chance, Skill and Luck. Baltimore, Penguin, 1960.

Coombs, C. H., and Pruitt, D. G.a Components of risk in decision making: Probability and variance preferences. $J$ Exp Psychol, 60:265, 1960.

Cutter, H. S. G., and Heilizer, F. H.; The development of some procedures for the assessment of risk. / Psychol, 68:21, 1968.

Edwards, W: Subjective probabilities inferred from decisions. Psychol Econ, 75:109, 1962.

Ellsberg, D:; Risk, ambiguity, and the savage axioms. Q/ Econ, 75:634, 1961.

Fiske, D. W. and Maddi, S. R.; A conceptual framework. In Fiske, D. W and Maddi, S. R. (Ed.): Functions of Varied Experience. Homewood, Dorsey Press, 1961.

Klausner, S. Z.i Fear and enthusiasm in sports parachuting. In Knight, J. $\mathrm{A}_{7}$ and Slovenko, R.: Motivations in Play, Games and Sports. Springfield, Thomas, 1967.

Klausner, S. Z.: The intermingling of pain and pleasure: The stress-seeking personality in its social context. In Klausner, S. Z.; Why Man Takes Chances: Studies in Stress Seeking. Garden City, Anchor Books, Doubleday and Company, 1968.

Knowles, E. S.: Luck and processing of risk information. Paper presented at the Eastern Psychological Association Convention, Philadelphia, Pennsylvania, 1969.

Knowles, E. S., Cutter, H. S. G., Walsh, D. H., and Casey, N. A.: Risk-taking as a personality trait. Soc Behay Pers, 7:123, 1973.

Kogan, N., and Wallach, M. A.: Risk taking as a function of the situation the person and the group. In New Directions in Psychology HI. New York, Holt, Rinehart and Winston, 1967.

Kogan, N., and Wallach, M. A.: Risk Taking: A Study in Cognition and Personality. New York, Holt, Rinehart and Winston, 1964.

Komorita, S. S.; A model for decision-making under risk. Am J Psychol, 77: 429, 1964.

Leuba, C.: Toward some integration of learning theories: The concept of 
optimal stimulation. Psycholkep, 7:27, 1955.

Lichtenstein, S. C.: Bases for preferences among three-outcome bets. / Exp Psychol, 69:162, 1965.

Liverant, $S_{2}$ and Scodel, A.: Internal and external control as determinants of decision making under conditions of risk. Psychol Reports, 7:59, 1967.

Luce, R. D., and Raiffa, H.: Games and Decisions: Introduction and Critical Achievement Motive. New York, Wiley, 1957.

McClelland, D. C., Atkinson, J. W., Clark, R. $\mathrm{A}_{\text {z }}$ and Lowell, E. L.: The Achievement Motive. New York, Appleton-Century-Crofts, 1953.

Pruitt, D. G.: Pattern and level of risk in gambling decisions. Psychol Rev, 69:187, 1962.

Scodel, A, Ratoosh, P., and Minas, J. S.: Some personality correlates of decision making under conditions of risk. Behav Sci, 4:19, 1959.

Shackle, G. L. S.; Decision, Order, and Time in Human Affairs. Cambridge, Cambridge University Press, 1961.

Shackle, G. L. S.: Expectation in Economics. Cambridge, Cambridge University Press, 1949.

Slovic, P.: Assessment of risk taking behavior. Psychol Bull, LXI(3):220, 1964.

Slovic, P.: Convergent validation of risk taking measures. I Abnorm Soc Psychol, 65:68, 1962.

Slovic, P., and Lichtenstein, S.: Relative importance of probabilities and payoffs in risk taking. / Exp Psychol Monograph, 78(5), part 2, 1968.

Strickland, L. J-, Lewickin, R. J-s and Katz, A. M.: Temporal orientation and perceived control as determinants of risk-taking. J Exp Soc Psychol, 2:143, 1966.

von Neumann, J-a and Morgenstern, O.: Theory of Games and Economic Behavior, Revised ed. Princeton, Princeton University Press, 1947.

Wallach, M. A-, and Kogan, N.: Aspects of judgment and decision-making interrelationships and changes with age. Behav Sci, 6:23, 1961.

Weinstein, E, and Martin, J.: Generality of willingness to take risks. Psychol Rep, 24:499, 1969.

Weinstein, M. S.: Achievement motivation and risk preference. Pers Soc Psychol, $23: 153,1969$.

Wendt, H. W:a Risk-taking as a function of pre-verbal 'imprinting? - Some data and speculations. Archiv fur die gesamte Psychologie, 773:325, 1969.

Ziller, R. C.: Vocational choice and utility for risk. / Counsel Psychol, 4.61, 1957. 


\title{
Chapter 19
}

\section{INDIVIDUAL DIFFERENCES IN CASINU GAMDLING?}

\author{
D. MICHAEL KuHLMan*
}

THIS CHAPTER ASKS IF individual differences in risk-taking exist 1 for the three casino games of 21, roulette and craps. Another way to phrase this question would be to ask if personality factors play any role in the way a person gambles in these casino games. For this discussion, personality factors and individual differences can be considered synonymous. The first step will be to see if people consistently differ from one another in terms of their casino gambling per se. Two aspects of gambling behavior will be measured: (1) how much money a person typically wagers which will be referred to as average bet size and, (2) the kind of odds a person chooses to expose himself to which will be called odds preference. The second step in this undertaking requires evidence suggestive of individual differences within the casino itself. Given such evidence, the second step will be to ask as to relationships of casino risk-taking with other measures taken outside the casino setting. The extracasino measures to be examined are: (1) a set of four paper-and-pencil personality measures and, (2) the person's response to a rather unique set of hypothetical gambles developed by Slovic and Lichtenstein (1968) called (at this point, somewhat cryptically) duplex gambles. This chapter will proceed by discussing the analysis of individual differences within the casino games, then present the data relevant to this point. Next, it will provide a more detailed description of the extracasino measures just mentioned, and present the relationships (if any) of these measures to casino risk-taking.

\footnotetext{
*The author wishes to express his gratitude to Jerry Storck, Bill Wilson and Grant Snyder for their assistance in this study.
} 


\section{Individual Differences in the Casino Games}

Investigation of individual differences for any form of behavior is conducted at two interrelated levels, and both will be focused on here. At the first level, one asks if there is test-retest reliability for a single given risk measure. As a specific example, one can ask if person $X^{\prime} s$ average bet size in 21 tends to be high, middle or low from one 21 session to the next. As another example, one could assess the test-retest reliability of odds preference in the game of roulette; if person X makes many (many is with reference to other players) 2 to 1 bets at time $a_{2}$ does he repeat himself at some later time? This level of analysis will be referred to as consistency within measures or reliability. The existence of reliability for a gambling measure would support the assertion that for a specific, well-defined form of risk-taking, at least part of the gambler's behavior is a function of intrapersonal (or personality) factors. (It is important to note that within-measure consistency for one form of risk behavior in no way guarantees such consistency in some other.) For the psychologist who wishes to speak of riskiness as a general, (i.e. not limited to a single, specific form of risk behavior), dimension of personality it is necessary that he demonstrate two things: (1) a set of risk-taking behaviors, each possessing the within-measure consistency (reliability) just described and, (2) relationships or consistency across these various measures which constitutes the second level of individual differences analysis mentioned above. Taking a specific example of across-measure consistency, one could ask if a person who makes large bets in 21 also makes large bets in roulette. As already mentioned, consistency of this second type is what most psychologists would require of any concept (in this case, the concept would be riskiness) before labelling it as an important or general personality dimension.

Now, to turn to the first purpose of this chapter, which can be concretely described with the following two questions: (1) Is there consistency over time for average bet size and for odds preference within each of the casino games, and (2) do these measures possess consistency across the casino games? 


\section{Method}

SUBJECTS. The subjects were sixty-four undergraduates at the University of Delaware, participating in a three weeks' winterim project on human gambling behavior. The group was overwhelmingly male (only five participants were female), and only three reported having any prior casino gambling experience.

PROCEDURE. During the first day of the project the students completed four standard pencil-and-paper personality tests (to be described later) and also responded to twenty-eight hypothetical duplex gambles (also to be described later). On the following day, students received detailed instructions on each of the casino games; the information on rules and game procedure was provided by Lemmel's book on casino gambling (Lemmel, 1966), though none of the participants possessed this book themselves. On the next day each student practiced playing each of the games which were run by a group of eight well-trained undergraduate dealers. On the following day, the students began a five-day series of gambling sessions, each session being run as follows. Each entire session lasted for ninety minutes, being composed of six 15 minute blocks. At the beginning of each session students were randomly paired, then each member of every pair gambled for three 15-minute blocks and observed his partner for the other three blocks. On each day every student gambled at and observed each of the three casino games.

As an observer, the student's task was to record every bet made by his partner as well as each bet's outcome. These records were made on standard forms which were provided to the students. As a gambler, each student began each block with thirty dollars in chips provided by the dealers. He could vary his bet size from one to ten dollars, and in roulette and craps was limited to two wagers on any spin of the wheel or toss of the dice. The actual bets allowed in craps and roulette and the odds they paid are presented in Table 19-I. In 21 a student was allowed to play but one hand although pair splitting and doubling down were permitted. An actual monetary incentive was provided as follows: At the beginning of the first session students were told that at the end 
TABLE 19-I

BET CATEGORIES AND ASSOCIATED PAY-OFF ODDS ALLOWED IN CRAPS AND ROULETTE

\begin{tabular}{lclc}
\multicolumn{1}{c}{ Crategory } & Odds & \multicolumn{1}{c}{$\begin{array}{c}\text { Roulette } \\
\text { Category }\end{array}$} & Odds \\
\hline 1. Line Bets & $1: 1$ & 1. Color; Odd/Even; Hi Lo & $1: 1$ \\
2. Big 6; Big 8 & $1: 1$ & 2. Column; Dozens & $2: 1$ \\
3. Field & $1: 1$ & 3. Line Play & $5: 1$ \\
4. Seven & $4: 1$ & 4. Quarter Play & $8: 1$ \\
5. Any Craps; Hard 10; & & 5. Street Play & $11: 1$ \\
$\quad$ Hard 4 & $7: 1$ & & \\
6. Hard 6; Hard 8 & $9: 1$ & 6. Split Play & $17: 1$ \\
7. Three; Eleven & $15: 1$ & 7. Straight Play & $35: 1$ \\
8. Box Cars; Snake Eyes & $30: 1$ & & \\
\hline
\end{tabular}

of the five-day series, one of the days and one of the games would be chosen at random. The student who won the most at that game on that day would receive a cash prize of $\$ 30.00$. In terms of the incentive then, each game and each day was equally important. When the five-day series had been completed, students were asked a final question, which was to rank order the three games from most to least preferred.

\section{Results}

Data for each student's daily gambling behavior was based on the first ten wagers he or she made in each fifteen-minute session. Thus, each day yielded three ( 1 for each game) measures of average bet size. Data for each student's odds preferences in craps and roulette was obtained by counting the number of bets he made in each of the eight craps categories (see Table 19-I) and in each of the seven roulette categories. Again, only the first ten wagers were counted. Therefore, for each day he gambled, every student provided eighteen casino gambling measures; three were average bet size, and the remaining fifteen indicated the frequency with which he chose high to low odds bets in craps and roulette. 


\section{Within Measure Consistency}

Consistency within each ofthese eighteen casino risk measures is indicated in Table $19-\mathrm{II}$, which presents test-retest reliabilities for each measure across pairs of immediately adjacent days. Due to the fact that not all students were able to attend each gambling session, the number of observations from one reliability coefficient to the next changes. As may be seen from rows 1, 2 and 3 of

\section{TABLE I9-II}

TEST - RETEST RELIABILITIES OF THE EIGHTEEN CASINO MEASURES ACROSS PAIRS OF IMMEDIATELY ADJACENT DAYS

\begin{tabular}{|c|c|c|c|c|}
\hline NUMBER AND LABEL OF MEAS. & Mon- $T$ wes & $T$ wes-Wed & Wed-Th & Th-Fri \\
\hline 1. Avg, Bet, 21 & $.62(54)^{*}$ & $.68(45)$ & $.47(38)$ & $.43(38)$ \\
\hline 2. Avg. Bet, Craps & .43 & .36 & .32 & .60 \\
\hline $\begin{array}{l}\text { 3. Avg. Bet, Roulette } \\
\text { CRAPS ODDS }\end{array}$ & .40 & .32 & .60 & .44 \\
\hline 4. Line Bets & .35 & .77 & .71 & .79 \\
\hline 5. Big 6; Big 8 & .54 & .30 & .66 & .67 \\
\hline 6. Field & .51 & 62 & .77 & .74 \\
\hline 7. Seven & .64 & .60 & .19 & .28 \\
\hline $\begin{array}{l}\text { 8. Any Craps; Hard 10; } \\
\text { Hard } 4\end{array}$ & .56 & .50 & .50 & .52 \\
\hline 9. Hard 6; Hard 8 & .69 & .48 & .43 & .51 \\
\hline 10. Three; Eleven & .01 & .03 & .80 & .68 \\
\hline $\begin{array}{l}\text { 11. Box Cars; Snake Eyes } \\
\text { ROULETTE ODDS }\end{array}$ & .07 & .26 & .57 & .24 \\
\hline 12. Color; Odd Even; Hi Lo & .49 & .71 & .73 & .75 \\
\hline 13. Column; Dozens & .36 & .44 & .70 & .70 \\
\hline 14. Line Play & .36 & .62 & .59 & .43 \\
\hline 15. Quarter Play & .22 & .62 & .56 & .60 \\
\hline 16. Street Play & -.02 & -04 & .01 & -.02 \\
\hline 17. Split Play & .62 & .00 & .00 & -10 \\
\hline 18. Straight Play & .11 & .08 & .03 & .00 \\
\hline
\end{tabular}

"Number in parentheses is the number of observations on which correlation is based. For $P<.05$, the critical $r$ for each of these sample sizes is: (1) $n-54, r=$ .27 , (2) $n=45, r=.29$, (3) $n=38, r=39$.

this table, the four bet size reliability coefficients for each game are significant at the .05 level. Thus, for this form of gambling behavior there appears to be some consistency over time in each game. Turning to within-measure consistency for odds prefer- 
ences in the game of craps, five of eight odds categories show significant $(p<.05)$ reliability coefficients for each of the four pairs of days. Specifically, see rows 4, 5, 6, 8 and 9 of Table I9-II. In the game of roulette, four of seven odds categories show significant reliability coefficients for all four pairs of days; (see rows 12, 13, 14 and 15 of Table 19-II.) For both of these games then, there is consistency over time for more than a majority of the odds categories. These data indicate the presence of intrapersonal factors determining gambling behavior in a fairly large set of casino gambling measures. We now turn to the question of consistency across these measures.

\section{Across-Measure Consistency}

To perform this analysis, a single average score, the average being taken over days, was computed for each student on each of the twelve casino measures which had indicated test-retest reliability in the preceding analysis. Something of a problem was created in achieving unbiased scores, however, due to the following two facts: (1) For each casino game, the mean amount wagered in the first ten bets increased from Monday to Friday. Also, the popularity of the various odds categories changed from day to day as well. (2) Only thirty-three of the total sixty-four students attended all five gambling sessions. The measurement problem created by these facts was dealt with as follows: First, students who missed more than two gambling days were excluded from this analysis. There were eight students excluded, leaving a total of fifty-six to provide data for the present analysis. Of these fiftysix, thirty-three were present all five days, fourteen were present for four, and nine were present for three days. Next, for the five gambling days, every student's raw score on each of the twelve consistent casino measures was converted to a standard, or $z$ score. The resultant $z$ score gives a direct indication of the degree to which a student was above or below the group mean for a given day, independent of the absolute value of that mean. Once the twelve $\mathrm{z}$ scores had been computed for each of the days the student had gambled, the final step was to compute a mean $\mathrm{z}$ score for the student on each of the twelve casino measures. This 
provided twelve mean $\mathrm{z}$ scores for every student, with each mean indicating a student's typical standing on the twelve forms of casino risk-taking. The correlations across this set of twelve measures is presented in Table 19-III. For an $n$ of 56, the critical $r$ for $p<.05$ is 0.26 . Any correlation which failed to reach statistical significance at this level is not presented in the table.

\section{TABLE I9-III}

Across-Measure Consistency of the Twelve Casino Measures which Showed Evidence of Ieit-Reveit Reliability

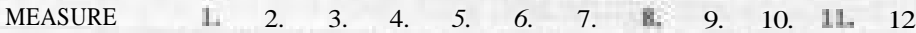

\begin{tabular}{l|l|l|l|l|l|l|l|l|l|l|l|l|l}
\hline 1. Avg. Bet, 21 & & .45 & .57 & .28 & & -.38 & & & & & & & \\
\hline 2. Avg Bet, Rovl & .45 & & .46 & & & & -.30 & & & & & & \\
\hline 3. Avg. Bet, Craps & .57 & .46 & & & & & -.30 & & & & & & \\
\hline
\end{tabular}

ODDS PREF.,

CRAPS

\begin{tabular}{l|l|l|l|l|l|l|l|l|l|l|l|l|l}
\hline 4. Line Bets & .28 & & & & & -.50 & -.35 & & & & & & \\
\hline 5. Big 6; Big 8 & & & & & & & -.31 & & .35 & & -.33 & & \\
\hline 6. Field & -.38 & & & -.50 & & & & -.33 & & & & -.39 & \\
\hline 7. Any Cr, H 10, H4 & & -.30 & -.30 & -.35 & -.31 & & & & & & & & \\
\hline 8. Hard 6: Hard 8 & & & & & & -.33 & & & & & & & \\
\hline
\end{tabular}

ODDS PREF,

ROULETTE

\begin{tabular}{l|l|l|l|l|l|l|l|l|l|l|l|l|l}
\hline 9. $1: 1$ & & & & & .35 & & & & & -.37 & -.46 & & \\
\hline $10.2: 1$ & & & & & & & & & -.37 & & & -.38 & \\
\hline $11.5: 1$ & & & & & -.33 & & & & -.46 & & & & \\
\hline $12.8: 1$ & & & & & & -.39 & & & & -.38 & & & \\
\hline
\end{tabular}

Note: This is a symmetric matrix. That is, the entry in row $i$, column $\mathrm{j}$ is the same as the entry in row $\mathrm{j}$, column i. Therefore, in the strict sense, presenting all entries alone and below the main diagonal is re-

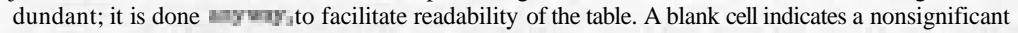
correlation coefficient at $P<0$,

The table shows average bet size possessing consistency across all casino games. Thus, large bettors in roulette tend also to make large bets in craps and 21 as well. The association of bet size and odds preference measures is nonexistent for the game of roulette. In craps, only four of a possible fifteen coefficients are significant. 
These four correlations suggest that large bettors in 21 tended to prefer line bets in craps and to avoid field bets; large bettors in roulette and craps tended to avoid the 7 to 1 odds category in craps. In total, Table 19-III suggests the independence of bet size and odds preference as risk measures.

We now examine associations across the odds preference measures themselves. First, consider across-measure association within each game. For both games the pattern is the same-namely negative correlations. In craps, four of ten possible correlations are significant and they are all negative. In roulette three of six possible correlations are significant, and they too are negative. This is what one would expect, since in each game, if a person tends to choose one odds category frequently, he must necessarily choose the others less frequently. Now consider consistency of odds preference across the two games. Table I9-III indicates very little across game consistency; only three of sixteen possible correlations are statistically significant. These three correlations suggest (1) people who favored Big 6/Big 8 craps bets tended to favor 1 to 1 roulette bets, (2) Big 6/Big 8 bettors tended to avoid line plays in roulette, and (3) people who favored field bets in craps tended to avoid quarter plays in roulette. These rather specific findings may be interesting in themselves, but they are hardly support for a general across measure consistency of odds preferences.

Two things may be said by way of summary to this point. First, of the eighteen measures originally examined, twelve possess consistency within themselves. Second, average bet size is a form of risk-taking that generalizes from one setting to another, whereas odds preference is only stable within a constant risktaking context.

Now, to turn to the second portion of this study and to find if gambling behavior which generalizes from one casino game to another also generalizes to other aspects of behavior which are not bound to a casino setting. This second portion will actually consist of two parts, the first being much more exploratory and much less systematic than the second. In both parts we will only examine average bet size as our casino behavior in that it is the only one we can currently claim to possess transsituational generality. 


\section{Relationship of Average Bet Size to Four Personality Measures}

As mentioned in the introduction, students completed four paper-and-pencil personality tests at the beginning of this gambling project. The four scales obtained measures of each student's (1) authoritarianism (Christie, Havel and Seidenberg, 1958), (2) desire for social approval (Crown and Marlowe, 1964), (3) internal-external locus of control (Rotter, 1966) and (4) optimum level of stimulation (Zuckerman, 1972). Each of these scales possesses high test-retest reliability, and each has been shown to correlate with a wide variety of behavior in nonpaper-and-pencil settings, i.e. each scale apparently taps a general dimension of personality. It was wondered if any of these four measures were correlated with average bet size in the three casino games. For the first three scales (authoritarianism, social desirability and locus of control) the answer is no. None of the nine correlations computed between these scales and the three bet size measures reached significance at $p<.05$. For optimum level of arousal measured by the Zuckerman Sensation Seeking Scale (or SSS) we are actually speaking of five measures. There is one general factor and four subscales having the names (1) thrill and adventure seeking (TAS), (2) experience seeking (ES), (3) disinhibition (DIS) and (4) boredom susceptibility (BS). Since the fourth subscale, or factor (BS) does not appear consistent across males and females, the female students were excluded from this SSS analysis. Of the fifteen correlations computed between the five sensationseeking measures and three bet size measures, only two were significant at $p<.05$. One of these was an $r$ of .32 between disinhibition and average bet size in 21 . The higher a (male) person's disinhibition score, the larger his 21 wagers tended to be. This finding seems consistent with Zuckerman's interpretation of this scale, "It consists of items which express the hedonistic 'Playboy philosophy": heavy social drinking, variety in sexual partners, 'wild parties," and gambling." The second (and final) significant correlation was a surprising negative $r$ of -90 between the TAS subscale and average bet size in craps. This subscale consists of $"$ "... items which express a desire to engage in outdoor sports or other activities involving elements of speed or danger" (Zucker- 
man, 1972). In total, then, these data suggest independence of these four personality measures and average bet size in casino games. In addition to these personality measures, students also responded to twenty-eight hypothetical duplex gambles developed by Slovic and Lichtenstein (1968) .

\section{Relationship of Duplex Gamble Response to Average Bet Size}

Slovic and Lichtenstein (1968) have pointed out that a two outcome (win-lose) gamble can be viewed as a multidimensional stimulus possessing a value on each of four risk dimensions, (1) $P(W)$, or probability of winning, (2) $\$ W$, or amount to be won, (3) $P(L)$, or probability of losing, and (4) $\$ L_{p}$ or amount to be lost. These same authors develop a model of risk-taking which assumes a person's response to a gamble will be a function of the salience (importance) he/she assigns to each of these four dimensions. In order to test this model, it is necessary to measure the salience of each risk dimension, independent of the other three. Slovic and Lichtenstein achieved such measurement via a specially-designed measuring instrument known as the duplex gamble. In their study, Slovic and Lichtenstein used the duplex gamble to test their risk model, and found two things of immediate relevance to the present study (1) support for their model and (2) differences between subjects as to which risk dimension was most important. This latter result caused this author to wonder if knowing a student's most important risk dimension (as measured by duplex gambles) would allow for prediction of his average bet size in the three casino games. In order to evaluate this possibility, the importance of each risk dimension was computed for each student, and he/she was assigned to one of four categories, based on his/her most important dimension." If two (or more) risk dimensions were of equal importance, that student was not categorized.

\footnotetext{
"For those acquainted with the duplex gamble, the following procedural details are in order: (1) Students responded to the gambles in bidding as opposed to rating format. (2) Importance, or salience of each dimension was determined as follows: First, a one-way analysis of variance was computed for each dimension; then $W^{*}$ was computed for each. W" gives the amount of variance in a subject's bids accounted for by each risk dimension.
} 
Of the fifty-six students, forty-one were categorizable, and the frequency of each category was as follows: (1) $P(W), 10$, (2) $\$ W$, 5, (3) $P(L), 1$ and (4) $\$ L, 25$. These four groups were reduced to two as follows: Group 1 is composed of the twenty-five students for whom $\$ L$ is most salient and Group 2 is composed of the remaining sixteen students for whom $\$ L$ is not most salient. If a relationship exists between salience of risk dimension and average wager size in the casino games, then we might well expect to see Group 1 students make smaller wagers (to minimize the amount of their losses) than students in Group 2 for whom aversion to losing money is a less systematic determinant of risk-taking. Table 19-IV presents the data relevant to this hypothesis. It shows the average bet size (expressed as a mean $\mathrm{z}$ score) in the three casino games for the two groups of students just described. A negative score indicates wagers of less than average size, and a

TABLE 19-IV

Average Bet Size in 21, Roulette and Craps

for Students Having $f L$ as Their Most Salient Risk Dimension

and for Students Having Some Other Factor

as Their Most Salient Risk Dimension

\begin{tabular}{cccc}
\hline MOST SALIENT & 21 & ROULETTE & CRAPS \\
\hline$\$ L$ & -.195 & -.276 & -.299 \\
Other than $\$ L$ & .166 & .258 & .138
\end{tabular}

Note: These entries are average $Z$ scores.

positive score indicates greater than average wagers. Clearly, these results are supportive of an association between casino wagering and duplex gamble responses. These data were submitted to a 2 (fL, not \$L) by 3 (Casino Game) analysis of variance with repeated measures on the second factor. (A least-squares solution was used.) Results of the analysis show a significant main effect for group $(F=6.519, d f=1,39, p<.05)$ and no effects for casino game or for interaction ( $F<1$ in both cases). Thus, there is support for the assertion that a heightened concern with losing money in the Slovic task is predictive of relatively small wagers in these casino games. The success of this hypothesis suggests a number ofpoints. 
First, it does appear that intrapersonal determinants ofwager size in casino gambling generalize to another form of risk-taking in a noncasino setting. The best interpretation of this, the writer feels, it to say that a person's gambling behavior may well be predictable if it is known which aspect (s) of gambles in general are most important to him; apparently, the duplex gamble procedure might provide such information. This interpretation in turn raises two additional points. First, the present finding that wager size shows consistency across games and odds preference does not might simply reflect the rather skewed distribution of most salient risk dimensions reported earlier. The dimension having most salience in this group of students was related to money (fL) which might explain why wager size showed the consistency it did. On the other hand, only a small number of students showed concern with either of the two probabilistic risk dimensions on the duplex gambles, which might explain the lack of consistency in odds preference measures over games in this study. These currently speculative points must await future gambling studies which will compare large groups representing each of the four risk dimensions.

Second, these results would seem to underscore a commonly made assertion that riskiness, as a general dimension of personality, be viewed as a multidimensional concept rather than being given the unidimensional (and unsuccessful) treatment it has traditionally received. The failure of the traditional approach is well-documented by Slovic (1972) who cites eleven different studies dealing directly with individual consistency in risk-taking, and states their results cast "... . doubt upon the existence of a general risk-taking propensity." The common procedure of such studies has been to operationally define risk in a number of ways, then to examine the correlations among these various risk measures which, as implied in the preceding sentence, are either very low or nonexistent. However, the failure of such studies to show individual differences may lie with an inadequate conceptualization of risk and/or riskiness, rather than with an absence of intrapersonal determinants of risk-taking behavior. The eleven studies cited by Slovic have operationally defined riskiness on various 
risk dimensions so that for one measure riskiness is measured in terms of a probability factor, and, for another, in terms of payoff, etc. However, if an individual places most weight on a single-risk dimension or a small subset of these dimensions, then we should only expect consistency in his/her risk-taking over situations in terms of this particular dimension(s). Perhaps an appropriate tack for future research on individual differences in risk-taking would be to focus on intrapersonal consistency of Slovic's four risk dimensions.

\section{REFERENCES}

Christie, R., Havel, J-, and Seidenberg, B.; Is the $F$ scale irreversible? $J A b$ norme Soc Psychol, 56:143, 1958.

Crown, D., and Marlowe, D.: The Approval Motive. New York, Wiley, 1964.

Lemmel, M.: Gambling: Nevada Style. New York, Doubleday and Company, 1966.

Rotter, J. B,3 Generalized expectancies for internal versus external control of reinforcement. Psychol Monographs, 80; 1966.

Slovic, P.: Information processing, situation specificity, and the generality of risk-taking behavior. / Pers Soc Psychol, 22(1): 1972.

Slovic, P., and Lichtenstein, S.: Relative importance of probabilities and payoffs in risk taking. / Exp Psychol Monograph, 75(3) part 2, 1968.

Zuckerman, Z.: Manual and Research Report for the Sensation Seeking Scale. Department of Psychology, University of Delaware, April, 1972. 


\section{Chapter 20}

\section{HISK-TAKING IN THE PRESENCE DF DTHEHS: HLACKJACK IN THE LABORATURY AND IN THE FIELD}

\section{G. P. Ginsisurg, JAMES J. Bliscovich AND ReNE C. HOWE*}

THIS CHAPTER DEALS with a series of laboratory and field studies 1 of changes in risk-taking that occur in the presence of other people. These changes have been studied for over a decade by social psychologists and have been named the risky shift because people usually appear to take large risks in the presence of others. Two competing explanations were proposed for this observation; one held that the presence of others allows for a diffusion of responsibility if something goes wrong, and the other contended that there is a culture value in our society which favors being moderately risky, although not foolishly so. However, neither of these explanations received clear support through experimentation. Also, over 80 percent of the risky shift studies had used a paper-and-pencil instrument which had never been intended as a measure of risk-taking. The few studies which did not use that instrument sometimes yielded conservative shifts, where people actually became less risky in the presence of others. The writers became interested in the phenomenon because of the importance of risk in everyday affairs, because of the growing importance of group decision-making in our culture and government, and because of the considerable ambiguity in the work produced by other investigators.

The studies summarized here were designed to avoid the methodological errors of others and to make sense out of the risky shift

"The assistance of Mr. Philip Knowles, graduate student in the Doctoral Program in Social Psychology, UNR, is gratefully acknowledged. Mr. Knowles has piloted and conducted a series of replication studies with female participants and both male and female dealers. 
findings by using a better risk-taking task. After summarizing these studies, some of their implications will be discussed for areas other than gambling, such as medicine and law.

A realistic gambling laboratory was set up and blackjack was studied using bet level as the measure of risk. The reasons for choosing blackjack were straightforward. First, people readily become involved in the game. Second, the player readily becomes aware of the consequences of his decision; it is not a hypothetical situation in which no outcomes occur. Third, for practical purposes each hand in blackjack can be considered to be randomly selected from all possible hands, and this facilitates statistical analysis. Finally, people enjoy playing it, and in psychological experiments it is not often that a task can be found that experimental participants enjoy. In addition, it was decided to use the amount bet as our measure of risk because it is so susceptible to statistical analysis.

The general experimental procedure is to have three people come to the departmental casino at a time. The casino has four slot machines, a six-position blackjack table and a one-way mirror through which the action can be observed and the amounts bet counted. The three participants are placed in separate waiting rooms, then taken one at a time into the casino to play alone against the house. Each player is given five dollars in chips, and he is asked to play as though he were playing with his own money and to try to win as much as he can. Also, he is told that the limits are between five cents and one dollar. All participants are male and know how to play blackjack at least moderately well.

After a player has played twenty hands, the game is stopped, and he is taken back to his waiting room. Then the next player is brought in. After all three participants have played alone, they are brought back to the casino as a group to play another twenty hands. We call the twenty hands played alone Session I, and the next twenty hands, Session II. For purposes of experimental control, there is usually a number of players who play the second set of twenty hands alone against the house (just as they did their first twenty hands). The details of experimental designs, instructions and statistical analyses can be found in the works listed in the bibliography (Blascovich, Veach and Ginsberg, 1973; Blascovich and 
Ginsberg, In press; Blascovich, Ginsberg and Howe, In press; Blascovich, Ginsberg and Veach, In press). In general, the average bet is compared in the last five hands of Session I when people are playing alone and with the average bet in the last five hands in Session II when they are playing in a group setting of some sort.

In addition to the laboratory studies, a field study in casinos was conducted. That will be described later, but first a set of five laboratory studies should be described. These are labeled Studies A to $\mathrm{E}$ and correspond to Figures A to E. All of the effects referred to were statistically significant and the detailed analyses can be found in our referenced papers.

\section{Study A}

In this study, the writers were concerned, first, with whether people would bet more in the presence of others, and, second, with whether deliberate discussion about the bet levels was necessary to bring about a shift in bets. Interest in the deliberate discussion stemmed from an argument among social psychologists (cf. Pruitt for a review), most of whom held that discussion within the group was necessary for the shift in risk to occur. Therefore, three different conditions of play were set up in Session II. In one condition, people played their second twenty hands alone (the Individual Control in Figure A) ; in another condition, players played their second twenty hands in groups of three in natural fashion (coacting group); and in the third condition, the player had to agree on a common bet before each hand (interacting group)

It was found that people in the individual control condition did not shift from the last block in Session I to the last block of Session II, but that both the coacting and interacting groups did shift upward from the last block of Session I to the last block of Session II. Furthermore, there was no difference between the coacting and interacting groups, demonstrating that deliberate discussion about bet levels was not a necessary condition for the shift in risk. Of course it may be a sufficient condition, but it appears not to be a necessary one as had been contended in the technical literature.

Also noted was an effect which has appeared in almost all of the 


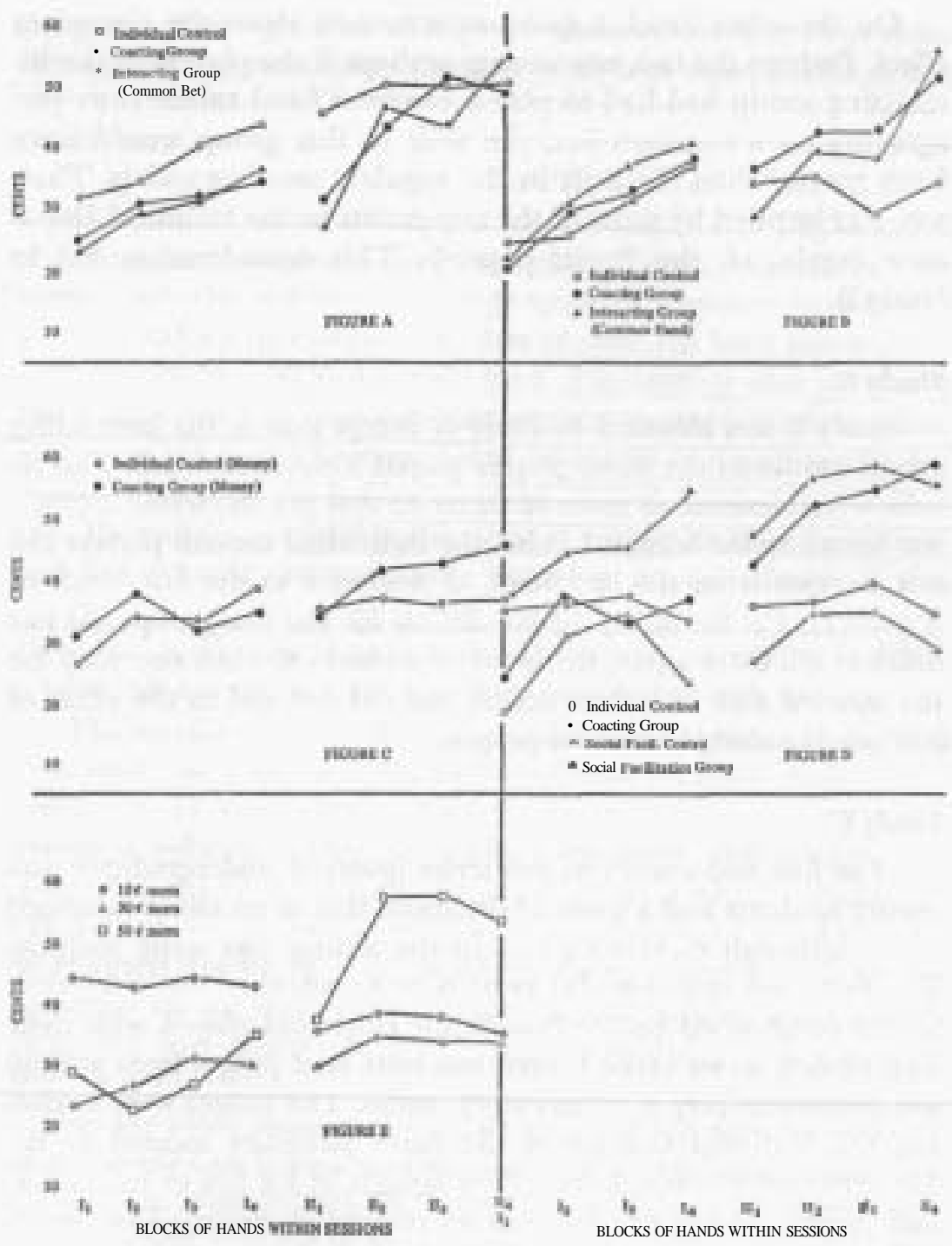

Figure 20-1.

writers' studies-a moderate increase in bets across Session I when people are playing alone. This appears to represent an adaptation effect, and it usually is not nearly as large as the group effect shown in Session II. 
On the other hand, a question remained about the discussion effect. Perhaps the task was wrong; perhaps if the players in the interacting group had had to play a common hand rather than just agreeing on a common bet, the shift in this group would have been greater than the shift in the regular, coacting group. That, too, was implied by some of the arguments in the technical literature (again, cf. the Pruitt papers). This consideration led to Study B.

\section{Study $B$}

Study B was identical to Study A except that in the interacting group condition the three players played a common hand. The results were identical to those of Study A; that is a moderate increase was found across Session I. Also, the individual control players did not increase from the last block of Session I to the last block of Session II. Furthermore, the conditions for the two groups did not differ at all. Once again, deliberate discussion was not necessary for the upward shift in risk to occur, and did not add to the effect of just playing along with other people.

\section{Study $C$}

The first two studies in this series involved undergraduate university students and a pretend situation, that is no money changed hands although everything else in the setting was quite realistic. However, the question did remain as to whether the risky shift would occur when people bought the chips and played with their own money, so we invited thirty-two state trial judges from around the country to play at a laboratory casino. The judges were attending the National College of the State Judiciary located at the University of Nevada, Reno. They bought in for five or ten dollars and played within the five-cent to one-dollar limits. The results were perfectly clear-the individual control players showed no change in betting level from the end of Session I to the end of Session II, but the coacting group players showed an unquestionable increase. The moderate increase across Session I was also noted as they adapted to the setting and the fall of the cards. Thus, at least in a low-stakes game, the same shift in risk level is produced 
by group play regardless of whether one's own money is at stake. This raises a question about exactly what is at stake, if real money makes no difference. This is an important issue, and it will be discussed later.

For the moment, however, consider why people are likely to take larger risks when in the presence of others. At the beginning of the chapter two explanations in the older technical literature were mentioned-the diffusion of responsibility explanation and the cultural value explanation. The first of these has been ruled out as a reason. People might share the buck if something does go wrong, but that is not why they take bigger risks in the first place. More recent investigations have suggested variations of the cultural value thesis which generally holds that people find through group activity that the socially acceptable risk level is higher than most of them had individually assumed. One variation on this theme is that group discussion allows people to learn of additional arguments in favor of a riskier position. However, the writers' studies indicate clearly that discussion is not necessary for a shift in risk to occur.

The second variation on the cultural value thesis is that group interaction provides for exchange of information about each other's risk levels. This exchange can occur without discussion; mere observation is sufficient. This is a social comparison explanation, and when it is combined with the assumption that moderate riskiness is valuable in our culture, it provides an explanation for the increase in riskiness during or after group interaction-that is each person comes to realize that he is not as risky, relative to others, as he originally had presumed. The writers' first three studies support this last explanation.

On the other hand, it is also possible that the mere presence of other people can bring about a risk increase even if no information about their preferred risk levels is exchanged; that is, the mere presence of others engaged in the same activity may be sufficient to augment a culturally conditioned response to bet more. This possibility led to Study D.

Study D

In Study D four conditions were set up. Two of them were the familiar individual control and coacting group conditions. The 
other two conditions involved barriers, or cubicles, that separated the players at the table so that they could not see each other or each other's cards or outcomes. These conditions are noted in Figure D as social facilitation conditions. The social facilitation control condition required the player to play his second twenty hands alone against the house, but in a cubicle. In the social facilitation group condition, Session II was similar to that of the coacting condition, except the three players sat within barriers at the table.

As in prior studies, the individual control players showed no change from the end of Session I to the end of Session II, while the coacting groups showed the usual large increase as a function of the group setting. The social facilitation control players also did not change their bet levels from Session I to Session II, demonstrating that playing in the barrier by itself did not bring about any shift. However, the effect of the social facilitation group condition is not clear. Looking at the black triangles in Figure D, it can be seen that there was a large, unexplained jump from the third to the fourth block in Session I. There is no difference between the bet levels of the last blocks in Sessions I and II, but if the third blocks of each of the sessions are compared, an increase in Session II will be noted." Furthermore, the general shapes and levels of the Session II curves for the two group conditions are almost identical. Therefore, there is a reasonable chance that the mere presence of other people engaged in the same task can activate culturally conditioned response to increase risk without any specific knowledge of other people's risk levels.

\section{Study $E$}

Given the operation of a general cultural pressure to be moderately risky, how important are the bet levels of one's immediate

"Since the social facilitation study has not yet been published, some technical information may be in order here. Based on a priori hypotheses that the fourth block of Session II would be greater than that of Session I, t-tests were conducted using formulations available from the senior author. The results revealed that the coacting condition yieldedl a significant shift $(\mathrm{p}<.0005)$ and that the two control conditions did not $(p>.15)$. The third block contrast for the social facilitation group condition proved significant $(.01<\mathrm{p}<.025)$. In addition, an analysis of variance has been conducted, but there has not been time to compute detailed simple effects analyses. 
partners? If a person is surrounded by low bettors, will he reduce his bet? Putting together prior studies, the writers predicted that high betting partners would bring about a large increase in a person's bet level, while low betting partners would bring about a moderate reduction in a person's bet level. Two confederates were used in Session II who always bet the same amount (10\% in the downward change condition, $30 \%$ in the no change condition, and $50 \%$ in the upward change condition). The data were complicated by a couple of high rollers ( $\$ 1.00$ bettors right from the start), but the predictions were supported strongly. The thirty-cent norm brought about no change between the last block of Session I and the last block of Session II, while the fifty-cent norm brought about a large increase and the ten-cent norm brought about a moderate decrease. Therefore, local norms interact with the general cultural norm toward riskiness.

\section{Study F — Field Study}

The writers felt it was important to test their laboratory findings in the field. Therefore, they collected data on blackjack games in casinos to assess the influence of other people's bets on a person's bet level. Seventy-two percent of the cases in which an upward shift was predicted actually did so; and 62 percent of the predicted downward shift actually occurred. The upward shift is statistically significant, but the small number of cases makes the downward shift undependable. However, the overall pattern of relationship between the predicted and actual shifts is firmly dependable, giving support to the laboratory findings-that is when a person is joined by people who bet higher than he has been betting, his bets are likely to increase; and if he is joined by relatively lower bettors, his bets will drop, although not as readily.*

\footnotetext{
*To qualify for inclusion a player had to play five or more hands alone and then five or more hands with one or more other persons. Only thirty-two cases were collected over four months in 1973 and three months in 1974. The overall contingency between predicted and actual data was evaluated by lambda according to procedures recommended by Dr. Lyle Warner, Department of Sociology, UNR.
} 
Predicted Shifts

$$
\begin{array}{lccccccll} 
& & + & = & - & \mathbf{S} & & \\
& + & 13 & 0 & 4 & 17 & & \text { Mode } \\
\text { Actual } & = & 1 & 1 & 1 & 3 & \text { Marginal } \\
\text { Shifts } & = & 4 & 0 & 8 & 12 & \text { Errors }
\end{array}
$$

$$
\mathrm{X}(\text { using modal prediction rule })=\frac{15-10}{15}=33
$$

$$
\text { 당 }=1.697, \mathrm{P}<.05 \text { (1-tail) }
$$

The value $\lambda=.33$ can be interpreted as proportion of variation in actual shifts accounted for by knowledge of predicted shifts.

Figure 20-2.

\section{SUMMARY OF DATA}

To briefly summarize the findings from the six studies, it appears that the presence of other people engaged in the same risky activity will lead to a moderate increase in risk level. Second, when the risk levels are observable, the presence of others engaged in the same risky activity will lead to a strong upward shift or to a moderate downward shift in risk level, depending on whether the others' risk levels are above or below the person's original risk level. Third, deliberate discussion of shifts in risk is not necessary to bring about a shift, but it may be sufficient. Finally, the results are the same whether or not one's own money is used in a lowstake game.

\section{Implications and Questions}

Certain inferences have been drawn from this data and the review of work by others. First, there does appear to be a general cultural value which favors riskiness, provided one stops short of foolhardiness. This is reflected in the reliable tendency of our players to increase their bets a moderate amount as they adapt to 
the situation. Second, the cultural value for riskiness also underlies the group influence that has been observed. The cultural value can be put into action by the mere presence of others, but it can be put into stronger action by the display of risk levels by others which are higher than one's own. The cultural value for riskiness also dampens the influence of low risk levels on the part of others. Furthermore, in complex risk situations such as foreign policy or corporate investment decisions, enactment of the cultural value may require both clarification of the issues and exchange of risk level preferences which in turn mean that discussion may be necessary in complex cases before the group-induced risky shift will be observed.

One major question remains-What is risk-taking? A review of the social psychological literature reveals that there have been very few attempts to define risk-taking, and those few attempts have been inadequate. Instead, it usually is considered self-evident, as was done to this point in this chapter. However, some conceptual clarification truly is in order especially since money proved not to constitute an adequate distinction between real and hypothetical risk-taking in our blackjack studies. Without justifying the writers' views, they will be offered here for the reader's consideration.

The writers believe that certain criteria must be met before it is reasonable to say that risk-taking is occurring. First, the person must recognize that something is or will be at stake, and that he is or will be engaging in risk-taking behavior. Second, the person must take action which makes the stake irreversible and which will lead to an outcome. A stake, in turn, requires both the possibility of loss and the possibility of gain. Of course, what may be lost need not be the same as what may be gained.

Furthermore, what is at stake may be symbolic rather than physical. In these studies, interviews with both the student participants and the trial judges strongly implied that blackjack-playing was seen as a skill, reflected in the amounts bet and, ultimately, the amounts won or lost. What was at stake was an aspect of self-esteem or pride. This interpretation is supported by recent works of others (Jellison and Riskind, 1970 and Jellison, Riskind and Broil, 1972) which demonstrate that riskiness is seen as ability. Thus, pride, skill, ability and self-esteem must be considered likely as symbolic 
stakes in risky situations.

If this line of thought is reasonable, then these risk-taking findings may well apply to other areas of life. For example, will a surgical team undertake a riskier intervention than a single surgeon? Will a judicial panel make a riskier sentence recommendation than a single judge? That, in fact, will be the writers' next research venture-in the near future they will collect sentencing recommendations from three-man panels of trial judges and also from individual trial judges, using a set of standardized cases. However, what constitutes a riskier sentence is not yet clear, but it should be comparable in principle to the risky actions of a gambler, a physician or a youngster contemplating marriage. Hopefully the studies will uncover it.

\section{REFERENCES}

Blascovich, J., and Ginsburg, G. P.: Emergent norms and choice shifts involving risk. Sociometry. In press.

Blascovich, J-, Ginsburg, G. P., and Howe, R.: Blackjack and the risky shift II. Monetary stakes. / Exp Psychol. In press.

Blascovich, J., Ginsburg, G. P., and Veach, T. L.: A pluralistic explanation of choice shifts on the risk dimension. IP Soc Psychol. In press.

Blascovich, J-, Veach, T. L., and Ginsburg, G. P.: Blackjack and the risky shift. Sociometry, 36:42, 1973.

Jellison, J. M., and Riskind, J. A.: A social comparison of abilities interpretation of risk-taking behavior. / Pers Soc Psychol, 15:375, 1970.

Jellison, J. M. Riskind, J. $\mathbf{A}_{-1}$ and Broil, $\mathbf{L}_{4}$ i Attribution of ability to others on skill and chance tasks as a function of level of risk. / Pers Soc Psychol, 22:135, 1972.

Pruitt, D. G.: Choice shifts in group discussion, / Pers Soc Psychol, 20:339, 1971.

Pruitt, D. G.: Conclusions: Toward an understanding of choice shifts in group discussion, / Pers Soc Psychol, 20:495, 1971.

Pruitt, D. G.; Informational requirements in making decisions, Am J Psychol, $74: 433,1961$. 


\title{
Chapter 21
}

\section{CUMPULSIVE GAMHLING AMD THE CONSCIOUS MOOD PERSPECTIVE}

\author{
ToMısMARTINEZ
}

\section{COMPULSIVE GAMBLING}

COMPULSIVE GAMBLING is not the most serious problem facing either sociology or society. Conceptualization and analysis, however, raise important theoretical problems, and as a social problem it is among the most baffling known to social scientists. The number of compulsive gamblers in the United States is variously estimated, from 6 to 12 million persons (Lindner, 1950 and Kennedy, 1967); the exact number, of course, will never be known. In an increasingly technological and leisure-oriented society, and with the growing number of states that are legalizing gambling, compulsive gambling is likely to increase.

This paper examines (1) some theoretical problems posed by subjecting compulsive gambling to formal analysis, and (2) the process of becoming a compulsive gambler. The conscious mood perspective is introduced as a theoretical device to explain becoming compulsively deviant. Data presented on the typical career experiences of compulsive gamblers is based upon a four-year study of gambling and gamblers in which fifty compulsive gamblers were interviewed in depth three or more times, and much participant observation took place (Martinez, 1971).

\section{COMPULSION}

The first theoretical problem arises with the term compulsive gambling. It implies a medical model that is typically avoided by sociologists. While the medical model is a popular everyday explanation of deviance, which has long been the case with compul- 
sive gambling (Lindner, 1950), interaction theorists (Lorber, 1967) have demonstrated that in many cases of illness, deviance is a function of the subject's performance. Deviance as illness is "a social designation, by no means given in the nature of medical fact," argues Gusfield (1967). Nevertheless, almost all of the social scientific literature on compulsion is written by psychiatrists and psychologists. The deviant label, compulsion, is typically applied to a behavioral pattern characterized by the continual commitment of an irrational act that usually violates the individual's personal standards (Laughlin, 1956) -

Freud (1925) found that neurosis is often linked with a belief in the omnipotence of thought. He even attempted to demonstrate that a belief in the omnipotence of thought corresponds to real fact. Fenichel (1945), who did the most extensive writing on compulsion, deems compulsion an obsession that is still felt as an impulse. In psychoanalytical theory, a repetitive thought by itself is merely an obsession; the thought becomes a compulsion when the obsessed person feels he must, and attempts to act upon the thought. The impulse feeling corresponds to sensing that a particular thought is a command from within. Over a period of time the compulsive behavior pattern consists of a repetitive set of activities.

According to Fenichel (1945), in the compulsive state of mind, certain repetitive thoughts possess an efficacy well beyond that granted to other thoughts, whether or not they are repetitive. The power granted to certain repetitive thoughts is an extension of power granted to authority figures during childhood experiences. The content of compulsive thinking is described as abstract, general and theoretical, and is isolated from concrete reality. The compulsive fears the power of his abstract and isolated thoughts which make him dependent upon his thinking. Instead of mastering the world by means of thinking, the compulsive thinking tends to master him. Not to act upon certain thoughts produces frustration and irritability. Restated sociologically, belief in the omnipotence of a particular thought could result in self-fulfilling prophecy (Thomas and Znanieck, 1927).

Finally, compulsion implies a sequence of behavior that could 
be conceived along career lines. As such, sociologists may study compulsively deviant career patterns in order to understand the nature of compulsive deviance, try to locate the theoretical importance of it in relation to the sociology of deviance, and still be free from a charge of charlatanism for performing a medical diagnosis.

\section{COMPULSIVE DEVIANCE}

The study of compulsive deviance is presently out of the mainstream of the sociology of deviance. The prominence of the political model advocated by interaction theorists has militated against the formal integration of compulsive deviance (Coder, 1971). In general, deviance theorists have had little to say about the general notion of compulsive deviance. The writer knows of only two theoretical articles by sociologists that bear specifically on it (Cressey, 1969 and Lemert, 1967). Both theorists have not been able to come fully to grips with the sociological import of compulsive deviance. Lemert (1967) distinguishes compulsive deviance from ordinary deviance on the basis that compulsive deviance is characterized by irresolution rather than resolution:

There are, however, some forms of recurrent deviance which reflect disturbances in the problem-solving and perceptual process itself, in which irresolution rather than solution of problems emerges as the key factor in deviance. In such deviance there is no easily discoverable or even inferable balance of pains and pleasures; indeed, there is much in the self-initiated actions of the individual which continually generates pain, hardship, defeat, and degradation, with little compensatory satisfaction. These are kinds of self-defeating, self-perpetuating behaviors, whose persistence defies common sense logic, whose baffling manifestations led Freud to several revisions of his thinking, and which present a discomfiting challenge to learning theory partisans.

The above type of behavior is considered a "neurotic paradox" (Lemert, 1967), and a more sociological term, "self-defeating," is offered in place of the medical term "compulsive." Lemert (1967, 1951) also attempts to label compulsive deviance a "classic case of secondary deviation," a term he coined, which was warmly received in the profession. However, it makes more sociological sense to conceive of compulsive gambling as a process of becoming, which at 
some stage may or may not be characterized by irresolution. Furthermore, the writer suggests, that because of the paucity of sociological knowledge about the nature of compulsive gambling, the primary rather than the secondary aspects of the deviation need further analysis.

The other sociologist who addresses the theoretical problem of compulsive deviance argues that "so-called compulsive crime" is no exception to his favorite sociological theory, differential association. Cressey (1969) conceives of compulsive deviance as a matter of self-identification, which is reflected in the "vocabulary of motives" employed in the performance of the compulsive role:

For example, a person might in some situations identify himself as a kleptomaniac, since that construct is now popular in our culture, and a full commitment to such an identification includes the use of motives which, in turn, release the energy to perform a so-called compulsive act. The more positive the conviction that one is a kleptomaniac the more automatic his behavior will appear. The subject's behavior in particular situations, then, is organized by his identification of himself according to the linguistic construct "kleptomaniac" or its equivalent. In the framework of role theory, it is this kind of organization which makes the behavior recognizably recurrent in the life history of the person. The fact that the acts are recurrent does not mean that they are prompted from within but only that certain linguistic symbols have become usual for the person in question.

Above it is noted that a "full commitment" to a compulsive identification acts as a type of receptacle containing the necessary vocabulary of motives, which in turn "release the energy" to perform the deviant act. The writer finds this formulation troublesome. Commitment to a set of experiences intrinsic to an enterprise and commitment to a set of language symbols associated with an enterprise are analytically distinguishable and do not necessarily occur together. Perhaps the term commitment is too weak to capture the essence of compulsive deviance. A stronger term might be total commitment, which would emphasize the compulsive character of the behavior in question and would eliminate from consideration those who participate in the enterprise noncompulsively. A sound sociological approach would be to identify and understand the social contingencies that make possible a total commitment to a compulsively deviant career. 


\section{BECOMING COMPULSIVELY DEVIANT}

The common cultural meanings experienced by the average participant in a given enterprise does not explain the subjective reward structure necessary for the development and maintenance of a total commitment. Theoretically, it might be expected that in the process of becoming compulsively deviant, the subject encounters a certain set of experiences and interprets them in a certain way (Becker, 1962) - Failure to have these experiences, or to interpret them in a certain way would prohibit the process of becoming. These experiences are key moments that become meaningful as the subject interprets them as pleasureable. Once defined as pleasureable, they may serve as indicators of identity. Without participating in these key moments, defining them as pleasureable, and then using them as indicators of identity, becoming compulsively deviant is unlikely.

The key moments in becoming compulsively deviant are characterized by a shift in mood that is registered in consciousness and interpreted as an indicator of self-esteem. Let shift refer to the alignment of the boundaries of self according to a given normative referent. Characterization of the process of becoming compulsively deviant by means of this definition enables the schematic presentation of the role of consciousness within the context of self-mediating experience.

\section{The Conscious Mood Perspective}

Identity-defining experiences could be called conscious moods, a term first used by Matza (1969). The term conscious mood designates the subjective indicator of a particular configuration of mind, self and society. In the creation of an identity the subject experiences a shift in conscious mood wherein mind, self and society, and the unity of meaning of all action are consideraed. What the writer calls the conscious mood perspective rests upon the possibility of describing the process of self-identification in terms of shared subjective indicators of meaningful behavior. Such a possibility is suggested by the logic of three influential theoretical perspectives, (1) experimental social psychological theory which says that be- 
havior becomes meaningful as it is "perceptually integrated into a shared interpretive perspective" (Alexander and Knight, 1971); (2) sociological signification theory, which holds that deviant behavior is a product of identity attributes emanating from self and others (Becker, 1962; Berger and Luckman, 1963; Goffman, 1961; and Lemert, 1967); and (3) naturalist theory which states that deviant behavior is filtered through the "philosophical inner life" of a subject, and thereby shapes identity (Matza, 1969). In the conscious mood perspective, the subject conceptualizes the social situation as a range of possible conscious moods entailed by the alternative identities and associated behaviors he encounters.

Ordinarily humans exist in one or another conscious mood, but not all conscious moods have important implications for self-defining. Shifts in configurations of mind, self and society are sensed in conscious mood. As we shall $s_{e}$, some shifts in conscious mood that have natural implications for self-defining are interpreted as pleasant, which are, in turn, "naturally" interpreted as a sense of high self-esteem (Sullivan, 1953).

The conscious mood perspective incorporates a naturalistic conceptualization of consciousness. Conceived naturalistically, consciousness is not merely and always the opposite of unconsciousness. Such an assumption would be specious. Instead, consciousness is conceived as a continuum. This is a departure from Mead's (1932) conception of consciousness, who believed that "life becomes conscious at those points at which the organism's own responses enter as part of the objective field to which it reacts." Thus, Mead implies that when the organism is not reacting to its own responses it is not conscious. Mead's perspective raises an important question, When the organism's own responses are only minimally taken into account, as opposed to when they are maximally taken into account, is one more or less conscious? Thus, there is the suggestion that Mead's conception of consciousness can nevertheless be used as a continuum, but Mead did not develop the notion of consciousness as continuum.

In a naturalistic conception of consciousness, mind, self and society exist as an integrated whole. All are objects standing in relation to one another. 
The problem is that the consciousness of mind, self and society are integrated. Whether wide-awake or just awakened, there is no consciousness of mind oblivious to self and society, no consciousness of self oblivious to mind and society, no consciousness of society oblivious to mind and self; except, it is sometimes said, under the influence of LSD, or much more plausibly, under the grip of certain extreme forms of "mental illness," or much more theatrically, under the hold of hypnotic trance. These extraordinary exceptions aside, the integration of consciousness of mind, self and society remains in the ordinary shifts of configuration. Once composed or put together - a process described by Mead — the ensemble of "system" ordinarily holds together. That system-the subject-shifts frequently in configuration or, as he senses, in conscious mood. But the shift occurs as a whole; the impossibility of segregated consequence is the very meaning of integration, or "system" (Matza, 1969).

Thus, what Mead's conception ofconsciousness calls variations in consciousness, naturalism would deem variations in conscious mood, entailed by the configuration of how mind, self and society stand in relation to one another. In the Meadian conception, consciousness comes and goes as the organism reacts and ceases to react to itself, whereas in the naturalistic version, consciousness is usually always there, either $h i g h$, low or in-between, existing as an integrated whole.

It appears that Parsons' (1954) conception of consciousness is related in a not entirely crude way to the naturalistic conception. Parsons defines consciousness as "a condition of heightened or amplified communication between subsystems of the individual personality system, or similarly between personalities as they are involved in roles in the social system." In a similar vein, Shibutani (1949) considers consciousness a form of "inner communication." The major difference between communication that takes place within the person and that which occurs between persons, according to Shibutani and consistent with Parsons' reasoning, is that the former is characterized by "inaudibility and brevity." Inner communication between subsystems means essentially that parts of the human organism are reacting to other internal parts. The variations in amplification and duration of the inner communication are taken into account by conceiving of consciousness as a continuum, which is, the writer believes, how it exists in nature any- 
way. Thus, conceiving of consciousness naturalistically not only preserves the totality of insights of Mead, Parsons and Shibutani regarding the nature of consciousness, but also sharpens them to better account for everyday reality.

\section{BECOMING A COMPULSIVE GAMBLER}

Theoretically, we begin with a subject who is willing (Becker, 1962 and Matza, 1969) to engage in gambling. The popular conception of gambling in American society does not generally serve as a subtle mechanism for social control, unlike the popular conceptions of, say, alcohol and hard drugs (Becker, 1962). Bloch (1951) points out that gambling is generally perceived as producing "no clear deteriorating effects upon the human organism or the social group," and that traditional American ambivalence toward gambling subverts the maintenance of a negative appraisal of participation. Typically, one begins to gamble with friends or family. Therefore, most people would ordinarily have little objection to engaging in gambling for the first time.

Now, the sequence of shifts that occur between and within conscious moods that characterize the process of becoming a compulsive gambler will be explained and described. Simply stated, as the subject moves from beginner to regular, and from regular to compulsive gambler, his conception of gambling changes as he experiences certain conscious moods, defines them as pleasant, and uses them as indicators of self-identity. Failure to do so would prevent progressive participation which makes possible the development of a total commitment to gambling. Noncompulsive gamblers do not experience the gamut of conscious moods of compulsive gambling; their experience is limited to conscious moods ordinarily associated with the common cultural meanings of gambling (as described by Goftman, 1967).

( Basically, there are five conscious moods that characterize the process of becoming a compulsive gambler. Each exists in dynamic interaction with the other four, and becomes possible with greater participation. They are (1) risk-taking, (2) here and now, (3) fantasy, (4) euphoria and (5) mysticism. In the lives of ordinary humans there is a paucity of such moods. Not every moment of gam- 
bling contains them, but they are important ingredients in the subjective reward structure of greater commitment. All are critical career contingencies. Without experiencing all of them, the subject is unlikely to undergo shift sufficiently to become a compulsive gambler.

The First conscious mood, risk-taking, is considered by most writers the essence of gambling, e.g. Goffman (1967). Elementary, mild forms of risk-taking generate or make possible qualitatively different subjective experiences than do complex, intense forms. Thus, the degree and nature of the risk-taking influences the particular shift of conscious mood. While Goffman (1967) considers risk-taking in gambling a "fateful situation," an opportunity to show strong character (which is a general cultural meaning), in gambling subculture the conscious mood of risk-taking involves much more than demonstrating strong character. When engaged in risk-taking, the subject has a sense of really living because mind and body are stimulated-become filled with life. Mind and body have a problem to attend to-managing the moment. Coordinating body with mind becomes of central importance. Failure to manage the moment successfully means certain loss of an agreed-upon value. The situational stimulation awakens the mind and body, and when control over such stimulation is achieved, movements appear easy, almost graceful and cool. This is the essence of the conscious mood of risk-taking in gambling, which can be enhanced through progressive betting. The other conscious moods are even more outside the experience of everyday life, and that is, in large measure, their attraction.

Here and now, the second conscious mood, means that the mind's full attention is on the situation at hand. Boredom, for example, is a state of existence that involves the mood of here and now, but lacks the stimulation of risk-taking. My use of the term here and now should be distinguished from a seemingly similar term "on." Entertainers talk about being "on" and "off," as Messinger, et al. 1962 note. In their view, when the subject is not "on," his perspective is "natural," more relaxed. This view was inspired by the comments of Sammy Davis, Junior, (Messinger, et al., 1962), "As soon as I go out the front door of my house in the morning, I'm on, Daddy, I'm on." It appears that Mr. Davis feels 
more relaxed with friends, "But when I'm with the group I can relax. We trust each other." However, the feeling of being on may not be altogether as unpleasant to the average entertainer who likes to perform. Performing under the watchful eye of others is conducive to producing a heightened awareness of one's existence at the very moment. Conceived naturalistically, being on means more than the strain of putting forth an impression of a character; it is a moment with a conscious mood of here and now.

Experiencing a conscious mood of here and now is considered by some prominent psychiatrists as a necessity for cure in psychotherapy (Maslow, 1970). At those moments when the mental patient renders an impression of being normal by demonstrating an awareness of an adherence to conventionality, or when $o n_{z}$ he has a consciousness of here and now.

Maslow (1961) presents a social scientific description of the conscious mood of here and now:

$\ldots$.. he can now listen better than at other times. Since he is least habitual and least expectant, he can fully listen without contamination by dragging in expectations based on past situations (which can't be identically like the present one), or hopes or apprehensions based on planning for the future (which means taking the present only as means to the future rather than as an end in itself) . . . Nor does he have to compare what is here with what is not here in order to evaluate it.

A mind concentrating on the immediate situation is free from other matters. The problems at hand are thought of more clearly and creatively. The development of the conscious mood of here and now in gambling is dependent upon (a) a mastery over the moves, and (b) a pattern of betting. Both build confidence that enable the subject to do a rare thing-define the moment as one that he can successfully manage. Successful management enables the subject to become more deeply involved in the game.

Typically, compulsive gamblers interpret the conscious mood of here and now as pleasant. Some common expressions of the mood of here and now are "Once I get into it, then I can relax;" "I feel alive when I'm in action;" and "I close off the world outside when I sit down at the gaming table." Thus, a sense of freedom from the worries of everday business such as paying bills is associated with the conscious mood of here and now. Once defined as pleasant, the 
mood of here and now makes greater involvement in gambling more attractive, and enables the player to experience other conscious moods that use the here and now as points of departure.

As deeper involvement in gambling is made possible while experiencing the here and now, part of the mind becomes free to participate in another conscious mood-that of fantasy. During the conscious mood of fantasy, the mind dreams luxurious dreams not usually generated by the routine of everyday life. A surreal fantasy configuration of mind, self and society is created which renders high esteem to self. A sense of high self-esteem is typically interpreted as feelings of power, but it is power of a special sort. It is literally dream power. In the mind of the deeply involved subject, control over destiny becomes possible through fantasy. I am what I imagine I am is the self-edifice that emerges.

Three general types of fantasies can be distinguished. While each type is experienced by most compulsive gamblers, a preference for one is not uncommon. The fantasies are usefully distinguished along a time dimension. Most people relate to time, and conscious mood is, after all, an emergent property.

Our point of departure into fantasyland begins with the recognition of the unity of existence as naturally divided between yesterday, today and tomorrow-I am, I was and I'm going to be. The first type of fantasy, then, is a reconstruction of past situational identity along lines more favorable than that which actually occurred. Type II fantasy is a distorted vision of what is presently taking place, casting self in a more glamorous light. Type III fantasy flatters self in a future state of affairs. In all fantasies other people supply the adulation while the subject takes it in proud stride.

In Type I fantasy, the kinds of situations that are refurbished are those especially prominent in the memory of the subject, largely because self was ambiguously or ill-defined. In the fantasy, the subject re-enters the situation with all the original cast present. The added elements not originally present are the learned abilities and hindsight of the subject. Armed with greater advantage than his adversaries, self in fantasy goes about doing whatever appears possible in retrospect. The subject is rewriting his personal biography in order to construct a social foundation for feeling a sense of high self-esteem. One compulsive gambler, for example, would imagine 
he was back in high school beating up his former rivals and outwitting them at every turn.

In the second type of fantasyland is the subject glowing around the image of self as the man of the moment. Gambling subculture is the usual setting for the fantasy. The subject sees self as having prestige, performing daring and forceful actions. One compulsive gambler, for instance, would imagine himself as an international gambler with international money backing him.

In Type III fantasy the subject is dreaming, hoping for a better life, a life filled with accolades he humbly accepts. The future is constructed around the notion of the windfall in gambling, a streak of uncanny luck. For example, one compulsive gambler would imagine himself as the builder of churches and hospitals, defining self as good-hearted.

As gambling becomes a medium for identity-fantasizing, total involvement becomes possible. Total involvement means a total investment of self for the moment. Along with a greater investment of self, commitment becomes conceivable. The externalization of fantasized self through game behavior strengthens the identitybuilding process. Acting like a big shot, for example, is more or less tolerated by other gamblers as are other performances.

The fourth conscious mood is euphoria, a highly desirable, but rare, state of affairs in the lives of most humans, probably the rarest of the four moods. It is typically short-lived, occurring usually during condensed moments of important events, such as winning a large pot after a calculated bluff or winning on a long shot. The experience of euphoria is typically defined as an occasion for celebration. Euphoria is experienced by the subject as body rapture marked by buoyancy and vigor. It is sometimes described as warm flashes across the stomach or an electric charge throughout the body by compulsive gamblers. There is little ambiguity about the meaning of euphoria-it is pleasant. After the subject has experienced euphoria he needs little help in assessing its meaning. To him it is a natural indicator of true meaning. If it feels right, it must be right, is the commonplace interpretive perspective applied to euphoria. Building an identity around euphoria is not only conceivable, but also usual. Gordon Allport 
(1937) made a similar observation.

The euphoric experience in compulsive gambling becomes a peak experience simulacrum. The peak experience, as defined by Maslow (1961), is "an acute identity-experience." It is a moment when the subject experiences most of his identity, where the real self is closest at hand. Mead (1932) used the term "sympathetic magic" to refer to the practice of people who engage in an activity to evoke some simulacrum of the response they are seeking from the world about.

Fantasy and euphoria are experienced as the subject passes from occasional to regular gambler. The passage from regular to compulsive is characterized by an intensification of shift which gambling subculture simply calls making the action faster. Shift is intensified as the subject begins to externalize his fantasized self which, in turn, heightens the euphoria. This is done initially by role-playing, which sets in motion a process of imaginary socialization. In the gambling subculture there is an available social mirror that reflects a tolerance for the subject's role-playing. This suggests to the subject that there is at least a quasi-objective basis for believing the fantasized self is a real possibility. Now the subject has helped to create the social conditions that make possible the fifth conscious mood of compulsive gambling-mysticism.

Gambling begins to take on ritualistic meaning. Theoretically, any activity that can be repeated could become a sacred ritual. The main requirement is a large investment of self. The subject has already made such an investment of self. The investment was made through increasingly frequent participation and through experiencing moments of total involvement. Sacred rituals dramatize identity. While the sacredness of rituals varies with the investment of self, the drama of rituals varies with the degree of seriousness of the participants. With identity, money and good feelings in the balance, the subject becomes quite serious about the enterprise. For this reason compulsive gamblers develop a low tolerance for other players who do not take the game equally serious; thus, one of the functions of sacred rituals in the gambling subculture, and perhaps in all cultures, is to demark the differ- 
ence between those who are and those who are not serious about the activities.

Sacred ritual makes possible the conscious mood ofmysticism.

People use ritual to attain mystiques not available in humdrum daily living. Some life styles — such as Orthodox Hindu, Jewish, Moslem have built-in mystique; but modern man lives in ritual nakedness. So, feeling the chill of the bareness of existence, he may wish to get together with others to do something that will give him a more intense feeling of himself and his relation to things. Mystique is essentially a feeling that there is something more, "beyond," something better underneath the wrappings of the package, a box within a box, quite different from and more exciting than that we already know. It might be a messianic fantasy, or a supernatural world scheme. In any case, it is a beyond not realized by mere technical means, rather in conflict with rationality, and requiring the nondiscursive language of ritual (Klapp, 1969).

The mystical experience is by nature transcendental. Shifting into the conscious mood of mysticism enables the subject to conceive of self transcendentally. It is described sometimes as a sense of communicating with the greater forces in nature or God. Psychologists (Bergler, 1957; Hunter and Bruner, 1928; Lindner, 1950; McGlothlin, 1956; Morehead, 1950; and Morris, 1957) who have written about the subjective meanings of gambling have sometimes referred to the gambler's sense of omnipotence derived from playing. Some contemporary philosophers, especially the existentialists, believe that humans actively seek a mystical experience to be in touch with God or feel God-like (Sartre, 1957).

Throughout the ages the conscious mood of mysticism has been realized in a variety of enterprises, although the social context that gives rise to mysticism has remained relatively the same, as Adler (1971) demonstrates. Gambling has been always an available societal alternative means of experiencing mystical meaning. The mood of mysticism confers a mysteriously compelling character to compulsive gambling. It is a special conscious mood of compulsive deviance that, in conjunction with the other moods, serves to reinforce and sustain identity. 


\section{BEING A COMPULSIVE GAMBLER}

As a compulsive gambler, the subject encounters a set of experiences not anticipated at the beginning of his career, as often happens in any career. The new experiences are directly related to his losing relatively large sums of money which he cannot afford to lose. Losing money did not characterize the beginning of the compulsive gambling career. Through more frequent participation the conception of gambling shifts from one of leisure to one where a sense of self-esteem is conceivable. This conceptual shift neutralizes the importance of playing mainly to win. Choosing to enhance his pleasure rather than his pocketbook, the compulsive gambler stays in the action for as long as possible. A logical result is playing until tapped out, or financially exhausted. Since compulsive gamblers are reasonably adept at playing, they could, and do, play for long periods of time-often until fatigued. Fatigue combined with overindulgence takes its toll. Betting becomes irrational, and losing results.

Financial loss is enhanced by a changing conception of money. Money becomes simply the means of staying in the action, and not the end of the action. As one compulsive gambler remarked with insight, "The size of the wager is immaterial. The whole point of money is to allow you to remain in action. Once you have no money, it's axiomatic. You're out of the action. They just push your chair away and get somebody who has some money. So you rush around to get some more, so you can get back into the action."

In commercial gambling establishments there is a clear psychological attempt to minimize the importance of money through the use of chips as pointed out by another compulsive gambler, "Chips are used because some people might be a little reticent to throw real money around. All your life you're taught that this paper is 'money' and should be taken seriously." Blaise Pascal (Polsky, 1967) describes the pool hustler in terms similar to a compulsive gambler. Staying in the action is more important than the money won or lost, but without it the game is substantially less meaningful. 
The most outstanding behavioral characteristics of compulsive gamblers in this phase of their career is their overt hostility toward society. Such hostility is related to their gambling behavior. They must make aggressive choices, and many of them while satisfying their craving for the action. Hostility is one of the traits that is so intimately related to the nature of the enterprise that anyone who participates frequently and intensively encounters a forced choice situation; the subject must be aggressive or be out of the action.

The experience of losing a large amount of money which was destined for other purposes is generally interpreted as unpleasant. Given a choice, the subject would, of course, prefer to win, but as a compulsive gambler other meanings vanquish the thought of quitting while ahead. The unpleasant experience of losing diminishes the power to dream, intruding upon more pleasant conscious moods. The loss of this power marks the beginning of identity dissatisfaction. The subject typically interprets the aftermath of losing as a moment of suffering; pain or suffering shifts the subject into a particular conscious mood serving as the mythical pinch that awakens one from a dream-like existence. The configuration of mind, self and society under this condition renders a negative evaluation of self. At such times compulsive gamblers typically say to themselves, / hate myself, or You stupid bastard.

\section{Dissonance and Deception}

The aftermath of losing constitutes a critical juncture in the career of the compulsive gambler. Resolutions are often made not to hurt oneself again in order to ease the pain of self-devaluation, but, unless the condition resembles the subject's conception of rock bottom, little energy is expended in adhering to the resolution. The function of the resolution is to resolve the dissonance. As losing continues, the dissonance increases. Dissonance also enters into the subject's psychic life through other events. Among the most prominent is the inception of deception. Deception arises in the context of increasing participation. In order to increasingly participate, more time and money must be avail- 
able to the subject. Obtaining both usually involves a host of deceptions of self and others. Some typical examples are (a) telling his friends, his family and himself he is going to the mountains to hunt, whereas he always goes there to gamble; (b) taking sick leave from work in order to gamble; (c) telling his spouse he has to work late; and (d) forging checks. Gambling that is illegal, of course, has a built-in deception.

Typical rationalizations are conjured, I deserve a little fun once in awhile, What the hell, it's harmless. Yet, the general cultural negative meaning also enters into consideration. Thus, along with the rationalization often comes a negative configuration such as I'm a bastard for doing this.

As deception emerges, it shifts the relative importance of other meanings. For instance, the notion of pure wholesome fun and sport and innocent curiosity that typically characterizes the subject's early conception of gambling becomes difficult to maintain in the light of the deception. As a consequence, the earlier meanings shift and, along with them, the subject's self-conception in relation to the enterprise.

In moments of dissonance, the subject makes an attempt to eradicate the conflict, but the conflict becomes more and more difficult to eradicate, and the compulsively deviant career becomes more and more unpleasant. This phase of the career was called "diluted suicide" by one compulsive gambler who was serving time in jail for forging because it is characterized by vain attempts to reorganize behavior in order to reduce the pain.

\section{Self-Devaluation}

At this point the subject becomes aware that something is not quite right. He cannot seem to stop hurting himself. His behavior appears automated, going through the rituals of gambling, but enjoying it less. The rituals have failed to produce any of the pleasant conscious moods. The subject perceives the real issue as the freedom to determine his own action, yet he is not ready to admit to himself that he has become compulsive about gambling. Instead, he develops what could be called an illusion of choice, the idea that he can take it or leave it, similar to drug addicts and 
alcoholics. Often the subject will consciously conceive of a new strategy for playing which would have the effect of turning losses into winnings, such as quitting while ahead. However, the problem that intrudes upon the subject's strategy is that once he becomes involved in the rituals, his perspective changes. He comes to crave the conscious moods so much that he refuses to withdraw from the game until the act is complete, and he taps out. A description of the state of mind during this stage of involvement is offered by a compulsive gambler:

$\mathrm{R}$ : The thing is in gambling, your brain, or your way of thinking is completely nil, which is hard to believe. No one would ever believe that. You can't think of nothing, and yet you can't ease your mind. If you only knew how to ease it for one-half second, you could get your senses back. Man, your mind is blown.

I: Why is it blown

R: You don't listen to people. You don't talk to people. You feel that your thoughts are either way out, or way in.

The completion of the act, which generally means losing all gambling resources, is now the mechanism that produces a sense of relief. With conflicts and dilemmas multiplying as the subject complicates his life through compulsive gambling, it becomes easier to give in to the desire to gamble rather than fight it, along with other related dilemmas.

As unglamorous and unpleasant events invade the subject's career, it becomes less pleasant to base identity on the enterprise; a firm basis for a negative self-evaluation develops. The activities that once enriched self now impoverish it, yet compulsive deviance is maintained by commitment to the rituals. The subject no longer takes an interest in other gamblers' ideas as he once did. He does not even look at their faces for fear of seeing himself. Existence is confirmed, but in a negative way; only a few bizzare moments in gambling bring to mind a sense of a meaningful existence.

Here another illusion arises-the compulsive deviant typically thinks that if he could only prove that he is actually wise rather than foolish by continued participation in an activity that causes him to suffer, then the tendencies toward negative self-evaluation 
will disappear. After moments of self-evaluation, the compulsive gambler envisions a future state of affairs in which he will look back on his deviant career as successful, but like all successful careers, laden with obstacles and setbacks that he must overcome. By renewing participation he is saying to himself that he will try again, this time a little wiser. Similar reasoning occurs among heroin addicts (Ray, 1964) ; however the sense of greater wisdom is usually short-lived.

\section{Rock Bottom}

After a series of losing aftermaths the subject develops an uneasiness about himself, quietly desperate, and in staggering financial debt. Under such conditions, the conception of trying to reorganize behavior becomes possible. However, before a serious effort is made the subject must conceive of his situation as rock bottom. Some usual events that are commonly interpreted as rock bottom are (a) actual or threatened incarceration, (b) loss of job, (c) family dissolution, and (d) near suicide. Once the social situation is conceived of as rock bottom, the subject shifts into the conscious mood of rock bottom. The conscious mood of rock bottom endures much longer than the ordinary moods of losing aftermaths. The subject knows the mood will not vanish with a good night's rest. The configuration of mind, self and society generates a depressing portrait of self. It is an image of a pitiable person. Reacting to that image, the subject feels pity for himself. There is no revitalizing fantasy, no euphoria. The poverty of the rituals yields a poverty of mysticism, but there is a strong mood of here and now and great potential for risk-taking. The subject is, in fact, psychologically overwhelmed by the here and now of his situation and the high risk of continued participation.

During moments of the conscious mood of rock bottom the subject turns witness against himself. He collaborates in building a negative portrait of himself. Stigmatizing self, the subject feels the burden and gravity of his identity. Not surprising, confusion is the normal state of existence in the face of massive self-devaluation. The process of discovering that self is performing acts which are now essentially self-defeating could be called an awakening. 
It is a rather rude awakening, presenting a stark unity of meaning that ordinarily might be ignored by the subject in order to maintain his fantasized ideal self, were it not for the gravity of the situation, making a judgment of self here and now imperative. That judgment is a renunciation of self and the deviant enterprise.

Here is the problem of the compulsive gambler in our society who is experiencing the conscious mood of rock bottom. He is a loner, does not open himself up easily to others, and has done many things he believes few would do or understand. He is down on himself, depressed and groping mentally for some answer to his problems. One young man who jumped off the Golden Gate bridge in 1967 left a note saying, "the cards, always the cards." Such is the configuration of mind, self and society that a sense of being hopelessly determined pervades his being. Matza (1969) describes this state of existence:

So unusual and pathetic are literal determinisms in the world of the subject, so unaccustomed are we to actual captivity that, rightly, we ponder the need for therapy and understandably, though perhaps wrongly, we conceive the condition as illness. A more modest concept of unease would have been more to the point since the feeling experienced by the captive subject is disquieting and strange. Unaccustomed to so tight a grip, confused by the periodic waning of intention, frightened by the inhuman sense that he is not conscious of a reason for his behavior, the subject himself experiences the condition of unease. It is not so much the behavior itself that necessarily strikes him as strange; more precisely, it is the lack of a sensed relation between himself and the thing being done. For good reason, the subject expects intention and exists in consciousness. That is his nature, and that all social organization and normative life is built on those assumptions is no denial of man's natural condition; it is the most compelling confirmation.

The enterprise which has become so utterly meaningful to the subject loses its sympathetic magic; in other words, it now fails to do the thing that it seemed to do the best-turn the subject on. Without being turned on, the subject begins to have major doubts about his existence, but this time without letup. The letup, the dream world where he could rescue some self-esteem has proven to be more of an anchor than a lifesaver, carrying him straight down to the abyss. What could have gone wrong? is one 
of the clearer questions the subject is now capable of formulating in a situation that renders a bleak configuration of mind, self and society. The boundaries of self during the conscious mood of rock bottom are draped around monsters that resemble the subject. More disturbing to the mind is the inability to gather mentally, and with ease, the boundaries, and place them around a more inspiring scene. The subject is unable to shift.

\section{A Note on Methodology}

After completion of the first two-year study of gambling in general, the writer expanded his research interests to include an intensive study of the deviant gamblers, those who seem to gamble compulsively. With sufficient observational experience it became possible to recognize different playing styles such as the compulsive and the professional. He extended himself socially to those whom he identified as compulsive gamblers, and became casual friends with several who gambled regularly where he was conducting research.

In the course of researching gambling, the writer played various games of chance, including several types of card games, dice, roulette, horse-racing, slots, keno and bingo. In four years, over 200 hours of playing time were logged. He observed and played in six commerical card parlors in California where gambling is legal at the discretion of the municipalities. Twenty visits were made to casinos in the Lake Tahoe-Reno, Nevada, area, and five visits to Las Vegas.

In order to gain greater access to compulsive gamblers, permission was obtained from the San Francisco chapter of Gamblers' Anonymous, which is modeled after Alcoholics' Anonymous. In studying Gamblers' Anonymous, seven months were spent attending their weekly meetings, and several informal visits were made at a later time. Taped interviews were conducted with twenty-five regular and occasional members, averaging about two hours per interview. About twelve GA members visited the writer's home for friendly conversations on gambling and their experiences as well as the functioning of GA. Since systematic appreciation derives from proximity, the writer chose to get close 
to the subjects. They lived and relived gambling experiences together. Much of the content of this study was presented to a formal meeting of GA as a measure of the writer's ability to render faithfully compulsive gambling. They recognized themselves in his rendition.

\section{SUMMARY}

This paper began with an examination of compulsive deviance as a sociological concept. The study of compulsive deviance is presently out of the mainstream of the sociology of deviance, due largely to the rejection of the medical model suggested by the term. Nevertheless, the term identifies a pattern of social behavior that can be studied along career lines. Compulsive gambling is one example.

The conscious mood perspective was introduced as a useful theoretical tool for rendering faithfully the process of becoming a compulsive gambler. In order to facilitate the application of the conscious mood perspective, the concept shift was redefined as the alignment of the boundaries of self according to a given normative referent. Contained within this perspective is a conception of consciousness as continuum. The subject conceptualizes the social situation as a range of possible conscious moods entailed by the alternative identities and associated behaviors he encounters.

Without experiencing certain conscious moods, the subject is unlikely to undergo shift sufficiently to become a compulsive gambler. Five major conscious moods that the subject ordinarily must encounter in order to become a compulsive gambler were identified and described. They are (1) risk-taking, (2) here and now, (3) fantasy, (4) euphoria and (5) mysticism. As a compulsive gambler, the activities of the game take on ritualistic meaning, which in turn serves to sustain total commitment to the gambling enterprise.

A total commitment to the gambling enterprise is associated with unanticipated and undesirable career contingencies that make the life of a compulsive gambler problematic. The most important problem is the loss of money. The dream world lifestyle of the compulsive gambler becomes painful as the subject 
experiences the conscious mood of rock bottom. Further research is needed in order to determine the applicability of the conscious mood perspective in explaining other forms of compulsive deviance.

\section{REFERENCES}

Adler, N.: Ritual, Release, and Orientation: The Maintenance of the Self in the Antinomian Personality. Paper presented at the conference, Marginal Religious Movements in America Today. Princeton University, April, 1971 , pp. 6-7.

Alexander, N. C., Jr., and Knight, G. W.: Situated identities and psychological experimentation. Sociometry,34:65, 1971.

Allport, G. W:i Personality: A Psychological Interpretation. New York, Holt and Company, 1937.

Becker, G. S.: Irrational behavior and economic theory. / Polit Econ, LXX (1):1, 1962.

Berger, P., and Luckman, T.: The Social Construction of Reality. New York, Free Press, 1963.

Bergler, E.: The Psychology of Gambling. New York, Hill \& Wang, Incorporated, 1957.

Bloch, H. A.: The sociology of gambling. Am J Saciol, 57:215, 1951.

Cotler, S. B.: The use of different behavioral treatment in treating a case of compulsive gambling. Behav Ther ${ }_{2} 2: 579,1971$.

Cressey, D. R.i Role theory, differential association, and compulsive crimes. In Cressey. D. R., and Ward, D. A.: Delinquency, Crime and Social Process. New York, Harper and Row, 1969, pp. 1114-1128.

Fenichel, O.: The Psychoanalytical Theory of Newrosis, New York, W. W. Norton, 1945.

Freud, 5.: Collected Papers. London, Hogarth, 1925.

Goffman, E.: Asylums. New York, Doubleday, 1961.

Goffman, E: Where the action is. In Goffman, E.: Interaction Ritual: Essays in Face-to-Fece Behavior. Chicago, Aldine, 1967, pp. 149-270.

Gusfield, J. R.: Moral passage: The symbolic process in public designation of deviance. Soc Prob, $15: 178,1967$.

Hunter, J., and Bruner, A.: Emotional outlets of gamblers. / Abnorm Soc Psychol, 23:38, 1928.

Kennedy, R. F.: The baleful influence of gambling. In Herman, R. D.i Gambling. New York, Harper and Row, 1967, p. 169.

Klapp, O. E.: Collective Search of Identity. New York, Holt, Rinehart and Winston, 1969.

Luughlin, H. P.: The Neurosis of Clinical Practice. Philadelphia, W. B. Sanders, 1956.

Lemert, E. M.: Human Deviance, Social Problems and Social Control. Engle- 
wood Cliffs, Prentice Hall, 1967.

Lemert, E. M.: Social Pathology. New York, MoGraw-Hill, 1951.

Lindner, R. M.: The psychodynamics of gambling. Ann Am Acad Polit Soc Sci, 269:93, 1950.

Lorber, J.: Deviance as performance: The case of illness. Soc Prob, I4:302, 1967.

Martinez, T.: Deviance and shift: A sociological study of gamblers and gambling, unpublished Ph.D. dissertation, 1971.

Maslow, A. H.: Motivation and Personality, 2nd ed. New York, Harper and Row, 1970.

Maslow, A. H.: Peak experiences as acute identity experiences. Am J Psychoanal, 21:254, 1961.

Matza, D.: Becoming Deviant. New York, Prentice-Hall, 1969.

McGlothlin, W. H.: Stability of choices among uncertain alternatives. Am J Psychol, LXIX.604, 1956.

Mead, G. H.: The Philosophy of the Present. Chicago, Open Court, 1932.

Messinger, S. et alli Life as theater: Some notes on the dramaturgic approach to social reality. Sociometry, 25:98, 1962.

Morehead, A. H.: The professional gambler. Ann Am Acad Polit Sci, 269:81, 1950.

Morris, R. P.: An exploratory study of some personality characteristics of gamblers. / Clin Psychol, l3:191, 1957.

Parsons, T.: Consciousness and symbolic processes. In Abramson, Harold A.: Problems of Consciousness. New York, Corlies and Macy, 1954, pp. 45-55.

Polsky, N.: Hustlers, Beats and Others. New York, Doubleday, 1967.

Ray, M. B.: The cycle of abstinence and relapse among heroin addicts. In Becker, Howard S.: The Other Side. New York, Free Press, 1964, pp. 163178.

Sane, J. P.: Existentialism and Human Emotions. New York, Philosophical Library, 1957.

Shibutani, T.: Society and Personality. Englewood Cliffs, Prentice-Hall, 1949.

Sullivan, H. S., in Perry, H. S., and Gawel, M. L.: The Interpersonal Theory of Psychiatry, New York, W. W. Norton, 1953.

Thomas, W. I-, and Znaniecki, F.: The Polish Peasant in Europe and America. New York, Alfred A. Knopf, 1927. 


\section{Chapter 22}

\section{EXCITEMENT: THE GAMBLER'S DRUG}

Winumar H. BOYD

HOR OUR PURPOSES GAMBLING is defined as participation in an event of uncertain outcome in which something of value is risked. Therefore, a gambler is defined as one who participates in gambling as defined above. Gamblers can be divided into two groups, pathological and nonpathological. The pathological gambler differs from the nonpathological gambler in many ways; two differences are that he gambles too much and loses too much.

Gambling of a pathological kind is a symptom of something being wrong in the gambler's personality. Gambling functions as an illusory treatment for this problem. Since it is a symptom like fever, which is a symptom of many disorders, then it follows that the cause of pathological gambling can never be discovered because the problem is not the symptom (gambling), but the underlying disorder.

Gambling produces excitement and involves a complex mental activity as opposed to the other addictions which usually involve a physical substance, e.g. heroin. The mental activity, which is a fantasy trip, may involve anything concerning gambling, ranging from planning a trip to Las Vegas to formulating a complex system employed to insure winning, to grandiose plans involving spending the winnings. This and the excitement involved blot out unpleasantness such as depression, and provide a sense of power, control and triumph in the face of helplessness and despair.

It is fruitless to try to discover, generally, the cause of compulsive or pathological gambling; however it is not fruitless to try to discover why a particular person gambles pathologically. Of particular importance in influencing a person's addictive gambling are the phenomena of beginner's luck and the history of a rela- 
tive, and particularly a parent, who gambled. Stresses have also been found such as the death of a parent, sibling or relative; the birth of a first child; the loss of a business; a divorce; and, paradoxically, successes, e.g. promotions or the buying of a new house, may precipitate pathological gambling. Then there are the secondary complications such as financial loss, marital problems and family difficulties which produce more stress which causes the gambler to gamble more in the style of a vicious cycle. It is these complications that usually bring the gambler into treatment with such symptoms as depression, suicide attempts, etc. It is convenient to look at pathological gambling in three tiers. First, there is something wrong with the personality. Second, gambling is sought as a sort of treatment or relief. Thirdly, it is the complications of the gambling involving the former in a vicious circular way, which bring the gambler into treatment.

Excitement is the sought after commodity in gambling. It is present from the moment the bet is made, perhaps even in anticipation of placing a bet, until the final outcome; then there is a rapid decline. Money is only the ticket to this game in which excitement is sought; therefore, winning or losing are relatively unimportant. Winning, of course, is desired for at least one reason, as opposed to losing; money is needed to enter the game. This excitement or state of euphoria is addicting, and, since it is so short-lived, it necessitates being repeated. Excitement is the state of euphoria, of power, of triumph and of control. In this state of mind the gambler is the master of his fate and all else is excluded. He is lost in a world of his own where everything is possible and the sky is the limit. There is no longer an outside reality. He is immersed in his own inner world where the odds do not apply to him. Even time is nonexistent, and in a certain sense he is insane in that he cannot evaluate his behavior in order to adapt to or take advantage of reality. In this case the reality means he cannot win because the mathematical odds are against him. The size of the bet needs to be appropriate to stimulate each gambler according to his own personality; that is, there must be enough wagered to make it a risk for that person. Money is not appreciated, at least it is not appreciated in the same way as it 
might be by someone else. It is not felt to be something that will bring him pleasure in itself or through other means such as purchasing something long-desired. It is good only for one purpose, and that is to gamble. This is illustrated by a comment made while discussing a wealthy person who gambles heavily, but whose business is such that his money supplies are continually replenished. The comment was, in effect, "What couldn't / do with that money?" This indicates the possible pleasure involved in spending it. This is not available to the gambler. If he could gain pleasure through other sources, such as a feeling of satisfaction, then perhaps he could stop when winning and curtail his losing; he would then have a different appreciation of money. However, insofar as he feels that it is only useful as a ticket to gambling, then it becomes useful only for that and nothing else. It seems that to appreciate money would be akin to having a broader awareness of its worth; that is like an elevation of consciousness that would be toward external reality rather than toward himself and his masturbatory and autistic-like activity.

How does the pathological gambler become addicted to excitement in the first place? What are the underlying factors in his personality? Gambling seems to be related to the addictions which produce something of a state of euphoria, excitement and such, like the manic phase of the manic-depressive illness, only not as disintegrating. It seems that there are other states in which this state of mind plays an important part; homosexuality, alcoholism and drug addiction come to mind. The sensation may not be the same in each of these unless one also talks in terms of relief of some intolerable state which could be described as a form of anxiety, boredom, etc. Of course there is always a specificity for each of the above conditions which is why one is chosen rather than the other. Of particular significance is the possible identification with a parent gambler. If the gambler, as in the states above, is searching for some kind of relief, then it brings us back to what must be an inability to find pleasure, satisfaction or usefulness in his relationships. Rather, he must experience them as in some way demanding from or abusing him; this is so profound that in no way, for example, can he value the woman he married because 
she is not the same as the woman he knew before. As he gets to know her better, his fantasy of her as the ideal person of his dreams collapses, and she becomes familiar in another way; that is, she is reminiscent of a person he once knew. She is perceived only as one who is inhibiting and critical, and like a stone around his neck-a constant reminder of every negatively experienced person or aspect of himself.

The essence of gambling is to avoid pain-that is, to replace this with the thrill or excitement. There is a replacement of something with something else-a changed mental state. He is mentally immersed in thoughts and schemes, anticipating gambling, and bathes in the imagined luxury of his winnings with which he does many grandiose things. The more intense this is, the more likely he is to be a pathological gambler. Why does the gambler choose gambling rather than another activity which could produce excitement or relieve anxiety? Sometimes the gambler even picks the same game as the parent who gambled. In one instance a gambler felt closest to his father while with him at the race track. He had little relationship with him elsewhere in his life. Thus, the track experience recaptured this part of the relationship and emphasized this in a magical, illusory way, de-emphasizing the bad part of the relationship. The reader is perhaps familiar with the human trait of consciously remembering what is pleasant and forgetting the unpleasant. When not gambling there is a return to an unpleasant mental state with unconscious determinants responsible for this, so, in an emotional way, a certain aspect of the relationship was resuscitated and the other denied. When not gambling, he feels the negative feelings such as boredom and a subtle insidious depression. To get to the root of this problem, obviously, the gambler must open himself to re-experiencing his pain that emanates from unconscious sources unavailable to him. With gambling as the illusory kind of treatment there is a strong tendency to return to the excitement, like an addict. This follows the principle existing in infancy of the organism seeking to relieve itself of pain, tension or displeasure-in order for pain to be tolerated there must be an experience of satisfaction associated with or related to it so that waiting or frustration can be toler- 
ated. If not, then the mental apparatus seeks to rid itself of pain in the only way possible, and that is through the construction of fantasy, probably in proportion to the pain. This fantasy is, as it is labeled, unrealistic-that is it does not conform to reality. The misperception of reality works on the other side also. It is not just pain or frustration felt within himself, but rather attributed to his environment so that he feels surrounded by pain-producing objects (persons) who are out to do him harm. Infantile fantasy persists unconsciously into adult life so that the gambler ceaselessly looks for what he thought once existed. It was useful for him as an infant since he was helpless and not equipped to deal with the pain in any other way as an adult would, but as an adult, it is archaic; the fantasy persists and results in his endless search for this ideal, ecstatic experience. The above, then, sheds some light on why the gambler seeks treatment only when desperate, and doesn't stay, especially when he feels better. His main emphasis is on defense, or to rid himself of displeasure rather than using a relationship for anything other than a toilet, for example, for pleasure. Therefore, perhaps we can understand the preference for gambling over sex. Sex involves a relationship with another person and is pleasurable. It falls short, other than producing biological relief, because the gambling itself is a primitive sexual (pleasure) state which takes precedence, and has other features such as privacy, solitude, control, manipulation and specificity, as well as offering a way to avoid contact with another person who has a mind of his own. 



\section{Part Five}

\section{THE MATHEMATICS DF GAMBLING}





\section{INTRODUCTION}

The way in which a mathematician approaches the study of gambling differs substantially from that of a social scientist. Instead of concerning himself with the behavior of the individuals or institutions surrounding gambling, or the complex moral and ethical issues raised by gambling, the mathematician examines the structures and rules of the games, estimates probabilities for winning and expected returns under various contingencies, and devises strategies which will fulfill certain objectives. In other words, gambling games are like puzzles waiting to be solved. Some, like craps, roulette and slot machines, offer too little choice or variety of situations to allow for the development of interesting or winning strategies. Others, like blackjack, poker and Faro, are rich enough in complexity, variation of circumstances and player choice to provide the opportunity for considerable strategic analysis. However, the games are often so complicated that, in the past, fruitful analysis had to wait until the age of the computer when high-speed computations and intricate model simulations could be carried out. This is the background of the articles of this section.

In Nevada's casinos, the game of blackjack plays a very important role in gaming operations, accounting for about 25 percent of total casino winnings. The game itself is relatively easy to play and can be learned in a matter of minutes; however, a novice gambler at blackjack will probably lose between 5 percent and 10 percent of his total money wagered to the casino in the long run. Because blackjack is played with a deck of cards, and because the actual probabilities of winning or losing depend upon the composition of the deck of cards from which the next hand is to be dealt, the information derived from observing the cards that have already been played can be used to revise the probabilities of winning and losing under different circumstances. Therefore, by betting large when the probabilities are in favor of the player, and small when they are against him, the player can 
theoretically turn the long-run expected value of the game in his favor.

This is the basic idea behind most so-called card-counting strategies in blackjack and other card games. In blackjack the

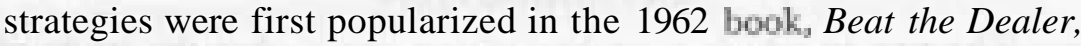
by Edward O. Thorp. Since that time a number of revisions and refinements on the Thorp strategies have been published, some of them improvements, and others mathematically fraudulent. The effect of the appearance of the blackjack strategies on Nevada gambling was two-fold-since casino owners realized there was finally a casino game which theoretically could be beaten in the long run, they feared the gambling tides would quickly turn against them; and since many players realized there was a casino game which theoretically could be beaten, their interest in gambling was increased appreciably. What actually happened was neither a boon to the players nor a disaster to the casinos. The houses' average win per bet on blackjack probably dropped slightly because of better players, but total casino winnings probably increased overall because of the stimulated interest and play in the game. It is rumored that Dr. Throp, et al., have done very well in the sale of their books, however.

The articles in this section are not for the casual reader who wants to learn how to win at blackjack. Rather, they represent sophisticated applications of mathematical techniques to the problems posed by complex gambling games. In the article by Edward Gordon, optimal strategies are devised for four-deck blackjack games using the analytical process of dynamic programming. A deck composition index is devised and decision rules are developed for playing blackjack based on the value of the index. The decision rules are compared to the strategies of Thorp and others, and expected values are computed for the strategy under various conditions. The strategy is then tested against a computer simulation of over a million hands played with four decks; the expected gain to the player is estimated at 1.36 percent of the total amount wagered.

Blackjack is also the subject of analysis of the article by James N. Hanson. Instead of generating a deck composition index based 
on only a few characteristics, such as the number ofaces, tens and non-tens in the deck, Hanson uses thirty composition parameters to apply to both playing and wagering strategies. Using nonlinear programming techniques, an optimal playing strategy is devised, then applied to various wagering strategies. Also, the parameters are checked for their sensitivity on the rate of return. Among the results derived by Hanson are that incorporating information on all thirty parameters theoretically increases the expected return at blackjack from Thorp's 1.28 percent to 1.95 percent. Then, by seeking out an optimal wagering strategy (with no maximum wager limit), the expected return can be raised to about 7.1 percent, but only at the expense of a falling expected median outcome and a higher probability of ruin. In generalizing his results the author states that these techniques could be applied to deterministic games in general as well as to other large stochastic problems.

The article by Peter Griffin looks at some simple card games and how playing strategies can be improved by assimilating information from the cards already used. Simplified games or pseudogames are devised to evaluate playing strategies under particular circumstances. How often the information on cards played will alter the best decision over the no-information situation is computed. The results of the pseudogames are compared to actual blackjack decisions and are found to be highly applicable to optimal blackjack strategies. The information from the pseudogames is then used to evaluate a number of popular blackjack card-counting strategies in terms of how often they tell the player the right thing to do, and the value of perfect information relative to the specific card-counting strategies is estimated.

The card game of Faro was one of the early popular games in Nevada gambling, but has become nearly extinct in modern casinos. A fairly simple game, it is played with a deck of cards and has a layout consisting of the thirteen card denominations. Players would bet on a card, and then, after dealing an inconsequential (soda) card, the cards would be dealt one by one from then on and would alternate between winning and losing. If the dealer dealt two in a row of a particular card, he would win half the 
amount bet on that card. In the final article of this section, Edward O. Thorp examines the basic wagers at the game of Faro and estimates the player's expected loss on the various wagers; he concludes that, by taking proper advantage of zero expectation bets, the player can reduce the house's advantage to well under 1 percent. Thorp then discusses the possible effects of nonrandom shuffling and how information about it could affect strategies and expected returns at Faro and other games such as blackjack. 


\title{
Chapter 23
}

\section{DPTIMUM STRATEGY IN BLACKJACK - A NEW ANALYSIS}

\author{
EDWARD GORDON
}

\section{INTRODUCTION}

THE MODERN SCIENTIFIC TREATMENT o£ blackjack strategies starts with the paper by Baldwin et al. published in 1956. In contrast to craps and roulette, which were analyzed centuries ago, the effective application o£ probability and optimization theory to blackjack had to await the availability of high speed computers. The Baldwin strategy is based upon the dealer and one player drawing one hand from a full deck. It was found that the player's expectation was -.006 . The subsequent interest stems from the fact that this expectation is more favorable than any other casino game (Wilson, 1965a) .

The expectation of more recent blackjack strategies has been improved by the introduction of deck composition indices. Thorp's (1962) tens ratio was the first of the scientific deck composition indices, and with a strategy which varied with the composition index the player could achieve a positive expectation. The more significant recent studies were reviewed by Wilson (1965b) .

Many casinos have gone from a single-deck game to double or quadruple-deck games, thus reducing the gain for anyone using an optimal single-deck strategy. The loss to the player comes from the fact that multiple decks give the player a somewhat less favorable expectation (Thorp, 1962) . In addition, a strategy optimized for a single deck need not be optimum for a multiple-deck game. Other casinos have experimented with rules changes, but the major change which has survived without adverse customer reaction of major proportions is to have the dealer hit on a soft 17 . 
This rule is followed at many of the downtown Las Vegas casinos. Many players think it favors them although it causes a loss in expectation of .002 (Thorp, 1962) .

The strategies reported in this paper were determined using an optimization technique based upon dynamic programming (Bellman and Dreyfus, 1962). The technique used will be described following the definition of the deck composition indices studied and their effects on the probability distribution for the next card drawn. The analysis used the simplifying assumption that the deck has so many cards that the dealer is faced with the same value of the deck composition index as the player, and, consequently, the card probability distributions are the same for both.

\section{DECK COMPOSITION REPRESENTATION}

The Thorp tens ratio is simply the ratio of non-tens to tens among the cards as yet unseen by the individual doing the counting. The procedure he recommends is to start at 36 for nontens and 16 for tens in a full single deck, and deduct one from the appropriate tally for each card seen (Thorp, 1962). For a fourdeck game, the initial numbers would be 144 to 64 respectively. Many players find it difficult to keep track of two independent tallies while playing blackjack.

Wilson (1965b) introduced a single point-count system based upon the observation that the most favorable cards for the player are aces and tens. To provide a balanced count, i.e. zero count for a full deck, each ace remaining was assigned a point value of four. For example, four decks contain 64 tens, 16 aces, and 128 other cards yielding a point value of $1 * 64+4 * 16-I^{*} 128=0$.

Another point-counting system is the high-low index attributed to Dubner by Wilson (1965b) . In that system the high cards consist of aces and tens equally weighted. To provide a balanced count, only twos through sixes are included in the low cards.

The deck composition representation used in this study is a variation on the Dubner high-low index with only tens considered as high cards, and the low group is limited to two to fives to provide a balanced count. Aces are separated from tens since their 
characteristics are very different, and it is desirable to separately determine their effects.

The key piece of information used in describing deck composition is the excess of low cards seen over tens. When the play is honest, the total number of low cards and tens is equal. Hence, UE, the excess of tens over low cards as yet unseen is the same as the excess of low cards seen. Let NL represent the total number of tens and low cards as yet unseen. The primary index used in the analysis is

$$
\mathrm{n}-5+4 * \mathrm{UE} / \mathrm{NL}
$$

If all of the low cards have been seen, the excess, UE, is equal to NL and the index takes on its maximum value, 9, whereas if all of the tens have been seen, the excess, UE, is equal to $-\mathrm{NL}$ and the index is equal to 1 . For a balanced deck, UE equals zero and the index value is 5 .

In general, UT, the number of tens in the unseen cards is $\mathrm{NL}(1+(\mathrm{n}-5) / 4) / 2$ which simplifies to

$$
\mathrm{UT}=\mathrm{NL}(\mathrm{n}-1) / 8
$$

while the number of unseen low cards is

$$
\mathrm{UL}=\mathrm{NL}(9-\mathrm{n}) / 8
$$

These relationships satisfy the identities

and

$$
\mathrm{UT}+\mathrm{UL}-\mathrm{NL}
$$

$$
\mathrm{UT}-\mathrm{UL}=\mathrm{UE}
$$

It is convenient to introduce an index, NA, relating the number of unseen aces, UA, to NL as follows:

$$
\mathrm{NA}=1+16^{*} \mathrm{UA} / \mathrm{NL}
$$

Hence, NA is 1 when there are no aces left, and it is 3 when the deck is of normal proportions, i.e. $\mathrm{UA}=4$ and $\mathrm{NL}=32$. Values of NA up to 5, i.e. double the normal proportion of aces, were considered in the study. We also introduce the index, $\mathrm{NI}_{2}$ for the intermediate cards (6's through 9's) relating the unseen number, $\mathrm{UI}$, to NL as follows:

$$
\mathrm{NI}--1+8 * \mathrm{UI} / \mathrm{NL}
$$

The total number of unseen cards is the sum of the number unseen for each type:

$$
\mathrm{UC}=\mathrm{UT}+\mathrm{UL}+\mathrm{UA}+\mathrm{UI}
$$


Solving equations 6 and 7 for UA and UI respectively and substituting in equation 8 yields

$$
\mathrm{UC}=\mathrm{NL}+\mathrm{NL}(\mathrm{NA}-1) / 16+\mathrm{NL}(\mathrm{NI}+1) 8
$$

which can be simplified to

$$
\mathrm{UC}=\mathrm{NL}\left(17+\mathrm{NA}+2^{*} \mathrm{NI}\right) / 16
$$

\section{PROBABILITY DISTRIBUTIONS}

The probability distributions which play the dominant role in the analysis are those regarding the next card drawn from the deck and possible outcomes for the dealer when he follows his prescribed rules.

\section{A. Single Card Probabilities}

Assuming that all cards as yet unseen have equal changes of being drawn as the next card, then the desired single-card probabilities are equal to the proportion of the type of card in the as yet unseen cards. For example, the probability of drawing a ten, $\mathrm{P}(10, \mathrm{n})$ can be determined as follows

$$
\begin{aligned}
& \mathrm{P}(10, \mathrm{n})=\mathrm{UT} / \mathrm{UC}=\frac{\mathrm{NL} / \mathrm{n}-1) / 8}{\mathrm{NL}(17+\mathrm{NA}+2 * \mathrm{~N})} \\
& \text { from equations } 2 \text { and } 10 \text {. This can be simplified to } \\
& \mathrm{P}(10, \mathrm{n})=2(\mathrm{n}-1) /(17+\mathrm{NA} 2 * \mathrm{NI})
\end{aligned}
$$

Similarly, using equations 6 to 10 the probability of drawing an ace is

$$
\mathrm{P}(1, \mathrm{n})=\mathrm{UA} / \mathrm{UC}-(\mathrm{NA}-1) /(17+\mathrm{NA}+2 * \mathrm{NI})
$$

Since the low card group is made up of twos, threes, fours and fives, we do not have any explicit information about each of these face values individually. However, if we assume each is equally likely, then the probability of drawing a low card with face value, $\mathrm{i}$, is

$$
\mathbf{P}(\mathrm{i}, \mathrm{n})=(\mathrm{UL} / 4) / \mathrm{UC}=(1 / 2) \quad(9-\mathrm{n}) /(17+\mathrm{NA}+2 * \mathrm{NI})
$$

For the intermediate card group, introducing the equally likely assumption yields as the probability for $\mathrm{i}=6,7,8$ or 9 $\mathrm{P}(\mathrm{i}, \mathrm{n})-(\mathrm{UI} / 4) \mathrm{UC}=(1 / 2)(\mathrm{NI}+1) /(17+\mathrm{NA}+2 * \mathrm{NI})$

To reduce the computational effort, entries were determined for the $\mathrm{P}(\mathrm{i}, \mathrm{n})$ matrix for $\mathrm{i}$ from 1 to 10 and $\mathrm{n}$ from 1 to 9 for the specified combination of values of NA and NI. These probabili- 
ties were used in the calculations described below to produce the desired results. The calculations were then repeated for another NA and NI combination until all combinations of NA from 1 to 5 and NI from 1 to 5 were covered.

\section{B. Dealer Outcome Probabilities}

It is convenient to designate the dealer outcomes in terms of an index, $i$, where the outcome is $16+i$. The index value, $i=6$, designates the situation in which the dealer has a total in excess of 21 regardless of the actual total. The entries in the dealer outcome probability matrix $\mathrm{D}(\mathrm{i}, \mathrm{j}, \mathrm{n})$ are developed utilizing two intermediate matrices, $H(i, j)$ and $S(i, j)$.

Although the dealer's up card index, $\mathrm{j}$, can only take on values from 1 to 10 , it is more efficient to start with $\mathrm{j}$ equal to 21 and work down from there. If we let $\mathrm{H}(\mathrm{i}, \mathrm{j})$ be the probability that the dealer will end up with outcome, $i$, if he now shows a total, $j$, then $\mathrm{H}(\mathrm{i}, 16+\mathrm{i})$ is equal to I. This follows because it is certain that, if he follows the rules, he will remain with whatever total in excess of 16 he has. Consequently, all other $\mathrm{H}$ values are zero when $\mathrm{j}$ is more than $\mathbf{1 6 .}$

If the dealer has a total of 16 , then for i from 1 to $5, \mathrm{H}(\mathrm{i}, \mathrm{I6})$ is equal to $\mathrm{P}(\mathrm{i}, \mathrm{n})$ since these outcomes result from the addition of a single card whose probability is $\mathrm{P}(\mathrm{i}, \mathrm{n}) \cdot \mathrm{H}(6,16)$ is equal to the sum of $\mathrm{P}(6, \mathrm{n})$ to $\mathrm{P}(10, \mathrm{n})$ since each of the single cards in excess of 5 produces a total in excess of 21 . Moving to lower values of $\mathrm{j}$, the computation considers both direct and indirect consequences. The direct consequences are those which yield a total $(j+k)$ of 17 or more with the addition of a single card of face value, $k$, and hence probability of occurrence, $P(k, n)$. The indirect consequences stem from a total $\mathrm{j}+\mathrm{k}$ less than 17. With the sequential downward progression of rows in the $\mathrm{H}$ matrix, the required information is available regarding these $\mathrm{j}+\mathrm{k}$ totals less than 17. Hence, one can add to the direct contribution the sum of products $\mathrm{P}(\mathrm{k}, \mathrm{n}) * \mathrm{H}(\mathrm{i}, \mathrm{j}+\mathrm{k})$ from $\mathrm{k}$ equal to 1 up until $\mathrm{j}+\mathrm{k}$ is equal to 16.

After $\mathrm{j}$ equal to $\mathbb{1 1}$ is reached, it is necessary to consider the possibility that an added ace is valued at 11 rather than 1 . For 
this purpose, the matrix $S(i, j)$ is used where $S(i, j)$ is the probability ofan outcome with index, $i$, when the dealer has a softtotal equal to $\mathrm{j}$. As in the case of the $\mathrm{H}$ matrix entries, the entry in the $\mathrm{S}$ matrix is equal to one when $\mathrm{i}$ is equal to $\mathrm{j}-16$ and $\mathrm{j}$ is a total for which the dealer must stand. For the casinos on the Strip in Las Vegas, the dealer must stand for any soft total of at least 17. Hence, $S(1,17)$ is equal to one in this analysis. The downward progression is similar to that for the $\mathrm{H}$ matrix except that a total $\mathrm{j}+\mathrm{k}$ in excess of 21 results in moving to the corresponding entry for $\mathrm{H}(\mathrm{i}, \mathrm{j}+\mathrm{k}-10)$ rather than switching to $\mathrm{i}$ equal to 6 as one would for a hard sum in excess of 21.

When the entries for the $S(i, j)$ matrix are completed down to $\mathrm{j}$ equal to 11 , the $\mathrm{H}(\mathrm{i}, \mathrm{j})$ matrix can be extended down to values of $\mathrm{j}$ less than 11. The relationship used can be written

$$
\left.\mathrm{H}(\mathrm{i}, \mathrm{j})=\mathrm{P}(\mathrm{l}, \mathrm{n})^{*} \mathrm{~S}(\mathrm{i}, \mathrm{j}+\mathrm{ll})+\underset{\mathrm{k}=2}{\mathrm{r}} \mathrm{P}(\mathrm{k}, \mathrm{n})^{*} \mathrm{H}(\mathrm{i}, \mathrm{j}+\mathrm{k}) \mathbf{C}\right)
$$

The desired probabilities $D(i, j, n)$ are equal to the value of $H$ $(i, j)$ computed for the corresponding value of $n$ except when the possibility of the dealer having a natural (10 plus ace) exists. When the dealer does have a natural, the player does not have an opportunity to draw additional cards, and the dealer's outcome becomes known with certainty. Hence, the probability matrix $\mathrm{D}(\mathrm{i}, \mathrm{j}, \mathrm{n})$ would never be used under those conditions, and the probabilities must be adjusted. Thus

$$
\mathrm{D}(\mathrm{i}, 10, \mathrm{n})=\mathrm{H}(\mathrm{i}, 10) /(1.0-\mathrm{P}(1, \mathrm{n}))
$$

except when $\mathrm{i}$ is equal to 5 and

$$
\mathrm{D}(5,10, \mathrm{n})=(\mathrm{H}(5,10)-\mathrm{P}(1, \mathrm{n}) /(1.0-\mathrm{P}(1, \mathrm{n}))
$$

Similar expressions apply for $\mathrm{j}$ equal to 1 (dealer has ace showing), with 1 replacing 10 and 10 replacing 1 in equations 17 and 18.

\section{PLAYER'S DECISION ALTERNATIVES}

The play is assumed to follow Las Vegas rules as they have been described by Baldwin et al. (1956) .

The decision alternatives addressed in this study are limited to the alternatives available to the player when he knows that the 
dealer's up card is $j$, the sum of the player's two cards is $k_{a}$ and the high-low deck composition index is $\mathrm{n}$. The composition indices NA and NI are presumed to be fixed in each case studied. Alternatives available to the player which are beyond the scope of this study include the choice of unit bet size and its variation with deck composition indices. Wilson has considered these questions at some length (Wilson, 1965b). The bet size and its variation with deck composition do not affect the optimal playing strategy for a given situation $(j, k, n)$, and will not affect the study results or the conclusions reached.

If the player's sum, $\mathrm{k}$, results from a pair, the player has the option of splitting the pair yielding two new sums, each one-half the previous value of $\mathrm{k}$. If one of the player's cards is an ace and it can be counted as eleven without exceeding a total of 21 , then the hand is soft. If both of the cards are aces, the usual decision will be to split the pair and draw one card to each ace. The analysis is subdivided into three facets:

1. Preliminary activities

2. Hit versus stand decisions

3. Doubling and pair splitting decisions.

\section{A. Expecting Gain from Preliminary Activities}

The first action which the player normally takes after being dealt his hand of two cards is to determine if he has a natural, i.e. an ace plus a ten or face card. If he does have a natural, he is expected to turn over his cards prior to any other action. Similarly, if the dealer has a ten showing, i.e. $j=10$, he checks to see if his down card is an ace, i.e. $\mathrm{i}=\mathrm{l}$. If the dealer does have an ace, he must declare it and all player hands which are not naturals lose. The contributions to the player's expected gain from each of the above possibilities can be evaluated as follows. The probability that the dealer has an up card of ten is $\mathrm{P}(10, \mathrm{n})$, and the probability that his down card is an ace is $\mathrm{P}(1, \mathrm{n})$. Consequently, the desired joint probability is $\mathrm{P}(10, \mathrm{n}) * \mathrm{P}(1, \mathrm{n})$. The player can obtain a natural in the same way a well as in the reverse order. Since the simplifying assumption is being made that the arrival of 
any card does not affect the probabilities of the cards that complete that hand, the probability that the player has a natural is $2 * P(10, n) * P(1, n)$. The contribution to the expected gain from the player having a natural at a payoff of $3: 2$ is

$$
\mathrm{x}(21, \mathrm{n})-3^{*} \mathrm{P}(10, \mathrm{n})^{*} \mathrm{P}(1, \mathrm{n}) *(1-\mathrm{P}(10, \mathrm{n}) * \mathrm{P}(1, \mathrm{n}) * 2)
$$

The factor of two was introduced inside the parentheses to allow for the possibility that the dealer's up card, $j=1$, and his down card, $i=10$, and vice versa. Similarly, the expected loss from the dealer having a natural, $\mathrm{d}=21$, is

$\mathrm{x}(\mathrm{d}=21, \mathrm{n})-2 * \mathrm{P}(10, \mathrm{n}) * \mathrm{P}(1, \mathrm{n}) *(1-\mathrm{P}(10, \mathrm{n}) * \mathrm{P}(1, \mathrm{n}) * 2)$

Thus, the net contribution of the player's gain from the three events considered so far, i.e. $k=21, j=10, i=\rrbracket$ or $j=1, i=10$, is $\mathrm{x}(21, \mathrm{n})-\mathrm{x}(\mathrm{d}=21, \mathrm{n})=\mathrm{P}(10, \mathrm{n}) * \mathrm{P}(1, \mathrm{n}) *(1-\mathrm{P}(10, \mathrm{n}) * \mathrm{P}(1, \mathrm{n}) * 2)$

If $j=1$, then the player is offered the opportunity to make an insurance bet. If he makes the bet, he wins one unit if $i=10_{i}$ and he loses one-half otherwise. Thus, his expected gain is

$$
\mathrm{x}_{\mathrm{I}}-\mathrm{P}(1, \mathrm{n})^{\bullet}\left[\mathrm{P}(10, \mathrm{n})-(1 / 2)^{*}(1-\mathrm{P}(10, \mathrm{n}))\right]
$$

which simplifies to

$$
x_{1}=P(1, n)^{*}\left[(3 / 2)^{\bullet} P(10, n)-1 / 2\right]
$$

Since there is an expected loss when $\mathrm{P}(10, \mathrm{n})$ is less than onethird, the insurance bet should not be taken under those conditions, and the expected gain from the insurance bet is based on the greater of zero or $3 / 2 * \mathrm{P}(10, \mathrm{n})-1 / 2$ which can be written AMAXI $\left(0,3 / 2^{*} P(10, \mathrm{n})-1 / 2\right)$. Thus, the expected gain from all of these preliminary activities is

$$
\begin{aligned}
& x_{p}=P^{\prime}(10, n)^{*} P(1, n)^{*}\left(1-2^{*} P(10, n)^{\bullet} P(1, n)\right)+P(1, n) \\
& \text { AMAX1 } 10,3 / 2 \cdot P(10, n)-1 / 2)
\end{aligned}
$$

B. Expected Gain from Hit Versus Stand Decision Consequences

Let us define $\mathrm{V}(\mathrm{j}, \mathrm{k}, \mathrm{n})$ as the conditional expected gain from a hard hand with sum equal to $\mathrm{k}$ when the dealer's up card equals $\mathrm{j}$ and the deck composition index is $\mathrm{n}$. This expected gain considers the alternatives-stand or hit. The effective gain from taking the alternatives of doubling down or pair splitting will be considered in the next section.

Let us define $x_{a}(k, n)$ as the conditional expected gain when 
the player has a hard sum equal to $\mathrm{k}$ and the deck composition index is $\mathrm{n}$. In computing this conditional expected gain, it should be noted that the consequences of the dealer having a natural were already included in $x_{p}$, thus the net contribution from $j=1$ is $\mathrm{P}(1, \mathrm{n}) \bullet(1-\mathrm{P}(10, \mathrm{n}))^{\bullet} \mathrm{V}(1, \mathrm{k}, \mathrm{n})$. Similarly, the net contribution from $j=10$ is $P(10, n) *(1-P(1, n)) * V(j, k, n)$. For all other values of $j$, the contribution is $P(j, n) * V(j, k, n)$. Hence the conditional expected gain

$$
\begin{aligned}
x_{e}(k, n)= & -P(1, n)^{*} P(10, n)^{*}(V(1, k, n)+V(10, k, n))+\underset{j=}{\Sigma} P(j, n) \\
& \cdot V(j, k, n)
\end{aligned}
$$

The evaluation of the entries in the $V(j, k, n)$ matrix makes heavy use of the probability matrices $P(i, n)$ and $D(i, j, n)$. When

a player has a total, $\mathrm{k}$, equal to 21 , there is no way for him to improve his hand so he is certain to stand. Furthermore, he will win unless the dealer ends up with 21 also (i.e. $i=5$ ). Hence, the expected gain

$$
\mathrm{v}(\mathrm{j}, 21, \mathrm{n})=1.0-\mathrm{D}(5, \mathrm{j}, \mathrm{n})
$$

It should be noted that both sides of this equation exclude naturals on the part of either the player or the dealer since these situations were covered in the preliminary activities.

When the player total, $\mathrm{k}$, is less than 21 , hitting (taking another card) enters as a logical possibility. One such logical possibility is drawing a ten when $\mathrm{k}$ is equal to 20 , yielding a total $\mathrm{k}+\mathrm{i}$ equal to 30 . Hence, it is convenient to admit values of $\mathrm{k}$ up to 30 in the $\mathrm{V}(\mathrm{j}, \mathrm{k}, \mathrm{n})$ matrix with the entries equal to $-\mathrm{l}$ (his expected gain in this case) for all values of $k$ in excess of 21 since the player is certain to lose.

For each value of $\mathrm{k}$ less than 21 the player must make a decision whether he wants to stand or hit. Since he must repeat the hit versus stand decision each time he has an opportunity to draw another card until he decides to stand, there is a multistage decision process. Such decision processes have been considered extensively by Bellman (1962) who has formulated the following principle of optimality for additive processes: "An optimal policy has the property that whatever the initial state and initial de- 
cision are, the remaining decisions must constitute an optimal policy with regard to the state resulting from the first decision."

The principle of optimality can easily be applied for the hitstand decision since the optimal decision and outcomes are known for $\mathrm{k}$ equal to 21 and all values greater and one can proceed in an optimal manner recursively down to lower values of $k$. For this purpose, two sets of expected values, E $(1, n)$ and $E(2, n)$ are determined for the value of $\mathrm{k}$ being analyzed. The set, $\mathrm{E}(1, \mathrm{n})$, represents the expected value of the outcome if the player stands when his total is $\mathrm{k}$ while the set, $\mathrm{E}(2, \mathrm{n})$, represents the expected value if a single card is drawn. The optimal decision for the $\mathrm{j}, \mathrm{k}, \mathrm{n}$ combination is the one which gives the greater expected value and that expected value is $\mathrm{V}(\mathrm{j}, \mathrm{k}, \mathrm{n})$ for subsequent processing since it is optimal.

Introducing the win-loss function $\mathrm{W}(\mathrm{i}, \mathrm{k})$ which is equal to +1 if $\mathrm{i}$ is equal to six and $\mathrm{k}$ is less than 22 or if $\mathrm{k}$ is less than 22 and greater than $16+\mathrm{i}$ where $\mathrm{i}$ is the dealer's outcome whose probability is $\mathrm{D}(\mathrm{i}, \mathrm{j}, \mathrm{n}) . \mathrm{W}(\mathrm{i}, \mathrm{k})$ is -1 otherwise, which includes $\mathrm{k}$ greater than 21 regardless of the value of $i$. Then it can be expressed

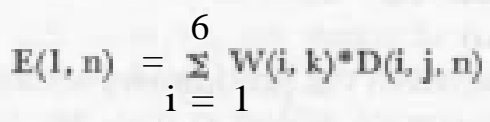

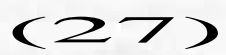

The expected value if a card is drawn and optimal decisions are followed thereafter is

$$
E(2, n)=\sum_{i=1}^{10} P(i, n)^{*} V(j, k+i, n)
$$

It should be noted that the index of summation has different meanings in equations 27 and 28 . In the former, $i$ is the index for dealer's outcomes, while in the latter it is the index designating the card drawn.

To determine the optimal decision for deck compositions other than those which correspond to the value of $n$ included in the analysis, the value of $n$ at which

$$
\mathrm{E}(3, \mathrm{n})=\mathrm{E}(1, \mathrm{n})-\mathrm{E}(2, \mathrm{n})
$$

is equal to zero was determined by cubic interpolation. The results are presented in Tables 23-I and 23-II for hard stand and 
soft stand for NA equal to 3 and NI equal to 3 . The index used in the tables, $\mathrm{XN}$, is equal to the count, UE, divided by the number of decks of cards as yet unseen (UC/52), thus

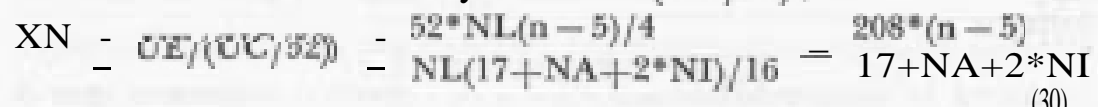

The analysis made for soft hands was similar using the matrix $\mathrm{T}(\mathrm{j}, \mathrm{k}, \mathrm{n})$ which is the expected value to the player who follows the optimal soft hit-stand decision when his soft total is $\mathrm{k}+10$, the dealer has $\mathrm{j}$ as his up card and the deck composition index is equal to $\mathrm{n}$. Again, start with the observation that when $\mathrm{k}$ is $1 \mathrm{l}$ so that the soft total is 21 , the optimal decision is to stand since no additional card can improve the hand. In this instance there is no need to introduce entries in the $\mathrm{T}$ matrix for $\mathrm{k}$ greater than $\mathrm{II}$ since the hand then becomes hard with the same total. For example, if the player has a soft total $\mathrm{k}+10$ and draws a card with face value, $i$, then if $\mathrm{k}+\mathrm{i}$ is more than $1 \mathrm{I}_{2}$, the resulting hard sum is $\mathrm{k}+\mathrm{i}$, and $\mathrm{V}(\mathrm{j}, \mathrm{k}+\mathrm{i}, \mathrm{n})$ is the expected value of the resulting hand if the optimal strategy is followed thereafter.

As in the case of the development of equation 25, it should be noted that instances in which either the player or the dealer has a natural are excluded from the current consideration since they were covered in the preliminaries, thus it follows that the conditional gain from hit-stand decisions with a soft hand

$$
\begin{aligned}
x_{i}(k, n)= & -P(1, n)^{*} P(10, n)^{*}\left(T(1, k, n)+T\left(10, k_{i} n\right)\right) \\
& 10 \\
& \sum P(j, n)^{*} T(j, k, n) \\
&
\end{aligned}
$$

Equations 25 and 31 each represent the expected gain from making optimal hit-stand decisions. For a hard hand with cards $k_{1}$ and $k_{2}$, the total

$$
\mathrm{k}=\mathrm{k}_{1}+\mathrm{k}_{\mathrm{a}}
$$

The probability of the player having a total, $\mathrm{k}$, for his first two cards can be determined by summing overall admissible value of $\mathrm{k}_{1}$, thus

$$
\mathrm{Pk}_{\mathrm{k}}=\stackrel{\mathrm{L} 2}{\mathrm{\Sigma}} \mathrm{P}\left(\mathrm{k}_{1}, \mathrm{n}\right)^{\bullet} \mathrm{P}\left(\mathrm{k}-\mathrm{k}_{1}, \mathrm{n}\right)
$$

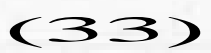

where L1 is the greater of 2 and $k-10$ while L2 is the lesser of 10 
and k-2. These limits follow because no two-card hard hand can have a card with face value less than 2 or more than 10 . For soft hands, either $k_{1}$ or $k_{2}$ must be an ace and the equivalent probability is

$$
\mathrm{Pak}=2^{*} \mathrm{P}(1, \mathrm{n}) \cdot \mathrm{P}(\mathrm{k}-1, \mathrm{n})
$$

TABLE 23-I

Hard Stand When Index XN Exceeds Entry

\begin{tabular}{|c|c|c|c|c|c|c|c|c|c|c|}
\hline $\begin{array}{l}\text { Dealer's } \\
\text { up Card J, } \\
\text { Players } \\
\text { Total }\end{array}$ & 2 & 3 & 4 & 5 & 6 & 7 & 8 & 9 & 10 & 1 \\
\hline $\mathrm{k}$ & & & & & & & & & & \\
\hline 20 & -320 & -82.0 & -32.0 & -52.0 & -32.9 & -52.0 & -320 & -320 & -520 & -320 \\
\hline 19 & -520 & -520 & $-\$ 2,0$ & $-52 a$ & -52.0 & -320 & -38.0 & -520 & -320 & $-32,0$ \\
\hline 18 & -520 & -820 & $-\$ 20$ & -520 & -32.0 & -520 & -829 & -320 & -380 & -320 \\
\hline 17 & -180 & -18.4 & -18.8 & -19.8 & -21.1 & -18.7 & -12.5 & -126 & -14.9 & -4.8 \\
\hline 16 & -7.1 & -7.9 & -8.7 & -9.7 & -9.4 & 4.1 & 3.7 & 2.7 & -0.0 & 7.5 \\
\hline 15 & -5.7 & -6.6 & -7.4 & -8.5 & -8.1 & 8.4 & 8.6 & 8.0 & 4.4 & 11.9 \\
\hline 14 & -8.7 & -4.8 & -5.7 & -6.8 & -6.4 & 15.4 & 18.5 & wnet & ..... & $* * * *$ \\
\hline 13 & -1.1 & -2.3 & -3.3 & -4.5 & -4.1 & 27.5 & nosen & *...* & nese & $* * *$ \\
\hline 12 & 2.3 & 0.9 & -0.3 & -1.6 & -1.1 & $* n$ & ***e* & neses & $* * * *$ & $* * * *$ \\
\hline
\end{tabular}

****Never stand under these conditions.

A player should never stand with $\mathrm{k}$ less than 12 since there is no way to exceed a total of 21 with only one card drawn.

\section{Expected Gain from Double and Pair Split Decisions}

In addition to the hit versus stand decision analyzed in the previous section, the player has additional opportunity with respect to the initial two-card hand. The player may decide to double his bet by doubling down and receiving only one additional card. If the two cards form a pair, the player has the opportunity to split the pair by adding an amount equal to the initial wager to cover the additional hand created.

The decision optimization procedure for the doubling and pair split decisions directly parallel the optimization procedure for the hit versus stand decision. In this instance, E $(1, n)$ represents $V(j, k, n)$. The expected gain for the optimal hit-stand decision when the player has an initial sum equal to $\mathrm{k}$ and the dealer has an up card with face value equal to $\mathrm{j}$. For the double 
down decisions

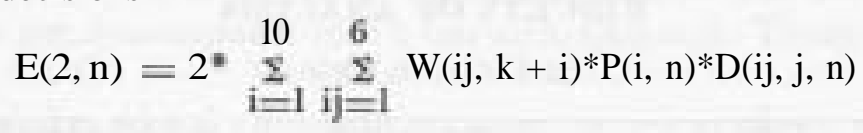

where $\mathbf{W}(\mathrm{ij}, \mathrm{k}+\mathrm{i})$ is the win-loss functioncomparing the possible dealer outcomes ij from 1 to 6 with the consequences of adding a card with face value, i, to the initial sum, k. The double down decision is favorable whenever $\mathrm{E}(2, \mathrm{n})$ is greater than $\mathrm{E}(1, \mathrm{n})$.

A somewhat more complicated treatment is required for the pair split decision. First, there is the expected gain contribution, $\mathrm{V}(\mathrm{j}, 2 * \mathrm{k}, \mathrm{n})-2 * \mathrm{~V}(\mathrm{j}, \mathrm{k}, \mathrm{n})$ before these values are adjusted to allow for the possible gains in expected value for the double down decision. Next, there is the loss in gain when the double down decision is favorable with an initial sum equal to $2^{*} k_{z}$ and then the possible gain from the new two-card sums resulting when the additional cards drawn favor making a hard double decision. To evaluate the effect, the gain for a hard double decision with initial sum, $\mathrm{k}^{1}$, can be written

$$
\mathrm{G}\left(\mathrm{j}, \mathrm{k}^{1}, \mathrm{n}\right)=\mathrm{E}(1, \mathrm{n})-\mathrm{E}(2, \mathrm{n})
$$

when the quantity is negative and zero otherwise. Then the change in expected gain due to making a pair split decision can be written

$$
\begin{aligned}
\mathrm{E}(3, \mathrm{n})= & \mathrm{V}\left(\mathrm{j}, 2^{*} \mathrm{k}, \mathrm{n}\right)-\mathrm{2}^{*} \mathrm{~V}(\mathrm{j}, \mathrm{k}, \mathrm{n})-\mathrm{G}\left(\mathrm{j}, 2^{*} \mathrm{k}, \mathrm{n}\right)+\underset{\mathrm{i}}{\Sigma} \mathrm{\Sigma}(\mathrm{i}, \mathrm{n}) \\
& { }^{\mathrm{G}} \mathrm{G}(\mathrm{j}, \mathrm{k}+\mathrm{i}, \mathrm{n})
\end{aligned}
$$

In this expression, the summation limits start at $i=2$ since the resulting sum would not be hard if $i$ is equal to 1 . The summation upper limit for values of $\mathrm{i}$ is $11-\mathrm{k}$ since the resulting sum, $\mathrm{k}+\mathrm{i}$, would then be 11 , the maximum hard sum for which doubling is favorable. If doubling is not permitted after a pair is split, the summation would be eliminated from equation 37 .

The expected gain from pair splits can be written as

$$
\mathrm{x}_{\mathrm{b}}=\sum_{\mathrm{j}=1}^{10} \sum_{\mathrm{k}=1}^{10}-\mathrm{E}(3, \mathrm{n}) \cdot \mathrm{P}(\mathrm{j}, \mathrm{n})^{\bullet} \mathrm{P}(\mathrm{k}, \mathrm{n})^{2} \quad \text { (38) }
$$

where $E(5, n)$ is the negative of the gain for each $j, k$ combination, and $P(j, n)$ is the probability the dealer has $\mathrm{j}$ as his up card; $\mathrm{P}(\mathrm{k}, \mathrm{n}){ }^{2}$ is the probability of a pair of $\mathrm{k}$ 's. 


\section{RESULTS OF ANALYSIS}

\section{A. Decision Rules}

The results of the optimization procedure can be expressed in terms of the critical value for the composition index, $\mathrm{XN}$, above which the decision is favorable and below which it is unfavorable. The results obtained for the hard-stand decision with NA and NI both equal to 3 are presented in Table 23-I. In presenting these results it is more meaningful to have the column for dealer's aces follow than for $\mathrm{j}$ equal to 10 since the critical values are closer than for $\mathrm{j}$ equals 2 . The results obtained for a composition index $\mathrm{XN}=0$ are compatible with those presented by Baldwin et al. They call for a hard stand with 13 against the dealer's 2 or $3 ; 12$ against 4, 5 or 6 ; and 17 against 7 through ace. The critical values are all negative at and above the limits they specify. The hard stand limit for 16 against a 10 is a borderline case. However, the dealer's ten would cause the index value to be negative in this instance so the directions are compatible. The results obtained are similar to the strategy recommended by Thorp, although there are some differences in the details. For example, Thorp's high-low index limits for 13 against the dealer's 2 or 12 against the dealer's 4 are slightly positive.

The optimization results for the soft stand decision are presented in Table 23- $\mathrm{II}_{2}$ and they are consistent with both the Baldwin and the Thorp recommendations. The hard double results are compatible with Thorp's tens ratio recommendations, but differ somewhat from Thorp's high-low index and Baldwin. The

\section{TABLE 25-II}

Soft Stand When Index XN Exceeds Entry

\begin{tabular}{ccccccccccc}
\hline Dealers" & & & & & & & & & \\
Up Card,j & 2 & 3 & 4 & 5 & 6 & 7 & 8 & 9 & 10 & 11 \\
20 & $*$ & $*$ & $*$ & $*$ & $*$ & $*$ & $*$ & $*$ & $*$ & $*$ \\
19 & $*$ & $*$ & $*$ & $*$ & $*$ & $*$ & $*$ & $*$ & $*$ & $*$ \\
18 & -11.0 & -11.6 & -11.6 & $-\mathbf{- 1 1 . 1}$ & -16.0 & -17.4 & -8.8 & +29.7 & 16.8 & 1.5 \\
\hline
\end{tabular}

Player should never stand with a soft total of less than 18 unless $\mathrm{XN}$ is greater than $14.5, \mathrm{j}$ is 7 and soft total is 17 .

"Never hit with a soft total in excess of 18 . However, there are conditions under which doubling should occur. 
index critical value for $\mathbb{I}$ versus an ace is 1.2 so that the player should not double down with a full deck $(\mathrm{XN}=0)$. Thorp's highlow index has a $-.0 \mathrm{~S}$ for this action. Baldwin recommends doubling with 9 against the dealer's 2 .

The soft double results differ significantly from published systems. Baldwin calls for not doubling down with 18 against the dealer's 2 or 3, and 16 against the dealer's 4 . Conversely, the value of 1.0 for 13 versus 5 would call for not doubling with a full deck. Similar differences are present compared with Thorp's strategies. Perhaps more significant is the observation that Thorp never shows soft doubling as favorable when the player total is 19 to 20 and the dealer has 7 or higher showing.

The pair split results show, in comparison with other published systems, general agreement. For example, there is a positive entry for the player's 4 against the dealer's 5 in contrast to the Baldwin recommendation in this case. Also, 7 against the dealer's 8 and 6 against the dealer's 7 are not favorable.

In considering the differences, it should be noted that the recommendations are based upon different models. The results are based upon the idealization of an infinite deck so that the composition index and distribution probabilities do not change between the player's making his first extra card decision and the dealer completing the play of his hand. The Baldwin strategy is based upon three of the cards being known to the player, his two cards and the dealer's up card, while Thorp's strategies are based upon one complete deck.

\section{B. Expected Value Gains}

In the previous section, the critical values for $\mathrm{XN}$ are presented only for the nominal conditions of NA equal to 3 and NI equal to 3 due to space limitations. The critical values change very little with changing values of NA. The expected value gains are presented for all combinations of NA and NI considered from 1 to 5 each. When the proportion of aces increases due to NA going from 1 to 5 , the expected gains always increase. In general, the expected gain decreases as the proportion of intermediate cards increases (NI goes from 1 to 5 ), presumably due to a dilu- 
tion effect.

Expected value minima occur when the deck composition index, $n$, is varied. These minima are due to the fact that a strategy which optimally responds to an abnormally high proportion of low cards can more than offset the unfavorable effects on a strategy which does not consider deck composition. For example, the critical values of $\mathrm{XN}$ presented in Table 23-I for a player's total of 17 call for the player to hit only when the value of $\mathrm{XN}$ is strongly negative, typically below -18 . Under these conditions, the proportion of low cards is so high that the player is better off taking another card. Since the dealer does not have this option, the situation tends to favor the player. The minima occur in the vicinity of $n$ equal to 4 which corresponds to an $\mathrm{XN}$ value of -8 .

Before the impact of the results presented can be fully assessed, it is necessary to consider the probability density with respect to NA, NI and 11. The optimization study provides no information on that subject since it responds to the question, What is the best strategy to follow when a particular NA, NI and $n$ combination occurs? A simulation was developed to provide frequency of occurrence information. Before considering the simulation and its results, it is necessary to turn our attention to one rule change with regard to pair splitting which has been made since Thorp's Beat the Dealer was written. Presumably, this rule change stems from Thorp's table assessing the impact of rule changes (Thorp, 1962) - In that table, forbidding double down after splitting a pair decreases the player's expected value by 0.13 percent, while permitting repeated pair splitting except for aces only increases the expected value by 0.024 percent. Thus, the house would benefit by -.1 percent from the change.

Prohibiting of subsequent doubling eliminates the summation from equation 37 leaving

$$
E(3, n)=V\left(j, 2^{*} k, n\right)-2^{*} V(j, k, n)-G\left(j, 2^{*} k, n\right)
$$

where the first term is the expected gain without allowance for pair splitting or doubling for one hand with initial sum $2 * k$, while the second term is for two hands with initial sum $\mathrm{k}$. The $\mathrm{G}$ function allows for those situations in which the initial sum could provide a gain from doubling and that gain is foregone to split 
the pair. For example, in the case of a pair of fives, the potentially large gain from doubling is more than sufficient to offset the potential gain from splitting except for strongly negative deck compositions.

If an extra card drawn immediately after splitting a pair matches the pair value, the player has the opportunity to split again. The probability that the next card has face value $\mathrm{k}$ is equal to $P(k, n)$ so that the probability that it is not equal to $k$ is equal to $1-\mathrm{P}(\mathrm{k}, \mathrm{n})$. The probability that an additional hand is created by pair splitting is $2 * \mathrm{P}(\mathrm{k}, \mathrm{n}) *[(1-\mathrm{P}(\mathrm{k}, \mathrm{n})]$ since the match can occur with either the first or second of the original cards. After the second split, the same probability for creating an additional hand applies. With the assumption of a deck composition that does not change, in principle, this could occur indefinitely which would be a geometric series with ratio equal to $2 * \mathrm{P}(\mathrm{k}, \mathrm{n})[1-\mathrm{P}(\mathrm{k}$, n) ]. The series must converge since this ratio cannot exceed its minimum value of $1 / 2$ which occurs when $P(k, n)$ is equal to $1 / 2$. The sum of the series is $1 /\left(1-2^{*} P(k, n) *[1-P(k, n)]\right)$ so that the expected gain is

$$
\text { Gain } 0-2 \mathrm{E}(3, \mathrm{n}) /\left(1-2 * \mathrm{P}(\mathrm{k}, \mathrm{n})^{\bullet}[1-\mathrm{P}(\mathrm{k}, \mathrm{n})]\right)
$$

In addition, there is the possibility that both of the new hands created by a pair split provide the opportunity to split again. For the initial pair split, this has a probability of occurrence of $[\mathrm{P}(\mathrm{k}, \mathrm{n})]^{2}$ and twice the gain given by equation 39 results. For each of the resulting four hands, further splitting can occur as indicated above. Since two hands are added for each such double split, expected gain from one additional double split is

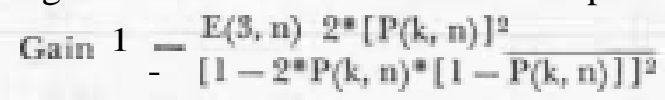

The quantity in the denominator is squared since there can be a string of splits before a double split occurs as well as a string following the double split. The analysis was limited to, at most, one double split to avoid excessive divergence from the quadruple deck case which is being approximated. In principle, with an infinite deck, pair splitting can go on forever, starting with a given pair, while even a quadruple deck does have a significant probability decrease with each subsequent pair split. In particular, the 
expected gain from splitting tens when $\mathrm{n}$ is equal to 9 is infinite for an infinite deck because the series of gains is divergent. However, the critical deck composition index at which a decision should change is not affected since the sign of the gain is the same as the sign of $\mathrm{E}(3, \mathrm{n})$ even though the value of the expected gain may be changed substantially.

The critical values of $\mathbf{X N}$ for the pair split decision were determined for the situation just discussed. Similarly, the expected value gains can change, and the values corresponding to Table 23III are given in Table 23-IV. The most significant effect on the

TABLE 2S-III

Effect of Deck Composition on Expected Gain, Percent

\begin{tabular}{|c|c|c|c|c|c|c|c|c|c|}
\hline $\mathrm{n}$ & 1 & 2 & 3 & 4 & 5 & 6 & 7 & 8 & 9 \\
\hline NI & \multicolumn{9}{|c|}{$N A=1$} \\
\hline 1 & 12.72 & 1.50 & -6.18 & -8.54 & -2.09 & 3.86 & 7.63 & 8.78 & 9.63 \\
\hline 2 & 7.07 & -1.63 & -6.99 & -8.18 & -3.07 & 1.54 & 5.41 & 7.80 & 10.18 \\
\hline 3 & 3.01 & -3.95 & -7.47 & -7.43 & -3.21 & 1.14 & 4.68 & 7.51 & 10.21 \\
\hline 4 & -4.04 & -5.58 & -7.66 & -6.79 & -2.97 & 1.08 & 4.49 & 7.39 & 10.11 \\
\hline 5 & -2.38 & -6.14 & -7.73 & -6.23 & -2.56 & 1.21 & 4.51 & 7.38 & 10.25 \\
\hline \multicolumn{10}{|c|}{$N A=2$} \\
\hline 1 & 16.38 & 5.33 & -2.40 & -5.53 & 0.01 & 6.85 & 11.58 & 14.05 & 16.10 \\
\hline 2 & 10.50 & 1.78 & -4.06 & -5.76 & -1.33 & 3.90 & 8.46 & 11.58 & 14.73 \\
\hline 3 & 6.17 & -0.92 & -4.96 & -5.60 & -1.84 & 2.82 & 7.04 & 10.38 & 13.50 \\
\hline 4 & 2.84 & -2.98 & -5.48 & -5.28 & -1.89 & 2.29 & 6.22 & 9.59 & 12.64 \\
\hline 5 & 0.22 & -4.09 & -5.87 & -5.01 & -1.71 & 2.05 & 5.77 & 9.03 & 16.16 \\
\hline \multicolumn{10}{|c|}{$N A=3$} \\
\hline 1 & 19.63 & 8.69 & 0.82 & -2.93 & 1.64 & 9.17 & 14.86 & 18.57 & 21.68 \\
\hline 2 & 13.55 & 4.84 & -1.43 & -3.52 & 0.01 & 5.87 & 10.99 & 14.92 & 18.78 \\
\hline $\mathrm{S}$ & 9.00 & 1.88 & -2.64 & -3.85 & -0.60 & 4.24 & 9.03 & 12.81 & 16.52 \\
\hline 4 & 5.46 & -0.47 & -3.49 & -3.83 & -0.85 & 3.30 & 7.74 & 11.49 & 14.85 \\
\hline 5 & 2.63 & -2.11 & -4.07 & -3.79 & -0.84 & 2.78 & 6.88 & 10.52 & 13.87 \\
\hline \multicolumn{10}{|c|}{$\mathrm{NA}=4$} \\
\hline 1 & 22.57 & 11.65 & 3.60 & -0.75 & 2.83 & 10.92 & 17.68 & 22.37 & 28.52 \\
\hline 2 & 16.20 & 7.55 & 1.13 & -1.55 & 1.28 & 7.38 & 13.02 & 17.87 & 22.31 \\
\hline 3 & 11.56 & 4.40 & -0.55 & -2.20 & 0.54 & 5.41 & 10.65 & 14.91 & 19.20 \\
\hline 4 & 7.85 & 1.86 & -1.64 & -2.46 & 0.12 & 4.17 & 9.01 & 13.11 & 16.85 \\
\hline 5 & 4.87 & -0.11 & -2.40 & -2.57 & -0.03 & 3.54 & 7.85 & 11.79 & 15.36 \\
\hline \multicolumn{10}{|c|}{$\mathrm{NA}=5$} \\
\hline 1 & 25.26 & 14.27 & 6.04 & 1.19 & 3.65 & 12.23 & 19.98 & 26.33 & 34.30 \\
\hline 2 & 18.78 & 9.99 & 3.41 & 0.19 & 2.39 & 8.48 & 14.81 & 20.37 & 26.25 \\
\hline 3 & 13.89 & 6.68 & 1.42 & -0.62 & 1.57 & 6.31 & 11.94 & 16.77 & 21.53 \\
\hline 4 & 10.04 & 4.00 & 0.11 & -1.11 & 1.05 & 4.85 & 10.04 & 14.44 & 18.68 \\
\hline 5 & 6.93 & 1.85 & -0.83 & -1.40 & 0.75 & 4.27 & 8.63 & 12.85 & 16.63 \\
\hline
\end{tabular}


TABLE 2S-IV

Expected Gain With Repeated Pair Splitting Permitted, Percent

\begin{tabular}{|c|c|c|c|c|c|c|c|c|c|}
\hline $\mathrm{n}$ & 1 & 2 & 3 & 4 & 5 & 6 & 7 & 8 & 9 \\
\hline NI & \multicolumn{9}{|c|}{$\mathrm{NA}=1$} \\
\hline 1 & 13.88 & 1.56 & -6.18 & -8.55 & -2.13 & 6.81 & 20.37 & 31.27 & 37.29 \\
\hline 2 & 7.58 & -1.62 & -6.99 & -8.19 & -3.11 & 2.52 & 13.35 & 25.80 & 39.24 \\
\hline 3 & 3.22 & -3.95 & -7.46 & -7.43 & -3.25 & 1.68 & 9.68 & 21.69 & 36.77 \\
\hline 4 & 0.05 & -5.57 & -7.64 & -6.70 & -3.00 & 1.45 & 7.81 & 18.28 & 32.62 \\
\hline 5 & -2.33 & -6.12 & -7.69 & -6.21 & -2.58 & 1.50 & 6.94 & 15.70 & 29.30 \\
\hline \multicolumn{10}{|c|}{$\mathrm{NA}=2$} \\
\hline 1 & 17.62 & 5.50 & -2.40 & -5.53 & -0.01 & 9.77 & 23.03 & 36.23 & 44.85 \\
\hline 2 & 11.12 & 1.84 & -4.06 & -5.76 & -1.36 & 5.02 & 15.62 & 27.82 & 42.09 \\
\hline 3 & 6.49 & -0.89 & -4.95 & -5.60 & -1.87 & 3.37 & 11.62 & 22.86 & 37.07 \\
\hline 4 & 3.00 & -2.96 & -5.46 & -5.26 & -1.91 & 2.65 & 9.25 & 19.14 & 32.26 \\
\hline 5 & 0.32 & -4.06 & -5.82 & -4.98 & -1.72 & 2.31 & 7.95 & 16.31 & 28.60 \\
\hline \multicolumn{10}{|c|}{$\mathrm{NA}=3$} \\
\hline 1 & 20.88 & 8.95 & 0.83 & -2.92 & 1.63 & 11.95 & 25.82 & 40.97 & 52.19 \\
\hline 2 & 14.22 & 4.97 & -1.42 & -3.52 & -0.01 & 7.10 & 17.40 & 30.18 & 45.38 \\
\hline 3 & 9.37 & 1.95 & -2.62 & -3.83 & -0.61 & 4.81 & 13.20 & 23.80 & 38.17 \\
\hline 4 & 5.68 & -0.42 & -3.45 & -3.80 & -0.86 & 3.66 & 10.52 & 19.90 & 32.02 \\
\hline 5 & 2.77 & -2.06 & -4.02 & -3.74 & -0.84 & 3.04 & 8.86 & 16.93 & 28.10 \\
\hline \multicolumn{10}{|c|}{$\mathrm{NA}=4$} \\
\hline 1 & 23.78 & 11.95 & 3.61 & -0.74 & 2.83 & 13.51 & 28.4 & 45.02 & 68.51 \\
\hline 9 & 16.98 & 7.71 & 1.15 & -1.54 & 1.27 & 8.64 & 18.74 & 32.72 & 48.56 \\
\hline 3 & 11.97 & 4.51 & -0.52 & -2.18 & 0.53 & 6.02 & 14.44 & 24.85 & 39.57 \\
\hline 4 & 8.11 & 1.94 & -1.61 & -2.43 & 0.13 & 4.54 & 11.58 & 20.53 & 32.24 \\
\hline 5 & 5.04 & -0.05 & -2.34 & -2.52 & -0.01 & 3.81 & 9.67 & 17.48 & 27.72 \\
\hline \multicolumn{10}{|c|}{$\mathrm{NA}=5$} \\
\hline 1 & 26.43 & 14.61 & 6.06 & 1.19 & 3.65 & 14.61 & 30.55 & 51.85 & 82.51 \\
\hline o & 19.46 & 10.17 & 3.44 & 0.20 & 2.38 & 9.73 & 20.31 & 34.97 & 55.57 \\
\hline 3 & 14.31 & 6.81 & 1.45 & -0.60 & 1.57 & 6.94 & 15.37 & 26.17 & 41.00 \\
\hline 4 & 10.32 & 4.09 & 0.15 & -1.08 & 1.07 & 5.23 & 12.40 & 21.01 & 32.98 \\
\hline 5 & 7.13 & 1.93 & -0.78 & -1.35 & 0.77 & 4.53 & 10.31 & 17.91 & 27.41 \\
\hline
\end{tabular}

critical values is the fact that many of the critical values have increased. These increases are sufficient so that the critical values for 2,3 and 6 against a dealer's 2 are now positive. These increases stem from the loss of the potential gain from hard doubling with the new hands created by the splitting. The most significant decreases in critical values are those associated with splitting of tens. In this case, there was no opportunity for a subsequent doubling down ${ }_{z}$ and the opportunity for repeated splits enhances 
the expected gain fromsplitting pairs. There is no change in the criteria for splitting aces since no further action is permitted once the decision to split a pair of aces is made.

The changes in expected gains presented in Table 23-IV are quite large when the composition index is high, indicating an abnormally high proportion of tens in the cards remaining. This high proportion of tens tends to increase the probability that the dealer will go bust and to increase the probability that the player will get another ten when he splits a pair of tens. Both of these tend to increase the player's expected gain. Smaller but still significant increases also occur when the value of $n$ is 1 so that there are twice as many low cards as normal and no tens are left. In this instance the probability of repeated splits is enhanced, but due to the low probability that the dealer will go bust, the gains are smaller.

For the normal deck composition case of $\mathrm{NA}=3, \mathrm{NI}=3$, and $\mathrm{n}=5$, there is .01 change in expected gain. This result differs somewhat from Thorp's loss of .1 percent due to the fact that with a single deck the first pair consumes half of the cards of a given nonten face value, drastically reducing the probability of subsequent pair splits. With the infinite deck assumption made in this analysis, there is no decrease in probability for subsequent pair splits and very little change occurs with a quadruple deck game.

\section{SIMULATION OF FOUR-DECK PLAY}

Although the analysis described above is based upon the assumption of an infinite deck, the situation of greater practical interest is the quadruple-deck game which has become common in Las Vegas. In particular, it is assumed that all cards are dealt up (visible to all players) except for the dealer's hole card; then the player has the most current information available for inferring the composition of the rest of the deck.

In the simulation results reported, the quadruple deck was shuffled slightly more than twenty thousand times. The play consisted of a succession of deals to seven players until at least 150 
cards had been used. Then it was time for another shuffle. Of the simulated shuffles, only eleven reached the limit with only six deals, and 2392 had an eighth deal. There was a total of 1,001,203 hands dealt to players. The shuffle used a technique suggested by Dr. David G. Carta based upon pseudorandom numbers which did not require a sort. The cards were very thoroughly mixed, more thoroughly than in actual casino play.

To reduce the effects of statistical variations on the results all strategies compared were exposed to the same card play, i.e. the same dealer cards and outcome, the same first two cards for each hand and the same extra cards for each hand for as many as the strategy calls for. The Baldwin and Wilson strategies, and both strategies presented by Thorp were evaluated along with the strategy defined in this study. That strategy used critical values which were developed as optimum for NA and NI both equal to 3.* The value of NA has very little effect on the critical effect of the optimal critical value; the variation in NI was not expected to be large. The results showed that the standard deviation in NI was 0.7 while it was 0.6 for NA. For the deck composition index, $\mathrm{XN}$, the standard deviation was 2.3. Only fifteen deals started with a value of $\mathrm{XN}$ less than -12 , and 116 started with $\mathrm{XN}$ equal to +10 or more out of 143,029 deals. Consequently, the very favorable situations shown in Tables 23-III and 23-IV for extreme values of $\mathrm{XN}$ are very infrequent. The results including the frequency distributions are summarized in Table 23-V.

The Baldwin strategy was used as the evaluation baseline and it had a gain of -0.70 percent with a standard error of estimate of 0.23 percent. Although they had expected values .01 percent greater, the Thorp basic strategy and that presented in the Facts of Blackjack (Nolan, 1970) are not significantly better in gain since the difference estimate has a standard error of .008 percent. The strategies which are composition-dependent did somewhat better (almost .2\%) when the bet size was not varied to take advantage of more favorable compositions. Larger gains resulted

\footnotetext{
*A complete set of critical values and an explanation of how to use them can be obtained by contacting the writer c/o DHM Associates, P. O. Box 216, San Dimas, Calif., 91773 .
} 
when the bet size was varied with deck composition as indicated in Table 23-V.

TABLE 23-V

Simulation Results

\begin{tabular}{|c|c|c|c|c|c|c|c|c|c|c|}
\hline & & & & Wilson & Strategy & & & & & \\
\hline Bet Size & 1 & 2 & 3 & 4 & 5 & 6 & 7 & 8 & 9 & 10 \\
\hline Limit & * & -5.5 & -1.5 & 1.5 & 3.5 & 5.5 & 7.5 & 9.5 & 11.5 & 13.5 \\
\hline Gain \% & -2.5 & -1.7 & -0.8 & -0.3 & 1.6 & 1.9 & 0.3 & -2.2 & 0.5 & 1.4 \\
\hline \multicolumn{11}{|l|}{ Standard } \\
\hline Error \% & 0.3 & 0.9 & 0.3 & 0.5 & 1.2 & 1.2 & 2.7 & 2.5 & 2.0 & 3.0 \\
\hline Frequency \% & 6 & 13 & 55 & 11 & 6 & 3 & 2 & 2 & 1 & 1 \\
\hline \multicolumn{11}{|c|}{ Thorps Tens Ratio } \\
\hline Bet Size & 1 & 1 & 1 & 1 & 1 & 2 & 3 & 4 & 5 & 6 \\
\hline Limit & $\cdots$ & 2.63 & 2.56 & 2.44 & 2.31 & 2.19 & 2.06 & 1.94 & 1.81 & 1.69 \\
\hline Gain \% & -1.6 & -14 & -1.3 & -1.4 & -1.1 & 0.0 & 1.5 & -0.6 & 1.1 & 1.1 \\
\hline \multicolumn{11}{|l|}{ Standard } \\
\hline Error \% & 0.8 & 0.9 & 0.9 & 0.9 & 0.2 & 0.4 & 0.8 & 1.1 & 0.9 & 1.3 \\
\hline Frequency \% & 5 & 3 & 6 & 11 & 32 & 19 & 13 & 6 & 3 & 2 \\
\hline \multicolumn{11}{|c|}{ Thorp High Low Index } \\
\hline Bet Size & 1 & 1 & 1 & 1 & 1 & 2 & 3 & 4 & 5 & 6 \\
\hline Limit & $*$ & -7 & -5 & -3 & -1 & +1 & +3 & +5 & +7 & +9 \\
\hline Gain \% & -5.9 & -13 & -0.9 & -0.2 & -0.6 & -0.6 & +0.5 & +2.6 & +3.5 & -0.1 \\
\hline \multicolumn{11}{|l|}{ Standard } \\
\hline Error \% & 1.0 & 0.6 & 0.6 & 0.3 & 0.1 & 0.8 & 0.6 & 0.8 & 1.4 & 0.8 \\
\hline \multirow[t]{2}{*}{ Frequency \% } & 9 & 7 & 11 & 13 & 33 & 11 & 7 & 4 & 2 & 3 \\
\hline & & & & This & Study & & & & & \\
\hline Bet Size & 1 & 1 & 1 & 1 & 1 & 1 & 2 & 3 & 4 & 5 \\
\hline Limit & & -9 & -7 & -5 & -3 & -1 & 1 & 3 & 6 & 10 \\
\hline Gain \% & -5.0 & -1.9 & -4.7 & -5.6 & -5.0 & -18 & +4.3 & +4.9 & +10 & +43 \\
\hline \multicolumn{11}{|l|}{ Standard } \\
\hline Error \% & 2.7 & 1.8 & 1.8 & 0.7 & 0.4 & 0.2 & 0.3 & 0.3 & 1.4 & 6. \\
\hline Frequency \% & 0.2 & 0.2 & 2 & 6 & 18 & 48 & 17 & 7 & 1 & 0.1 \\
\hline
\end{tabular}

"Contains results for index values less than value in adjacent column while "*indicates greater than.

The Thorp tens ratio strategy gave a gain of .54 percent for each unit of increase over a flat bet. The Thorp high-low index had a gain of .58 percent for each unit of increase over a flat bet. The strategy described earlier in this study yielded a gain to the player of 1.90 for each unit of increase over a flat bet. Allowing for the gains from flat bets over the Baldwin baseline, the net 
gains are .03 percent for both of the Thorp strategies with a unit increase and 1.36 percent for the playing strategy described previously in this study. The Wilson strategy only involves changes in bet size without changing the playing strategy with index values, and it was somewhat better than a flat bet but still negative, -.40 percent.

The standard error values given in Table 23-V are based upon subdivision of the simulation into five subjects and determining the variation from the average values observed. Consequently, the error estimates have uncertainties of the order of a factor of 2 . In general, the standard error tends to be larger as the proportion of observations falling into the group (frequency) decreases. However, most of the gain percentages are statistically significant at the 5 percent level. The right-hand portion of the table contains the more favorable deck compositions, and nearly all of the gain values are positive whereas they are all negative for the left-hand portion of the table. That is why the variable bet strategies produce a greater gain than a flat bet strategy.

\section{CONCLUSIONS}

A new blackjack-playing strategy has been developed for the four-deck version which has become common in Las Vegas. The strategy was developed applying dynamic programming techniques to determine the optimal decisions in each case. An infinite deck approximation was used, i.e. the deck composition was assumed to be the same for every card the dealer took and for the first card the player takes in each decision-making situation.

The playing strategy developed was then tested using a simulation of four-deck play with all cards to each of the seven players dealt up to maximize the information available to the players. The basic strategies (those without keeping track of composition) yielded an average loss of only 0.7 percent, which is consistent with the 0.5 percent reported by Thorp. The deck composition dependent playing strategies described by Thorp brought the gain up to 0.03 percent when the bet was increased for favorable composition. The playing strategy described in this paper yielded 
a gain of 1.36 percent when a similar bet variation scheme was used.

\section{REFERENCES}

Baldwin, R. R., Cantey, WV, E., Maisel, H., and McDermott, J.: The optimum strategy of blackjack. J Am Stat Assoc, 51:429, 1956.

Bellman, R. E., and Dreyfus, S. E.: Applied Dynamic Programming. Princeton, Princeton University Press, 1962.

Nolan, W. L.: The Facts of Blackjack. Las Vegas, Gambler's Book Club, 1970.

Thorp, E. O.: Beat the Dealer. New York, Blaisdell Publishing Company, 1962.

Wilson, A. N.: Casinos, cards, and computers. Datamation, November, 1965a.

Wilson, A. N.; The Casino Gambler's Guide. New York, Harper and Row, $1965 b$. 


\title{
Chapter 24
}

\section{NONLINEAR PROGRAMMING, SIMULATION AND BAMBLING THEOHY APPLIED TO BLACKJACK}

JAMES N. HANSON

\begin{abstract}
PProximations OF OPTIMAL STRATEGIES for maximizing gain at A blackjack are obtained. A convexity analysis relates the gain to strategy parameters. A generalization of Thorp's strategy form and his assumption that the player's advantage is related additively to the advantage associated with each trial has been used. Thirty parameters are associated with wagering and playing. An alternate direction optimization preceeded further optimization by the Powell optimizer. Thorp's strategy was used as the initial approximation. The function evaluation was computed from a simulation. A sequence of successively stronger winning strategies evolved but were accompanied by rapidly increasing variance of gain. The terminal strategy was capable of increasing the gain by a factor of 7 after 1,000 hands. This solution might be regarded as an approximate solution to the Pontryagin-Kolmogorov equations for the appropriate optimal stochastic process.
\end{abstract}

\section{INTRODUCTION}

In 1962, Thorp published winning strategies for blackjack. Since that time many additional studies have been performed (Wilson, 1965) and special attention has been focused on simplifying Thorp's strategy (Epstein, 1967; Noir, 1969; and Revere, 1971). Though this author in 1966 developed and used a simplification of Thorp's strategy similar to Revere's, it will be the subject of this 
paper to complicate Thorp's strategy. Specifically, Thorp's strategy will be generalized so that not only the density of 10 'sin the deck, but the density of all cards will be used to develop a playing strategy. The thirty parameters of this generalization will be determined by an optimization starting from Thorp's strategy. Actually, several hundred parameters occur, but only the thirty associated with computing the bet size and playing decision indicators are found to be sensitive for optimizing. The rules for casino blackjack and their variations are discussed in detail in Thorp (1962), and Revere (1971). We shall adopt the standard Las Vegas rules and terminology found in Thorp $(1962)$. The relatively new and infrequent betting option, surrender, will not be considered.

Let $\mathrm{q}$ be the playing decision indicator, and a, the instantaneous advantage, be the bet size indicator. Also let $n_{p}$ be the number of cards played, $n_{n_{1}}$ be the number of cards remaining with value $i$, and let $c_{\Perp}$ and $k_{4}$ be constants associated with card values $i=1$, $\cdots, 10$; where $\mathrm{i}=1$ corresponds to the ace-count, $\mathrm{i}=10$ to the ten-count, etc. Following Thorp (1962) we define

$$
\left.a-a_{0}+\sum_{i=1}^{10} \quad a_{i}(52-n p)\right)^{-1}
$$

where the $a_{1}$ may be regarded as the change of advantage due to removing card i from the deck. The summation symbol used here is understood to be over all cards played. Throughout this paper single-deck blackjack will be assumed as evidenced by the 52 in this formula. Corrections for multideck blackjack are discussed in Thorp (1962) and Revere (1971) (Also see Gordon, Chapter 23). Generalizing Thorp's indicator we adopt

$$
s=\bar{z}_{i=1}^{-10} c_{i}\left(52-n_{p}-n_{r}\right)\left(k_{i}+n_{r}\right)-1
$$

Thorp's strategy, which will be our initial approximate optimal strategy, is given by $c_{10}=1, c_{1}(i \neq 0)=0, k_{10}=0, a_{0}=.021$ and $\mathrm{a}_{1}(\mathrm{i}=1, \cdots, 10)=(-.315, .175, .210, .280, .385, .210, .140$, $.000,-.105,-.245)$. The constant $a_{q}$ is the advantage when the deck is complete, i.e. the constraint

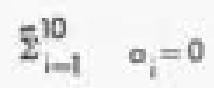


from which $a_{2}$ is computed to be dependent

$$
a_{2}=-\left(a_{s}+\cdots+4 a_{10}+a_{1}\right)
$$

The value of a will be subsequently related to the optimal bet size, and a is a playing decision indicator which is to be compared with the elements of a sequence of decision matrices. The indices of the matrices are the players total, 3-21, card count versus the dealer's up-card, 2-11, and their order is (surrender), insurance, pair-split, soft doubling down, hard doubling down and stand. If the computed value of $s$ is greater than the appropriate entry in the matrix sequence, then do the indicated decision. In the ensuing optimization we shall adopt Thorp's matrices (1962), but because of the generalized formula it will not be necessary to have any exceptions where the decision polarity is reversed.

\section{OPTIMAL BET SIZE}

If $\mathrm{C}_{\mathrm{n}}$ is the current capital after $\mathrm{n}$ bets where $\mathrm{f}$ is the constant fraction of current capital wagered at each bet starting from an initial capital $\mathrm{C}_{0}$, then

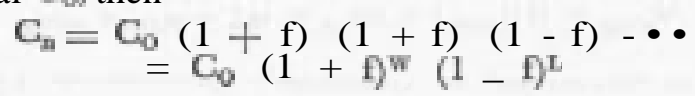

The plus sign indicates the bet was won, and the minus, that it was lost, and $\mathrm{W}$ and $\mathrm{L}$ are, respectively, the total number of wins and losses. We proceed in the manner of Kelly (1956) and define gain, G, by

$$
\begin{aligned}
G & =\lim _{n \rightarrow \infty} n^{-1} \ln \left(C_{n} / C_{0}\right) \\
& =\lim _{n \rightarrow-\infty}(\mathbf{W} / \mathbf{n}) \ln (1+f)+(\mathbf{L} / \mathbf{n}) \ln (1-f) \\
& =p \ln (1+\mathbf{f})+\mathbf{q} \ln (\mathbf{I}-\mathbf{f})<
\end{aligned}
$$

where $\mathrm{p}$ and $\mathrm{q}$ are the probabilities of winning and losing, i.e.

$$
\mathbf{p}+\mathbf{q}=1, \mathbf{p}=\lim _{n \rightarrow m}(\mathbf{W} / \mathbf{n})
$$


We next consider maximizing G,

$$
G_{\max }=\max \{G(f) \mid-f \leq 0, f-1 \leq 0\}
$$

Recall the following theorem due to Kuhn and Tucker (Arrow, Hurwicz and Uzawa, 1958). Let $\mathrm{f}(\mathrm{x}): \mathrm{E}^{\mathrm{m}} \rightarrow \mathrm{E}^{1}$ and $\mathrm{g}(\mathrm{x}): \mathrm{E}^{\mathrm{a}} \rightarrow \mathrm{E}^{\mathrm{m}}$ be convex functions over a domain $\mathrm{D}$ where $\mathrm{g}(\mathrm{x})-\mathrm{O}$, and let there exist some $\mathrm{x}^{0}$ such that $\mathrm{g}\left(\mathrm{x}^{0}\right)<\mathrm{O}$; then, for $\mathrm{x}$ to maximize $f(x)$ subject to $g(x)-O$, it is necessary and sufficient that there exist $y-O$ such that $\bar{x}, y(1)$ is a saddle point of $\phi(x, y)-f(x)+$ $\mathrm{y}^{\mathrm{T}} \mathrm{g}(\mathrm{x})$. If in this theorem we set $\mathrm{x}=\mathrm{f}, \mathrm{f}(\mathrm{x})=\mathrm{G}(\mathrm{f})$ and $\mathrm{g}=$ $\left(-\mathrm{f}_{2} \mathrm{f}-1\right)^{\mathrm{T}}$ (and note we may pick $\left.\mathrm{x}^{\circ}-\frac{1}{2}\right)$, we have

$$
\Phi\left(f, y_{1}, y_{2}\right)=G(f)+y_{1}(-f)+y_{2}(f-1)
$$

from which $2 \phi / 2 \mathrm{f}=2 \phi / 2 \mathrm{y}_{1}=2 \phi / 2 \mathrm{y}_{2}=\mathrm{O}$ yield

$$
f_{\text {opt }}=p-q=2 p-1=a
$$

ie. the optimal fractional bet is precisely the advantage. Also

$$
G_{\operatorname{mox}}=G(\text { fpt })=\ln C_{0}+\ln 2+p \operatorname{lnp}+q \ln q
$$

which can be recognized as Shannon's information rate (Arrow, Hurwicz and Uzawa, 1958). Bellman (1961) obtains the same result using dynamic programming.

It is from this betting model that the objective function for optimizing the strategy will be developed. The above result may be interpreted as, in order to maximize the rate of gain of current capital, it is necessary to wager that fraction of the current capital equal to the instantaneous advantage, provided $\mathrm{a}>\mathrm{O}$. Clearly if $\mathrm{a}=\mathrm{O}$, then $\mathrm{f}=\mathrm{O}$.

\section{CONNECTION BETWEEN CURRENT CAPITAL AND ADVANTAGE}

A minimum bet $b_{m}$ will be wagered if advantage a - O. It will be assumed that $\mathrm{C}_{\mathrm{m}}$ is positive and sufficiently large so that $\mathrm{b}_{\mathrm{mi}}$ may be effectively zero. Therefore, $\mathrm{C}_{\mathrm{n}}$ may be approximated by

$$
c_{n}^{*}=c_{0} \quad \text { II } \quad\left(1+f_{i}\right)^{W_{i}}\left(1-f_{i}\right)^{L_{i}}+b_{m}(w-a),(i=0,1, \ldots)
$$


where $\mathrm{C}_{\mathrm{m}}{ }^{*}$ is the current capital at time (trial) $\mathrm{n}, \mathrm{E}_{\mathrm{i}}$ is the fraction of current capital wagered on some trial $\mathrm{i}, \mathrm{W}_{\Perp}$ and $\mathrm{L}_{4}$ are the number of trials won or lost when fraction $\mathrm{f}_{\mathrm{l}}$ was bet, $\mathrm{w}$ and $\vartheta$ are the number of trials won or lost when a - O.

The approximation given by this equation is imprecise in that the flat (constant) bets are not separable, but intermingled with the fractional bets. To leave off the betting strategy for a - O would only reduce the accuracy of this approximation for the general problem of mixed fractional and flat betting. For the moment it will be assumed that the trial number $\mathrm{n}$ shall not include ties (i.e. trials not resulting in a win or loss), i.e.

$$
N=\sum_{i=0}\left(w+L_{i}\right)+(w+2)=N_{1}+N_{2}
$$

where $N_{1}$ is the sumation.

If $\mathrm{p}$ is the probability of success at a given trial, and $\mathrm{q}-1-\mathrm{p}$, the probability of failure, then the advantage a for this trial is

$$
\mathrm{q}=\mathrm{p}-\mathrm{q}=2 \mathrm{p}-1
$$

Let

$$
n_{i} \equiv w_{1}+L_{i}, N_{2}=w+2
$$

i.e. $n_{\|}$is the number of decisions at fractional bet size $f_{m}$ and $N_{2}$ is the total number of decisions when a - O. Hence the advantage corresponding to $\mathrm{E}_{\mathrm{s}}$ is

or

$$
a_{4}-P i-q_{1}=\left(W_{1} / n_{4}\right)-\left(L_{4} / n_{4}\right)
$$

Furthermore, the optimal relation will be chosen,

which maximizes the rate of gain of current capital. 
Only very rarely is $a_{b}$ and therefore $f_{12}$ in excess of $1_{1}$. Hence, the first term of $\mathrm{C}_{\mathrm{n}}{ }^{*}$, denoted by $\mathrm{C}_{\mathrm{n}}{ }^{1}$, may be simplified by the binomial theorem

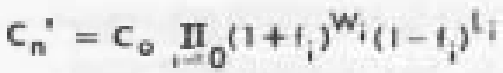

$$
\begin{aligned}
& =C_{0} \Pi_{i}\left[1+w_{i} f_{i}+(1 / 21)\left(w_{i}-1\right) f_{i}^{2}+\ldots\right]\left[1-t_{i} f_{i}+(1 / 2 !)\left(t_{i}-1\right) f_{i}^{2}+\ldots\right] \\
& =C_{0} \prod_{i=0}\left(1+w_{i} f_{i}\right)\left(1-t_{i} f_{i}\right) \\
& =\mathrm{C}_{0} \Pi_{i=0}\left(1+\mathrm{w}_{i} f_{i}-\mathrm{t}_{i} \mathrm{f}_{i}-\mathrm{w}_{i} \mathrm{~L}_{i} f_{i}^{2}\right) \\
& \approx c_{0} \prod_{i=0}\left[1+\left(w_{i}-L_{i}\right) r_{i}\right] \\
& =C_{0} \prod_{i=0}\left(1+t_{i}\right) w_{i}-t_{i} \\
& =\mathrm{C}_{\mathrm{o}} \prod_{i=0}\left(1+\mathrm{o}_{i}\right)^{n_{i} \mathrm{o}_{i}}
\end{aligned}
$$

Again, by the binomial theorem this equation becomes

$$
\begin{aligned}
C_{n}{ }^{\prime} & =C_{0}{ }_{i=0} I_{0}\left(1+n_{i} a_{i}{ }^{2}\right) \\
& =C_{0}\left(1+\sum_{i=0} n_{i} a_{i}{ }^{2}\right)
\end{aligned}
$$

Interpreting this equation as a Reimannian sum gives

$$
c_{n^{\prime}}=\mathrm{c}_{0}\left(1+\int_{a=0} n(a) \quad a^{2} \mathbf{d a}\right)
$$

where $\mathrm{n}$ is assumed to be expressible in terms of $\mathrm{a}$, and since $\mathrm{C}_{\mathrm{m}}{ }^{\prime}$ is the expected current capital for positive a, the limits of integration are from 0 to 1 . Let $\Phi$ (a) be the probability density function (p.d.f.) of a, then

$$
\mathbf{n}(\mathbf{a})=\Phi(\mathrm{a}) \mathrm{N}_{1}
$$

where $\mathrm{N}_{1}$, is the number of decisions when a $>$ O, i.e.

Then

$$
N_{1}=\mathbf{z}_{i=0}^{\infty} n_{i}
$$

$$
C_{a}^{*}=C_{0}\left(1+N_{1} \int_{0}^{1} \Phi(a) a^{2} d a\right)+b_{m}(w-2)
$$


Let $\mathrm{N}_{\mathrm{W}}$ and $\mathrm{N}_{\mathrm{L}}$ be the total number of decisions won or lost, and a be the overall advantage, then

$$
\begin{aligned}
& N=N_{W}+N_{L} \\
& N_{W}-N_{L}=N_{0}
\end{aligned}
$$

Furthermore, let $N_{1, W}, N_{1, \mathrm{~L}}$ be the number of decisions won or lost when a $>\mathrm{O}$, then

$$
\begin{gathered}
\mathrm{N}_{1}=\mathrm{N}_{1, \mathrm{~W}}+\mathrm{N}_{1, \mathrm{~L}} \\
\mathrm{~N}_{1, \mathrm{~W}}-\mathrm{N}_{1, \mathrm{~L}}=\mathrm{N}_{2} \bar{\sigma}_{1}
\end{gathered}
$$

where $\overline{\mathbf{a}}_{1}$ will be taken as the effective overall advantage. (The contribution to $\mathrm{C}_{\mathrm{n}}$ for $\mathrm{a}-\mathrm{O}$ might be sufficiently small so that these trials may be disregarded.)

Note that a and $a_{1}$ must also satisfy

$$
\bar{\sigma}=(1 / 2) \int_{-1}^{1} \Phi(a) d a_{e} \bar{\sigma}_{1}=\int_{c}^{1} \Phi(a) d a
$$

Hence, a check on the eventual calculations will be

$$
\left(N_{W}-N_{L}\right) / N=\bar{a}=\int_{-1}^{1} a \Phi(a) d o,\left(N_{1, W}-N_{1, L}\right) / N_{1}=\bar{a}_{1}=\int_{0}^{1} a \Phi(a) d a
$$

Let $\lambda$ be the number of ties; $A$, the total number of trials; $\mathrm{p}_{\mathrm{A}}$ the probability of a tie; $\Lambda_{1}$ and $\Lambda_{2}$ the number of ties for $\mathrm{a}>\mathrm{O}$; and $\mathrm{a}<\mathrm{O}$, then

$$
p \lambda_{1}=\lambda_{1} / \Lambda_{1}, A=X+N=\Delta_{1}+\Delta_{2}, \lambda=\lambda_{1}+\lambda_{2}, \sigma \equiv(w-2)
$$

If $\mathrm{n}^{\prime}$ is the trial index inclusive of ties we have

$$
C_{n^{*}}^{*}=C_{0}\left[1+\Lambda_{1}\left(1-P_{\lambda_{1}}\right) \int_{0}^{1} \Phi(a) a^{2} d a\right]+b_{m} \cdot \Delta
$$

Therefore the rate at which the game is played and the rate of change of current capital is

$$
\dot{C}^{*} \equiv c_{0} \dot{\Lambda}_{1}(1-p) \int_{0}^{1} \Phi(a) o^{2} \mathrm{da}+\dot{\Lambda}^{b} m^{\sigma}
$$


Note that if, in the derivations, the $\mathrm{W}_{1} \mathrm{~L}_{1} \mathrm{f}_{1}{ }^{2}$ term had not been neglected, the above integral would be replaced by

$$
\int_{0}^{1} \Phi(a) a^{2} d a-(1 / 4) N_{1} \int_{0}^{1} \Phi^{2}(a) a^{2}\left(1-a^{2}\right) d a
$$

\section{Exponential Form for Current Capital, the Objective Function}

Remember that

$$
W_{i}+L_{i}=n_{i}, W_{i}-t_{i}=n_{i} a_{i}, C_{n}^{\prime}=C_{0} \prod_{i=0}\left(1+f_{i}\right) W_{i}\left(1-f_{i}\right)^{t_{i}, f_{i}=a_{i}}
$$

from which

$$
\begin{aligned}
& W_{i}=(1 / 2) n_{i}\left(1+a_{i}\right)_{e} L_{-}=(1 / 2) n_{i} ;\left(1-a_{i}\right] \\
& \ln C_{n}^{\prime}=\operatorname{In} C_{0}+\sum_{i=0} w_{i} \ln \left(1+a_{i}\right)+\sum_{i=0} L_{i} \ln \left(1-a_{i}\right)
\end{aligned}
$$

Combining these last two equations gives

$$
\begin{aligned}
\ln C_{n}= & =\ln C_{0}+(1 / 2) .2 \text { n. }\left(1+a_{i}\right) \ln \left(1+a_{0}\right)+(1 / 2), n \cdot\left(1-a_{-}\right) \ln \left(1-a_{i}\right) \\
& =\ln C_{0}+(1 / 2) \int_{0}^{1} n(a)(1+a) \ln (1+a) d a+(1 / 2) \int_{0}^{1} n(a)(1-a) \ln (1-a) d a
\end{aligned}
$$

Therefore, taking the antilog of each side and using $n(a)-\Phi(\mathrm{a}) \mathrm{N}_{1}$

$$
\begin{aligned}
C_{n}{ }^{\prime} & =C_{0} \exp \left\{(1 / 2) \int_{0}^{1}{ }^{n}(a)[(1+a) \ln (1+a)+(1-a) \ln (1-a)] d a\right\} \\
& =C_{0} \exp \left\{(1 / 2) N_{1} \int_{0}^{1} \Phi(a)[(1+a) \ln (1+a)+(1-0) \ln (1-a)] d a\right\}
\end{aligned}
$$

or in terms of total trials

$C_{n^{\prime}}=C_{a} \exp \left\{(1 / 2) A_{1}\left(1-p \lambda_{1}\right) f_{1}^{\prime} \Phi(0)[(1+0) \ln (1+a)+(1-0) \ln \{1-0)] d o\right\}$ 
Then, if the expression in the brackets is donated by $S_{1} A_{1}$ i.e.

$$
\begin{aligned}
& \mathrm{s}_{1}=\Delta_{1}(1 / 2)\left(1-p_{\lambda_{1}}\right) j^{*} \Phi(a)[(1+a) \ln (1+a)+(1-a) \ln (1-a)] \text { da } \\
& \text { equation } \mathrm{C}_{\mathrm{n}}{ }^{\prime} \text { becomes }
\end{aligned}
$$

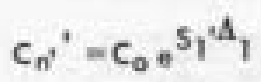

where $S_{1}{ }^{\prime}$ is to be determined by a suitable monte carlo method and, furthermore, is expected to be positive. Then, adding on the contribution due to flat bets for $\mathrm{a}-\mathrm{O}$,

$$
\begin{aligned}
& C_{n^{*}}=C_{0} \exp \left\{(1 / 2) \Lambda_{1}\left(1-p \lambda_{1}\right) \int_{0}^{1} \Phi(a)[(1+a) \ln (1+a)+(1-a) \ln (1-a)] d a\right. \\
&+b_{m} \sigma \Lambda \\
&=C_{0} e^{S_{1} \Lambda_{1}}+s_{2} \Lambda_{2} \\
& \text { where } \\
& S_{2}=b_{m} \sigma
\end{aligned}
$$

Introducing another observable quantity, $\mathrm{k}$, such that

$$
\Delta_{1}=\mathrm{kA}
$$

then $\mathrm{k}$, as well as $\sigma_{z}$ is an observable quantity. Combining yields

$$
\mathrm{C}_{n^{\prime}} *=\mathrm{c}_{\mathrm{e}} \mathrm{s}^{\mathrm{s}} \mathrm{A}+\mathrm{s}_{2} \mathrm{~A}
$$

Note that this equation is our objective function, and is exact if $b_{m}$ can be chosen to be zero. Essentially it is the integral in $S_{1}$ that must be maximized. Differentiating by time gives

$$
\dot{\mathrm{C}}^{*}=\mathrm{C}_{0} \mathrm{~s}_{1} \ddot{\mathrm{A}}_{e} \mathrm{~s}_{1} \Lambda+\mathrm{s}_{2} \dot{\Lambda}
$$

or if one is interested in the change of current capital per trial

$$
d C^{*} / d A=C_{0} s_{1}{ }^{s_{1} A}+s_{2}
$$




\section{MIN-MAX BETTING}

At this time it is of some interest to compare optimal fractional betting with betting a flat (constant) amount, $\mathrm{B}_{\text {䊐 }}$ for $\mathrm{a}>\mathrm{O}$, and $\mathrm{b}_{\mathrm{m}}$ for $\mathrm{a}-\mathrm{O}$, i.e. a maximum and a minimum bet

$$
\begin{aligned}
C_{n} & =C_{0}+B_{m} \sum_{i=1}^{\sum_{j}}\left(W--L_{i}\right)+b_{m}(w-a) \\
& =C_{0}+B_{m} i_{i=1}^{\sum_{i} a_{i}}+b_{m}(w-a) \\
& =C_{0}+B_{m} \int_{0}^{1} n(a) a d a+b_{m}(w-a) \\
& =C_{0}+B_{m} N_{1} \int_{0}^{1} \Phi(a) a d a+b_{m}(w-a)
\end{aligned}
$$

or in terms of the number of trials

$$
\begin{aligned}
\bar{C}_{n^{\prime}} & =C_{0}+B_{m} A_{1}\left(1-P_{\lambda_{1}}\right) \int_{0} \Phi(a) \mathbf{a} \mathbf{d a}+b_{m} \sigma \Lambda \\
& =C_{0}+A k B_{m}\left(1-p_{\lambda_{1}}\right) \int_{0}^{1} \Phi(a) a d a+b_{m} \sigma A \\
& =C_{0}+\mathbf{A T}
\end{aligned}
$$

where $\mathbf{T}$ is defined as

$$
\mathbf{T} \equiv k_{B_{m}}\left(1-p_{\lambda_{1}}\right) \int_{0}^{1} \Phi(a) a d a+b_{m} \sigma
$$

One may compute the breakeven point for fractional betting over min-max betting, i.e. if $B_{m}$ is large enough, the slope of $C_{m}$, may be larger than $\mathrm{dC}^{*} / \mathrm{dA}$ at $\mathrm{n}=\mathrm{O}$. However, the fractional betting must eventually overtake min-max betting as long as $S_{1}>\mathrm{O}$, no matter how small $S_{1}$ might be. Furthermore, the risk of ruin for min-max betting is undoubtedly very large compared to fractional betting (Epstein, 1967) - Let $y$ be the breakeven point. Then $\gamma$ is the value of A which satisfies

$$
\begin{aligned}
& \mathrm{C}=\mathrm{C}_{0}+\mathrm{AT} \\
& \mathrm{c}=\mathrm{C}_{0} e^{\mathrm{s}_{1} \mathrm{~A}}+\mathrm{S}_{4} \mathrm{~A}
\end{aligned}
$$


or

$$
f(A)=e^{S_{1} \Lambda}-1-\sigma \Lambda=0, \sigma=\left(T-S_{2}\right) / C_{0}
$$

In the casino game fractional betting must be dropped and min$\max$ betting initiated when the bet size reaches the house limit, i.e. the point at which $\operatorname{Exp}[\mathrm{aC}]>$ maximum allowable bet. More explicitly

$$
A p=\left\{\Lambda \mid \operatorname{Exp}[a C]=C(\Lambda) \int_{g} \Phi(a) \text { a da }=B_{\max }\right\}
$$

\section{Numerical Example}

One thousand hand-generated hands (trials) were played using Thorp's ten-count strategy (1962) and optimal fractional betting. Figure 24-1 shows the observed normalized p.d.f. of a. The following numerical values were also observed

$$
\begin{aligned}
& C=100, b_{m}=1, \Delta=1000 \\
& \int_{0}^{1} \Phi(a)[(1+a) \ln (1+a)+(1-a) \ln (1-a)] d a=4 \times 10^{-3} \\
& \Lambda_{1}=472, \lambda_{1}=41, P_{\lambda_{1}}=41 / 472=.0868 \\
& \Delta_{2}=528, \lambda_{2}=47, P \lambda_{-}=47 / 528=.0890 \\
& k=.472 \\
& \sigma=-1 / 1000=-10^{,-3} \\
& s_{1}=.86 \times 10^{-3} \\
& S_{2}=-10^{3}
\end{aligned}
$$


Therefore

$$
\begin{aligned}
& \widetilde{C}_{n^{\prime}}{ }^{*}=100 \mathrm{e}^{.86 \times 10^{-3 \Lambda}}-10^{-3 \Lambda} \\
& \mathrm{C}^{*}(1000)=100 e^{.86}-1 \simeq 230
\end{aligned}
$$

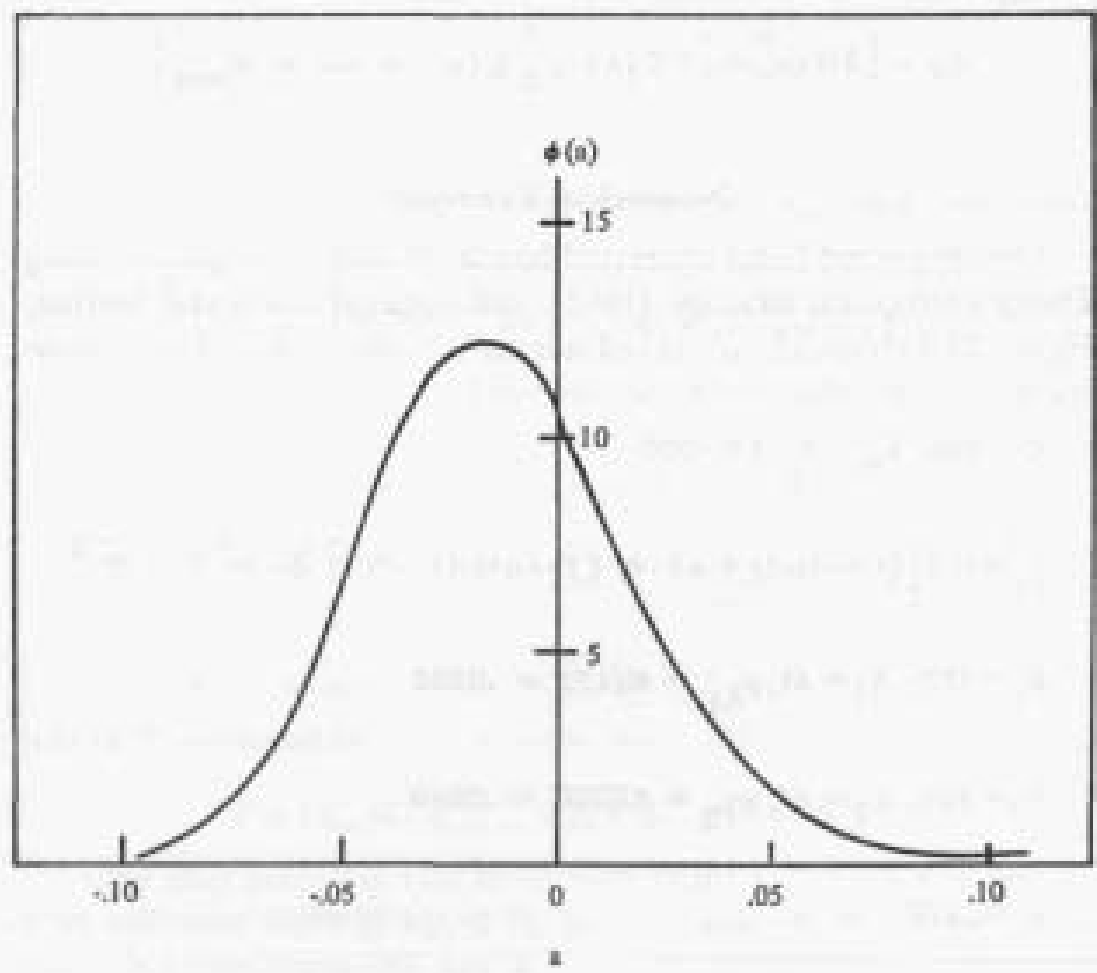

The observed p.d.f. of a for 1000 hand generated trials

Figure 24-1.

To compare with min-max betting with $B_{m}=10$, compute

$$
\begin{aligned}
& \int_{v}^{1} \Phi(0) \text { a da }=.7 \times 10^{-2} \\
& T=.28
\end{aligned}
$$


Therefore

$$
\begin{aligned}
& \tilde{c}_{n^{\prime}}=100+.28 \Lambda \\
& c(1000)=380
\end{aligned}
$$

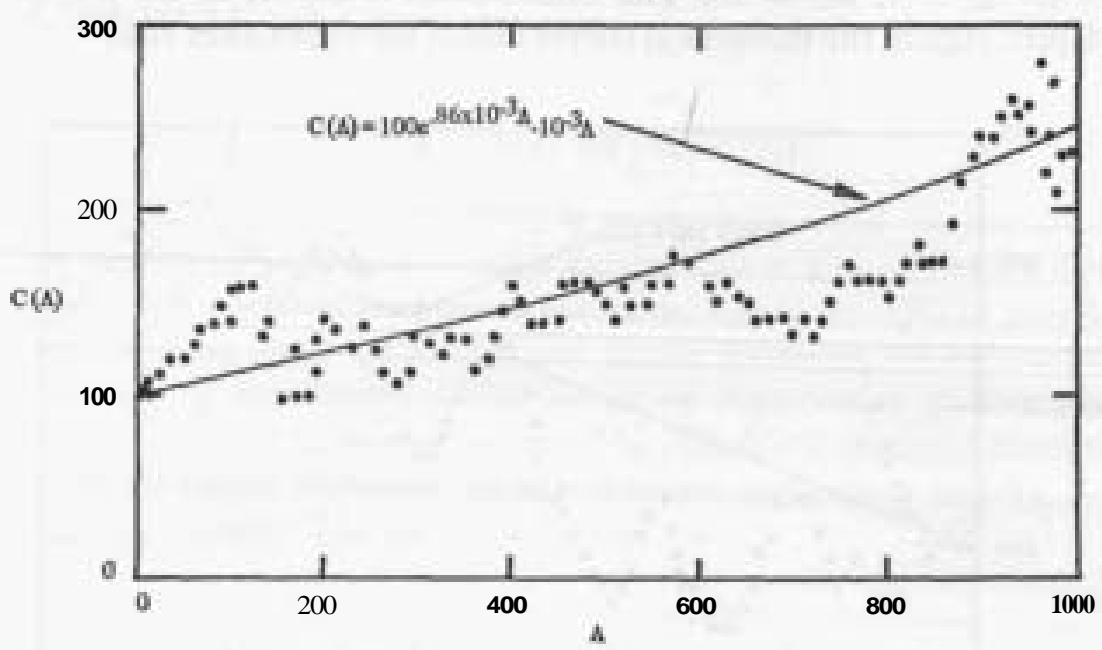

Outcome of 1000 played hands (every tenth plotted) played by Thorp intratep and optimal fractional betting, $C(0)=100, b_{m}=1$, betting rounded off to nearest O.S wit, 52 tad deck played only if 7 cauer remain.

Figure24-2.

The actual plot of every fifth hand is shown in Figure 24-2 along with theoretical $\mathrm{C}=\mathrm{C}$ (A) plot as just calculated. The fit seems tolerable. One can now compute the overall advantage and effective advantages of this run

$$
\begin{aligned}
& \bar{a}=(\mathbf{N}-\mathbf{N}) / \mathbf{N}=(\mathbf{4 5 0}-\mathbf{4 6 2}) / 912=-.013 \\
& \bar{a}_{1}=\left(N_{1, W}-N_{1,4}\right) / N_{1}=(217-214) / 431=+, 007
\end{aligned}
$$

and note from independent calculations

$$
\int_{\sim}^{1} \square \Phi(a) \quad d a=+.007
$$


This agreement may be coincidental since these figures cannot be computed with any confidence on only 1000 hands. However, these advantages are reasonable and compare well with figures derived from data in Thorp (1962).

The same 1000 hands were also played using min-max betting with $b_{m}=1, B_{m}=10$. The information is shown in the below figure. Again, the theoretical curves match the data rather well.

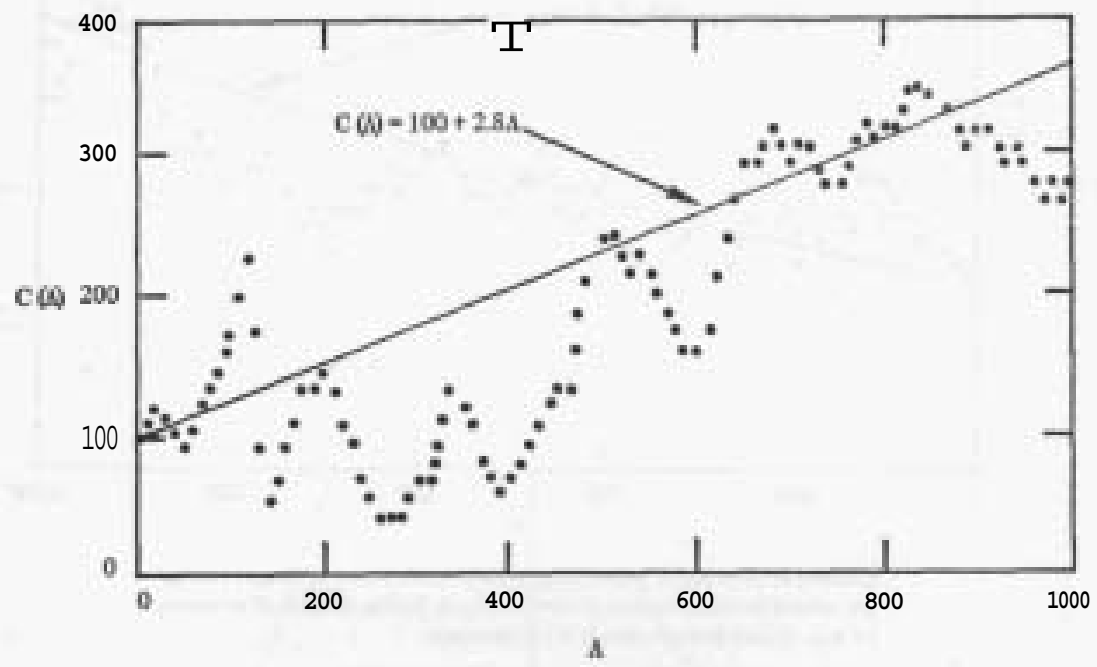

Outcome of 1000 played hands (every tenth plotted) played by Thorp's strategy and min-max settiv $\mathrm{C}(\mathrm{O})=\mathbf{1 0 0}, \mathrm{nm}_{\mathrm{m}}=1 \mathrm{M}, \mathrm{Bm}_{\mathrm{m}}=1$ betting has been rounded off to nearest 0.5 unit, 52 cuud deck poyed only if 7 cards remain.

Figure 24-3.

It is of some interest to compute the expected bet size and its variation for the case of fractional betting from the observed p.d.f. of the advantage. First, note that the distribution (p.d.f.) of bet sizes is given by

$$
f(b)= \begin{cases}\Phi(b / c) / \int_{0}^{1} \Phi(a) d a_{e}, & >0, \int_{0}^{f} f(b) d b=1 \\ 0 & , a \leq 0\end{cases}
$$


where $\mathrm{b}$ is the bet size, $\mathrm{b}_{\mathrm{m}} \mathrm{aC}$, and, again, the influence of betting $\mathrm{b}=\mathrm{b}_{\mathrm{m}}$ when $\mathrm{a}-\mathrm{O}$ is being neglected. Therefore

$$
\operatorname{Exp}(b)=(1 / C) \int_{0}^{C}(a C) f(b) d(a C)=C \int_{0}^{1} a\left[\Phi(a) / \int_{0}^{1} \Phi(a) d a\right] d a=018 C
$$

$\operatorname{Var}(b)=(1 / C) \int_{0}^{C}(a C-p c)^{2} \mathbf{f}(\mathbf{b}) d(a C)$

$$
-c^{2} \int_{0}^{1}(a-\rho)^{2}\left[\Phi(a) / \int_{0}^{1} \Phi(a) d a\right] d a=.10 c^{2}
$$

where the tail of $f(b)$ was taken to be an exponential (in the spirit of Poisson's distribution) which fits the data at $\mathrm{a}=.15$, and a 0 at $\mathrm{a}=1$. This arbitrariness places the figure $\operatorname{Var}(\mathrm{b})=.15 \mathrm{C}$ in considerable doubt since the second and higher moments are influenced strongly by the nature of the associated distribution in its tails. Obviously 1000 trials is far too small to permit confident calculation of this number. However, these two values for $\operatorname{Exp}(b)$ and $\operatorname{Var}(b)$ seem reasonable. The standard deviation is

$$
\operatorname{std}(b)=\sqrt{\operatorname{Var}(b)}=.31 \mathrm{C}
$$

Finally, it will be noted that this particular run of 1000 trials was quite favorable as will be seen later on the basis of several million computer-generated hands.

\section{BLACKJACK OPTIMIZATION}

The standard Las Vegas rules for blackjack. (Thorp, 1962), a monte carlo card shuffler and dealer, the above formulas for a and s, and the decision matrices were coded in Fortran. For any choice of the thirty parameters $a_{\mathrm{b}} \mathrm{c}_{\mathrm{b}} \mathrm{k}_{\mathrm{l}}(\mathrm{i}=1, \cdots, 10)$ and of the several hundred elements of the decision matrices, the corresponding value of the current capital after $\mathrm{n}$ trials can be obtained. The relative outcome after 1000 trials has been chosen as the standard measure for comparing strategies where the strategy is defined by a particular set of values of the parameter. Two estimates of C (1000) / $\mathrm{C}(\mathrm{O})$ are available; one is the direct observed outcome and the other is the predicted, or theoretical, outcome based on the statistical estimate given by the derived formula $\mathrm{C}(\mathrm{n})=\mathrm{C}(\mathrm{O}) \exp \left(\mathrm{S}_{1} \mathrm{~A}\right)$ 


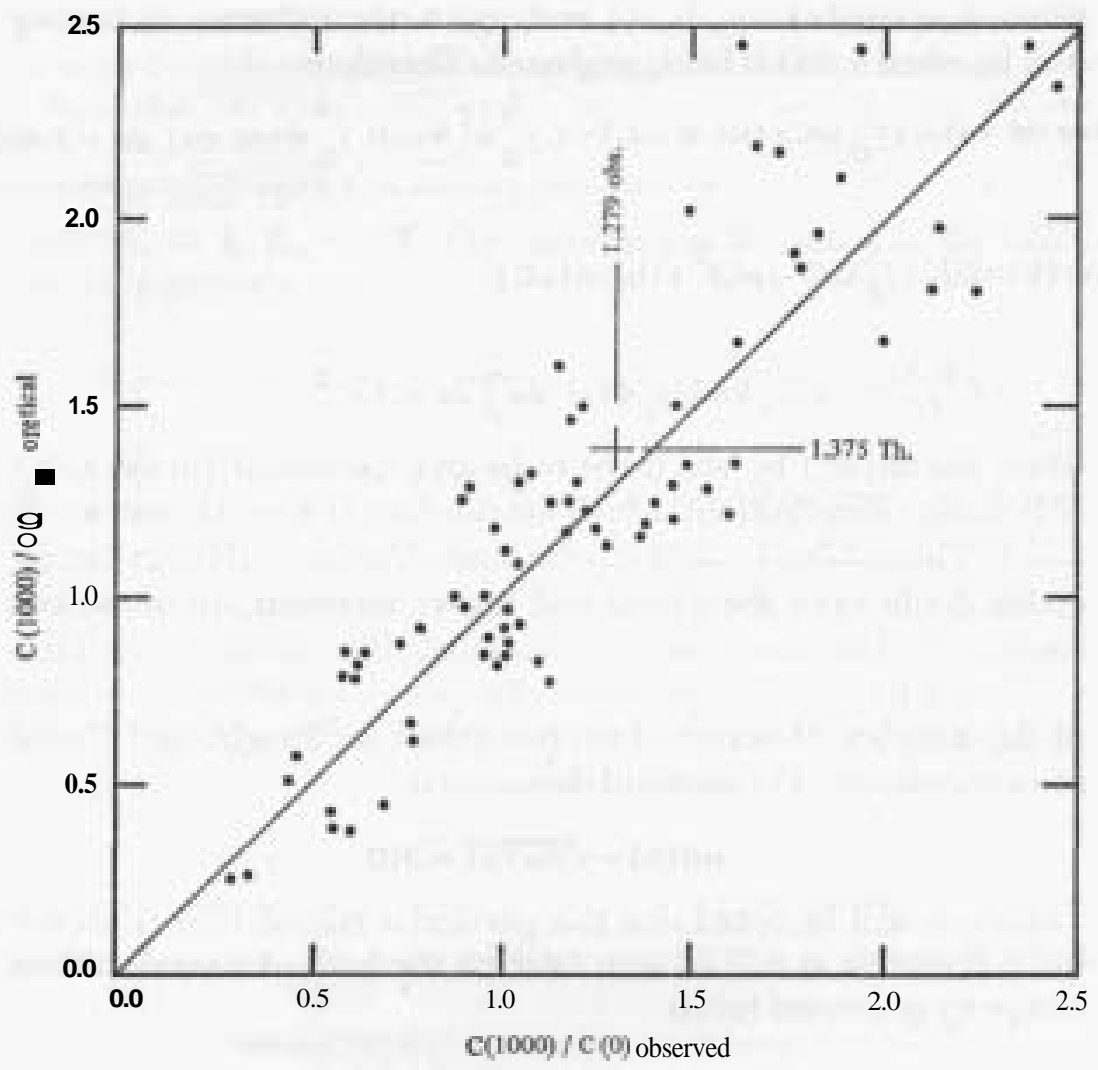

A comparison of the observed C (1000)/ C (0) with the theoretical for Thorp's strategy (with $10-0110$ ), Each point is the result of 1000 hands of blackjack. Edata points.

Figure 24-4.

$+S_{2} \mathrm{~A}$. These will be referred to as the observed and theoretical estimates, respectively. The close agreement of these two estimates as shown in Figure 24-4 indicates that either could be used to compute $\mathrm{R}=\operatorname{Exp}[\mathrm{C}(1000) / \mathrm{C}(\mathrm{O})]$. The slope of the data in Figure 24-4 may be estimated by $1.375 / 1.279 \cong 1.09$ which agrees well with the ideal value of L. Similar calculations for subsequent strategies with a larger data base gives slopes close to 1 spread throughout $1 \pm .1$ and with mean very close to 1 . The spread of the data in Figure 24-4 indicates that a blackjack player using his strategy very 
nearly 50 percent of the time actually will do worse than his advantage would indicate, and the other 50 percent he will do better than he should. The value of $\mathrm{R}$ for Thorp's strategy for 1000 values of $\mathrm{C}(1000) / \mathrm{C}(\mathrm{O})$ is 1.280 . This number is based on one million hands. The larger of $\mathrm{R}$ (observed) or $\mathrm{R}$ (theoretical) averaged over one hundred values will be used to define the function value for performing the optimization. In this way the writers tend to insure that an uphill gradient of $\mathrm{R}$ is sensed when, in fact, there is a hill to go up, i.e. here is a probability that a better strategy would yield a lower R. This happened only rarely and was corrected for by simulating $\mathrm{R}$ by a new set of random numbers.

All stimulations were performed with the well-tested random generator (Ralston and Wilf, 1967) found in the IBM Scientific Subroutine Package (1972). Interactive experiments with changing the decision matrix elements of Thorp's strategy indicated that $\mathrm{R}$ was insensitive to small changes and that Thorp's numbers are probably optimal. On this basis, Thorp's decision matrices were adopted, and the optimization was performed on thirty indicator parameters only.

An alternate directions optimization of sixty iterations was then performed on the thirty parameters, i.e. each coordinate direction was scanned twice. Figure 24-5 shows that this resulted in increasing $\mathrm{R}$ from 1.28 to 1.95 . From this it was apparent that $\mathrm{a}_{0}$ was the most sensitive parameter followed in order by $a_{10} a_{5}$ and $a_{1}$. Since the Powell method (Hammelblau, 1972) also does not require an analytic expression for the gradient of the objective function, it was used to complete the optimization. Figure 24-5 shows that after several hundred iterations the Powell method converged to $\mathrm{R}=7.132$. The parameters for this strategy are listed in Table 24-I along with those of Thorp's for comparison.

\section{Numerical Results}

The vast amount of computations needed to prepare this study were performed over several years at The Cleveland State University Computing Center by an IBM ${ }^{\circledR} 360 / 50$ and, later, by an IBM $370 / 145$.

The optimization generated a sequence of several hundred 


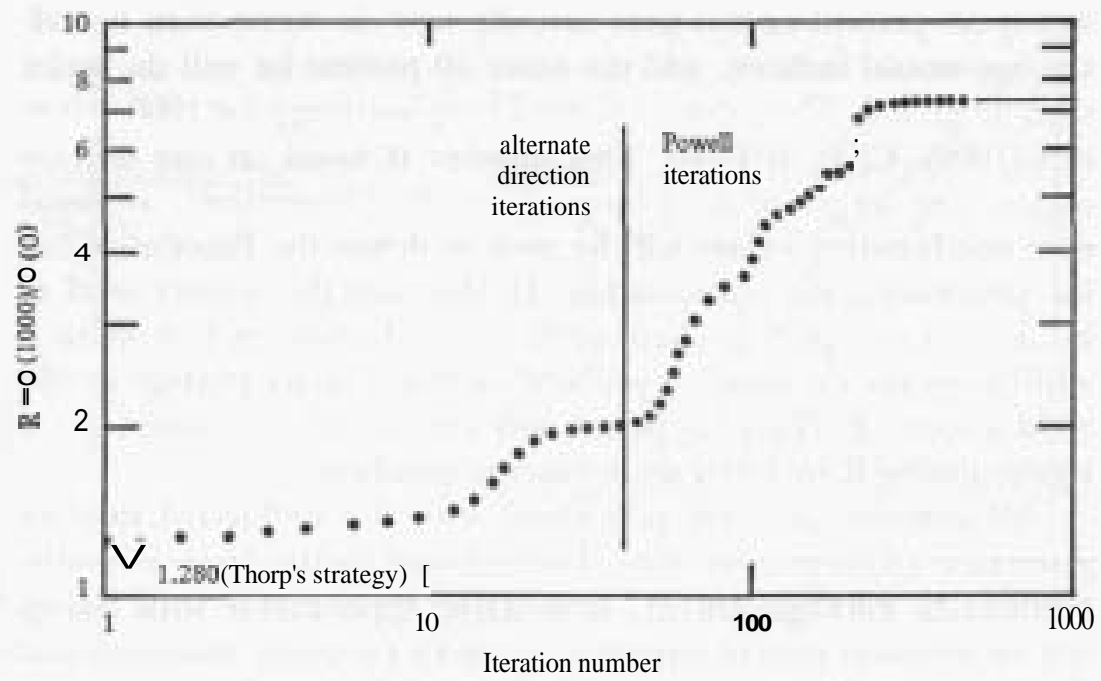

Comergence of the nonlinear program for optimizing blackjack. A function evaluation using 50 1000-handruns was used.

Figure 24-5.

strategies with increasing $\mathrm{R}$ as indicated in Figure 24-5. However, maximizing $\mathrm{R}=\operatorname{Exp} \mathrm{C}(1000) / \mathrm{C}(\mathrm{O})$ is at odds with minimizing the variance of $\mathrm{C}(1000) / \mathrm{C}(\mathrm{O})$ - Figure 24-6 summarizes how the

TABLE 24:I

Parameter for the Optimal Blackjack Strategy and the Initial (Thorp's) strategy

\begin{tabular}{|c|c|c|c|c|c|c|}
\hline \multirow[b]{2}{*}{$i$} & \multicolumn{3}{|c|}{ Optimal Strategy } & \multicolumn{3}{|c|}{ Thorp's Strategy } \\
\hline & $c_{1}$ & $\mathbf{k}_{\mathbf{y}}$ & $x_{1}$ & $c_{1}$ & $\mathbf{k}_{1}$ & $\mathbf{z}_{1}$ \\
\hline 0 & $\ldots$ & $\cdots$ & 0.06250 & 0 & $+\ldots$ & -0.210 \\
\hline 1 & 0.00383 & 1.00000 & -0.28100 & 0 & $\ldots$ & $-0,315$ \\
\hline 2 & -0.01090 & 1.01648 & 0.23762 & 0 & $\ldots$ & 0.175 \\
\hline 3 & 0.0 & 1.00008 & 0.21204 & 0 & $+\cdots$ & 0.210 \\
\hline 4 & 0.01000 & 1.02000 & 0.28250 & 0 & $\ldots$ & 0.280 \\
\hline 5 & -.01000 & 1.00008 & 0.54252 & 0 & $\ldots$ & 0.385 \\
\hline 6 & 0.0 & 1.00008 & 0.21005 & 0 & $\ldots$ & 0.210 \\
\hline 7 & 0.0 & 1.00008 & 0.14070 & 0 & $\ldots$ & 0.140 \\
\hline 8 & 0.0 & 1.00008 & $-0.055 \%$ & 0 & $\ldots$ & 0.0 \\
\hline 9 & 0.0 & 1.00008 & -0.08750 & 0 & $\ldots$. & -0.105 \\
\hline 10 & 0.99750 & 0.00357 & -0.90450 & 1 & 0 & -0.245 \\
\hline
\end{tabular}




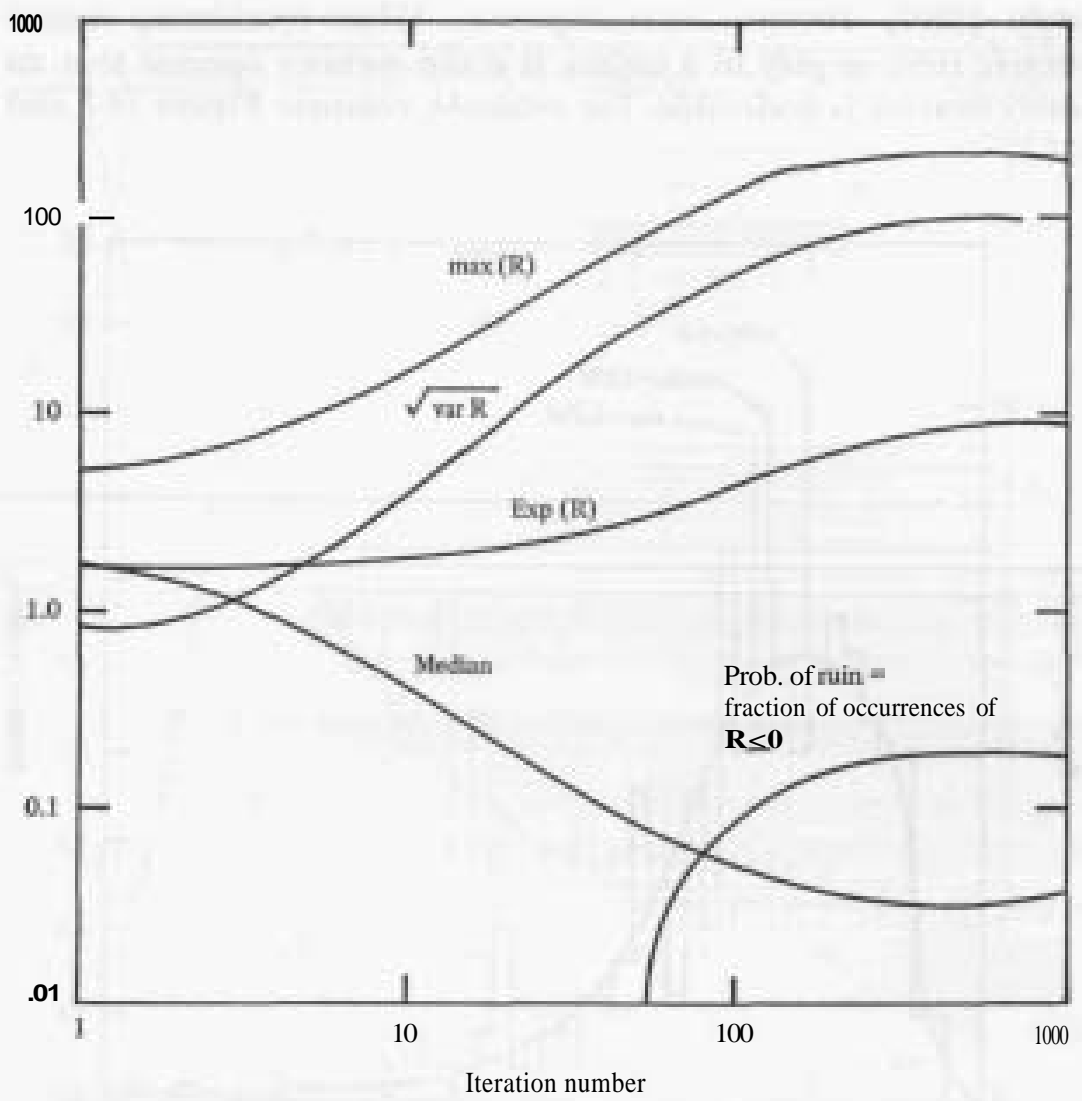

Statistics on $\mathrm{R}=\mathrm{C}(1000) / \mathrm{C}(0)$ versus iteration number

Figure 24-6.

maximum value, standard deviation, expectation and median of $\mathrm{C}(1000) / \mathrm{C}(0)$ and the probability of ruin vary throughout the optimization sequence. Note that the objective of maximizing $\mathrm{R}$ has produced a probability of ruin of about 0.30 , and a median of 0.06 . In these simulations a deck penetration of forty-two cards, a minimum bet of $b_{m}=1$ and no maximum bet limit were used; all bets were rounded to the nearest half unit. The fact is that in the casino game a maximum bet is invoked, and, furthermore, severe implicit restrictions are placed on varying the bet size (Revere, 1971). Ep- 
stein (1967) discusses other objectives. When considering the effective rules of play in a casino, it is the author's opinion that an early strategy is preferable. For example, compare Figure 24-7 and 24-8.

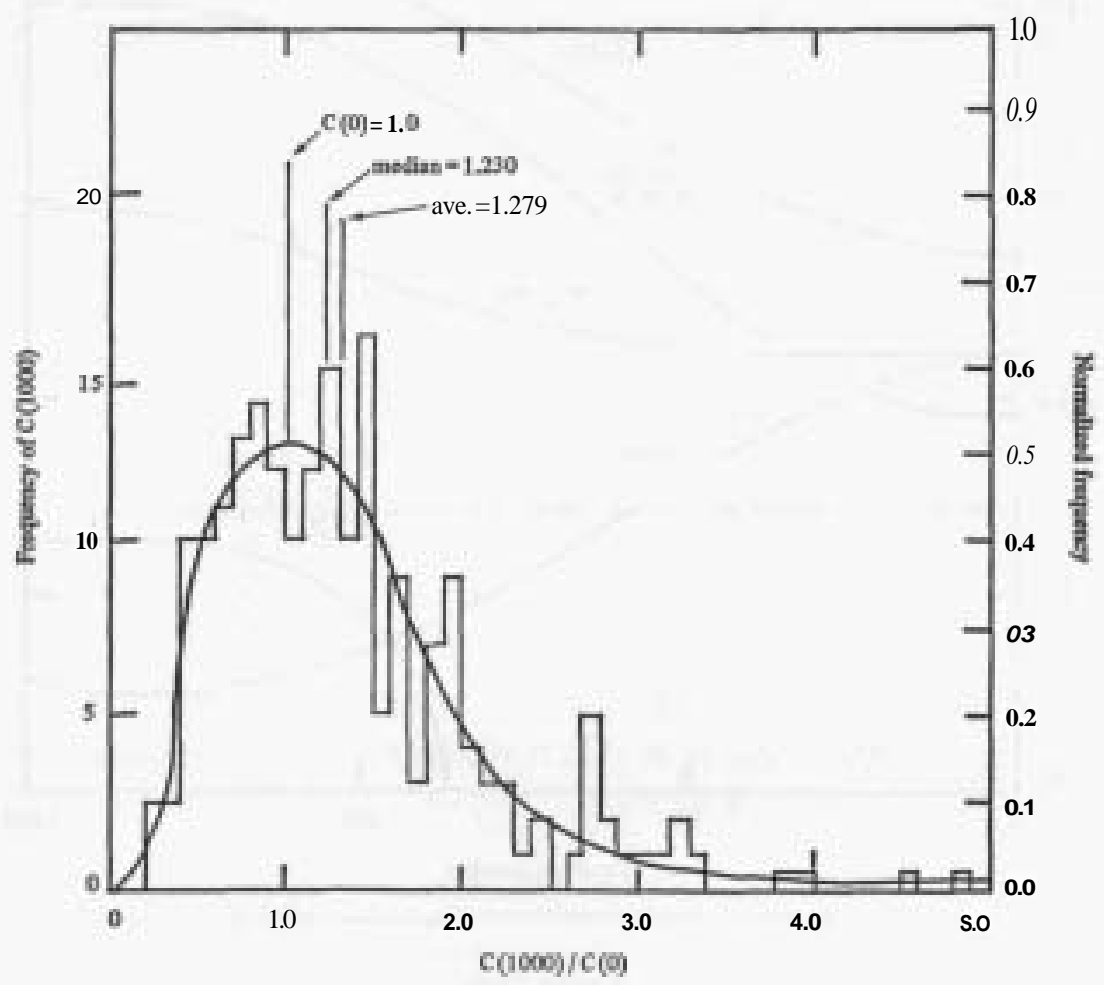

A simulation of Thorp's strategy for 200 data points of 1000 hands each.

Figure 24-7.

\section{Conclusions}

Thorp (1962) and Braun (Revere, 1971) have used combinatorial calculus to develop winning strategies for blackjack. This paper has used a different method, i.e. nonlinear programming, to derive a sequence of winning strategies. In this way, an optimal strategy for maximizing rate of winning was derived for a particular 


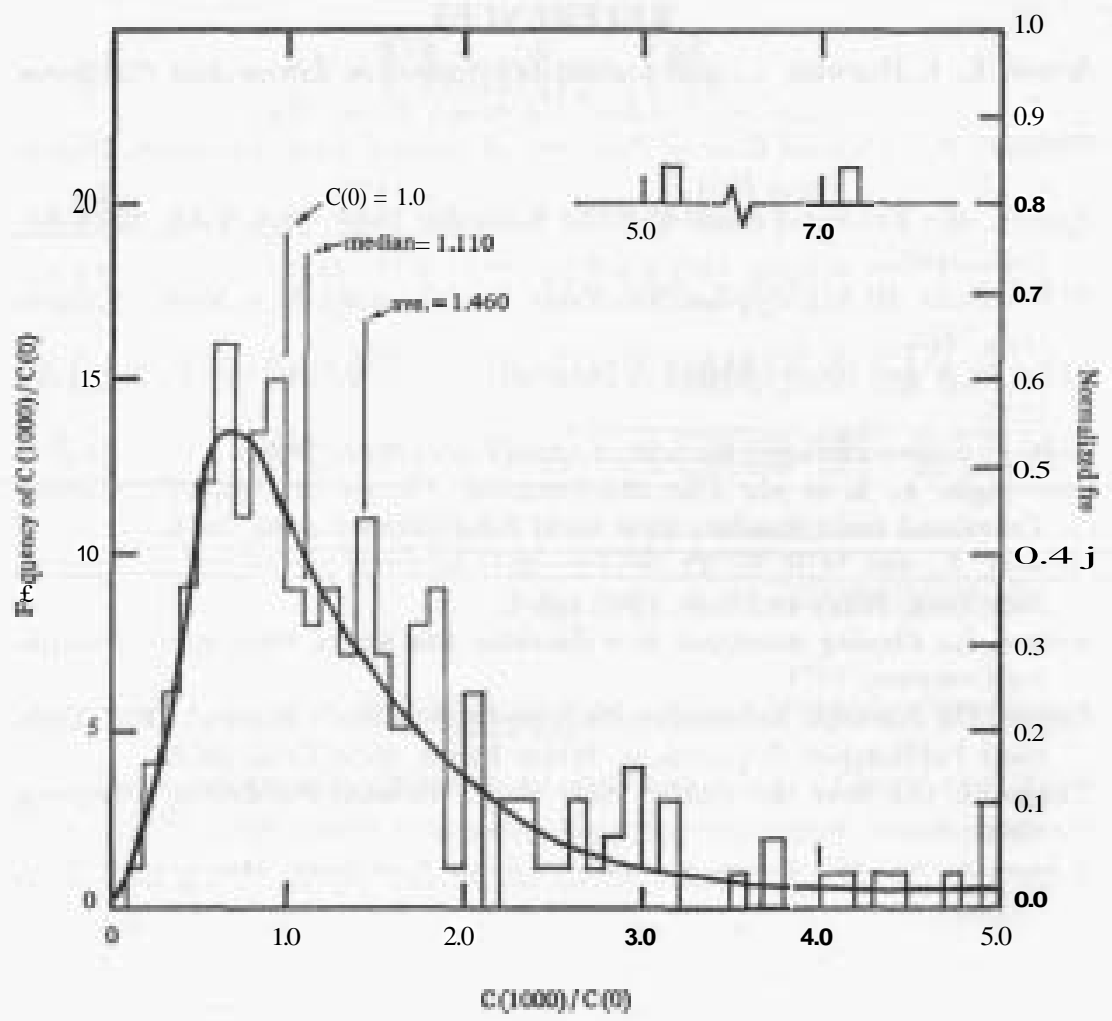

A simulation of the 20th strategy in the optimization vequense, 200 data points 1009 hands each.

Figure 24-8.

strategy form. Even though this solution required an enormous amount of computation, it is worth noting that it represents an approximate solution to Pontryagin's (1965) optimal solution for the Kolmogorov equations. Furthermore, the methods used here were not completely indicative of only the game of blackjack, but have possible applications to deterministic games in general. Moreover, these calculations suggest the power of using nonlinear programming to solve large stochastic problems. 


\section{REFERENCES}

Arrow, K. J, Hurwicz, L., and Uzawa, H.: Studies in Linear and Nonlinear Programming. Stanford, Stanford University Press, 1958.

Bellman, R.: Adaptive Control Processes: A Guided Tour. Princeton, Princeton University Press, 1961.

Epstein, R.: Theory of Gambling and Statistical Logic. New York, Academic Press, 1967.

Himmelblau, D. M.: Applied Nonlinear Programming. New York, McGrawHill, 1972.

Kelly, J.: A new interpretation of information rate. Bell System Tech J, July, 1956.

Noir, J.: Casino Holiday. Berkeley, Oxford Street Press, 1969.

Pontryagin, L. S. et alis The Mathematical Theory of Optimal Processes. Translated from Russian. New York, John Wiley \& Sons, 1965.

Ralston, A., and Wilt, H. S.: Mathematical Methods for Digital Computers. New York, Wiley and Sons, 1967, vol. 2.

Revere, L.: Playing Blackjack as a Business. Las Vegas, Paul Mann Publishing Company, 1971.

System/370 Scientific Subroutine Package Programmer's Manual. IBM Technical Publications Department, White Plains, New York, 1972.

Thorp, E. O.: Beat the Dealer. New York, Blaisdell Publishing Company, 1962.

Wilson, A. N.: The Casino Gambler's Guide. New York, Harper and Row, 1965. 


\title{
Chapter 25
}

\section{THE RATE DF BAIN II PLAYER EXPEC- TATION FOH EARD GAMES CHARACTER- IZED BY SAMPLING WITHUUT REPLACE- MENT AND AN EVALUATION OF CARD COUNTING SYSTEMS}

\author{
PETER GRIFFIN
}

\begin{abstract}
The fundamental theorem of card-counting (Thorp and Walden, 1973) establishes the increasing variance and nondecreasing nature of player expectation for games characterized by sampling without replacement. An approximate expression is developed here for the player's gain in expectation as a function of the number of unplayed cards for a certain class of such games. Evidence is presented that many games of interest such as blackjack may be approximately of this class. In addition, a method of evaluating cardcounting systems is developed.

\section{Introduction}

Consider the following games played with a standard fifty-twocard deck: 1. In Red-Black (Thorp and Walden, 1973), a deck of cards is dealt through one at a time. Before each card is turned the player has the option of wagering, at even money, that the next card will be red. For a full deck the game has 0 expectation, but, as the cards are dealt, the deck will be favorable about half the time for this wager. The player who keeps track of the composition of the unplayed cards (the card counter) will recognize and be able to exploit the favorable situations. 2. A deck of
\end{abstract}


cards is dealt through one-at-a-time. The player who wagers receives two units if the next card is a heart, three units for a diamond, and loses one unit for a spade and five units for a club. Full-deck expectation for the player is $-2,25$ if the wager is accepted. Once again, as the deck is depleted, there will occasionally arise favorable situations; the card counter will bet only in these cases. (This is the suit-payoff game.)

Intuition (as well as the fundamental theorem) suggests that things get better for the card counter as the deck is increasingly depleted. A formula will be presented which approximates quite well the card counter's expectation as the deck is dealt through. The class of games to which the formula applies will be defined, and it will be argued (empirically) that it is approximately applicable to changes of strategy which occur in the game of blackjack.

\section{Derivation of the Approximation}

Suppose the payoff in a game of cards is determined only by the next card played rather than by some subsequent arrangement of more than one card. Let pi be the player's payoff for the $\mathrm{i}^{\mathrm{w}} \mathrm{card}$ in the deck. Then, if it is assumed for simplicity of exposition a fiftytwo-card deck (the generalization is immediate and obvious),

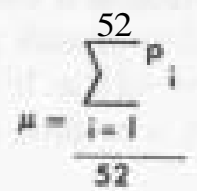

is the player's expectation and

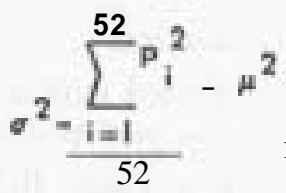

is the variance of the payoff.

For a subset of $\mathrm{n}$ remaining cards the player's expectation is

$$
\bar{x}=\frac{\sum_{i=1}^{n} x_{i}}{n}
$$

where $\mathrm{X}_{\mathrm{a}}$ is the payoff of the $\mathrm{i}^{\mathrm{th}}$ card in the subset. 


$$
\operatorname{Var}\left(\sum_{i=1}^{n} x_{i}\right)=n \sigma^{2}+n(n-1) \operatorname{Cov}(X \underset{i \neq i}{i \neq i} i
$$

$\underset{i \neq i \quad i j}{\operatorname{Cov}(x, x)}=\frac{1}{52} \sum_{i=1}^{52} p_{i}\left(\frac{1}{51} \sum_{i+i} p_{i}\right)-\mu^{2}$.

$$
\frac{1}{52 \cdot 51} \sum_{i=1}^{52, p_{i}\left(52 \mu-p_{i}\right)-\mu^{7}=}
$$

$$
\frac{1}{51}\left(\mu^{2}-\frac{\sum^{2} p_{i}}{52}\right)=-\frac{\sigma^{2}}{51}
$$

From this

$$
\operatorname{Var}\left(\sum_{i=1}^{n} x_{i}\right)=n \sigma^{2}\left(\frac{52-n}{51}\right)
$$

Let

$$
\left.b^{2}=\operatorname{Vor} X=\begin{array}{ll}
\frac{z^{2}}{n} & (52-2 \\
\text { V } 51^{2}
\end{array}\right)
$$

By a version of the central limit theorem for correlated summands (Erdos, and Renyi, A.z 1959), $\mathrm{X}$ is approximately normally distributed. Assume $\mu-0$, and that the card counter only accepts the wager when it is favorable. (If $\mu>0$, then one is approximating what the card counter saves by not betting.) The card counter's ex- 
pectation with $\mathrm{n}$ cards remaining, $\mathrm{E}(\mathrm{n})$, can be approximated by an integral,

$$
E(n)-\frac{1}{\sqrt{2 \pi^{b}}} \int_{0} 7 e^{-\frac{1}{2}\left(\frac{\bar{x}-\mu}{b}\right)^{2}} d \bar{x}
$$

Standardizing

$$
\bar{x} \text { by } y=\frac{\bar{x}-\mu}{b}
$$

$$
E(n) \sim \frac{b}{\sqrt{2 \pi}} e^{\frac{-\mu^{2}}{2 b^{2}}}-|\mu| \cdot \int_{\frac{\mu y}{b}}^{+\infty} \frac{1}{\sqrt{2 \pi}} e^{-\frac{y^{2}}{2}} d y
$$

(The integral in the second term is an approximation to the probability that the bet will be favorable.)

Scrutiny of this relation in each variable separately shows $E(n)$ increases as $\mathrm{n}$ decreases, as $\sigma$ increases and as $|\mu|$ decreases.

A comparison of the approximate and actual values of $\mathrm{E}(\mathrm{n})$ is exhibited for the two examples in Tables 25-I and 25-II. The expectation for example 1 follows a curious pattern with $\mathrm{E}(2 \mathrm{n}+1)=$ $\mathrm{E}(2 \mathrm{n})$; hence, the approximation was evaluated halfway between these two integers.

TABLE \%-I

ACTUAL AND APPROXIMATE EXPECTATIONS FOR RED BLACK GAME

\begin{tabular}{ccc}
$\begin{array}{c}\text { Number of Cards } \\
\text { Remaining }\end{array}$ & Actual Expectation & Approximation \\
\hline 1 & .5000 & .5670 \\
2,3 & .2451 & .2486 \\
4,5 & .1801 & .1815 \\
10,11 & .1105 & .1111 \\
20,21 & .0689 & .0693 \\
30,31 & .0467 & .0469 \\
40,41 & .0296 & .0298 \\
46,47 & .0192 & .0192 \\
48,49 & .0150 & .0150 \\
50,51 & .0098 & .0096 \\
\hline
\end{tabular}


TABLE 25-II

ACTUAL AND APPROXIMATE EXPECTATIONS FOR SUIT PAYOFF GAME

\begin{tabular}{ccc}
$\begin{array}{c}\text { Number of Cards } \\
\text { Remaining }\end{array}$ & Actual Expectation & Approximation \\
\hline 1 & 1.2500 & 1.1207 \\
2 & .8039 & .7501 \\
3 & .5796 & .5848 \\
11 & .2255 & .2254 \\
21 & .1093 & .1094 \\
31 & .0520 & .0515 \\
41 & .0160 & .0153 \\
48 & .0012 & .0011 \\
49 & .0005 & .0004 \\
50 & .00000 & .00002 \\
\hline
\end{tabular}

\section{Application to Blackjack}

Blackjack. (Epstein, 1967 and Thorp, 1962) differs from the previous assumptions in many respects; the player may hold any one of fifty-five hands, and the dealer exposes any one of ten distinct cards. The player's payoff is often not determined by the next card, but rather by two or perhaps more cards. The player's possible changes in strategy can be thought of as many embedded subgames.

Consider the player who holds a total of 16 when the dealer shows a ten. The exact cards comprising the player's total are important only as they reveal information about the remaining cards in the deck, so suppose temporarily that the player possesses a piece of paper on which is written his current total of 16 , and that the game of 16 versus 10 is played from a fifty-one-card deck (52 less the dealer's 10 ). Computer calculations show that the player who draws a card to such an abstract total of 16 has an expectation of -5267 , while if he stands on 16 , his expectation is $-.5350 . \mathrm{He}$ is therefore .0083 better off to draw than stand for a full fifty-one-card deck.

Suppose now that it is known that one 5 has been removed from the deck. Faced with this reduced fifty-card deck, the player's 
expectation by drawing is -.5574 while his expectation by not drawing is -.5396 . In this case he should stand on 16; the effect of the removal of one 5 is a reduction of the original .0083 favorability for drawing by .0261 to,- 0178 . In similar fashion one can determine the effect of the removal of each type of card. These effects are given in Table 25-III.

TABLE 5 -III

EFFECT OF REMOVAL ON FAVORABILITY OF HITTING 16 VERSUS 10

\begin{tabular}{|c|c|c|c|c|c|c|c|c|c|c|}
\hline Card Removed & A & 2 & 3 & 4 & 5 & 6 & 7 & 8 & 9 & 10 \\
\hline $\begin{array}{l}\text { Effect of } \\
\text { Removal }\end{array}$ & $-.005 s$ & $3-0055$ & -0099 & -0181 & -0261 & .0170 & -.0067 & .0000 & .0066 & .0123 \\
\hline
\end{tabular}

The average of these effects for the fifty-one-carddeck is 0 since the player's gain in expectation by hitting is unchanged over all such removals.

Now, construct a one-card payoff game of the type encountered in section 2 where the player's payoff is

$$
\mathbf{P}_{1}=.0083-50 \mathrm{E}_{1}
$$

$E_{1}$ is the effect just described of the removal of the $i^{\text {it }}$ card and $50=51-1$. (Recall that our game is played from a fifty-one, rather than a 52-card deck.) The player's expectation is $\mu=.0083$ just as the blackjack player gains an average of .0083 by hitting 16 against a ten rather than standing. By construction, $E_{4}$ is also the effect of removing the $\mathrm{i}^{\mathrm{t}}$ card from the single card payoff game, which will henceforth be referred to as the pseudogame.

Approximate determination of whether the blackjack player should hit or stand for a particular subset of the full deck can be made by considering the favorability or nonfavorability of the pseudogame. In addition, the amount the player gains or loses by hitting is approximately the payoff of the pseudogame for the particular subset.

The two games, 16 versus 10 and the pseudogame, would be precisely equivalent if, in 16 versus 10 (a) the player's expectation for a subset of the full deck were the same for a homogeneously proportional fifty-one-card deck, and (b) there were additive, noninteractive effects due to removing and replacing cards of different 
types in a fifty-one-card deck. The degree to which the two games differ is attributable to the assumptions being only approximately applicable to blackjack. They do apply to the pseudogame.

Subsets of size $5,11,17$ and 23 were simulated 2550 times each, with simultaneous conduction of " $\mathbf{K}$ versus dealer's 10 " (K- -12 , $13,14,15,16)$ and the corresponding pseudogames. The results are exhibited in Table 25-IV.

\section{TABLE 25-IV}

COMPARISON OF ACTUAL BLACKJACK STRATEGIES WITH PSHUDOSTRATEGIES AND APPROXIMATIONS TO THE PSEUDO STRATEGIES

\begin{tabular}{|c|c|c|c|c|c|c|c|}
\hline \multirow{2}{*}{$\begin{array}{l}\text { Cards } \\
\text { Remaining } \\
\text { in Deck }\end{array}$} & \multirow[t]{2}{*}{$\begin{array}{c}\text { Flayers } \\
\text { Total }\end{array}$} & \multicolumn{2}{|c|}{$\begin{array}{c}\text { Actual } \\
\text { Bleckitek Game }\end{array}$} & \multicolumn{2}{|c|}{ Pseudo Game } & \multicolumn{2}{|c|}{$\begin{array}{l}\text { Approximation to } \\
\text { the Frmula Game }\end{array}$} \\
\hline & & (a) & (b) & (c) & (d) & (e) & 10 \\
\hline \multirow{5}{*}{5} & 12 & .307 & .0555 & .321 & .0623 & .316 & .0644 \\
\hline & 13 & .348 & .0824 & .415 & .0866 & .363 & .0841 \\
\hline & 14 & .437 & .0872 & .461 & .0879 & .397 & .0890 \\
\hline & 15 & .436 & .0651 & .424 & .0754 & .429 & .0747 \\
\hline & 16 & .495 & .1049 & .501 & .1061 & .488 & .1027 \\
\hline \multirow{5}{*}{11} & 12 & .214 & .0221 & .218 & .0253 & .220 & .0252 \\
\hline & 13 & .311 & .0367 & .311 & .0392 & .291 & .0389 \\
\hline & 14 & .327 & .0402 & .351 & .0430 & 341 & .0460 \\
\hline & 15 & .401 & .0347 & .397 & .0419 & .386 & .0406 \\
\hline & 16 & .503 & .0641 & .492 & .0672 & .480 & .0632 \\
\hline & 12 & .137 & .0097 & .155 & .0111 & .149 & 0113 \\
\hline & 13 & .222 & .0189 & .233 & .0201 & .230 & .0210 \\
\hline \multirow[t]{5}{*}{17} & 14 & .288 & .0254 & .300 & .0265 & 291 & .0271 \\
\hline & 15 & .351 & .0224 & .354 & .0265 & .345 & .0258 \\
\hline & 16 & .492 & .0454 & .478 & .0474 & .472 & .0461 \\
\hline & 12 & .087 & .0040 & .095 & .0048 & .092 & .0047 \\
\hline & 13 & .164 & .0104 & .181 & .0114 & .169 & .0109 \\
\hline \multirow[t]{3}{*}{23} & 14 & .243 & .0169 & .251 & .0180 & .239 & .0165 \\
\hline & 15 & .317 & .0155 & .311 & .0180 & .305 & .0173 \\
\hline & 16 & .486 & .0358 & .473 & .0371 & .464 & .0346 \\
\hline
\end{tabular}


Column a gives the frequency of change in strategy for $\mathrm{K}$ versus 10 , and column $\mathrm{b}$ gives the gain in player expectation due to recognizing these changes in strategy. Columns $\mathrm{c}$ and d give the corresponding figures for the pseudogames while columns e and $\mathrm{f}$ give the estimated frequencies and expectation gains obtained with the approximation methods of section 2 applied to the pseudogames.

TABLE 25-V

EFFICIENCIES FOR PSEUDOSTRATEGIES AS DETERMINERS OF STRATEGY IN BLACKJACK

\begin{tabular}{|c|c|c|c|c|c|}
\hline $\begin{array}{c}\text { Players } \\
\text { Total }\end{array}$ & $\begin{array}{l}\text { Number of } \\
\text { Cards } \\
\text { Remaining }\end{array}$ & 5 & 11 & 17 & 23 \\
\hline 12 & & .867 & .946 & .956 & .957 \\
\hline 13 & & .913 & .940 & .960 & .951 \\
\hline 14 & & .947 & .944 & .960 & .971 \\
\hline 15 & & .921 & .957 & .968 & .970 \\
\hline 16 & & .908 & .971 & .979 & .983 \\
\hline
\end{tabular}

Table $25-\mathrm{V}$ gives an efficiency rating for the pseudogames as determiners of strategy in the actual blackjack situations. The figures are obtained by subtracting the expectation lost due to errors by the pseudostrategies from the figures in column b, Table 25-IV, and dividing the result by column $\mathrm{b}$. There are two types of errors the pseudostrategies are penalized for-hitting when standing is correct, and standing when hitting is correct. The pseudogames, as determiners of strategy, are better with larger subsets of the deck; by construction they are perfect with fifty cards left. Reduced numbers of simulations were conducted with the dealer presumed to show various cards other than a ten; they exhibited similar agreements and efficiencies.

\section{Evaluation of Card-Counting Systems}

A card-counting system is an assignment of point values to the cards remaining in or deleted from the deck. In practice the card counter assigns values to the cards he sees removed from the deck, the values of which are opposite to the worth of the cards if they remained in the deck; nevertheless analysis is easier in terms of the 
point values remaining in the deck.

In theory any assignment of points is permissible, but simple integers are more tractable for the human memory. In addition it is desirable to have the restriction that the count be balanced in that the sum of the point values for a full deck be zero. Some possible systems for playing the suit payoff game are exhibited in Table 25-VI.

TABLE 25-VI

POINT VALUES AND CORRELATION COEFFICIENTS FOR CARD-COUNTING SYSTEMS FOR SUIT PAYOFF GAME

\begin{tabular}{crrrrr}
\hline System & Spades & Hearts & Diamonds & Clubs & P \\
\hline A & -1 & 2 & 3 & -5 & 1.00 \\
A $^{-}$ & 3 & -9 & -13 & 19 & -1.00 \\
B & 1 & 1 & 1 & -3 & .884 \\
C & 0 & 0 & 1 & -1 & .908 \\
D & 1 & -1 & 0 & -0 & .341 \\
E & 0 & 1 & 1 & -2 & .984 \\
\hline
\end{tabular}

The average point value of the remaining cards would be used as a decision index to take the wager or not. System A is optimal (point values are precisely the payoffs) but not balanced. It could be translated into a balanced count $\mathbf{A}^{\prime}$ where point values are proportional to the effect of removal of a single card of each suit. The point values for $A^{\prime}$ would be assigned as the cards were removed. In this case the wager would be favorable if the total point values assigned divided by the number of unplayed cards was greater than $\mathbb{L}$.

System B balances clubs against nonclubs. Systems C and D ignore two suits and balances the remaining ones against each other while $\mathrm{E}$ ignores spades and balances clubs against the red suits.

The derivations in section 2 establish that the card-counting system's average point values themselves are approximately normally distributed; their utility for playing the suit payoff game will be seen to depend on their correlation coefficients with the actual payoffs for the game. Since $A^{\prime}$ is a linear function of A (by the discussion of pseudogames in section 8 ), we could more easily change the signs of the point values and correlate the card-counting systems with $A^{\prime}$ since it is also balanced. 
To derive the approximate relation between a card-counting system and a single-card payoff game (with a fixed number ofcards remaining in the deck) we will assume that $X$, the average payoff for the $\mathrm{n}$ card subset, and $\mathrm{Y}$, the average point value for the cardcounting system, are bivariate normal with correlation coefficient $p$ and marginal distributions as in section 2 . For simplicity, assume a balanced point count normed so the $\mathrm{Y}$ is $\mathrm{N}(0,1)$. We have the density

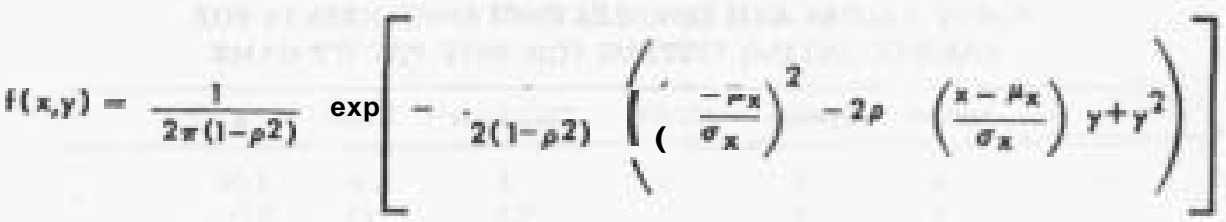
and the relation

$$
' E(X \mid Y=y)=\mu_{x}+\rho \frac{\sigma_{x}}{\sigma_{y}}\left(y-\mu_{y}\right)=\mu_{x}+\rho \sigma_{x} y
$$

Setting the conditional expectation equal to zero, and assuming as in section 2 that $\mu_{x}-0$, one will find the critical index for the card-counting system to accept the wager to be

$$
y>\frac{\left|\mu_{x}\right|}{\rho \sigma_{x}}
$$

Thus, the gain available from using this system will be given by the double integral

$$
h(\varphi)=\int_{-\infty}^{+\infty} \int \frac{\left|\mu_{x}\right|}{\rho \sigma_{x}} x \cdot f(x, y) d y d x
$$

By completing the square on $\mathrm{x}$ in the exponent of the density and interchanging the order of integration, one obtains

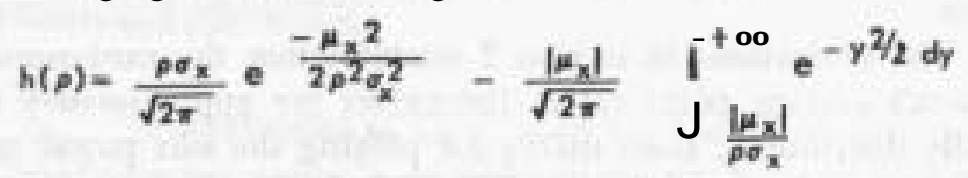

which is the same as $E(n)$ from section 2 with $p \sigma_{x}$ replacing $b$.

Defining the efficiency of a card-counting system to be the ratio of profit from using the system to total profit possible, $\mathrm{E}(\mathrm{n})$ if $\mu_{x}=$ $\mathrm{O}$, the efficiency will be precisely equal to $p$, the correlation coefli- 
cient. In any case, $\mathrm{h}(\mathrm{p})$ can be shown to be an increasing functionof $\mathrm{p}$ by the same argument which established $\mathrm{E}(\mathrm{n})$ to be an increasing function of cr.

Further, rewriting

$$
h(\rho)=\rho\left[\frac{\sigma_{x}}{\sqrt{2 \pi}} e^{-\left(\frac{\mu_{x}}{\rho}\right)^{2} / 2 \sigma_{x}^{2}}-\left|\frac{\mu_{x}}{p}\right| \cdot \frac{1}{\sqrt{2 \pi}} \int_{\left|\frac{\mu_{x}}{\rho}\right|_{/ \sigma_{x}}^{+\infty}} e^{-y^{\overline{1} / 2} d y}\right]
$$

the argument may be invoked that $\mathrm{E}(\mathrm{n})$ decreases as $|\mu|$ increases to conclude, since

$$
\left|\frac{\mu_{x}}{\rho}\right| \geq\left|\mu_{x}\right| \text {, that } h(\rho) \leq \rho \cdot E(n)
$$

and that efficiency will be less than $\mathrm{p}$ if $\mathrm{p}<1$ and $\mu_{x} \neq 0$.

A similar, but slightly more detailed argument establishes that if the preceding conditions hold, then the efficiency must improve as the deck is depleted. Since $n$ is discretely bound away from zero one cannot conclude that efficiency approaches $\mathrm{p}$ as $\mathrm{n}$ decreases, but this tendency appears to exist if $\mathrm{p}$ is large or $|\mu| / \sigma$ is small.

TABLE 25-VII

ACTUAL (a) AND ESTIMATED (b) EFFICIENCIES FOR CARD COUNTING SYSTEMS FOR SUIT PAYOFF GAME

\begin{tabular}{ccccccccc}
\hline \multicolumn{2}{c}{$\mathrm{B}$} & \multicolumn{2}{c}{$\mathrm{C}$} & \multicolumn{2}{c}{$\mathrm{D}$} & \multicolumn{2}{c}{$\mathrm{E}$} \\
\hline $\mathrm{a} / p$ & \multicolumn{2}{c}{.884} & \multicolumn{2}{c}{.908} & \multicolumn{2}{c}{.341} & \multicolumn{2}{c}{.984} \\
1 & .800 & .872 & .600 & .898 & .400 & .277 & 1.000 & .982 \\
2 & .927 & .867 & .774 & .894 & .305 & .251 & 1.000 & .982 \\
3 & .951 & .862 & .876 & .891 & .282 & .231 & .974 & .981 \\
13 & .827 & .829 & .866 & .865 & .136 & .118 & .981 & .976 \\
26 & .806 & .782 & .838 & .826 & .036 & .037 & .973 & .969 \\
39 & .737 & .686 & .791 & .747 & -.002 & .000 & .948 & .954 \\
47 & .558 & .483 & .857 & .573 & .000 & .000 & 1.000 & .916 \\
48 & .770 & .412 & .310 & .508 & .000 & .000 & .770 & .900 \\
49 & 1.000 & .275 & .000 & .383 & .000 & .000 & 1.000 & .867 \\
\hline
\end{tabular}

Table 25-VII exhibits a comparison of the actual efficiency of the card-counting systems for the suit payoff game with the esti- 
mated efficiencies obtained by the bivariate normal assumption. Some contradictions to the previous conclusions may be observed in the actual efficiencies and are attributable to the bivariate normal being only an approximation to the discrete fluctuations of a finite deck of cards. For the same reason poor agreement between actual and estimated efficiencies is characteristic of the beginning and end of the deck, good agreement being found in the middle.

\section{Card-Counting Systems in Blackjack}

The application of section 4 to card-counting systems for blackjack depends, again, on the degree to which that game's many strategic variations can be approximated by a single-card payoff game. Previously mentioned simulations suggest the approximations are good and that the conclusions of section 4 could be reasonably applied to such blackjack systems.

In blackjack a one-card counting system is used for many purposes; first of all, to determine if the deck is favorable for the player or not, and, subsequently, to conduct any of more than one hundred different possible variations in strategy once the hand has been dealt. Such systems are generally constructed for the sensitivity to the favorability of the deck for betting purposes and have widely differing correlation coefficients for the many possible variations in strategy.

TABLE 25-VIII

BLACKJACK. CARD COUNTING SYSTEMS

\begin{tabular}{lrrrrrrrrrr}
\hline & $A$ & 2 & 3 & 4 & 5 & 6 & 7 & 9 & 9 & 10 \\
\hline Ten Count & 4 & 4 & 4 & 4 & 4 & 4 & 4 & 4 & 4 & 9 \\
Hi Lo & 1 & 1 & 1 & 1 & 1 & 1 & 0 & 0 & 0 & -1 \\
Einstein & 0 & 0 & 1 & 1 & 1 & 1 & 0 & 0 & 0 & -1 \\
Optimal & 242 & 290 & 473 & 773 & 1073 & 671 & 581 & -37 & -466 & -900 \\
\hline
\end{tabular}

Some blackjack systems and their point values appear in Table 25-VIII. In practice the cumbersome integers assigned in the ten count are not used; rather one keeps track of the proportion of tens left in the deck. The hi-lo system has the best correlation coefficient for detecting favorable compositions of the deck, 
about .95 , while for this purpose the Einstein (1967) system achieves .86 and the ten count, .71 .

Table 25-IX exhibits a weighted averaged efficiency for the three systems in conducting seventy variations in strategy. The seventy variations were decisions on whether to double down or not with totals of 10 and 11 , and whether to hit or stand with totals of 12 through 16 against the ten possible dealer up cards. The weighting reflected the frequency of occurrence of each play. Calculations were based on the normal approximation methods of the previous sections. The last column gives an estimate of the amount of expectation to be gained from knowledge of the precisely optimal strategy in blackjack.

TABLE 25-IX

EFHICIENCIES OF BLACKJACK CARD COUNTING SYSTEMS

\begin{tabular}{cccccc}
\hline$n$ & Ten Count & Hi Lo & Einstein & Optimal & $\begin{array}{c}\text { Correct } \\
\text { Strategy Gain }\end{array}$ \\
\hline 10 & .55 & .50 & .59 & - & $2.82 \%$ \\
20 & .54 & .47 & .57 & .66 & $1.21 \%$ \\
30 & .55 & .46 & .57 & - & $.56 \%$ \\
40 & .59 & .45 & .57 & - & $.22 \%$ \\
\hline
\end{tabular}

Correlation coefficients ranged from a worthless .19 (ten count, player total of 16 versus dealer 7) to a nearly perfect .99 (ten count, player total of 12 versus dealer 6 ) .

A card counter could improve on the previous figures by being sensitive to the presence or absence of the important cards his system does not recognize. For example, the Einstein coefficient for betting could be raised from .86 to .93 if a proper evaluation of the density of aces were made simultaneously.

Although card-counting systems with more than two nonzero integers are difficult to apply, it is interesting to quest for the balanced point count which would maximize efficiency for the seventy variations in strategy mentioned. A technique of dynamic programming was used to arrive at the card-counting system referred to as optimal in Tables 25-VIII and 25-IX. The optimization was conducted with twenty cards in the deck; it is conceivable that slightly different integers would be obtained for different values of $n$. 


\section{Conclusion}

Jt seems likely that strategies and expectation fluctuations for baccarat, Trente et Quarante and multiple-deck blackjack could be well approximated by the methods proposed here. The larger the deck of cards the more likely it would appear that the assumptions $\mathrm{a}$ and $\mathrm{b}$ of section 3 would be met.

\section{REFERENCES}

Einstein, C.: How to Win at Blackjack. New York, Cornerstone Library, Incorporated, 1967.

Epstein, R.: Theory of Gambling and Statistical Logic. New York, Academic Press, 1967.

Erdos and Renyi, A.: On the Central Limit Theorem for Samples from a Finite Population. Matem, Kutato Intezet Kolzem, 1959, vol. 4, p. 49.

Thorp, E. O.: Beat the Dealer. New York, Blaisdell Publishing Company, 1962.

Thorp, E. $\mathrm{O}_{z}$ and Walden, W. E.: The fundamental theorem of card counting. Int J Game Theory, 2(2), 1973. 


\title{
Chapter 26
}

\section{PHIBABIIITIES ANI STRATEGIES FDR THE GAME DF FARD}

\author{
EDWARD 0. THORP*
}

\section{INTRODUCTION}

THE PRESENT GAME OF FARO was derived by French gamblers I from the Venetian game of bassette and the Italian hocca, which in turn was adapted from the German landsquenet. The latter was played as early as 1400 (Epstein, 1967; Foster, 1963; Riddle, 1963; and Wilson, 1965).

A predecessor of today's game was mathematically analyzed by DeMoivre (1756), Euler (1766) and Montmort (1708). They correctly calculated the player's expectation for certain bets, and their efforts yielded a chapter in the development of probability theory (Todhunter, 1865) - It is therefore surprising that all treatments of modern faro are either erroneous or inadequate.

To illustrate the diversity of erroneous opinions, Wilson (1965) quotes the 1957 Encyclopedia Britannica assertion that "it is empirically estimated that the house retains 2.5 percent of the amount bet." So-called empirical estimates are not refutable, but it will be shown that 1.5 percent and less is the actual state of affairs. He also quotes the 1962 Collier's Encyclopedia absurdity that "the bank's advantage is apparently at least 4 percent, but expert mathematicians (sic) believe it to be nearer 15 percent."

Scarne (1961) claims the house edge on splits (defined below) is approximately 2 percent. In reality, the edge varies with the split with over one hundred distinct values which range from a

\footnotetext{
"The author thanks John Clark, Richard Epstein and Allan Wilson for their comments. This work was supported by AFOSR Grants 70-1870 and 70-1870A.
} 
high of 50 percent to a low of 0.526 percent if unresolved bets are omitted, and from 50 percent to 0.043 percent ifthey are included. Some approximation! Riddle (1963) oscillates vaguely between 2 percent and 0 percent for the house edge, and seems to believe that it is 2 percent on splits, and, of course, 0 percent on ranks, only one of which remains.

Collver (1966) claims that for a bet at the first turn on the same rank as soda (the first card), the house edge is 0.79 percent, and for a bet on another rank, it is 1.57 percent. The bet thus described is not well-defined. Is the bet left on for only one turn or until the end? Is this the edge given that the bet is resolved or the edge without this condition? Whichever interpretation one chooses, the figures cited are wrong. Collver's other claims about the house edge are comparable.

Epstein (1967) gives the house edge as 2.94 percent for the wager on $Q$ to win when four $Q$ cards remain. Actually, the figure varies depending on how many non-Q cards also remain when the bet is placed. The range is from 1.564 percent to 30 percent if one omits unresolved bets, and from 0.235 percent to 30 percent if one includes them. The figures of 2 percent when three $Q$ cards remain and 1.02 percent when two $\mathrm{Q}$ cards remain are similarly defective. Epstein agrees and has been kind enough to check the correctness of a portion of these calculations.

Wilson (1965) computes the player expectation for a bet on a specified rank as $-1 / 66$, or about -1.5 percent, assuming no knowledge of soda. His usage, "Suppose you are betting on Q to win. ... As the deck is played through, eventually a Q will appear," (Cohen; 1970) and "as you placed your bet at the beginning of the game . . " (Wilson, 1965) indicates that the player places a bet at turn one and lets it remain until it is resolved. The correct value in this case is -1.9808 percent.

Wilson said that what he actually calculated was the player's expectation assuming he continuously maintains a constant bet on a rank until that rank is exhausted. Thus no knowledge of the already played cards is used. Observe that this procedure leads to the resolution of 2, 3 or 4 bets. The argument in Wilson (1965) applies if one then interprets "player's expectation" as "player's 
expectation per (unit) bet resolved."

The problem thus solved is of minor interest because it assumes the player ignores (some or all of) the knowledge of which cards have already been played, but this information is always publicly and continuously displayed for the use of the players. It is employed by virtually everyone and significantly increases their expectation. Thus, Wilson's results lack practical interest.

Mathematically, the argument (the version in Wilson (1965) was pointed out by Braun) amounts to the following. Assume that a player bets on $Q$ to win at a time when $m$ cards of rank $Q$ remain and $\mathrm{n}$ cards of rank $\mathrm{X} \leftarrow \mathrm{Q}$ remain. The frequencies of occurrence of the events $(\mathrm{Q}, \mathrm{Q}),(\mathrm{X}, \mathrm{Q})$ and $(\mathrm{Q}, \mathrm{X})$ which resolve the bet on the next turn are, respectively, $\mathrm{m}(\mathrm{m}-\mathrm{l}), \mathrm{nm}$ and $\mathrm{mn}$. Thus the player's conditional expectation $G_{c}(m, n ; 1)$, given that the bet is resolved on the next turn, is $-(m-1) / 2(m-1+2 n)$. Since the argument holds for any turn with the same information set, one may conclude that, for the player who bets on Q to win, given the information that $4-\mathrm{m}$ cards of rank $\mathrm{Q}$ and $52-\mathrm{n}$ cards of rank $\mathrm{X} \neq \mathrm{Q}$ are gone, the player's expectation per resloved bet is $-(m-1) / 2(m-1+2 n)$.

Wilson's case of no information has this interpretation: If a turn is selected at random and a rank (to win) is selected at random, the player's expectation per resolved bet is $-1 / 66$ or about -1.5 percent. As a matter of general interest, the only mathematically competent collections in English on games of chance are the excellent presentations of Epstein (1967) and of Wilson (1965).

Below the preceding is fully clarified and correct figures are supplied for the situations in question. The house edge in faro may theoretically be cut to less than 0.0006 percent. Also the confusion is removed in concepts and terminology that surround previous treatments of the game, and general formulas are given for the player's expectation in various bets. How empirically observed nonrandom shuffling may be applied to yield positive expectation for the player is also shown. This is of academic rather than practical interest because faro is now rarely played. However, the methods have other applications. 


\section{RULES AND PROCEDURES}

A single deck of fifty-two (bridge) cards is placed face up in a dealing box. Cards are dealt face up, one card at a time being exposed at the top of the box. The suits have no mathematical significance; only the rank, i.e. the denomination, matters. As the cards are dealt, a casekeeper uses an abacus-like device to record the number of cards of each rank that have been played. This information is on view for all participants.

The first card, called soda, is inactive. Then cards are dealt in pairs. The first of the pair is the losing card, and the second is the winning card. The losing card is drawn from the box and placed immediately to the side in the losing pile. (The winning card stays momentarily in the box). After the settlement of this hand or turn, bets may be made or withdrawn. Then another pair of cards is drawn. The process continues until twenty-five pairs or fifty cards plus the original soda card have been played.

If a player bets one unit on a specified rank to win (say Q), then he wins one unit if the next two cards are $(X, Q)$ in that order, where $\mathrm{X}$ is any card not of rank $\mathrm{Q}$. He loses his bet if the order is $\mathrm{Q}, \mathrm{X}$, and loses half his bet if $\mathrm{Q}, \mathrm{Q}$ occurs. If $\mathrm{X}, \mathrm{X}$ occurs, he neither wins nor loses, and he then may alter or remove his bet. The player who wants to bet on $\mathrm{Q}$ to lose simply coppers his bet with a metal marker. He then wins on $(\mathrm{Q}, \mathrm{X})$, loses on $(\mathrm{X}$, $Q)$, loses half on $(Q, Q)$, and is unaffected by $(X, X)$. Note that a bet on $\mathrm{Q}$ to win (or a bet to lose) has zero expectation if one $\mathrm{Q}$ remains and has negative expectation if more than one $Q$ remains. A bet on a rank when more than one card of that rank remains is called a split or a bet on a split. The actual occurrence of two cards of the same rank is also called a split.

When only three cards remain, the separate wager of calling the turn may be made, i.e. guessing the order of the last three cards. For three distinct ranks, the payoff is 4 to 1 , correct odds are 5:1 and the house edge is $162 / 3$ percent. For two distinct ranks (a cat hop) the payoff is 2:1 for guessing the location of the odd card. If all three cards have the same rank, the payoff is $2: 1$ for guessing the location of the odd color. The player has 0 expectation in these bets. 
Other wagers are available. A bet on even to win wagers that the (rank of the) winning card is even. (Whether the ace is odd or even depends on whether it is thought of as 1 or 14 . This discussion does not depend on which choice is made. One is arbitrarily chosen as the value for the ace. Similar remarks apply for the high and low bets below.) A one unit bet wins one unit if $(\mathrm{O}, \mathrm{E})$ appears on the next turn, loses if $(\mathrm{E}, \mathrm{O})$ appears, loses one-half if two cards of the same rank appear, and is otherwise unaffected. Let $\mathrm{E}$ denote any even card and $\mathrm{O}$ any odd card. Coppering the bet is a bet on even to lose, simply reverses the payoff on $(\mathrm{O}, \mathrm{E})$ and $(\mathrm{E}, \mathrm{O})$, and is in fact a bet on odd. Bets on even or on odd have zero expectation if and only if one card of each rank remains.

A bet on high (low) wagers that the winning (losing) card is the higher (lower) of the two. If the two cards have equal rank, the bet is unaffected. Thus the high and low bets have 0 expectation.

Under the assumption that the deck is randomly shuffled (all permutations equally likely), the analysis of coppered bets is mathematically identical to that of uncoppered bets so coppered bets will not be discussed separately. Even and odd are equivalent so odd need not be discussed. High and low are equivalent so low need not be discussed.

\section{Variations}

In the studies of De Moivre (1756), Euler (1766) and Montmort (1708) there was no soda. Cards were dealt in pairs beginning with the first and continuing until the end. The only bet considered was on $Q$ to win. Bets once placed had to remain until a $\mathrm{Q}$ appeared. If only one $\mathrm{Q}$ were in the deck and on the last pair the order were $(X, Q)$, the player neither won nor lost. If only two Q's were in the deck and the last pair as $(\mathrm{Q}, \mathrm{Q})$, the player lost his entire bet. Thus, all bets had negative player expectation whereas, under current rules, a bet on $\mathrm{Q}$ when only one remains has zero player expectation.

The most comprehensive discussions of current rules appear in Foster (1963) and Riddle (1963). Other accounts are given by 
(Collver, 1966; Epstein, 1967; Frey, 1956; Scarne, 1961; and Wilson, 1965). The player's expectation in the variation in Frey (1956), where bets on Q once placed must remain until a $Q$ appears and which more closely resembles the game of (DeMoivre, 1756; Euler, 1766; and Montmort, 1708, will be given in the course of the treatment of this bet.

The many compound bets described in Foster (1963) are each equivalent to simultaneous bets on several ranks. The analysis follows from that given below for one rank so they are not considered further.

Sometimes the first card of a pair is considered the winning card and the second is the loser. If random shuffling is assumed the expectations of all bets are unchanged and the analysis follows from this one. Thus, this variation will not be discussed further.

\section{ANALYSIS OF THE EVEN BET}

A one-unit bet wins one unit if the second card is even and the first is odd, loses if the first card is even and the second is odd, loses one-half unit if they have the same rank, and is unaffected otherwise. The probabilities of a one-unit win or loss are equal by symmetry so the player's expectation $(G)$ is $-S / 2$ where $S$ is the probability the two cards are of equal rank (a split) . Suppose there are $\mathrm{m}$ (i) cards of rank i. In practice the values of $i$ are 1,2 , $\cdots, 13$, the values of $\mathrm{m}(\mathrm{i})$ are $0,1,2,3,4$ and $\mathrm{s} \leq \mathrm{s}=\Sigma_{1}^{13} \mathrm{~m}(\mathrm{i}) \leq 51$ with s odd.

Then the probability $\mathrm{S}-\mathrm{s}^{-1}(\mathrm{~s}-1)^{-1} \mathrm{\Sigma}_{1=1}^{18} \mathrm{~m}(\mathrm{i})(\mathrm{m}(\mathrm{i})-1)$ and the player's expectation

$\left.G(m(1), \cdots, m(13))--2^{-1}-1 / s-1\right)^{-1} \sum_{i=1}^{13} m(i)(m(i)-1)=-\left\{s^{-1} \sum_{i=1}^{13} m(i)^{2}-1\right\} / 2(s-1)$

On the first turn this is $-1 / 34=-2.94$ percent. By coincidence this is the figure incorrectly given by Epstein for a very different bet. On the twenty-fifth (and last) turn, the possible rank distribution of the remaining three cards and corresponding $G$ values are $(1,1,1)_{,} \mathrm{G}=0 ;(2,1), \mathrm{G}=-1 / 6,(3,0), \mathrm{G}=-1 / 2$.

In general $G$ is maximized for fixed $s$ by distributing the $s$ cards among the thirteen ranks as evenly as possible, i.e. so that $\max \{\mathrm{m}(\mathrm{i}): 1 \leqq i \leq 13\} \leq \min \{\mathrm{m}$ (i) $: 1 \leqq i \leqq 1\}\}+1$. 


\section{Proof}

It suffices to observe that if this is not already the case, changing one card from a rank of maximum m(i) to a rank of minimum $\mathrm{m}$ (i) decreases $\sum \mathrm{m}$ (i) 2 and, hence, increases G. Similarly, $\mathrm{G}$ is minimized for fixed $\mathrm{s}$ by completely filling one rank at a time and putting any remaining cards in one rank. From this one can readily determine the maximum and minimum non-zero values of $\mathrm{G}$ which arise. The maximum occurs uniquely at $(2,1, \cdots \bullet 1)$ and is $-1 / 182=-0.55$ percent. The minimum occurs uniquely at $(3,0)$ and is -50 percent.

If there are $\mathrm{m}=\mathrm{m}(2)+\mathrm{m}(4)+\cdots$ even cards and $\mathrm{n}=\mathrm{n}(\mathbf{1})$ $+\mathrm{n}(3)+\cdots$ odd cards, the probability $\mathrm{N}(\mathrm{m}(1), \cdots, \mathrm{m}(1 \mathrm{~s}))$ that the bet is unresolved on the next turn satisfies $N+S=\{(m)$ a $\left.+(n)_{2}\right\} /(m+n)_{a}$ where $(a)_{t}$ means $a(a-1) \cdots(a-b+1)$ if $a$ 르 $\mathrm{b} \geqq 1$ and $\mathrm{a}, \mathrm{b}$ are integers. From the foregoing one can determine $\mathrm{G}_{\mathrm{G}}\left(\mathrm{m}(1), \cdots \mathrm{r}_{2} \mathrm{~m}(13)\right)$ for a single turn, the player's expectation given the condition that the bet is resolved.

The study of $\mathrm{G}_{\mathrm{G}}$ is of enormous complexity when the bet is allowed to stay for $\mathrm{k}$ turns, and $\mathrm{l}<\mathrm{k} \leqq[\mathrm{n} / 2]+1$ where $[\mathrm{x}]$ means the greatest integer less than or equal to $\mathrm{x}$ for any real number $\mathrm{x}$. The method of analysis and its difficulties will be apparent from the analysis below of the bet on a rank. Because of the comparative lack of interest in the even bet, this analysis of $\mathrm{G}_{\mathrm{G}}$ for $\mathrm{k}>1$ will not be pursued.

\section{THE EVEN BET: VARIATION}

It is assumed in the following variation of the even bet that a unit bet wins with the event $(\mathrm{O}, \mathrm{E})$, loses with the event $(\mathrm{E}, \mathrm{O})$, and loses one-half unit if either $(\mathrm{E}, \mathrm{E})$ or $(\mathrm{O}, \mathrm{O})$ occurs. On the next turn the bet will be resolved. Let $m$ even cards and $n$ odd

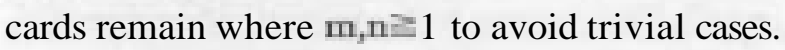

The bet wins with probability $\frac{m n}{2}\left(\begin{array}{c}m+n \\ 2\end{array}\right)^{-1}$, loses with the same probability, and loses one-half unit with probability $S(m, n)-$ $\left.f(?)^{+}\left(\begin{array}{c}n \\ 2\end{array}\right)\right]\left(\begin{array}{c}m+n \\ 2\end{array}\right)^{-1}$. Thus the player's expectation is $G(m, n)=$ $-\mathrm{S} / 2=-\mathrm{m}(\mathrm{m}-1)+\mathrm{n}(\mathrm{n}-1)\} / 2(\mathrm{~m}+\mathrm{n})(\mathrm{m}+\mathrm{n}-1)$. 
We note that $\mathrm{G}(\mathrm{m}, \mathrm{n})=\mathrm{G}(\mathrm{n}, \mathrm{m})$ and that when $\mathrm{m}+\mathrm{n}=\mathrm{c}$ is fixed, $\mathrm{G}$ decreases strictly as $\mathrm{m}-\mathrm{c} / 2 \mid$ increases. Thus in the region of actual play, where $\mathrm{m}+\mathrm{n}$ is odd and $\mathrm{I} \leq \mathrm{m}, \mathrm{n} \leq 26$, the largest, i.e. least negative, values of $G(m, n)$ are for $m=n \pm 1$, closest to the diagonal. The smallest values are on the edges: $m=1$ and $n-$ $2,4, \cdots, 26$; $\mathrm{n}=26$ and $\mathrm{m}=1,5, \cdots, 25$; and similarly for $\mathrm{m}$ and $\mathrm{n}$ reversed.

We find $G(1, n)=1 /(n+1)-1 / 2$ and $G(m, 26)=26 m /(m+25)$ $(m+26)-1 / 2$. Now $G(m, 26)$ is strictly increasing for $1 \leqq m \leqq 25$ so the smallest value of $G(m, n)$ which arises is $G(1,26)--46.3$ percent.

To find the greatest value of $G(m, n)$ in play, find the maximum for $G(m, m+1), 1 \leq m \leq 25, m$ odd. Since $G(m, m+1)=$ $-\mathrm{m} / 2(2 \mathrm{~m}+1)=1 / 4(2 \mathrm{~m}+1)-1 / 4$, this occurs for $\mathrm{G}(1,2)=$ $-1 / 6=-16.7$ percent. In case the bet on even is not allowed on the last turn, the maximum expectation is $\mathrm{G}(2,3)=-1 / 5=-20$ percent. The even and odd bets in this variation are so unfavorable compared with what is found below for the bet on a rank (Q), that they should never be played.

If the variation were modified so that $(\mathrm{O}, \mathrm{O})$ had no effect, this version of the even bet might be of interest. In particular, it would have zero expectation if, and only if, one even card remained. The analysis of this second variation follows from our analysis of the bet on Q below; simply replace Q with $\mathrm{E}$ and $\mathrm{X}$ with $\mathrm{O}$ throughout.

\section{THE HIGH BET: VARIATION}

The high bet has zero expectation as described. However, the following variation is of interest: A one-unit bet wins one unit if the second card is higher than the first, loses if the first card is higher than the second, and loses one-half unit if they have the same rank. The analysis and numerical results coincide with that of the even bet except it will be noted that the high bet is always resolved on the next turn so that $\mathrm{G}=\mathrm{G}_{\mathrm{S}}$ thus simplifying.

\section{THE BET ON A RANK}

Suppose the player bets on the rank Q to win. Let a randomly mixed pack of cards contain $m$ cards of rank $Q$ and $n$ cards of 
ranks different than $\mathrm{Q}$.

The number of pairs dealt (i.e. the number of turns) from the deck is $t=[(m+n) / 2]$. In the present game $m+n$ is odd and pairs are dealt until one card remains.

Assume the player leaves his bet on until a Q appears and the bet is settled or for $\mathrm{k}$ turns where $\mathrm{l} \leq \mathrm{k} \leq \mathrm{t}$. He removes the bet after $\mathrm{k}$ turns if the outcomes have all been $\mathbf{X}, \mathbf{X}$.

The following probabilities will be of interest: $W(m, n ; k)$, the probability that event X,Q settles the bet and the player wins; $\mathrm{L}(\mathrm{m}, \mathrm{n} ; \mathrm{k})$, the probability that event $\mathrm{Q}, \mathrm{X}$ settles the bet and the player loses; $S(m, n ; k)$, the probability that event $(Q, Q)$ terminates the bet (a split) and the player loses half his bet; and $\mathrm{N}(\mathrm{m}, \mathrm{n} ; \mathrm{k})$, the probability that $(\mathrm{X}, \mathrm{X})$ occurs on all $\mathrm{k}$ turns so that the player neither wins nor loses (no resolution). The reader will also wish to know $G(m, n ; k)$, the player's expectation per unit bet, and $\mathrm{G}_{\mathrm{g}}(\mathrm{m} \cdot \mathrm{n}, \mathrm{k})$, the player's (conditional) expectation per unit bet, given that $(\mathrm{X}, \mathrm{X})$ does not occur on all $\mathrm{k}$ turns, i.e. that the bet is resolved.

Note that $\mathrm{W}(\mathrm{m}, \mathrm{n} ; \mathrm{k})=\mathrm{L}(\mathrm{m}, \mathrm{n} ; \mathrm{k})$ follows from symmetry (the randomness of the shuffle, i.e. that all deck permutations are equally probable) - Thus,

$$
\begin{aligned}
& G=W-L-5 / 2=-S / 2, \\
& G_{C}-G /(1-N) \text {, } \\
& W+L+S+N=1 \text { so } W+L=1-(S+N), \\
& \text { and } \mathrm{W}=\mathrm{L}-(1-5-\mathrm{N}) / 2
\end{aligned}
$$

Thus, it suffices to compute $\mathrm{S}$ and $\mathrm{N}$ to obtain all the desired quantities.

$\mathrm{N}(\mathrm{m}, \mathrm{n} ; \mathrm{k})$ is the probability that the first $2 \mathrm{k}$ cards are all $\mathrm{X}$. Therefore, $\mathrm{N}(\mathrm{m}, \mathrm{n} ; \mathrm{k})=0$ if, and only if, $2 \mathrm{k}>\mathrm{n}$. If $2 \leq 2 \mathrm{k} \leq \mathrm{n}$,

$$
N\left(m_{i} n_{i} k\right)=\left(\begin{array}{c}
n \\
2 k
\end{array}\right) /\left(\begin{array}{c}
m+n \\
2 k
\end{array}\right)=(n)_{2 k} /(m+n)_{2 k}=(m+n-2 k)_{m} /(m+n)_{m} .
$$




\section{Computation of $S(m, n ; k)$}

If $m=1, S(m, n ; k)=0$. If $m=2$, there are $n+2$ cards remaining. A tie can occur only if the two Q cards are in positions $(1,2)$, $(3,4), \cdots \cdot(2 \mathrm{k}-\mathrm{l}, 2 \mathrm{k})$ respectively. Thus there are $\mathrm{k}$ ways to select the location of the two Q cards to terminate a bet on $\mathrm{Q}$ in a tie during the first $k$ turns. There are $\left({ }^{0+2}\right)$ equiprobable locations in all for the two Q cards, thus, it is concluded that

$$
S(2, n, k)-\left(\begin{array}{c}
n+2 \\
2
\end{array} \quad k=2 k /(n+2)_{2}\right.
$$

when $1 \leq k \leqq[n / 2]+1 \equiv t$.

In actual play $m+n$ is always odd, hence $n$ is odd if $m=2$. If a bet is allowed (or required) to remain until it is resolved or the last turn ends, $S(2, n ; t)=1 /(n+2)$.

If $m>2$, there are $\left({ }_{m}^{m+n}\right)$ equiprobable ways to select the locations of the $m$ cards of rank Q. If $2 \mathrm{j} \leq \mathrm{n}+2$, then $\left({ }^{m+n-2 \pi}\right)$ such selections end the wager in a tie on the $j^{\text {th }}$ turn. A Q must appear for some $\mathrm{j} \leqq[n / 2]+1$ so the wager cannot end in a tie when $2 j>n$ +2 . Thus,

$$
\left.s(m, n ; k)-\left(\begin{array}{c}
m+n \\
m
\end{array}\right)-1\left(\begin{array}{c}
m+n-2 \\
m-2
\end{array}\right)+\left(\begin{array}{c}
m+n-4 \\
m-2
\end{array}\right)+\cdots+\left(\begin{array}{c}
m+n-2 k \\
m-2
\end{array}\right)\right\}
$$

where $\mathrm{k}^{\prime}=\min (\mathrm{k},[\mathrm{n} / 2]+1)$.

The method of Bernoulli and Montmort (see Todhunter, 1865) yields for $m>2$ the equivalent forms

$s(m, n ; k)=\left(\begin{array}{c}m+n \\ m\end{array}\right)^{-1}\left\{\sum_{i=1}^{m-2} 2^{-1}\left[\left(\begin{array}{c}n+m-i \\ m-i\end{array}\right)-\left(\begin{array}{c}n-2 k^{\prime}+m-i \\ m-i\end{array}\right)\right]+k 22^{2-m}\right\}$

$S(m, n ; k)=\left(\begin{array}{c}m+n \\ m\end{array}\right)^{-1}\left\{\sum_{i=1}^{m-2}-(-2)^{-i}\left[\left(\begin{array}{c}m+n \\ m-i\end{array}\right)-\left(\begin{array}{c}m+n-2 k^{\prime} \\ m-i\end{array}\right)\right]+(-2)^{2-m} k^{\prime}\right\}$

When $\mathrm{m}=3_{4} \mathrm{~S}(3, \mathrm{n} ; \mathrm{k})=\left(\mathrm{n}+\mathrm{s}^{3}\right)^{-1} \mathrm{k}^{\prime}\left(\mathrm{n}+2-\mathrm{k}^{\prime}\right.$ and for a bet left on for $n / 2+1=t$ turns, $S(3, n ; t)=\$(n+2) / 2(n+1)(n+3)$. 
When $\mathrm{m}=4$, then

$$
\left.S(4, n ; k)=\frac{1}{2}\left(\begin{array}{c}
n+4 \\
4
\end{array}\right)^{-1}\left\{(n+4)_{3}-(n+4-2 k)_{3}\right) / 31-k(n+3-k)\right\}
$$

or equivalently

$$
\frac{i}{2}\left(\begin{array}{c}
n+4 \\
4
\end{array}\right)^{-1}\left\{\left((n+3)_{3}-(n+3-2 k)_{3}\right) / 31+k(n+2-k)\right\}
$$

Now $\mathrm{n}$ is odd in actual play, and the wager must terminate for some $\mathrm{j} \leqq[\mathrm{n} / 2]+\mathrm{l}=(\mathrm{n}+\mathrm{l}) / 2=\mathrm{t}$. Thus $\mathrm{S}(4, \mathrm{n} ; \mathrm{t})=\mathrm{S}(4, \mathrm{n} ; \mathrm{t}+1)=$ $(2 \mathrm{n}+7) /(\mathrm{n}+2)(\mathrm{n}+4)$.

The general formulae become,

$$
\begin{aligned}
& \text { for } \left.m=1, S-0 ; N=(n-2 k+1) /(n+1) ; G=G_{C}=0 \text {. For } m=2,5(2, n ; k)-2 k /(n+2)\right)_{2} \text { ) } \\
& N(2, n ; k)=(n-2 k+2)_{2} /(n+2)_{2} ; G(2, n ; k)=-k /(n+2){ }_{2} G_{C}(2, n ; k)=-1 / 2(2(n-k)+3) \text {. } \\
& \text { For } m=3, s\left(3, n_{j} k\right)=\left(\begin{array}{c}
n+ \\
3
\end{array}\right) \mathbf{k}^{\prime}\left(n+2-k^{\prime}\right)_{j} N\left(3, n_{j} k\right)-\left(n+3-2 k^{\prime}\right)_{3} /(n+3)_{3} \\
& G=-\frac{1}{2}\left(\begin{array}{c}
n+3 \\
3
\end{array}\right)^{-1} k^{\prime}\left(n+2-k^{\prime}\right) ; G_{C}(3, n ; k)=-3 k^{\prime}(n+2-k) /\left((n+3)_{3}-\left(n+3-2 k^{\prime}\right)_{3}\right) \text {. } \\
& \text { For } m \geq 3,5\left(m_{2}, i k\right) \text { is given by any forms }(1),(2) \text { or }(3), N(m, n ; k)= \\
& (n)_{2 k} /(m+n)_{2 k} ; G=-S / 2 ; G_{C}=-S / 2(1-N) \text {. }
\end{aligned}
$$

For completeness note that two more forms equivalent to (1), (2) and (3) may be obtained from methods developed by Euler. One form follows by expanding $S(m, n ; t)$ and $S(m, n-2 k ; t-2 k)$ from (2) or (3) in partial fractions to obtain $S(m, n ; k)=S(m, n ; t)$ $-\mathrm{S}(\mathrm{m}, \mathrm{n}-2 \mathrm{k} ; \mathrm{t}-2 \mathrm{k})$. (See Todhunter, 1865.) The other form is in terms of contour integrals analogous to that given in Euler (1766).

\section{NUMERICAL RESULTS FOR RANK BETS}

If soda is a Q and a bet is placed on Q from the first turn and allowed to remain, if necessary, until the end, then $\mathrm{S}=75 / 2499$, $\mathrm{N}=0$ and $\mathrm{G}=\mathrm{G}_{\mathrm{C}}=-75 / 4998=-1.5006$ percent. (Here and in the sequel last digits are rounded off.)

If soda is an $\mathrm{X}$ and a bet is placed on $\mathrm{Q}$ and allowed to remain until the bet is decided, then $\mathrm{S}=101 / 2499, \mathrm{~N}=0$ and $\mathrm{G}=\mathrm{G}_{\mathrm{Q}}$ $=-101 / 4988=-2.02081$ percent. The player who ignores soda, then immediately places a bet on $\mathrm{Q}$, letting it remain until the bet is decided, has $\mathrm{S}=33 / 833, \mathrm{~N}=0$ and $\mathrm{G}=\mathrm{G}_{\mathrm{c}}=-33 / 1666=$ 1.9808 percent. 
The value $\mathrm{G}_{\mathrm{c}}=-1.5006$ percent above is the best player expectation available when placing a bet on the first turn and letting it remain until decided or until the end. Since this opportunity arises on the first turn ofevery deal, -1.5006 percent is a first simplistic candidate for the player's expectation. In any case, it is a lower bound for the player's expectation, given any reasonable playing strategy.

\section{PLAYER'S EXPECTATIONS FOR RANK BETS}

Now comes the question of principal interest for the bet on a rank, namely, What is the player's expectation? The question is not meaningful unless it is specified (1) whether one wants $G$ or $\mathrm{G}_{\mathrm{C}}$ and (2) whether (a) the number of turns, $\mathrm{k}$, that the bet remains is arbitrary, or (b) is always until the bet is resolved or theend, i.e. $\mathrm{k}=\mathrm{t}=[\mathrm{n} / 2]+\mathrm{l}$.

The writer favors $G_{\mathrm{G}}$ rather than $\mathrm{G}$ as the quantity of importance. The first reason is mathematical; the payoffs for a one unit bet are $1,-1,-1 / 2$ and 0 for $G$. For $G_{\mathrm{g}}$ they are $1,-1$ and $-1 / 2$. Thus, using $G_{\mathrm{g}}$ views the bet more nearly as a Bernoulli trial. The theory of Bernoulli trials is highly developed; questions of utility theory, optional stopping and optimal gambling strategies are perhaps more readily resolved here than in any other context. (See, for instance, Thorp, 1969). The second reason is practical; the probability of a bet being resolved on a single turn is generally very small. The player tends to think of the resolution of the bet as the basic entity rather than the turn or the other procedural aspects of the game.

Begin by studying the behavior of $\mathrm{G}_{\mathrm{G}}(\mathrm{m}, \mathrm{n} ; \mathrm{k})$ as $\mathrm{m}, \mathrm{n}$ and $\mathrm{k}$ vary. Thus $\mathrm{G}_{\mathrm{Q}}(\mathrm{m}, \mathrm{n} ; \mathrm{l})=-(\mathrm{m}-1) / 2(\mathrm{~m}-1+2 \mathrm{n})$ which shows that $\mathrm{GO}(\mathrm{m}, \mathrm{n} ; 1)$ is strictly decreasing as $\mathrm{n}$ decreases for each fixed $m$. Now let $p(m, n ; j)-p$ be the probability that the bet is resolved on the $j^{\text {to }}$ turn. Then

$$
G(m, n ; k)=p_{1} G_{C}(m, n ; 1)+p_{2} G_{C}(m, n-2 ; 1)+\cdots+p_{k} G_{C}(m, n-2(k-1) ; 1)
$$


and

$$
G_{c}\left(m, n_{i} k\right)-p_{1} G_{C}(m, n, 1) / z_{1}^{k} p_{i}+p_{2} G_{C}(m, n-2,1) / z_{1}^{k} p_{i}+\cdots+p_{k} G_{C}\left(m, n-2(k-1)_{i} 1\right) / \Sigma_{1}^{k} p_{i}
$$

and

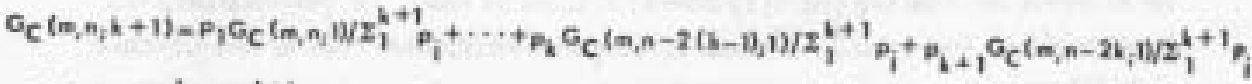

$$
\begin{aligned}
& =G_{c}\left(m_{,}, k\right) z_{i}^{k} p_{i} / z_{i}^{k+1} p_{i}+p_{k+1} G_{C}\left(m, n-2 k_{j} 1\right) / z_{i}^{k+1} p_{j}
\end{aligned}
$$

Since $\mathrm{G}_{\mathrm{G}}(\mathrm{m}, \mathrm{n} ; 1)>\mathrm{G}_{\mathrm{c}}(\mathrm{m}, \mathrm{n}-2 ; 1)>\cdots>\mathrm{G}_{\mathrm{o}}(\mathrm{m}, \mathrm{n}-2 \mathrm{k} ; 1)$ and $\mathrm{GO}(\mathrm{m}, \mathrm{n} ; \mathrm{k})$ is a convex combination of the first $\mathrm{k}$ of these, it follows that $G_{c}(m, n ; k)>G_{0}(m, n ; k+1)$ when $P_{k+1}>0$, but $P_{k+1}>0$ when $\mathrm{k} \leq \mathrm{n} / 2$ so $\mathrm{G}_{\mathrm{g}}$ is strictly decreasing as $\mathrm{k}$ increases over the entire set of $k$ which can occur. For fixed $m \geq 2$ and $n, G_{\mathrm{g}}(m, n ; k)$ is greatest when $\mathrm{k}=\mathrm{l}$ and least when $\mathrm{k}=[\mathrm{n} / 2]+1$.

For fixed $m \geq 2, G_{g}(m, n ; 1)$ increases strictly as $n$ increases so $\mathrm{G}_{\mathrm{G}}(\mathrm{m}, \mathrm{n} ; \mathrm{k})$ is maximized by choosing $\mathrm{k}=\mathrm{l}$ and $\mathrm{n}$ as large as possible. For the bet on $Q$ when $m=2$ the maximum value of $G_{c}(2, n ; k)$ is $\mathrm{G}_{\mathrm{c}}(2,47 ; 1)=-1 / 190=-0.526$ percent. This is the maximum GO for the bet on $\mathrm{Q}$ for any $\mathrm{m} \geqq 2$. It will be shown below that it is unique. It is also the maximum for all negative expectation bets in the game. Thus, in the event the player is limited by the house to negative expectation bets, -0.526 percent is an upper bound for the expectation from any strategy. When $\mathrm{m}=3$, the maximum is $\mathrm{G}_{\mathrm{c}}(3,48 ; 1)=-1 / 98=-1.020$ percent. For $\mathrm{m}=4, \mathrm{G}_{\mathrm{c}}(4,47 ; 1)=$ $-3 / 194=-1.564$ percent.

The fact that for fixed $m \geq 2, G_{\mathrm{C}}(\mathrm{m}, \mathrm{n} ; \mathrm{k})$ is uniquely least when $\mathrm{k}=[\mathrm{n} / 2]+1$ shows that the old rule requiring bets to stay until the end or until resolved was the unique best choice of $\mathrm{k}$ that the house could impose. To find out which $\mathrm{G}_{\mathrm{Q}}(\mathrm{m}, \mathrm{n} ; \mathrm{k})$ are greatest, fix $m \geq 2$ and study $G_{c}(m, n ;[n / 2]+1)=f(n)$. Letting $\mathrm{t}=[\mathrm{n} / 2]+1$, compare

$$
H(n)=G_{C}(m, n ; t)-p_{1} G_{C}\left(m_{1}, n\right)+p_{2} G_{C}(m, n-2 ; 1)+\cdots+p_{t} G_{C}\left(m, n-2(t-1)_{i} 1\right)
$$

and

$H(n+2)=G_{C}(m, n+2, t+1)-P_{0} G_{C}(m, n+2 ; 1)+\bar{p}_{1} G_{C}(m, n ; 1)+\cdots+\bar{p}_{1} G_{C}(m, n-2(t-1) ; 1)$ 
It can easily be seen that $\mathrm{P}_{\mathrm{j}}<\mathrm{P}$; for $\mathrm{I} \leqq \mathrm{j} \leqq t$ and, by a convexity argument similar to the one previously used, it follows that $\mathrm{f}(\mathrm{n})$ decreases strictly as $\mathrm{n}$ decreases. Thus, the unique minimum for $\mathrm{G}_{\mathrm{c}}(\mathrm{m}, \mathrm{n} ; \mathrm{k})$ and fixed $\mathrm{m} \geq 2$ is $\mathrm{G}_{\mathrm{g}}(\mathrm{m}, 1 ; 1)=-(\mathrm{m}-1) / 2(\mathrm{~m}+\mathrm{l})$ if $m$ is even and is $G_{\mathrm{Q}}(m, 0 ; 1)=-1 / 2$ if $m$ is odd. In particular, the least values for $m=2,3$ and 4 , respectively, are $-1 / 6,-1 / 2$ and $-3 / 10$.

To conclude the study of $\mathrm{G}_{\mathrm{C}}(\mathrm{m}, \mathrm{n} ; \mathrm{k})$, note that when $\mathrm{m}+\mathrm{n}=\mathrm{c}$ is fixed, $\mathrm{G}_{\mathrm{c}}(\mathrm{m}, \mathrm{n} ; \mathrm{l})$ is strictly increasing as $\mathrm{m}$ decreases. Therefore, the player who wishes to maximize his (conditional) expectation per bet that is resolved should limit himself to the following policy if he can alter his bet after each turn: Limit bets to ranks with a minimum (positive) number of cards remaining.

Next consider the behavior of $\mathrm{G}(\mathrm{m}, \mathrm{n}, ; \mathrm{k})$. It is evident from (1) that $G(m, n ; k)$ is strictly decreasing with $k$ increasing. Thus the maxima occur for $k=1$, i.e. $G(m, n ; 1)=-(m)_{2} / 2(m+n)=$ and the minima occur for $k=[n / 2]+1$. For fixed $m, G(m, n ; 1)$ increases strictly with $\mathrm{n}$. Thus, for fixed $\mathrm{m}$, the maxima are: for $\mathrm{m}=2, \mathrm{G}(2,47 ; 1)=-1 / 2952=-0.043$ percent which is the maximum for any $m \geqq 2$; for $m=8, G(3,48 ; 1)=-1 / 850=-0.118$ percent; for $\mathrm{m}=4, \mathrm{G}(4,47 ; 1)=-1 / 425=-0.235$ percent.

Since $G(m, n ; t)=G_{\mathrm{g}}(m, n ; t)$ and we have shown that the latter decreases strictly as $n$ decreases, then $G(m, n ; k)$ has for fixed $m$ the same minima: for $m=2, G(2,1 ; 1)=-1 / 6$; for $m=3, G(3,0 ; 1)$ $=-1 / 2$, which is the minimum for any $m \geq 2 ;$ and for $m=4, G(4$, $1 ; 1)=-3 / 10$.

\section{PLAYER EXPECTATION AND STRATEGIES}

At each turn the player may make a variety of bets, and may alter or remove existing bets. The prescription he follows for doing this is called a strategy. Strategies may, of course, be either pure or mixed. To maximize the player's expectation, $\mathrm{G}_{\mathrm{G}}$ per unit bet that is resolved, the obvious strategy is to only make zero expectation bets. Recall that the zero expectation bets are the bet on a rank when $m=1$ and the bets on high or low, and the bets on even or odd if $\mathrm{m}$ (i) $\$ 1$ for all ranks i. Coppering these bets or combining them also yields zero expectation. 
To prevent this zero expectation strategy it is a custom in some games and a rule in others that a player must make a negative expectation bet on any given deal before he can make zero expectation bets.

The player who wants to minimize expectation may regard the expected loss on his first bet as a fee, f, to be paid for the opportunity of placing bets at zero expectation. If $\mathrm{A}$ is the expected amount that will be bet at zero expectation and resolved, then the player's goal is to minimize f/A, the expected loss per unit bet. The previous results show that the player can minimize $f$ by betting only on turn two, only on a rank containing just two cards, and only placing a minimum bet. Taking the minimum as one unit, the fee per resolved bet is 0.00526 units. In the event the bet is resolved, the player, from turn three on, bets the maximum of $\mathrm{M}$ units on every zero expectation bet that appears.

This strategy does not quite maximize A because the strategy of betting the minimum on the rank of the soda card at turn one allows, when resolved, zero expectation bets from turn two. However, the increase in $\mathrm{f}$ to 1.020 percent, or almost double, is surely not offset by a corresponding increase in A.

The strategy of betting at turn two on a rank with two cards may minimize f/A, but it has practical disadvantages. First, the probability that on turn two some rank will have exactly two cards is $18 / 425=4.235$ percent. The probability the bet will be resolved on this turn is $95 / 1176=8.078$ percent. Thus, the probability that the player following this strategy will have the opportunity to make zero expectation bets is a mere 0.372 percent.

The strategy does lead to an incredibly small house advantage f/A, however. Supposing a maximum bet of 500 units and a conservatively estimated expected number of ten resolved zero expectation bets after turn two, we find $\mathrm{A}=5,000$ and $\mathrm{f} / \mathrm{A}$ is about $10^{-4}$. This is an approximate upper bound for the house edge in faro, over all player strategies, given that the player must make and complete an unfavorable bet on a given deal before placing zero expectation bets.

Even though the foregoing strategy is impractical, others which give a very small house edge are practical. For instance, 
suppose that the player bets one unit on every rank at turn one. Then at least one bet is resolved, so zero expectation bets may be placed from turn two. Noting that $S(m, n ; 1)=(m) 2 /(m+n) 2$ yields $\mathrm{E}=1 / 34=2.941$ percent. Thus for a one-dollar minimum, the fee is a mere three cents per deal. If, as before, $\mathrm{A}=5,000$, the house edge is about $6 \times 10^{-6}$. For practical purposes this is negligibly different from zero.

Many authors have said that proper exploitation of zero expectation bets could reduce the house advantage in the modern game to an unprofitable level. However, no one has previously quantified this level nor realized how incredibly tiny it is. Thus, the writer concludes that the house edge in faro is under some circumstances theoretically less than 0.0006 percent! (In practice, the player who boldly exploits this may be inhibited by the casino. Thus, a more realistic appraisal might be that the house edge is determined by an informal negotiation between house and player, and has a lower bound below $0.0006 \%$ ) This leads, in the next section, to consideration of whether the analysis of nonrandom shuffling gives the player a theoretical, and even a practical, edge.

Practical revisions of the existing rules which would make the game more palatable for the house are also to be considered. One simple revision would be to eliminate the zero expectation bets. This could be further strengthened to require that a bet, once placed, must remain either until resolved or until the end of the deal.

Another revision might be to require the player to keep a oneunit bet on a rank from turn one. If the player always chooses a rank of minimum $m \geq I$, what is his expected loss per bet that is resolved? What is the expected number of bets that will be resolved per deck? These questions can obviously be solved to acceptable approximation by simulation.

\section{NONRANDOM SHUFFLING AND FAVORABLE PLAYER STRATEGIES}

Card games have been played for centuries, and today there are hundreds of them that are well-known (Foster, 1963 and Frey, 1956) - There is an extensive literature of the heuristic, and to a 
lesser extent of the mathematical, analysis of these games. Virtually without exception these treatments tacitly or explicitly assume random shuffling.

Since human shuffling seems intuitively to be, and in fact is, decidedly nonrandom, it is surprising that previous work on nonrandom shuffling seems to consist only of Thorp and Walden (unpublished) and of Epstein (1967) which includes Epstein (1964). It is even more surprising because the play of many games is significantly altered when one considers the nonrandomness of human shuffling. In particular, there are simple winning strategies at blackjack, baccarat and faro which are based on the nonrandomness of human shuffling (Thorp and Walden, unpublished). The player in poker and bridge who uses knowledge of shuffling processes may gain a distinct advantage.

The general analysis of nonrandom shuffling and its application in particular instances is too complex and extensive to present here. The writer intends to publish it subsequently and shall limit himself here to indicating how an analysis of nonrandom shuffling might proceed to develop practical favorable strategies in faro.

A common form of shuffling for one fifty-two-card deck is to begin by cutting the deck into two approximately equal parts. These two parts are then riffled together. The cut and riffle may be repeated several times. A final cut generally follows. The study of this form of shuffling is facilitated by passing to a very crude mathematical model of it.

Assume that the $2 \mathrm{~N}$ cards, numbered $1,2, \cdots, 2 \mathrm{~N}$, are cut into two equal parts. Then the cards are riffled at which time cards $c_{\text {a }}$ and $c_{x}$, at locations $i$ and $N+i$ respectively, $I \leqq i \leq N$, vie for locations $2 \mathrm{i}-1$ and $2 \mathrm{i}$. Assume that, with probability one half, the outcome for $i$ is $c_{-} \rightarrow 2 i-1$ and $c \quad \rightarrow 2 i$, and that, with probability one-half, the outcome for $i$ is $c_{1} \rightarrow 2 i$ and $c_{\mathrm{S}+1} \rightarrow 2 i-1$. Assume also that for different values of $i$ the outcomes are independent, thus the process $\mathrm{s}$ (shuffle) of the cut followed by a riffle may produce any one of $2^{\mathrm{s}}$ distinct permutations, each with probability $2^{-x}$,

Define the square matrix $\mathrm{P}$ of order $2 \mathrm{~N}$ by letting the element 
$P_{14}$ be the probability that $s$ sends $c_{1}$ to location $j$. Then $P_{1,21-1}=$ $P_{1, \Omega}=0.5, I \leqq i \leqq 2 N$, where all subscripts are taken modulo $2 \mathrm{~N}$, and $P_{\mathrm{t}}=0$ otherwise. It follows by induction that the $\mathrm{i}^{\mathrm{t}}$ row of $P^{n+1}=\left(q_{v}\right)$ is the average of the rows $2^{n} i_{2} 2^{n} i-1_{2} \cdot \cdots, 2^{n}(i-1)+1$ $(\bmod 2 N)$ of $\mathrm{P}$. Thus $\mathrm{q}_{\mathrm{s}}$ is $\left(\mathrm{\Sigma}_{\mathrm{b}}\right) / 2^{\mathrm{D}}$ where the row index $\mathrm{i}$ runs through the values $2^{\circ} \mathrm{r}_{2} 2^{\mathrm{r}} \mathrm{r}-1,{ }_{3}^{\mathrm{i}} \cdot \cdots, 2^{\mathrm{a}}(\mathrm{r}-1)+1(\bmod 2 \mathrm{~N})$ in the sum with repetitions in the summation being counted according to their multiplicity.

The maximum $\mathrm{M}$ over the $\mathrm{q}_{13}$ will be attained by $\mathrm{q}_{1,1,} \mathrm{q}_{1,2,}$

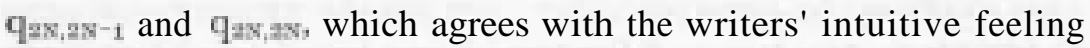
that $\mathrm{s}$ mixes the deck better toward the center and more poorly toward the end. We find $M=f\left(2^{n-1} / N\right) / 2^{n}$ where $f(x)=x$ when $x$ is an integer and $f(x)=[x+1]$ when $x$ is not an integer. If $k$ is the greatest integer for which $2^{*}<N$, then $P^{*}$ will contain a zero if, and only if, $I \leqq n \leqq k$. In particular, $q_{1,2 x}=0$. The minimum 뜨

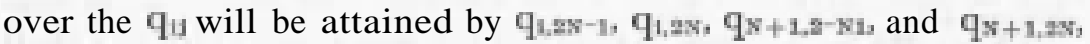
and has value $\left[2^{n-1} / \mathrm{N}\right] / 2^{*}$. When $2^{*}<\mathrm{N}, \mathrm{M}-\mathrm{m}=\mathrm{M}$. When $2^{*} \geq \mathrm{N}$, $\mathrm{M}-\mathrm{m}=0$ if $\mathrm{N}$ divides $2^{\mathrm{D}}$, and if not, then $\mathrm{M}-\mathrm{m}=2^{-\mathrm{n}}$, This shows the rate at which $\lim P^{\mathrm{N}}$ approaches the matrix $(1 / 2 \mathrm{~N})$.

In particular, when $2 \mathrm{~N}=52, \mathrm{P}^{\mathrm{N}}$ still contains numerous zeros after five shuffles, and for four, five and six shuffles, $M=1 / 32,1 / 32$ and $3 / 128$, respectively. Although six shuffles eliminate the zeros from $\mathrm{P}^{*}$, six shuffles do not necessarily produce all permutations with positive probability. However, one can find a lower bound for the number of shuffles required to do this by noting that $\mathrm{s}$ is a combination of $2^{20}$ permutations. Hence, in $\mathrm{k}$ shuffles one can generate at most $\left(2^{25}\right)^{k}$ permutations and obtain the desired lower bound by requiring that $20 m \geq(2 N)$ ! Thus, $k \geqq 9$ when $2 N=52$.

This leaves the question of whether $s$ is in fact an asymptotically random shuffling procedure. By this it is meant that if $\mathrm{cr}$ is any permutation and $\mathrm{P} \quad\left(\mathrm{s}^{\mathrm{D}}\right)$ is the probability $\mathrm{n}$ repetitions of $\mathrm{s}$ produce $c r$, then $\lim _{\mathrm{n}^{\prime} \mathrm{Q}^{\sigma^{\sigma}}}\left(\mathrm{s}^{\mathrm{*}}\right)$ exists and is $\mathrm{I} /(2 \mathrm{~N})$ !

For illustrative purposes only suppose now that this mathematical model describes the faro shuffling procedure. After a deck is used it consists of two equal piles whose order is known to the player. Suppose the piles are picked up and riffled according to 
this model. Then it is as though the piles were initially stacked one on top the other, giving a known initial order to the deck, and $s$ was then applied once. Now apply s an additional number oftimes for a total of $\mathrm{n}$ and follow it by a final cut near the center.

Consider cards $c_{1}$ and $c_{2}$ at initial locations 1 and 2. Let $\left\{Y_{1}: 1 \leq i\right\}$ be independent identically distributed Bernoulli random variables: $P\left(Y_{1}=0\right)=P\left(Y_{1}=1\right)=1 / 2$. Define $\left\{X_{1}: 1 \leqq i\right\}$ by $\mathrm{X}_{1}=\mathrm{Y}_{\mathrm{2}-1}+\mathrm{Y}_{2 \mathrm{i}}$ Let $\mathrm{d}\left(\mathrm{c}_{1}, \mathrm{c}_{2} ; \mathrm{n}\right)$ be the number of cards separating $c_{2}$ from $c_{1}$ after $n$ shuffles, counting forward from $c_{1}$ ("around the end" past 52 if necessary) to $c_{2}$. Then it can be shown that $d\left(c_{1}, C_{2} ; 1\right)$ $=\mathrm{X}_{1}, \mathrm{~d}\left(\mathrm{~d}, \mathrm{c}_{2} ; 2\right)=2 \mathrm{X}_{1}+\mathrm{X}_{2}$ and $\mathrm{d}\left(\mathrm{c}_{1}, \mathrm{c}_{2} ; 3\right)=2^{2} \mathrm{X}_{1}+2 \mathrm{X}_{2}+\mathrm{X}_{8}$. This formula fails for $n>3$ because $c_{1}$ and $c_{2}$ interact.

Suppose now that $\mathrm{n} \leq \$$ and the final cut includes at least sixteen cards in the top stack. Then both $c_{1}$ and $c_{m}$ will appear in that order in the lower part of the deck that is going to be played. Given $\mathrm{n}$, which is in practice observable, one can calculate the distribution of $d\left(c_{1}, c_{2} ; n\right)$.

Take $\mathrm{n}=1$ to illustrate the ideas, and set $\mathrm{d}=\mathrm{d}\left(\mathrm{c}_{1}, \mathrm{c}_{2} ; 1\right)$. Then $\mathrm{P}(\mathrm{d}=0)=\mathrm{P}(\mathrm{d}=2)=1 / 4$ and $\mathrm{P}(\mathrm{d}=1)=1 / 2$. When the player sees $c_{1}$ appear in play, he knows $c_{2}$ is close behind. If $c_{1}$ is the second card in a turn, then if $\mathrm{c}_{2}$ appears on the next turn (this happens with probability $3 / 4$ ), the probability is $1 / 9$ that it will be the first member of the pair and $2 / 3$ that it will be the second member. Thus the conditional player expectation on the rank $Q$ of $c_{2}$ to win is $+1 / 3$ if it is the last $Q$. If $c_{2}$ fails to appear, then it will appear with certainty as the first card on the subsequent turn, and the expectation of the bet on $\mathrm{Q}$ to lose is +100 percent on this turn if it is the last of its rank. The treatment for $n=2,3$ and for when the number of remaining $Q$ cards is $m_{1}$ and the number of others is $\mathrm{m}_{\mathrm{g}}$ is evident.

It is not the details that the writer wishes to illustrate here, but rather enough of the ideas to indicate that a practical approach is feasible.

The approach might proceed as follows. The player transmits all relevant information by radio link to a computer. He interrogates the computer in the same way when he wishes instructions. The computer evaluates the shuffling and estimates the corre- 
sponding distribution functions. Observed shuffling processes $\mathrm{s}$ fall into a few general types as does the final cut. For each type (perhaps for each individual) and for each $\mathrm{n}$ a table could be constructed giving the distribution of the distance by which $c_{q+1}$ follows $\mathrm{Ci}$ for each $\mathrm{i}, \mathrm{I} \leq \mathrm{i} \leq 52$. Smoothing procedures and statistical decision procedures would allow one to use the data as it is accumulated so that advantages might be available as early as the second use of the deck.

In games the writer has observed, used decks are sometimes placed in a wheel containing several of them. The wheel is spun and a deck is drawn at random for the next play. This is overcome by constructing a separate table for each deck and using this knowledge to identify the selected deck after the first few cards appear.

The reader is not expected to attempt to exploit the possibility of nonrandom shuffling to achieve positive expectation. The game does not justify the effort. The writer simply wishes to show that such possibilities are feasible. The interesting mathematical aspects of nonrandom shuffling will be developed, and practical applications to games of wider interest will be given in subsequent papers. 


\section{APPENDIX 26-I}

\section{POSSIBLE APPLICATION OF NONRANDOM SHUFFLING TO BLACKJACK}

T ET $\left(\mathrm{c}_{1}, \cdots \cdot \mathrm{c}_{\mathrm{n}}\right)$ BE THE ORDER of an n-card deck just prior to 1 shuffling for the next deal. Call this the initial order. Thus $\mathrm{C}_{\mathrm{a}}$ denotes the card in the $\mathrm{i}^{\mathrm{\omega}}$ position. For $\mathrm{I} \leqq \mathrm{i} \leqq \mathrm{n}_{2}$ define the follower of $\mathrm{q}$ to be $\mathrm{c}_{1+1}$, and define the antecedent of $\mathrm{q}$ to be $\mathrm{c}_{1-1}$ where subscripts are modulo $n$.

Assume now that a shuffling procedure, s, consisting perhaps of some riffles and cuts, is applied to the deck. Assume that the procedure

$$
s=z_{i=1}^{n !} P_{i} \sigma_{i}
$$

has fixed probabilities pi of realizing each permutation $\sigma_{1-}$ This means that the probability characteristics of $s$ do not change from one application of $s$ to another, i.e. that $s$ is time-invariant or stationary.

Let the permutation $\sigma$ be a particular occurrence of $s$. The new order

which places

$$
\left(c_{\sigma(1)} \ldots+\epsilon_{\sigma(n)}\right)
$$

$$
\text { c } \sigma(i)
$$

in location $\mathrm{i}, \mathrm{l} \leqq \mathrm{i} \leq \mathrm{n}$, is called the final order. This is the order in which the cards will be dealt.

\section{Experiment}

Choose an empirical procedure and record for $s$ the following data: Define

$$
d\left(c_{\sigma(i)} \cdot \epsilon_{\sigma}(i)+1\right)
$$


to be the number of cards in the final order which separate

$$
\text { s(i) }
$$

from its follower in the initial order,

\section{$\sigma(i)+1$}

Let

$$
D\left(c_{\sigma(i)} \cdot c_{\sigma(i)}+1\right)=D_{i}-d\left(c_{\sigma(i)}, c_{\sigma(i)+1}\right) \text { if } c_{\sigma(i)+1} \text { follows } c_{\sigma(i)}
$$

in the final order. Let

$$
D\left(c_{\sigma(i)}, c_{\sigma(i)}+1\right)=D_{i}=-1
$$

otherwise. Record Di for each i (perhaps by tallying on graph paper) .

After several shuffles, a picture of the distribution of $D_{\Perp}$ given i will appear. The conditional distribution given $D_{1}>0$, i.e. given that the follower of

$$
c_{\sigma(i)}
$$

still follows it in the final order, is expected to be the anticipated useful predictor.

Two shuffles to try are: (a) one cut near the center, followed by a riffle, and (b) try (a) iterated $\mathrm{k}$ times, for $\mathrm{k}=2,3, \cdots \bullet$, as indicated by results at the time.

The writer suspects that the plot in (a) if suitably applied (and perhaps modified by replacing $D_{\mathbb{l}}$ by the directed distance $\sigma_{\|}$obtained by counting forward, around the end of the deck if necessary), will generate (b) .

For simplicity, number the cards $1,2, \cdots, \mathrm{n}$, and always start with initial order $\mathrm{Ct}=\mathrm{i}, \mathrm{I} \leqq \mathrm{i} \leqq \mathrm{n}$.

A sufficiently nonrandom prediction gives a practical procedure for one deck, Note, too, the immediate application to acelocation in bridge and poker.

Several decks present problems of indistinguishability of distinct cards. The effect is to rapidly average or smooth the distribution and "wash out" nonrandomness of the prediction. 
A virtue of the method is its simplicity to apply in practice, relative to other methods. In rubber bridge, for instance, cards are played in little packets of four, called tricks. It is often convenient to note the antecedents of a key card within a trick. If the order within the trick is not disturbed then one knows the antecedent of the key card in the initial order. It is generally the case that the trick order is not disturbed, and it is generally the case that one can confirm this by observation in the specific instance.

It is questionable whether one can locate the trick in the initial order well enough to use knowledge of the variation with $i$ of the distribution of $D_{1}$. If one cannot use this knowledge, and must instead use the average distribution D of Di then it will depend on whether $\overline{\mathrm{D}}$ is sufficiently nonuniform.

\section{REFERENCES}

Cohen, J.: The nature of gambling. Scientia, CV:\, 1970.

Collver, D. I.: Scientific Blackjack and Complete Casino Guide. New York, ARCO Publishing Company, 1966.

DeMoivre, A.: The Doctrine of Chances, 3rd ed. London, Millar, 1756. Photographically reprinted, New York, Chelsea, 1967.

Epstein, R.: Theory of Gambling and Statistical Logic. New York, Academic Press, 1967.

Epstein, R. A.: Card Prediction for a Shuffled Deck. Hughes Aircraft Company, Report TP-64-19-11, UP-68, July, 1964.

Euler, L.: Sur I'Advantage du Banquier aw Jeu Pharaon. Histoire de L'Academie Royale des Sciences et Belles-Lettres, 1766.

Foster, P. F.: Foster's Complete Hoyle-An Encyclopedia of Games. New York, Lippincott, 1963.

Frey, R. Lai Rules of Games-According to Hoyle. New York, Fawcett Publications, 1956.

Montmort, P. R. d.: Essai d'Analyse sur les Jeux de Hazards. Paris, J. Quil$\operatorname{lan}_{1} 1708$.

Riddle, M. A.: The Weekend Gambler's Handbook. New York, Random House, 1963.

Scarne, J.: Scarne's Complete Guide to Gambling. New York, Simon and Schuster, 1961.

Thorp, E.: Optimal gambling systems for favorable games. Rev Ine Statistical Institute, 37:3, 1969. 
Thorp, E. O.p and Walden, W.: The Solution of Games by Computer. Unpublished manuscript.

Todhunter, Li: A History of the Mathematical Theory of Probability, 1st ed. Cambridge, 1865. Textually unaltered reprint, New York, Chelsea, 1949.

Wilson, A. N.: The Casino Gambler'a Guide. New York, Harper and Row, 1965. 



\section{DATE DUE SLIP}
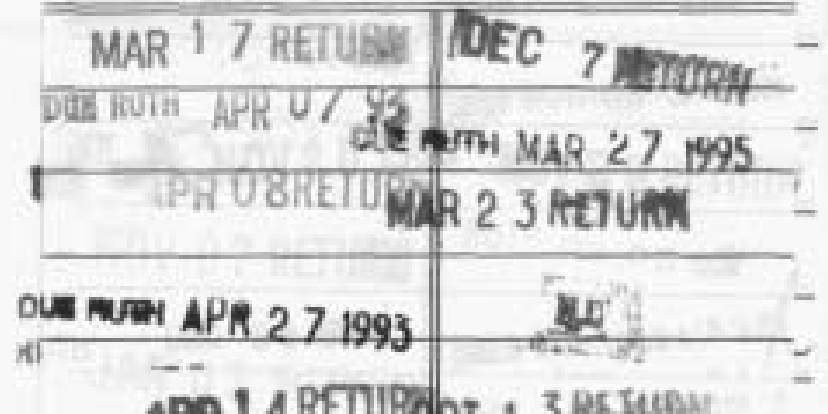

APP 1.4PETIPEOT + 3 BESHEY

Due Ruth NOV $24^{\prime} 93$ NOV 18 rtiung

\begin{tabular}{|c|c|}
\hline $0 r=0$ & BEEURN ON23 $3 \mathrm{og}$ \\
\hline Shas pitt NFC. g $^{\prime} 93$ & 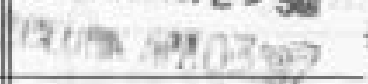 \\
\hline UEC O 5 RETURA & Furata a \\
\hline
\end{tabular}

DUE BATI APR 27'94 RETUANAPR 261009

- APR 23 BETURR APR 121999 -

DUES

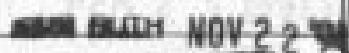

NOV21 Rs

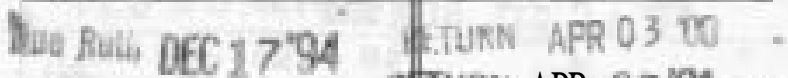

$=$ nftum APR O3Ot


HY 6713 618 1976 [-2

GAMBLING AND 50CIETY

ANTERDISCIPLINARY STUDIES ON THE

SUBJECT OF GAMBLING

39269154 HSS

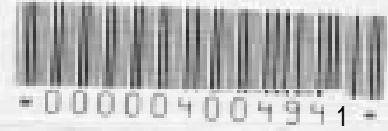

HV6713G181976 C. 2

Gambling and society;

O172837R MAIN 
